\title{
HIGH-TEMPERATURE NUCLEAR HEAT SOURCE STUDY
}

Prepared under Contract AT(04-3)-167

Project Agreement No. 54 for the San Francisco Operations Office U.S. Atomic Energy Commission

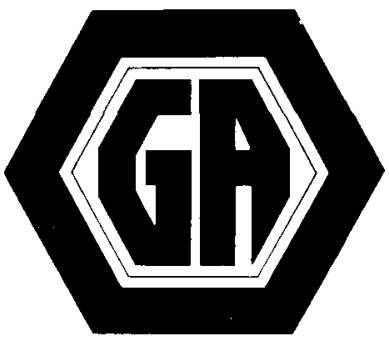


This report was prepared as an account of work sponsored by the United States Government. Neither the United States nor the United States Atomic Energy Commission, nor any of their employees, nor any of their contractors, subcontractors, or theır employees, makes any warranty, express or 1 mplied, or assumes any legal liability or responsibility for the accuracy, completeness or usefulness of any information, apparatus, product or process disclosed, or represents that its use would not infringe privately owned rights

Printed in the United States of America Available from

National Technical Information Service

U.S. Department of Commerce 5285 Port Royal Road Springfield, Virginia 22161

Price: Printed Copy $\$ 10.60$; Microfiche 


\section{DISCLAIMER}

This report was prepared as an account of work sponsored by an agency of the United States Government. Neither the United States Government nor any agency Thereof, nor any of their employees, makes any warranty, express or implied, or assumes any legal liability or responsibility for the accuracy, completeness, or usefulness of any information, apparatus, product, or process disclosed, or represents that its use would not infringe privately owned rights. Reference herein to any specific commercial product, process, or service by trade name, trademark, manufacturer, or otherwise does not necessarily constitute or imply its endorsement, recommendation, or favoring by the United States Government or any agency thereof. The views and opinions of authors expressed herein do not necessarily state or reflect those of the United States Government or any agency thereof. 


\section{DISCLAIMER}

Portions of this document may be illegible in electronic image products. Images are produced from the best available original document. 
NOTICE

This report was prepared as an account of work sponsored by the United States Government. Neither the United States nor the United States Energy Research and Development Administration, nor any of their employees, nor any of their contractors, subcontractors, or their employees, makes any warranty, express or implied, or assumes any legal liability or responsibility for the accuracy, completeness or usefulness of any information, apparatus, product or process disclosed, or represents that its use would not infringe privately owned rights.

\section{HIGH-TEMPERATURE NUCLEAR HEAT SOURCE STUDY}

Prepared under

Contract AT(04-3)-167

Project Agreement No. 54

for the

San Francisco Operations Office

U.S. Atomic Energy Commission

GENERAL ATOMIC PROJECT 0854 DATE PUBLISHED - DECEMBER 30, 1974

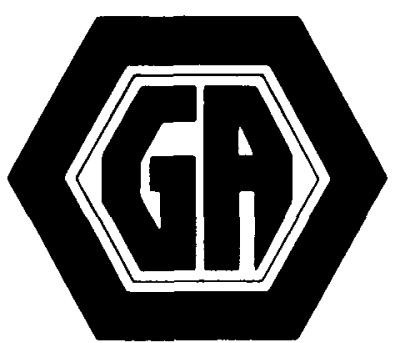

GENERAL ATOMIC 
0

0

•

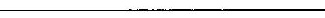


CONTENTS

1. ABSTRACT . . . . . . . . . . . . . . . . . . 1-1

2. INTRODUCTION AND SUMMARY . . . . . . . . . . . . . . . . 2-1

2.1. Process Heat Reactor . . . . . . . . . . . . . . . 2-1

2.2. Commercial Steam-Producing HTGR . . . . . . . . . . 2-6

2.2.1. Nuclear Steam Supply System . . . . . . . . . 2-6

2.2.2. Core and Major Components . . . . . . . . . 2-11

2.2.3. Auxiliary Systems . . . . . . . . . . . 2-16

2.2.4. Plant Control . . . . . . . . . . . . 2-16

3. PROCESS HEAT USES . . . . . . . . . . . . . . . . . . . . 3-1

3.1. Overview . . . . . . . . . . . . . . . 3-1

3.1.1. Recovery and Upgrading of Fossil Fuels . . . . . 3-5

3.1.2. Primary Metals . . . . . . . . . . . 3-6

3.1.3. Chemicals . . . . . . . . . . . . . . 3-7

3.1.4. Papermaking . . . . . . . . . . . . . . 3-7

3.1.5. Stones, Clays, and Ceramics .......... 3-8

3.2. Methods for Applying Nuclear Process Heat . . . . . . 3-8

3.2.1. Steam-Hydrocarbon Reforming . . . . . . . 3-9

3.2.2. Special Steam Cycles . . . . . . . . . . 3-12

3.2.3. Intermediate Loop . . . . . . . . . . 3-14

3.2.4. Thermochemical Water Splitting . . . . . . . 3-17

4. HYDROGEN PRODUCTION BY STEAM-METHANE REFORMING . . . . . . . . . 4-1

4.1. The HTGR and Steam-Hydrocarbon Reforming . . . . . . . . 4-1

4.2. Process Description ................. 4-2

4.3. AEC Code of Accounts Check List for Nuclear Process Heat

Plant ..................... 4-14

5. DESIGN . . . . . . . . . . . . . . . . . 5 5-1

5.1. Standard HTGR Nuclear Steam System . . . . . . . . . . 5-1

5.1.1. Introduction . . . . . . . . . . . . . . 5-1

5.1.2. Reactor ................... . 5-1

5.1.3. Reactor Coolant System . . . . . . . . . . 5-4 
5.1.4. Prestressed Concrete Reactor Vesse1 . . . . . 5-4

5.1.5. Auxiliary Systems . . . . . . . . . . 5-6

5.1.6. Engineered Safety Features . . . . . . . 5-6

5.1.7. Instrumentation and Contro1 . . . . . . . . 5-7

5.1.8. Fuel Handling and Storage . . . . . . . . . 5-8

5.1.9. Radioactive Waste Systems . . . . . . . . 5-10

5.2. Process Heat Reactor . . . . . . . . . . . . . 5-11

5.2.1. Design Discussion ............. . 5-11

5.2.2. $1200^{\circ} \mathrm{F}$ Plant .............. 5-11

5.2.3. $1400^{\circ} \mathrm{F} \mathrm{Plant} \mathrm{.} \mathrm{.} \mathrm{.} \mathrm{.} \mathrm{.} \mathrm{.} \mathrm{.} \mathrm{.} \mathrm{.} \mathrm{.} \mathrm{.} \mathrm{.} \mathrm{5-19}$

5.2.4. $1600^{\circ} \mathrm{F}$ Plant . . . . . . . . . . . . 5-23

5.2.5. $1800^{\circ} \mathrm{F}-2000^{\circ} \mathrm{F}$ Plants .......... 5-30

5.3. HTGR/Reformer Materials . . . . . . . . . . . 5-31

5.4. Reformer Location Studies . . . . . . . . . . . 5-42

6. REACTOR FUEL AND CORE . . . . . . . . . . . . . . . 6-1

6.1. Process Heat Core Descriptions . . . . . . . . . . . 6-1

6.1.1. Introduction . . . . . . . . . . . . 6-1

6.1.2. Design Modifications . . . . . . . . . . 6-3

6.1.3. Core Designs for Process Heat HTGR . . . . . . 6-7

6.1.4. Effect of Changes in Core Inlet Temperatures . . 6-23

6.2. Fuel Mass Balance .... . . . . . . . . . 6-30

6.3. Fission Product Release . . . . . . . . . . . . 6-30

7. OPERATION AND MAINTENANCE . . . . . . . . . . . . . . . 7-1

7.1. Nuclear Process Heat Plant Staffing Versus Temperature • - 7-1

7.2. Plant Avallability and P1ant Capacity Factor Versus

Temperature ....... . . . . . . . . . . 7-5

8. ECONOMICS FOR NUCLEAR PROCESS HEAT PLANT . . . . . . . . . . 8-1

8.1. Capital costs .................. 8-1

8.1.1. Capital Cost Changes . . . . . . . . . . 8-1

8.1.2. Capital Cost Scaling Factors . . . . . . . . . 8-8

8.1.3. Payment Schedule for Nuclear Process Heat Supply
System . . . . . . . . . . . . . . 8-8

8.2. Fuel Cycle Costs . . . . . . . . . . . . . . 8-11

8.3. Operation and Maintenance Costs for Nuclear Process Heat

Plant . . . . . . . . . . . . . . . 8-11 
8.3.1. Station Staffing .............. 8-11

8.3.2. Contract In-Service Inspection . . . . . . . 8-16

8.3.3. Consumables . . . . . . . . . . . . 8-16

8.3.4. Waste Disposal . . . . . . . . . . 8-17

8.3.5. Catalyst . . . . . . . . . . . . 8-18

8.3.6. Bullding Heating and Auxiliary Boiler and Communications . . . . . . . . . . . . 8-18

8.3.7. Maintenance Supplies . . . . . . . . . 8-19

8.3.8. Nuclear Insurance and Annual License Fee . . . . 8-19

8.3.9. Miscellaneous Operating and Maintenance . . . . 8-20

8.3.10. Scaling Factors . . . . . . . . . . . . 8-20

9. SAFETY CONSIDERATIONS . . . . . . . . . . . . . . . . . 9-1

9.1. Design Basis Depressurization Accident . . . . . . . . . 9-1

9.1.1. Sequence of Events . . . . . . . . . . . . 9-2

9.1.2. Primary System Depressurization . . . . . . . 9-2

9.1.3. Containment Pressure and Temperature Response . . 9-4

9.1.4. Core Cooling Using Auxiliary Cooling Loops . . . 9-4

9.1.5. Design Bases . . . . . . . . . . . . . 9-16

9.1.6. Radioactivity Release Sources . . . . . . . 9-16

9.1.7. Coolant Inventory .............. 9-17

9.1.8. Summary of Radioactivity Released to Containment . 9-17

9.1.9. Environmental Consequences . . . . . . . . . 9-17

9.1.10. Summary of Results . . . . . . . . . . . 9-23

9.2. Loss of Main Loop Cooling (LOMLC) . . . . . . . . . . 9-23

9.3. Product Contamination . . . . . . . . . . . . . 9-26

9.3.1. Tritium and Hydrogen Permeation .... . . . . 9-27

9.3.2. Fission Product to Product Gas Leak . . . . . . 9-35

9.4. Process Gas and Secondary System Leak to Containment . . 9-37

9.4.1. Process Leak to Containment . . . . . . . . . 9-37

9.4.2. Secondary System Leaks to Containment . . . . . 9-37

9.5. Process Heat Exchanger Failure in the PCRV . . . . . . . . 9-38

9.6. Containment Isolation Criteria . . . . . . . . . . 9-38

9.7. Steam Leak Into PCRV . . . . . . . . . . . . . . 9-39

9.8. Effects of Fission Product Increase . . . . . . . . . 9-39 
10. RESEARCH AND DEVELOPMENT REQUTREMENTS . . . . . . . . . . . . 10-1

10.1. Research and Development Program . . . . . . . . . 10-1

10.1.1. Development of Advanced HTGR Fuel Systems for

Process Heat Applications . . . . . . . . . 10-1

10.1.2. Core Components . . . . . . . . . . 10-10

10.1.3. Materials Research ... . . . . . . 10-13

10.1.4. Thermal Barrier .............. . 10-64

10.1.5. Reformer Catalysts and Reformer Performance Testing .............. 10-71

10.1.6. Helium Circulator Drive Turbine Testing . . . 10-74

10.2. Design Development Program . . . . . . . . . 10-77

10.2.1. Schedule . . . . . . . . . . . . 10-77

10.2.2. Program Cost . . . . . . . . . . 10-79

10.2.3. Significant Components ......... . 10-79

10.2.4. Preliminary Design Phase . . . . . . . 10-80

10.2.5. Detail Design Phase . . . . . . . . . . 10-83

10.3. Research and Development Summary and Conclusions . . . 10-84

11. CONCLUSIONS AND RECOMMENDATIONS . . . . . . . . . . . . . 11-1

11.1. Conclusions . . . . . . . . . . . . . . . 11-1

11.2. Recommendations . . . . . . . . . . . . . . 11-1

APPENDIX A. EFFECT OF LOWERING THE HTGR HELIUM CORE OUTLET

TEMPERATURE ON THE ECONOMICS OF HYDROGEN

PRODUCTION FOR A COAL GASIFICATION PLANT . . . . . . . A-1

APPENDIX B. CORE FUEL ELEMENT AND THERMAL PARAMETER DETAILS . . . . B-1

APPENDIX C. PROPERTIES OF SELECT CERAMICS . . . . . . . . . . . C C-1

\section{FIGURES}

2-1. Process heat HTGR ................... . 2-3

2-2. Helium heat transfer loop . . . . . . . . . . . . . 2-4

2-3. General arrangement of large HTGR nuclear steam supply system . . . . . . . . . . . . . . . . . 2-12

2-4. Overall plant flow diagram of typical secondary cooling system...................... 2-15

3-1. Flowsheet for direct reduction of fron ore using an HTGR . . . 3-11

3-2. Production of steam for tar sands recovery . . . . . . . . 3-13

3-3. Nuclear process heat flowsheet for a petroleum refinery and petrochemical complex producing 300,000 BPD of oil, 1500 TPD of ammonia, and $10^{9} \mathrm{lb} / \mathrm{yr}$ of ethylene ........... 3-15 
3-4. Oil shale recovery and upgrading plant; capacity $=2000,000$

BPD synthetic crude ................ 3-16

4-1. Simplified flowsheet for process heat HTGR hydrogen production plant . . . . . . . . . . . . . . . . . 4-5

4-2. Heat load division between steam generator and reformer as a function of process temperature . . . . . . . . . . . . 4-9

4-3. Flowsheet showing process steps for hydrogen production with a process heat HTGR .. . . . . . . . . . . . . 4-11

5-1. $1200^{\circ} \mathrm{F}$ reformer plant arrangement . . . . . . . . . . 5-12

5-2. Common return pipe reformer . . . . . . . . . . . . . 5-13

5-3. $1400^{\circ} \mathrm{F}$ reformer plant arrangement . . . . . . . . . . 5-20

5-4. Integral return tube reformer . . . . . . . . . . . . 5-21

5-5. High-temperature reformer plant arrangement . . . . . . . . 5-28

5-6. Reformer located inside PCRV . . . . . . . . . . . . . . 5-45

5-7. Reformer located outside PCRV . . . . . . . . . . . . . 5-46

6-1. Design I average channel temperature distributions . . . . . 6-11

6-2. Design I hot channel temperature distributions . . . . . . . 6-12

6-3. Design II average channel temperature distributions . . . . . 6-14

6-4. Design II hot channel temperature distributions . . . . . . . 6-15

6-5. Design III average channel temperature distributions . . . . . 6-18

6-6. Design III hot channel temperature distributions . . . . . . . 6-19

6-7. Design IV average channel temperature distributions . . . . 6-21

6-8. Design IV hot channel temperature distributions . . . . . . 6-22

6-9. Design $\mathrm{V}$ average channel temperature distributions..... . 6-25

6-10. Design $V$ hot channel temperature distributions . . . . . . 6-26

6-11. Reactor outlet temperature and core pressure drop versus helium inlet temperature - 132-hole fuel block . . . . . . . 6-27

6-12. Reactor outlet temperature and core pressure drop versus helium inlet temperature - 210-hole fuel block . . . . . . . 6-28

6-13. Reactor outlet temperature and core pressure drop versus helium inlet temperature - 210-hole fuel block; improved fuel . . . . . . . . . . . . . . . . . . 6-29

6-14. Equilibrium material balance flowsheet for reference HTGR at $8.4 \mathrm{~W} / \mathrm{cm}^{3}$ (non-recycle case) .......... . . 6-31

6-15. Equilibrium material balance flowsheet for reference HTGR at $8.4 \mathrm{~W} / \mathrm{cm}^{3}$ (4-yr annual recycle).......... . 6-32

6-16. Equilibrium material balance flowsheet for reference HTGR at $\mathrm{C} / \mathrm{Th}=200$ using TRISO/TRISO fuel with a 3 -yr fuel cycle 
6-17. Relative strontium release versus temperature . . . . . 6-36

6-18. Kr-85m R/B temperature dependence - Fort St. Vrain fuel . . 6-38

6-19. Xe-138 R/B temperature dependence - Fort St. Vrain fuel . . . 6-39

8-1. Capital cost scaling factor versus process heat reactor thermal power . . . . . . . . . . . . . . . . 8-9

8-2. Payment schedule (cash flow to vendor) for nuclear process system . . . . . . . . . . . . . . . . 8-10

8-3. Operating and maintenance cost scaling factor versus process heat reactor thermal power ............. . 8-21

9-1. Primary system pressure as a function of time . . . . . . . 9-5

9-2. Helium leak rate as a function of time . . . . . . . . . 9-6

9-3. Containment pressure as a function of time . . . . . . . . . 9-7

9-4. Containment temperature as a function of time . . . . . . . 9-8

9-5. Energy input into containment as a function of time . . . . . 9-9

9-6. PCRV gas composition and heat capacity as a function of time for DBDA; based on $1600^{\circ} \mathrm{F}$ reactor outlet temperature, 34.0-psia pressure, two CACS loops operating ............ 9-13

9-7. Core outlet and inlet temperatures as a function of time for DBDA; based on $1600^{\circ} \mathrm{F}$ reactor outlet temperature, 34.0-psia pressure, two CACS loops operating............ 9-14

9-8. Flow, heat removal, and heat generation as a function of time for DBDA; based on $1600^{\circ} \mathrm{F}$ reactor outlet temperature, 34.0-psia pressure, two CACS loops operating........... . 9-15

9-9. Core inlet and outlet temperatures as a function of time for LOMLC; based on $1600^{\circ} \mathrm{F}$ reactor outlet temperature . . . . . . 9-24

9-10. Flow, heat removal, and heat generation as a function of time for LOMLC; based on $1600^{\circ} \mathrm{F}$ reactor outlet temperature . . . 9-25

9-11. Steam/graphite reaction rates . . . . . . . . . . . . 9-40

10-1. Process heat HTGR/reformer system . . . . . . . . . . 10-16

10-2. Schematic of technique for compression loading many specimens to different stresses under controlled atmosphere and high temperatures . . . . . . . . . . . . . . . 10-32

10-3. Simulated HTGR helium supply system (once-through flow) . . . 10-33

10-4. Rate of attack ( $j_{S i}$ ) of silicon in oxygen-helium mixtures of constant total pressure at $1410^{\circ} \mathrm{C}$ as a function of oxygen partial pressure, $\mathrm{P}_{2}^{\mathrm{O}}$................... . . 10-42

10-5. Schematic of thermoelectric generator showing how materials are held in compression ... . . . . . . . . . 10-50 
10-6. Schematic of ring converter thermoelectric couple across section. The thermoelectric elements are supported in cantilever, and the 2-mil silver collector is flexible enough to absorb any stresses. The temperature differential

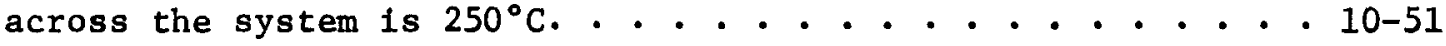

10-7. Ceramic reformer tube joined to metallic tube with mechanical joint . . . . . . . . . . . . . . . . 10-53

10-8. Carborundum Company design for mechanical joining of SiC tube to SiC tubesheet .. . . . . . . . . . . . . 10-55

10-9. Thimble design of ceramic tube allowing free axial expansion . 10-56

10-10. Ceramic tube with one fixed end and one sliding seal (possibly both ends could use sliding seals) . . . . . . . . . . 10-58

10-11. Formation of ceramic tubes by brazing together many smaller shapes .. . . . . . . . . . . . . . . . . 10-59

10-12. Program schedule for hydrocarbon reforming . . . . . . . 10-78

\section{TABLES}

2-1. Process heat reactor study: summary of fuel design condtions........................ 2-7

2-2. Process heat reactor study: summary of mechanical characteristics .. . . . . . . . . . . . . . . . 2-8

2-3. Process heat reactor study: summary of process design conditions........................ 2-9

2-4. Process heat reactor study: summary of capital, operating, and research and development costs ... . . . . . . 2-10

2-5. HTGR plant parameters . . . . . . . . . . . . . . . 2-13

3-1. Survey of process industries . . . . . . . . . . . . . 3-2

4-1. Reformer feed and effluent compositions and physical properties...................... 4-4

4-2. Reformer conversion data ................ . 4-7

4-3. Heat loads and flow rates................ . 4-8

4-4. Makeup boiler feedwater requirements . . . . . . . . . . 4-13

5-1. Thermodynamic data for process heat plant . . . . . . . . . 5-24

5-2. Mechanical data for process heat plant . . . . . . . . 5-25

5-3. Basis for initial materials selection criterion . . . . . . . 5-32

5-4. Material candidates for reformer components . . . . . . . . 5-34

5-5. Chemical analyses (typical) of high-temperature alloys requiring gas/material interaction studies in HTGR helium environment .................... 5-35 
5-6. High-temperature alloy stress rupture values for $1000 \mathrm{hr}$. . 5-36

5-7. High-temperature alloy stress rupture values for $10,000 \mathrm{hr}$. . 5-37

5-8. Material candidates for core outlet duct cover plates . . . 5-38

5-9. Candidate materials for valve components as a function of material temperature . . . . . . . . . . . . . 5-39

5-10. Comparison of costs for candidate reformer materials in tube shape .. . . . . . . . . . . . . . . . 5-41

5-11. Properties of thermal barrier candidate materials . . . . . 5-43

5-12. Design parameters used for reformer location comparison . . . 5-48

5-13. Reformer location cost comparison . . . . . . . . . . 5-49

6-1. Designs for process heat reactor . . . . . . . . . . . 6-2

6-2. Axial profiles . . . . . . . . . . . . . . 6-8

6-3. Design I - core and fuel cycle parameters . . . . . . . . 6-9

6-4. Design II - core and fuel cycle parameters . . . . . . . . 6-13

6-5. Design III - core and fuel cycle parameters . . . . . . . 6-17

6-6. Design IV - core and fuel cycle parameters . . . . . . . . 6-20

6-7. Design V - core and fuel cycle parameters . . . . . . . . 6-24

6-8. Relative Cs-137 release rates for a 3000-MW(t) plant . . . . 6-34

6-9. Core conditions for process heat study . . . . . . . . 6-35

6-10. $\mathrm{Kr}-85 \mathrm{~m} \mathrm{R} / \mathrm{B}$ versus temperature . . . . . . . . . . . . 6-41

7-1. Station staffing versus temperature for nuclear process heat plant . . . . . . . . . . . . . . . . . 7-2

7-2. Scheduled outage versus temperature . . . . . . . . . . 7-6

7-3. Catalyst change-out schedule for one reformer-- $1200^{\circ} \mathrm{F}$ process heat case . . . . . . . . . . . . . . . . . 7-8

7-4. Catalyst change-out schedule for one reformer-- $1400^{\circ} \mathrm{F}$ process heat case .. . . . . . . . . . . . . . 7-9

7-5. Catalyst change-out schedule for one reformer-- $1600^{\circ} \mathrm{F} / 1800^{\circ}-$ $2000^{\circ} \mathrm{F}$ process heat case . . . . . . . . . . . 7-10

8-1. Differential costs for nuclear process heat plant . . . . . 8-2

8-2. Ground rules for equilibrium fuel cycle costs . . . . . . . . 8-12

8-3. Fuel cycle cost based on AEC guideline and LADWP public bid data................... . . . 8-14

8-4. Annual operation and maintenance costs . . . . . . . . . 8-15

9-1. Initial containment conditions . . . . . . . . . . . . 9-10

9-2. Containment variables as a function of reactor outlet temperature . . . . . . . . . . . . . . . . . . . . • 
9-3. CACS parameters . . . . . . . . . . . . . . .

9-4. Relative activity released from PCRV to reactor containment during $\mathrm{DBDA}$....... . . . . . . . . . . . 9-18

9-5. DBDA doses at EAB and $\mathrm{LPZ}$. . . . . . . . . . . . 9-21

9-6. Hydrogen and tritium permeation . . . . . . . . . . . . 9-31

9-7. Doses due to reformer failure . . . . . . . . . . . 9-36

9-8. Relative change in fission product primary circuit activity, plateout, and reformer tubesheet doses.. . . . . . . . . 9-41

10-1. Schedule for initial and integral irradiation tests of advanced HTGR fuel system . . . . . . . . . . . . . . . . 10-9

10-2. HTGR/reformer component material requirements . . . . . . . 10-18

10-3. Summary of HTGR/reformer materials testing requirements . . 10-25

10-4. Estimated time frame and costs for performing required tests - 10-28

10-5. Estimate of minimum number of specimens for each required exposure temperature . . . . . . . . . . . . . 10-29

10-6. Summary of 12-month ceramic materials development program . . 10-65

10-7. Properties for thermal barrier candidate materials . . . . 10-70

10-8. Comparison of helium circulator characteristics . . . . . . 10-75

10-9. Summary of estimated research and development costs . . . . 10-85 


\section{ABSTRACT}

This report presents the results of a study performed for the U.S. Atomic Energy Commission to investigate the uses of the high-temperature gas-cooled reactor (HTGR) as a process heat source. The capability of the General Atomic Company HTGR to develop high temperatures for process heat is discussed. The design of a nuclear process system for steam-methane reforming at temperatures of $1200^{\circ}, 1400^{\circ}, 1600^{\circ}, 1800^{\circ}$, and $2000^{\circ} \mathrm{F}$ is described, and the capital and operating costs of the plant are presented. The research and development efforts for fuel materials, special reactor equipment, and design development are discussed in detail in conjunction with their schedules and costs. Predicted capltal costs are shown not to vary greatly with temperature, but development time and costs are shown to be large at and above a process heat temperature of $1600^{\circ} \mathrm{F}$. The item requiring major development at a process temperature of $1600^{\circ} \mathrm{F}$ is a ceramic process heat exchanger. Beyond this temperature, a major fuel development program is needed unless an advanced fuel management scheme is adapted for the process heat reactor. 


\section{INTRODUCTION AND SUMMARY}

At the request of the U.S. Atomic Energy Commission, a study was performed to assess the available technology of gas-cooled reactors and investigate their potential for supplying process heat to high-temperature industrial processes. The study investigated the technical and economic implications of producing process temperatures of $1200^{\circ}, 1400^{\circ}, 1600^{\circ}$, $1800^{\circ}$, and $2000^{\circ} \mathrm{F}$.

As a basis for the investigation, the General Atomic High-Temperature Gas-Cooled Reactor (HTGR) was adapted for the process heat study conditions. The HTGR is a thermal reactor utilizing helium as a coolant and having an a11-ceramic core composed of thorium and uranium fuel with graphite as a moderator. This combination has enabled the HTGR to develop core outlet temperatures far higher than other reactor systems. For production of electricity, these temperatures permit the production of high-temperature, high-pressure steam, leading to high cycle efficiency. For the present application, the high temperatures permit the insertion of a steam-methane reformer in the helium circuit ahead of the steam generator, while still allowing the generation of high-temperature, high-pressure steam. As in other current HTGR designs, all the primary system components are contained in one large prestressed concrete reactor vessel (PCRV) because of the many advantages afforded by this form of construction.

\subsection{PROCESS HEAT REACTOR}

The standard commercial HTGR can readily be modified for process heat purposes by placing a process heat exchanger in series with and upstream of the steam generator. In the present study, steam-methane reforming was selected for the production of $\mathrm{H}_{2}$ as a typical petrochemical process; and 
for purposes of this report, the reformer was assumed to be located within the PCRV, although the possibility of an intermediate heat transfer loop has not been ruled out.

The addition of a helium-heated steam-methane reformer in a wall cavity of the PCRV is shown in Fig. 2-1. This reformer is similar in size to the existing steam generators, and it can be installed and removed in the same manner as they are.

The process heat HTGR operates as follows. Helium flows downward through the core, where it is heated to a temperature about $200^{\circ} \mathrm{F}$ above the required process temperature. The helium passes through one of the radial ducts going to the reformer and then passes upward through the reformer cavity. Heat is transferred through the reformer tube walls to the steammethane mixture. The helium then flows through the circumferential duct (not shown in Fig. 2-1) to the adjacent steam generator cavity, where it passes downward over the steam generator coils. It next passes upward around the steam generator and into the helium circulator, where it is compressed. It then passes through the upper horizontal duct and back into the core.

An overall process flow diagram is shown in Fig. 2-2 for a helium outlet temperature of $1620^{\circ} \mathrm{F}$. The steam-methane mixture is preheated before it enters the reformer. It passes through the reformer, where $\mathrm{H}_{2}$, $\mathrm{CO}$, and $\mathrm{CO}_{2}$ are formed in the presence of a nickel catalyst with the addition of heat from the helium. Reformer outlet conditions are between $1200^{\circ}$ and $2000^{\circ} \mathrm{F}$, as required by the study. Downstream processing of this mixture will shift the $\mathrm{CO}$ plus $\mathrm{H}_{2} \mathrm{O}$ to $\mathrm{H}_{2}$ and $\mathrm{CO}_{2}$ and scrub out the $\mathrm{CO}_{2}$, leaving $\mathrm{H}_{2}$, the remainder being $\mathrm{CH}_{4}$. The once-through steam generator takes feedwater and produces 2500-psig steam at $955^{\circ} \mathrm{F}$, the same as in the conventiona1 HTGR.

The reformer itself represents the one new piece of equipment in the HTGR. Although it is expected that the design will differ significantly from that of the steam generator, the experience and technical information 


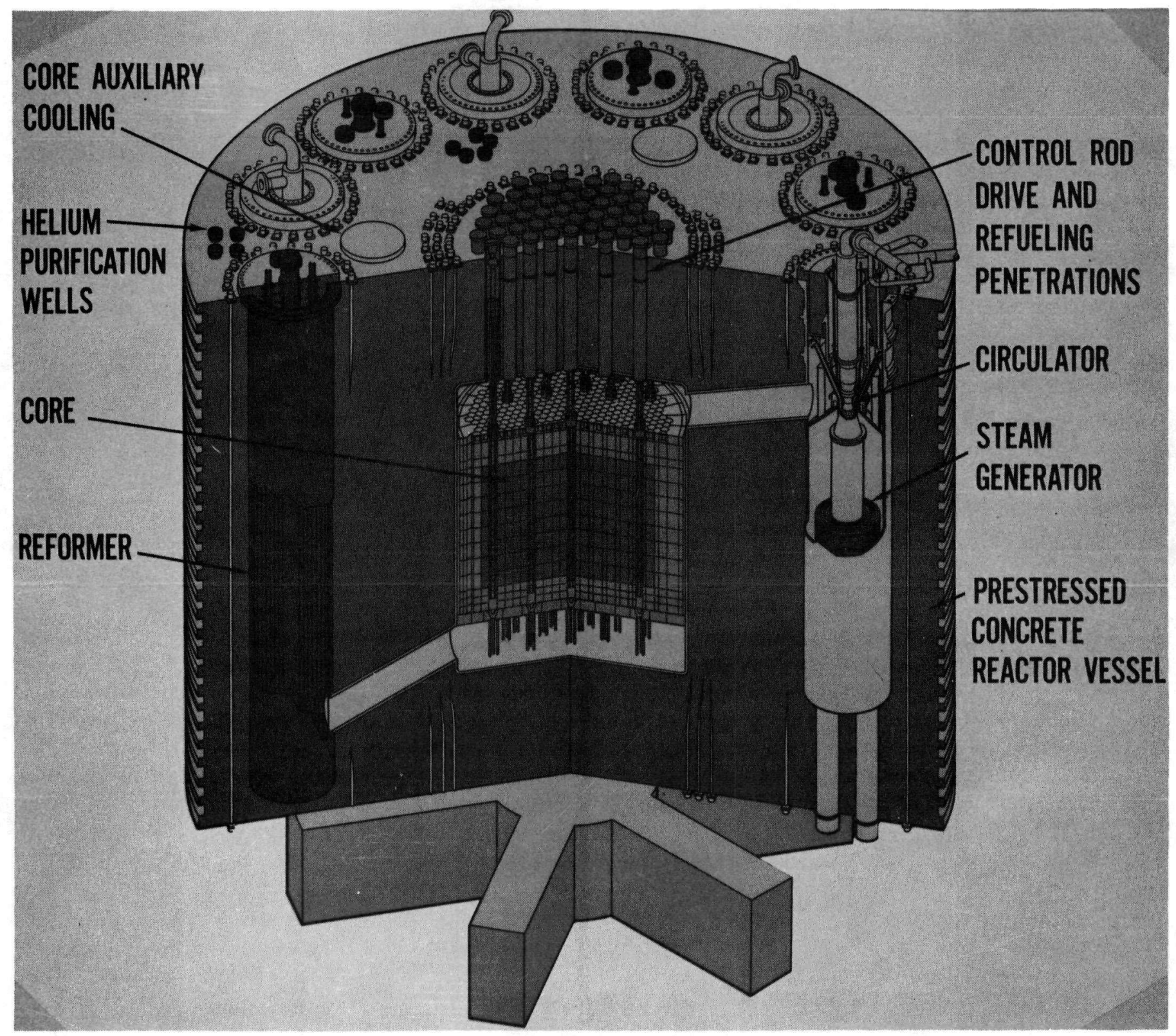

Fig. 2-1. Process heat HTGR 


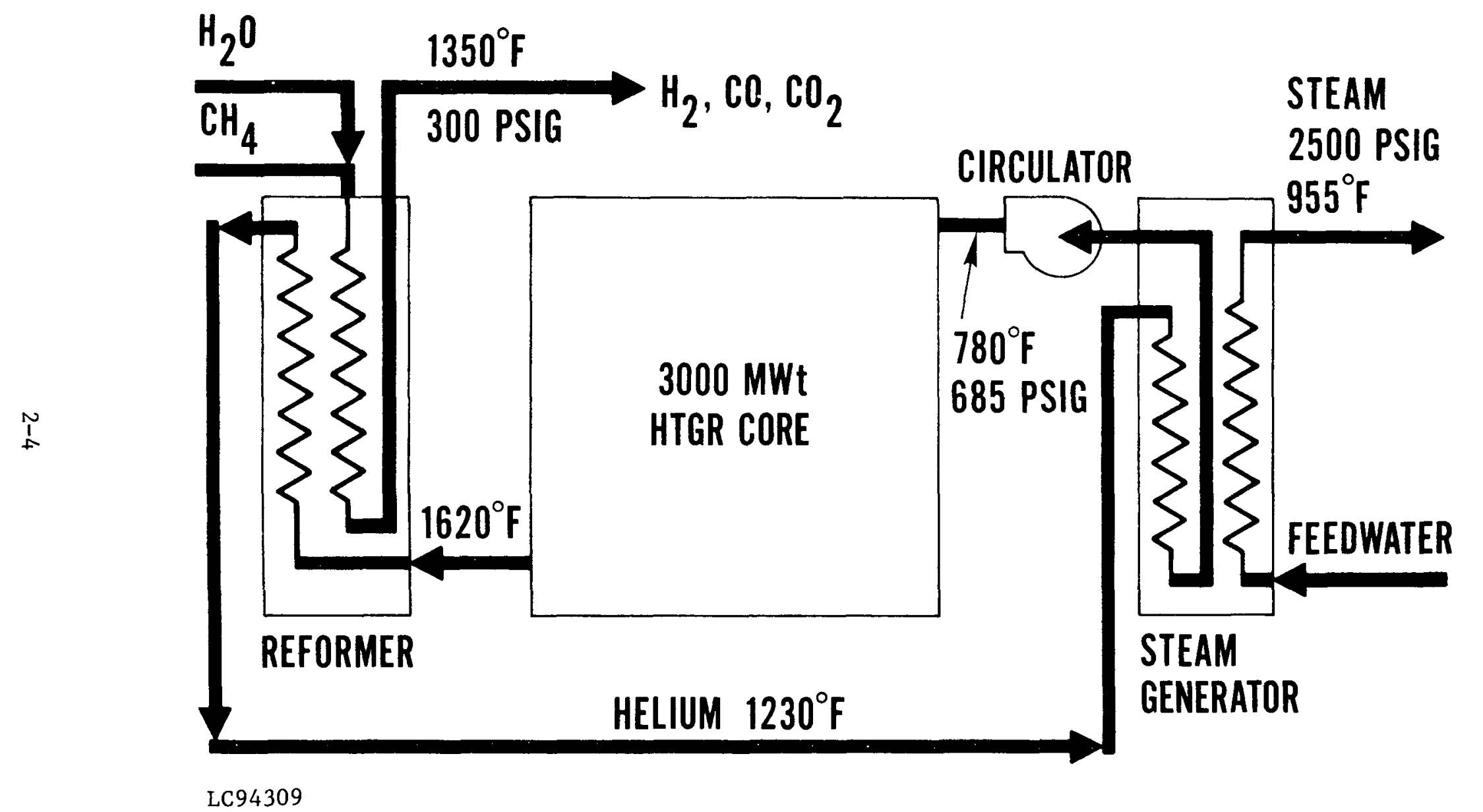

Fig. 2-2. Helium heat transfer loop 
gained in developing the HTGR steam generator will be most valuable. A program is present1y under way at General Atomic Company to develop the nuclear-heated reformer.

In the standard HTGR, helium leaves the core at about $1400^{\circ} \mathrm{F}$, while for the process heat HTGR studied, core outlet temperature varies from $1400^{\circ}$ to $2200^{\circ} \mathrm{F}$.

A summary of the significant changes and additions at the various temperature levels is presented below.

\section{$1200^{\circ} \mathrm{F}$ Process Temperature}

1. Add a metallic reformer to the standard HTGR.

\section{$1400^{\circ} \mathrm{F}$ Process Temperature}

1. Add a metallic reformer to the standard HTGR.

2. Change to an advanced thermal barrier using refractory metal cover plates over high-quality fibrous insulation.

\section{$1600^{\circ} \mathrm{F}$ Process Temperature}

1. Change from a metallic reformer to a ceramic or superalloy reformer.

2. Utilize an advanced thermal barrier using metallic materials.

3. Employ the most advanced fuel particles available today.

\section{$1800^{\circ} \mathrm{F} / 2000^{\circ} \mathrm{F}$ Process Temperature}

1. Utilize a ceramic reformer. 
2. Replace the advanced metallic thermal barrier with an a11-ceramic one.

3. Change to a fuel having enhanced high-temperature stability and increased fission product retention.

A synopsis of the fuel design characteristics, reactor mechanical variations, and process design conditions and costs is presented in Tables 2-1 through 2-4.

With the majority of process heat uses below $1600^{\circ} \mathrm{F}$, the use of a nuclear process heat reactor seems close at hand. Research and development programs for temperatures below $1600^{\circ} \mathrm{F}$ are of a short-term nature, and costs and risks do not appear excessive.

Safety considerations show that at all temperatures, the primary safety problem is associated with a reformer or process line explosion breaching the reactor and containment. Preliminary studies indicate that this problem is amenable to solution with the reformer retained inside the PCRV.

\subsection{COMMERCIAL STEAM-PRODUCING HTGR}

A basic understanding of the standard commercial steam-producing HTGR is valuable in understanding how it may be adapted to process heat uses. Therefore, a brief description of the 3000-MW(t) HTGR for electric power production is presented below.

\subsubsection{Nuclear Steam Supply System}

The major components of the reactor system (including the reactor core, control rod drive assemblies, steam generators, helium circulators, and core auxiliary cooling system) are contained within the PCRV. The general arrangement of the nuclear steam supply system (NSS) equipment within the 
PROCESS HEAT REACTOR STUDY: SUMMARY OF FUEL DESIGN CONDITIONS

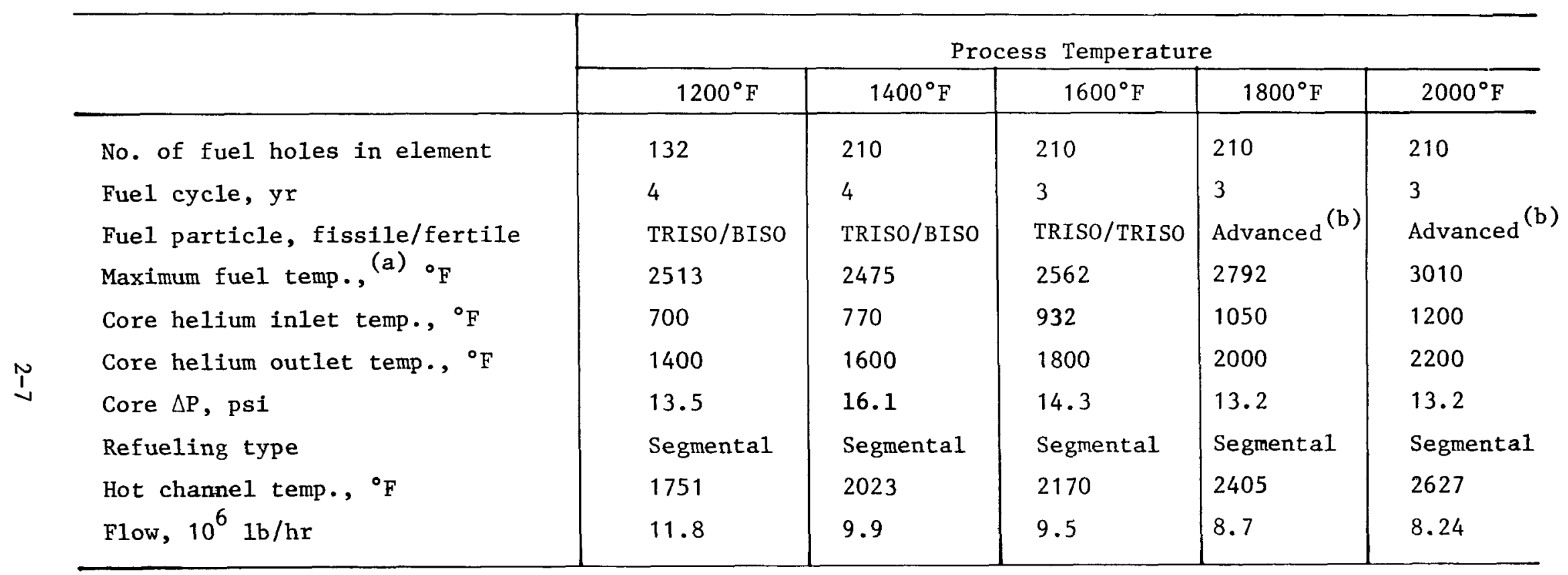

(a) Commercial HTGR value is $2560^{\circ} \mathrm{F}$.

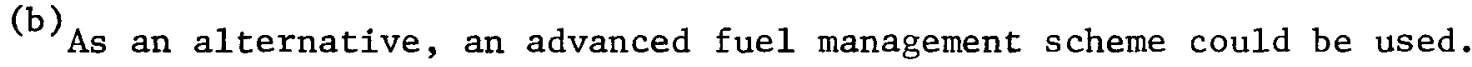


TABLE 2-2

PROCESS HEAT REACTOR STUDY: SUMMARY OF MECHANICAL CHARACTERISTICS

\begin{tabular}{|c|c|c|c|c|c|}
\hline & \multicolumn{5}{|c|}{ Process Temperature } \\
\hline & $1200^{\circ} \mathrm{F}$ & $1400^{\circ} \mathrm{F}$ & $1600^{\circ} \mathrm{F}$ & $1800^{\circ} \mathrm{F}$ & $2000^{\circ} \mathrm{F}$ \\
\hline \multicolumn{6}{|l|}{ PCRV } \\
\hline $\begin{array}{l}\text { Max. external diameter } \\
(\mathrm{OD} \times \mathrm{h} t) \text {, ft }\end{array}$ & $115 \times 84$ & $115 \times 84$ & $108 \times 84$ & $108 \times 84$ & $108 \times 84$ \\
\hline $\begin{array}{l}\text { Core cavity } \\
\text { (ID } \times h t), \text { ft-in. }\end{array}$ & $37 \times 47-4$ & $37 \times 47-4$ & $37 \times 47-4$ & $37 \times 47-4$ & $37 \times 47-4$ \\
\hline Normal working pressure, psig & 710 & 710 & 710 & 710 & 710 \\
\hline Number of reformers & 6 & 6 & 4 & 4 & 4 \\
\hline $\begin{array}{l}\text { Reformer cavity size } \\
(\text { ID } x h t), \text { ft-in. }\end{array}$ & $13-6 \times 34$ & $13-6 \times 62-5$ & $13-6 \times 62-6$ & $13-6 \times 62-6$ & $13-6 \times 62-6$ \\
\hline Reformer tube material & $\mathrm{HK}-40$ & $\mathrm{HK}-40$ & $\begin{array}{l}\text { SiC or super- } \\
\text { alloys (a) }\end{array}$ & $\mathrm{SiC}$ & $\mathrm{SiC}$ \\
\hline Number of steam generators & 6 & 6 & 4 & 4 & 4 \\
\hline Insulation cover plate material & Hastelloy $\mathrm{X}$ & Mo-TZM & $\begin{array}{l}\text { Carbon } \\
\text { composite }\end{array}$ & $\begin{array}{l}\text { Carbon } \\
\text { composite }\end{array}$ & $\begin{array}{l}\text { Carbon } \\
\text { composite }\end{array}$ \\
\hline
\end{tabular}

(a) Some superalloys may be suitable at this temperature. 
TABLE 2-3

PROCESS HEAT REACTOR STUDY: SUMMARY OF PROCESS DESIGN CONDITIONS

\begin{tabular}{|c|c|c|c|c|c|}
\hline & \multicolumn{5}{|c|}{ Process Temperature } \\
\hline & $1200^{\circ} \mathrm{F}$ & $1400^{\circ} \mathrm{F}$ & $1600^{\circ} \mathrm{F}$ & $1800^{\circ} \mathrm{F}$ & $2000^{\circ} \mathrm{F}$ \\
\hline $\begin{array}{l}\text { Reformer product } \\
\left(\mathrm{H}_{2}+\mathrm{CO}\right) \text {, MMSCFD }\end{array}$ & 920 & 1543 & 1743 & 1859 & 2091 \\
\hline $\begin{array}{l}\text { Process gas flow (wet), } \\
10^{6} \mathrm{lb} / \mathrm{hr}\end{array}$ & 6.81 & 6.81 & 4.94 & 3.06 & 3.06 \\
\hline Dry gas feed $\left(10^{6} \mathrm{lb} / \mathrm{hr}\right)$ & 1.192 & 1.192 & 1.192 & 1.192 & 1.192 \\
\hline Steam:gas mole ratio & $4.5: 1$ & $4.5: 1$ & $3.0: 1$ & $1.5: 1$ & $1.5: 1$ \\
\hline Maximum process gas temp., ${ }^{\circ} \mathrm{F}$ & 1200 & 1400 & 1590 & 1790 & 1940 \\
\hline Process gas $\Delta P$, psi & 68 & 215 & 170 & 87 & 72 \\
\hline $\begin{array}{l}\text { Process gas outlet pressure, } \\
\text { psia }\end{array}$ & 300 & 300 & 400 & 500 & 600 \\
\hline Reformer heat duty, $10^{9} \mathrm{Btu} / \mathrm{hr}$ & 2.50 & 4.82 & 5.84 & 6.38 & 7.45 \\
\hline $\begin{array}{l}\text { Steam generator heat duty, } \\
10^{9} \mathrm{Btu} / \mathrm{hr}\end{array}$ & 8.00 & 5.68 & 4.66 & 4.12 & 3.05 \\
\hline Number of reformers & 6 & 6 & 4 & 4 & 4 \\
\hline Total reformer area, $\mathrm{ft}^{2}$ & 152,094 & 245,694 & 212,608 & 223,352 & 223,352 \\
\hline
\end{tabular}


TABLE 2-4

PROCESS HEAT REACTOR STUDY: SUMMARY OF CAPITAL, OPERATING, AND RESEARCH AND DEVELOPMENT COSTS

\begin{tabular}{|c|c|c|c|c|c|}
\hline & \multicolumn{5}{|c|}{ Process Temperature } \\
\hline & $1200^{\circ} \mathrm{F}$ & $1400^{\circ} \mathrm{F}$ & $1600^{\circ} \mathrm{F}$ & $1800^{\circ} \mathrm{F}$ & $2000^{\circ} \mathrm{F}$ \\
\hline $\begin{array}{l}\text { Capital cost (increase over standard } \\
\text { NSS), } \$ 1000\end{array}$ & 66,518 & 67,670 & 88,586 & 100,173 & 106,000 \\
\hline $\begin{array}{l}\text { Research and development and design } \\
\text { development costs, } \$ 1000\end{array}$ & 49,845 & 51,345 & 65,175 & 78,330 & 78,330 \\
\hline $\begin{array}{l}\text { Annual operating and maintenance } \\
\text { costs, } \$ 1000\end{array}$ & 4,326 & 4,007 & 3,827 & 3,887 & 3,737 \\
\hline Fuel cycle cost, c/MMBtu & 20.70 & 21.15 & 25.90 & $25 \cdot 90$ & 25.90 \\
\hline $\begin{array}{l}\text { Earliest time of first plant } \\
\text { offering, yr }\end{array}$ & 4 & 4 & 6 & 8 & 8 \\
\hline
\end{tabular}


PCRV is shown in Fig. 2-3. Typical NSS parameters and steam plant characteristics for a 3000-MW(t) HTGR are shown in Table 2-5.

The six steam generators and circulators are located in cavities spaced symmetrically around the central cavity. Process and service connections to the steam generators are made through penetrations at the bottom of the PCRV, while circulator connections are at the top. Three additional cavities contain core auxiliary cooling loops, each consisting of an auxiliary circulator and heat exchanger. Seventy-three control rod drives, each operating two control rods, are located in penetrations at the top of the PCRV. These penetrations also provide access for fuel reloading operations.

\subsubsection{Core and Major Components}

Each HTGR plant size [770 MW(e), $1160 \mathrm{MW}(\mathrm{e})$ ] uses the same basic components as building blocks in the NSS, including steam generators, main and auxiliary circulators, control rod drives, fuel elements, fuel building equipment, and auxiliary support systems for the circulators, for primary coolant cleanup, and for radioactive gas handling.

\subsubsection{Fuel. The reactor core is made up of hexagonally shaped fuel} elements approximately $14 \mathrm{in.} \mathrm{across}$ the flats by $31 \mathrm{in.} \mathrm{high.} \mathrm{The} \mathrm{fuel,}$ in the form of bonded coated fissile $\left(\mathrm{UC}_{2}\right)$ and fertile $\left(\mathrm{ThO}_{2}\right.$ ) particles, is located in axial blind holes in the graphite fuel elements. Axial open coolant holes are provided for helium flow through the elements. The fuel elements are stacked in columns eight blocks high. The active core is surrounded by graphite reflector elements, and the entire assembly is mounted on a graphite block support floor.

2.2.2.2. Steam Generators. Each once-through steam generator is composed of two separate, helically colled tube bundles, one for the main steam section (economizer-evaporator-superheater) and the other for the reheater section. Feedwater enters the economizer at $3100 \mathrm{psig}$ and $370^{\circ} \mathrm{F}$ at rated load. Superheated steam at $2500 \mathrm{psig}$ and $950^{\circ} \mathrm{F}$ is brought out the bottom 


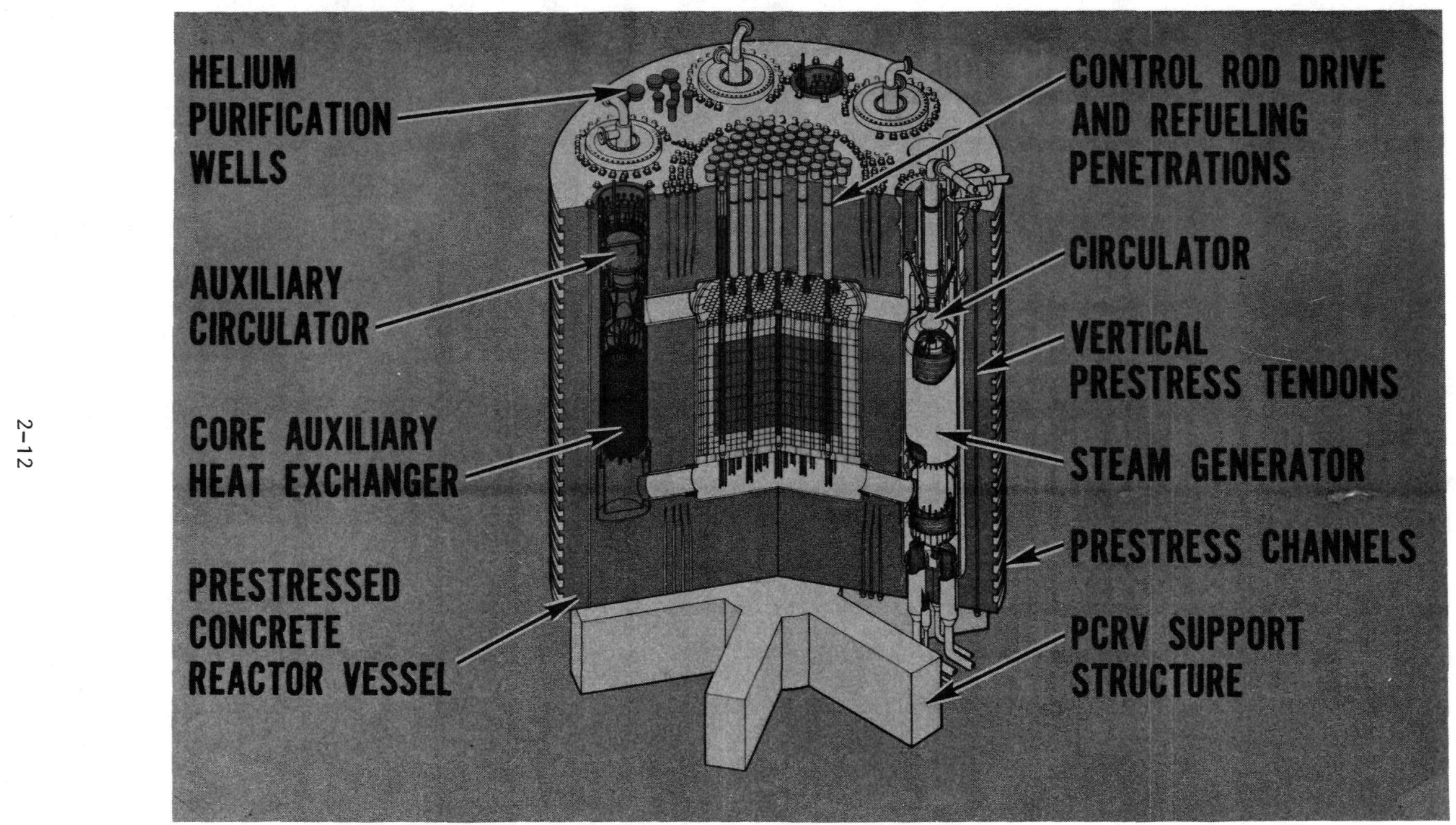

Fig. 2-3. General arrangement of large HTGR nuclear steam supply system 
TABLE 2-5

HTGR PLANT PARAMETERS

\begin{tabular}{l|l}
\hline Nominal net plant output & $1160 \mathrm{MW}(\mathrm{e})$ \\
Reactor thermal output & $3000 \mathrm{MW}(\mathrm{t})$ \\
Primary coolant (helium) flow & $11.23 \times 10^{6} \mathrm{lb} / \mathrm{hr}$ \\
Primary coolant temperature (cold/hot) & $605 / 1366^{\circ} \mathrm{F}$ \\
Primary coolant pressure & $725 \mathrm{psia}$ \\
Core dimension (diameter/height) & $28 / 21 \mathrm{ft}$ \\
Number of fuel elements/columns & $3944 / 493$ \\
Average fuel burnup & $95,000 \mathrm{MWd} / \mathrm{tonne}$ \\
PCRV external dimensions (diameter/height) & $100 / 91 \mathrm{ft}$ \\
Number of control rods (two per drive) & 146 \\
Number of helium circulators/steam generators & 6 \\
Steam conditions & $2400 / \mathrm{psig/}$ \\
Reheat steam conditions at IP turbine & $950^{\circ} \mathrm{F} / 1000^{\circ} \mathrm{F}$ \\
Main steam flow & $575 \mathrm{psig} / 1000^{\circ} \mathrm{F}$ \\
Reheat steam flow & $8,060,000 \mathrm{lb} / \mathrm{hr}$ \\
Net thermal efficiency & $7,960,000 \mathrm{bb} / \mathrm{hr}$ \\
Turbine back pressure & $38.5 \%$ \\
\hline
\end{tabular}


penetration in the PCRV and headered into the main steam piping to the main turbine. After expansion in the high-pressure section of the main turbine, the steam is returned to the NSS, where it enters the circulator turbine inlet valves. Cold reheat steam from the circulator turbines is directed into the reheater sections of the steam generators. The reheater sections are mounted below the main steam bundle and are exposed to the high-temperature helium leaving the core. The hot reheat steam leaves the reheaters at $570 \mathrm{psig}$ and $1000^{\circ} \mathrm{F}$ and returns to the intermediate-pressure section of the main turbine. An overall flow diagram of this secondary cooling system is shown in Fig. 2-4.

\subsubsection{Circulators. Each primary coolant loop is equipped with an} identical helium circulator. The circulator unit consists of a singlestage axial flow compressor and a single-stage steam-turbine drive. The circulators are driven by cold reheat steam from the main turbine.

\subsubsection{PCRV. The PCRV is composed of an internal steel liner acting as} a sealing membrane, a thermal barrier and cooling system to limit concrete temperatures, penetrations and closures to provide access to the vesse1 cavities, and high-strength concrete with bonded reinforcing steel and prestressing systems to provide strength. The liner, concrete, reinforcing steel, and prestressing function as a composite structural system. In addition to serving as the primary coolant system pressure boundary, the PCRV provides shielding for the reactor core. The liner, which is a ductile carbon steel, also serves as the interior form for the concrete during construction.

The thermal barrier consists principally of ceramic fiber insulation blankets installed on the helium side of the PCRV liner. An exception is the thermal barrier on the PCRV floor or directly below the core, where fused silicon blocks are used to supplement the ceramic fiber blankets.

2.2.2.5. Core Auxiliary Cooling. The core auxiliary cooling system has three cooling loops that circulate and cool primary system helium if the main loops are out of service. Each cooling loop includes a heat exchanger, 


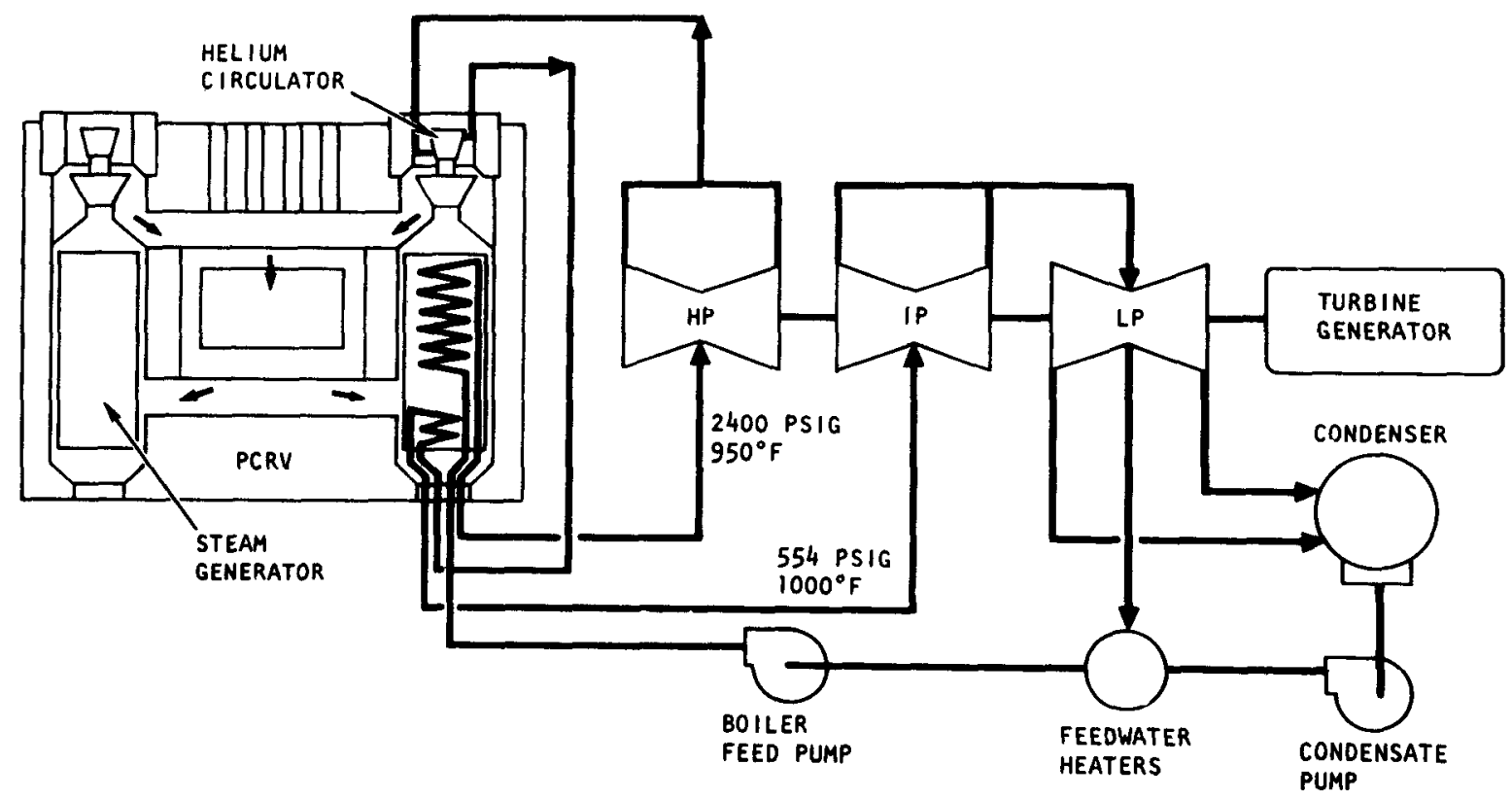

Fig. 2-4. Overall plant flow diagram of typical secondary cooling system 
an auxiliary circulator, and a helium shutoff valve, all located within the PCRV. A closed cooling water circuit external to the PCRV for each loop removes heat and rejects it to the atmosphere via air-cooled heat exchangers.

\subsubsection{Auxiliary Systems}

The auxiliary fluid systems for the NSS consist of the main circulator service system, auxiliary circulator service system, helium purification system, radioactive waste systems, and radioactive gas recovery system. Separate service modules are provided for each of the main and auxiliary circulators so that every circulator operates as a separate and independent system.

\subsubsection{Plant Control}

The control system is designed to allow the plant to automatically follow load. It maintains reactor power and main turbine inlet steam conditions at required levels through all ranges of normal plant operation. Three major plant automatic control loops minimize deviations of reheat steam temperature, main steam temperature, and main steam pressure from programmed setpoints during transients. Each control loop responds to changes in turbine-generator load so that steady-state operation at the new load point occurs within a specified time interval. The normal operating range of the major automatic control loops extends from $25 \%$ to the ful1-1oad rating. 


\section{PROCESS HEAT USES}

The details of the processes appropriate for nuclear heat applications are beyond the scope of this report. However, a brief summary of industrial process heat requirements is presented to establish methods for applying nuclear heat which are compatible with the process industries.

\subsection{OVERVIEW}

The industrial sector of the economy accounted for $43 \%$ of the total energy consumption in the United States in 1973. At present, industrial energy needs are supplied primarily by fossil fuels, with approximately $26 \%$ being used for fired heat, $40 \%$ for process steam, $24 \%$ for electricity, and $9 \%$ for feedstock. Table 3-1 1ists the major process heat consumers with their energy consumptions and the associated process temperatures. The processes are categorized as (1) recovery and upgrading of fossil fuels; (2) primary metals; (3) chemicals; (4) papermaking; and (5) stones, clays, and ceramics. Of these, the chemical industry consumes the largest fraction, $20 \%$, with nearly half attributable to feedstock. Chemicals are followed by primary metals, $19 \%$; petroleum refining, $11 \%$; papermaking, $9 \%$; and stones, clays, and ceramics, $9 \%$.

Several industrial processes have energy requirements that are compatible with large [2000- to 3000-MW(t)] HTGRs, both with regard to size and temperature requirements. Over the range of temperatures considered in the present study, the maximum process temperature of the major energyconsuming processes is $1700^{\circ} \mathrm{F}$ for direct reduction of iron ore. Several processes require process heat at temperatures from $1100^{\circ}$ to $1500^{\circ} \mathrm{F}$, primarily for steam-hydrocarbon reforming. Olefin furnaces also require process heat in this range, but the total energy consumption is far less than for steam-hydrocarbon reforming. 
TABLE 3-1

SURVEY OF PROCESS INDUSTRIES

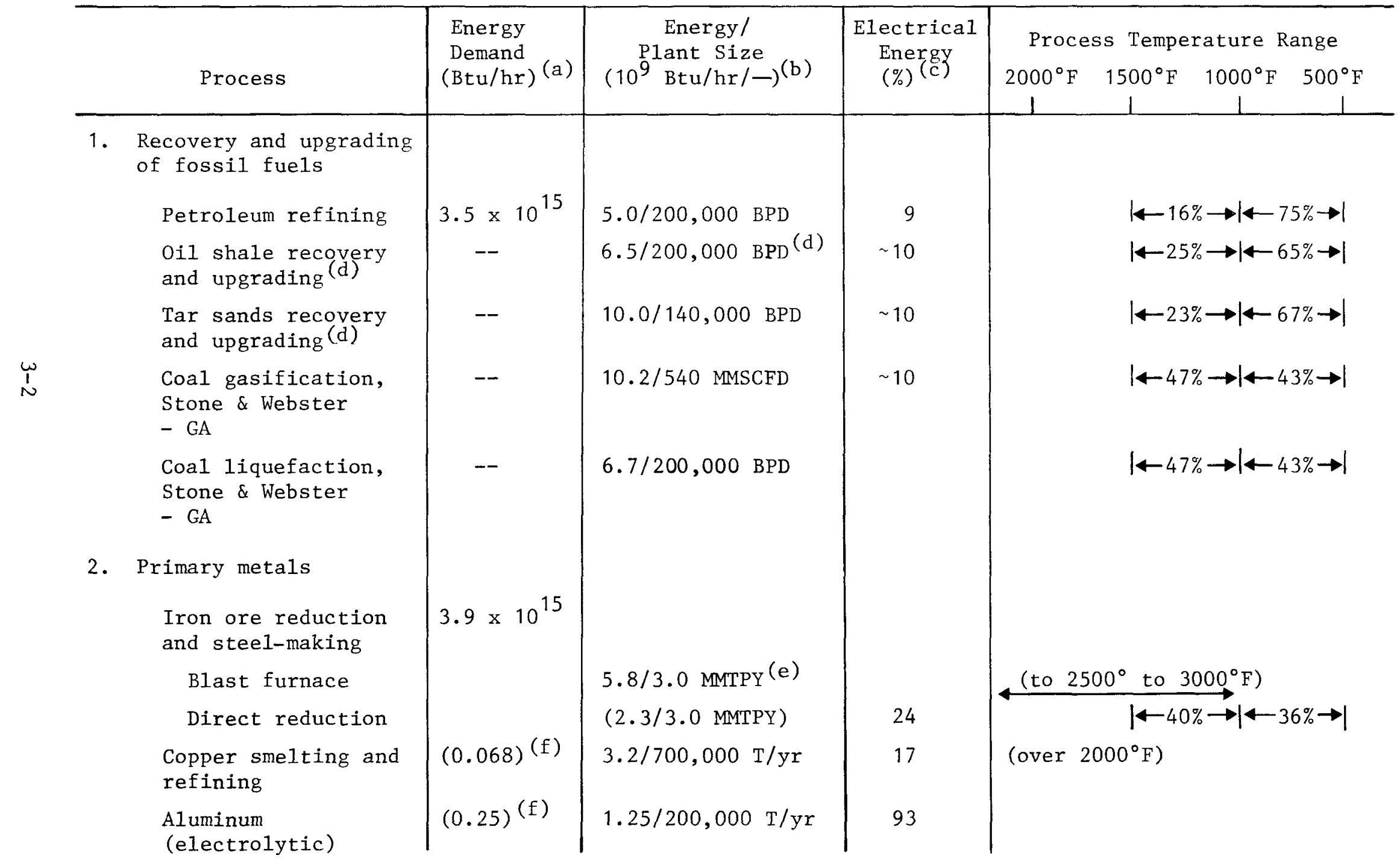


TABLE 3-1 (Continued)

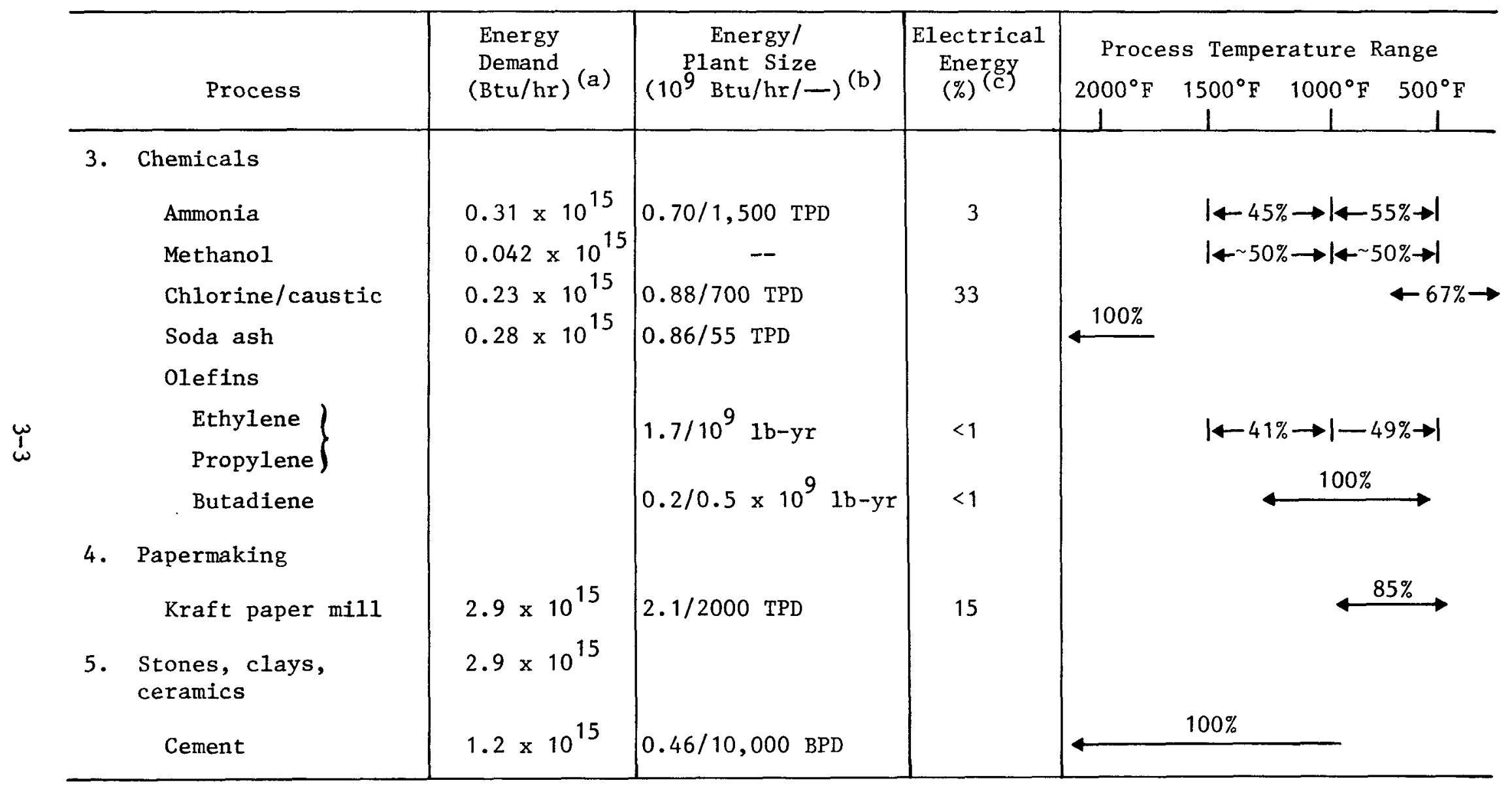


(a) Estimates of 1973 energy use based on Stanford Research Institute data. Equivalent energy of feedstock is included.

(b) Plant capacities are intended to be typical of present-day large plants. Energy requirements do not include fossil fuels used as feedstock except where noted.

(c) Calculated by GA based on Stanford Research Institute analysis.

(d) Calculated by GA based on Stanford Research Institute analysis.

(e) Process heat requirements and feedstock requirements are included.

(f) Estimated from typical process heat requirements per unit metal and total 1973 production. 


\subsubsection{Recovery and Upgrading of Fossil Fuels}

Present energy consumption in upgrading of fossil fuels is almost entirely in petroleum refining. The energy use in petroleum refining varies considerably from one refinery to another, depending on the severity of processing and the extent of petrochemical production. A sampling of a few large refineries indicated variations in energy use from $3.0 \times 10^{9}$ to $6.5 \times 10^{9} \mathrm{Btu} / \mathrm{hr}$ (about 900 to $2000 \mathrm{MW}$ ) when normalized to 200,000-BPD capacity. A1though many existing refineries are small, a capacity of 200,000 BPD is considered practical for a modern refinery. Presently, grass roots refineries have capacities of about 150,000 BPD, and over $25 \%$ of the refining capacity in the United States is in refineries producing more than 200,000 BPD.

Maximum process temperatures of $1500^{\circ} \mathrm{F}$ are employed in steam-hydrocarbon reformers for production of hydrogen. Hydrogen consumption in refineries has increased dramatically in the past decade with the advent of hydrocracking and increased hydrodesulfurization capacity. The major deterent limiting hydrocracking capacity today is the cost of hydrogen. All other refinery operations require temperatures of $1000^{\circ} \mathrm{F}$ or below. About $80 \%$ of the process heat is in the form of fired heat.

The possible future development of alternate sources of crude oil offers more promising applications for nuclear heat. As indicated in Table 3-1, production of synthetic crudes from tar sands, coal, and oil shale deposits requires substantially more energy per barrel of oil than conventional petroleum refining. Significant quantities of hightemperature heat are required for production of hydrogen for upgrading to synthetic crudes. Therefore, coal gasification and liquefaction using nuclear heat can provide the means of using nuclear energy for district heating and transportation as well as industrial process heat. Coal gasification also requires large quantities of high-temperature heat. The coal gasification figures in Table 3-1 are for the Stone \& Webster - General Atomic process, in which half of the process heat requirements are for steam-hydrocarbon reforming to make hydrogen. 
The potential for conservation of fossil fuels by the substitution of nuclear fuels is great, particularly in the areas of oil shale and tar sands recovery and coal gasification and liquefaction. However, low-grade by-product fuels are generally used to supply process heat requirements. For example, steam for tar sands recovery is generated using by-product coke obtained from upgrading of the bitumen. About one-third of the process heat requirements in a typical oil refinery are supplied by lowgrade fuels. If substitution of nuclear process heat is to be economical, additional upgrading of these low-grade fuels to readily marketable products will be necessary.

\subsubsection{Primary Metals}

The iron and steel industry accounts for almost two-thirds of the energy consumption of the primary metals industries. Although conventional blast furnace processes require temperatures beyond the range of HTGR technology, direct reduction of iron ores with hydrogen and carbon monoxide is now competitive. Maximum temperatures in direct reduction processes are about $1700^{\circ} \mathrm{F}$. After reduction, the reduced iron briquettes are fed to an electric arc furnace for conversion to steel. A 3000-MW(t) HTGR could supply the energy needs for production of about 6 MMTPY of finished steel. This is considerably greater than the capacity of present modern steel-making plants but may prove feasible.

Copper and aluminum smelting and refining are additional energyconsuming industrial processes (see Table 3-1). Almost the entire energy consumption for aluminum smelting is in the form of electrical energy, and no special considerations are required for application for nuclear power. In the smelting of copper, direct fired heat is used and temperatures are higher than the temperatures considered in this study. 


\subsubsection{Chemicals}

The chemical industry is characterized by a multitude of diverse processes and associated products. Some of the larger energy consumers are given in Table 3-1. The processes listed account for about $50 \%$ of the total energy consumption of the chemical industry if consumption of feedstock is included. These processes provide an indication of the varied process heat requirements of the industry. Ammonia and methanol production require large quantities of fired heat for production of hydrogen and hydrogen and $\mathrm{CO}$, respectively. Olefins require substantial quantities of fired heat, but the process heat requirements are overshadowed by the consumption of fossil fuels as feedstock. Chlorine caustic production requires large quantities of steam and electricity. Several processes require temperatures beyond the range of HTGR technology, manufacture of soda ash being an example.

Even for the largest energy-consuming processes in the chemical industry, the energy demand for present plants is insufficient to merit a large HTGR as a power source. However, the interdependence of the members of the chemical industry has led to the formation of large chemical complexes along the Gulf Coast in Louisiana and Texas with energy requirements of several thousand megawatts. A large HTGR could supply process heat for several plants in a large chemical complex.

\subsubsection{Papermaking}

Paper mills use large quantities of low-pressure steam and electricity. In Kraft mills, process steam requirements are about $23 \mathrm{MMBtu} /$ ton of paper if steam produced from burning waste products is excluded. Electric power requirements account for about $10 \%$ of the energy consumption. Modern large mills have capacities of about 2000 TPD and energy requirements of $2.1 \times 10^{9} \mathrm{Btu} / \mathrm{hr}(610 \mathrm{MW})$. A1though the energy requirements are too small to be economically feasible for an HTGR, supplying process heat for a paper mill and electric power for residential use may be feasible with an HTGR. 
3.1.5. Stones, Clays, and Ceramics

In genera1, the temperatures required by the stone, clay, and ceramics industries are too high to be feasible applications for nuclear process heat. Table 3-1 lists only cement manufacture, but it accounts for about $50 \%$ of the energy requirements of these industries. The majority of the process heat requirements are in the form of direct fired heat in rotary kilns used for cement burning. Temperatures of about $1150^{\circ} \mathrm{C}$ are required. Application of nuclear heat would be possible only if electrothermal processes for cement burning were developed.

\subsection{METHODS FOR APPLYING NUCLEAR PROCESS HEAT}

It is clear from the survey presented in section 3.1 that the majority of energy intensive processes require high-temperature fired heat. For nuclear process heat to make a significant impact on energy use in the industrial sector, it must provide a reasonable substitute for fired heat as well as generate steam and electrical power. Three general approaches for supplying nuclear process heat have been considered:

1. Special steam cycles.

2. Intermediate heat transfer loop.

3. Steam-hydrocarbon reforming.

For selected processes or chemical complexes where process steam and electrical power supply the entire energy demand, conventional HTGRs coupled with special steam power cycles tailored to the process needs would be applicable. An intermediate loop would be generally applicable but particularly suited for processes with several units requiring hightemperature heat. Steam-hydrocarbon reforming is included in a separate category because of its large present and future potential use in a variety of industries.

The possible application of nuclear process heat to thermochemical water splitting is treated as a separate topic. 


\subsubsection{Steam-Hydrocarbon Reforming}

Steam-hydrocarbon reforming for the production of hydrogen or reducing gas is a common process in many industries. With the increase in hydrocracking and hydrotreating in petroleum refineries in the past decade, refineries now account for $45 \%$ of the demand for hydrogen, with ammonia production accounting for another $45 \%$. Production of methanol accounts for about $3 \%$ of the total $\mathrm{H}_{2}$ demand. Potential future needs for hydrogen or reducing gas are in production of synthetic crudes for oil shale and tar sands, coal gasification, and direct reduction of iron ores. For direct reduction of iron ores and for coal gasification, the process heat requirements are primarily for the production of hydrogen or reducing gas. In ammonia manufacture almost all the heat requirements are also for reforming, but current economical plant sizes for ammonia production are too small to justify a large HTGR. For ammonia and other smaller hydrogen users, an HTGR producing merchant hydrogen might be appropriate.

The widespread use of steam-hydrocarbon reforming justifies its consideration as a special topic. In certain processes, steam-hydrocarbon reforming accounts for all the high-temperature furnace heat requirements, making possible a specialized HTGR with a steam-methane reformer located inside the PCRV and directly heated by the primary loop helium. Examples of such processes are coal gasification and liquefaction by the Stone \& Webster process and iron and steel production, both of which are discussed below. Use of an intermediate heat transfer loop to provide reformer process heat with reformers outside the PCRV is also possible. The external reformer arrangement is discussed in more detail in Section 3.2.3.

Stone \& Webster Engineering Corporation and General Atomic Company are currently developing a coal gasification process with process heat supplied by a 3000-MW( $t$ ) HTGR. The process converts coal to liquids or SPG by hydrogenation of coal solutions. For production of 540 MMSCFD of SPG, the reformer alone accounts for $47 \%$ of the process heat requirements, with the production of steam for the reformer feed accounting for an additional $42 \%$. 
The top process temperature in the reformer is $1350^{\circ} \mathrm{F}$, and the top helium temperature is around $1600^{\circ} \mathrm{F}$. About $50 \%$ of the process heat requirements are above $1000^{\circ} \mathrm{F}$.

Direct reduction of iron ore is currently competitive with reduction in blast furnaces. In direct reduction, iron ore is reduced by $\mathrm{H}_{2}+\mathrm{CO}$ which is produced by steam-hydrocarbon reforming. The reduced iron briquettes are fed to an electric arc furnace to make steel. Process temperatures of $1700^{\circ} \mathrm{F}$ are required in the reformer in order to reduce the methane content to acceptable levels. The flowsheet shown in Fig. 3-1 was developed by the American Iron and Steel Institute for an HTGR with a top helium temperature of $1600^{\circ} \mathrm{F}$. The nuclear-heated reformer is followed by a fossil-fired reformer to obtain process temperatures of $1700^{\circ} \mathrm{F}$. The unconverted reducing gas leaving the iron ore reduction bed which is normally used to fire the reformer is recycled.

The principal use of hydrogen in the chemical industry is for production of ammonia, with production of methanol second. The economical plant size for modern ammonia plants is 1500 TPD, which would have energy requirements of $0.7 \times 10^{10} \mathrm{Btu} / \mathrm{hr}$, far below the output of a large HTGR. Application of a large HTGR to ammonia production would be practical if the ammonia plant were associated with a large chemical complex. An alternate approach would be to produce merchant hydrogen for ammonia production and other processes. Some difficulties with this approach may arise from the specific requirements of various processes. In conventional ammonia plants, the reformer products are mixed with air and fed to a secondary reformer for partial oxidation. Obtaining the proper stoichiometric ratio of nitrogen and hydrogen requires a specific reformer effluent composition. In addition, the by-product $\mathrm{CO}_{2}$ from hydrogen production is often used to make urea. In methanol synthesis both hydrogen and $\mathrm{CO}$ are required. Whether economical means of transportation are available for merchant hydrogen is also questionable.

Alternate processes for production of hydrogen are available. Electrolytic hydrogen has not been discussed because it is currently not 


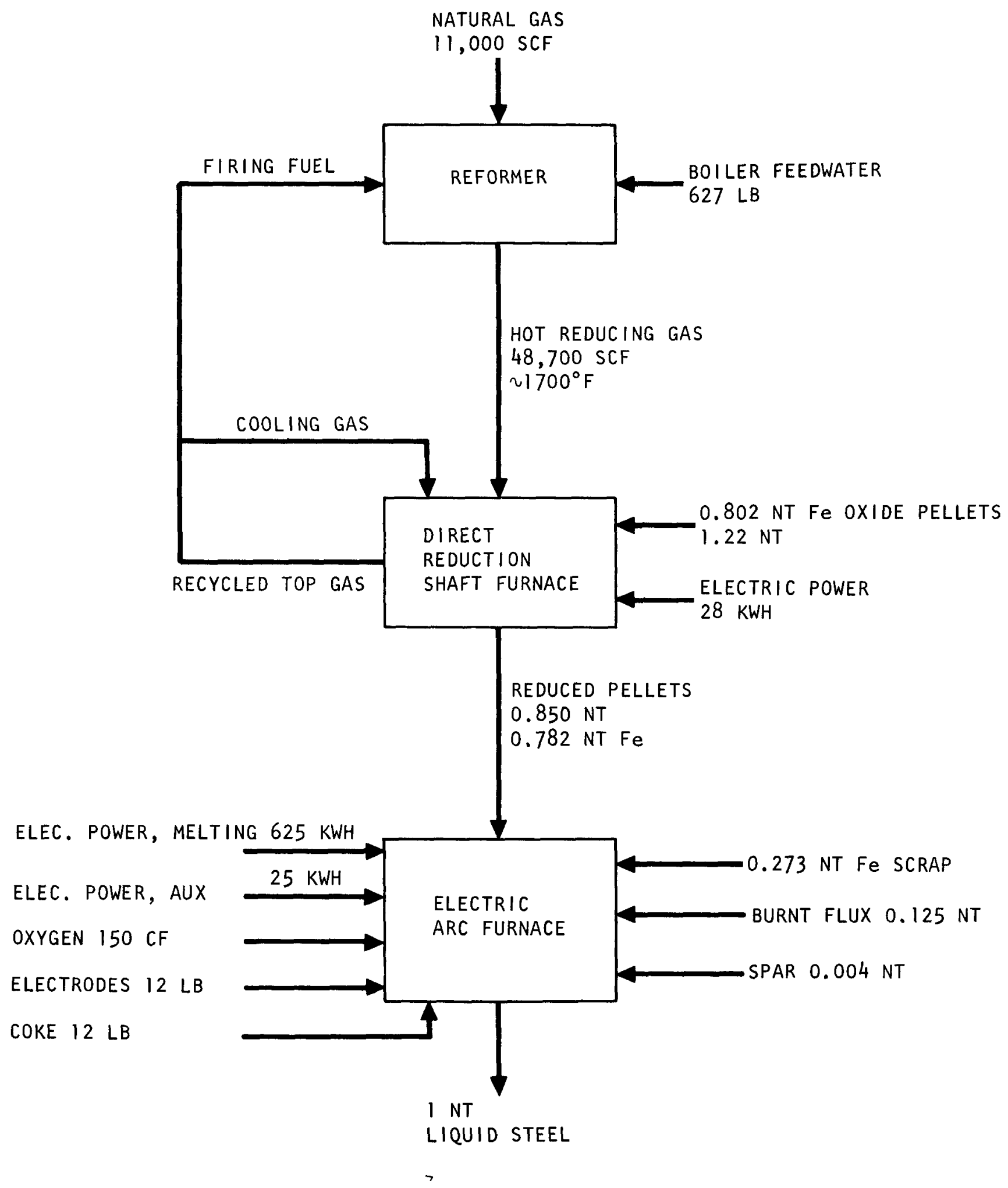

Fig. 3-1. Flowsheet for direct reduction of iron ore using an HTGR 
economical for most uses, and its future economic potential rests primarily on electrolytic cell development rather than development of suitable nuclear reactors. Partial oxidation has also not been discussed because the burning of fossil fuels as a heat source is inherent in the process. Thermochemical water splitting is a possible future source of hydrogen and is discussed in Section 3.2.4.

\subsubsection{Special Steam Cycles}

Several industrial processes require only steam and electrical power to fulfill process energy requirements. These include several chemical processes and papermaking. None of these plants are currently of sufficient size to merit a large HTGR; however, several chemical complexes are potential markets. An alternate possibility is to combine process heat requirements with residential electric power needs. Tar sands has also been included in this section because large quantities of steam are required for the recovery operation. In general, industrial process steam temperature requirements are less than $1000^{\circ} \mathrm{F}$ and we11 within the present temperature capabilities of the HTGR. An exception is production of butadiene by steam-cracking of butenes, where low-pressure, $1200^{\circ} \mathrm{F}$ steam is required.

A diagram of an HTGR applied to in situ tar sands recovery is shown in Fig. 3-2. Only the steam requirements for recovery of the bitumen from the tar sands have been considered. The steam requirements of $8.5 \times 10^{6}$ $\mathrm{lb} / \mathrm{hr}, 1500 \mathrm{psi}$, and $635^{\circ} \mathrm{F}$ steam would yield about 170,000 BPD of synthetic crude after upgrading. The temperature requirements are well within available HTGR technology. Additional process heat for upgrading would be required, including fired heat for hydrotreators, fractionators, cokers, and steam-hydrocarbon reformers.

An alternate approach using an intermediate loop could satisfy both recovery and upgrading process heat requirements. 
$2400 \mathrm{PSI}, 950^{\circ} \mathrm{F}$

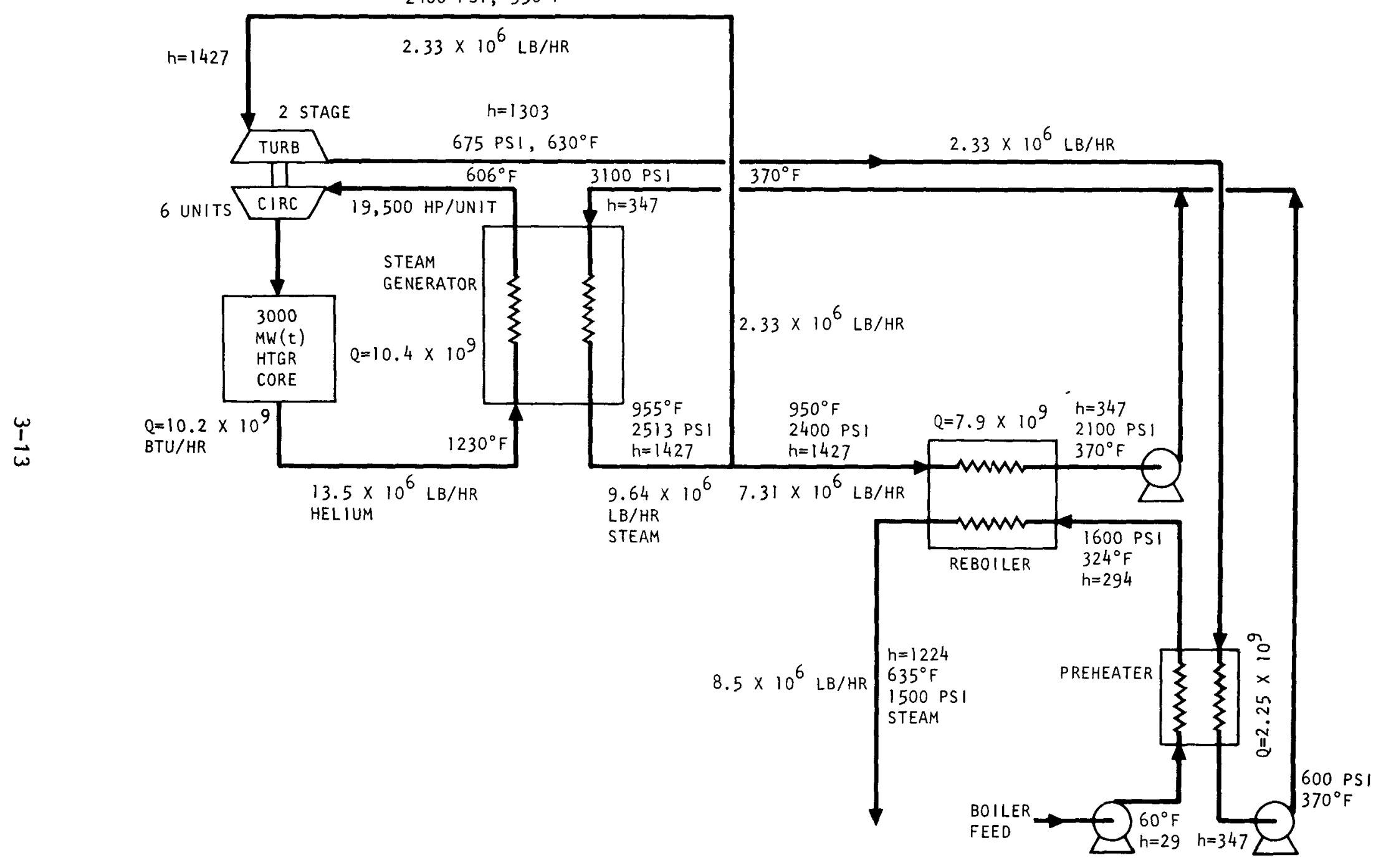

Fig. 3-2. Production of steam for tar sands recovery 


\subsubsection{Intermediate Loop}

An intermediate heat transfer loop would be generally applicable as a substitute for fired heat as well as for generation of process steam. It is particularly suited, however, for process heat in refineries and petrochemical complexes and other processes where fired heaters are used for several process units.

A flowsheet for a 300,000-BPD refinery also producing one billion $1 \mathrm{~b} / \mathrm{yr}$ of ethylene and $1500 \mathrm{TPD}$ of ammonia is shown in Fig. 3-3. The intermediate hot helium loop substitutes convective heating for fired heating in steam-hydrocarbon reformers, an ethylene furnace, catalytic crackers, catalytic reformers, hydrotreaters, and crude stills. A steam generator inside the PCRV generator provides for process steam and electric power. The hot helium loop supplies $54 \%$ of the process heat requirements. Maximum temperatures required are $1400^{\circ}$ to $1500^{\circ} \mathrm{F}$ for steam-methane reformers and $1500^{\circ} \mathrm{F}$ for ethylene furnaces. The maximum helium temperature in the primary loop is $1620^{\circ} \mathrm{F}$, which generates $1550^{\circ} \mathrm{F}$ helium in the intermediate 1oop. Higher helium temperatures would be desirable for both processes.

An HTGR applied to recovery and upgrading of kerogen in oil shale is shown in Fig. 3-4. Heat requirements for retorting are provided by hot gases heated by the intermediate loop. The intermediate loop also provides process heat for the hydrofining, fractionators, cokers, and steam-methane reforming required for upgrading the kerogen to a synthetic crude. The process heat requirements for the recovery operations were based on Stanford Research Institute's analysis of the Union II Retort Process. The maximum process temperatures required are for steam-methane reforming. Retorting of the oil shale and other refining operations require temperatures of less than $1000^{\circ} \mathrm{F}$. Process steam and electric power account for about onethird of the process heat requirements. 


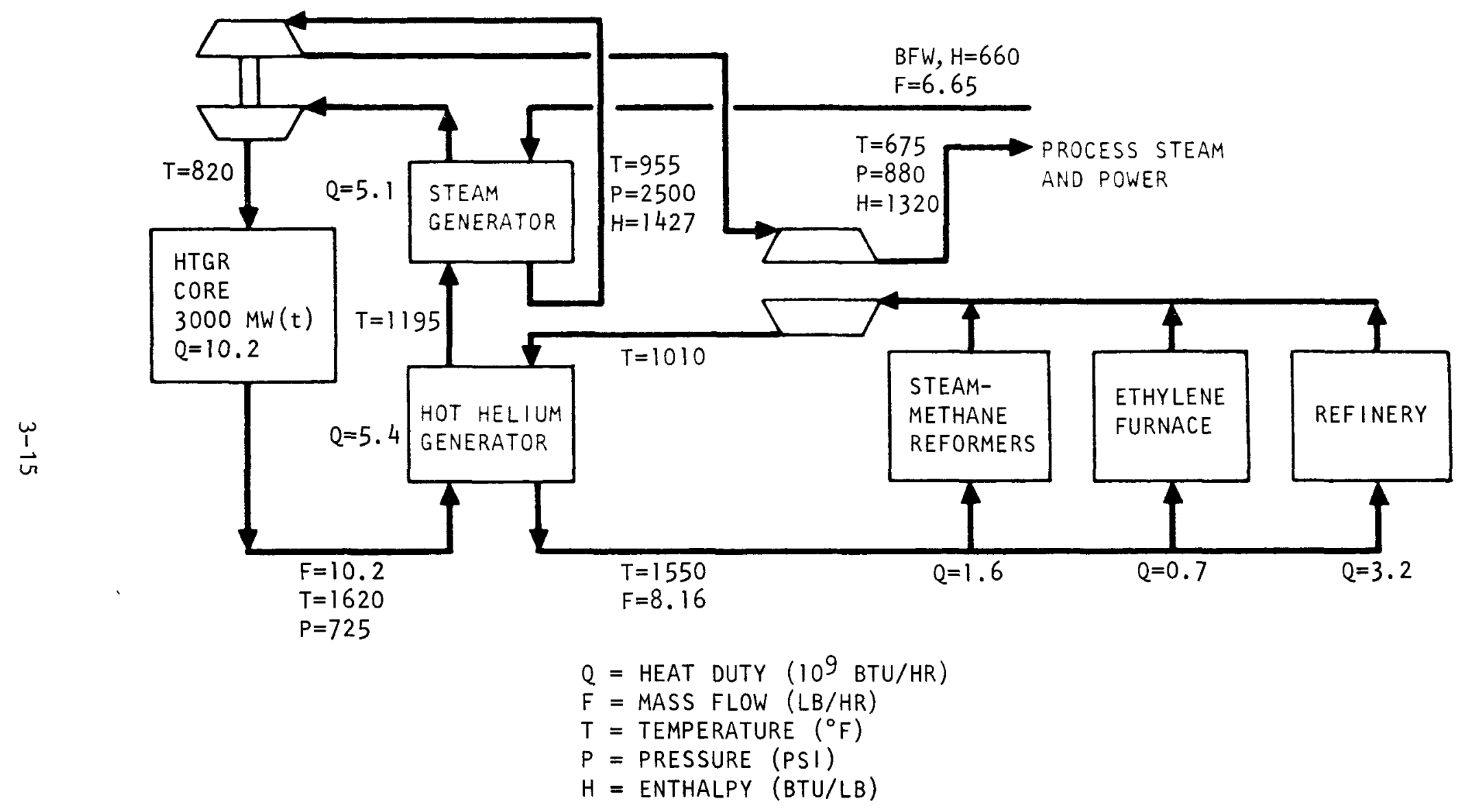

Fig. 3-3. Nuclear process heat flowsheet for a petroleum refinery and petrochemical complex producing $300,000 \mathrm{BPD}$ of oil, $1500 \mathrm{TPD}$ of ammonia, and $10^{9} \mathrm{lb} / \mathrm{yr}$ of ethylene 


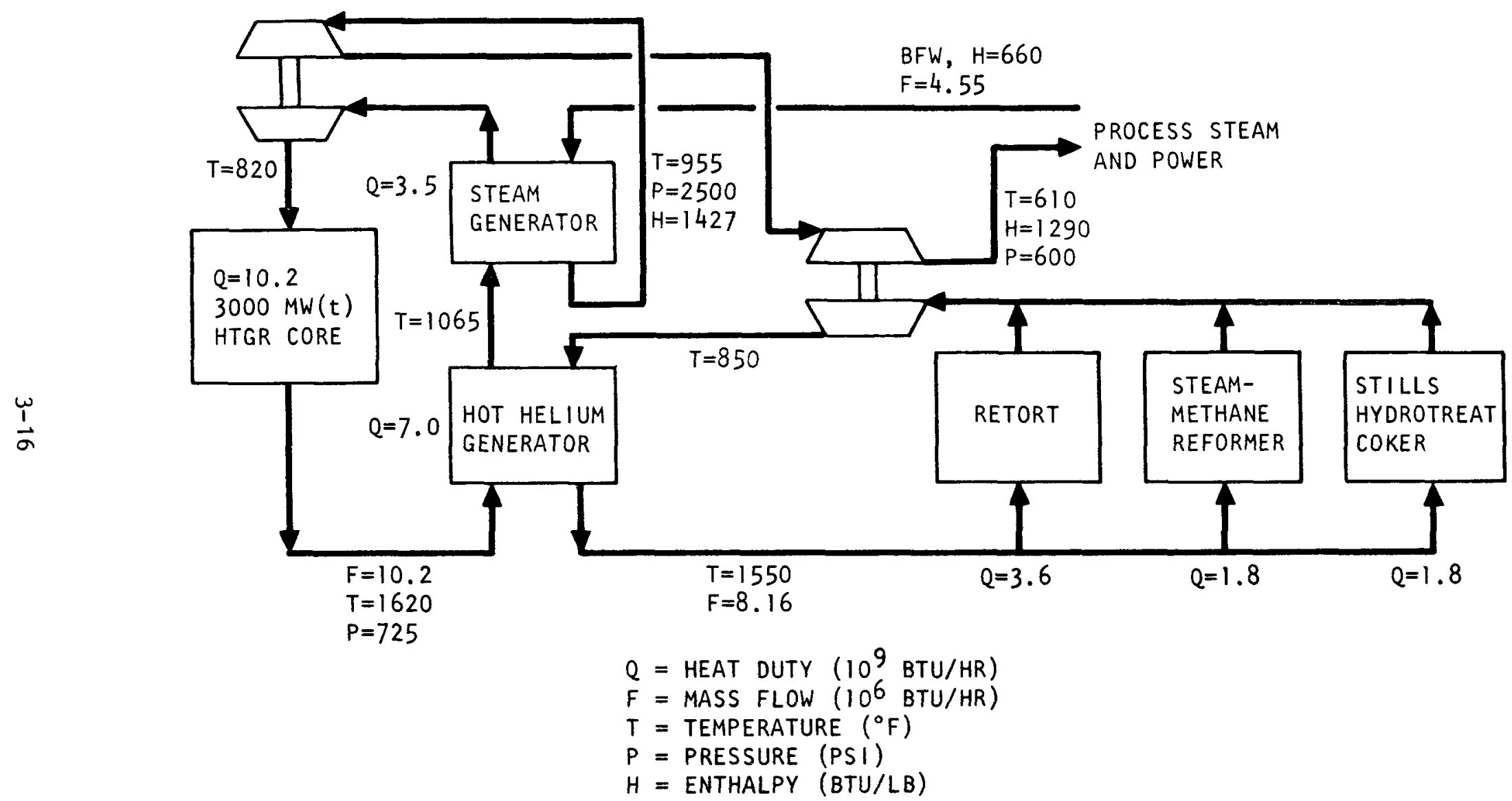

Fig. 3-4. 0il shale recovery and upgrading plant; capacity $=200,000$ BPD synthetic crude 
As previous1y discussed, an intermediate loop providing process heat for steam-methane reforming is an alternative to the use of internal reformers for processes such as coal gasification, iron ore reduction, and production of merchant hydrogen. This subject is discussed in further detail in Section 5.

\subsubsection{Thermochemical Water Splitting}

The use of nuclear energy for thermochemical splitting of water is a potential future source of hydrogen and a potential substitute for fossil fuels. At the present time, several laboratories around the world are searching for new thermochemical water-splitting methods. A few dozen chemical cycles have been published, only a few of which, if any, appear to be economically attractive.

In 1972, General Atomic, Northeast Utilities Service Company, and Southern California Edison initiated an effort to use a computer to perform a general search of chemical thermodynamics with the objective of finding all water-splitting cycles that fall within a large but well defined field of compounds. This computer search has uncovered several thousand cycles. A parallel experimental and analytical effort is screening the cycles discovered by the search, the objective being to select a few very promising cycles representing the best of the vast field searched.

At the present stage of development, it would be premature to select and discuss the details of a particular cycle. However, the several thousand cycles identified by the computer can be grouped into a few families of similar chemical systems about which some general comments can be made.

At the present time, the peak temperature required in the reaction zone can be suggested for several families of cycles. Several subgroups of cycles involve either the decomposition of sulfuric acid or a metal sulfate: 


$$
\mathrm{H}_{2} \mathrm{SO} \longrightarrow \mathrm{H}_{2} \mathrm{O}+\mathrm{SO}_{2}+1 / 2 \mathrm{O}_{2}
$$

or

$$
\mathrm{M}_{\mathrm{x}} \mathrm{SO}_{4} \longrightarrow \mathrm{M}_{\mathrm{x}} \mathrm{O}+\mathrm{SO}_{2}+1 / 2 \mathrm{O}_{2}
$$

The reaction temperature for both of these reactions is usually determined by decomposition of sulfur trioxide:

$$
\mathrm{SO}_{3} \longrightarrow \mathrm{SO}_{2}+1 / 2 \mathrm{O}_{2}
$$

This occurs at about $1550^{\circ} \mathrm{F}$.

Another family of cycles follows the Mk-1 cycle discovered at Ispra. The high-temperature reaction in this case is

$$
\mathrm{CaBr}_{2}+2 \mathrm{H}_{2} \mathrm{O} \longrightarrow 2 \mathrm{HBr}+\mathrm{Ca}(\mathrm{OH})_{2}
$$

The reaction temperature is about $1360^{\circ} \mathrm{F}$. Substituting magnesium for calcium leads to a temperature of about $1000^{\circ} \mathrm{F}$ for this reaction, but other reactions in these cycles are at higher temperatures.

Two families of cycles involve the reverse Deacon process at about $1450^{\circ} \mathrm{F}$ :

$$
\mathrm{Cl}_{2}+\mathrm{H}_{2} \mathrm{O} \longrightarrow-1 / 2 \mathrm{O}_{2}+2 \mathrm{HCl}
$$

One family uses the reaction as written; the other appears as the hydrolysis of a metal chloride:

$$
\mathrm{M}_{\mathrm{x}} \mathrm{Cl} 2+\mathrm{H}_{2} \mathrm{O} \rightarrow \mathrm{M}_{\mathrm{x}} \mathrm{O}+2 \mathrm{HCl}
$$


This reaction is usually mediated by the reverse Deacon process and therefore occurs at about the same temperature.

In conclusion, several families of water-splitting cycles are avai1able at process temperatures below $1600^{\circ} \mathrm{F}$. Efficiency arguments will probably favor the upper end of this temperature range. A1so, the corrosive chemicals involved at these high temperatures will require metallurgical development to qualify a process heat exchanger for these applications.

\section{References}

3-1. Kremenik, S. F., "Coal Gasification by the Lurgi Process," Eleventh Annual Technical Meeting, Southern California AlChE, Los Angeles, Apri1 16, 1974.

3-2. Fisher, H., "Conversion of Coal to Liquids," Eleventh Annual Technical Meeting, Southern California AIChE, Los Angeles, April 16, 1974 . 


\section{HYDROGEN PRODUCTION BY STEAM-METHANE REFORMING}

\subsection{THE HTGR AND STEAM-HYDROCARBON REFORMING}

This report examines the application of HTGRs to the production of hydrogen by steam-methane reforming. Justification for the selection of the steam-methane process for consideration lies in its importance as an industrial process, both in the present and in the future, and its compatibility with an HTGR. The steam-methane reforming process is considered one of the most promising candidates for nuclear heat applications for the following reasons:

1. The process is common to, or has potential applications in, several energy-intensive industries.

2. Of the processes requiring high-temperature heat in the range of $1000^{\circ}$ to $2000^{\circ} \mathrm{F}$, the steam-methane reforming process accounts for the majority of the energy demand.

3. Large quantities of energy are required.

4. The process can be adapted to convective heating, making it compatible with an HTGR.

In addition, the steam-methane reforming process was a convenient selection for purposes of this report because:

1. Existing process technology facilitated more detailed study and discussion of the process heat exchanger and its relation to the nuclear plant. 
2. The process requires consideration of several safety problems which will be common to many processes (e.g., explosive process gases).

3. The process requires heat over a wide range of temperatures. Thus, it allows discussion over the entire temperature range specified in the scope of this study.

\subsection{PROCESS DESCRIPTION}

The process heat HTGR operates as follows. Helium flows downward through the core (see Fig. 2-1), where it is heated to a temperature about $200^{\circ} \mathrm{F}$ above the required process temperatures. The helium passes through one of the radial ducts going to the reformer and then passes upward through the reformer cavity. Heat is transferred through the reformer tube walls to the steam-methane mixture. The helium then flows through the circumferential duct (not shown) to the adjacent steam generator cavity, where it passes downward over the steam generator coils. It next passes upward around the steam generator and into the helium circulator, where it is compressed. It then passes through the upper horizontal duct and back into the core.

A process flow diagram is shown in Fig. 2-2. The steam-methane mixture is preheated before it enters the reformer. It passes through the reformer, where $\mathrm{H}_{2}$, $\mathrm{CO}$, and $\mathrm{CO}_{2}$ are formed in the presence of a nickel catalyst with the addition of heat from the helium. Reformer outlet conditions are between $1200^{\circ}$ and $2000^{\circ} \mathrm{F}$ as required by the study. Downstream processing of this mixture will shift the $\mathrm{CO}$ plus $\mathrm{H}_{2}$ to $\mathrm{H}_{2}$ and $\mathrm{CO}_{2}$ and scrub out the $\mathrm{CO}_{2}$, leaving $\mathrm{H}_{2}$, the remainder being $\mathrm{CH}_{4}$. The once-through steam generator takes feedwater and produces 2500 -psig steam at $955^{\circ} \mathrm{F}$, the same as in the conventiona1 HTGR.

The main reforming reactions, which are endothermic, are as follows: 


$$
\mathrm{CH}_{4}+\mathrm{H}_{2} \mathrm{O} \longrightarrow \mathrm{CO}+3 \mathrm{H}_{2} \quad \text {. }
$$

When higher-molecular-weight hydrocarbons are involved, the following reactions also occur:

$$
\begin{aligned}
& \mathrm{C}_{2} \mathrm{H}_{6}+2 \mathrm{H}_{2} \mathrm{O} \longrightarrow 2 \mathrm{CO}+5 \mathrm{H}_{2} \\
& \mathrm{C}_{3} \mathrm{H}_{8}+3 \mathrm{H}_{2} \mathrm{O} \longrightarrow 3 \mathrm{CO}+7 \mathrm{H}_{2} \\
& \mathrm{C}_{4} \mathrm{H}_{8}+4 \mathrm{H}_{2} \mathrm{O} \longrightarrow
\end{aligned}
$$

The appearance of $\mathrm{CO}_{2}$ in the reformer effluent is an indication of the occurrence of the exothermic shift reaction,

$$
\mathrm{CO}+\mathrm{H}_{2} \mathrm{O} \longrightarrow \mathrm{CO}_{2}+\mathrm{H}_{2} \quad \text {. }
$$

When hydrogen is the primary product, the shift reaction (4-5) and the reforming reaction (4-1) are both used to produce hydrogen to yield the following overall plant reaction:

$$
\mathrm{CH}_{4}+2 \mathrm{H}_{2} \mathrm{O} \longrightarrow \mathrm{CO}_{2}+4 \mathrm{H}_{2} \text {. }
$$

Table 4-1 shows the compositions and the flow rates of the reformer feed and effluent gases in the five cases under study. The feed shown is typically a synthetic pipeline gas. These cases represent the process conditions at which the reformer outlet temperatures are $1200^{\circ}, 1400^{\circ}$, $1590^{\circ}, 1790^{\circ}$, and $1940^{\circ} \mathrm{F}$; the process gas feed temperature is $1050^{\circ} \mathrm{F}$ in al1 cases.

A simplified overall flowsheet of a hydrogen plant is shown in Fig. 4-1. After leaving the reactor, the reformer effluent flows through a feed effluent heat exchanger and other heat recovery equipment, where it is cooled to about $500^{\circ} \mathrm{F}$. The reformer effluent then passes through the shift-converter in which, with the aid of catalyst, the carbon monoxide 
TABLE 4-1

REFORMER FEED AND EFFLUENT COMPOSITIONS AND PHYSICAL PROPERTIES

\begin{tabular}{|c|c|c|c|c|c|c|c|c|c|c|}
\hline \multirow[b]{2}{*}{ Components } & \multicolumn{2}{|c|}{$\begin{array}{c}\text { Process Temp. } \\
1200^{\circ} \mathrm{F} \\
\end{array}$} & \multicolumn{2}{|c|}{$\begin{array}{c}\text { Process Temp. } \\
1400^{\circ} \mathrm{F}\end{array}$} & \multicolumn{2}{|c|}{$\begin{array}{c}\text { Process Temp. } \\
1600^{\circ} \mathrm{F} \\
\end{array}$} & \multicolumn{2}{|c|}{$\begin{array}{c}\text { Process Temp. } \\
1800^{\circ} \mathrm{F}\end{array}$} & \multicolumn{2}{|c|}{$\begin{array}{c}\text { Process Temp. } \\
2000^{\circ} \mathrm{F} \\
\end{array}$} \\
\hline & $\begin{array}{l}\text { Feed } \\
(\% \text { Dry })\end{array}$ & $\begin{array}{l}\text { Effl. } \\
(\% \text { Dry })\end{array}$ & $\begin{array}{l}\text { Feed } \\
(\% \text { Dry })\end{array}$ & $\begin{array}{l}\text { Eff } 1 . \\
(\% \text { Dry })\end{array}$ & $\begin{array}{l}\text { Feed } \\
\text { (\% Dry) }\end{array}$ & $\begin{array}{c}\text { Eff } 1 . \\
(\% \text { Dry })\end{array}$ & $\begin{array}{l}\text { Feed } \\
(\% \text { Dry })\end{array}$ & $\begin{array}{l}\text { Effl. } \\
\text { (\% Dry) }\end{array}$ & $\begin{array}{l}\text { Feed } \\
(\% \text { Dry })\end{array}$ & $\begin{array}{c}\text { Effl. } \\
\text { (\% Dry) }\end{array}$ \\
\hline $\mathrm{H}_{2}$ & 13.3 & 57.87 & 13.3 & 70.12 & 13.3 & 71.15 & 13.3 & 70.46 & 13.3 & 72.56 \\
\hline $\mathrm{CH}_{4}$ & 86.7 & 25.11 & 86.7 & 10.81 & 86.7 & 8.14 & 86.7 & 7.15 & 86.7 & 4.04 \\
\hline Co & - & 4.08 & -- & 6.18 & -- & 11.72 & -- & 19.12 & - & 21.02 \\
\hline $\mathrm{CO}_{2}$ & -- & 12.94 & -- & 12.84 & -- & 8.99 & -- & 3.27 & -- & 2.38 \\
\hline Total (dry) & 100.00 & 100.00 & 100.00 & 100.00 & 100.00 & 100.00 & 100.00 & 100.00 & 100.00 & 100.00 \\
\hline $\mathrm{H}_{2} \mathrm{O}$ & 450.00 & 152.46 & 450.00 & 102.50 & 300.00 & 56.84 & 150.00 & 18.65 & 150.00 & 15.38 \\
\hline Tota1 (wet) & 550.00 & 252.46 & 550.00 & 202.50 & 400.00 & 156.84 & 250.00 & 118.65 & 250.00 & 115.38 \\
\hline Total (dry), lb-mol/hr & 69,308 & 172,470 & 69,308 & 234,724 & 69,308 & 244,174 & 69,308 & 240,873 & 69,308 & 259,344 \\
\hline Total (dry), 1b/hr & $1,191,580$ & $2,074,570$ & $1,191,580$ & $2,476,454$ & $1,191,580$ & $2,437,070$ & $1,191,580$ & $2,255,354$ & $1,191,580$ & $2,346,169$ \\
\hline Mo1. weight (wet) & 17.85 & 15.64 & 17.85 & 14.33 & 17.79 & 12.89 & 17.66 & 11.34 & 17.66 & 10.24 \\
\hline Pressure, psia & 368 & 300 & 515 & 300 & 570 & 400 & 587 & 500 & 672 & 600 \\
\hline Temp., ${ }^{\circ} \mathrm{F}$ & 1050 & 1200 & 1050 & 1400 & 1050 & 1590 & 1050 & 1790 & 1050 & 1940 \\
\hline
\end{tabular}




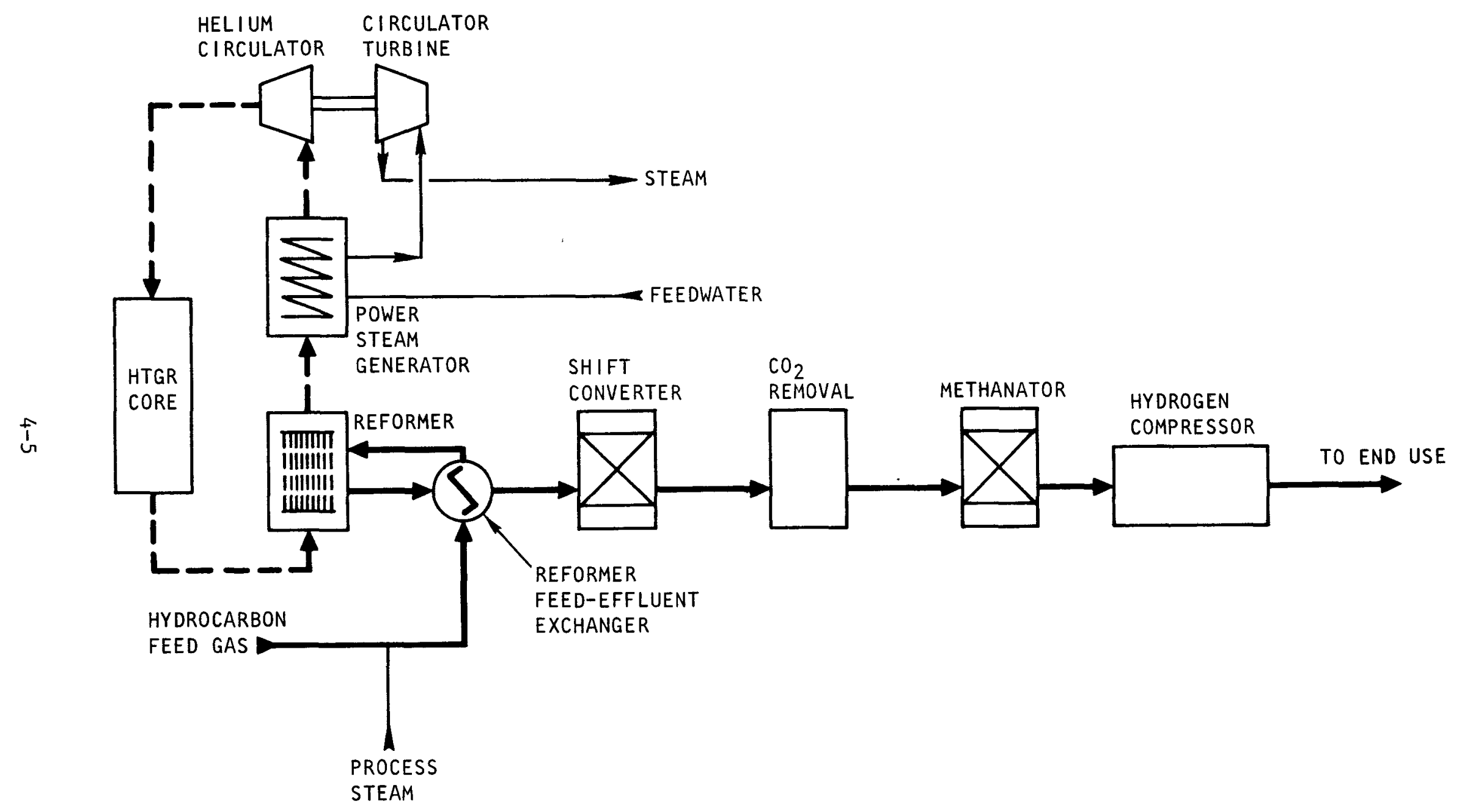

Fig. 4-1. Simplified flowsheet for process heat HTGR hydrogen production plant 
content is converted to carbon dioxide and hydrogen by the water-gas shift reaction $(4-5)$ :

$$
\mathrm{CO}+\mathrm{H}_{2} \mathrm{O} \longrightarrow \mathrm{CO}_{2}+\mathrm{H}_{2} \text {. }
$$

The shift converter products then flow to the $\mathrm{CO}_{2}$-removal system, where most of the water vapor is condensed and the $\mathrm{CO}_{2}$ is removed and vented to the atmosphere.

Following $\mathrm{CO}_{2}$ removal, the stream normally flows to a methanator for the final $\mathrm{CO}$ and $\mathrm{CO}_{2}$ cleanup. The conversion of the residual $\mathrm{CO}$ and $\mathrm{CO}_{2}$ is as follows:

$$
\begin{aligned}
& \mathrm{CO}+3 \mathrm{H}_{2} \longrightarrow \mathrm{CH}_{4}+\mathrm{H}_{2} \mathrm{O} \text {, } \\
& \mathrm{CO}_{2}+4 \mathrm{H}_{2} \longrightarrow \mathrm{CH}_{4}+2 \mathrm{H}_{2} \mathrm{O} \text {. }
\end{aligned}
$$

The methanation reaction is exothermic and is considered a further purification process for obtaining carbon-monoxide-free hydrogen. However, if the hydrogen product is used merely as a reducing agent, such as in the steel industry, carbon monoxide in the product stream is desirable and the purification steps may be eliminated.

In cases where the fraction of hydrocarbons converted to hydrogen is low, as shown in Table 4-2, it frequently proves economical to separate the residual methane from the hydrogen and recycle this methane to the reformer feed. A discussion of this case is presented in Appendix A.

The heat load division between the steam generator and the reformer for each process temperature is shown in Table 4-3 and F1g. 4-2. It is easily seen that the reformer load can be progressively larger as the process temperature is increased, because the equilibrium constant of reaction (4-1) becomes more favorable as the temperature is increased. This change in the equilibrium constant also favors the use of a lower steam-methane ratio as the temperature becomes progressively higher. This 
TABLE 4-2

REFORMER CONVERSION DATA

\begin{tabular}{c|c|c|c}
\hline $\begin{array}{c}\text { Process } \\
\text { Temp. } \\
\left({ }^{\circ} \mathrm{F}\right)\end{array}$ & $\begin{array}{c}\text { Steam:Gas } \\
\text { Ratio }\end{array}$ & $\begin{array}{c}\text { Pressure } \\
\text { (psia) }\end{array}$ & $\begin{array}{c}\text { Hydrocarbon } \\
\text { Conversion }\end{array}$ \\
\hline 1200 & $4.5: 1$ & 300 & 27.9 \\
1400 & $4.5: 1$ & 300 & 57.8 \\
1590 & $3.0: 1$ & 400 & 66.9 \\
1790 & $1.5: 1$ & 500 & 71.3 \\
1940 & $1.5: 1$ & 600 & 82.6 \\
\hline
\end{tabular}


TABLE 4-2

REFORMER CONVERSION DATA

\begin{tabular}{c|c|c|c}
\hline $\begin{array}{c}\text { Process } \\
\text { Temp. } \\
\left({ }^{\circ} \mathrm{F}\right)\end{array}$ & $\begin{array}{c}\text { Steam:Gas } \\
\text { Ratio }\end{array}$ & $\begin{array}{c}\text { Pressure } \\
\text { (psia) }\end{array}$ & $\begin{array}{c}\text { Hydrocarbon } \\
\text { Conversion }\end{array}$ \\
\hline 1200 & $4.5: 1$ & 300 & 27.9 \\
1400 & $4.5: 1$ & 300 & 57.8 \\
1590 & $3.0: 1$ & 400 & 66.9 \\
1790 & $1.5: 1$ & 500 & 71.3 \\
1940 & $1.5: 1$ & 600 & 82.6 \\
\hline
\end{tabular}


TABLE 4-3
HEAT LOADS AND FLOW RATES
$(a)$

\begin{tabular}{l|c|c|c|c}
\hline \multirow{2}{*}{$\begin{array}{c}\text { Process } \\
\text { Temp. } \\
\left({ }^{\circ} \mathrm{F}\right)\end{array}$} & \multicolumn{2}{|c|}{$\begin{array}{c}\text { Heat Duty } \\
\left(10^{9} \mathrm{Btu} / \mathrm{hr}\right)\end{array}$} & \multicolumn{2}{|c}{$\left(\mathrm{H}_{2}+\mathrm{CO}\right)$} \\
\cline { 2 - 5 } & Reformer & $\begin{array}{c}\text { Steam } \\
\text { Generator }\end{array}$ & $\mathrm{Lb} / \mathrm{Hr}$ & SCFD \\
\cline { 2 - 5 } 1200 & 2.50 & 8.00 & 398,317 & $920 \times 10^{6}$ \\
1400 & 4.82 & 5.68 & 737,983 & $1543 \times 10^{6}$ \\
1600 & 5.84 & 4.66 & $1,152,003$ & $1743 \times 10^{6}$ \\
1800 & 6.38 & 4.12 & $1,632,426$ & $1859 \times 10^{6}$ \\
2000 & 7.45 & 3.05 & $1,906,497$ & $2091 \times 10^{6}$ \\
\hline
\end{tabular}

(a) Core thermal output $=3000 \mathrm{MW}(\mathrm{t})$. Pumping power is approximately $80 \mathrm{MW}(\mathrm{t})$ for all cases. 


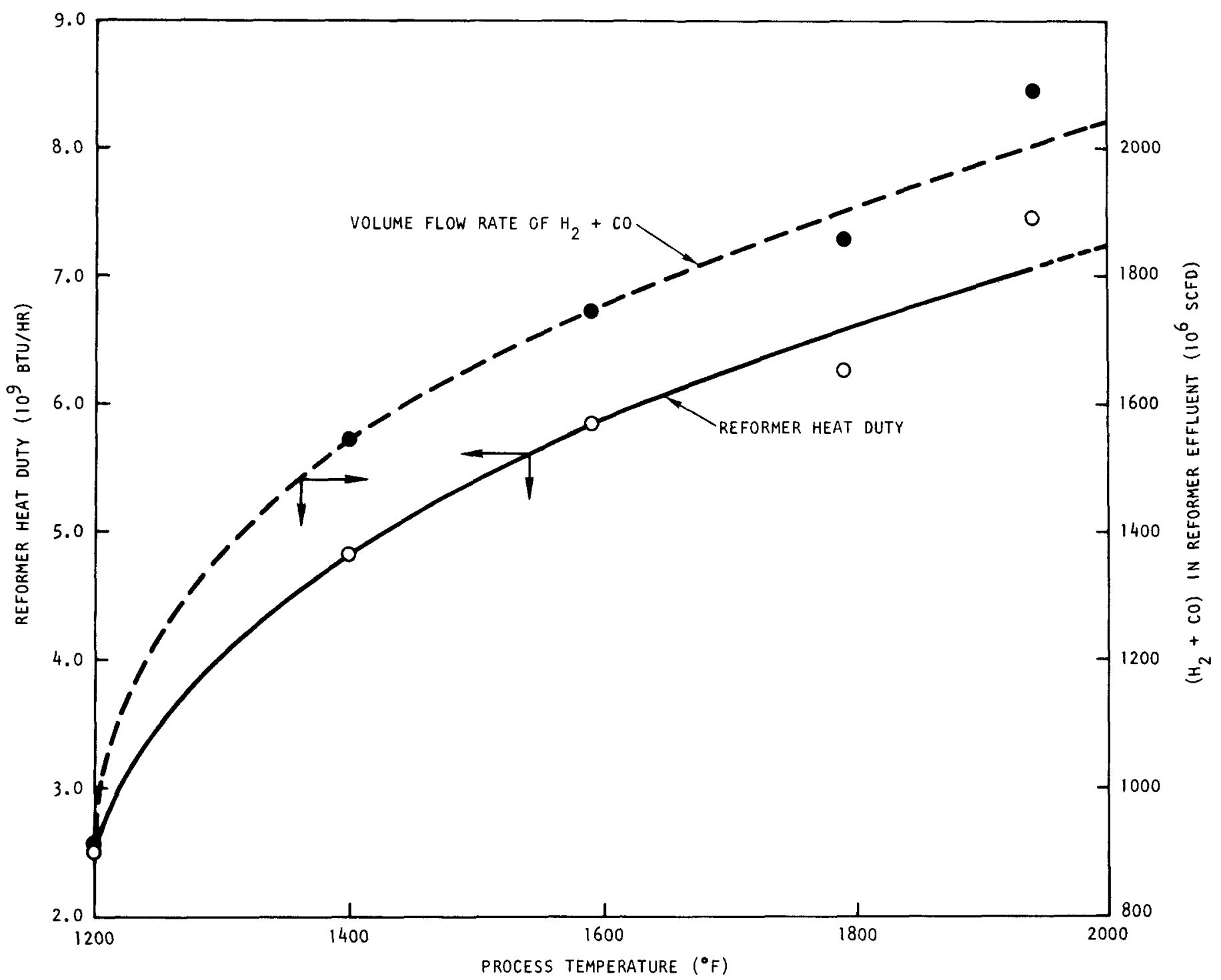

Fig. 4-2. Heat load division between steam generator and reformer as a function of process temperature 
means that a larger proportion of the reformer heat load is devoted to the reforming reaction rather than sensible heat. These changes allow substantial increases in conversion and hydrogen production at higher temperatures without increasing reformer size.

Additional improvements occur at higher process temperatures which are not immediately obvious without a detailed investigation of downstream process equipment and hydrogen end use. At the highest temperatures, $1800^{\circ}$ and $2000^{\circ} \mathrm{F}$, the reformer effluent is directly usable, without further processing, as reducing gas in the direct reduction of iron ore. In addition, as the process temperature increases, so can the reformer outlet pressure. This decreases the reformer tube stress and reduces the size of the downstream processing equipment and reduces compressor horsepower if the end use of the product is at a higher pressure. These differences can be very significant and should be the basis for further study.

A general flowsheet illustrating the process steps for hydrogen production is shown in Fig. 4-3. The detailed processing steps associated with the five cases under study are beyond the scope of this report. However, the flowsheet in Fig. 4-3 is typical for hydrogen production.

The reformer feed gas is mixed with steam, preheated by the reformer effluent in exchanger E-2, and fed to the reformer, R-2. The reformer effluent is cooled to about $500^{\circ} \mathrm{F}$ by heat exchange with the reformer feed in exchanger E-2 and boiler feedwater in exchanger E-4. The reformer products then enter the shift converter. In the shift converter, additiona1 hydrogen is produced by the water-gas shift reaction. Typically, about $90 \%$ to $95 \%$ of the $\mathrm{CO}$ in the reformer effluent is converted to $\mathrm{CO}_{2}$. Depending on the reformer steam-gas ratio, additional steam may be added prior to shift conversion to provide favorable equilibrium conditions for the shift reaction.

The effluent gas from the shift converter provides heat for the $\mathrm{CO}_{2}$ stripper reboiler, E-5 (discussed below), while excess steam in the process 


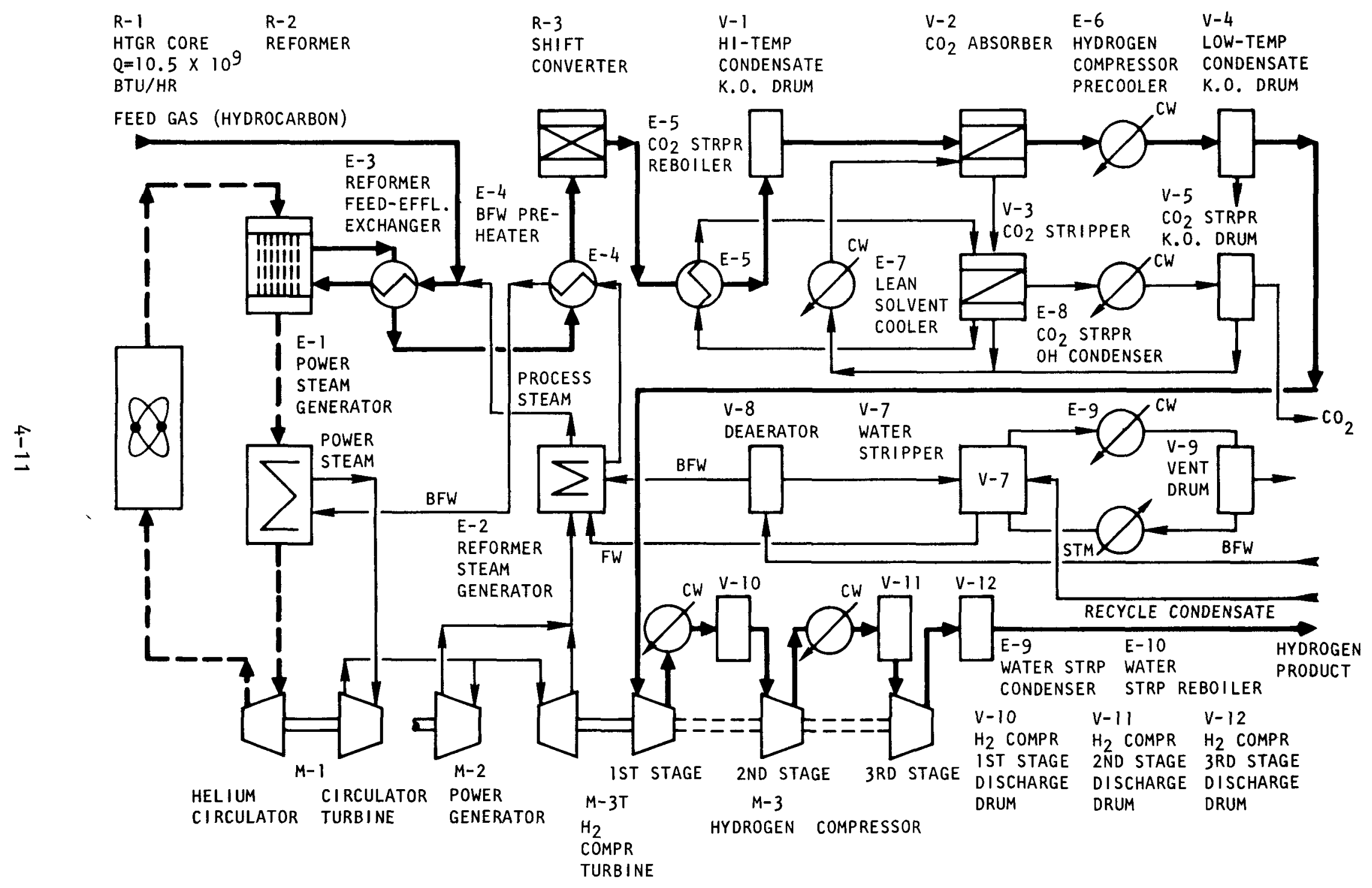

Fig. 4-3. Flowsheet showing process steps for hydrogen production with a process heat HTGR 
gas is condensed and later removed in the high-temperature knockout drum, $\mathrm{V}-1$.

The process gas then flows to the $\mathrm{CO}_{2}$-removal unit, where carbon dioxide in the process gas is removed by absorption with a hot potassium carbonate solution, $\mathrm{V}-2$. The hot potassium carbonate system for $\mathrm{CO}_{2}$ removal has the following characteristics:

1. Sensible heat and the associated heat exchange equipment are not required because the absorption and regeneration are carried out at the same temperature.

2. The solubility of gas components other than acid gases in the hot potassium carbonate solution is low.

3. Loss of potassium carbonate is low.

The $\mathrm{CO}_{2}$-rich solution from the $\mathrm{CO}_{2}$ absorber enters the $\mathrm{CO}_{2}$ stripper, $\mathrm{V}-3$, for regeneration. The stripper overhead product containing steam and $\mathrm{CO}_{2}$ is cooled in the $\mathrm{CO}_{2}$ stripper condenser, $\mathrm{E}-8$, and water is recovered in the $\mathrm{CO}_{2}$ stripper knockout drum for recycle to the lean potassium carbonate solution. The remaining $\mathrm{CO}_{2}$ is vented to the atmosphere. The lean potassium carbonate solution returns to the $\mathrm{CO}_{2}$ absorber via the lean solvent cooler, $\mathrm{E}-7$.

The effluent gas from the $\mathrm{CO}_{2}$ stripper contains primarily $\mathrm{H}_{2}$ with the unconverted methane and some residual $\mathrm{CO}, \mathrm{CO}_{2}$, and water. The residual $\mathrm{CO}$ and $\mathrm{CO}_{2}$ can be converted back to methane, if desired, by methanation. After cooling and water separation, E-6 and V-4, the hydrogen product is compressed to the desired pressure in multistage compressors.

Excess steam recovered from the reformer effluent, $V-1$ and $V-4$, is recycled to the process steam generator, E-2, which generates required steam for the reformer feed. Makeup boller feedwater requirements are shown in Table 4-4. 
TABLE 4-4

MAKEUP BOILER FEEDWATER REQUIREMENTS

\begin{tabular}{c|c|c|c|c}
\hline & $\begin{array}{c}\text { Steam in } \\
\text { Reformer } \\
\text { Effluent } \\
\begin{array}{c}\text { Temp. } \\
\left({ }^{\circ} \mathrm{F}\right)\end{array}\end{array}$ & $\begin{array}{c}\text { Steam } \\
\text { in Feed } \\
\left(10^{6} 1 \mathrm{~b} / \mathrm{hr}\right)\end{array}$ & $\begin{array}{c}\text { Steam } \\
\text { Used up } \\
\text { in Process } \\
\left(10^{6} 1 \mathrm{~b} / \mathrm{hr}\right)\end{array}$ & $\begin{array}{c}\text { Reformer } \\
\text { Eff1uent } \\
\text { Condensible } \\
\text { Steam } \\
(\mathrm{gpm})\end{array}$ \\
\hline 1200 & 4.74 & 5.62 & 0.88 & 9480 \\
1400 & 4.33 & 5.62 & 1.29 & 8660 \\
1600 & 2.50 & 3.75 & 1.25 & 5000 \\
1800 & 0.81 & 1.87 & 1.06 & 1620 \\
2000 & 0.72 & 1.87 & 1.15 & 1440 \\
\hline
\end{tabular}


Process heat and power are supplied by the power steam generator, E-1. Steam at $2500 \mathrm{psi}$ and $955^{\circ} \mathrm{F}$ is produced by heat exchange with the HTGR primary coolant helium. The high-pressure, high-temperature steam supplies the power requirements of the helium circulator, power generator, and hydrogen compressor. Steam leaving the hydrogen compressor turbine is condensed in the process steam generator, E-2. Boiler feedwater preheat is supplied by heat exchange with the reformer effluent, E-4.

\subsection{AEC CODE OF ACCOUNTS CHECK LIST FOR NUCLEAR PROCESS HEAT PLANT}

This section contains an equipment list for the nuclear process heat plant. The code accounts used in Ref. 4-1 and outlined in Ref. 4-2 were used as the basis for this equipment 1ist. Systems included in the base scope of supply for the nuclear process system (NPS) are denoted by an asterisk. All equipment in the base scope of supply, such as the steam generators, main helium circulators, core auxiliary exchangers, etc., is common to either the steam or process heat plant, except for the reformer modules, which are specific only to the process heat application. Account 23, turbine plant equipment and electric plant equipment associated with electricity generation in the standard steam plant, has not been included. For the process heat plant, equipment utilizing steam and associated auxiliaries will be determined by customer requirements.

Each line item and/or separate piece of equipment is designated with an $E, L$, and/or $M$ to signify equipment, labor, or materials. Since most of the equipment supplied in the base scope by General Atomic is provided in modularized units, installation by the purchaser must include field labor and necessary field materials.

\section{References}

4-1. "770-MWe Central Station Power Plants Investment Cost Study," Vol. V, "High Temperature Gas-Cooled Reactor Plant," USAEC Report WASH-1230, United Engineers and Constructors, Inc., December 1973.

4-2. "Guide for Economic Evaluation of Nuclear Reactor Plant Designs," USAEC Report NUS-531, NUS Corporation, January 1969. 


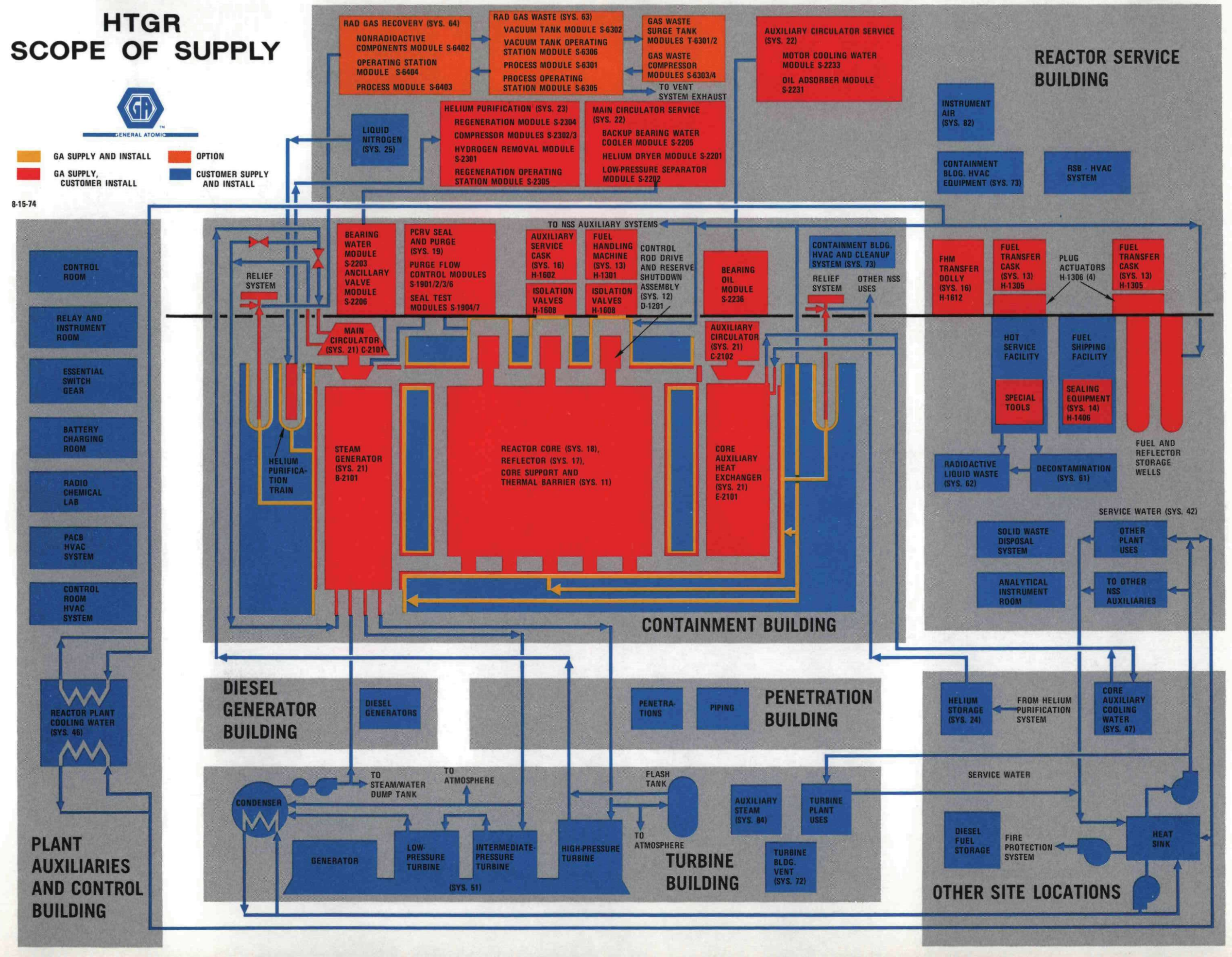


$$
\text { . }
$$ 


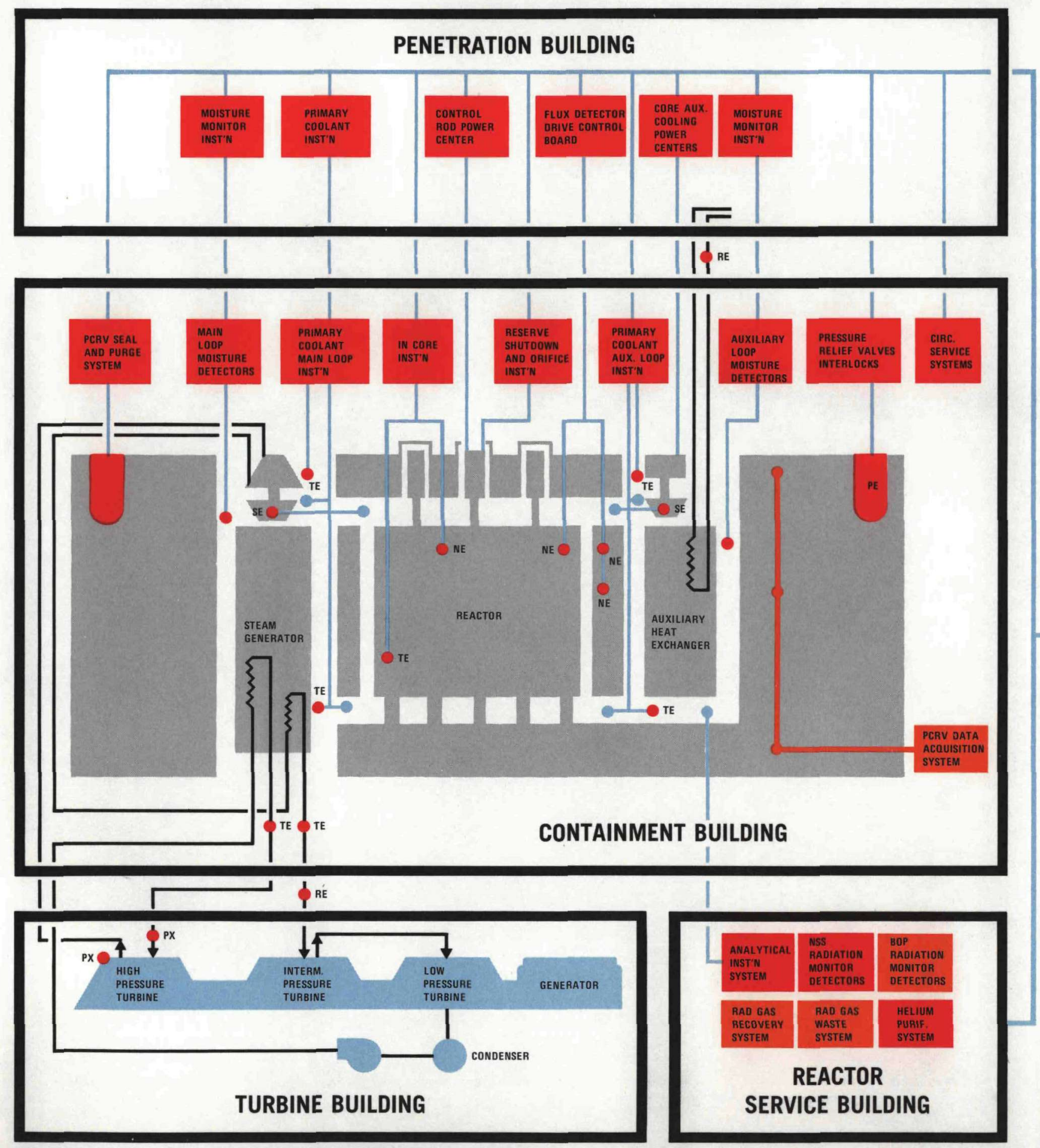

HTGR

I\&C SCOPE OF SUPPLY

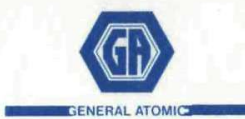

$E=$ DETECTOR $\quad R=$ RADIATION

$F=$ FLOW $\quad S=$ SPEED $\quad$ GA SUPPL

$\begin{array}{lll}N=\text { NUCLEAR } & T=\text { TEMPERATURE } & \text { OPTION } \\ \mathrm{P}=\text { PRESSURE } & \mathrm{X}=\text { TRANSMITTER } & \text { CUSTOMER SUPPLY }\end{array}$

3.1.74

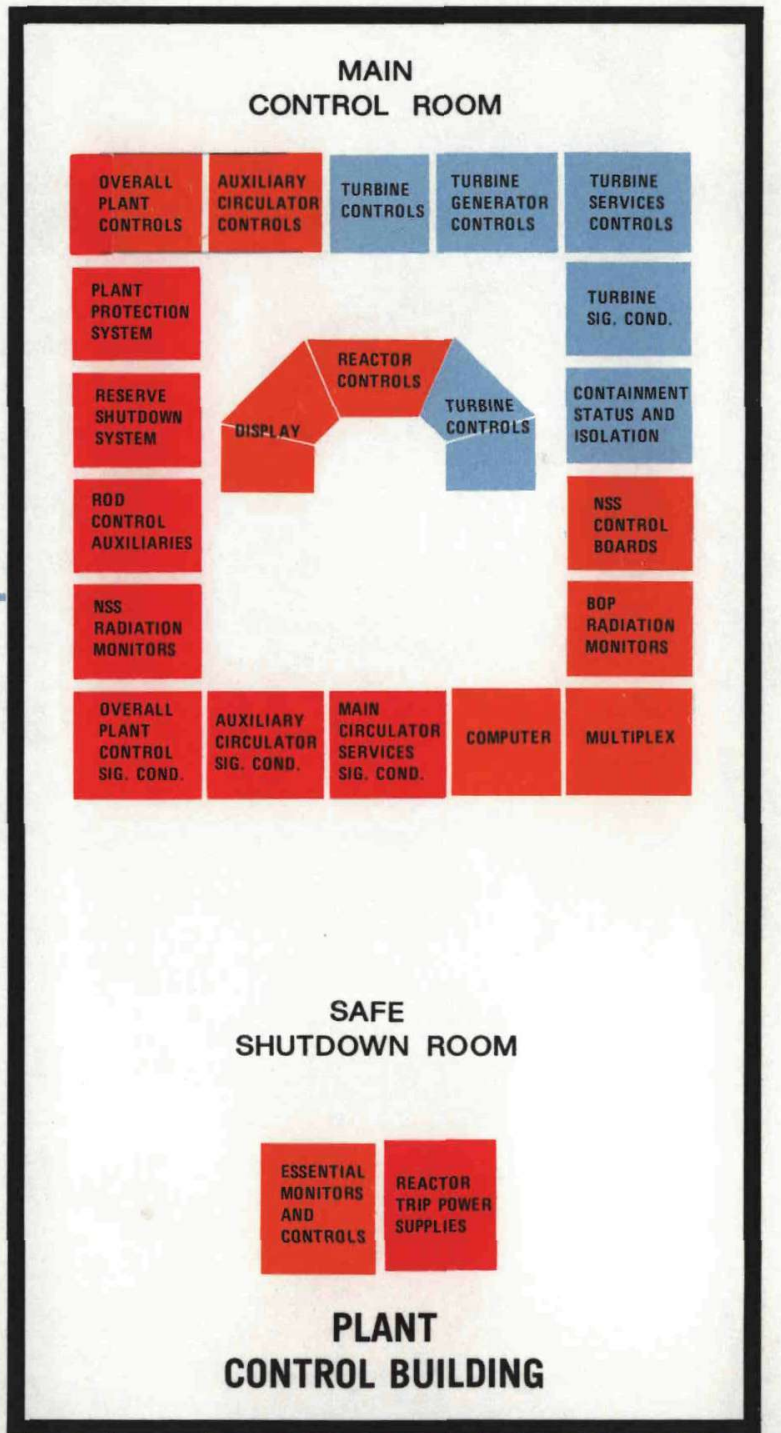


○

0

0 
Account No.

20
Description

LAND AND LAND RIGHTS

Same as Account No. 20

in $\operatorname{Ref}$. 4-1 
Account No.

21

STRUCTURES AND IMPROVEMENTS

Same as Account No. 21

in $\operatorname{Ref}$. 4-1 
REACTOR PLANT EQUIPMENT

\begin{tabular}{ll}
$\frac{\text { Reactor Equipment }}{\text { PCRV Support Structure }}$ & \\
\hline Concrete Work & (L \\
$*$ Formwork & $(\mathrm{M}$ \\
$*$ Reinforcing steel & $(\mathrm{L}$ \\
*Embedded steel & (M \\
& (I
\end{tabular}

Prestressed Concrete Reactor Vessel

Concrete Work

* Forms including concrete guide walls, rebar prestressed channel, tendon, anchors and PCRV bottom head soffit

*Construction joints

*Reinforcing steel

*Cadwe11

*Concrete

*Embedded steel

Precast Panels

Concrete Work

* Formwork

(L

*Reinforcing steel

*Concrete

(L

(M

(L

*Embedded steel

(M

Bnbedded steer

(I

*Channel liner

(M

(L

(M

*Pane1 support structure

(L

(M

Prestressing System

*Tendon tubes

(L

*Tendon bearing plates and anchor assemblies 
*Vertical tendon prestressing wires (L

*Circumferential

*No-Ox-1d-cm casing filler (grease) (L

*Steam Generator Plug

(M

*Wire Winding Machine (Lease) (L

(1) .

Thermal Barrier (1) (L

*PCRV Liners and Penetrations, including (L Cooling Tubes (M

Reactor Internals

* Reactor internals including vertical core support floor, floor posts, lateral core (L support, core to liner seal $(1)$ (M

*Permanent side reflector (E

Installation (L

*Hexagon reflector blocks (E

Installation (L

Reactor control system (1) (M

Installation (L

*PCRV pressure relief system (L

(M

Main Heat Transfer and Transport Systems

Reactor Core Coolant Systems

$*$ Main helium circulators (1)

Installation

(L

(L and by-pass valves

(M

Main Helium Circulator Service System

* Bearing water module

* Back-up bearing water cooling module

* Low pressure separator compressor module

* Helium drier module

*Shutdown bearing water filters (E

Installation

(L

Piping including fittings, hangers and supports, etc.

* Steam generators (1)

*Reformers

Installation

( $\mathrm{M}$

(E

(E

(L

(1) Includes special installation equipment

(M 
Account No.
Description

Safeguards Cooling Systems

* Core auxiliary circulators $(1)$

(E

Installation

Core auxiliary circulator controls

Installation

(L

(M

(E

(L

(M

Auxiliary Circulator Service System

*Auxiliary circulator motor cooling modules

*Auxiliary circulator bearing oil and replacement tank

*Auxiliary circulator oil absorber module (E Installation

(L

(M

Piping including fittings, valves, hangers (L and supports, etc.

*Core auxiliary cooling water heat exchangers (1)

(M

(E

Installation

(L

(M

Radioactive Waste Treatment and Disposal

Liquid Waste Processing Equipment

* Precoat tank

( $\mathrm{E}$

Installation

(L

(M

*Hold-up tanks (E

Installation

(L

(M

*High activity liquid waste storage tank

(E

Insta1lation

(L

(M

*Intermediate activity waste storage tank

(E

Installation

(L

(M

* Low activity waste storage tanks (E

Installation (L

(M

*Radwaste demineralizer head tank (E

Installation

(M

* Liquid radwaste filter precoat pump and motor

(E

Installation

(L

(M

${ }^{(1)}$ Includes special installation equipment 
*Hold-up pumps and motors (E Installation (L

*High activity liquid waste tank pump
and motor Installation (L motor (E Installation (L

* Low activity waste pumps and motors Installation (I

* Radwaste duplex sump pumps and motors, with cans Installation

(E

(L

(M

* Radwaste demineralizer pump and motor (E Installation (L

* Reserve osmosis unit (E Installation

* Radwaste demineralizers (E Installation (L

* Radwaste cesium specific demi Installation (L supports, etc. Insulation (L

Gaseous Wastes and Off-Gas Processing System

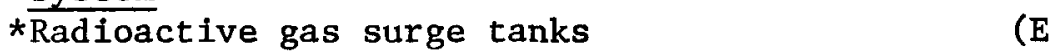
Installation (L

Insta11ation (M

* Radioactive gas vacuum tank (E Installation (L

* Radioactive gas recovery transfer tank (E Installation (L

*Radioactive gas liquid drain tank (E Installation 
Account No.

Description

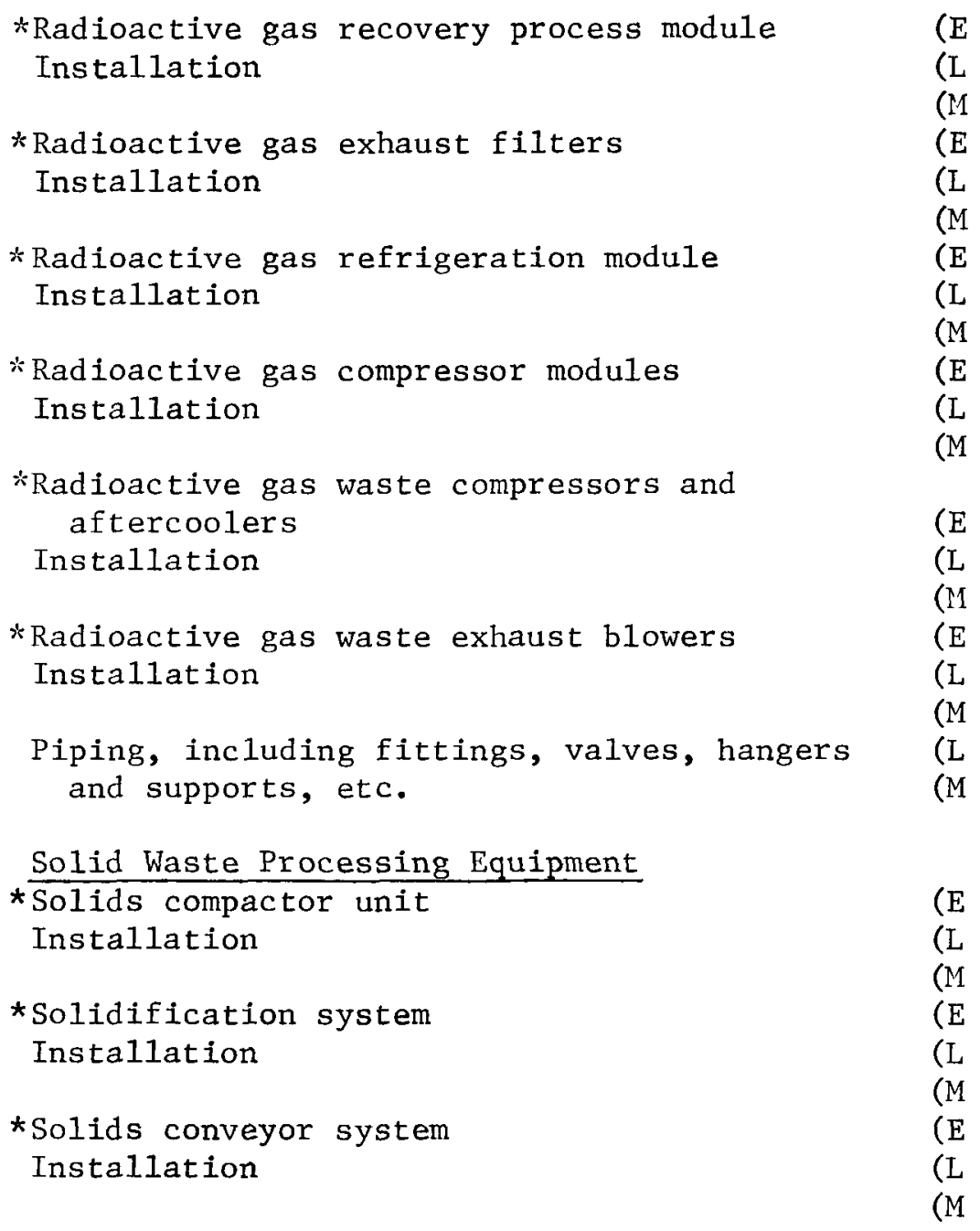

Nuclear Fuel Handling and Storage Equipment

Fuel Handling Tools and Equipment

*Fuel handling machine

*Clean fuel loading tool

*Fuel transfer cask

*Storage well plug actuator

*Refueling accessories

*Auxiliary service cask

*Fuel shipping scaling equipment

* Core service manipulator tool

* Reactor Isolation valve

* Rod removal tool

*FHM transfer dolly

* Special equipment and tools

*In-core service equipment

(E

Installation

(L

(M 


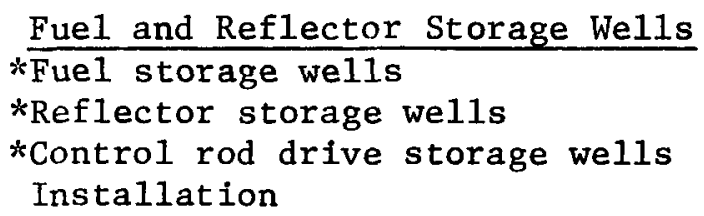

Fuel Handling Purge and Evacuation System

Fuel handling purge vacuum pumps and motors

Installation

Fuel handling purge vacuum pump suction knock-out drums

Fuel handling purge storage well filters

Fuel handling purge vacuum pump discharge oil mist filters

Piping, fittings, valves, hangers and supports, etc.

Other Reactor P1ant Equipment

Coolant Receiving Storage and Make-Up

Systems

He1ium storage tanks

(E

Installation

(L

(M

High pressure helium supply tanks (E

Installation

(L

(M

Helium transfer compressors (E

(L

(M

Helium supply compressors

(E

(L

(M

Piping

(L

(M

Steam/Water Dump System

Steam/Water dump tank

(

Installation

(L

Steam/Water dump tank transfer pumps

(M and motors

(E

Installation

(L

(M 
Piping, fittings, valves, hangers and supports

Nitrogen Cooling System

Nitrogen recondenser units

Liquid nitrogen storage tank

Nitrogen surge tank

(E

Installation

(L

Piping, fittings, valves, hangers and (L supports, etc.

Primary Coolant Purification System

* Purified helium compressor modules

Compressor auxiliaries module

*Purification well vacuum pump

*Helium purification modules

* Helium regeneration module

*Hydrogen removal module

(

Installation

(L

(M

Piping, including fittings, valves, hangers (L and supports, etc.

Auxiliary Cooling Systems

Reactor Plant Cooling Water System

Reactor plant cooling water pumps and motors

Installation

(E

(L

Reactor plant make-up pumps and motors

(M

Installation

(E

(L

Reactor plant cooling water surge tanks

Installation

Reactor Plant Cooling Water Chemical

Feed System

Skid-mounted chemical feed systems including chemical feed pump, chemical feed tank, piping, valves, etc.

Installation

Reactor plant cooling water heat 
Reactor plant cooling water mixed bed demineralizers

Installation

(E

Installation

(L

Reactor plant cooling water bypass filters

(M

Installation

Reactor plant cooling water piping, including fittings, valves, hangers and supports, etc.

(L

(II

(L

(M

Core Auxiliary Cooling Water System

Core auxiliary cooling water main circulating pumps and motors

Installation

(E

(L

Core auxiliary cooling water auxiliary circulating pumps and motors

(M

Installation

(E

(L

Core auxiliary cooling water make-up pumps and motors

(M

Installation

(E

(L

(M

Core auxiliary cooling water pressurizers

Installation

(E

(L

(M

Core Auxiliary Cooling Water Chemical

Feed System

Skid-mounted chemical feed systems including chemical feed pump, chemical feed tank, piping, valves, etc.

(E

Installation

Core auxiliary cooling water system service water heat exchangers

(L

(M

Installation

(E

(L

Core auxiliary cooling water purification heat exchangers

(M

Installation

(E

(L

Core auxiliary cooling water system ion exchangers

Installation 
Gas stripper return pumps and motors

Core auxiliary cooling water gas strippers

Installation

Core auxiliary cooling water piping, including fittings, valves, hangers and supports, etc.

Nuclear Chilled Water System

Nuclear chilled water pumps and motors

Nuclear chilled water surge tank

Nuclear chilled water chillers Installation

Nuclear chilled water system piping, including fittings, valves, hangers and supports, etc.

Decontamination System

Decontamination equipment

Miscellaneous Suspense Items Fina1 Alignment and Checking

Allowance for miscellaneous checking and adjusting of equipment after initial rotation tests

\section{Field Painting}

Allowance for painting of all reactor

(L plant equipment and piping

Qualification of Welders

Cost of qualifying welders and welding

(L procedure

Preliminary Operating

Allowance for stand-by craft labor 
Account No.
Description

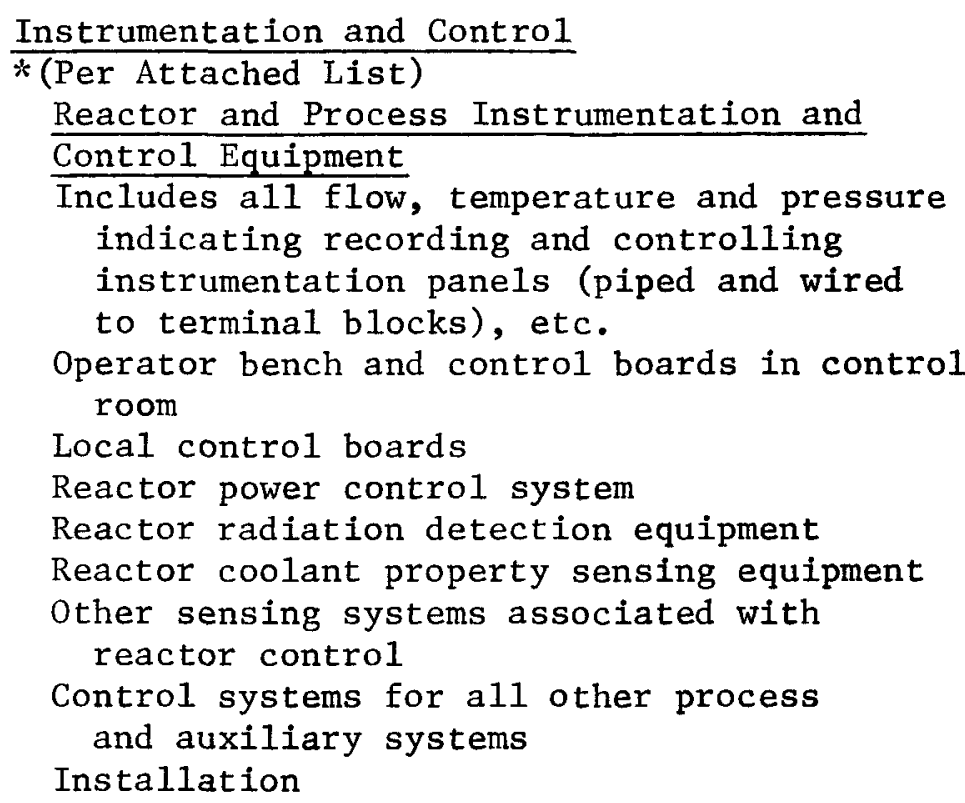

(E

(L

(M

Automatic Monitoring and Computation

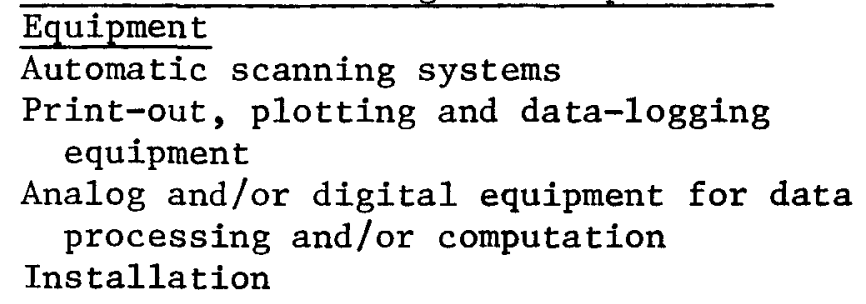

Monitoring Systems

Heat transport/transfer system and other process systems radiation monitors

Personne1 and area radiation monitors within buildings and portable survey instruments

Primary system integrity monitors

Equipment operational surveillance systems In-core fuel and/or structure monitors Valve position sensors

Failed fuel element detection equipment Containment leakage monitoring systems Containment closure position sensors Installation

Isolated Indicating and Recording Gauges, Meters and Instruments

Control and Instrument Piping and Tubing 4-30 
Instrumentation and Control

*PCRV Instrument and Electrical Equipment *FHM Control Station *PCRV Seal and Purge System

*Helium Purification System Instrumentation Equipment

*Nuclear and In-Core Instrumentation Equipment

*Analytical Instrumentation System Equipment

*Reserve Shutdown Actuation System Equipment and Instrumentation

* Rod Control System Instrumentation Equipment

*Variable Orifice Control System Instrumentation Equipment

*Steam Generator Instrumentation Equipment

*Primary Coolant Instrumentation Equipment

* Main Circulator Signal Control Board

*PPS Instrumentation Equipment

*Overall Plant Control System Instrumentation Equipment

*Radiation Monitoring System Instrumentation Equipment

*Operational Protection System

*Data Acquisition and Processing System -

Dual Computer 
ELECTRIC PLANT EQUIPMENT

Switchgear

Generator Equipment Switchgear

Geherator air circuit breaker

Installation

Neutral grounding equipment inclyding

transformer, resistor, etc.

Installation

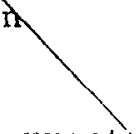

Generator Current and Pgtential Transformers

Bushing-type current tyansformers

Installation

Potential transformers, fuses, etc.
Installation

Surge Protedtion Equipment including lightnipg arrestors and capacitors

Installation

Exciter switchgear including exciter field breaker

Installation

\section{Station Service}

Station Service Switchgear

Switchgear, metal-clad, indoor-type including automatic fast transfer scheme logic

Class IE switchgear, meta1-clad, indoortype including qualification and sample testing, protective relaying for the diesel generator units and automatic sequential loading and load shedding logic

Installation

\section{Station Motor Control Centers}

480 volt motor control centers
Installation
Class IE 480 volt motor control centers,
including qualification and sample
testing and guaranteed starter
momentary capability


Station Service Equipment

Station Service and Start-up Transformers

Unit auxiliary transformer

Installation

Station auxiliary transformer

Installation

Foundations for transformers

Low Voltage Unit Substations and

Lighting Transformers

Unit Substations and Transformers

480 volt substations

(E

Installation

(L

Class IE 480 volt substations

(M

Installation

(E

(L

Lighting load center

(M

Installation

(E

(L

Miscellaneous transformers

Installation

\section{Auxiliary Power Sources}

Battery System

Batteries - Class IE complete with

seismic racks including qualification

(E

Installation

(L

Class IE charging equipment, including (M qualification

(E Insta1lation

(L

Auxiliary Generators

Diesel Engine/Generator Units

Diesel generators complete with controls

(E Installation

Fuel oil storage and transfer facilities

Automatic sprinkler system 
Gas-Turbine/Generator Units

Internal combustion turbine generator unit complete with auxiliary systems, switchgear and control, protection and surveillance system

Inverters - Class IE

Installation (L

Switchboards

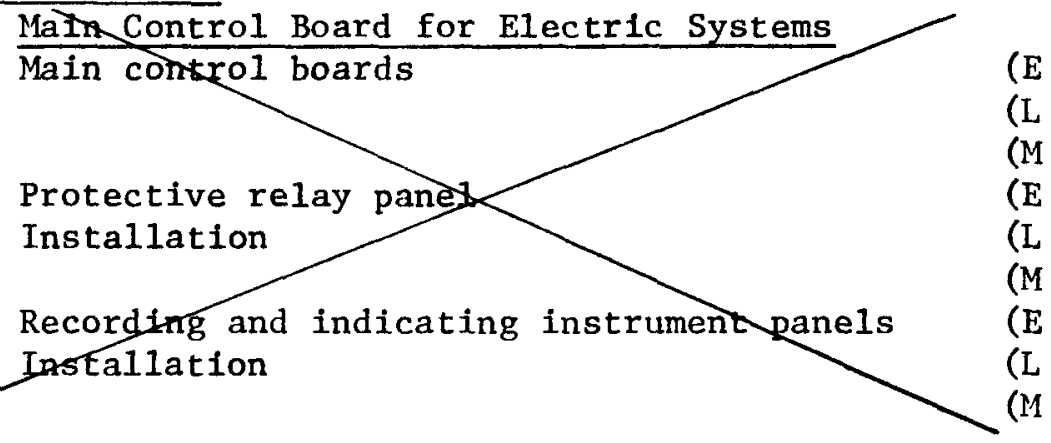

Auxiliary Power and Signal Boards

Class IE a-c power distribution panels including power, lighting and uninterruptible power supply panels and qualification of Class IE panels (E

Installation (L

Battery Control and D-C Distribution Panels

Class IE d-c switchboards including ACBs and qualification (L

Class IE d-c motor control centers including qualification (L

Class IE d-c power distribution panels including qualification (L

Station battery fuses (E

(L

(M

Protective Equipment General Station Grounding System Station grounding system 
Account No.

Description

Lightning protection

(L

Cathodic protection

(M

(L

$(\mathrm{M}$

Fire Protection System

Automatic fire protection for transformers (L

(M

245

Electrical Structures and Wiring Containers

Underground Duct Runs

Concrete envelope including excavation, etc. (L

Manholes

(M

$(\mathrm{L}$

$(\mathrm{M}$

Cable Trays

Includes trays, supports, hangers, etc. (E

(L

(II

Conduit

Includes power, control and instrumentation

(L conduit, fittings, etc.

(M

Other Structures

Concrete footings for bus supports (L

(M

246

Power and Control Wiring

Generator Circuits Wiring

Main Generator Bus

Forced-cooled isolated phase bus between generator and main power transformer; self-cooled, isolated phase bus between tap and unit auxily transformer, tap and surge protection equipment and neutral eonnection Instatlation

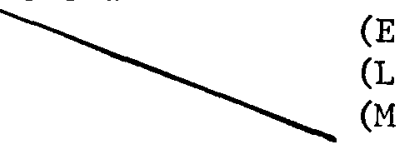

Diese1 Generator Bus

Non-segregated phase bus duct between diese1 generator unit and switchgear (E Installation 
Station Service Power Wiring

High Voltage Cable and Bus

( $1 \mathrm{kV}$ and above)

Unit and station auxiliary transformers to unit and plant switchgear, nonsegregated phase bus duct

Installation

High voltage cable $(5 \mathrm{kV})$

Low Voltage Cable and Bus

(below $1 \mathrm{kV}$ )

Low voltage cable (480 volts and less) (L

Control Wiring

Multi-conductor, 1,000 volt

Instrumentation Wiring

(L

(M

Containment Penetrations 
MISCELLANEOUS PLANT EQUIPMENT Transportation and Lifting Equipment

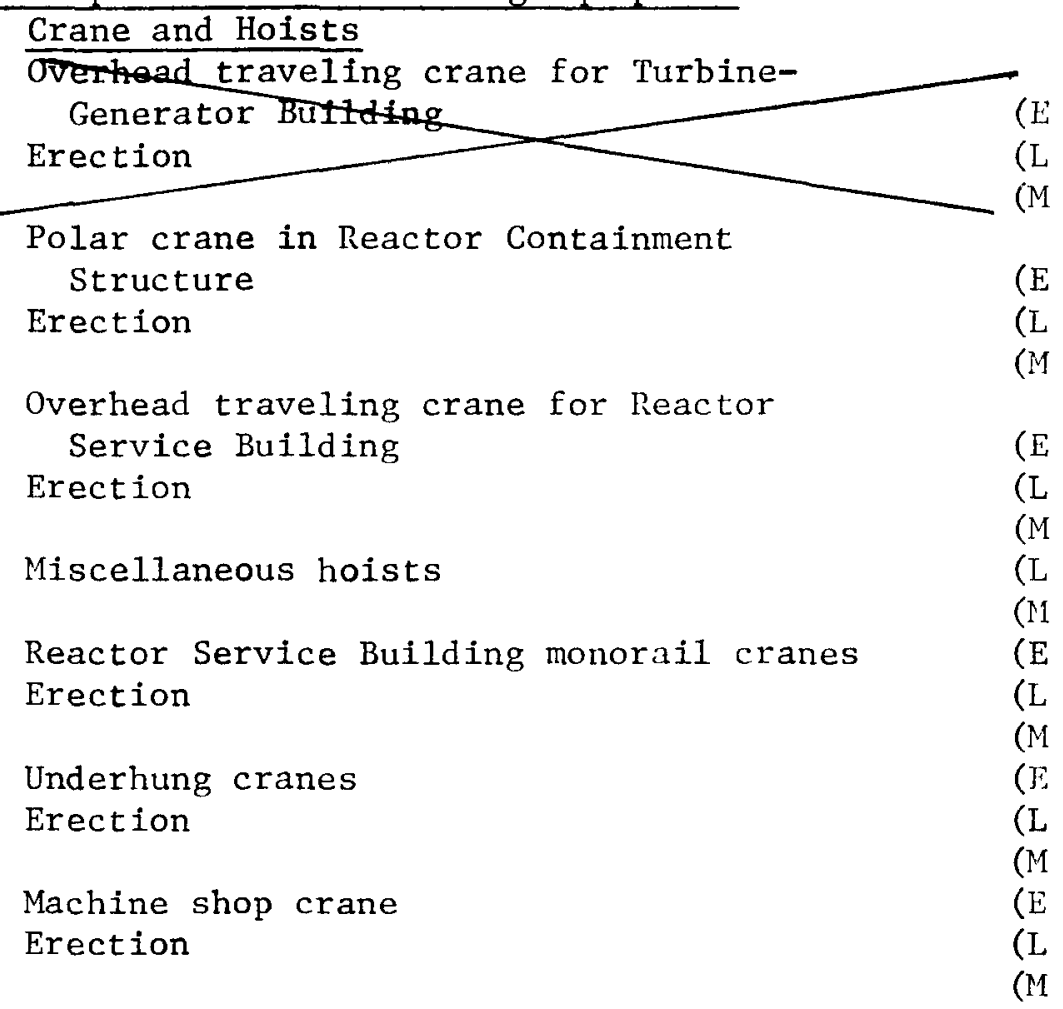

Air, Hydraulic, Water and Steam Service Systems

Air Systems

Station service air compressors with control equipment, intercooler, aftercooler, intake filter, receiver, etc., and motor drives

Installation

Instrument air compressors with control equipment, motors coolers, filters, silencer, receiver, etc.

Installation

(E

Instrument air dryers
Installation

(E

Air distribution piping (excludes
instrument air and control piping) (L 


\begin{tabular}{ll} 
Water Systems & \\
\hline Nuclear Service water System & \\
Nuclear service water pumps and motor & (E \\
drives & (L \\
Installation & $(\mathrm{M}$ \\
& (E \\
Iuclear service water booster pumps and \\
motors
\end{tabular}


Treated water transfer pump and motor drive (E Installation of pump and motor (L

Raw water treating system (E

Installation (L

Treated water storage tank $\quad(E$

(L

(M

Installation

(L

(M

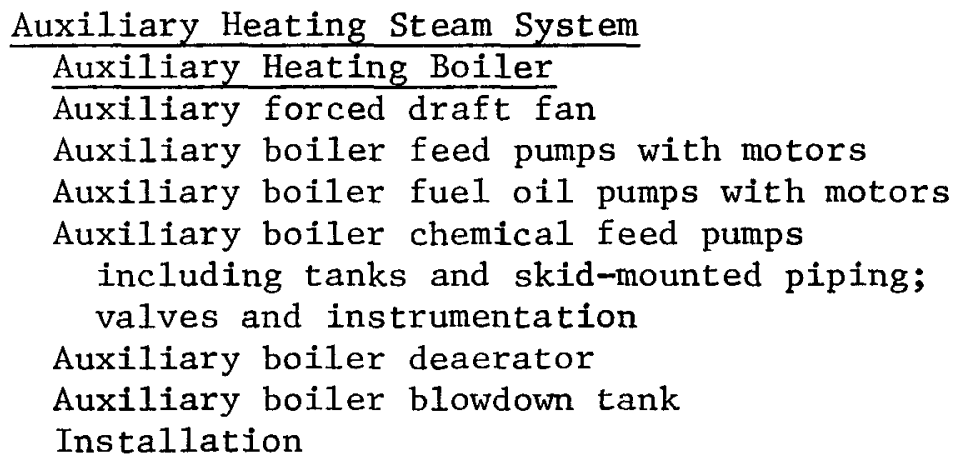

Hydraulic Power System Hydraulic pumps and motors Hydraulic pressure storage tanks Hydraulic fluid reservoir with integral fluid coolers Hydraulic fluid filters (E Installation

Communications Equipment Local Communications Systems Public Address and Inter-Communication System

Handsets, speakers, wire, etc.

Signal Systems

Fire detection system (E

Noise monitoring system (E 
Account No.

254
Description

Furnishings and Fixtures

Safety Equipment

Portable fire extinguishers, fire

blankets, etc.

$(E$

Shop, Laboratory and Test Equipment Chemical Laboratory

Special 1aboratory furniture and fixtures (E Installation

(L

(M

Office Equipment and Furnishings

office furniture

(E

Change Room Equipment

Lockers and benches

(E

Installation

(L

(M

Dining Facilities Cafeteria equipment

(E

Installation
(L

(M 
Account No.

91

911

912

913
Description

UNDISTRIBUTED COSTS

Engineering, Construction Management and Field Supervision

(Professional Services)

* Engineering design and drafting

*Licensing expense

*Home office purchasing and expediting services

* Home office construction management

*Field supervision

*Quality assurance/quality control

* Relocation expense of personnel

* Job office expense

Other Undistributed Costs

(Classified)

*Temporary facilities

(L

(M

(L

(M

(L

(M

Other Undistributed Costs

(Unclassified)

* Operator training

(M

* Spare parts

(M

Owner general office and administrative cost (M 
Account No.

91

911

912

913
Description

UNDISTRIBUTED COSTS

Engineering, Construction Management and

Field Supervision

(Professional Services)

Engineering design and drafting

Licensing expense

Home office purchasing and expediting services

Home office construction management

Field supervision

Quality assurance/quality control

Relocation expense of personnel

Job office expense

Other Undistributed Costs

(Classified)

Temporary facilities

(L

Construction equipment

(M

(L

(M

(L

(M

environmental and OSHA requirements

Other Undistributed Costs

(Unclassified)

Operator training

(M

Spare parts

Owner general office and administrative cost
(M

(M 


\section{DESIGN}

\subsection{STANDARD HTGR NUCLEAR STEAM SYSTEM}

\subsubsection{Introduction}

The following description of the HTGR Nuclear Steam System (NSS) is based on the Fulton Generating Station Preliminary Safety Analysis Report (PSAR). Extensive references are made in this description to various sections, tables, and figures in the Fulton PSAR. Design changes necessary for the process heat plant are discussed in Section 5.2.

The reactor design is based on the same fundamental principles demonstrated in the 40-MW(e) prototype HTGR in Peach Bottom Township, Pennsylvania, on the system of the Philadelphia Electric Company. The fuel and the major reactor systems and components are based on the technology employed in the Fort St. Vrain Nuclear Generating Station. Heat is produced by fission utilizing a uranium-thorium fuel cycle. Graphite is used for the moderator, core structure, and reflector and helfum as the primary coolant.

\subsubsection{Reactor}

The reactor core is made up of 3944 hexagonally shaped fuel elements. Each element is approximately $14 \mathrm{in.} \mathrm{across}$ the flats and $31 \mathrm{in.} \mathrm{high.} \mathrm{The}$ fuel, in the form of coated particles of uranium dicarbide as the fissile material and thorium oxide as the fertile material, is located in vertical blind holes in the fuel elements. Vertical coolant holes are provided for hellum flow through the fuel elements. The fuel elements are stacked in columns eight elements high, so that the active core height is $20.8 \mathrm{ft}$. The core is made up of 493 column, giving an active core mean diameter of $27.7 \mathrm{ft}$. The active core is divided into 73 refueling regions and is 
surrounded by graphite reflector elements. The entire assembly is mounted on a graphite block floor, which, in turn, is supported by graphite columns. The general reactor arrangement is shown in Fig. 4.1.3-1. ${ }^{*}$ The basic core description and performance are summarized in Section $4.1^{*}$ and Table 4.1.4-1.*

Each of the 73 fuel regions is composed of a central control fuel column surrounded by six columns of standard fuel elements, except at the core periphery where reflector columns replace some of the fuel columns.

Core heat removal is accomplished by the downward flow of the helium coolant through the fuel columns. Variable flow control valves in each refueling region help balance the coolant flow through the various core regions in proportion to region power production and thereby regulate the fuel temperatures in the core.

The bulk of the coolant passes down the coolant channels within the fuel element columns. The remaining part of the flow is divided nearly equally between the slde reflector, the control rod channels, and the small clearances between individual fuel element columns in the active core. The performance parameters conform to a conservative core design in which the fuel and graphite temperatures are below design safety limits.

The reactor is controlled by means of 73 control rod pairs, a total of 146 contro1 rods. Each pair of control rods is suspended by cables operated by a motor-driven rod drive mechanism. The control rods, which contain boron carbide, move in vertical channels in the central column of fuel elements in each region.

A reserve shutdown system is provided that releases neutron-absorbing pellets containing boron carbide into the core. The reserve shutdown system, which is independent of the normal reactor control system, provides a means of introducing negative reactivity into the core. This system is manually

\footnotetext{
*Fulton Generating Station PSAR.
} 
actuated in the unlikely event that the normal control rod system fails to function (see Section 4.2.3.2)*.

Neutron flux information for monitoring, protection, and control systems is supplied from neutron detectors located in wells in the prestressed concrete reactor vessel (PCRV) wall outside the liner. In-reactor neutron detectors and thermocouples at each refueling region outlet provide additional information for flux monitoring and control.

Burnable poison in the form of graphite rods containing up to $5 \mathrm{wt}-\%$ natural boron in the form of $\mathrm{B}_{4} \mathrm{C}$ is used to control part of the core excess reactivity and to flatten the transverse core power distribution.

The fuel temperature coefficients and the isothermal temperature coefficient (sum of fuel and moderator coefficient) are negative for all fuel cycles and all normal and transient temperatures. The helium coolant has a positive but negligible reactivity worth due to its scattering properties. Thermalization of fast neutrons increases when the helium density increases; however, the pressure coefficient is negligible.

Fuel loading is based upon a 4-yr cycle; that is, approximately onefourth of the core will be replaced on an annual basis. The initial fuel loading will consist of approximately $1725 \mathrm{~kg}$ of highly enriched uranium $(93 \% \mathrm{U}-235)$ and $37,487 \mathrm{~kg}$ of thorium.

As the U-235 is fissioned, fissionable material (U-233) is formed from the neutron capture by the thorium atoms. The U-233 which does not fission in situ may be recovered from the fuel during reprocessing and either sold or returned to the reactor. The average burnup at equilibrium is about 98,000 $\mathrm{MWd} /$ metric ton of uranium and thorium. Recycle of the U-233 is not planned during the initial years of core operation; however, eventual recycle

*Fulton Generating Station PSAR. 
of the accumulated U-233 is possible. Under recycle equilibrium conditions, the fresh fuel will contain a new change of U-235 and thorium plus reprocessed $\mathrm{U}-233$.

\subsubsection{Reactor Coolant System}

The helium coolant transfers heat from the reactor core to the secondary coolant system. Helium is particularly desirable as a reactor coolant since it is chemically inert, is stable, has excellent heat transfer characteristics, and does not undergo phase change. The reactor arrangement is shown in Fig. 4.1.3-1* and significant parameters are given in Table 4.1.4-1. * The reactor coolant system (i.e., primary coolant system) ${ }^{(1)}$ contains six independent primary coolant loops, each having a helium circulator and a steam generator. Helium is circulated by means of the steam-turbine-driven axial flow helium circulators. Flow is downward through the reactor core, upward through the once-through steam generators, and then back to the helium circulators. Flow through the steam generator is shown in Fig. 5.5.1-1. * Each helium circulator is provided with a reactor coolant shutoff valve whose purpose is to limit reverse coolant flow through a nonoperating loop.

Since the coolant loops and their components are all located in cavities within the PCRV, the boundary for reactor coolant flow is provided by the PCRV cavity liners and the penetration liners and closures, while the PCRV itself provides the structural support to withstand the reactor coolant operating pressure.

\subsubsection{Prestressed Concrete Reactor Vesse1}

The PCRV, which is housed within the reactor containment, is a multicavity pressure vessel that houses the reactor core, the reactor coolant system, and portions of the secondary coolant system.

\footnotetext{
*Fu1ton Generating Station PSAR.

(1) Primary coolant and reactor coolant are used interchangeably throughout this document.
} 
The reactor core is located within a central cavity. The core cavity is surrounded by six steam generator cavities and three core auxiliary cooling loop cavities. Radial ducts at the top and bottom of the core cavity connect to these surrounding cavities.

The PCRV contains continuous internal steel liners which act as the reactor coolant flow boundary and sealing membrane. The PCRV provides the structural support for the pressure forces exerted by the reactor coolant. Thermal barriers (insulation) are attached to the inside of the liners, and cooling systems limit concrete and liner temperatures on the outside. The PCRV is constructed of high-strength concrete reinforced with reinforcing bars and is prestressed vertically and circumferentially. The liner, concrete, reinforcing steels, and prestressing steels function as a composite structure (see Section 5.4.1).* The PCRV is cast integrally with a support structure and reactor containment base mat.

PCRV overpressure is prevented by two $100 \%$ capacity rellef valves (see Section 5.2.2). * Effluent from the relief valves is discharged into the reactor containment.

PCRV overpressure protection in the event of a steam leak is provided by a steam generator isolation and dump system. The system minimizes steam/ water inleakage to the reactor coolant following a postulated failure in the economizer-evaporator-superheater section of a steam generator. Upon detection of moisture in the helium of the faulty loop, the steam generator is isolated, and the steam/water inventory of the leaking economizerevaporator-superheater is dumped to a dump tank (see Section 7.6.1.1).*

Orificing at the inlet end of each economizer tube (accomplished through the use of small-diameter tubes) is designed to prevent static and dynamic instability over the operating range of the steam generator. In addition, these tubes provide a restriction on the maximum possible steam/water inleakage

\footnotetext{
${ }^{\star}$ Fulton Generating Station PSAR.
} 
rate to the reactor coolant system in the event of a total offset rupture of a tube in the main steam/water section.

\subsubsection{Auxiliary Systems}

A number of auxiliary systems are provided to perform functions necessary for operation, maintenance, and refueling of the station. These systems include the helium purification system and radioactive gas recovery system. (See Chapter $9 .^{*}$ )

5.1.5.1. Helium Purification System. The helium purification system removes radioactive material and chemical impurities from the reactor coolant system by continuously purifying a side stream of gas. The purified helium is used for purging helium circulator seals, control rod drives, instruments and valves, and PCRV penetrations. The purification system also purifies helium transferred from the reactor coolant system to the helium storage system during depressurization of the reactor for maintenance and/or refueling.

\subsubsection{Radioactive Gas Recovery System. The radioactive gas recovery} system processes radioactive gases collected by the radioactive gas waste system. Gases processed by this system are separated into two streams: (1) a concentrated stream containing radioactive noble gases and tritium, suitable for return to the reactor coolant system, and (2) residual gases that are returned to the radioactive gas waste system for processing.

\subsubsection{Engineered Safety Features}

Engineered safety features are included in the station design to provide for the mitigation of the consequences of postulated limiting or faulted conditions. These engineered safety features include the core auxiliary cooling system (CACS).

\footnotetext{
${ }^{*}$ Fulton Generating Station PSAR.
} 
The CACS provides an independent means of cooling the reactor in the event that sufficient cooling capacity by the main cooling loops is not available (see Section 6.3, "Core Auxiliary Cooling System"). The three auxiliary cooling loops installed in the PCRV can also provide core cooling during station shutdown. They may be used if the main loops are out of service. Any two loops can cool the core; the third is provided for redundancy. Each independent auxiliary cooling loop consists of a motor-driven helium circulator, a water-cooled heat exchanger, and associated service systems. Heat is dissipated to the atmosphere by means of the air-cooled heat exchanger in the CACS.

\subsubsection{Instrumentation and Control}

Overall plant control is accomplished by an automatic load-following system from about $25 \%$ to $100 \%$ of rated load with minor operator action as needed.

The reactor monitoring system consists of the nuclear instrumentation for routine startup, automatic control, shutdown, and reactor protection, and an in-reactor system for monitoring core performance.

The nuclear instrumentation consists of three extended, wide-range logarithmic channels, three linear power channels, and an automatic neutron flux control channel. This instrumentation provides an indication of neutron flux level and rate of neutron flux change for routine startup and power operation of the reactor. It also provides the necessary trip outputs for alarms, interlocks, and reactor protection. Redundant instruments are provided in the reactor protection system.

The data acquisition and processing (DAP) system is a reliable dual computer-based instrumentation and processing system. Major functions of the DAP system are monitoring of inputs, performing extensive calculations

\footnotetext{
*Fulton Generating Station PSAR.
} 
on these inputs, notifying the operator of abnormal situations, and generating various displays and logs for use by operating personnel.

\subsubsection{Fue1 Handling and Storage}

Fuel handling is conducted by utilizing specialized equipment that provides for safe remote-controlled removal of spent fuel from the reactor, insertion of fresh fuel into the reactor, and storage of new and spent fuel.

Fuel handling is accomplished with the reactor shut down and the reactor coolant system depressurized to slightly below atmospheric pressure. The fue1 handling equipment and procedures are such that gas-tight integrity of the reactor coolant system and the fuel storage facilities is maintained at al1 times. Spent fuel is kept under a helium environment at temperatures below the normal service temperature. Shielding is provided to maintain personnel exposure in compliance with occupational standards.

Fuel handling equipment is moved and positioned within both the Reactor Containment Building and the Reactor Service Building by crane and is transferred between these buildings through the refueling access opening of the reactor containment by a rail-mounted transfer dolly.

The principal equipment utilized for fuel handling operations is as follows:

A fuel handling machine removes and replaces fuel and reflector elements in the reactor. During refueling, the fuel handling machine, which is shielded and gas-tight, is placed over a refueling penetration in the PCRV. A fuel transfer mechanism within the machine travels down into the reactor cavity, picks up a fuel or reflector element, and carries it back into the machine for inspection. 
A fue1 transfer cask transports spent fuel and reflector elements between the fuel handling machine and fuel storage. Fuel is removed from the fuel handling machine and placed in the fuel transfer cask. The reactor containment crane places the transfer cask on the transfer dolly that transports the cask to the Reactor Service Building. The Reactor Service Building crane is used to place the fuel transfer cask onto the storage wells.

Reactor isolation valves provide shielding and sealing of refueling penetrations during the refueling operation. A reactor isolation valve is connected to the refueling penetration and serves as a radiation and atmospheric barrier when the control rod drive assembly is removed and neither the fuel handling machine nor the auxiliary service cask is connected to that refueling penetration.

An auxiliary service cask is placed over the refueling penetrations to remove and install control rod drive and reserve shutdown assemblies before and after refueling. The auxiliary service cask is a gas-tight shielded containment, equipped with a cable-suspended grappling device for handling of control assemblies.

A transfer dolly transports the fuel handling machine, auxiliary service cask, and fuel transfer casks between the reactor containment and the Reactor Service Building.

Fuel storage wells in the Reactor Service Building store spent fuel in a dry, inert helium atmosphere. External cooling coils surrounding the fuel storage wells circulate cooling water for dissipation of decay heat. The wells are designed to prevent criticality under any circumstance. The wells are gas-tight and water-tight.

After cooldown of the spent fuel, the fuel is transferred to a spent fuel sealing facility by means of the fuel transfer cask and Reactor Service Building crane. In this facility, the fuel is placed in fuel storage cans. The fuel storage cans are placed in shipping containers, which are then 
sealed and leak tested in the sealing facility. The sealed shipping containers are then transferred to a temporary storage area in preparation for loading and shipment to the reprocessing plant.

5.1.9. Radioactive Waste Systems

The radioactive waste systems collect, process, and prepare for disposal anticipated and potentially radioactive wastes in a controlled and safe manner so that availability of the plant is not limited. Discharges comply with the allowable limits as established by $10 \mathrm{CFR} 20$ and the intent of the proposed Appendix I to 10 CFR 50 published in the Federal Register, June 13, 1971.

During normal operations only sma11 quantities of liquid waste are generated at the station. These liquid wastes are collected, processed, and analyzed for compliance with governing regulations upon discharge. Liquid waste which is radioactive is processed for offsite disposal. Liquid waste which is generally free of radioactivity is sampled, processed, monitored, and then discharged into the cooling tower blowdown line if within applicable 1imits.

Releases from the radioactive gas waste system comply with governing regulations. Gas waste resulting from station operation, which is generally free of radioactivity, is processed through a process vent system where these gases are filtered, monitored, and then released to the atmosphere.

Gas waste resulting from a radioactive source is processed through the gas waste system and the gas recovery system. The gas waste system provides for the collection, compression, temporary storage, and testing of radioactive gases released from the station. The gas recovery system is a cyclic, dynamic, cryogenic adsorption process. The low-temperature adsorption systems recover and return helium to the reactor coolant, adsorb and hold the radioactive gases on the charcoal beds and release them in a controlled manner back to the PCRV cavity, and adsorb and hold other gases (CO, $\mathrm{N}_{2}$, and $\mathrm{O}_{2}$ ) that result from reactions and outgassing of graphite in the reactor core, before releasing them to the gas waste system for subsequent release to the atmosphere. 
During normal operation, only small quantities of solid waste are generated at the station. Production of solid waste arises from the replacement of titanium sponge in the hydrogen getter units. Solid waste also results from equipment being replaced through routine maintenance or by termination of equipment operation. Other solid waste results from the fixation of liquid radwaste designated for drumming. Solid waste is placed into containers, sealed, and shipped to an approved burial location for radioactive solid waste.

\subsection{PROCESS HEAT REACTOR}

\subsubsection{Design Discussion}

Process heat plants employing the primary features of the HTGR steam plant can be designed for process gas effluent temperatures of $1400^{\circ} \mathrm{F}$ with only minor modifications, while still retaining state-of-the-art materials utilization. Effluent temperatures up to $2000^{\circ} \mathrm{F}$ are also feasible through the use of various high-temperature materials throughout the system. However, mechanical design tolerances become increasingly stringent as higher-temperature materials become necessary.

\subsection{2. $1200^{\circ} \mathrm{F} \mathrm{P1ant}$}

5.2.2.1. Reformer Description. Figure 5-1 shows the general configuration of all the process heat plants discussed herein. As can be seen, the PCRV arrangement is quite similar to that of the HTGR steam plant. The primary difference is the addition of six steam-methane reformers in the slightly larger PCRV between each of the reduced-capacity steam generators.

The reformers (see Fig. 5-2) are patterned after start-of-the-art fossil-fired reformers using presently available catalyst pellets. They incorporate straight tubes packed in a full tube field hanging vertically from a single tubesheet. The helium from the core passes through on the shell side from bottom to top, while the process gas is introduced at the top end of the tubes through the tubesheet. The catalyst pellets are 


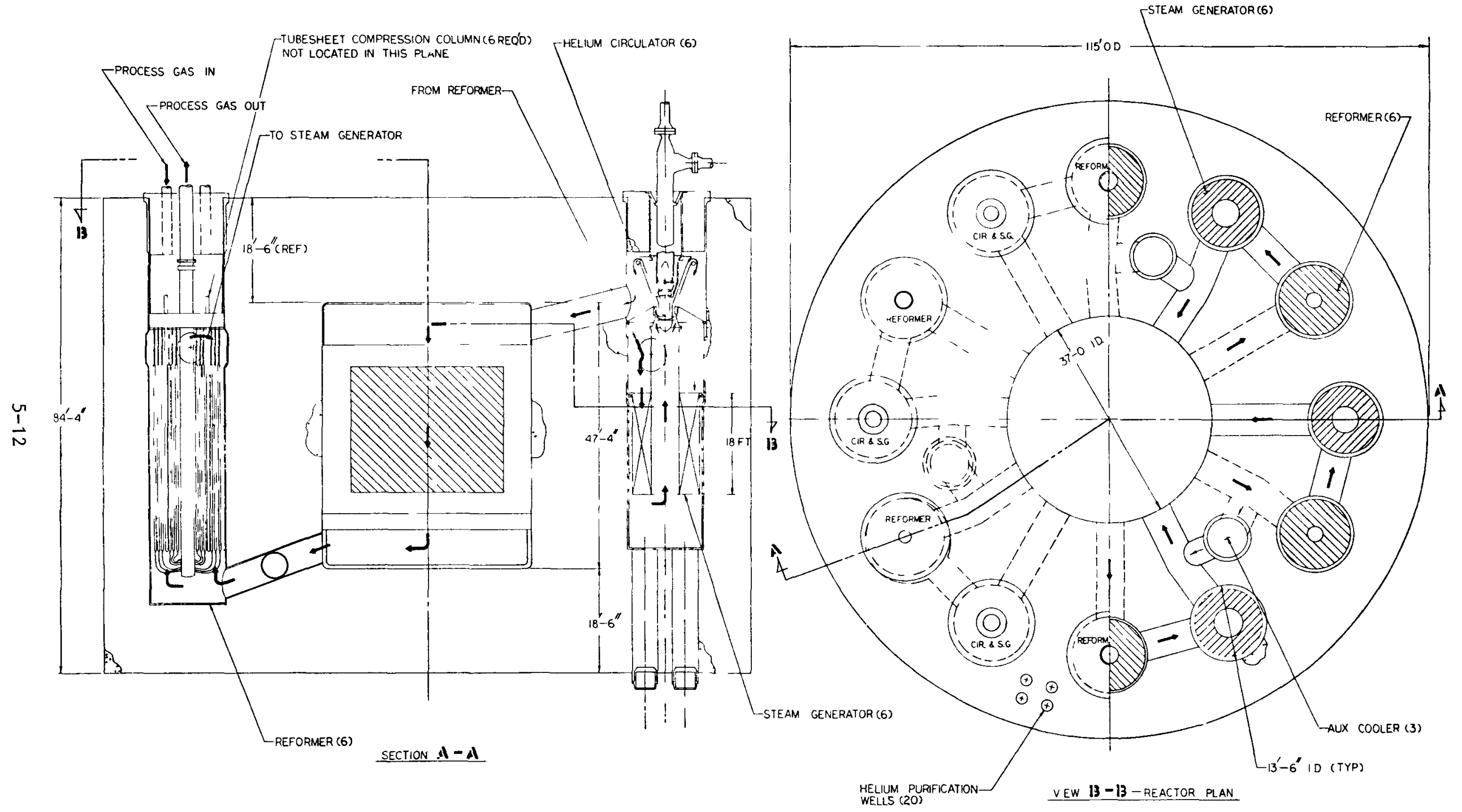

Fig. 5-1. $1200^{\circ} \mathrm{F}$ reformer plant arrangement 


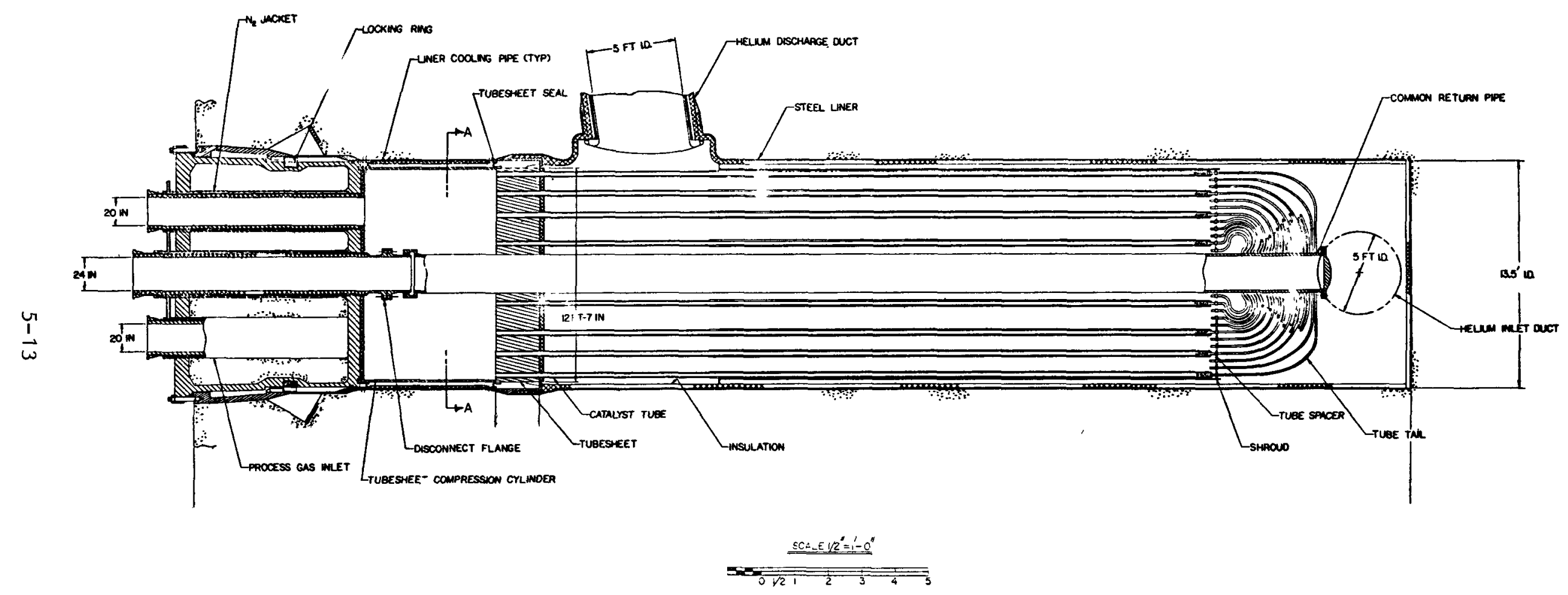

Fig. 5-2. Common return pipe reformer 
packed in approximately 800 tubes above a small grate at the lower end of each tube. The gas is heated by the tube wall as it passes through the catalyst bed and is exhausted through a semiflexible pigtail welded to the bottom of the tube. The pigtail conducts the gas to a common return pipe located in the center of the tube field which ducts the converted gas out through the top of the reformer.

The reformer tubes are fabricated of $\mathrm{HK}-40$ and are sized in accordance with standard engineering practice. They have a total length of $28 \mathrm{ft}$, including a 22-in. tubesheet penetration and $26 \mathrm{ft}$ of active (catalyst bed length) region. The wall thickness is $1 / 2$ in. over the entire tube length except for the upper $8 \mathrm{ft}$, where the outer diameter is reduced and the wall thickness is $3 / 16$ in. This reduction enhances the radial outflow of helium to the discharge scroll and, in addition, since the tubes penetrate the tubesheet and are welded to the top surface, creates a higher tubesheet ligament efficiency, thereby minimizing the required tubesheet thickness. The reduction in wall thickness is possible by virtue of the lower operating temperatures at the top end of the reformer. The wall thickness in the lower portion of the tubes was determined by hoop stress and double node buck1ing 1imitations, satisfying ASME Pressure Vesse1 Code requirements.

The catalyst tubes are hung from a tubesheet machined from a Type 304 stainless steel forging. This tubesheet has a top surface cladding of Incoloy 800 , which is applied by repeated weld passes of Incoloy 800 followed by machining and final hole boring. The cladding is necessary because of corrosion problems which austenitic steels experience in the presence of high-temperature steam. Six 7.5-in.-diameter columns are bolted to the cavity plug and extend down to the tubesheet to act as compression members or tubesheet stays. The columns are sized to withstand the normal long-term operating compression load from the flexing of the tubesheet due to the approximately 325-psi pressure differentia1. They also must withstand the added load due to occasional depressurization (emergency condition) of the process gas system with the ful1 700-psi helium pressure below the tubesheet. The columns are essentially solid, except for cooling passages through which water is circulated to control 
the thermal expansion, which must approximate that of the peripheral hold-down cylinder. Both the hold-down cylinder and the compression columns are fabricated of HK-40.

It should be noted that detailed design of an indeterminant "stayed" tubesheet of this sort is outside the scope of this study. Analysis of the allowable bending loads in the tubesheet as well as the allowable compression loads in the cylinder and the columns and their interaction is a highly complex problem. Cursory investigations indicate that the geometries and dimensions noted are about right, but a detailed study program is required.

The catalyst tubes extend through the tubesheet and are welded to the top surface. Lateral spacing is maintained throughout the field below the reduced-diameter section by 1/4-in.-wide by 12-in.-1ong strips welded to each tube at $5-\mathrm{ft}$ intervals along its length which act as spacers. Cold clearance is provided to allow for radial thermal expansion of each tube.

Flow plugs which fill the voids in the tube field beneath the locations of the tubesheet compression columns are provided to maintain helium flow velocities in these regions. These plugs are bolted to the tubesheet and are fabricated of 3/16-in. sheet Type 304 stainless steel. Their length is the same as the catalyst tubes. A 1-1/4-in.-OD pigtail is welded to the bottom of each tube to take the converted process gas to the common return pipe. The wall thickness is $1 / 8 \mathrm{in.,}$ and the tube is dimensioned to allow approximately 1/2-in. differential thermal expansion between the catalyst tubes and the return pipe, to which it is also welded.

The centrally located common return pipe is also fabricated from HK- 40 . This pipe is sized to maximize the catalyst tube packing efficiency and thus operates with relatively high gas velocities. This results in an outside diameter of $24 \mathrm{in.,}$ which requires a wall thickness of 2 in. 
The return pipe passes through the center of the tubesheet and continues up through the PCRV cavity plug to external connections. The pipe is allowed to move vertically with respect to the tubesheet by means of a flexible sea1. This allows for both thermal expansion of the pipe, which is rigidly fixed to the plug, and pressure flexing of the tubesheet.

The 12-1/2-ft-diameter tubesheet is mounted on peripheral brackets around the edge of the cavity. These brackets support the tubesheet and tubes while the system is depressurized. When full helium pressure is applied, the tubesheet tends to lift off these support brackets but is held in place by a compression cylinder and the six compression columns (as shown in Fig. 5-2). These components transmit the tubesheet pressure load to the cavity plug. The cylinder also provides an annular cooling space for the upper cavity wall. A flexible pressure seal is provided between the tubesheet periphery and the cavity wall as well as between the compression cylinder upper end and the cavity wall.

The cavity plug is a $10-\mathrm{ft}-\mathrm{thick}$, steel-lined concrete structure through which the inlet and effluent process gases are passed. The two inlet ducts are each $20 \mathrm{in}$. in inside diameter, while the discharge duct is a continuation of the 24-in.-ID return pipe. Except for these ducts, the plug is a standard HTGR steam plant cavity closure held in place by a primary top bolt circle and a secondary "breech lock."

The cavity and ducting liners are similar to those of the HTGR steam plant in that they are 1/2-in.- to 3/4-in.-thick carbon steel. Increased use of composite material thermal barriers is necessary owing to the higher-temperature conditions.

5.2.2.2. Steam Generator. The steam generator associated with the "lowtemperature" reformer is similar to the steam plant model except that it has the reheater section removed and is designed for higher-pressure operation. The reformer steam generator power is approximately the same as that of the main HTGR steam plant steam generator power without the reheater (which normally accounts for $16 \%$ of the total heat 1 oad). It is 
therefore proposed to adopt a steam generator using the HTGR economizer, evaporator, and superheater design but with the reheater removed and with rearranged helium inlet and exit ducting (the helium is introduced to the top of the tube bank first and subsequently returned to the top of the assembly). This configuration results in an active tube bank length reduction from 43.6 to $34.8 \mathrm{ft}$ and a concomitant reduction in helium pressure drop. The steam generator receives its inlet helium from the reformer discharge at a temperature about $150^{\circ} \mathrm{F}$ lower than the HTGR inlet helium temperature.

5.2.2.3. Circulator. Once through the steam generator, the helium is compressed in the circulator, which is mounted above the steam generator in a manner similar to the HTGR steam plant arrangement. The circulator turbine is powered by steam from the steam generator, which is then exhausted to the plant process steam line. The circulator pumping load is somewhat higher than in the HTGR steam plant, with a mass flow rate of approximately $2 \times 10^{6}$ lb per hour and a $4.5 \%$ head rise. The steam turbine conditions differ markedly in that the steam generator output of the reformer plant is $2500 \mathrm{psi}$ at $950^{\circ} \mathrm{F}$, whereas the steam plant turbine inlet conditions are $900 \mathrm{psi}$ and $705^{\circ} \mathrm{F}$. This difference indicates not only the necessity for a new turbine design but a new, integrated, close-coupled turbine-compressor assembly as we11. Particular emphasis will be required on design of the steam-helium seals and bearing supports because of the much higher differential pressure across this interface relative to the HTGR steam plant assemblies.

5.2.2.4. Thermal Barrier Design. To control the heat loads into the liner cooling system, the surfaces of the PCRV cavities and penetrations will be covered by thermal barriers, which consist of ceramic fiber blanket material, cover plates, seal sheets, and attachment studs.

Because the helium will flow through the cavities and interconnecting ducts at different temperatures, the thermal barrier designs in these areas will be different and will have the following major classifications: 
Class 1. Designed for service in areas normally exposed to helium at $500^{\circ}$ to $1000^{\circ} \mathrm{F}$ (upper core cavity, core inlet duct, circulator area).

Class 2. Designed for service in areas normally exposed to helium at temperatures to $1500^{\circ} \mathrm{F}$ (upper reformer cavity, reformer discharge ducts).

Class 3. Suitable for the same service as Class 2 in normal operation but having the capability to withstand temperatures up to $2500^{\circ} \mathrm{F}$, which might result from streaks of abnormally hot gas under some core outlets, especially during the auxiliary cooling operation. (This insulation will be used only under the core outlets, i.e., on the bottom head and the auxiliary loop lower ducts.)

The thermal barrier is prefabricated in the form of blankets and various metal components. Because permeation resistance is an inherent property of the fibrous insulation blanket, the metal parts do not require extreme-precision fit to accomplish sealing functions. All metal parts are dimensioned to accommodate thermal expansion clearances and fabrication and erection tolerances. The thermal barrier is attached by screwing an extension onto a short 5/8-in. threaded stud, which is arc-welded to the liner. Hastelloy $X$ cover plates with oversize holes at the attachment fixtures allow for thermal expansion by sliding. All sliding movements are accomplished between pairs of nitrided (case-hardened) Nitralloy 135 bearing plates, which will not weld or gall under service conditions.

The insulation for the core outlet ducts for Class 2 insulation will incorporate a double-wall inner duct through which cold helium can be pumped, thus maintaining the ducts at a temperature below that of the hot helium flowing through them from the core outlet. To allow for differential thermal expansion between the relatively hot and the relatively cold portions of the Class 2 thermal barrier, several types of sliding joints similar to those in Class 1 will be employed. These joints must slide, 
unlubricated, with a minimum of friction and without galling or welding, in a clean dry helium environment. In locations where the sliding joints are exposed to temperatures in excess of $800^{\circ} \mathrm{F}$, a flame-sprayed chromium carbide coating, which has been found to form a reliable bearing surface, will be applied directly to the metal components.

For the lower plenum of the main core cavity, a two-component design (Class 3 insulation) consisting of ceramic blocks over ceramic fiber blankets will be applied.

The actual insulation material to be used is a ceramic fiber blanket material of high chemical purity. Fibers in this blanket are an aluminasilica ceramic made by a melting and spinning process. The melting temperature is $3200^{\circ} \mathrm{F}$. The material is supplied in blanket form at a density of $8 \mathrm{lb} / \mathrm{ft}^{3}$. These blankets are compressed against the PCRV liner by 1/4-in. cover plates to a final installed density of about $12 \mathrm{lb} / \mathrm{ft}^{3}$. In the process, the applied pressure, which is initially about 3 psi, causes the blanket to conform very closely to liner surface irregularities, and the compression force also helps to support the blankets.

\subsection{3. $1400^{\circ} \mathrm{F} \mathrm{Plant}$}

The basic layout of the $1400^{\circ} \mathrm{F}$ process heat plant (Fig. 5-3) is similar to that of the "low-temperature" plant described in section 5.2.2. However, there is a distinct difference in the reformer and process gas ducting. As shown in Fig. 5-4, the reformer for the $1400^{\circ} \mathrm{F}$ plant is essentially similar to that of the low-temperature plant (Fig. 5-2), except that the 24-in.-ID process gas return duct has been eliminated. Instead, individual tubes have been inserted into each catalyst tube to carry the converted product gas back to the top of the reformer. These tubes are laid along the top of the tubesheet between tube holes and run in clusters up to the cavity walls to a toroidal manifold. This manifold is connected, in turn, to two discharge ducts which take the gas through the cavity plug to external connections. Incorporation of the "integral return tube" (IRT) design provides several benefits: 


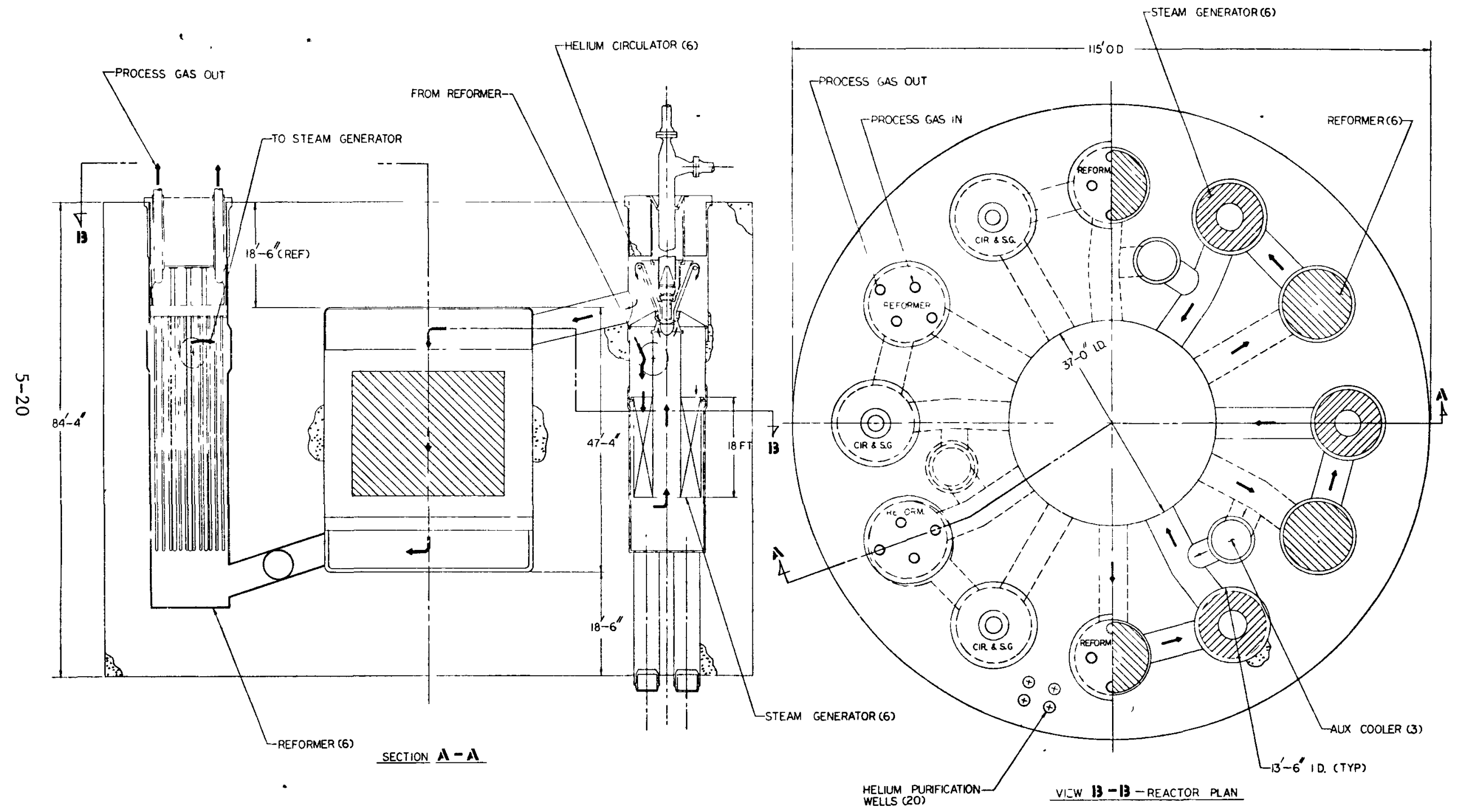

Fig. 5-3. $1400^{\circ} \mathrm{F}$ reformer plant arrangement

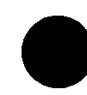




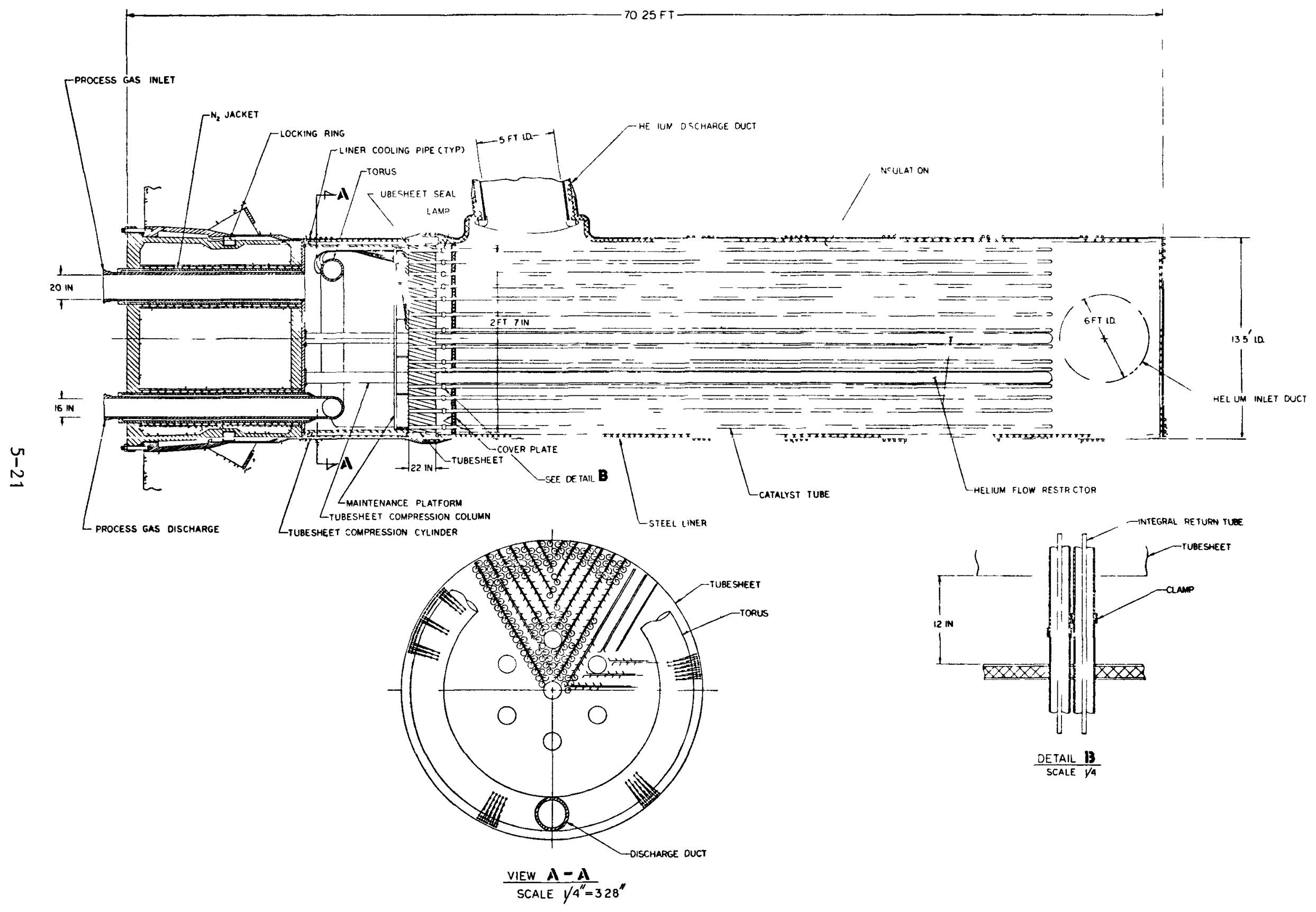

Fig. 5-4. Integral return tube reformer 
1. Differential thermal expansion problems between the common return pipe and the catalyst tubes are eliminated. These problems become increasingly difficult as the requirement for using lowductility, high-temperature materials becomes more prevalent. The IRT is anchored only at the tubesheet and thus is allowed to "float" vertically, lateral position being retained by several spacers.

2. A degree of heat recuperation is available, since the IRTs act as heat exchanger tubes. This effect becomes more pronounced as the product gas temperature is increased. The net effect is that the preheating effect and the increase in effective heat transfer area serve to decrease the required process gas inlet temperature, which allows the tubesheet and catalyst tube inlet sections to operate cooler than would be the case using the common return pipe.

3. In the event of a leaky tube, tube plugging can be accomplished on both inlet and outlet from above the tubesheet.

4. Elimination of the center return duct provides space for more catalyst tubes, thereby increasing the heated surface area. However, a seventh compression column and flow plug are added in the center of the tube field, which detracts somewhat from this advantage.

One disadvantage accrues with the IRT, which pertains to maintenance procedures. Catalyst pellet removal is accomplished through a vacuum operation (see Section 7) from above the tubesheet. A vacuum tube is inserted in the open ends of each catalyst tube to rapidly lift contaminated pellets out of the tube. With the IRT design, the available space for the vacuum pipe is considerably reduced. However, it is expected that with a smaller catalyst pellet (1/4 in. by $1 / 4 \mathrm{in}$. instead of the $5 / 8$ in. by $5 / 8$ in. pellets in the low-temperature plant), there will be sufficient clearance to insert a smaller-diameter pipe. 
Other differences between the $1200^{\circ} \mathrm{F}$ plant and the $1400^{\circ} \mathrm{F}$ plant (see Tables 5-1 and 5-2) include a slight reduction in steam requirements and helium flow rates, higher temperatures, an increase in active length, and a higher catalyst bed pressure drop owing to the smaller catalyst pellets.

\subsection{4. $1600^{\circ} \mathrm{F} \mathrm{Plant}$}

As the process gas maximum temperature requirements increase, so, of course, do the maximum component temperatures. "Conventional" reformer materials, i.e., high chromium- and nickel-based steels, are adequate for components exposed to temperatures in the $1200^{\circ}$ to $1500^{\circ} \mathrm{F}$ range and subjected to long-term stresses. HK-40, a high chromium cast alloy, has a stress for rupture in $200,000 \mathrm{hr}$ of $4500 \mathrm{psi}$ at $1500^{\circ} \mathrm{F}$, but this drops to 1300 psi at $1700^{\circ} \mathrm{F}$. Primary pressure stress in the $1 / 2-i n$.-wa11 catalyst tubes is about 1500 psi for normal operating conditions, or about $30 \%$ of the 1ong-term stress for rupture. Short-term emergency stress due to loss of process gas pressure results in a maximum hoop stress of 500 psi, which is offset by the short-term stress for rupture value of approximately $30,000 \mathrm{psi}$. Tube buckling (short term) is primarily a function of Young's modulus and lies well within the ASME required safety factor for this design at both the hot, thick-wall lower end and at the cooler, reducedthickness upper end.

Certain components of the $1600^{\circ} \mathrm{F}$ outlet plant will reach higher temperatures than can be accommodated by these "conventional" materials. For example, the lower ends of the catalyst tubes will operate at about $1700^{\circ} \mathrm{F}$, and the lower thermal barrier cover plates will operate at the temperature of the helium $\left(1800^{\circ} \mathrm{F}\right)$, with high-temperature streaks up to $250^{\circ}$ higher in the regions near the reactor discharge. The catalyst tube shroud and the tube field plugs will operate at near helium temperature. Such components are therefore candidates for higher-temperature materials. The two categories of high-temperature materials which apply are refractory metals and ceramics.

\footnotetext{
* The properties of these materials are discussed in section 5.3.
} 
TABLE 5-1

THERMODYNAMIC DATA FOR PROCESS HEAT PLANT

\begin{tabular}{|c|c|c|c|c|c|}
\hline & \multicolumn{5}{|c|}{ Nominal Outlet Temperature } \\
\hline & $1200^{\circ} \mathrm{F}$ & $1400^{\circ} \mathrm{F}$ & $1600^{\circ} \mathrm{F}$ & $1800^{\circ} \mathrm{F}$ & $2000^{\circ} \mathrm{F}$ \\
\hline 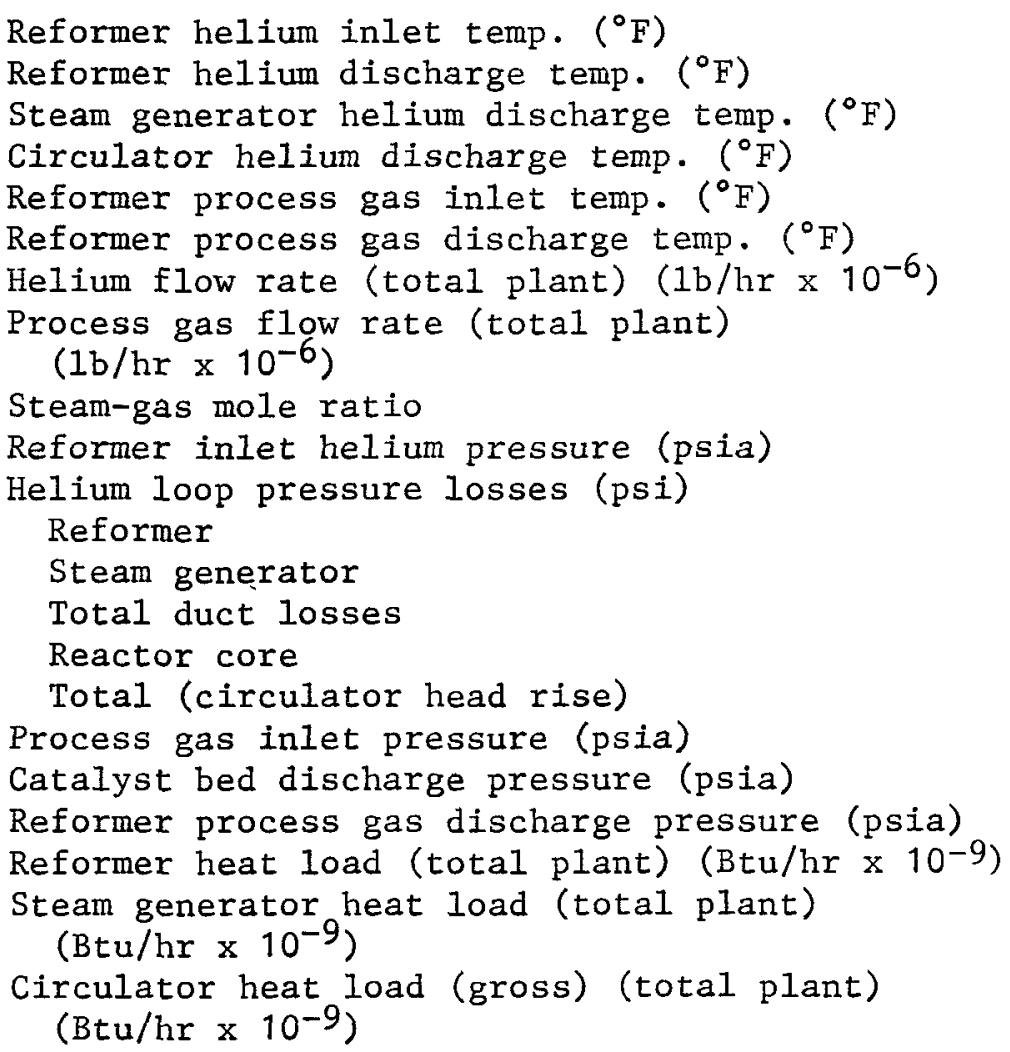 & $\begin{array}{c}1400 \\
1206 \\
686 \\
700 \\
1050 \\
1200 \\
12.1 \\
6.81 \\
4.5: 1 \\
700 \\
7.4 \\
8.0 \\
2.1 \\
13.5 \\
31.0 \\
368 \\
300 \\
290 \\
2.91 \\
7.59 \\
0.21\end{array}$ & $\begin{array}{c}1600 \\
1232 \\
755 \\
770 \\
1050 \\
1400 \\
10.2 \\
6.81 \\
4.5: 1 \\
700 \\
\\
7.2 \\
7.0 \\
1.6 \\
16.1 \\
31.9 \\
515 \\
300 \\
272 \\
4.65 \\
5.85 \\
0.19\end{array}$ & $\begin{array}{c}1800 \\
1341 \\
914 \\
932 \\
1050 \\
1590 \\
9.77 \\
4.94 \\
3: 1 \\
700 \\
13.6 \\
6.5 \\
2.4 \\
14.3 \\
36.8 \\
570 \\
400 \\
287 \\
5.55 \\
4.95 \\
0.22\end{array}$ & $\begin{array}{c}2000 \\
1460 \\
1029 \\
1050 \\
1050 \\
1790 \\
8.91 \\
3.06 \\
1.5: 1 \\
700 \\
8.0 \\
6.5 \\
2.1 \\
13.2 \\
29.8 \\
587 \\
500 \\
426 \\
5.96 \\
4.54 \\
0.24\end{array}$ & $\begin{array}{c}2200 \\
1538 \\
1176 \\
1200 \\
1050 \\
1940 \\
8.47 \\
3.06 \\
1.5: 1 \\
700 \\
\\
7.7 \\
6.5 \\
2.1 \\
13.2 \\
29.5 \\
675 \\
600 \\
531 \\
6.95 \\
3.55 \\
0.26\end{array}$ \\
\hline
\end{tabular}


TABLE 5-2

MECHANICAL DATA FOR PROCESS HEAT PLANT

\begin{tabular}{|c|c|c|c|c|c|}
\hline & \multicolumn{5}{|c|}{ Process Gas Discharge Temperature } \\
\hline & $1200^{\circ} \mathrm{F}$ & $1400^{\circ} \mathrm{F}$ & $1600^{\circ} \mathrm{F}$ & $1800^{\circ} \mathrm{F}$ & $2000^{\circ} \mathrm{F}$ \\
\hline Number reformers & 6 & 6 & 4 & 4 & 4 \\
\hline Number steam generators & 6 & 6 & 4 & 4 & 4 \\
\hline Reformer tube bundle OD (ideal) ( $f t$ ) & 12.25 & 12.0 & 12.0 & 12.0 & 12.0 \\
\hline Number catalyst tubes per reformer & 828 & 828 & 1433 & 1746 & 1746 \\
\hline Catalyst tube length ( $f t$ ) & 26 & 42 & 42 & 42 & 42 \\
\hline Catalyst tube ID (in.) & 3.5 & 3.5 & 3.0 & 2.5 & 2.5 \\
\hline Catalyst tube OD (upper end) (in.) & 3.75 & 3.75 & 3.375 & 2.875 & 2.875 \\
\hline Catalyst tube OD (lower end) (in.) & 4.5 & 4.5 & 3.375 & 2.91 & 2.91 \\
\hline $\begin{array}{l}\text { Catalyst tube pitch (triangular array) } \\
\text { (in.) }\end{array}$ & 4.77 & 4.77 & 3.62 & 3.28 & 3.28 \\
\hline Return pipe ID (in.) & 24 & -- & -- & -- & - \\
\hline Return pipe OD (in.) & 28 & -- & -- & -- & -- \\
\hline Return pipe pigtail ID (in.) & 1.0 & - & -- & -- & -- \\
\hline Return pipe pigtail OD (in.) & 1.25 & -- & -- & - & $-\infty$ \\
\hline Return tube ID (in.) & - & 1.0 & 0.625 & 0.5 & 0.5 \\
\hline Return tube OD (in.) & -- & 1.375 & 0.75 & 0.625 & 0.625 \\
\hline Tube shroud max. OD (nom) (ft) & 12.75 & 12.5 & 12.5 & 12.5 & 12.5 \\
\hline Tube shroud thickness (in.) & $1 / 4$ & $1 / 4$ & $1 / 4$ & $1 / 4$ & $1 / 4$ \\
\hline Cavity insulation thickness (in.) & 3 & 3 & 3 & 3 & 3 \\
\hline Tubesheet thickness (in.) & 22 & 22 & 22 & 22 & 22 \\
\hline He discharge scroll height (in.) & 60 & 60 & 90.5 & 60 & 60 \\
\hline $\begin{array}{l}\text { He discharge scroll max. depth (in.) } \\
\text { Total heat transfer surface (per }\end{array}$ & 20 & 20 & 13.25 & 20 & 20 \\
\hline reformer) $\left(f t^{2}\right)$ & 25,349 & 40,949 & 53,152 & 55,838 & 55,838 \\
\hline Catalyst tube material & $\mathrm{HK}-40$ & $\mathrm{HK} 40$ & SiC & SiC & SiC \\
\hline Return pipe material & $\mathrm{HK}-40$ & $\mathrm{HK} 40$ & Superthm. & Superthm. & Superthm. \\
\hline Pigtail material & Inc 800 & -- & -- & -- & -- \\
\hline Shroud material & 304 SS & 304 SS & - & -- & -- \\
\hline Tubesheet material & 304 SS (a) & 304 SS (a) & $304 \mathrm{sS}^{(\mathrm{a})}$ & 304 sS (a) & 304 SS (a) \\
\hline
\end{tabular}

${ }^{(a)}$ Cladding on process gas surfaces. 
The reformer materials which are contacted by the process gas, i.e., catalyst tubes, return tubes, tubesheet, ducts, etc., must be able to withstand not on1y high temperatures but a fairly corrosive atmosphere as we11. A large amount of data is available regarding the corrosion resistance of the more common high-temperature structural materials, but long-term experience is lacking in this area concerning refractory metals. Ceramic materials, however, demonstrate a high degree of corrosion resistance, which suggests that they be considered as prime candidates for reformer materials.

Of the ceramic materials, silicon carbide and silicon nitride appear attractive as structural materials. The fundamental mechanical properties of the silicon-based ceramics, like those of other materials, are almost entirely derived by destructive testing methods. Like other brittle materials, however, a much greater scatter in values is recorded than for more ductile materials. It is, of course, mandatory to design a component within the known limits of reproducibility of the material and also to be able to define a reasonable probability for failure. Through careful design, decreased reliance on material ductility to forgive errors, and development testing, the desired results can be achieved.

The strength of a ceramic material is generally referred to in terms of its modulus of rupture (M). It is determined from simple beam or cross-breaking tests where a load (W) to fracture is applied. Then $\mathrm{M}=3 \mathrm{WL} / 2 \mathrm{bd}^{2}$, which can be used to obtain maximum design stress values by use of the Weibull statistical concept, in which failure probability is influenced by the stressed volume or surface area of the component. If surface flaws control strength, surface instead of volume considerations apply. With ceramic materials, a combination of surface and volume effects are usually involved. Thus, the relationship between the mean fracture strengths $\sigma_{1}$ and $\sigma_{2}$ of components with stress volumes $V_{1}$ and $V_{2}$ (or surfaces $A_{1}$ and $A_{2}$ ) having statistically uniform flaw distribution is

$$
\frac{\sigma_{1}}{\sigma_{2}}=\left(\frac{v_{2}}{v_{1}}\right)^{1 / m} \quad \text { or } \quad=\left(\frac{A_{2}}{A_{1}}\right)^{1 / m} \text {, }
$$


where $\mathrm{m}$ is the Weibull modulus, which is inversely related to materials property variability.

The foregoing approach is used primarily for determination of safe tensile loads on a ceramic component. The compression strength of ceramic materials is typically considerably higher than the tensile or crossbreaking value. This indicates the desirability of designing ceramics under compression modes in areas of high stress.

The proposed design for the high-temperature reformer plants utilizes silicon carbide for the lower reformer tubes and Supertherm for the integral return tubes. Figure 5-5 shows the layout of the $1600^{\circ} \mathrm{F}$ plant, which is similar to that of the $1400^{\circ} \mathrm{F}$ plant (Fig. 5-1). Except for detailed dimensions, the principal differences in the designs are:

1. Reduction of the number of reformers and steam generators to four per plant.

2. Use of ceramic materials in high-temperature tube applications.

3. Addition of a "low-temperature" tube transition zone at the top of the reformer tubes.

As in the lower-temperature reformers, the catalyst tubes are hung from a full-span tubesheet mounted on the cavity liner. The catalyst tubes are fabricated of different materials at different levels. Welded to the tubesheet top surface as in the lower-temperature plant, the upper tube sections are of HK-40 and extend below the lower surface of the tubesheet a distance of $4 \mathrm{in.} \mathrm{A} \mathrm{4-in.} \mathrm{length} \mathrm{of} \mathrm{a} \mathrm{low-expansion} \mathrm{iron-nicke1-}$ cobalt alloy (Kovar or Nicosea1) is used as an HK-40/silicon carbide interface material (Fig. 5-4). This is a vacuum-melted, low-expansion alloy used for making hermetic seals with hard glass and ceramic materials. Its chemical composition is controlled within narrow limits to tailor the thermal expansion properties. It is readily machineable and can be satisfactorily electric arc or resistance welded. The interface section 


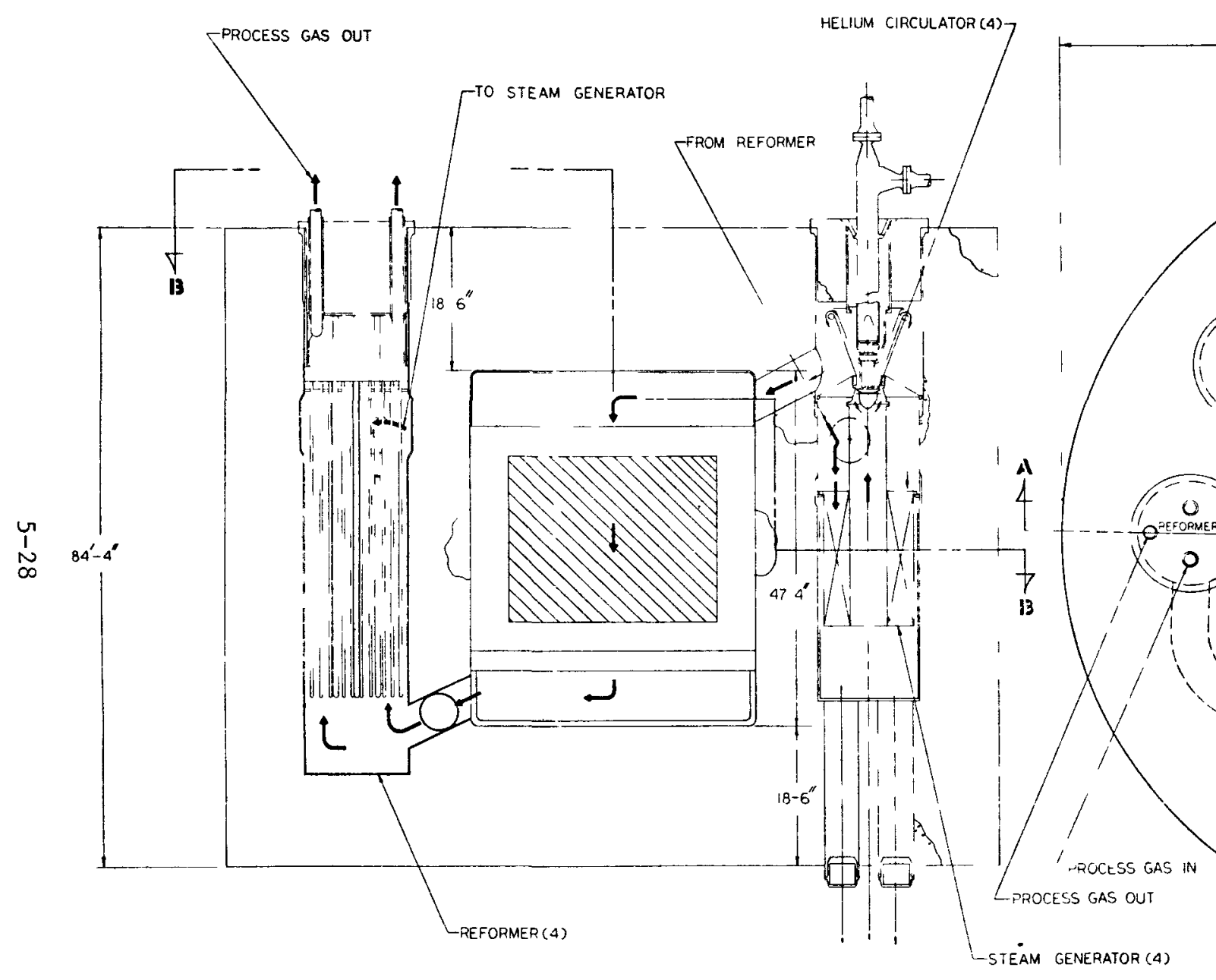

SECTIONN A-A

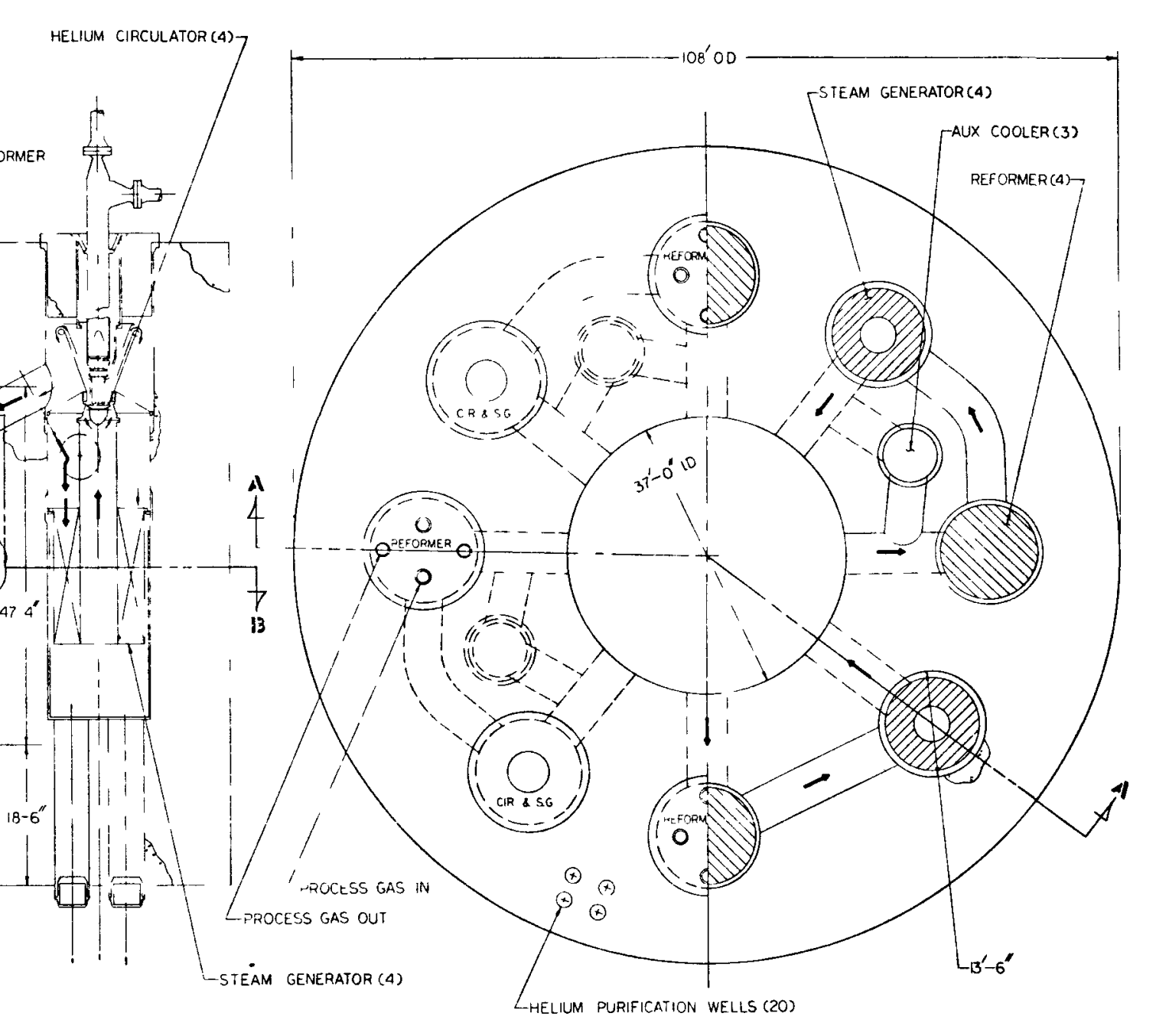

VIEW 13-13 - REACTOR PLAN

Fig. 5-5. High-temperature reformer plant arrangement 
has a machined clamping face which mates with a similar face on the silicon carbide catalyst tube. The other end of this piece is welded to the HK-40 tube stub protruding from the tubesheet. The main tube length of silicon carbide is then clamped to this Kovar section with two soft copper gaskets. Below the clamp is a 2-in. layer of insulation fabricated of two 1/4-in. Hastelloy $X$ cover plates with a layer of alumina-silica fiber material similar to the PCRV liner insulation blankets. This insulation layer blocks the flow of helium from reaching the lower surface of the tubesheet, the HK-40 tube stubs, and the tube clamp sections. In addition, it reduces heat conducted from the outer cover surface and allows the incoming process gas within the tubes to maintain the tubesheet and the upper tube sections at approximately the inlet gas temperature $\left(1050^{\circ} \mathrm{F}\right)$. The upper ends of the tubes are slightly reduced in diameter (inside diameter is constant) in a manner similar to the low-temperature plant. The purpose is to reduce radial cross flow differential pressure and to improve the tubesheet ligament efficiency. The minimum wall thickness was calculated based on conservative silicon carbide fracture strength data at the design temperatures. A safety factor for hoop stress was introduced based on an assumed Weibu11 modulus of 18 , in the absence of actual test data, and an additional factor of 3 . Buckling stability calculations were based on Young's modulus data for silicon carbide and a safety factor of 2.5 .

At present, detailed design of a high-temperature reformer of this type utilizing large ceramic components can be only conceptual owing to the dearth of empirical data and design experience. To date, little information regarding large ceramic parts, especially those with high surface to volume ratios such as long tubes, is available. Therefore, until better design data are developed to extend the Weibull concept or equivalent, large castings or extrusions of silicon carbide can be taken only as concepts. Nevertheless, the performance potential appears realistically achievable and sufficiently great to make a full-scale development program highly rewarding. A development program is described in Section 10. 
The general features of the steam generator for the $1600^{\circ} \mathrm{F}$ plant are basically similar to those of the steam generators of the lowertemperature plants and the HTGR. The main differences are as follows:

1. Dimensional changes provided to allow $30 \%$ greater helium flow capacity but about $75 \%$ of the steam capacity of the HTGR units.

2. Expanded use of Incoloy 800 throughout the superheater section.

In addition, the entire shroud assembly is fabricated of Incoloy 800. Also, as discussed for the lower-temperature plants, the reheat section is eliminated and the hot helium is introduced to the cavity at the top of the steam generator tube bank.

\subsection{5. $\quad 1800^{\circ} \mathrm{F}-2000^{\circ} \mathrm{F}$ Plants}

The high-temperature reformer plants are virtually the same as the $1600^{\circ} \mathrm{F}$ plant with regard to design features and materials. Differences lie mainly in their dimensions, which change owing to the different thermodynamic requirements. The process gas flow rate (Table 5-1) is decreased owing to a $50 \%$ decrease in the steam-gas mole ratio. The reformer heat load is increased, and the steam generator load is decreased.

The decrease in steam generator load, coupled with an increase in inlet temperature, results in a considerable reduction in the size of the steam generators in the high-temperature plants. The tube bundle volume required for the steam generators decreases from $14,700 \mathrm{ft}^{3}$ (21 ft in length) for the $1200^{\circ} \mathrm{F}$ plant to $8100 \mathrm{ft}^{3}$ (18 ft in length) for the $1600^{\circ} \mathrm{F}$ plant to $3140 \mathrm{ft}^{3}$ (10 ft in length) for the $2000^{\circ} \mathrm{F}$ plant.

A slight increase in circulator power is required for the highertemperature plants (Table 5-1) in spite of the decreased helium mass flow rates due to the lower-density helium. The circulator turbine development for the higher-temperature plants will require further emphasis, in addition to the unique high steam-helium pressure differential requirements discussed 
previously for the lower-temperature plants. As shown in Table 5-1, the head rise required of the compressor for all the plants is in excess of $4 \%$, with the highest $\Delta \mathrm{P} / \mathrm{P}$ being slightly over $5 \%$ for the $1600^{\circ} \mathrm{F}$ plant. This is a fairly safe goal for a single-stage pump provided that the blade speed can be set at a fairly high value. However, with the higher core inlet temperatures involved in the higher-temperature plants (Table 5-1), disk and blading stresses become critical at the high speeds required. Thus, development of high-temperature machinery is required, including design with higher-temperature rotating parts using, for example, "super" $12 \%$ chrome steels and/or progressing to multistage compressors to operate at lower stress levels.

\subsection{HTGR/REFORMER MATERIALS}

An initial materials selection criterion for a structural design analysis of process heat HTGR/reformer systems must consider the parameters and requirements listed in Table 5-3 in conjunction with the material properties given in the table.

Since few materials have been investigated for more than $10 \mathrm{yr}$ under stress in reformer oxidizing atmospheres, an initial selection of materials must be based on extrapolation and temperature-time parametric relationships with strength. Thus, after evaluation of melting points at the maximum temperatures of anticipated operation, candidate materials become those which have known resistance to high-temperature oxidation, hightemperature stability and strength, and resistance to thermal shock. For service at temperatures above $1200^{\circ} \mathrm{F}$, the classes of materials appearing as candidates would be the iron-nickel-chromium alloys, nickel or cobalt superalloys, dispersion-strengthened nickel alloys and low-porosity ceramics ( $\mathrm{SiC}, \mathrm{Si}_{3} \mathrm{~N}_{4}$, and $\mathrm{Al}_{2} \mathrm{O}_{3}$ ), and refractory metals (tungsten and tantalum). For nonoxidizing or weakly oxidizing conditions, molybdenum alloys and carbon composites would be attractive materials. 
TABLE 5-3

BASIS FOR INITIAL MATERIALS SELECTION CRITERION

Operating Parameters

Material Properties

Design Requirements

Nomina1 Conditions - Reformer

Process steam temperature/ID wall temperature) of reformer components

Component stresses due to $\angle P$ and external loading

Helium coolant temperature/OD wall temperature of reformer components and reactor components

Thermal barrier ducting temperature

Operating time at temperature

Number of shutdown and maintenance sequences

Material melting point (ASME Pressure Vessel code - Section III Stress-rupture value

Stress to cause $1 \%$ total strain in
operating time Class I components:

Design stress $2 / 3$ average stress-rupture

Stress to cause onset of tertiary U Design stress Cause $1 \%$ total strain in com-

creep

Low-cycle (thermal) fatigue

ponents in operating time

Design stress Cause onset of tertiary creep

in operating time

roperty values as a function (temperature and time)

HTGR helium environment
and reactor components
Process stream $\left(\mathrm{CH}_{\mathrm{x}}+\mathrm{H}_{2} \mathrm{O}\right.$

reformer components

(Environmental/material interactions) (No leaking

and potential loss of material No cracking

and/or strength

Uniform loss of effective material

in inches/year

Non-Nominal Conditions

Temperature streaking

Emergency overheat

Rapid shutdown

Environmental perturbations: fluctuation

in impurity level of HTGR helium

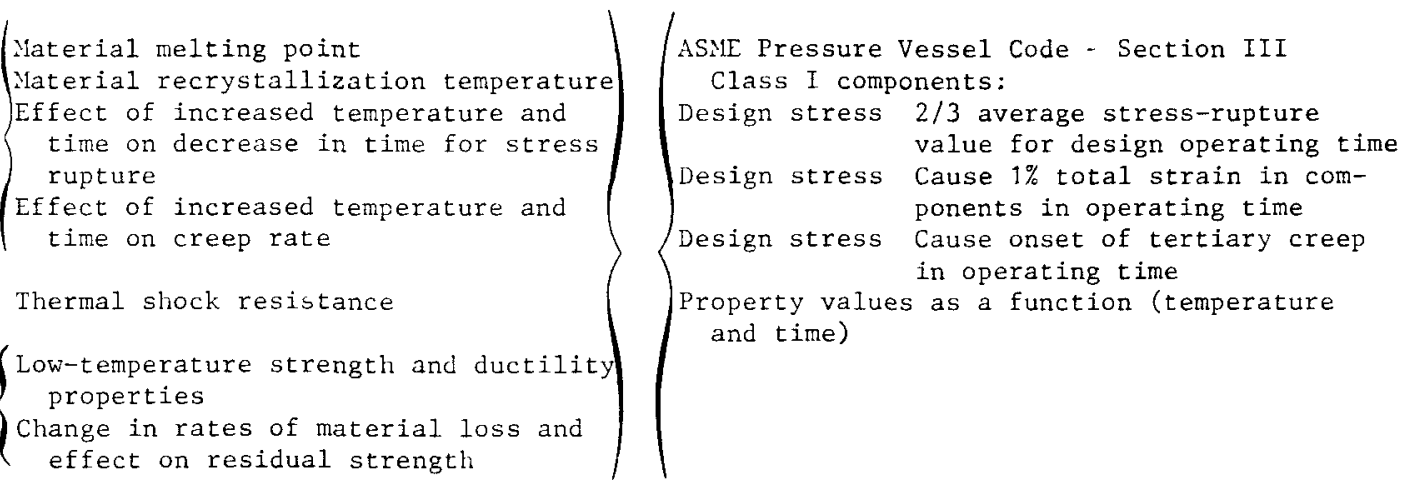

Change in steam/methane ratıo

No leaking

No cracking 
A second-order materials selection criterion considers material property values which affect design efficiency, ease of fabrication, and reliability:

\author{
Design Efficiency Factors \\ Modules of elasticity \\ Oxidation rate \\ Thermal conductivity \\ Thermal coefficient of expansion \\ Weld properties
}

\title{
Fabrication and Reliability Factors
}

Weldability

Ductility

Fracture toughness

For components of large size or quantity, material costs and fabrication costs became unavoidable selection factors. Materials offering extreme reliability can often offset low-cost materials requiring frequent attention and repair.

Selection of candidate structural materials for the process heat HTGR/reformer systems will be strongly dependent on operating temperatures. Table 5-4 lists the likely material candidates for reformer components for various operating temperatures. Table 5-5 lists the high-temperature alloys, both cast and wrought, which have desirable properties for reformer applications and require further evaluation, particularly gas/material interaction studies in HTGR helium environment. Stress-rupture values for 1000 and $10,000 \mathrm{hr}$ are given in Tables 5-6 and 5-7, respectively. Table 5-8 lists the likely material candidates for core outlet duct cover plates. Valve parts and housings are typically of ferritic steels below $950^{\circ} \mathrm{F}$ and would require a change to the austenitic stainless steels for higher-temperature designs, as shown in Table 5-9. 
TABLE 5-4

MATERIAL CANDIDATES FOR REFORMER COMPONENTS

\begin{tabular}{|c|c|c|c|c|}
\hline \multirow{2}{*}{$\begin{array}{c}\text { Reformer Tube ID } \\
\text { and Process } \\
\text { Stream Temp. } \\
\left({ }^{\circ} \mathrm{F}\right)\end{array}$} & \multirow{2}{*}{$\begin{array}{c}\text { Reformer OD } \\
\text { and HTGR } \\
\text { Helium Temp. } \\
\left({ }^{\circ} \mathrm{F}\right)\end{array}$} & \multirow{2}{*}{$\begin{array}{l}\text { Infrequent } \\
\text { Maximum } \\
\text { Temp. } \\
\left({ }^{\circ} \mathrm{F}\right)\end{array}$} & \multicolumn{2}{|c|}{$\begin{array}{c}\text { Candidate Structural } \\
\text { Materials }\end{array}$} \\
\hline & & & Class & Material \\
\hline 1200 & 1400 & 1600 & $\begin{array}{l}\mathrm{Fe}-\mathrm{Cr}-\mathrm{Ni} \\
\text { alloys }\end{array}$ & $\begin{array}{l}\text { Incoloy } 800 \\
\text { (wrought), } \\
\text { HK-40 (cast) }\end{array}$ \\
\hline 1400 & 1600 & 1800 & $\begin{array}{l}\mathrm{Fe}-\mathrm{Cr}-\mathrm{Ni} \\
\text { alloys }\end{array}$ & $\begin{array}{l}\text { Incoloy } 800 \text {, } \\
\text { HK- } 40, \\
\text { IN519 }\end{array}$ \\
\hline & & & Superalloys & Hastelloy $\mathrm{X}$ \\
\hline 1600 & 1800 & 2000 & $\begin{array}{l}\text { Above alloys, } \\
\text { dispersion-- } \\
\text { strengthened }\end{array}$ & $\begin{array}{l}\text { Incoloy } 800, \\
\text { HK- } 40, \\
\text { IN519, } \\
\text { Haste1loy X }\end{array}$ \\
\hline & & & Ni-alloys & $\begin{array}{l}\text { Inconel } \\
\text { MA753 }\end{array}$ \\
\hline & & & Ceramics & $\begin{array}{l}\mathrm{SiC} \\
\mathrm{Si}_{3} \mathrm{~N}_{4}, \mathrm{Al}_{2} \mathrm{O}_{3}\end{array}$ \\
\hline 1800 & 2000 & 2200 & Ceramics & $\begin{array}{l}\mathrm{SiC}, \mathrm{Si}_{3} \mathrm{~N}_{4}, \\
\mathrm{Al}_{2} \mathrm{O}_{3}\end{array}$ \\
\hline 2000 & 2200 & 2400 & Ceramics & $\begin{array}{l}\mathrm{SiC}, \mathrm{Si}_{3} \mathrm{~N}_{4}, \\
\mathrm{Al}_{2} \mathrm{O}_{3}\end{array}$ \\
\hline
\end{tabular}


TABLE 5-5

CHEMICAL ANALYSES (TYPICAL) OF HIGH-TEMPERATURE ALLOYS REQUIRING GAS/MATERIAL INTERACTION STUDIES IN HTGR HELIUM ENVIRONMENT

(Analyses in Weight - Percent)

\begin{tabular}{|c|c|c|c|c|c|c|c|c|c|c|c|c|c|}
\hline Alloy & C & $\mathrm{Mn}$ & $\mathrm{Si}$ & $\mathrm{Cr}$ & $\mathrm{Ni}$ & Mo & $\mathrm{Nb}$ & W & Co & $\mathrm{A} 1$ & $\mathrm{Ti}$ & $\mathrm{Fe}$ & Other \\
\hline$H K-40$ & 0.40 & 1.5 & 1.5 & 26 & 20 & -- & -- & -- & -- & -- & -- & Balance & \\
\hline HT-Mod & 0.15 & 1.5 & 1.5 & 21 & 33 & -- & -- & -- & -- & -- & -- & Balance & \\
\hline $\mathrm{HP}-50$ & 0.50 & 1.5 & 1.5 & 27 & 35 & -- & -- & -- & -- & -. & -- & Balance & \\
\hline HN & 0.40 & 1.5 & 1.5 & 21.5 & 25.5 & -- & -- & -- & -- & -- & -- & Balance & \\
\hline IN519 & 0.30 & 0.75 & 1.0 & 24 & 24 & -- & 1.5 & -- & - & -- & -- & Balance & \\
\hline Supertherm & 0.50 & 1.5 & 1.5 & 28 & 35 & -- & -- & 5 & 15 & -- & -- & Balance & \\
\hline MoRe 2 & 0.40 & 1.5 & 1.5 & 33 & 50 & -- & -- & 17 & -- & -- & - & Balance & \\
\hline $\mathrm{NA} 22 \mathrm{H}$ & 0.50 & 1.0 & 1.5 & 28 & 48 & -- & -- & 5 & -- & -- & -- & Balance & \\
\hline HOM3 & 0.45 & 1.0 & 1.0 & 25.5 & 45.5 & 3.5 & -- & 3.5 & 3.5 & -- & -- & Balance & \\
\hline M36X & 0.45 & 1.0 & 1.0 & 25 & 35 & -- & 1.5 & - & -- & -- & -- & Balance & \\
\hline M900 & 0.18 & 1.3 & 1.7 & 21 & 33 & -- & 1.5 & -- & -- & -- & - & Balance & \\
\hline IN800H & 0.08 & 0.75 & 0.4 & 20.5 & 32 & -- & -- & -- & -- & 0.30 & 0.30 & Balance & \\
\hline IN802 & 0.35 & 1.0 & 0.5 & 21 & 33 & -- & -- & -- & -- & 0.60 & 0.60 & Balance & \\
\hline IN807 & 0.10 & 1.0 & 1.0 & 20 & 40 & -- & -- & 5 & 8 & -- & - & Balance & \\
\hline RA330 & 0.05 & 1.5 & 1.25 & 19 & 35 & -- & -- & -- & -- & -- & -- & Balance & \\
\hline RA333 & 0.05 & 1.5 & 1.25 & 25 & 45 & 3 & -- & 3 & 3 & -- & -- & Balance & \\
\hline IN601 & 0.05 & 0.5 & 0.25 & 23 & Bal. & -- & -- & -- & -- & 1.35 & -- & 14 & \\
\hline IN617 & 0.07 & -- & -- & 22 & Bal. & 9.0 & -- & -- & 12.5 & 1.0 & - & - & \\
\hline IN7 18 & 0.04 & 0.20 & 0.30 & 18.5 & Bal. & 3.1 & 5.0 & - & -- & 0.4 & 0.9 & 18.5 & \\
\hline Hastelloy $\mathrm{X}$ & 0.15 & 0.3 & 0.3 & 21.8 & Bal. & 9.0 & - & 0.6 & 2.0 & -- & -- & 18.5 & \\
\hline N155 & 0.15 & 1.5 & 0.5 & 21 & 20 & 3.0 & 1.0 & 2.5 & 20 & -- & -- & Balance & \\
\hline HS188 & 0.08 & 1.0 & 0.5 & 22 & 22 & - & - & 14 & $\mathrm{Bal}$. & -- & -- & 1.5 & $0.08 \mathrm{La}$ \\
\hline MA753 & 0.05 & -- & -- & 20 & Bal. & -- & -- & -- & - & 1.5 & 2.5 & -- & $1.3 \mathrm{Y}_{2} \mathrm{O}_{3}$ \\
\hline$L-605$ & 0.10 & 1.5 & 0.5 & 20 & 10 & -- & -- & 15 & Bal. & -- & -- & -- & \\
\hline Mo-TZM & 0.02 & -- & -- & -- & -- & $\mathrm{Bal}$. & -- & -- & -- & -- & 0.5 & -- & $0.08 \mathrm{Zr}$ \\
\hline
\end{tabular}


TABLE 5-6

HIGH-TEMPERATURE ALLOY STRESS RUPTURE VALUES FOR 1000 HR

\begin{tabular}{|c|c|c|c|c|c|c|}
\hline \multirow[b]{2}{*}{ Alloy } & \multirow[b]{2}{*}{ Form } & \multicolumn{5}{|c|}{ Stress (psi) for $1,000-\mathrm{Hr}$ Life at: } \\
\hline & & $1400^{\circ} \mathrm{F}$ & $1500^{\circ} \mathrm{F}$ & $1600^{\circ} \mathrm{F}$ & $1800^{\circ} \mathrm{F}$ & $2000^{\circ} \mathrm{F}$ \\
\hline $\mathrm{HK}-40$ & Cast & 14,000 & - & 7,000 & 3,000 & 1,500 \\
\hline HT-Mod & & - & 5,500 & 3,700 & -- & -- \\
\hline HP-50 & & - & - & 5,900 & 3,250 & 1,500 \\
\hline IN519 & & -- & -- & 6,800 & 3,600 & -- \\
\hline Supertherm & & 18,000 & -- & 10,000 & 5,000 & 3,000 \\
\hline MoRe2 & & - & -- & -- & - & 2,150 \\
\hline $\mathrm{NA} 22 \mathrm{H}$ & & -- & -- & -- & 4,200 & 1,650 \\
\hline HOM3 & & - & -- & -- & 4,200 & 1,650 \\
\hline M36X & & -- & -- & -- & 4,700 & 1,650 \\
\hline M900 & 1 & -- & -- & 4,600 & 2,300 & -- \\
\hline IN800 & Wrought & 9,500 & 5,000 & 3,700 & 1,700 & 700 \\
\hline IN802 & & 16,000 & - & 10,000 & 3,800 & 1,400 \\
\hline IN807 & & -- & 5,650 & 3,800 & 1,725 & 780 \\
\hline RA330 & & 8,000 & 5,400 & 3,700 & 1,500 & -- \\
\hline RA333 & & 15,000 & 10,300 & 7,000 & 2,600 & -- \\
\hline N155 & & -- & 16,000 & - & -- & -- \\
\hline IN601 & & -- & 6,400 & - & 2,100 & 1,000 \\
\hline IN617 & & -- & 16,000 & -- & 4,000 & 1,700 \\
\hline IN7 18 & & 20,000 & -- & -- & -- & -- \\
\hline Hastelloy X & & -- & 10,000 & -- & 2,300 & 900 \\
\hline HS 188 & & -- & 16,000 & -- & 3,600 & -- \\
\hline MA753 & & 35,000 & 25,000 & 22,000 & 18,000 & $\begin{array}{l}16,000 \\
\left(1900^{\circ} \mathrm{F}\right)\end{array}$ \\
\hline $\begin{array}{l}\text { L-605 } \\
\text { Mo-TZM } \\
\text { ( } 65 \% \text { cold worked) }\end{array}$ & 1 & 24,000 & 17,000 & 10,000 & $\begin{array}{r}3,600 \\
50,000\end{array}$ & -- \\
\hline
\end{tabular}


TABLE 5-7

HIGH-TEMPERATURE ALLOY STRESS RUPTURE VALUES FOR 10,000 HR

\begin{tabular}{l|c|c|c|c|c}
\hline \multirow{2}{*}{ A11oy } & \multicolumn{5}{|c}{ Stress (psi) for $10,000-\mathrm{Hr}$ Life at : } \\
\cline { 2 - 6 } & $1400^{\circ} \mathrm{F}$ & $1600^{\circ} \mathrm{F}$ & $1800^{\circ} \mathrm{F}$ & $2000^{\circ} \mathrm{F}$ & $2200^{\circ} \mathrm{F}$ \\
\hline HK-40 & 9,500 & 4,200 & 1,800 & 800 & -- \\
HT-Mod & 5,200 & 2,400 & -- & -- & -- \\
HP-50 & -- & 3,900 & 2,700 & 900 & 180 \\
HN & -- & - & 1,950 & 510 & -- \\
IN519 & -- & 4,400 & 1,800 & -- & -- \\
Supertherm & 16,000 & 7,500 & 4,000 & 1,600 & 300 \\
MoRe 2 & -- & -- & -- & -- & -- \\
NA22H & -- & -- & 2,500 & 940 & 150 \\
HOM3 & -- & -- & 2,500 & 940 & 150 \\
M36X & 7,800 & 4,300 & -- & -- & -- \\
M900 & 7,000 & 3,400 & 1,600 & -- & -- \\
IN800 & 5,600 & 2,100 & -- & - & - \\
IN802 & 11,000 & 4,800 & 1,800 & 550 & -- \\
IN807 & -- & 2,700 & 1,200 & 530 & -- \\
RA330 & 5,600 & 2,200 & 1,800 & - & - \\
RA333 & 11,000 & 4,700 & 1,300 & -- & - \\
Mo-TZM & & & 47,000 & & \\
(co1d worked 64\%) & & & & & \\
\hline
\end{tabular}


TABLE 5-8

MATERIAL CANDIDATES FOR CORE OUTLET DUCT COVER PLATES

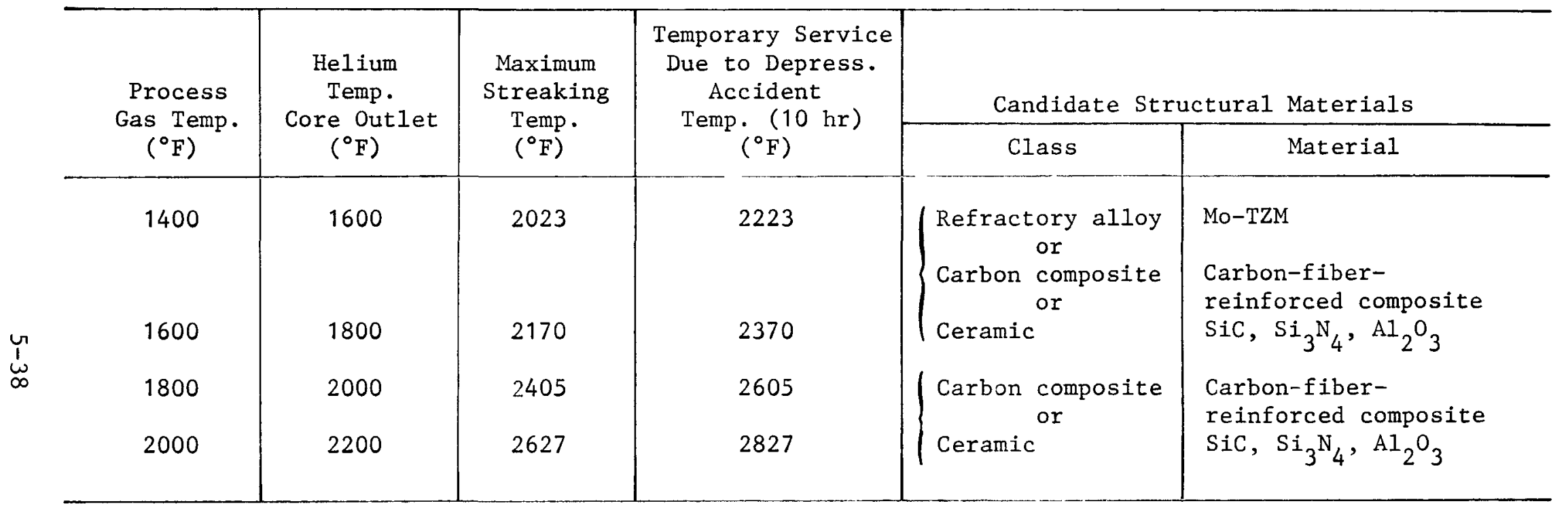


TABLE 5-9

CANDIDATE MATERIALS FOR VALVE COMPONENTS AS A FUNCTION OF MATERIAL TEMPERATURE

\begin{tabular}{|c|c|c|c|c|c|}
\hline \multirow{2}{*}{$\begin{array}{c}\text { Reference Case } \\
\text { Process Stream } \\
\text { Temp. } \\
\left({ }^{\circ} \mathrm{F}\right)\end{array}$} & \multicolumn{3}{|c|}{ Temperature of Valve Components $\left({ }^{\circ} \mathrm{F}\right)$} & \multicolumn{2}{|c|}{$\begin{array}{l}\text { Candidate } \\
\text { Structural Material }\end{array}$} \\
\hline & Relief Valve & $\begin{array}{l}\text { Main Circulator } \\
\text { Shut-off Valve }\end{array}$ & $\begin{array}{c}\text { Auxiliary Circulator } \\
\text { Shut-off Valve }\end{array}$ & $\begin{array}{l}\text { Material } \\
\text { Class }\end{array}$ & Alloy \\
\hline 1200 & 700 & 689 & 648 & $\begin{array}{l}\text { Ferritic } \\
\text { steel }\end{array}$ & $2-1 / 4 \mathrm{Cr}-1 \mathrm{MO}$ \\
\hline 1400 & 770 & 759 & 713 & $\begin{array}{l}\text { Ferritic } \\
\text { steel }\end{array}$ & $2-1 / 4 \mathrm{Cr}-1 \mathrm{Mo}$ \\
\hline 1600 & 932 & 921 & 863 & $\begin{array}{l}\text { Austenitic } \\
\text { stainless } \\
\text { steels }\end{array}$ & $321,347,316$ \\
\hline 1800 & 1050 & 1039 & 972 & $\begin{array}{l}\text { Austenitic } \\
\text { stainless } \\
\text { steels }\end{array}$ & $321,347,316$ \\
\hline 2000 & 1200 & 1189 & 1111 & $\begin{array}{l}\text { Austenitic } \\
\text { stainless } \\
\text { steels }\end{array}$ & $321,347,316$ \\
\hline
\end{tabular}


The cast materials receive their high-temperature strength from second-phase carbides and solid-solution strengthening alloying elements. These factors and relatively large grain size establish good creep resistance. All alloys can be cast in an air atmosphere by the centrifugal casting process. Selection of any one alloy is mainly a trade-off of cost versus strength or creep resistance for a desired wall thickness. Compatibility with HTGR helium environment could also be a major criterion, as these alloys represent a good range of resistance to oxidation and carburization.

The wrought alloys chosen represent the spectrum of iron-nicke1chromium and superalloys for application above $1500^{\circ} \mathrm{F}$. All receive hightemperature strength from solid-solution alloying elements and from carbides (to a lesser degree than cast alloys). Some have alloying elements for $\gamma^{\prime}$ precipitation hardening below $1500^{\circ} \mathrm{F}$. Oxidation and carburization resistance will vary for these alloys, and thus their compatibility with HTGR helium environment may vary.

Table 5-10 shows a comparison of costs for materials supplied as tubing in large quantity. The use of a cost factor relative to the conventional reformer tubing material seems an appropriate way of looking at costs, since nickel and chromium costs are changing rapidly and almost all of these alloys would be similarly affected. Many of the wrought alloys would be rolled and welded into tubing, while some can be extruded to shape. The cast tubes typically are made by the centrifugally casting process.

Austenitic stainless steel sheet $(304,316)$ presently costs in the range $\$ 1.00 / 1 \mathrm{~b}$ to $\$ 1.50 / 1 \mathrm{~b}$. Molybdenum alloy TZM as sheet typically costs $\$ 25 / 1 b$. Carbon-fiber-reinforced composites can range from $\$ 50 / 1 \mathrm{~b}$ to over $\$ 100 / 1 b$ for special grades and shapes, but with a simpler configuration in block shape and large quantities could cost near $\$ 25 / 1 \mathrm{~b}$. Carbon-felt insulation costs approximately $\$ 25 / 1 b$. Quantity and property tolerance are significant factors in the cost of most of the carbon materials. Ceramic materials like silicon carbide or $\mathrm{Si}_{3} \mathrm{~N}_{4}$ presently cost $\$ 17 /$ in . 
TABLE 5-10

COMPARISON OF COSTS FOR CANDIDATE REFORMER MATERIALS IN TUBE SHAPE

\begin{tabular}{|c|c|c|}
\hline Alloy & Form & Cost Factor (a) \\
\hline $\begin{array}{l}\text { HK-40 } \\
\text { HT-Mod } \\
\text { HP-50 } \\
\text { IN519 } \\
\text { Supertherm } \\
\text { MoRe2 } \\
\text { NA22H } \\
\text { HOM3 } \\
\text { M36X } \\
\text { M900 }\end{array}$ & $\mid$ & $\begin{array}{l}1.0 \\
1.15 \\
1.25 \\
1.07 \\
3.0 \\
4.0 \\
2.5 \\
4.5 \\
1.3 \\
1.3\end{array}$ \\
\hline $\begin{array}{l}\text { IN800 } \\
\text { IN802 } \\
\text { IN807 } \\
\text { RA330 } \\
\text { RA333 } \\
\text { N155 } \\
\text { IN601 } \\
\text { IN617 } \\
\text { IN718 } \\
\text { Haste11oy X } \\
\text { HS188 } \\
\text { MA753 } \\
\text { L605 } \\
\text { Mo-TZM }\end{array}$ & Wrought & $\begin{array}{l}1.41 \\
1.48 \\
1.67 \\
1.41 \\
6 \\
4 \\
4 \\
4 \\
4 \\
6 \\
7 \\
4.5 \\
7 \\
14.0\end{array}$ \\
\hline
\end{tabular}

(a) As compared with $\mathrm{HK}-40$ at $\$ 1.35 / 1 \mathrm{~b}$. 
for a 4-in.-diameter tube with a 1/2-in. wall thickness. This is equivalent to $\$ 42.82 / 1 b$. Based on large quantities, a cost of $\$ 15 / 1 \mathrm{~b}$ for tubing was used in this report.

Candidate insulation materials for thermal barriers exposed to highertemperature process heat designs, as 1isted in Table 5-8 for the duct cover plates, will require material change both for the thermal barrier ceramic blanket insulation for core outlet ducts and for the ceramic insulation for the core support floor. The materials presently used in the HTGR are ceramic (both silica and alumina/silica types) blankets assembled in layers for the insulation. The core support floor insulation consists of one layer of dense silica block which sees direct helium impingement, and then two layers of porous, 1ow-conductivity block followed by multilayers of ceramic blankets. The use of silica blankets is questionable at these temperatures, since partial sintering and possible devitrification might be expected, which could result in a decrease in resiliency with time and thus in thermal conductivity changes. Also, transport of silicon oxide due to its high volatility may occur to an intolerable degree. Therefore, carbon felt should be considered instead for the blanket insulation, since the forementioned problems would not occur with this material. An attractive replacement for silica block insulation is a carbon-fiber reinforced laminate composite (in block form) material impregnated with a non-sulfur-bearing organic polymer. Properties of these and present HTGR materials are compared in Table 5-11.

\subsection{REFORMER LOCATION STUDIES}

Studies have been made of two locations for the reformers. One location would be in sidewall cavities in the PCRV similar to the steam generator location in the current HTGR steam power plants. Several specific geometric arrangements of reformers, steam generators, and circulators have been considered. The best access to the PCRV for installation and maintenance of equipment is at the top face, since the refueling is done from this end. The weight and size of the refueling machine establish a minimum requirement for crane capacity and clearance 
TABLE 5-11

PROPERTIES OF THERMAL BARRIER CANDIDATE MATERIALS

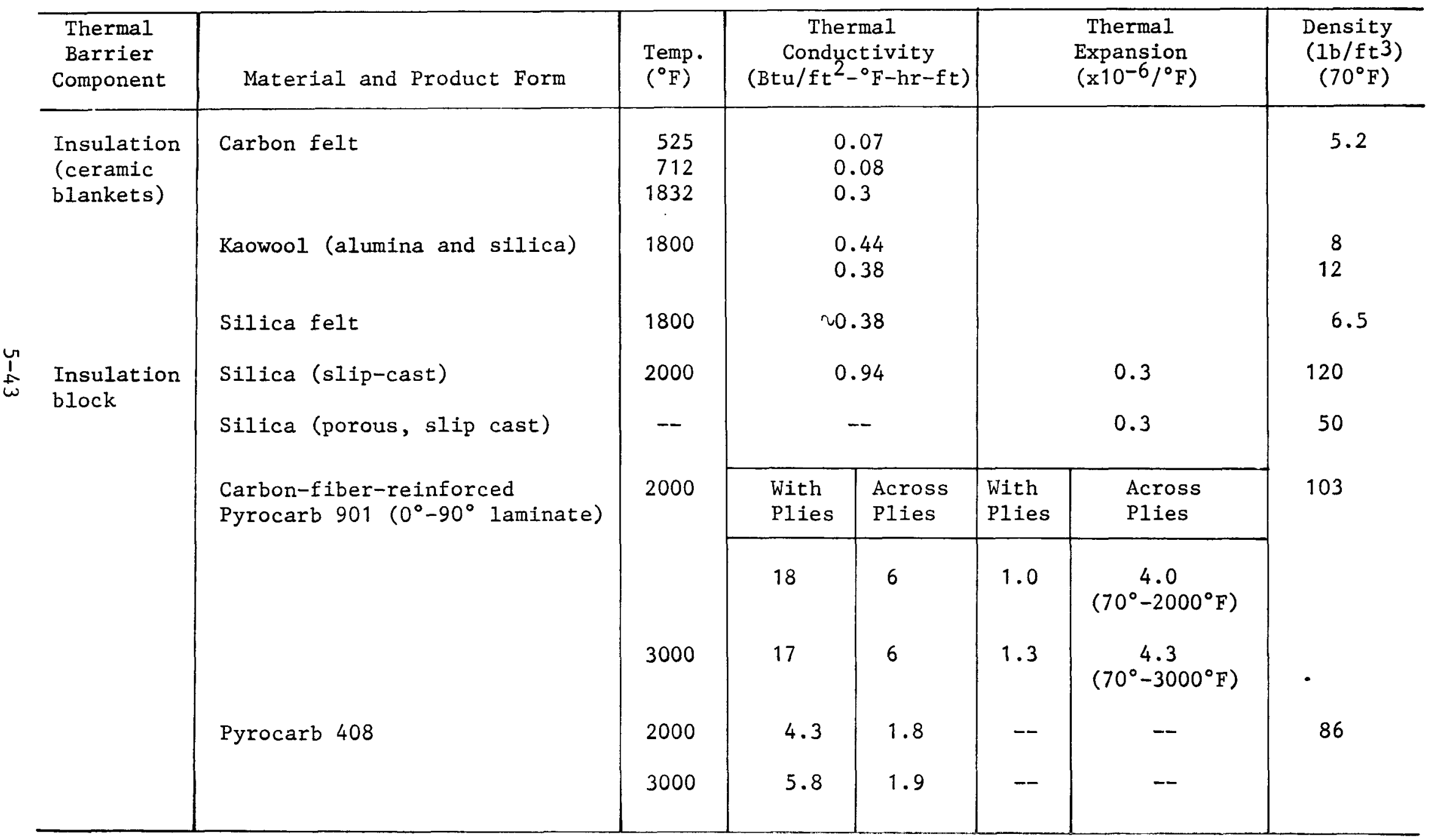


above the PCRV and improve the need for a 1arge equipment access door in the containment building for getting this equipment in and out. The specific arrangement utilized for this study had the reformer and steam generators located such that they could be installed and removed from the top face of the PCRV. With this location, the primary helium leaves the core and passes directly over the steam generator. Inside the reformer tubing is the steam and methane mixture and the nickel catalyst. This arrangement is shown in Fig. 5-6.

The alternate reformer location puts the reformer in a separate pressure vessel located outside of the PCRV and the containment vesse1. A separate secondary heat transfer loop is used to take the heat from the primary helium loop and transport it to the reformer. This secondary loop contains helium circulators, piping, valves, and controls. Located in the PCRV in the primary helium circuit is a heat exchanger that transfers the heat from the primary to the secondary loop. The steam generators are located in the primary helium circuit as before. Top access for this equipment is also maintained. This arrangement is shown in Fig. 5-7.

An additional case is a1so possible but was not included in the present study. The steam generator could be placed in the secondary heat transfer loop. This case could potentially simplify the primary helium circuit.

The advantages of locating the reformer inside the PCRV are as follows :

1. Reduced surface area of the reformer, since the primary coolant temperature can be used directly on the reformer.

2. Elimination of all intermediate loop piping, valves, heat exchangers, and circulating equipment.

3. Simplification of plant control and instrumentation by eliminating an additional interacting loop. 


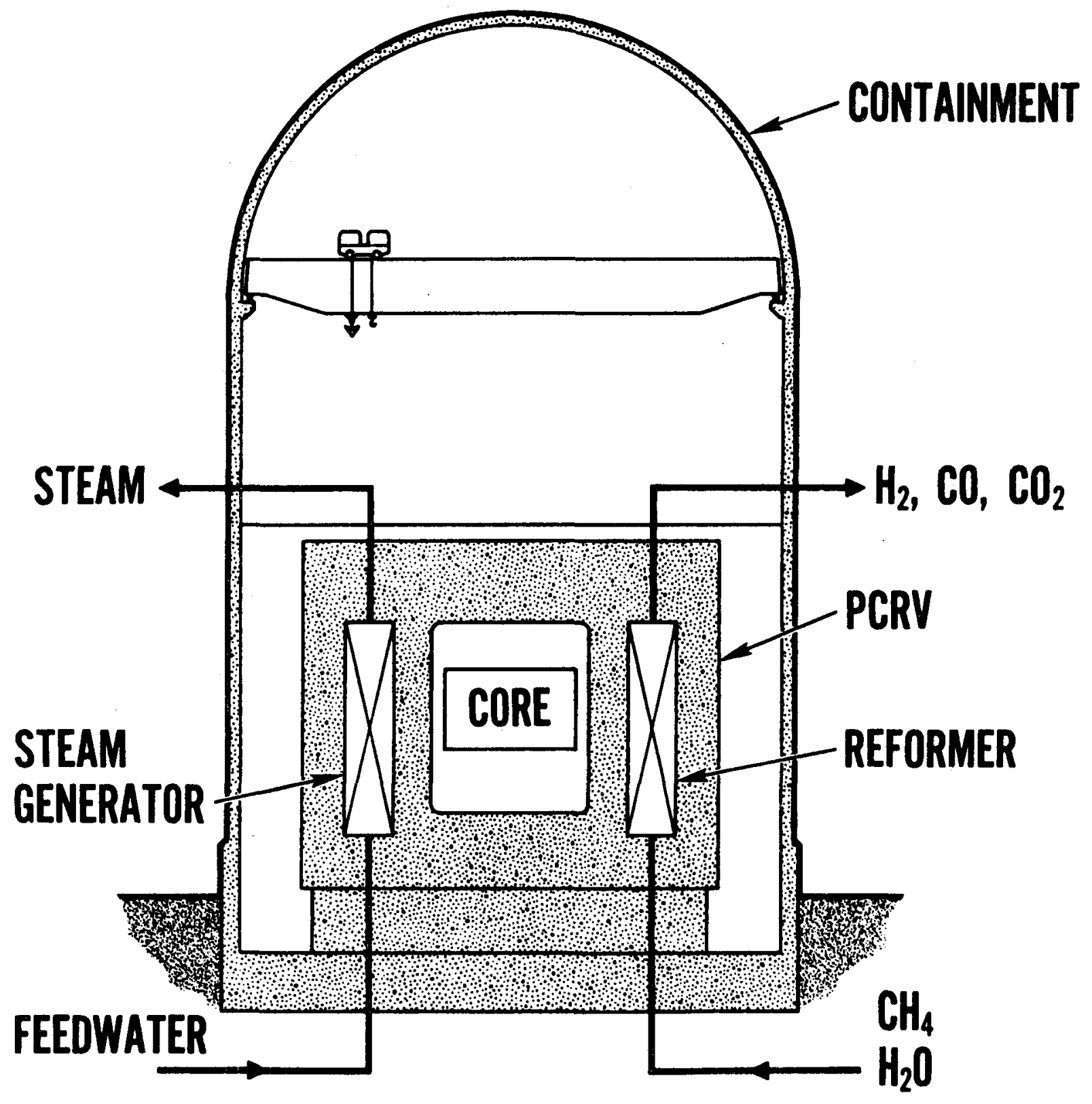

LC91149

Fig. 5-6. Reformer located inside PCRV 


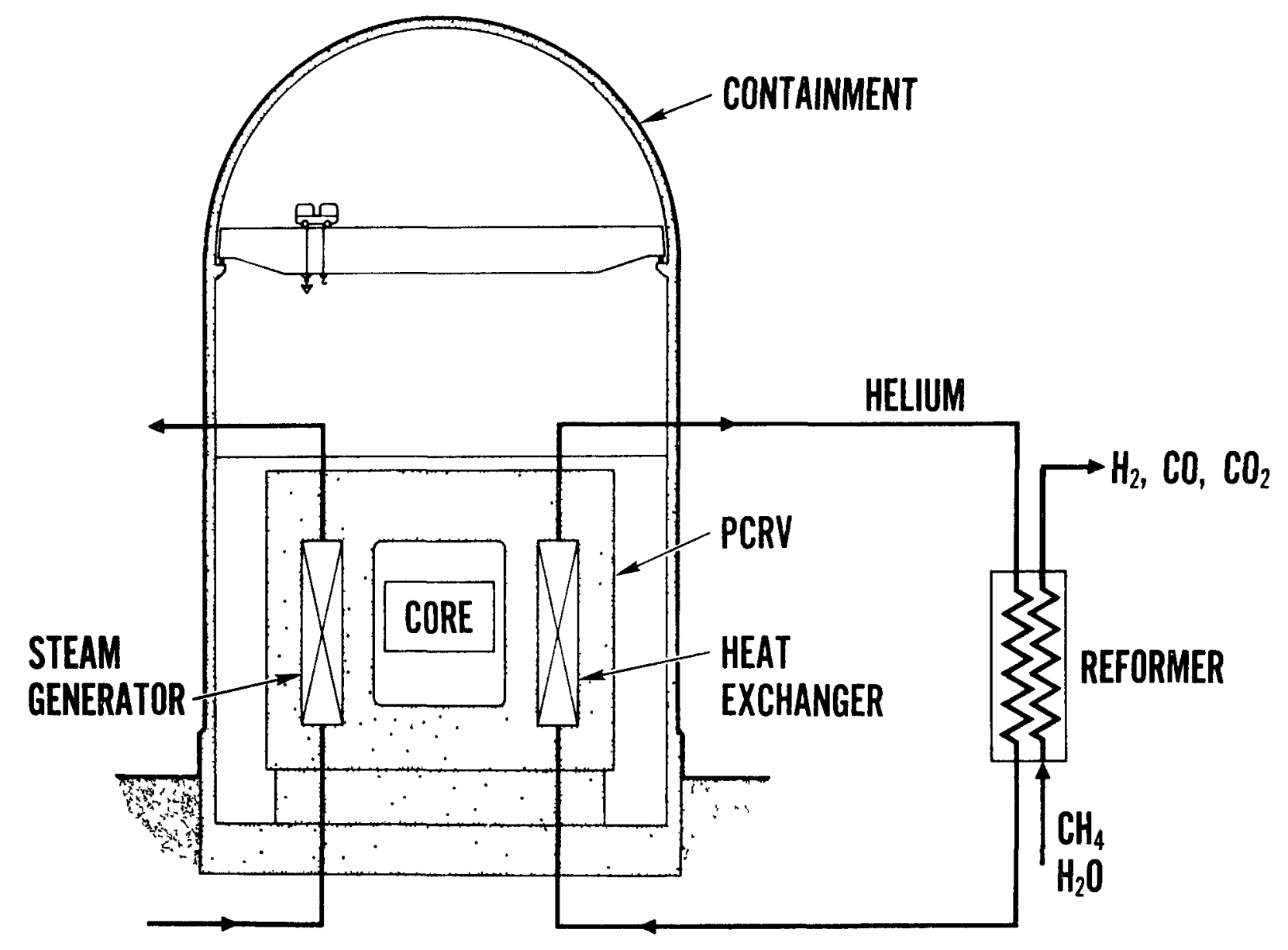

LC91150

Fig. 5-7. Reformer located outside PCRV 
Features favoring an intermediate loop are:

1. Complete isolation of the process fluids from the nuclear reactor, with a second fluid loop as a buffer.

2. Improved access for reformer maintenance and catalyst changing, provided by locating it away from the reactor.

For each configuration, preliminary process flow diagrams and mechanical designs were developed. Table 5-12 shows the design parameters used for the comparison. Along with the technical evaluation, a simplified cost comparison was prepared, as shown in Table 5-13. The results of this comparison show that the use of an intermediate loop and external reformer would increase the direct capital cost approximately $\$ 45$ million over that for the internal reformer. For the external reformer case, additional capital is required for intermediate loop equipment including a helium-helium heat exchanger, helium circulators, and additional piping. In addition, the external reformer is more expensive because more heat transfer area is required to compensate for the lower heat flux resulting from a lower temperature driving force for heat transfer in the reformer itself. The external reformer case shows a net savings in PCRV and secondary containment cost because the helium-helium heat exchangers are smaller than the reformer, which reduces the overall PCRV size. Additional savings in capital result from eliminating the need to inert the containment to prevent an explosion in the event that the process gas is released to the containment. However, other safety measures for preventing an explosion could be used (see Section 9.4.1) which could reduce this cost differential substantially.

The net increase of $\$ 45$ million in the cost required for the intermediate loop does not appear to be justifiable on the basis of improved access for operation and maintenance. From the results of this work, it was concluded that for current designs, the reformers should be located within the PCRV. 
TABLE $5-12$

DESIGN PARAMETERS USED FOR REFORMER LOCATION COMPARISON

\begin{tabular}{l|c|c}
\hline & $\begin{array}{c}\text { External } \\
\text { Reformer Case }\end{array}$ & $\begin{array}{c}\text { Internal } \\
\text { Reformer Case }\end{array}$ \\
\hline Reactor thermal power & $3000 \mathrm{MW}(\mathrm{t})$ & $3000 \mathrm{MW}(\mathrm{t})$ \\
Methane feed to reformer & $500 \mathrm{MMSCFD}$ & $500 \mathrm{MMSCFD}$ \\
Primary hot helium temp. (at heat exch) & $1620^{\circ} \mathrm{F}$ & $1620^{\circ} \mathrm{F}$ \\
Primary cold helium temp. & $970^{\circ} \mathrm{F}$ & $970^{\circ} \mathrm{F}$ \\
Secondary hot helium temp. & $1450^{\circ} \mathrm{F}$ & -- \\
Secondary cold helium temp. & $1230^{\circ} \mathrm{F}$ & -- \\
Reforming pressure & $30 \mathrm{~atm}$ & $30 \mathrm{~atm}$ \\
Steam-methane ratio & 6 & 6 \\
Reformer outlet temp. & $1350^{\circ} \mathrm{F}$ & $1350^{\circ} \mathrm{F}$ \\
\hline
\end{tabular}


TABLE 5-13

REFORMER LOCATION COST COMPARISON

\begin{tabular}{|c|c|c|}
\hline \multirow[b]{2}{*}{ Item } & \multicolumn{2}{|c|}{$\begin{array}{l}\text { Relative Cost } \\
\text { (millions) }\end{array}$} \\
\hline & $\begin{array}{l}\text { Internal } \\
\text { Reformer }\end{array}$ & $\begin{array}{l}\text { External } \\
\text { Reformer }\end{array}$ \\
\hline PCRV, containment & $\$ 13$ & \\
\hline External reformer & & $\$ 18$ \\
\hline Helium-helium exch & & 33 \\
\hline Secondary circulators & & 5 \\
\hline Secondary piping & & 12 \\
\hline Helium purification & 3 & \\
\hline Inerting downtime & 6 & \\
\hline Inerting equipment & 1 & \\
\hline Total & $\$ 23$ & $\overline{\$ 68^{(a)}}$ \\
\hline
\end{tabular}

${ }^{(a)}$ Cost increase for external reformer $=\$ 45$ million. 


\section{REACTOR FUEL AND CORE}

\subsection{PROCESS HEAT CORE DESCRIPTIONS}

\subsubsection{Introduction}

A total of five core designs for process heat application have been developed based on current 3000-MW( $t$ ) HTGR technology and a number of modifications to it. In order to make the HTGR attractive for process heat applications, it is desirable to increase the coolant gas outlet temperature of the core without increasing fuel temperatures. The following modifications help make this possible: changes to the graphite block design, use of TRISO coatings on all fuel particles, reduced carbonto-thorium ratio, and a 3-yr fuel cycle. The five core designs have been analyzed for radial segmental zoned cores. The results are summarized in Table 6-1.

The peak fue1 temperature for the Fulton $3000-M W(t)$ HTGR is $2560^{\circ} \mathrm{F}$. Current fuel technology permits the manufacture of fuel particle whose integrity is maintained up to temperatures of this leve1. The designs given in Table 6-1 can be divided into two groups, the first including Designs I - III and the second, Designs IV and V. The designs in the first group are feasible with present fuel technology. The designs in the second group will require advancements in fuel technology to make them feasible.

The approach in developing reactor core designs for the process heat study was to select several design modifications and obtain as high a core outlet helium temperature as possible with current HTGR fuel technology. The core size was kept the same as the 493-column Fulton core. 
TABLE 6-1

DESIGNS FOR PROCESS HEAT REACTOR

\begin{tabular}{r|c|c|c|c|c|c|c|c}
\hline Design & $\begin{array}{c}\text { Process } \\
\text { Temp. } \\
\left({ }^{\circ} \mathrm{F}\right)\end{array}$ & $\begin{array}{c}\text { No. of } \\
\text { Fuel Holes } \\
\text { Per Block }\end{array}$ & $\begin{aligned} \text { Cycle } \\
(\mathrm{yr})\end{aligned}$ & $\mathrm{C} / \mathrm{Th}$ & $\begin{array}{c}\mathrm{T}_{\text {in }} \\
\left({ }^{\circ} \mathrm{F}\right)\end{array}$ & $\begin{array}{c}\mathrm{T}_{\text {out }} \\
\left({ }^{\circ} \mathrm{F}\right)\end{array}$ & $\begin{array}{c}\text { Max. Fuel } \\
\text { Temp. } \\
\left({ }^{\circ} \mathrm{F}\right)\end{array}$ & $\begin{array}{c}\text { Core Pressure } \\
\text { Drop } \\
\text { (psi) }\end{array}$ \\
\hline I & 1200 & 132 & 4 & 240 & 700 & 1400 & 2513 & 13.5 \\
II & 1400 & 210 & 4 & 240 & 770 & 1600 & 2475 & 16.1 \\
III & 1600 & 210 & 3 & 200 & 932 & 1800 & 2562 & 14.3 \\
IV & 1800 & 210 & 3 & 200 & 1050 & 2000 & 2792 & 13.2 \\
V & 2000 & 210 & 3 & 200 & 1200 & 2200 & 3010 & 13.2 \\
\hline
\end{tabular}


Many of the design modifications used in the study are discussed below. Using these modifications, calculated coolant, graphite, and fuel temperature distributions are then given for the five core designs of Table 6-1.

\subsubsection{Design Modifications}

6.1.2.1. Graphite Block Design. In establishing the current reference design for General Atomic's commercial HTGR, severa1 fuel block designs were considered. Among those studied were elements having 132, 168, and 210 fuel holes per standard block (see Figs. B-1, B-2, and B-3 in Appendix B). In each of the fuel block designs, the fuel volumes are equal and the minimum graphite web thickness between holes was held constant. The fuel element design having 210 fuel holes per block is being used in the Fort St. Vrain Nuclear Generating Station. A block having 132 fuel holes has been chosen as the reference fuel element for the 1160-MW(e) commercial HTGR. Intermediate to these two designs is a 168 fuel hole per block design. Thus, there are at least three existing block designs for consideration as the fuel element for the process heat HTGR core.

One of the disadvantages of using a fuel block with a larger number of fuel and coolant holes is that it increases the core pressure drop. In addition, as the fuel rod diameter decreases, the number of rods which must be fabricated increases. There is also an increase in the number of holes which must be machined into the fuel blocks. The cost of fabricating the fuel thus increases. The resulting fuel cycle cost, relative to the commercial HTGR design, is about $0.45 \mathrm{c} / 10^{6} \mathrm{Btu}$ for the 210 fuel hole block and $0.23 \mathrm{c} / 10^{6}$ Btu for the 168 fuel hole block.

6.1.2.2. TRISO Coatings on A11 Fue1 Particles. The advantage associated with the use of TRISO coatings on all fuel particles is reduced fuel rod shrinkage. Fuel rods made of TRISO-coated particles shrink less than rods consisting of BISO-coated particles. It is predicted that the use of TRISO-coated kernels will reduce the rod shrinkage by about a factor of 3 . This reduced rod shrinkage will result in a reduction in the gap between 
the fuel rod and the fuel hole surface, which will then decrease the temperature drop across the gap and hence lower the fuel temperature.

Another advantage of this type of fuel is a reduction in the metallic fission product release. This would result in the circuit components being more readily accessible for maintenance.

The use of TRISO-coated particles, which contain a silicon carbide layer, results in an increase in the amount of silicon loaded into the core. Silicon acts as a neutron poison, and hence its presence increases the fissile fuel requirements. The increase in the silicon load in the process heat reactor relative to that of the HTGR would increase the fuel cycle cost by about $0.45 \mathrm{c} / 10^{6} \mathrm{Btu}$. The costs quoted here are 0 - to 15 -yr levelized costs.

6.1.2.3. Reduced Carbon-to-Thorium Ratio. A reduced carbon-to-thorium ratio implies an increase in the mass of thorium loaded into the core. Increasing the thorium load increases the conversion ratio; i.e., more thorium is converted to U-233. This tends to reduce the difference in fissile content between fresh and discharged fuel. Consequently, when fresh fuel is loaded into the core, its fissile content does not differ as much from that of the older fuel. This results in less power peaking in the fresh fuel; in other words, it results in a reduction in the age peaking factor. Hence, the advantage of reducing the carbon-to-thorium ratio is a reduction in the radial power factors, which thereby reduce the maximum fuel temperatures. A reduction in carbon-to-thorium ratio from 240 to 200 results in about a $2.4 \%$ reduction in radial power peaking factors.

The increased thorium load necessitates maintaining a higher core average fissile load to meet reactivity requirements. This increases the fabrication costs and in-core working capital charges for this fue1. A compensating effect is an increase in the amount of U-233 recovered when the fuel is reprocessed. The net effect on the fuel cycle cost is very 
dependent on the in-core working capital rate, the cost of uranium ore separative work costs, reprocessing costs, etc. Depending on the actual values of these various cost parameters, the effect on fuel cycle cost can vary from about $+0.23 c / 10^{6}$ Btu to about $-0.23 c / 10^{6} \mathrm{Btu}$.

6.1.2.4. Three-Year Fuel Cycle. The commercial HTGR employs a graded refueling scheme in which about one-fourth of the core is refueled each year (with an $80 \%$ load factor). This results in differences in local power density because of the distribution of fuel of different ages (i.e., different fissile content) in the core. This component of the power peaking factor is referred to as the "age peaking" effect. The maximum short-term fuel temperature is sensitive to the magnitude of the region peaking factors. Consequently, design changes or operating strategies which lead to lower region-power-peaking (e.g., reduced age peaking effects) also result in a lower maximum fuel temperature. (Reducing the average core power density is also an effective and straightforward means of reducing the maximum fuel temperatures.)

Age peaking effects are reduced by short fuel in-core residence times. Operating the core on a 3-yr cycle instead of 4-yr cycle reduces the region power peaking factors and intraregion power tilts by about $4 \%$ to $5 \%$.

There are potential fuel cycle cost penalties associated with these modes of operation. However, in the process heat market, these additional costs for achieving high gas temperatures may well be acceptable.

6.1.2.5. Axial Push-Through Fuel Management. Axial push-through fuel management is, as the name implies, a scheme for "pushing" the fuel blocks through the reactor core from top to bottom. Fresh fuel is loaded at the top of the core, and depleted fuel is removed from the bottom. Since the HTGR operates on a 4-yr cycle and the active core is eight blocks high, fresh fuel is loaded as the top two layers each year while depleted fuel in the bottom two layers is discharged. Thus, the fuel blocks progress 
down through the core, two layers at a time, on an annual basis. A11 fuel in a given layer is of the same age. Work on this program has been privately funded, and comments are presented only for general information in order to indicate the advantages of possible further effort in this area.

This axial shuffling refueling scheme has many advantages, the principal ones being as follows:

1. No age peaking. A major cause of the radial power peaks in the HTGR is the age difference (i.e., fissile content difference) in various adjacent refueling regions. By employing an axia1 push-through fuel management scheme, the fuel in each horizontal layer is of the same age. This produces a rather smooth and flat power distribution in the radial and azimuthal directions.

2. Approximately ideal power profile. The increased number of fuel zones (4) and the power profile shaping resulting from the fuel depletion and axial shuffling produce an axial power profile which approaches the ideal exponential shape. This too tends to lower the peak fuel temperature.

3. Reduced fast fluence. The fast neutron fluence is about $32 \%$ lower than for the reference HTGR. This is due to the fact that the fuel blocks spend only a short time at the location of highest fast flux and then are moved to positions of lower fast flux.

4. Reduced core pressure drop. The core pressure drop is equal to the pressure drop of the region with the highest power peaking factor. This high-powered region receives the most flow and hence has the highest pressure drop. Because the maximum region peaking factor (i.e., radial power peaking factor) is lower with an axial push-through scheme, the maximum coolant flow rate in a column and hence the core pressure drop are reduced. 
5. Smaller core. The concept of utilizing a smaller core at higher power density, i.e., $>10 \mathrm{~W} / \mathrm{cm}^{3}$, with axial shuffling may yield other significant plant cost savings due to the reduction in core size. The data reported herein are based on the assumption of the same power density as for the reference design.

6. Simplification of core design. This is achievable through the removal of plenum elements, flow control valves, and thermocouples at the core exit.

6.1.2.6. Improved Fuel Technology. To obtain helium outlet temperatures as high as $2000^{\circ} \mathrm{F}$, the above design modifications are not sufficient to keep peak fuel temperature within current fuel technology. For Designs I - V, an improved fuel capable of operating at temperatures as high as $3010^{\circ} \mathrm{F}$ is assumed. This is about $450^{\circ} \mathrm{F}$ higher than the peak fuel temperature in commercial HTGRs.

\subsubsection{Core Designs for Process Heat HTGR}

Using the commerical HTGR and one or more of the design modifications discussed above, a total of five core designs have been established. For each of these designs, analysis has been made to calculate average and peak coolant, graphite, and fuel temperatures. In addition, the core pressure drop has been calculated. The results of these calculations are discussed below.

6.1.3.1. Design I $-1200^{\circ} \mathrm{F}$ Process Temperature. A core helium outlet temperature of $1400^{\circ} \mathrm{F}$ required for Design I can be easily obtained without any modifications to the commercial HTGR. With an $8 \%$ increase in helium flow, the peak flow temperature is $2513^{\circ} \mathrm{F}, 46^{\circ} \mathrm{F}$ lower than the peak fuel temperature in the commercial HTGR.

The balanced three-zone axial profile used for this design is given in Table 6-2. The major core parameters calculated for this design are shown in Table 6-3. The axial coolant, graphite, and fuel temperature 
TABLE 6-2

AXIAL PROFILES

\begin{tabular}{l|c|c|c|c|c}
\hline Design I & Design II & Design III & Design IV & Design V & $\begin{array}{c}\text { All Designs } \\
\text { APF(a) }\end{array}$ \\
\hline 0.8179 & 0.9132 & 0.9226 & 0.9365 & 0.9460 & 1.6241 \\
0.9129 & 1.0192 & 1.0298 & 1.0453 & 1.0559 & 1.7345 \\
1.0269 & 1.1465 & 1.1583 & 1.1759 & 1.1878 & 1.6489 \\
1.0934 & 1.2207 & 1.2333 & 1.2520 & 1.2647 & 1.8240 \\
1.1314 & 1.2632 & 1.2762 & 1.2955 & 1.3086 & 1.5723 \\
1.1409 & 1.2738 & 1.2869 & 1.3064 & 1.3196 & 1.4951 \\
1.1409 & 1.2738 & 1.2869 & 1.3064 & 1.3196 & 1.3511 \\
1.2359 & 1.3798 & 1.3941 & 1.4152 & 1.4295 & 1.1741 \\
1.1631 & 1.0270 & 1.0120 & 0.9903 & 0.9776 & 0.7795 \\
1.1526 & 1.0177 & 1.0029 & 0.9814 & 0.9689 & 0.6138 \\
1.1003 & 0.9715 & 0.9573 & 0.9368 & 0.9250 & 0.4979 \\
1.0270 & 0.9068 & 0.8935 & 0.8745 & 0.8633 & 0.3963 \\
0.9118 & 0.8051 & 0.7934 & 0.7764 & 0.7665 & 0.2222 \\
0.8071 & 0.7127 & 0.7023 & 0.6873 & 0.6785 & 0.1651 \\
0.6145 & 0.5036 & 0.4966 & 0.4846 & 0.4710 & 0.1210 \\
0.7181 & 0.5885 & 0.5802 & 0.5663 & 0.5504 & 0.1391 \\
\hline
\end{tabular}

(a) ${ }_{\mathrm{APF}}=\mathrm{Axial}$ power factor. 
TABLE 6-3

DESIGN I - CORE AND FUEL CYCLE PARAMETERS

\begin{tabular}{|c|c|c|}
\hline & Reactor Core Power & $3000 \mathrm{MW}(\mathrm{t})$ \\
\hline 2 . & Helium Inlet Temperature & $700^{\circ} \mathrm{F}$ \\
\hline 3. & Helium Outlet Temperature & $1400^{\circ} \mathrm{F}$ \\
\hline 4. & He1ium F1ow & $11.7767 \times 10^{6} 1 \mathrm{~b}_{\mathrm{m}} / \mathrm{hr}$ \\
\hline 5 . & Inlet Pressure & 725 psia \\
\hline 6 . & Refueling Scheme & Radial segmental zoning \\
\hline 7. & Fuel Residence Time & $4 \mathrm{yr}$ \\
\hline 8. & Fue1 Block Design & 132 fuel hole block \\
\hline 9 . & Equilibrium C/Th Ratio & 240 \\
\hline 10. & Average Moderator Temperature & $1418^{\circ} \mathrm{F}$ \\
\hline 11. & Peak Moderator Temperature & $2114^{\circ} \mathrm{F}$ \\
\hline 12. & Average Fuel Temperature & $1671^{\circ} \mathrm{F}$ \\
\hline & Peak Fuel Temperature & $2513^{\circ} \mathrm{F}$ \\
\hline & Core Pressure Drop & $13.5 \mathrm{psi}$ \\
\hline 15. & Maximum Fast Neutron Fluence & $\begin{array}{l}8 \times 10^{21} \mathrm{n} / \mathrm{cm}^{2} \\
(E>0.18 \mathrm{MeV})\end{array}$ \\
\hline 16. & $\begin{array}{l}\text { Hot Channel Helium Outlet } \\
\text { Temperature }\end{array}$ & $1751^{\circ} \mathrm{F}$ \\
\hline
\end{tabular}


distributions in an average channel and a hot channel are shown in Figs. 6-1 and 6-2, respectively. Design I for process heat applications will have a core pressure drop of 13.5 psi. Additional core thermal parameters for this design are given in Appendix $B$.

6.1.3.2. Design II $-1400^{\circ} \mathrm{F}$ Process Temperature. This design requires a reactor outlet temperature of $1600^{\circ} \mathrm{F}$ and a core inlet temperature of $770^{\circ} \mathrm{F}$. If these gas conditions are used in the commercial HTGR design, the peak graphite and fuel temperatures are significantly higher than corresponding temperatures in the commercial HTGR with normal gas conditions. In order to reduce these temperatures, a 210 fuel hole standard block similar to the block used in the Fort St. Vrain reactor is adopted. With this block design, the peak fuel temperature is $2475^{\circ} \mathrm{F}$, about $75^{\circ} \mathrm{F}$ lower than the peak fuel temperature in the Fulton plant.

The axial profile for this design is balanced to give the same fuel temperature at the bottom of each fuel zone. This axial profile is shown in Table 6-2. As can be seen, a steeper axial profile is required for Design II than for Design I. The major core design parameters calculated for Design II are given in Table 6-4. The axial coolant, graphite, and fuel temperatures for an average and a hot channel are shown in Figs. 6-3 and 6-4, respectively. The use of a 210 fuel hole block causes the pressure drop in Design II to increase to 16.1 psi. Additional core thermal parameters for this design are given in Appendix B.

6.1.3.3. Design III $-1600^{\circ} \mathrm{F}$ Process Temperature. This design requires a reactor outlet temperature of $1800^{\circ} \mathrm{F}$ and a core inlet temperature of $932^{\circ} \mathrm{F}$. These gas conditions necessitate some additional design modifications relative to Design II. In addition to a 210 fuel hole block, a 3-yr cycle and a reduced carbon-to-thorium ratio of 200 are adopted. Both of these design changes reduce the radial peaking factor and intraregion tilt, as noted previously. These modifications bring the peak fuel temperature to $2562^{\circ} \mathrm{F}$, which is very close to the peak fuel temperature in the commercial HTGR. 


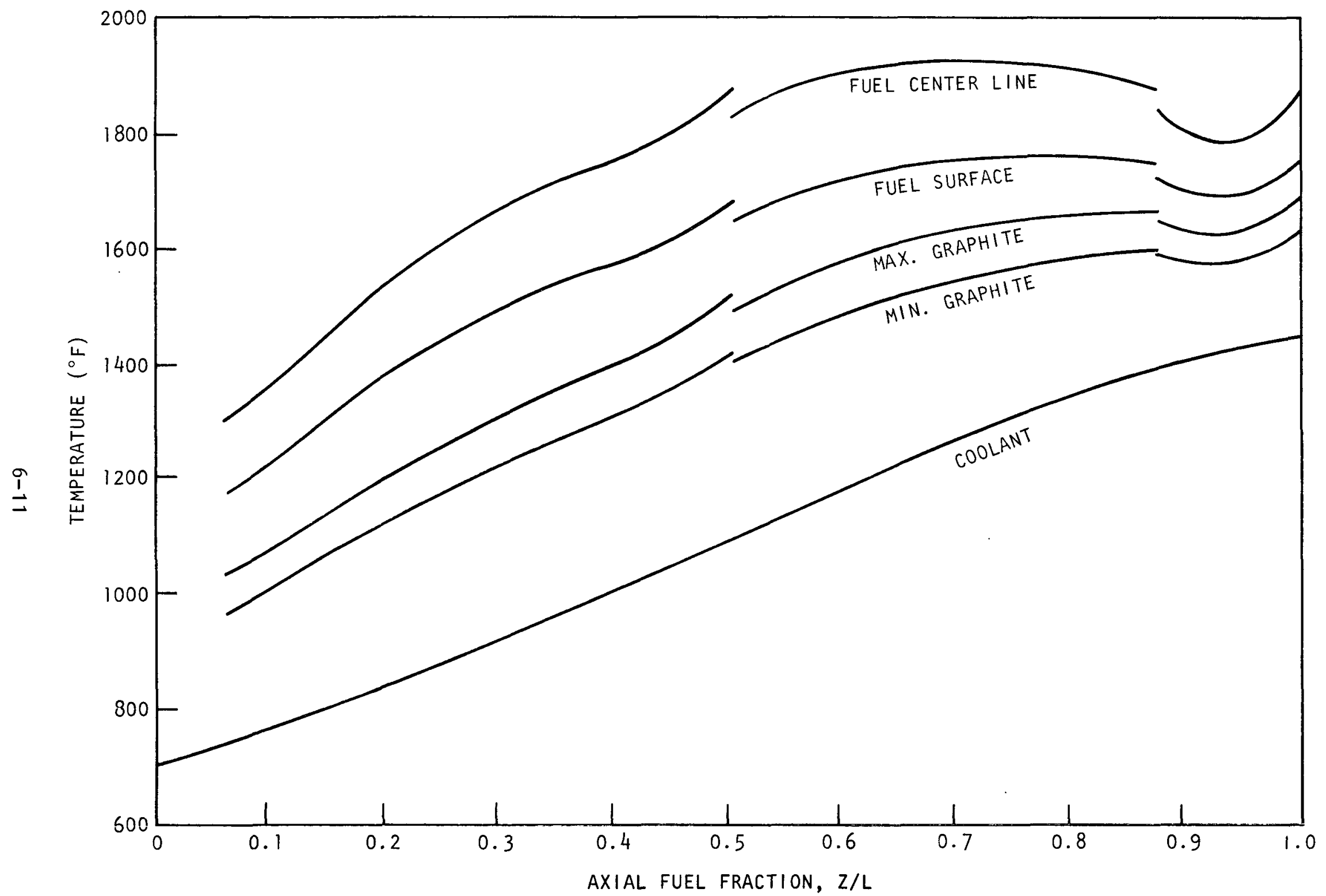

Fig. 6-1. Design I average channel temperature distributions 


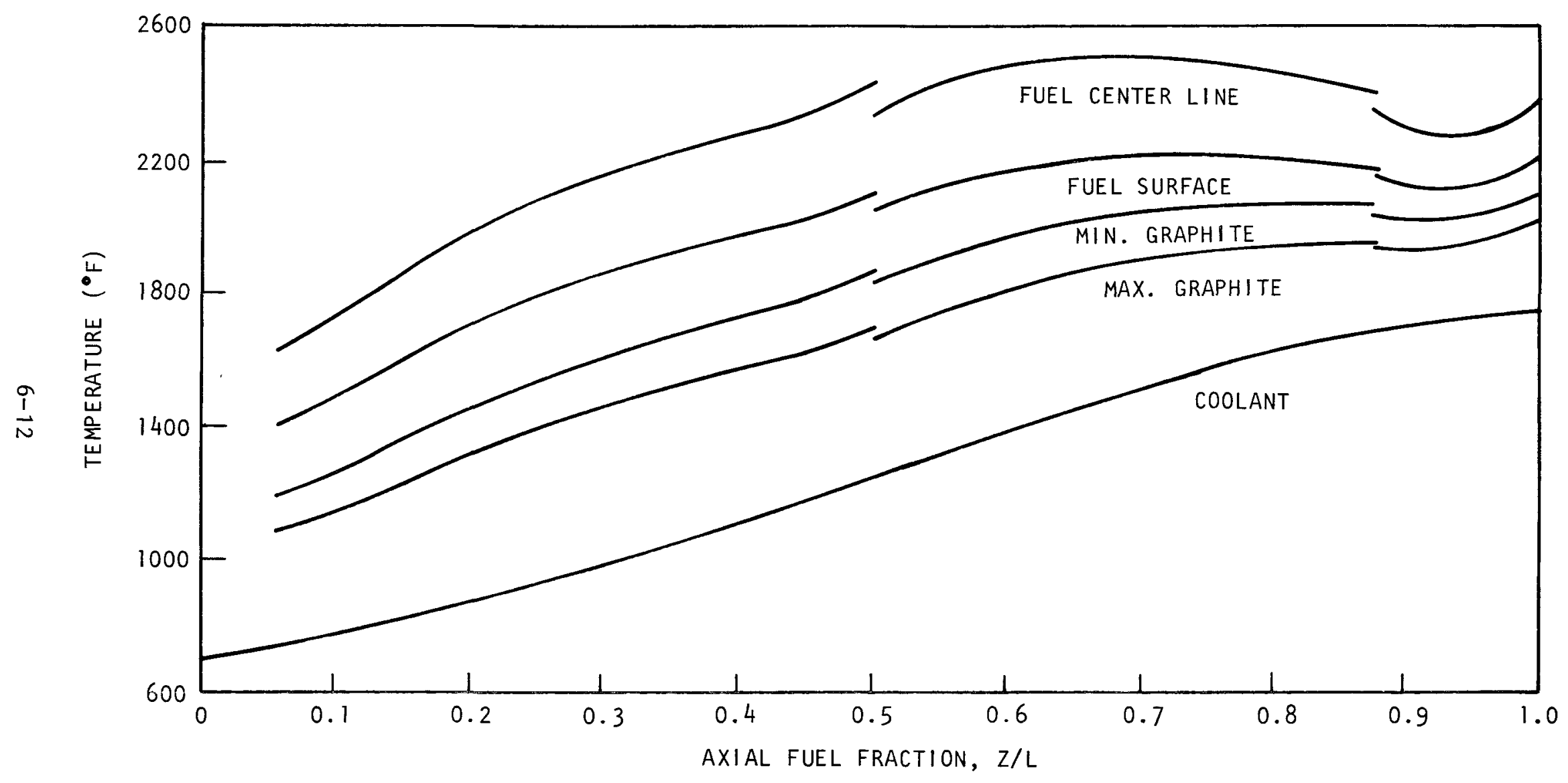

Fig. 6-2. Design I hot channel temperature distributions 
TABLE 6-4

DESIGN II - CORE AND FUEL CYCLE PARAMETERS

\begin{tabular}{|c|c|c|}
\hline & Reactor Core Power & $3000 \mathrm{MW}(\mathrm{t})$ \\
\hline 2 . & Helium Inlet Temperature & $770^{\circ} \mathrm{F}$ \\
\hline 3 . & Helium Outlet Temperature & $1600^{\circ} \mathrm{F}$ \\
\hline 4 . & Helium Flow & $9.9322 \times 10^{6} 1 \mathrm{~b}_{\mathrm{m}} / \mathrm{hr}$ \\
\hline 5 . & Inlet Pressure & 725 psia \\
\hline 6 . & Refueling Scheme & Radial segmental zoning \\
\hline 7. & Fuel Residence Time & $4 \mathrm{yr}$ \\
\hline 8. & Fuel Block Design & 210 fuel hole block \\
\hline 9 . & Equilibrium $\mathrm{C} / \mathrm{Th}$ Ratio & 240 \\
\hline 10. & Average Moderator Temperature & $1541^{\circ} \mathrm{F}$ \\
\hline 11. & Peak Moderator Temperature & $2273^{\circ} \mathrm{F}$ \\
\hline 12. & Average Fuel Temperature & $1698^{\circ} \mathrm{F}$ \\
\hline 13. & Peak Fue1 Temperature & $2475^{\circ} \mathrm{F}$ \\
\hline 14. & Core Pressure Drop & 16.1 psi \\
\hline 15 . & Maximum Fast Neutron Fluence & $\begin{array}{l}8 \times 10^{21} \mathrm{n} / \mathrm{cm}^{2} \\
(\mathrm{E}>0.18 \mathrm{MeV})\end{array}$ \\
\hline 16. & $\begin{array}{l}\text { Hot Channe1 Helium Outlet } \\
\text { Temperature }\end{array}$ & $2023^{\circ} \mathrm{F}$ \\
\hline
\end{tabular}




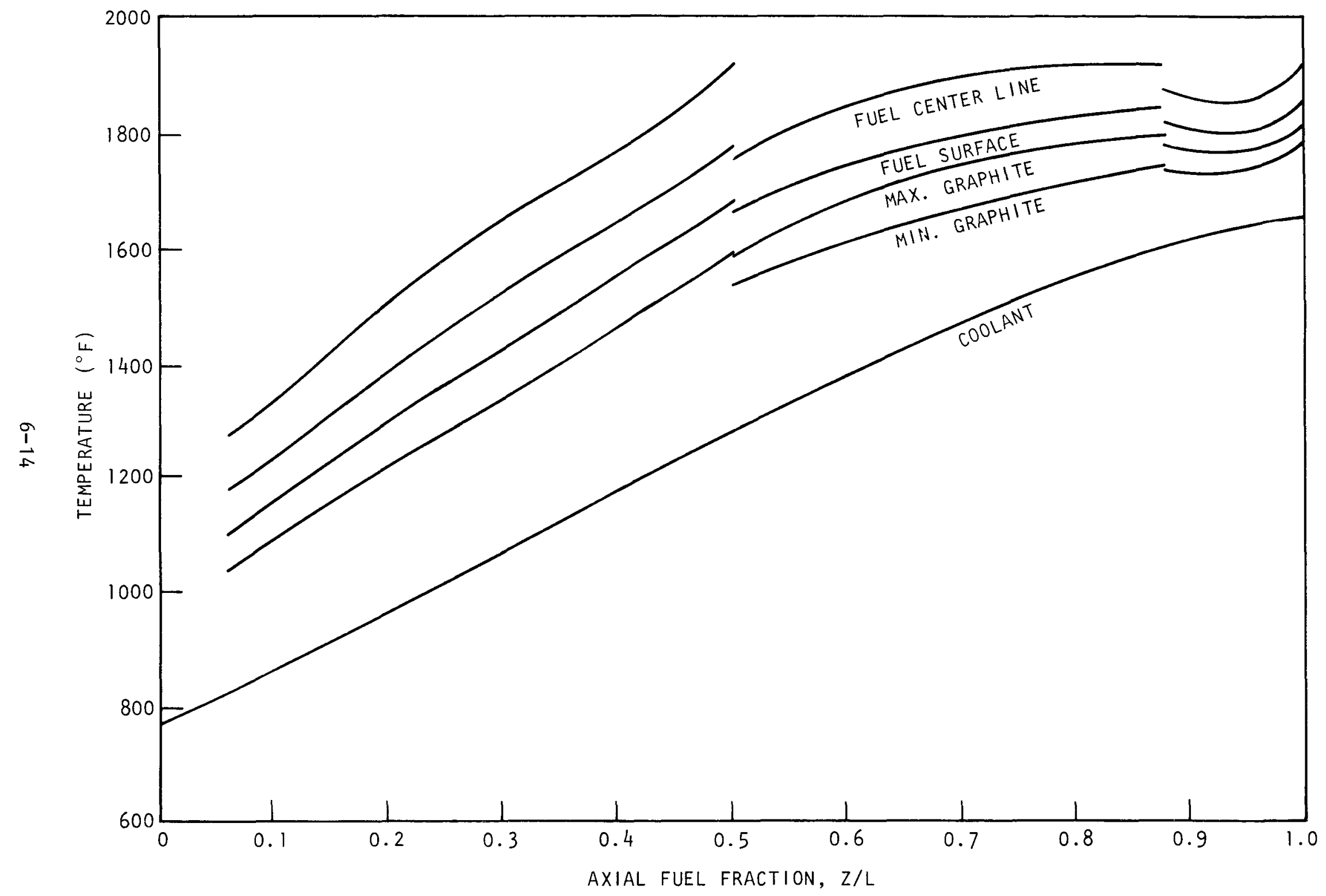

Fig. 6-3. Design II average channel temperature distributions

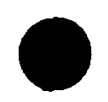




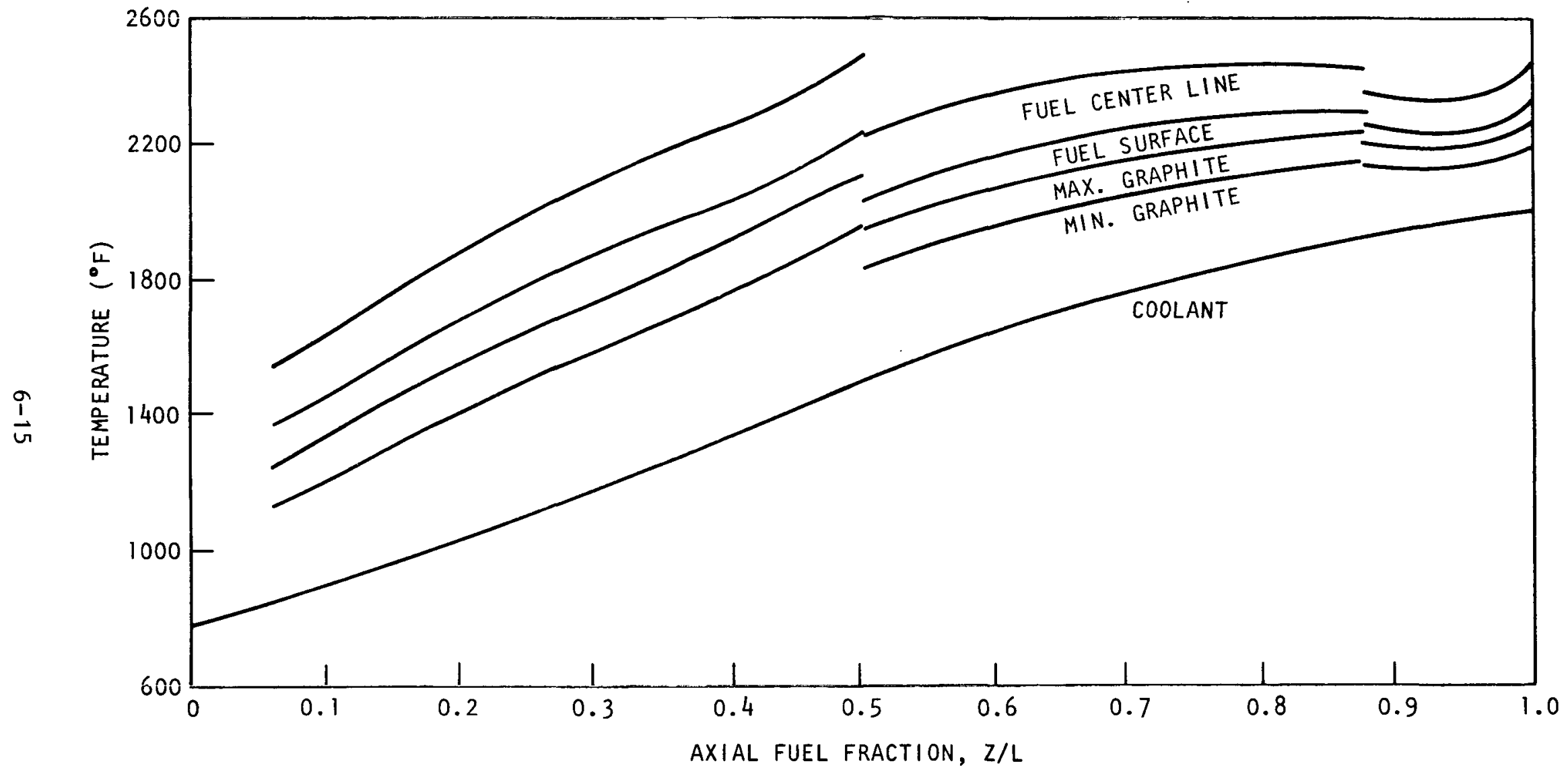

Fig. 6-4. Design II hot channel temperature distributions 
The axial profile for this design is compared with the profiles for Designs I and II in Table 6-2. The major core design parameters calculated for this design are given in Table 6-5. The axial coolant, graphite, and fuel temperature distributions for an average and a hot channel are shown in Figs. 6-5 and 6-6, respectively. The core pressure drop for Design III is only $14.3 \mathrm{psi}, 1.8 \mathrm{psi}$ lower than for Design II. This reduction is a result of decreased core helium flow. Additional core thermal parameters for the Design III are given in Appendix B.

6.1.3.4. Design IV $-1800^{\circ} \mathrm{F}$ Process Temperature. This design requires a reactor outlet temperature of $2000^{\circ} \mathrm{F}$ and a core inlet temperature of $1050^{\circ} \mathrm{F}$. These temperatures are significantly higher than commercial HTGR conditions. The design modifications discussed in Sections 6.1.3.1 through 6.1.3.3 are not sufficient to reduce peak fuel temperatures below $2560^{\circ} \mathrm{F}$, the peak fuel temperature in the commercial HTGRs. For this design, it was assumed that improved fuel technology will allow peak fuel temperatures in excess of the $2560^{\circ} \mathrm{F}$ maximum commercial HTGR fuel temperature.

The use of a 210 fuel hole block, a 3-yr cycle, and a reduced carbonto-thorium ratio gives a peak fuel temperature of $2792^{\circ} \mathrm{F}$. This is about $232^{\circ} \mathrm{F}$ above the Fulton reactor peak fuel temperature. A steeper axial profile required for this design is given in Table 6-2. Major core design parameters are given in Table 6-6. The axial coolant, graphite, and fuel temperature distributions for an average and a hot channel are shown in Figs. 6-7 and 6-8, respectively. The core pressure drop is 13.2 psi. Additional thermal parameters for this design are given in Appendix $B$.

6.1.3.5. Design $\mathrm{V}-2000^{\circ} \mathrm{F}$ Process Temperature. This design requires a helium outlet temperature of $2220^{\circ} \mathrm{F}$ and a core inlet temperature of $1200^{\circ} \mathrm{F}$. It includes the same modifications to the commercial HTGR as Design IV, but has a peak fuel temperature of $3010^{\circ} \mathrm{F}$. It is clear that some highly improved fuel particles will be required for this design. 
TABLE 6-5

DESIGN III - CORE AND FUEL CYCLE PARAMETERS

\begin{tabular}{l|l}
\hline 1. Reactor Core Power & $3000 \mathrm{MW}(\mathrm{t})$ \\
2. Helium Inlet Temperature & $932^{\circ} \mathrm{F}$ \\
3. Helium Outlet Temperature & $1800^{\circ} \mathrm{F}$ \\
4. Helium Flow & $9.4974 \mathrm{x} 10^{6} \mathrm{lb} / \mathrm{hr}$ \\
5. Inlet Pressure & $725 \mathrm{psia}$ \\
6. Refueling Scheme & Radial segmental zoning \\
7. Fuel Residence Time & $3 \mathrm{yr}$ \\
8. Fuel Block Design & $210 \mathrm{fuel} \mathrm{hole} \mathrm{block}$ \\
9. Equilibrium C/Th Ratio & 200 \\
10. Average Moderator Temperature & $1734^{\circ} \mathrm{F}$ \\
11. Peak Moderator Temperature & $2402^{\circ} \mathrm{F}$ \\
12. Average Fuel Temperature & $1886^{\circ} \mathrm{F}$ \\
13. Peak Fuel Temperature & $2562^{\circ} \mathrm{F}$ \\
14. Core Pressure Drop & $14.3 \mathrm{psi}$ \\
15. Maximum Fast Neutron Fluence & $8 \times 10^{21} \mathrm{n} / \mathrm{cm}^{2}$ \\
16. Hot Channel Helium Outlet & $2170^{\circ} \mathrm{F}$ \\
\hline
\end{tabular}




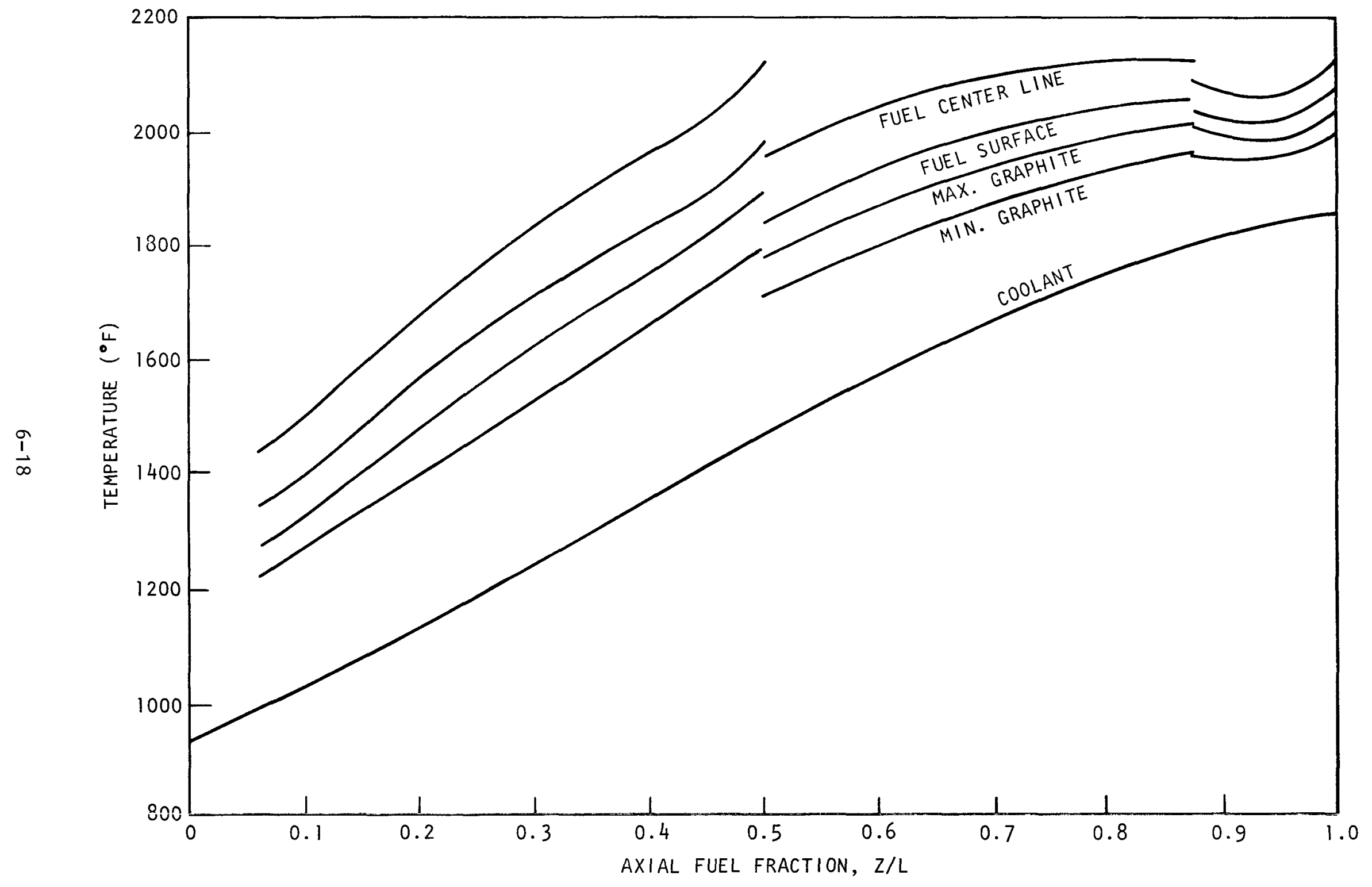

Fig. 6-5. Design III average channel temperature distributions 


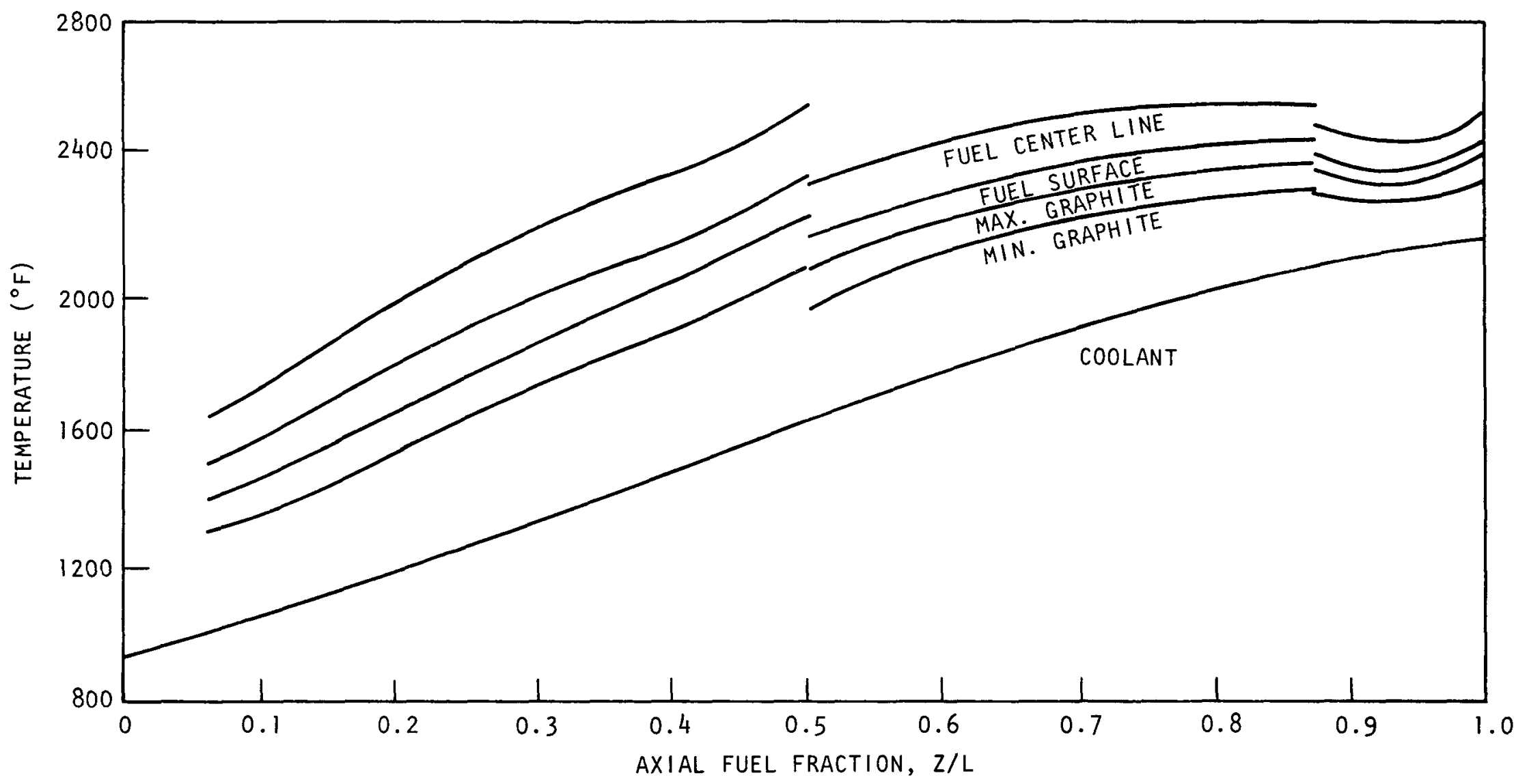

Fig. 6-6. Design III hot channe1 temperature distributions 
DESIGN IV - CORE AND FUEL CYCLE PARAMETERS

\begin{tabular}{l|l} 
1. Reactor Core Power & $3000 \mathrm{MW}(\mathrm{t})$ \\
2. Helium Inlet Temperature & $1050^{\circ} \mathrm{F}$ \\
3. Helium Outlet Temperature & $2000^{\circ} \mathrm{F}$ \\
4. Helium Flow & $8.6776 \times 10^{6} 1 \mathrm{~b}_{\mathrm{m}} / \mathrm{hr}$ \\
5. Inlet Pressure & $725 \mathrm{psia}$ \\
6. Refueling Scheme & Radial segmental zoning \\
7. Fuel Residence Time & $3 \mathrm{yr}$ \\
8. Fuel Block Design & $210 \mathrm{fue} 1 \mathrm{hole} \mathrm{b} 1 \mathrm{ock}$ \\
9. Equilibrium C/Th Ratio & 200 \\
10. Average Moderator Temperature & $1922^{\circ} \mathrm{F}$ \\
11. Peak Moderator Temperature & $2641^{\circ} \mathrm{F}$ \\
12. Average Fuel Temperature & $2069^{\circ} \mathrm{F}$ \\
13. Peak Fuel Temperature & $2792^{\circ} \mathrm{F}$ \\
14. Core Pressure Drop & $13.2 \mathrm{psi}$ \\
15. Maximum Fast Neutron Fluence & $8 \times 10^{21 \mathrm{n} / \mathrm{cm}} 2$ \\
16. Hot Channel Helium Outlet & $2405^{\circ} \mathrm{F}$ \\
\hline
\end{tabular}




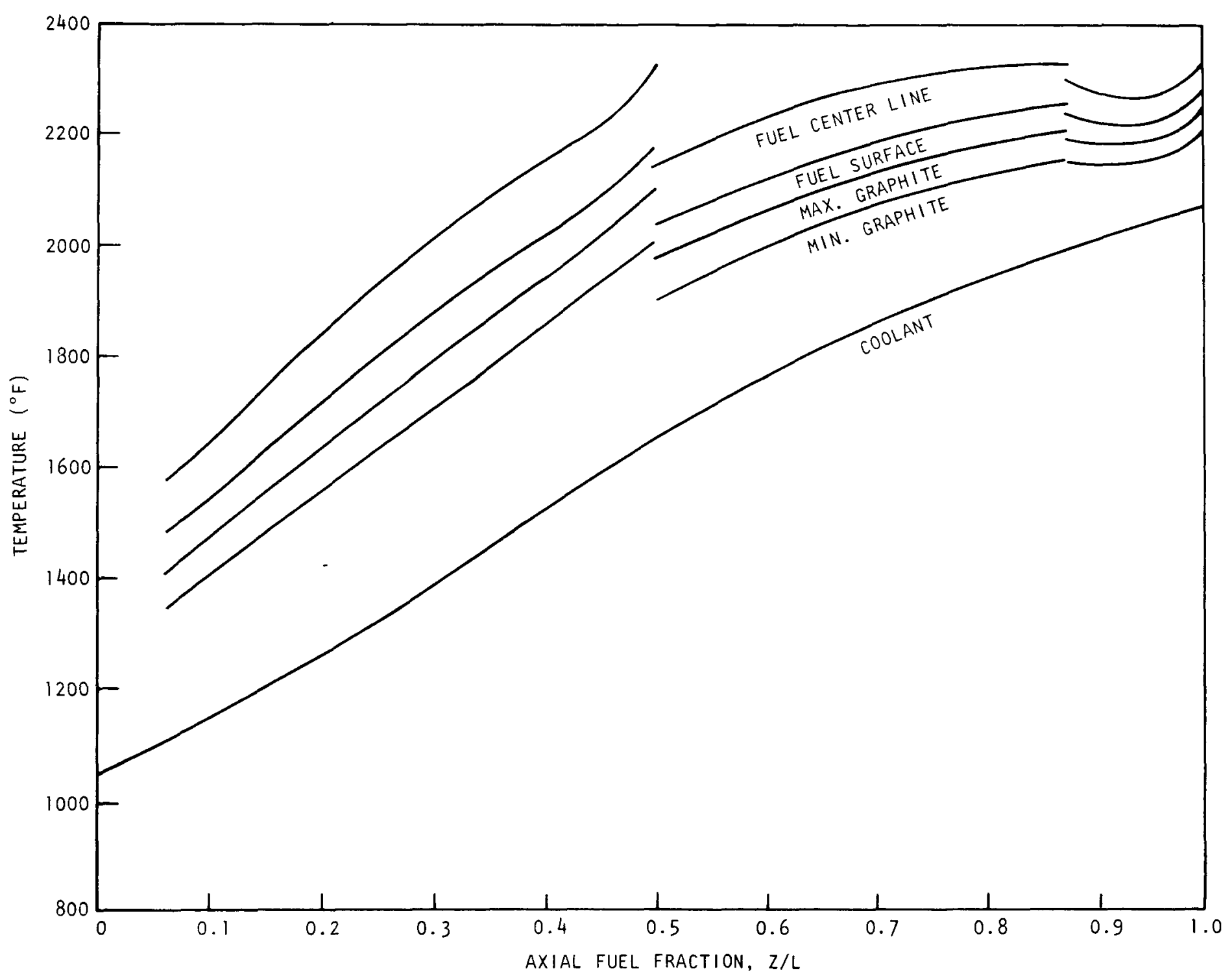

Fig. 6-7. Design IV average channel temperature distributions 


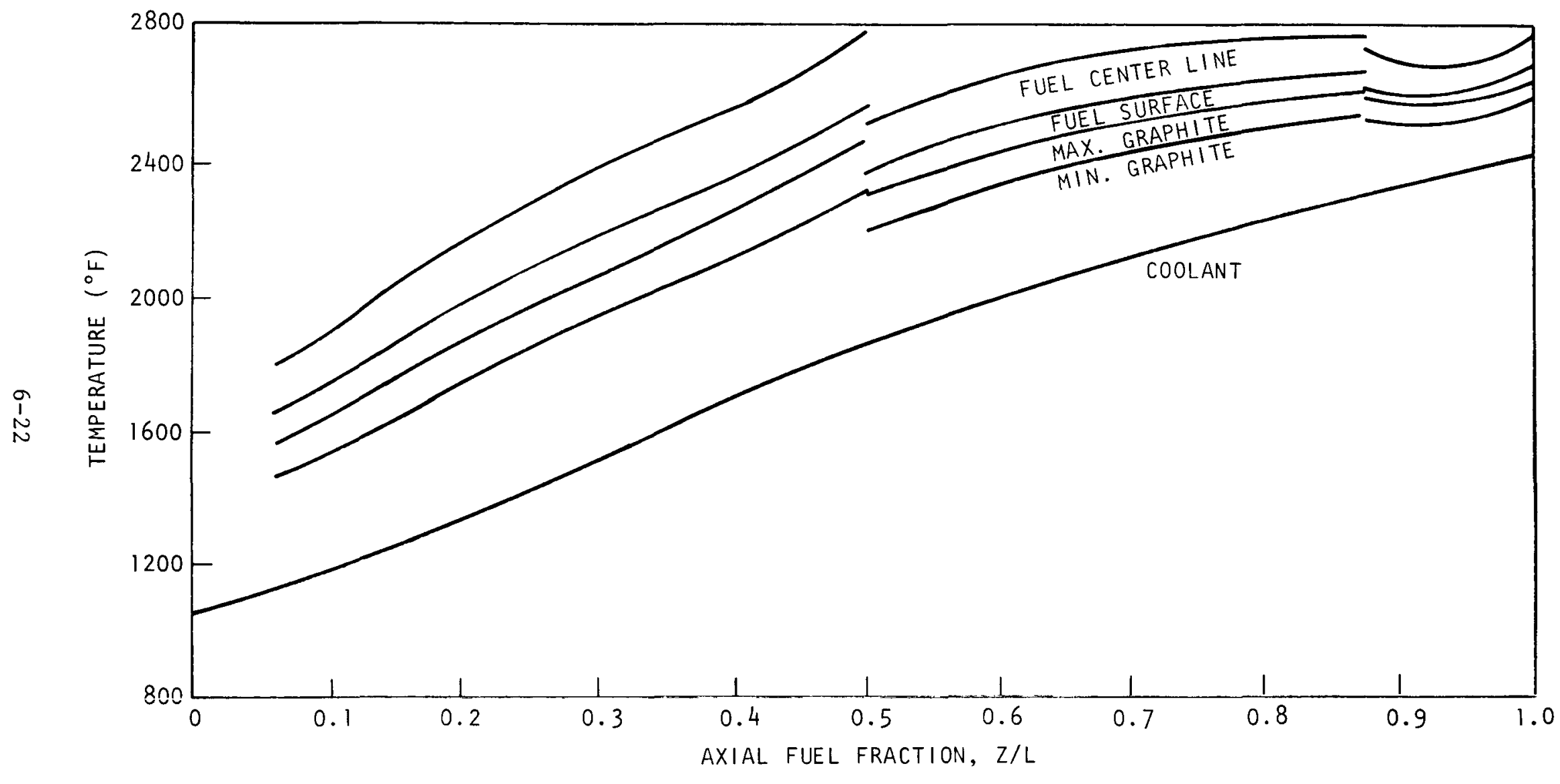

Fig. 6-8. Design IV hot channel temperature distributions 
Design $V$ requires a very steep axial profile with $60 \%$ of the heat generated in the top half and $40 \%$ of the heat generated in the bottom half of the core. This profile is given in Table 6-2. The major core parameters for this design are given in Table 6-7. The coolant, graphite, and fuel temperature distributions for an average and a hot channel are shown in Figs. 6-9 and 6-10, respectively. The core pressure drop for this design is about the same as for Design IV, since the effect of decreased helium flow is offset by increased core inlet and outlet temperatures. Additional core thermal parameters for Design $V$ are given in Appendix B.

\subsubsection{Effect of Changes in Core Inlet Temperatures}

The five designs considered above have fixed core inlet and outlet temperatures. In practice, it is possible to achieve any temperature between $1400^{\circ}$ and $2200^{\circ} \mathrm{F}$.

Figure 6-11 shows the region outlet temperature for the commercia1 HTGR as a function of inlet temperature. The peak fuel temperature for all gas temperatures is maintained at $2559^{\circ} \mathrm{F}$. The core pressure drop as a function of inlet temperatures is also shown in Fig. 6-11.

The use of a 210 hole fuel block allows an increase in the coolant exit temperature without any increase in peak fuel temperatures. Figure 6-12 gives the same information as Fig. 6-11 for the 210 hole fuel block.

Improved fuel capable of operating at peak fuel temperatures as high as $2940^{\circ} \mathrm{F}$ will permit much higher coolant temperatures. By using this fuel and a 210 fuel hole block, much higher helium temperatures can be achieved, as shown in Fig. 6-13. The core pressure drop for such a design is also shown in Fig. 6-13. 
TABLE 6-7

DESIGN V - CORE AND FUEL CYCLE PARAMETERS

\begin{tabular}{l|l}
\hline 1. Reactor Core Power & $3000 \mathrm{MW}(\mathrm{t})$ \\
2. Helium Inlet Temperature & $1200^{\circ} \mathrm{F}$ \\
3. Helium Outlet Temperature & $2200^{\circ} \mathrm{F}$ \\
4. Helium Flow & $8.2437 \times 10^{6} \mathrm{lb}_{\mathrm{m}} / \mathrm{hr}$ \\
5. Inlet Pressure & $725 \mathrm{psia}$ \\
6. Refueling Scheme & Radial segmental zoning \\
7. Fuel Residence Time & $3 \mathrm{yr}$ \\
8. Fuel Block Design & $210 \mathrm{fue} 1 \mathrm{hole} \mathrm{block}$ \\
9. Equilibrium C/Th Ratio & 200 \\
10. Average Moderator Temperature & $2114^{\circ} \mathrm{F}$ \\
11. Peak Moderator Temperature & $2863^{\circ} \mathrm{F}$ \\
12. Average Fuel Temperature & $2257^{\circ} \mathrm{F}$ \\
13. Peak Fuel Temperature & $3010^{\circ} \mathrm{F}$ \\
14. Core Pressure Drop & $132 \mathrm{psi}$ \\
15. Maximum Fast Neutron Fluence & $8 \times 10^{21 \mathrm{n} / \mathrm{cm}} 2$ \\
16. Hot Channel Helium Outlet & $2627^{\circ} \mathrm{F}$ \\
\hline
\end{tabular}




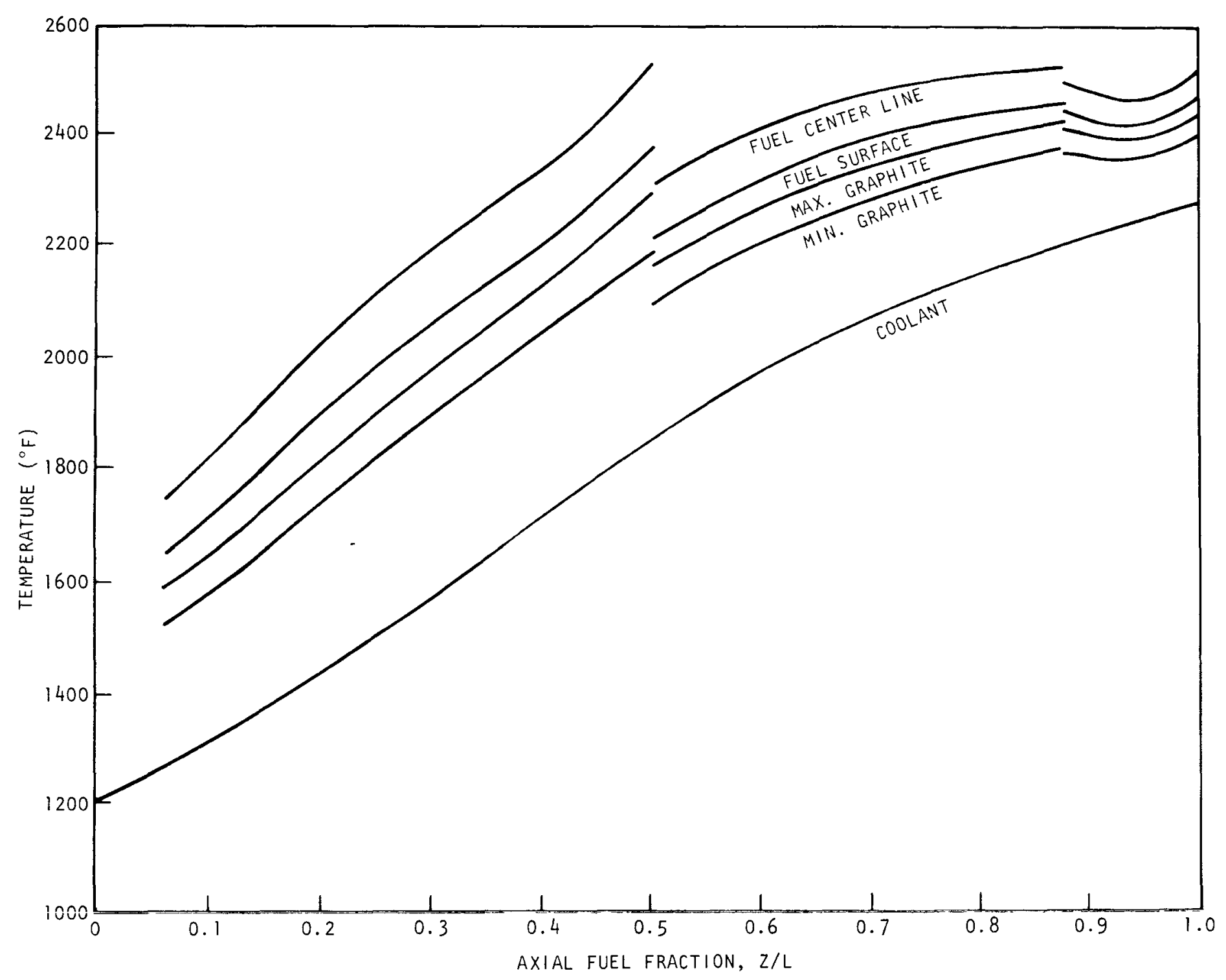

Fig. 6-9. Design $V$ average channel temperature distributions 


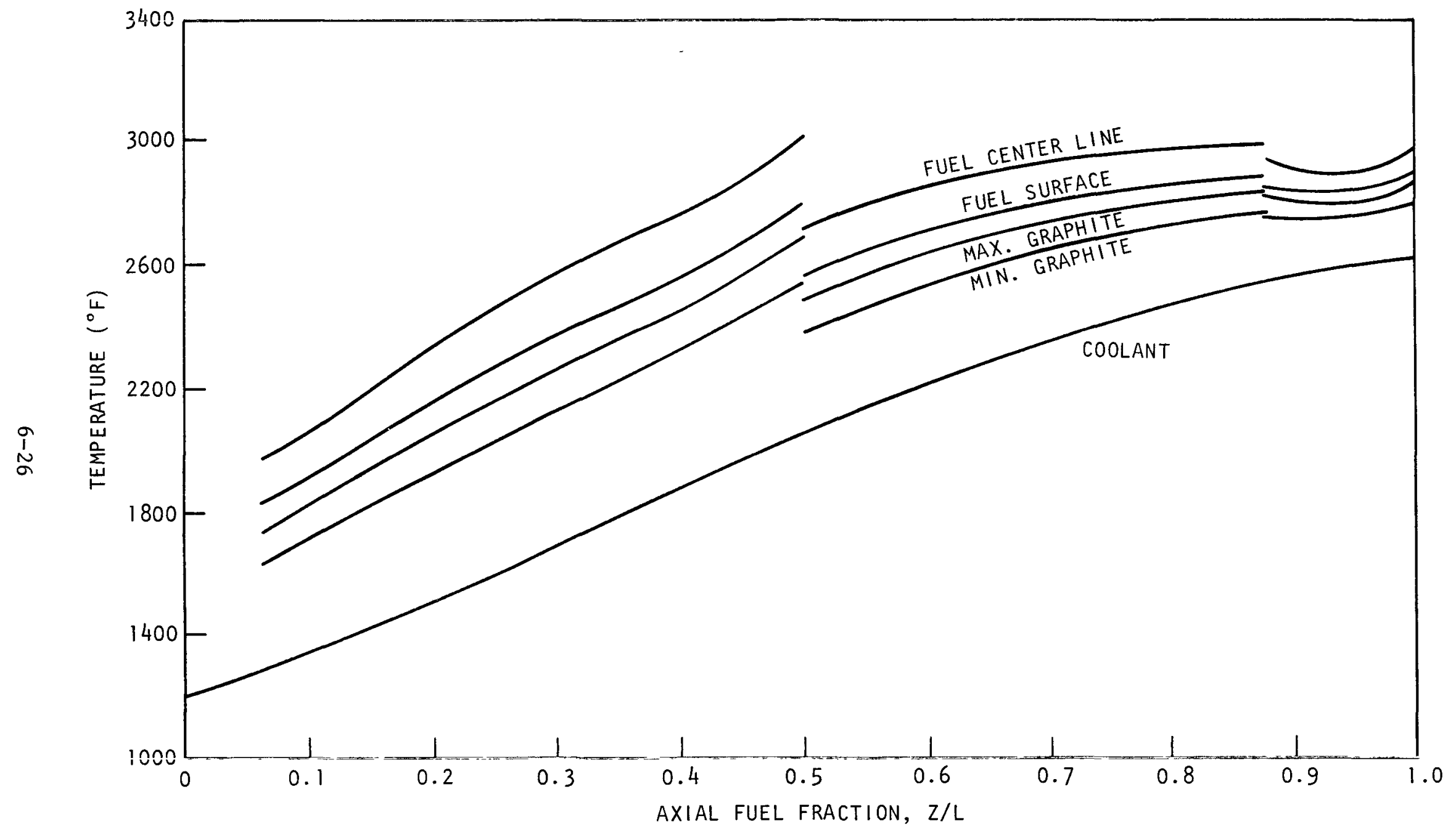

Fig. 6-10. Design $V$ hot channel temperature distributions 


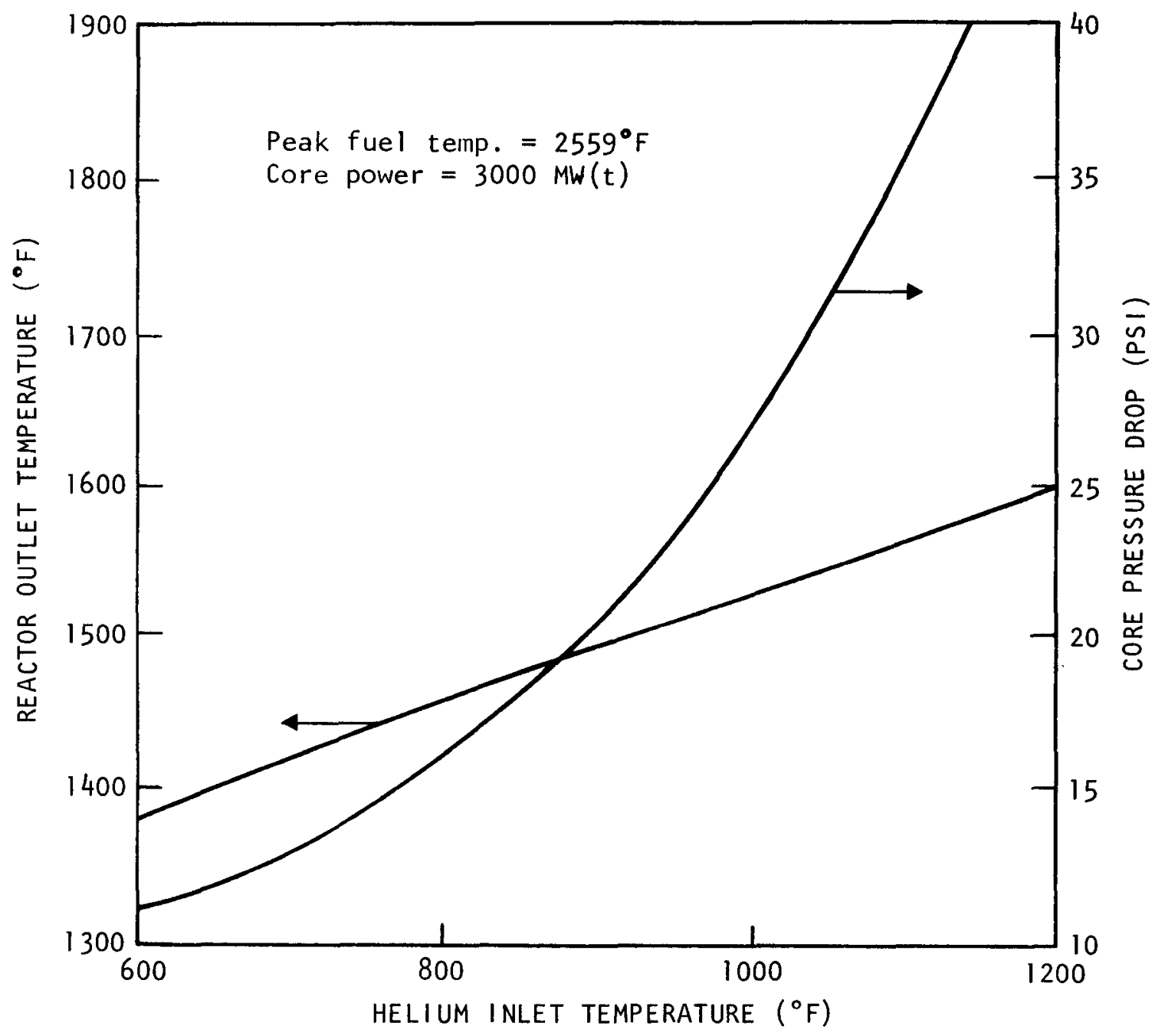

Fig. 6-11. Reactor outlet temperature and core pressure drop versus helium inlet temperature - 132-hole fue1 block 


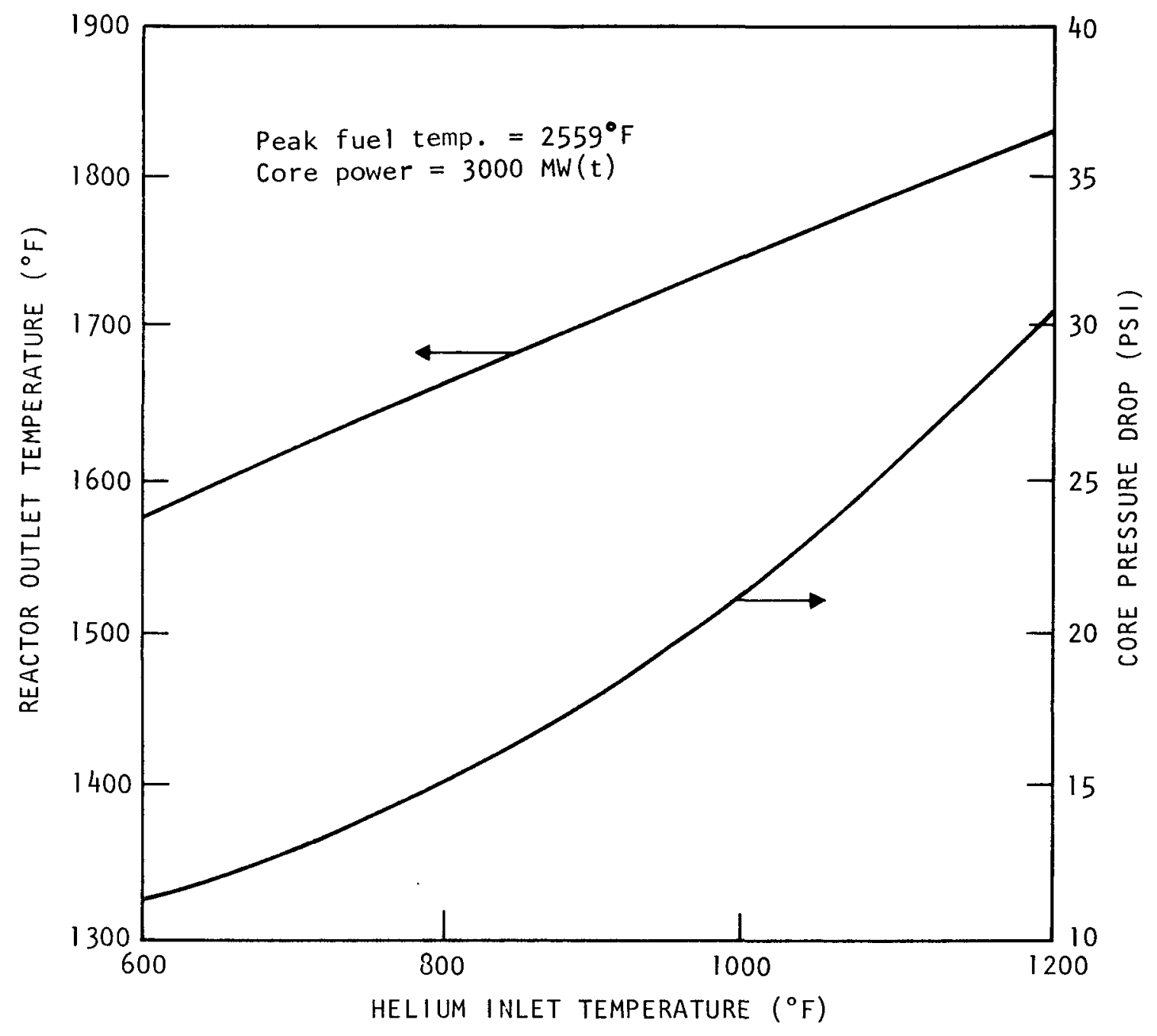

Fig. 6-12. Reactor outlet temperature and core pressure drop versus helium inlet temperature - 210-hole fue1 block 


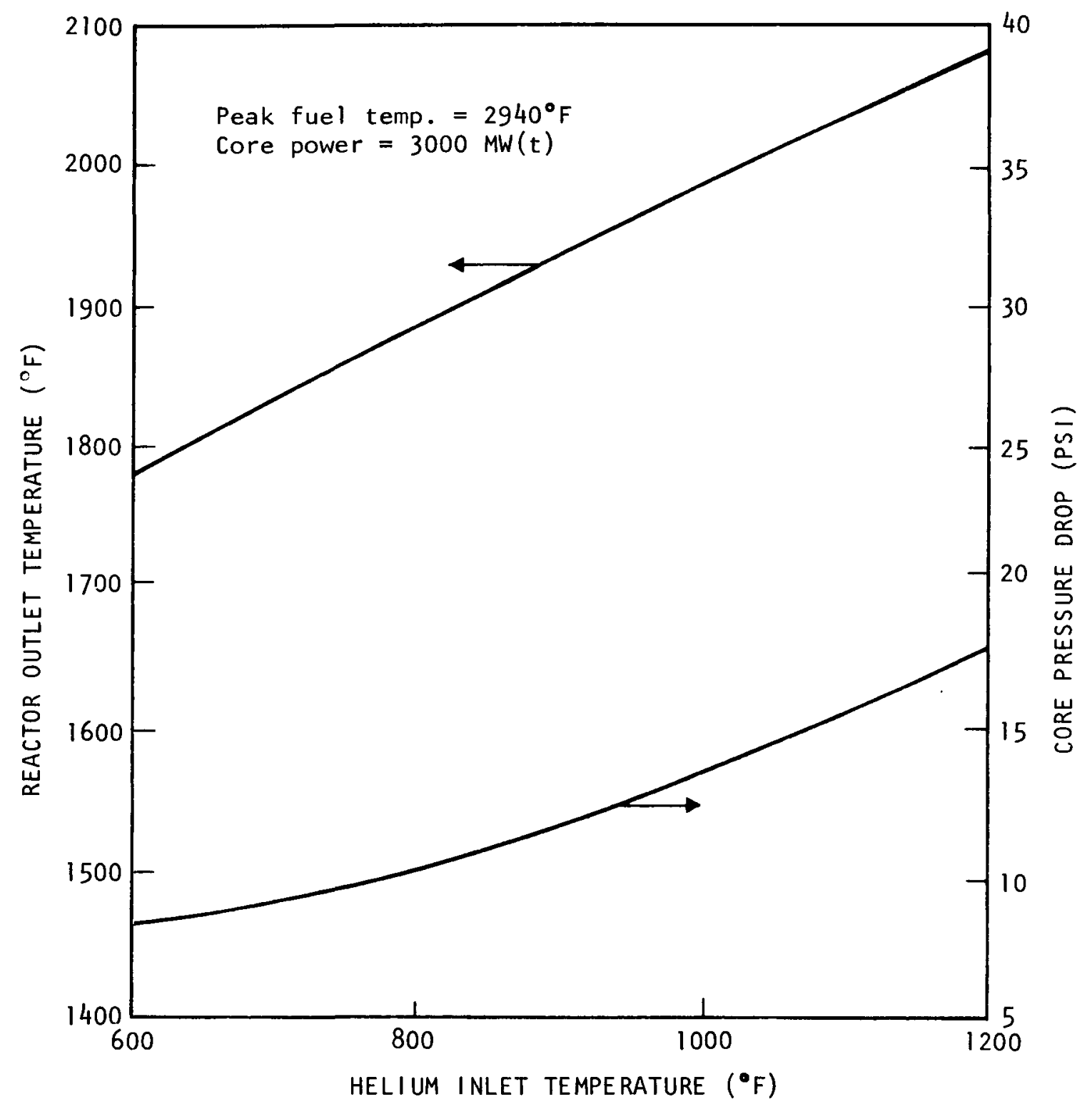

Fig. 6-13. Reactor outlet temperature and core pressure drop versus helium inlet temperature - 210-hole fuel block; improved fuel 


\subsection{FUEL MASS BALANCE}

Figures 6-14, 6-15, and 6-16 present fuel mass balances in the form presented in Ref. 6-1. In Figs. 6-14 and 6-15, the fuel mass balance for the $1200^{\circ}$ and $1400^{\circ} \mathrm{F}$ cases with and without fuel recycle are shown. Figure 6-16 presents the fuel mass balance for $1600^{\circ} \mathrm{F}$ and above using TRISO/TRISO fuel with a 3-yr fuel cycle. It is assumed that the higher temperatures requiring an advanced fuel will be essentially identical to the $1600^{\circ} \mathrm{F}$ case.

\subsection{FISSION PRODUCT RELEASE}

Design and expected fission product release rates for the HTGR steam plant should also be acceptable for operation of process heat plants. However, both gaseous and metallic fission product releases are quite temperature sensitive. Hence, the higher operating temperatures experienced in the process heat core require changes in fuel design to maintain acceptable release rates.

Table 6-8, adapted from Ref. 6-2, summarizes expected cesium-137 release rates for steam plants and process heat plants of different fuel designs. Designs described under 1,2, and 3 can be achieved with current technology. Those described under 4 and 5 require adoption of more advanced fuel fabrication technology.

Table 6-8 describes cesium release for a process heat reactor with a $950^{\circ} \mathrm{C}\left(1742^{\circ} \mathrm{F}\right)$ coolant outlet temperature. Various core inlet and outlet temperatures will affect maximum fuel temperatures, as shown in Table 6-9 (Ref. 6-3), and hence will also affect fission product release. Figure 6-17, adapted from Ref. 6-4, illustrates the effects of changes in fuel and graphite temperature in a TRISO/BISO core on relative release for strontium, which is very temperature sensitive. The base peak fuel temperature in this figure is taken as $1350^{\circ} \mathrm{C}\left(2462^{\circ} \mathrm{F}\right)$. A constant fuel particle failure fraction is assumed. Cesium release is less sensitive to temperature variation than strontium release. 


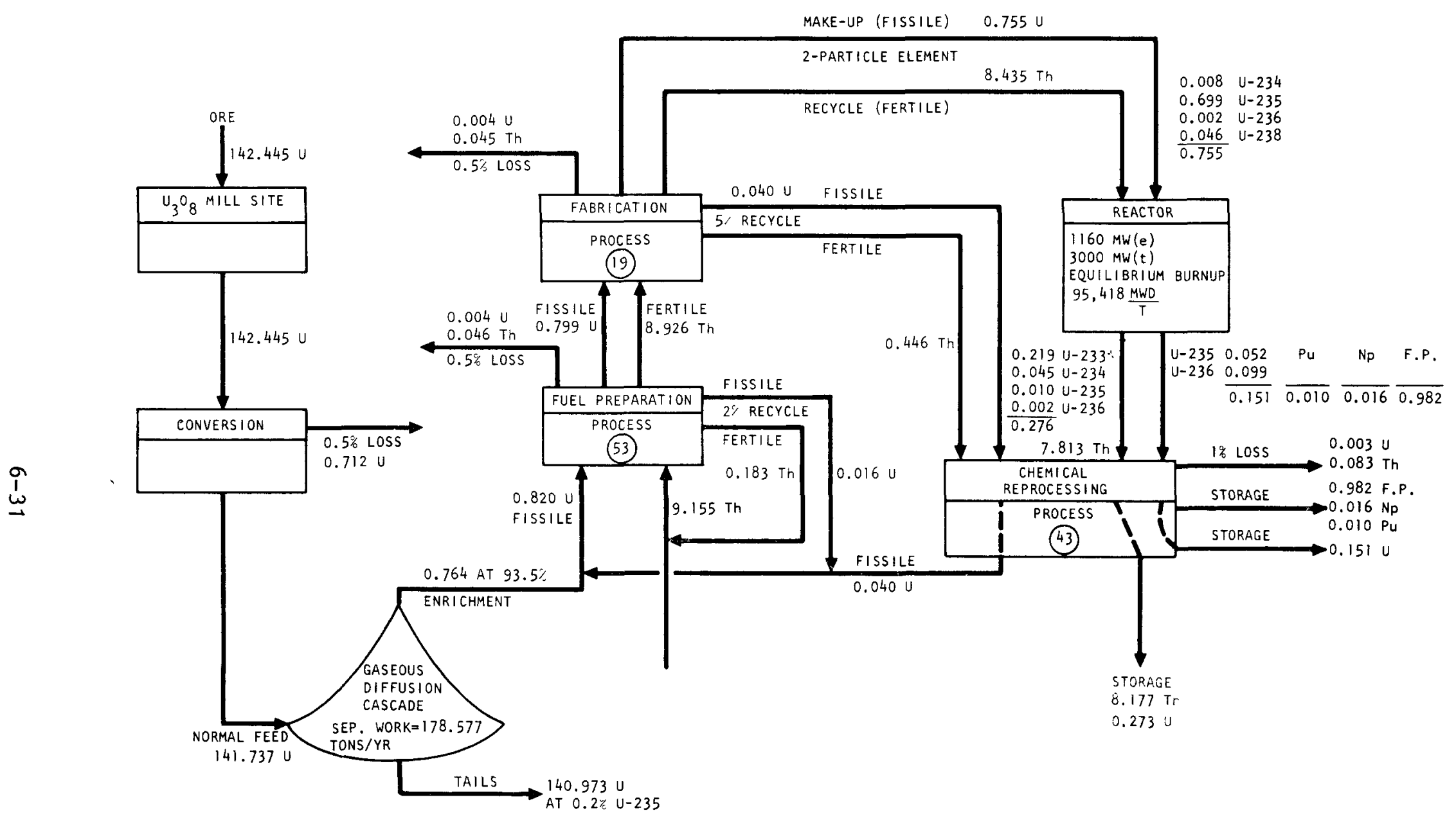

FLOW RATES IN METRIC TONS/YEAR

INCLUDING Pa-233, SINCE ALMOST ALL Pa-233 DECAYS INTO AT 80\% REACTOR LOAD FACTOR

$U-233$ AFTER 250 DAYS OF CODLING AND 541 LIN

$\left(\mathrm{Pa}-233\right.$ HALF-LIFE $\mathrm{t}_{1 / 2}=27$ DAYS)

Fig. 6-14. Equilibrium material balance flowsheet for reference HTGR at $8.4 \mathrm{~W} / \mathrm{cm}^{3}$ (non-recycle case) 


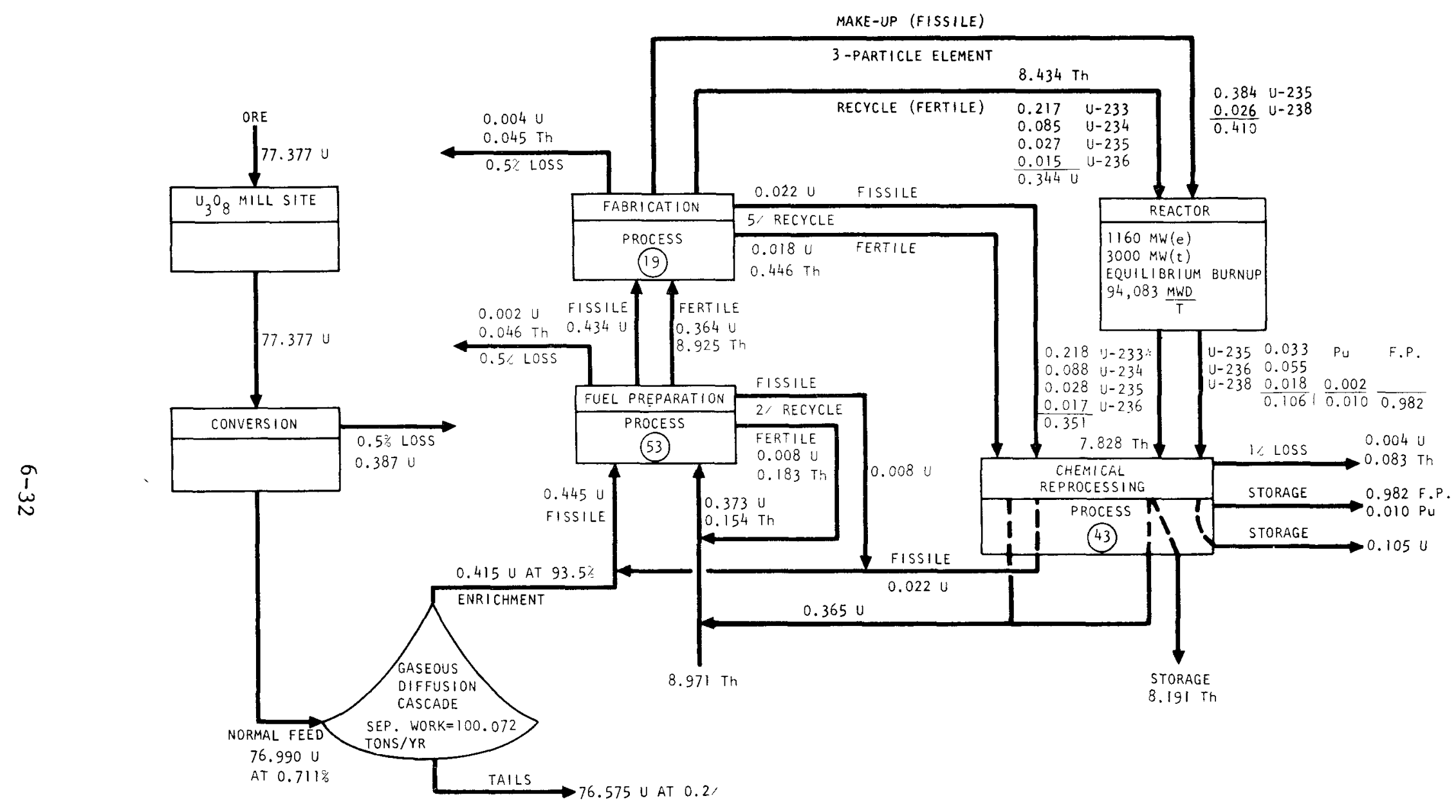

FLOW RATES IN METRIC TONS/YEAR AT $80 \%$ REACTOR LOAD FACTOR

*INCLUdiNG Pa-233, SinCE almost all Pa-233 decays INTO J-233 AFTER 250 DAYS OF COOLING AND SHIPPING
$\left(\right.$ Pa-233 HALF-LIFE $\mathrm{t}_{1 / 2}=27$ DAYS)

Fig. 6-15. Equilibrium material balance flowsheet for reference HTGR at $8.4 \mathrm{~W} / \mathrm{cm}^{3}$ (4-yr annual recycle) 


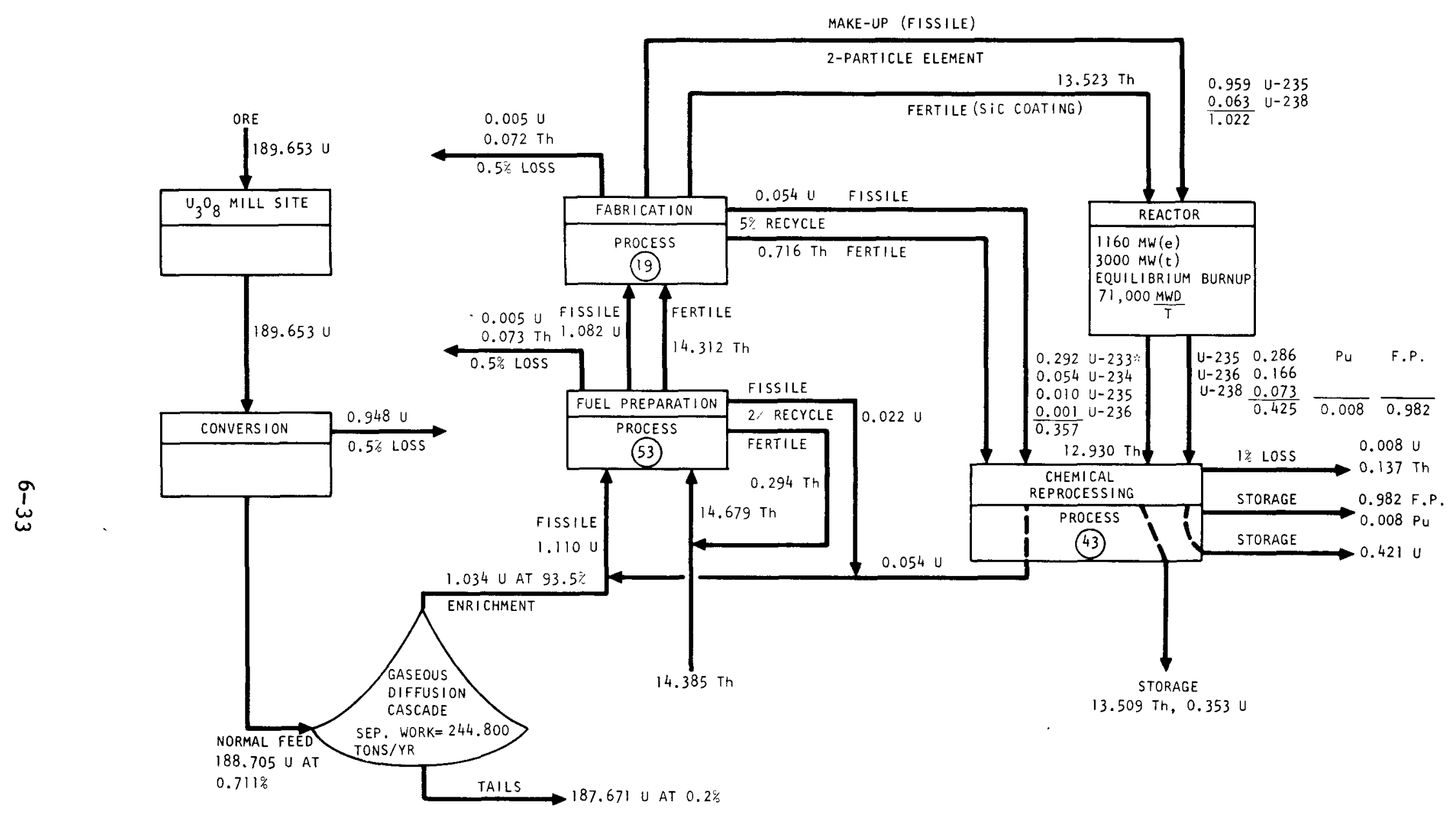

FLOW RATES IN METRIC TONS/YEAR

AT $80 \%$ REACTOR LOAD FACTOR

*INCLUDING Pa-233, SINCE ALMOST ALL Pa-233 DECAYS INTO

U-233 AFTER 250 DAYS OF COOLING AND SHIPPING

$\left(\mathrm{Pa}-233\right.$ HALF-LIFE $\mathrm{t}_{1 / 2}=27$ DAYS)

Fig. 6-16. Equilibrium material balance flowsheet for reference HTGR at $\mathrm{C} / \mathrm{Th}=200$ using TRISO/TRISO fuel with a 3-yr fuel cycle 
TABLE 6-8

RELATIVE Cs-137 RELEASE RATES FOR A 3000-MW(t) PLANT

\begin{tabular}{l|c}
\hline \multicolumn{1}{c|}{ Design } & Relative Release \\
\hline $\begin{array}{l}\text { 1. Steam Plant: } \mathrm{T}_{\text {out }}=740^{\circ} \mathrm{C}, \\
\text { 8-row b1ock, TRISO/BISO, } \\
8.4 \mathrm{~W} / \mathrm{cm}^{3}\end{array}$ & 1.0 \\
$\begin{array}{l}\text { 2. Process Heat Plant: } \mathrm{T}_{\text {out }}=950^{\circ} \mathrm{C}, \\
\text { 10-row block, TRISO/BISO }\end{array}$ & 65 \\
3. Like 2, TRISO/BISO & 1.6 \\
4ike 3, reduced uranium \\
$\begin{array}{l}\text { contamination from } \\
5 \text { x } 10^{-4} \text { to } 5 \text { x } 10^{-5}\end{array}$ \\
$\begin{array}{l}\text { Like 4, reduced EOL } \\
\text { failed fraction from } \\
0.01 \text { to 0.001 }\end{array}$
\end{tabular}


TABLE 6-9

CORE CONDITIONS FOR PROCESS HEAT STUDY

\begin{tabular}{c|c|c|c}
\hline $\begin{array}{c}\text { Core } \\
\text { Outlet } \\
\begin{array}{c}\text { Temp. } \\
\left({ }^{\circ} \mathrm{F}\right)\end{array}\end{array}$ & $\begin{array}{c}\text { Core } \\
\text { Inlet } \\
\text { Temp. } \\
\left({ }^{\circ} \mathrm{F}\right)\end{array}$ & $\begin{array}{c}\text { Maximum } \\
\text { Fuel } \\
\text { Temp. } \\
\left({ }^{\circ} \mathrm{F}\right)\end{array}$ & $\begin{array}{c}\text { Block } \\
\text { Type }\end{array}$ \\
\hline 1400 & 700 & 2513 & 8 row, 132 fuel holes \\
1600 & 770 & 2475 & 10 row, 210 fuel holes \\
1800 & 932 & 2562 & 10 row, 210 fuel holes \\
2000 & 1050 & 2792 & 10 row, 210 fuel holes \\
2200 & 1200 & 3010 & 10 row, 210 fuel holes \\
\hline
\end{tabular}

(a) See Appendix B for details. 


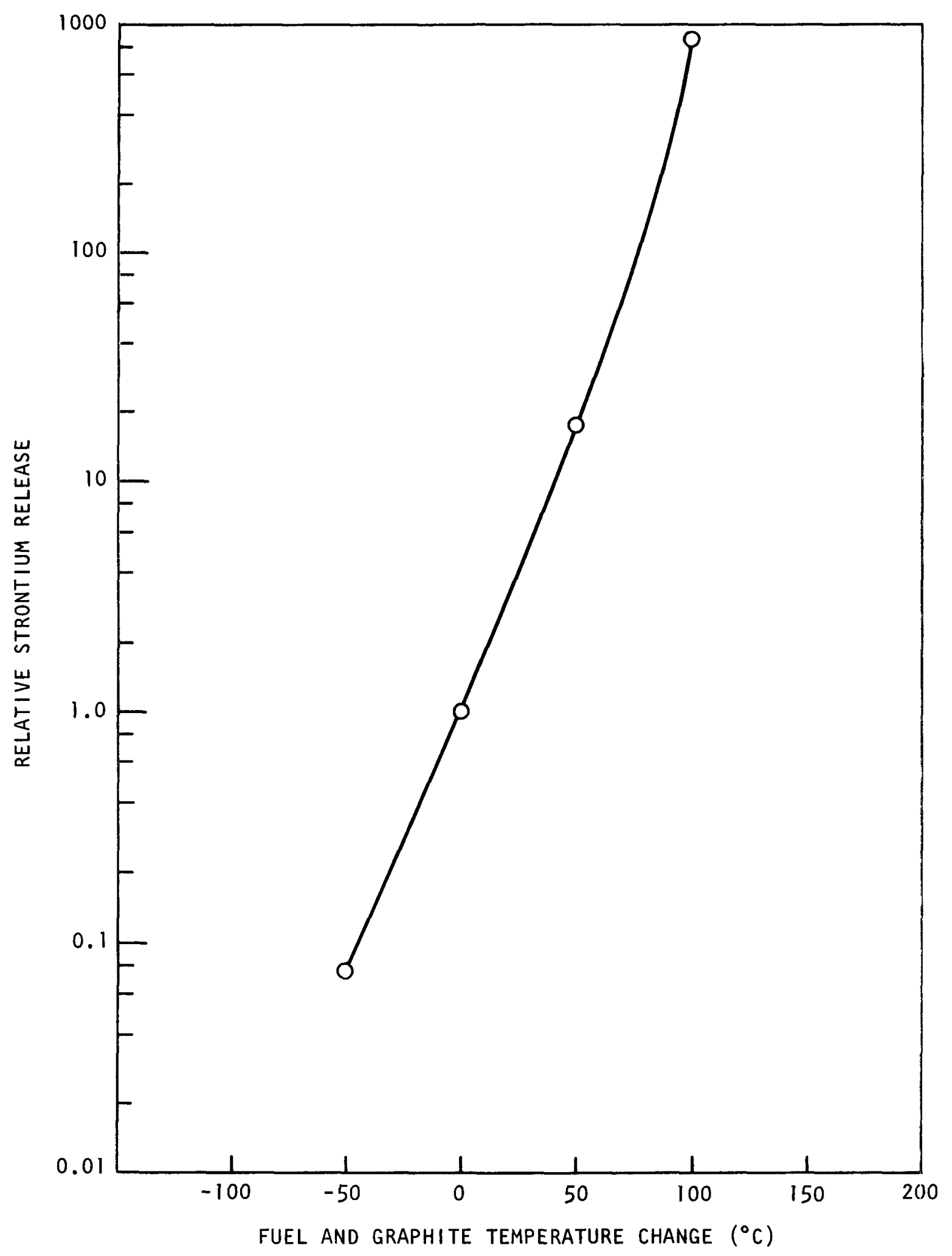

Fig. 6-17. Relative strontium release versus temperature 
Certain changes in fuel particle design can reduce release. A comparison of designs 2 and 3 in Table 6-8 shows the effect on cesium release of adopting a TRISO/TRISO core. Since strontium is thought to be retained in BISO particles largely by the fuel kernel, the effect of an all-TRISO core on release of that fission product would be less dramatic, but still substantial. Yet another design change, which would reduce metallic fission product release by perhaps one order of magnitude for some species, is the use of dopants in the BISO kernels to retard kernel release (Ref. 6-5). Use of alloyed pyrolytic carbon coatings (silicon carbide alloying) is also expected to reduce BISO particle metallic release to some extent. These latter two design changes require application of technology still under development.

Gaseous fission product release, expressed in terms of the $\mathrm{R} / \mathrm{B}$ ratio (release to birth), is also quite temperature sensitive. Figures 6-18 and 6-19 show the temperature dependence of the release of $\mathrm{Kr}-85 \mathrm{~m}$ and Xe-138, respectively, for as-manufactured Fort St. Vrain fuel rods (Ref. 6-6). Similar behavior is expected for process heat plant fuel. Curves of $R / B$ versus temperature for a given isotope can be described by the following relationship:

$$
\mathrm{R} / \mathrm{B}(\mathrm{T})=(\mathrm{R} / \mathrm{B})_{\mathrm{m}}+(\mathrm{R} / \mathrm{B})_{\mathrm{o}} \exp \left[\left(\frac{1}{\mathrm{~T}_{\mathrm{o}}}-\frac{1}{\mathrm{~T}}\right) \frac{\mathrm{Q}}{\mathrm{R}}\right],
$$

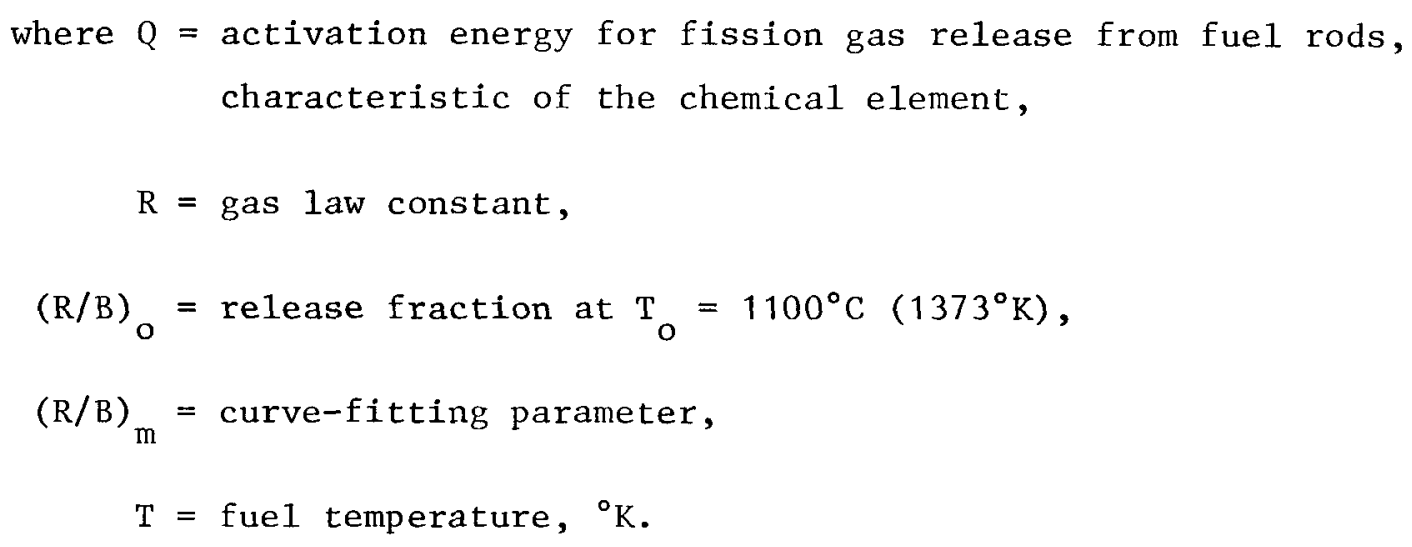




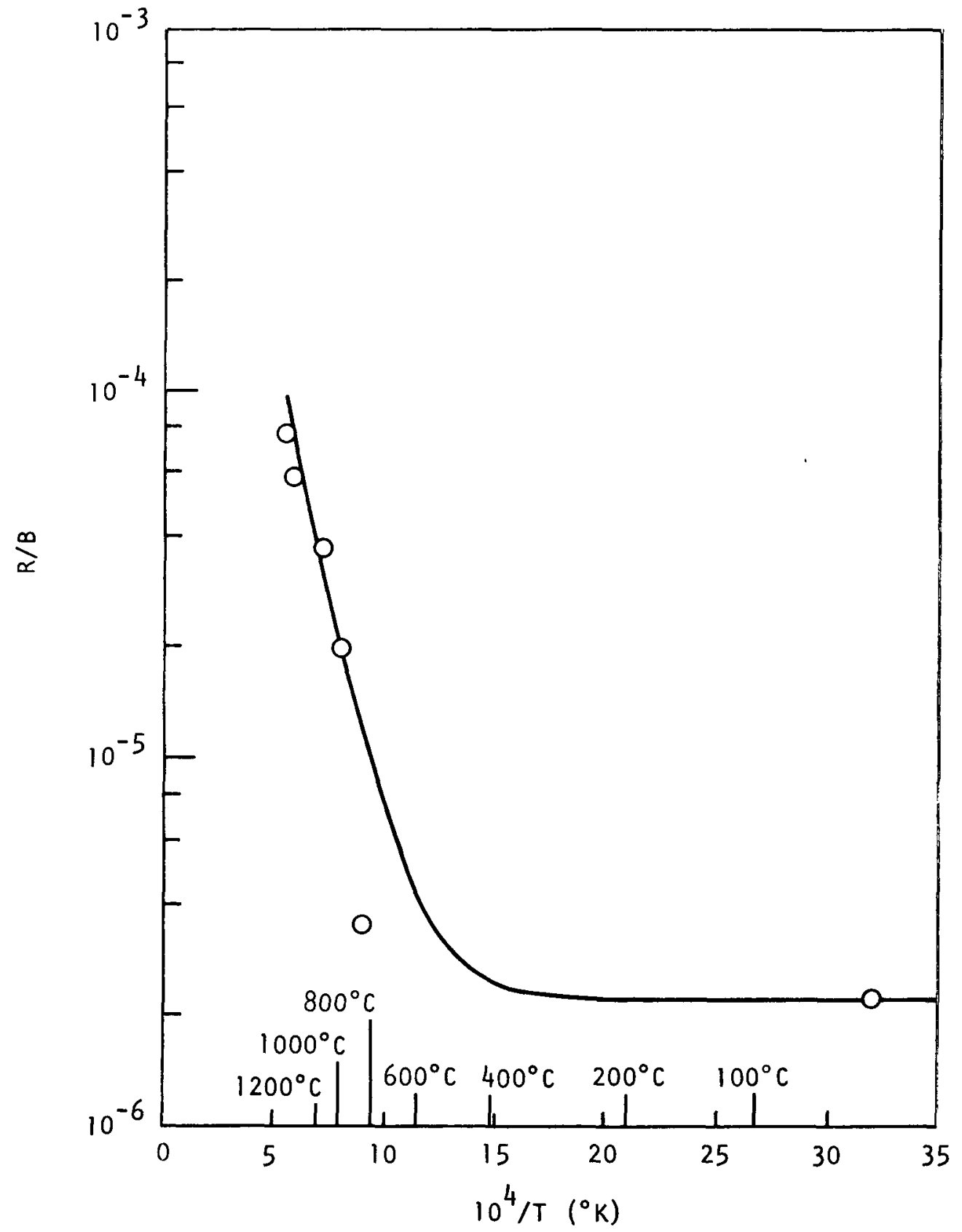

Fig. 6-18. Kr-85m R/B temperature dependence - Fort St. Vrain fuel 


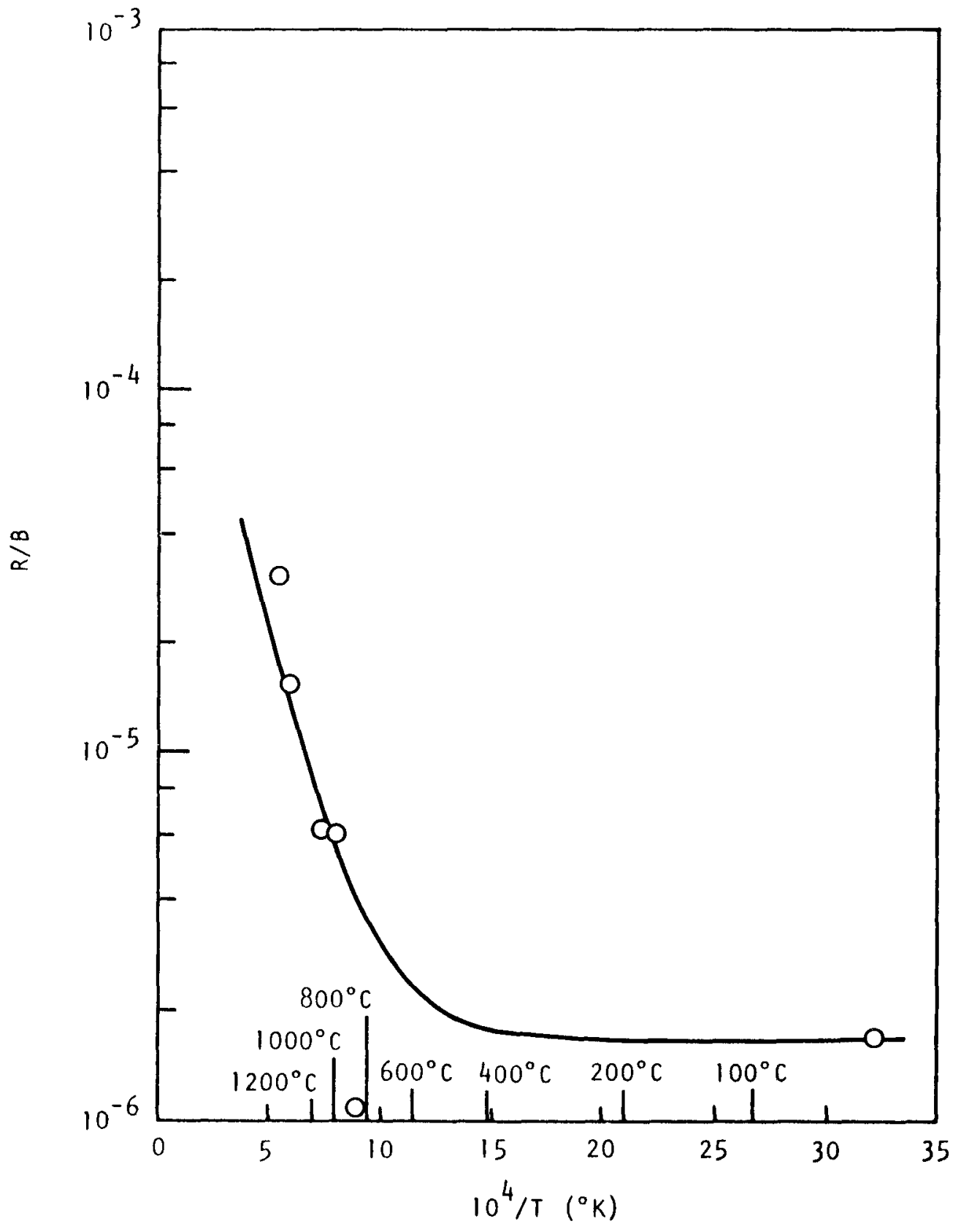

Fig. 6-19. Xe-138 R/B temperature dependence - Fort St. Vrain fuel 
As can be seen from Figs. 6-18 and 6-19, the higher operating temperatures of the process heat reactor will necessitate lower particle failure fractions to maintain gaseous $R / B$ at present levels. For example, using the Fort St. Vrain data $Q=12.7 \mathrm{kcal} / \mathrm{mole},(\mathrm{R} / \mathrm{B})_{\mathrm{O}}=3 \times 10^{-5}$, and $(R / B)_{m}=2.2 \times 10^{-6}$ and the maximum fuel temperatures of Table 6-9, the peak local values of $\mathrm{R} / \mathrm{B}$ for $\mathrm{Kr}-85 \mathrm{~m}$ shown in Table 6-10 are obtained.

\section{$\underline{\text { References }}$}

6-1. "Reactor Fuel Costs for Nuclear Power Evaluation," USAEC Report WASH-1099, Oak Ridge National Laboratory, December 1971.

6-2. Brandes, S., et al., "High Temperature Reactors with Block Type Fuel Elements with High Coolant Gas Temperatures," Atomwirtschaft, to be pub1ished.

6-3. Scheffel, W. J., General Atomic Company, private communication.

6-4. Rovner, L., Genera1 Atomic Company, "Intuition Tests for Fuel Block Fission Product Release, unpublished data.

6-5. Sterling, S., General Atomic Company, "Doped Fuel Program and Cesium Release Calculations," unpublished data.

6-6. Haire, M. J., and D. W. McEachern, "Gaseous Radioactivity Levels in the Primary Coolant of an HTGR," General Atomic Report GA-A12946, to be issued. 
TABLE 6-10

$\mathrm{Kr}-85 \mathrm{~m}$ R/B VERSUS TEMPERATURE $(\mathrm{a})$

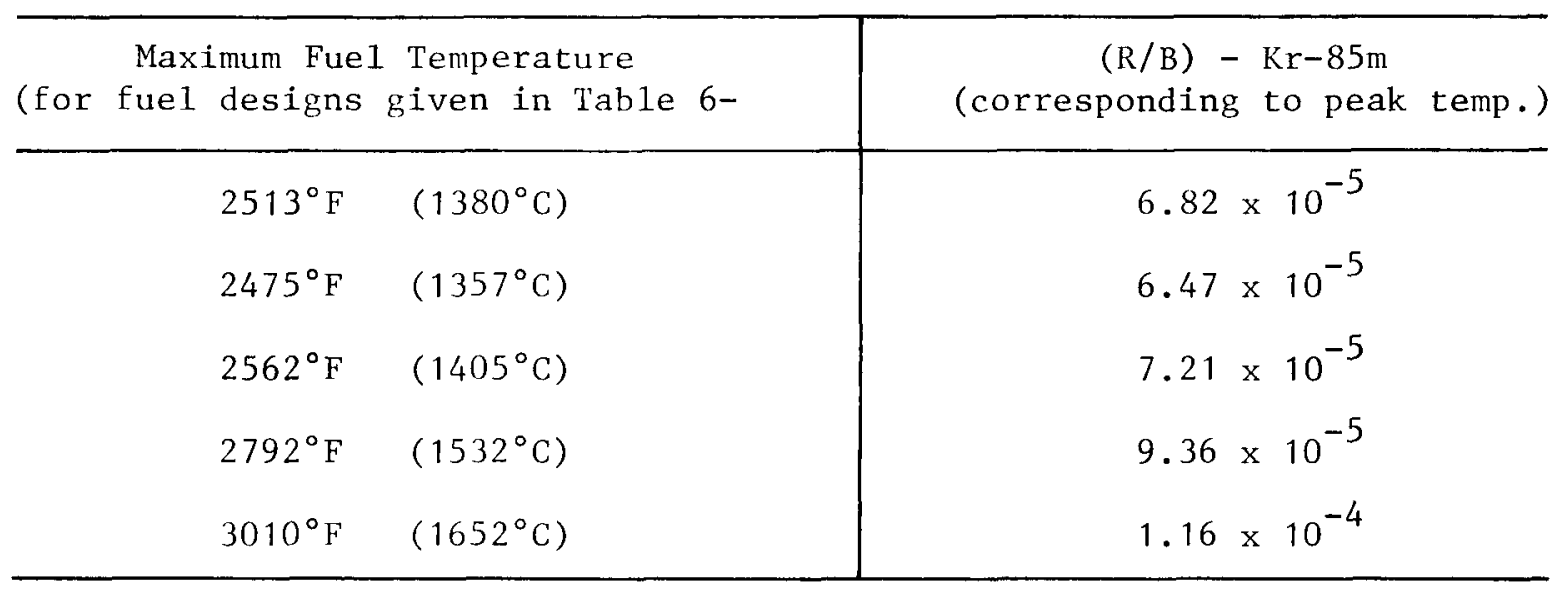

(a) Based on data for as-manufactured Fort St. Vrain fuel rods. 
$\bullet$

•

0 


\section{OPERATION AND MAINTENANCE}

\subsection{NUCLEAR PROCESS HEAT PLANT STAFFING VERSUS TEMPERATURE}

Station staffing for the nuclear process heat plant increases above the 81 people needed for the standard steam plant owing to the greater number of maintenance-related items. As shown in Table 7-1, the manpower requirements of a mature process heat plant vary from 85 for a process gas outlet temperature of $1200^{\circ} \mathrm{F}$ to 94 for a gas outlet temperature of $2000^{\circ} \mathrm{F}$. Staffing for the base plant was developed from manpower requirement studies prepared by General Atomic.

Allowances in the maintenance and technical departments of the plant staffing have been expanded for the process heat cases. Also, an additional clerk to handle accounting work generated by the increase in personnel is provided. Operating and plant management personnel are assumed constant over the range of cases considered.

Normal reactor plant operations using an automatic plant control system will not be considerably different from operation of the standard steam plant. Five crews of five people should be adequate for normal power operations of a single HTGR unit. One more trained and licensed supervisor, control operator, and auxiliary operator will provide for promotions, transfers, resignations, and retirements. Thus, a total operating staff of 28 people is sufficient.

The responsibilities of the operating crew include monitoring of the main and auxiliary control boards, recording of certain required control parameters on a periodic basis, and visual checking of plant equipment in modularized components such as pumps, valves, and piping assemblies. One licensed operator is required at the console of the data acquisition and 
TABLE $7-1$

STATION STAFFING VERSUS TEMPERATURE FOR NUCLEAR PROCESS HEAT PLANT

\begin{tabular}{|c|c|c|c|c|}
\hline & \multirow[b]{2}{*}{$\begin{array}{l}\text { Base } \\
\text { Plant }\end{array}$} & \multicolumn{3}{|c|}{ Process Heat P1ant } \\
\hline & & $\begin{array}{l}1200^{\circ}- \\
1400^{\circ} \mathrm{F}\end{array}$ & $1600^{\circ} \mathrm{F}$ & $\begin{array}{l}1800^{\circ}- \\
2000^{\circ} \mathrm{F}\end{array}$ \\
\hline \multicolumn{5}{|l|}{ P1ant Management } \\
\hline Superintendent (SRO) & 1 & 1 & 1 & 1 \\
\hline Ass' $^{\prime} t$ superintendent (SRO) & 1 & 1 & 1 & 1 \\
\hline \multicolumn{5}{|l|}{ Operations } \\
\hline Shift supervisor (SRO) & 6 & 6 & 6 & 6 \\
\hline Control operators (RO) & 11 & 11 & 11 & 11 \\
\hline Auxiliary operators & 11 & 11 & 11 & 11 \\
\hline \multicolumn{5}{|l|}{ Technical } \\
\hline Technical supervisor & 1 & 1 & 1 & 1 \\
\hline Engineers, chemists, etc. & 6 & 6 & 7 & 7 \\
\hline Technicians & 9 & 10 & 10 & 11 \\
\hline Maintenance & & & & \\
\hline Maintenance supervisor & 1 & 1 & 1 & 1 \\
\hline Ass't maint. supervisors & 2 & 2 & 3 & 3 \\
\hline Craftsmen and repairmen & 16 & 19 & 21 & 24 \\
\hline Janitors & 3 & 3 & 3 & 3 \\
\hline \multicolumn{5}{|l|}{ Administrative and Security } \\
\hline Administrative officer & 1 & 1 & 1 & 1 \\
\hline Ass't admin. officer & 1 & 1 & 1 & 1 \\
\hline Payroll clerk & 1 & 1 & 1 & 1 \\
\hline Clerks & 5 & 5 & 6 & 6 \\
\hline Safety officers & 5 & $\underline{5}$ & $\underline{5}$ & 5 \\
\hline Tota1 & 81 & 85 & 90 & 94 \\
\hline
\end{tabular}


processing computer during operation within the normal range (25\% to $100 \%)$ of the plant control system. A second operator is needed part-time at the console for load variations outside the $25 \%$ to $100 \%$ range. For instance, during a startup from refueling, equipment such as cooling tower fans, circulating water pumps, feedwater pumps, helium circulator auxiliaries, etc., need to be restarted. These operations require the assistance of the second operator for approximately $10 \%$, or $2 \mathrm{hr}$, of the startup time at the console. A shift supervisor and two auxiliary operators complete the shift crew.

Steam generation in the process heat plant has been modified to exclude reheat, thereby simplifying the control loop around the steam generator. The reformers will be a once-through, countercurrent flow heat exchanger with isolation valve requirements similar to those of the steam generator. Additional purging lines for introduction of inert gases and/or steam during startup and shutdown are required. Adaptation of the automatic plant control system to include the control loops for the reformer will not significantly complicate the monitoring of important control variables. It will be a trade-off with the simplification of the steam generation control sequence. Thus, additional operating personnel are not required for operation of the nuclear process heat plant.

For the standard steam plant that has reached operating maturity, a maximum of 16 days per year is required for the refueling of one-quarter of the core. The refueling of each region consists of a series of computer-controlled machine operations, reducing the probability of delays due to human error. The minimum number of men per shift for a refueling operation in the standard plant is estimated as follows:

1 Overall Refueling Supervisor

2 Operators, fue1 handling machine and auxiliary service cask

1 Health Physics Supervisor

1 Operator, fuel transfer cask

1 Operator, refueling equipment transfer dolly 
2 Crane Operators, Reactor Service Building crane and Reactor Containment Building crane

2 Crane Riggers

1 Reactor Operator (main contro1 room)

2 Mechanics

13 TOTAL

Off-line refueling for the process heat plant will be accomplished during a reactor downtime of 16 or 22 days maximum for a 4- or 3-yr fue1 cycle, respectively. The downtime is from full power to full power and is controlled by the speed of the refueling machine. The fuel handling system will transfer new fuel and reflectors from fuel storage in the Reactor Service Building to the reactor and spent fuel and reflectors from the reactor to fuel storage. Selected in-core instrumentation such as the flux-mapping unit sensor and thermocouples will be removed and replaced during the refueling operations. Manpower requirements to accomplish the necessary annual refueling are provided for in the base plant schedule. No new refueling techniques are to be utilized in the nuclear process heat reactor other than the change in fuel cycle length. Hence, no additions to plant staffing due to refueling will be made.

Studies indicate (see, for example, Ref. 7-1) that turbines and their auxiliaries are one of the principal types of equipment causing forced outages in nuclear power plants. However, for the nuclear process heat plant, equipment utilizing steam and associated auxiliaries will be determined by customer requirements. Exclusion of the reheat loop in the steam generator reduces turbine plant requirements and simplifies maintenance. However, because of the uncertainty of steam utilization equipment, no attempt has been made to reduce maintenance manpower.

The increase in the number of maintenance-related items, such as valves, seals, and instruments and controls, associated with the reformers accounts for the increase in maintenance and technical personnel. Servicing and repair of equipment will be scheduled during the annual 
refueling period. Major equipment design life for components such as the reformer, steam generator, and main helium circulator will be $30 \mathrm{yr}$. Catalyst replacement and in-service inspection will be done on a contract basis with the work performed during refueling. Plant labor will be used for subsequent barreling of the catalyst for disposal as a low-level radioactive waste.

Higher-strength alloys, such as a stabilized austenitic stainless steel, will be used in piping assemblies and valves for temperature service in excess of $950^{\circ} \mathrm{F}$. Below this temperature, low-alloy stee 1 is sufficient. Increased maintenance problems usually associated with higher creep stress and excessive thermal cycling in the low-alloy steels as temperatures increase will be held in check by utilization of these higherstrength alloys. Therefore, higher temperatures are not expected to cause increased maintenance problems.

\subsection{PLANT AVAILABILITY AND PLANT CAPACITY FACTOR VERSUS TEMPERATURE}

Plant availability for a standard steam plant is the percent of total time in a given period that a plant was available for producing electricity. It is equal to the time the generator was available for electricity production divided by the total time during the period. For the nuclear process heat plant, plant availability will be defined as the percent of total time in a given period that the plant was producing hydrogen.

The plant capacity factor for a standard steam plant is the ratio of the total energy generated in a fixed period of time to the total energygenerating capability during the same period, expressed as a percentage. The plant capacity factor for the nuclear process heat plant will be defined as the percent of rated hydrogen production capacity, in MMSCFD, the plant actually produced.

Table 7-2 outlines the total days of scheduled outage attributable to refueling and catalyst replacement for each process heat case. A detailed breakdown of the catalyst change-out schedule for one reformer at each 
TABLE 7-2

SCHEDULED OUTAGE VERSUS TEMPERATURE

\begin{tabular}{|c|c|c|c|c|c|c|}
\hline & \multirow{2}{*}{$\begin{array}{l}\text { Base } \\
\text { Plant }\end{array}$} & \multicolumn{5}{|c|}{ Process Gas Outlet Temperature } \\
\hline & & $1200^{\circ} \mathrm{F}$ & $1400^{\circ} \mathrm{F}$ & $1600^{\circ} \mathrm{F}$ & $1800^{\circ} \mathrm{F}$ & $2000^{\circ} \mathrm{F}$ \\
\hline Refueling periods per year & 1 & 1 & 1 & 1 & 1 & 1 \\
\hline $\begin{array}{l}\text { Catalyst change-out, } \\
\text { reformers/yr }\end{array}$ & N.A. & 6 & 3 & 1 & 1 & $1 / 2$ \\
\hline $\begin{array}{l}\text { Refueling outage time, } \\
\text { days }\end{array}$ & 16 & 16 & 16 & 22 & 22 & 22 \\
\hline $\begin{array}{l}\text { Catalyst change-out time } \\
\text { in excess of refueling } \\
\text { time, days }\end{array}$ & N.A. & 1 & -- & -- & -- & -- \\
\hline $\begin{array}{l}\text { Total scheduled outage, } \\
\text { days }\end{array}$ & 16 & 17 & 16 & 22 & 22 & 22 \\
\hline Plant availability, \% & 95.6 & 95.3 & 95.6 & 94.0 & 94.0 & 94.0 \\
\hline $\begin{array}{l}\text { Percent of max. load for } \\
\text { availability, days }\end{array}$ & 83.7 & 83.9 & 83.7 & 85.1 & 85.1 & 85.1 \\
\hline Fue1 capacity factor, $\%$ & 80.0 & 80.0 & 80.0 & 80.0 & 80.0 & 80.0 \\
\hline
\end{tabular}


temperature case is provided in Tables 7-3 through 7-5. If more than one reformer is to have catalyst changed, two can be accommodated at once. Initial and final purging and catalyst drying are performed at one time for all the reformers; therefore, the time allotments for these procedures can be excluded from the time sequence calculation for successive pairs.

One refueling period per year is required for all the cases considered. However, the 4-yr fuel cycle changes to a 3-yr cycle for the temperature cases above and including $1600^{\circ} \mathrm{F}$. The change in fuel cycle increases refueling downtime from 16 to 22 days. The same fuel handling machine and equipment as in the present standard steam plant design will be utilized. If axial push-through refueling is considered, it will be necessary to handle the entire core while replacing one-fourth of the core per year. Additional design and investment for new fuel handling equipment will keep the time outage within 16 days for axial push-through refueling.

Catalyst life increases at the higher temperatures, thus reducing catalyst replacement frequency. Lower carbon deposition rates as the temperature rises are the primary factor. Also, a slight decrease in catalyst activity can be tolerated at these elevated temperatures. The use of contract labor for catalyst change-out will allow much of the work to be performed during the refueling period. Catalyst in two reformers can be changed without hindering the refueling operation. Successive reformers will also have the catalyst replaced in pairs.

High-temperature requirements will demand higher-strength alloys for valves, valve parts, instruments, and various piping assemblies. Downtime for unscheduled maintenance due to temperature-related failures should be minimal in all cases. The major equipment components, such as the reformer and steam generator, are assumed designed for a 30-yr 1ifetime.

Tube plugging in either the reformer or steam generator can be accomplished with conventional or re-designed tube-plugging equipment. In the event of a major reformer or steam generator failure requiring replacement, the loop can be isolated and the plant run on only five of 
TABLE 7-3

CATALYST CHANGE-OUT SCHEDULE FOR ONE REFORMER $1200^{\circ} \mathrm{F}$ PROCESS HEAT CASE(a)

12. Breaks, including lunch (steps 2-9) ${ }^{(e)}$

${ }^{(a)}$ Common return tube design: catalyst tube ID $=3.5$ in.; 828 tubes, $26 \mathrm{ft}$ long, per reformer.

(b) Based on $6 \mathrm{~min} /$ tube vacuuming time, removal of vacuum hose at $1 / 2$ $\mathrm{ft} / \mathrm{sec}$, and $30 \mathrm{sec}$ to move to another tube. Four men per reformer.

(c) Total volume is $1520 \mathrm{ft}^{3}$ per reformer with a 2-in. schedule 40 pipe delivering $4.4 \mathrm{ft}^{3} / \mathrm{min}$.

(d) Based on settling velocity of $4.7 \mathrm{ft} / \mathrm{sec}$; automatic equipment can fill 10 tubes in $10 \mathrm{~min}$, with $10 \mathrm{~min}$ allowed for moving to the next section.

(e) Assumes no loss of productivity per shift change, two 30-min breaks, and one 40-min lunch break per shift. 
TABLE 7-4

CATALYST CHANGE-OUT SCHEDULE FOR ONE REFORMER $1400^{\circ} \mathrm{F}$ PROCESS HEAT CASE(a)

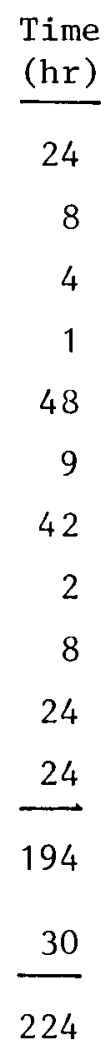

1. Purge reformer during depressurization of PCRV

2. Remove connecting piping from top head of reformer

3. Health physics inspection

4. Lower men with vacuum equipment to internal floor grating

5. Vacuum out catalyst (b)

6. Fill tubes with deionized water ${ }^{(c)}$

7. Float catalyst into tubes $(d)$

8. Remove men and equipment

9. Rep1ace connecting piping (reverse of step 2)

10. Dry catalyst

11. Purge reformer and repressurize (reverse of step 1)

Subtota1

12. Breaks, including lunch (steps 2-9) ${ }^{(e)}$

(a) Integral return tube design: catalyst tube ID $=3.5$ in.; integral return tube $O D=1.375$ in., $I D=1.0$ in.; 828 tubes, $42 \mathrm{ft}$ long, per reformer.

(b) Based on $12 \mathrm{~min} /$ tube vacuuming time, removal of vacuum hose at $1 / 2$ $\mathrm{ft} / \mathrm{sec}$, and $30 \mathrm{sec}$ to move to another tube. Four men per reformer.

(c) Total volume is $2154 \mathrm{ft}^{3}$ per reformer with a 2-in. schedule 40 pipe delivering $4.4 \mathrm{ft}^{3} / \mathrm{min}$.

(d) Based on settling velocity of $4.7 \mathrm{ft} / \mathrm{sec}$; automatic equipment can fill 10 tubes in $20 \mathrm{~min}$, with $10 \mathrm{~min}$ allowed for moving to next section.

(e) Assumes no loss of productivity per shift change, two 30-min breaks, and one 40-min lunch break per shift. 
TABLE 7-5

CATALYST CHANGE-OUT SCHEDULE FOR ONE REFORMER $1600^{\circ} \mathrm{F} / 1800^{\circ}-2000^{\circ} \mathrm{F}$ PROCESS HEAT CASE(a)

\begin{tabular}{lc} 
& $\begin{array}{c}\text { Time } \\
\text { (hr) }\end{array}$ \\
1. Purge reformer during depressurization of PCRV & 24 \\
2. Remove connecting piping from top head of reformer & 8 \\
3. Health physics inspection & 4 \\
4. Lower protective shields to form floor & 4 \\
5. Health physics inspection & 4 \\
6. Lower men with vacuum equipment to top of floor & 1 \\
7. Vacuum out catalyst (b) & $83 / 101$ \\
8. Fill tubes with deionized water (c) & $11 / 10$ \\
9. Float catalyst into tubes (d) & $72 / 88$ \\
0. Remove men and equipment & 2 \\
1. Open shields (reverse of step 3) & 4 \\
2. Replace connecting piping (reverse of step 2) & 8 \\
3. Dry catalyst & 24 \\
4. Purge reformer and repressurize (reverse of step 1) & 24 \\
\hline
\end{tabular}

Subtotal $273 / 306$

15. Breaks, including lunch (steps 2-12) ${ }^{(e)}$

Tota1

(a) Integral return tube design, $1600^{\circ} \mathrm{F}$ case: catalyst tube ID $=3.0$ in.; integral return tube $\mathrm{OD}=0.75 \mathrm{in.}, \mathrm{ID}=0.625 \mathrm{in.;} 1433$ tubes, $42 \mathrm{ft}$ long, per reformer. Integral return tube design, $1800^{\circ}-2000^{\circ} \mathrm{F}$ case: catalyst tube $\mathrm{ID}=2.5$ in.; integral return tube $\mathrm{OD}=0.625 \mathrm{in} ., \mathrm{ID}=0.50 \mathrm{in}$.; 1746 tubes, $42 \mathrm{ft}$ long, per reformer.

(b) Based on $12 \mathrm{~min} /$ tube vacuuming time, removal of vacuum hose at $1 / 2$ $\mathrm{ft} / \mathrm{sec}$, and $30 \mathrm{sec}$ to move to next tube. Four men per reformer.

(c) Total volume is $2898 \mathrm{ft}^{3}\left(1600^{\circ} \mathrm{F}\right.$ case) and $2444 \mathrm{ft}^{3}\left(1800^{\circ}-2000^{\circ} \mathrm{F}\right.$ case) per reformer with a $2-$ in. schedule 40 pipe delivering $4.4 \mathrm{ft}^{3} / \mathrm{min}$.

(d) Based on settling velocity of $4.7 \mathrm{ft} / \mathrm{sec}$; automatic equipment can fill 10 tubes in $20 \mathrm{~min}$, with 10 min allowed for moving to next section.

(e) Assumes no loss of productivity per shift change, two 30-min breaks, and one 40-min lunch break per shift. 
the six loops at a slightly reduced capacity until a spare can be shipped to the facility. At temperatures of $1600^{\circ} \mathrm{F}$ and above, the reformer tubes will be made of a high-density ceramic. Further research and development in the field of ceramics is indicated. A shorter life for the ceramictubed reformer would necessitate complete removal of the reformer and replacement with a spare. This operation requires approximately $95 \mathrm{hr}$. Retubing of the pulled reformer would ready it for use as the next replacement. A central service facility would need to be provided by the reformer manufacturer to accomplish the retubing. This would necessitate a shipping cask for the reformer which can easily be handled in the Reactor Service Building.

Based on the total days of scheduled outage as outlined in Table 7-2, 90\% availability is expected at a11 temperatures. Unplanned maintenance of secondary equipment such as turbines and their auxiliaries should not reduce availability below 90\%. Associated turbine equipment will be 1 ess involved for the process heat plant than for the standard steam plant because of elimination of steam reheat. As a result, the number of forced outages usually attributable to turbine-related equipment will be reduced.

Intermediate storage tanks for the process feed gas and product gas are assumed. This provides the greatest flexibility between the nuclear and non-nuclear portions of the plant and is one of the items in determining the plant capacity factor. Process feed and product gas tanks allow the nuclear plant to operate when the non-nuclear portion is down for periodic maintenance. Cyclic variations in load should be negligible for the nuclear plant except during startup and shutdown procedures. Feed quality will be nearly constant over any given period because of complete mixing in the feed gas tank. The plant capacity factor for the nuclear process plant will be equal to that for an electric-generating plant which is currently limited by fuel life. For the standard steam plant, 3000-MW(t) HTGR, full power years on a 4 -yr fuel cycle are 3.2 or $80 \%$ capacity. The reduction in fuel cycle from 4 to $3 \mathrm{yr}$ reduces full-power years to 2.4 while still maintaining $80 \%$ capacity. 
The nuclear process heat plant has an added advantage over the steam plant in maintaining and possibly surpassing the $80 \%$ capacity factor. A process heat plant is subject to very little load variation compared with the steam plant, which must reflect power grid changes. Further development in fuel technology that would improve full-power years above the $80 \%$ capacity warranted today will push the plant capacity factor for the process heat plant closer toward the upper limit of $90 \%$ (based on plant availability).

\section{Reference}

7-1. "Evaluation of Nuclear Power Plant Availability," USAEC Office of Operations Evaluation Report OOE-ES-001, January 1974. 


\section{ECONOMICS FOR NUCLEAR PROCESS HEAT PLANT}

\subsection{CAPITAL COSTS}

Differential prices for a 3000-MW( $t$ ) nuclear process heat reactor have been developed and are presented in Table 8-1. The alternate public bid to the Los Angeles Department of Water and Power for a nuclear steam supply represents the base point from which all differential prices have been developed. These differentials, when added to the bid price of $\$ 178,503,300$ (escalated to Ju1y 1974), thus represent a preliminary estimate of the price which General Atomic Company might offer in a commercial bid on a nuclear process heat HTGR with terms and conditions generally similar to the Los Angeles Department of Water and Power offering.

The Los Angeles Department of Water and Power alternate bid was made public in July 1974. The alternate bid price quoted for the scope of supply considered in this report was $\$ 169,358,000$ as of February 1,1974 . In developing the prices given in this report, prices were escalated from February 1, 1974 to July 1, 1974. The differentials presented in Table 8-1 reflect added equipment, size differences, and higher-strength materials employed as temperatures increase. A description of the changes is presented below.

\subsubsection{Capital Cost Changes}

8.1.1.1. Account 221 - Reactor Equipment. Additional cavities for the reformers account for increases in the costs of the liners, penetrations, and closures. Six cavities for the $1200^{\circ}$ and $1400^{\circ} \mathrm{F}$ cases and four cavities for the remaining cases are included. The size of the PCRV increases to accommodate the reformer penetrations. Higher PCRV construction costs are reflected in this account. 
TABLE 8-1

DIFFERENTIAL COSTS FOR NUCLEAR PROCESS HEAT PLANT

(Thousands of Dollars, July 1974)

\begin{tabular}{|c|c|c|c|c|c|c|}
\hline \multirow{2}{*}{\multicolumn{2}{|c|}{ Standard NSS List (a) }} & \multicolumn{5}{|c|}{ NPS } \\
\hline & & $\begin{array}{c}1200^{\circ} \mathrm{F} \\
\text { Case }\end{array}$ & $\begin{array}{c}1400^{\circ} \mathrm{F} \\
\text { Case }\end{array}$ & $\begin{array}{c}1600^{\circ} \mathrm{F} \\
\text { Case }\end{array}$ & $\begin{array}{c}1800^{\circ} \mathrm{F} \\
\text { Case }\end{array}$ & $\begin{array}{c}2000^{\circ} \mathrm{F} \\
\text { Case }\end{array}$ \\
\hline 221 & $\begin{array}{l}\text { PCRV liners, penetrations, and } \\
\text { closures (L,M) } \\
\text { PCRV thermal barrier (E,L,M) } \\
\text { PCRV pressure relief system (E) } \\
\text { Control rod drives and reserve shutdown } \\
\text { assembly and material (E) } \\
\text { Reactor core assembly (E) } \\
\text { PCRV support structure (L,M) } \\
\text { Prestressed concrete reactor } \\
\text { vessel (L,M) } \\
\text { Precast panels (L,M) } \\
\text { Prestressing system (L,M) } \\
\text { Wire-winding machine (lease) (M) }\end{array}$ & & & & & \\
\hline \multirow[t]{2}{*}{222} & $\begin{array}{l}\text { Main Heat Transfer and Transport Systems } \\
\text { Main helium circulator (E) } \\
\text { Steam generator module (E) } \\
\text { Main circulator speed regulating } \\
\text { equipment (E) } \\
\text { Main helium circulator service } \\
\text { system (E) }\end{array}$ & $30,092.8$ & $26,940.1$ & $53,938.7$ & $58,302.1$ & $55,463.4$ \\
\hline & Reformer module $(E)$ & $36,949 \cdot 3$ & $42,423.4$ & $64,047.3$ & $66,627.8$ & $66,627.8$ \\
\hline
\end{tabular}

(a) Reformer module cost differentials are included in account 222 total differential. 
TABLE 8-1 (Continued)

\begin{tabular}{|c|c|c|c|c|c|c|}
\hline \multirow{2}{*}{\multicolumn{2}{|c|}{ Standard NSS List ${ }^{(a)}$}} & \multicolumn{5}{|c|}{ NPS } \\
\hline & & $\begin{array}{c}1200^{\circ} \mathrm{F} \\
\text { Case }\end{array}$ & $\begin{array}{c}1400^{\circ} \mathrm{F} \\
\text { Case }\end{array}$ & $\begin{array}{l}1600^{\circ} \mathrm{F} \\
\text { Case }\end{array}$ & $\begin{array}{c}1800^{\circ} \mathrm{F} \\
\text { Case }\end{array}$ & $\begin{array}{c}2000^{\circ} \mathrm{F} \\
\text { Case }\end{array}$ \\
\hline 223 & $\begin{array}{l}\text { Safeguards Cooling Systems } \\
\text { Aux. helium circulators (E) } \\
\text { Core aux. heat exchanger module (E) } \\
\text { Aux. helium circulator service } \\
\text { system (E) }\end{array}$ & -- & -- & 16.3 & 17.1 & 17.6 \\
\hline 224 & $\begin{array}{l}\text { Radioactive Waste Treatment and Disposal } \\
\text { Rad. gas recovery system (E) } \\
\text { Rad. gas waste system (E) } \\
\text { Rad. liquid waste system (E) } \\
\text { Rad. solid waste system (E) }\end{array}$ & 567.4 & 639.8 & 984.8 & 959.8 & $1,188.8$ \\
\hline 225 & $\begin{array}{l}\text { Nuclear Fuel Handling and Storage } \\
\text { Equipment } \\
\text { Fuel handling tools and equipment (E) } \\
\text { Fuel and reflector storage wells (E) }\end{array}$ & -- & -- & 708.3 & 737.3 & 770.9 \\
\hline 226 & $\frac{\text { Other Reactor Plant Equipment }}{\text { Helium purification system (E) }}$ & $2,699.7$ & $2,699.7$ & $3,702.7$ & $3,853.8$ & $7,763.4$ \\
\hline
\end{tabular}


TABLE 8-1 (Continued)

\begin{tabular}{|c|c|c|c|c|c|c|}
\hline \multirow{2}{*}{\multicolumn{2}{|c|}{ Standard NSS List (a) }} & \multicolumn{5}{|c|}{ NPS } \\
\hline & & $\begin{array}{c}1200^{\circ} \mathrm{F} \\
\text { Case }\end{array}$ & $\begin{array}{c}1400^{\circ} \mathrm{F} \\
\text { Case }\end{array}$ & $\begin{array}{c}1600^{\circ} \mathrm{F} \\
\text { Case }\end{array}$ & $\begin{array}{c}1800^{\circ} \mathrm{F} \\
\text { Case } \\
\end{array}$ & $\begin{array}{c}2000^{\circ} \mathrm{F} \\
\text { Case } \\
\end{array}$ \\
\hline 227 & $\begin{array}{l}\text { Instrumentation and Control } \\
\text { PCRV instr. and electrical equipment (E) } \\
\text { FHM control station (E) } \\
\text { PCRV seal and purge system (E) } \\
\text { Helium purification system instr. } \\
\text { equipment (E) } \\
\text { Nuclear and in-core instr. equipment (E) } \\
\text { Analytical instr. system equipment (E) } \\
\text { Reserve shutdown actuation system equip. } \\
\text { and instr. (E) } \\
\text { Rod control system instr. equipment (E) } \\
\text { Variable orifice control system instr. } \\
\text { equipment (E) } \\
\text { Primary coolant instr. equipment (E) } \\
\text { Main circ. signal control board (E) } \\
\text { PPS instr. equipment (E) } \\
\text { Overall plant control system instr. } \\
\text { equip. (E) } \\
\text { Rad. monitoring system instr. equip. (E) } \\
\text { Operational protection system (E) } \\
\text { DAP - dual computer - NSS (E) }\end{array}$ & 79.2 & 79.2 & 72.7 & 75.5 & 78.9 \\
\hline
\end{tabular}


TABLE 8-1 (Continued)

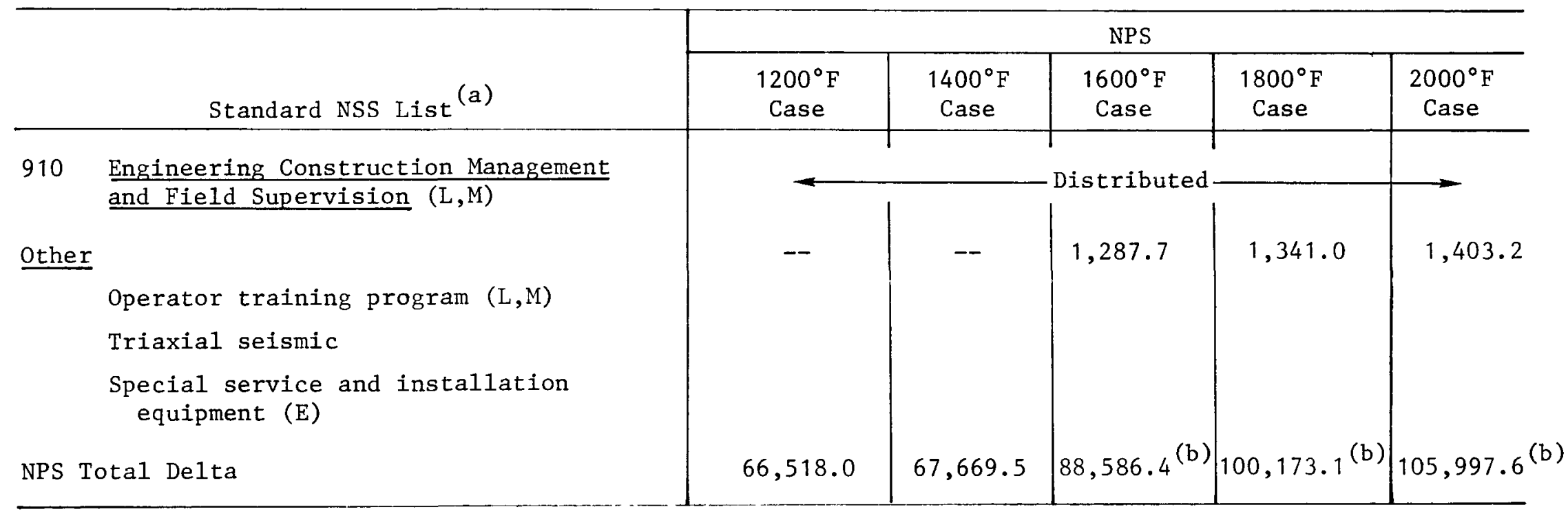

(a) $E$ = equipment

$\mathrm{L}=1 \mathrm{abor}$

$\mathrm{M}=$ materials

(b)

$1800^{\circ} \mathrm{F}$; and $\$ 35,000,000$ at $2000^{\circ} \mathrm{F}$. 
Thermal barrier costs increase with rising temperature because of the greater number of hot regions in the primary coolant circuit, which necessitates upgrading of the thermal barrier. For the $1200^{\circ} \mathrm{F}$ case, the insulation materials are the same as for the standard steam plant. For the $1400^{\circ}$ and $1600^{\circ} \mathrm{F}$ cases, Mo-TZM is used for the cover plates, and hightemperature ceramics are used for the $1800^{\circ}$ and $2000^{\circ} \mathrm{F}$ cases. Installation costs for the thermal barrier are included.

Core inlet temperatures rise proportionately with increasing helium outlet temperatures. At temperatures in excess of $900^{\circ} \mathrm{F}$, the PCRV pressure relief system will be made of austenitic stainless steel. This change in temperature takes place at the $1600^{\circ} \mathrm{F}$ case.

An iron-based alloy cladding is now employed on the control rods. With higher fuel temperatures starting at the $1600^{\circ} \mathrm{F}$ case, high-temperature metal claddings will be used.

High-temperature design of the reactor core assembly requires increased metal thicknesses for the plenum elements.

8.1.1.2. Account 222 - Main Heat Transfer and Transport System. Highpressure steam turbine drives and increased horsepower requirements account for cost increases for the main helium circulators. For cases above and including $1600^{\circ} \mathrm{F}$, the shutoff valve assembly will be made from austenitic stainless steel.

Reheat in the steam generator is eliminated for the process heat cases, while increasing helium temperatures require the use of more hightemperature metals. The overall cost of the steam generators decreases for all cases considered.

The admission and bypass valves to the main helium circulator decrease in size because of the lower flow rates in the process heat cases. Steam pressure increases to approximately 2400 psia account for higher costs attributable to more complicated hydraulic controls. 
An increase in the cost of the main helium circulator service system is expected owing to the higher cooling duties required with rising temperatures.

The cost of the reformers has been estimated for the materials proposed and discussed in Section 5.2 of this report. A cost of $\$ 15 / 1 b$ was used for the ceramic materials utilized at $1600^{\circ} \mathrm{F}$ and above.

8.1.1.3. Account 223 - Safeguards Cooling System. The shut-off valves in the auxiliary cooling loops change to austenitic stainless steel at the $1600^{\circ} \mathrm{F}$ case and above. No other changes for the auxiliary helium circulators, heat exchangers, or service system are expected to result from the higher temperatures.

8.1.1.4. Account 224 - Radioactive Waste Treatment and Disposal. In the event of a reformer tube leak, the gaseous contents of the reformer and outlet gas line will be blown down to the radioactive gas and liquid waste system via a dump tank. After a decay and cooling period of approximately $55 \mathrm{hr}$, the dump tank will be vented to the gas waste system and the condensed water drained to the liquid waste system. Additional storage tank capacity is provided.

The contaminated catalyst will be vacuumed out and pneumatically conveyed to a holding silo for decay and subsequent disposal as a low-level radioactive waste.

Gas recovery system equipment is increased to provide hydrocarbon oxidation equipment upstream of the absorber trains.

8.1.1.5. Account 225 - Nuclear Fuel Handling and Storage Equipment. The fuel cycle is changed from 4 to $3 \mathrm{yr}$ in the $1600^{\circ} \mathrm{F}$ case and above. Additional storage wells for fuel and reflector blocks are needed in the fuel storage monolith located in the Reactor Service Building. 
8.1.1.6. Account 226 - Other Reactor Plant Equipment. The helium purification system is expanded because of the increase in flow for the process heat cases, as discussed in Section 9.

8.1.1.7. Account 227 - Instrumentation and Contro1. The instrumentation and electrical equipment for the monitoring of the prestressing tendons increases proportionately with the size of the PCRV. Temperature elements for the helium and process gas side of the reformer are added. Also, the DAP is modified to include the control loops for the reformers.

8.1.1.8. Account 910 - Engineering Construction Management and Field Supervision for the NSS/NPS. Costs for this account are distributed throughout the various items of the nuclear steam supply system and the process heat supply system.

8.1.1.9. Other. After the change to ceramic reformer tubes at the $1600^{\circ} \mathrm{F}$ case, a protective floor must be laid down over the tubesheet before the catalyst can be vacuumed out and replaced. A handling machine capable of fitting over the reformer penetrations and lowering the shielding floor is provided.

\subsubsection{Capital Cost Scaling Factors}

Figure 8-1 shows the scaling factors versus reactor thermal power curve to be used in determining the ratio of NPS capital costs to various plant sizes.

\subsubsection{Payment Schedule for Nuclear Process Heat Supply System}

Figure 8-2 shows the payment schedule to the vendor for the nuclear process system as a percent of total cost versus time in months. This curve is based on the Los Angeles Department of Water and Power (LADWP) bid. A similar curve is anticipated for the nuclear process heat supply system. 


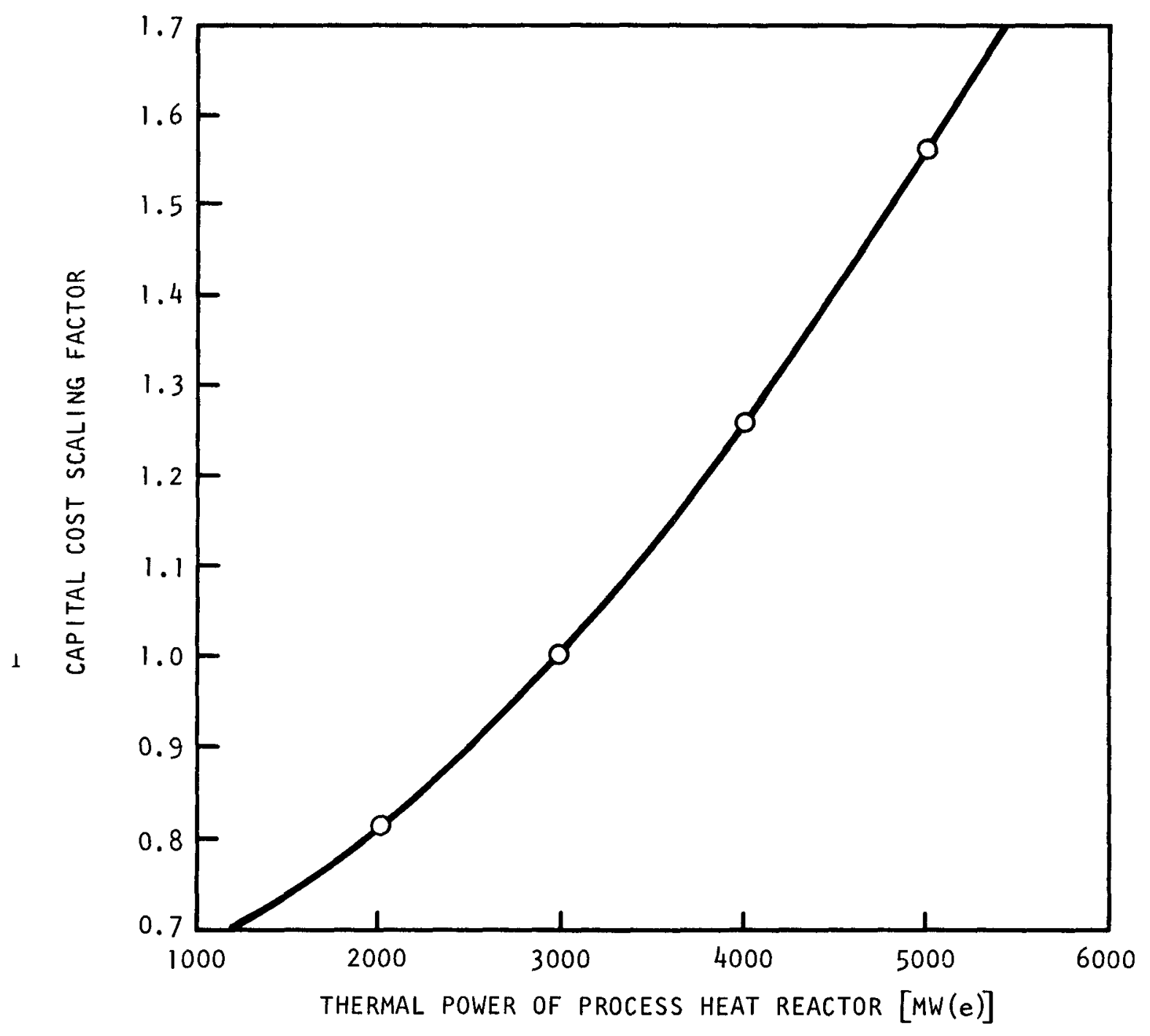

Fig. 8-1. Capital cost scaling factor versus process heat reactor thermal power 


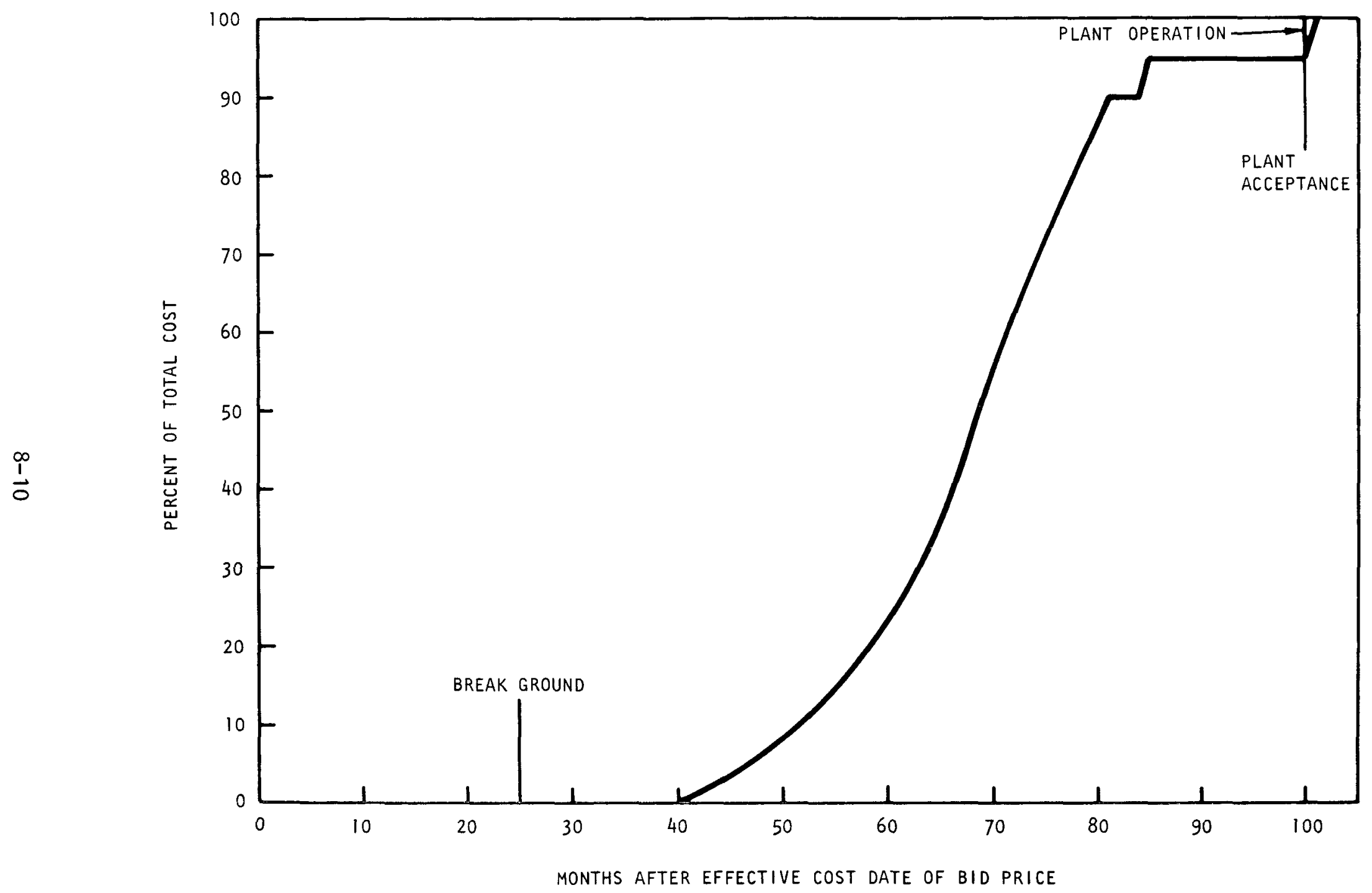

Fig. 8-2. Payment schedule (cash flow to vendor) for nuclear process system 
The initial time period is the effective date of the bid price established by the customer. Plant acceptance and payment of the final $5 \%$ within 30 days of acceptance are the final time period. Actual plant construction is shown commencing 24 months after the initial time. Operation of the plant is shown occurring simultaneously with plant acceptance.

\subsection{FUEL CYCLE COSTS}

Table 8-2 presents the ground rules for the calculation of fuel cycle costs. General Atomic Company fuel prices from the Los Angeles Department of Water and Power public bid are followed by an asterisk; all other prices are based on the AEC guidelines provided under program letters.

Table 8-3 presents the fuel cycle costs for the $1200^{\circ}, 1400^{\circ}$, and $1600^{\circ} \mathrm{F}$ and above cases without recycle.

\subsection{OPERATION AND MAINTENANCE COSTS FOR NUCLEAR PROCESS HEAT PLANT}

Primary factors affecting the increase in operation and maintenance costs for the process heat plant are increased staffing requirements due to increased maintenance-related items, costs associated with catalyst replacement, and higher costs attributable to the change from a 4- to 3-yr fuel cycle. The estimated operation and maintenance costs for the standard steam plant and the nuclear process heat plants are listed in Table 8-4. Process gas outlet temperatures indicate the various process heat cases.

\subsubsection{Station Staffing}

Staffing requirements for the nuclear process heat plant increase with temperature according to Table $7-1$. An average salary of $\$ 19,300$ was used as provided in the guidelines established by the AEC for this study. Fringe benefits and supervision allowance at rates of $30 \%$ and $10 \%$, respectively, are included. 
TABLE 8-2 GROUND RULES FOR EQUILIBRIUM FUEL CYCLE COSTS ${ }^{(a)}$

\begin{tabular}{|c|c|c|c|}
\hline & & Fue1 Type & \\
\hline & $\begin{array}{c}\text { 4-Yr Non-Recycle } \\
8.4 \mathrm{~W} / \mathrm{cm}^{3} \\
\text { TRISO/BISO }\end{array}$ & $\begin{array}{c}\text { 3-Yr Non-Recycle } \\
8.4 \mathrm{~W} / \mathrm{cm}^{3} \\
\text { TRISO/TRISO }\end{array}$ & $\begin{array}{c}4-Y r \text { Recycle } \\
8.4 \mathrm{~W} / \mathrm{cm}^{3} \\
\text { TRISO/BISO }\end{array}$ \\
\hline Fresh Fab. & & & \\
\hline$\$ /$ element ${ }^{*}$ & 2974 & 2974 & 2974 \\
\hline$\$ / \mathrm{kg}^{*}$ & 319 & 269 & 303 \\
\hline Refab. & & & \\
\hline \$/element ${ }^{*}$ & -- & -- & 3620 \\
\hline$\$ / \mathrm{kg}^{*}$ & -- & -- & 383 \\
\hline Reprocessing (AEC), $\$ / \mathrm{kg}$ & 120 & 120 & 120 \\
\hline Spent Fuel Shipping (AEC), $\$ / \mathrm{kg}$ & 50 & 50 & 50 \\
\hline Fresh Fuel Shipping (AEC), $\$ / k g$ & 25 & 25 & 25 \\
\hline Fresh fab., kg/element & 9.321 & 11.06 & 9.828 \\
\hline Refab. & & & \\
\hline $\mathrm{kg} / \mathrm{U}-233$ element & -- & -- & 9.464 \\
\hline $\mathrm{kg} / \mathrm{U}-235$ element & -- & -- & 8.003 \\
\hline Reproc., kg/element & 8.367 & 10.433 & 8.411 \\
\hline Equil., No. elements/yr & 986 & 1315 & 986 \\
\hline Fresh fab. & 986 & 1315 & 385 \\
\hline Refab. U-233 & 0 & 0 & 571 \\
\hline Refab. U-235 & 0 & 0 & $30^{(b)}$ \\
\hline
\end{tabular}


TABLE 8-2 (Continued)

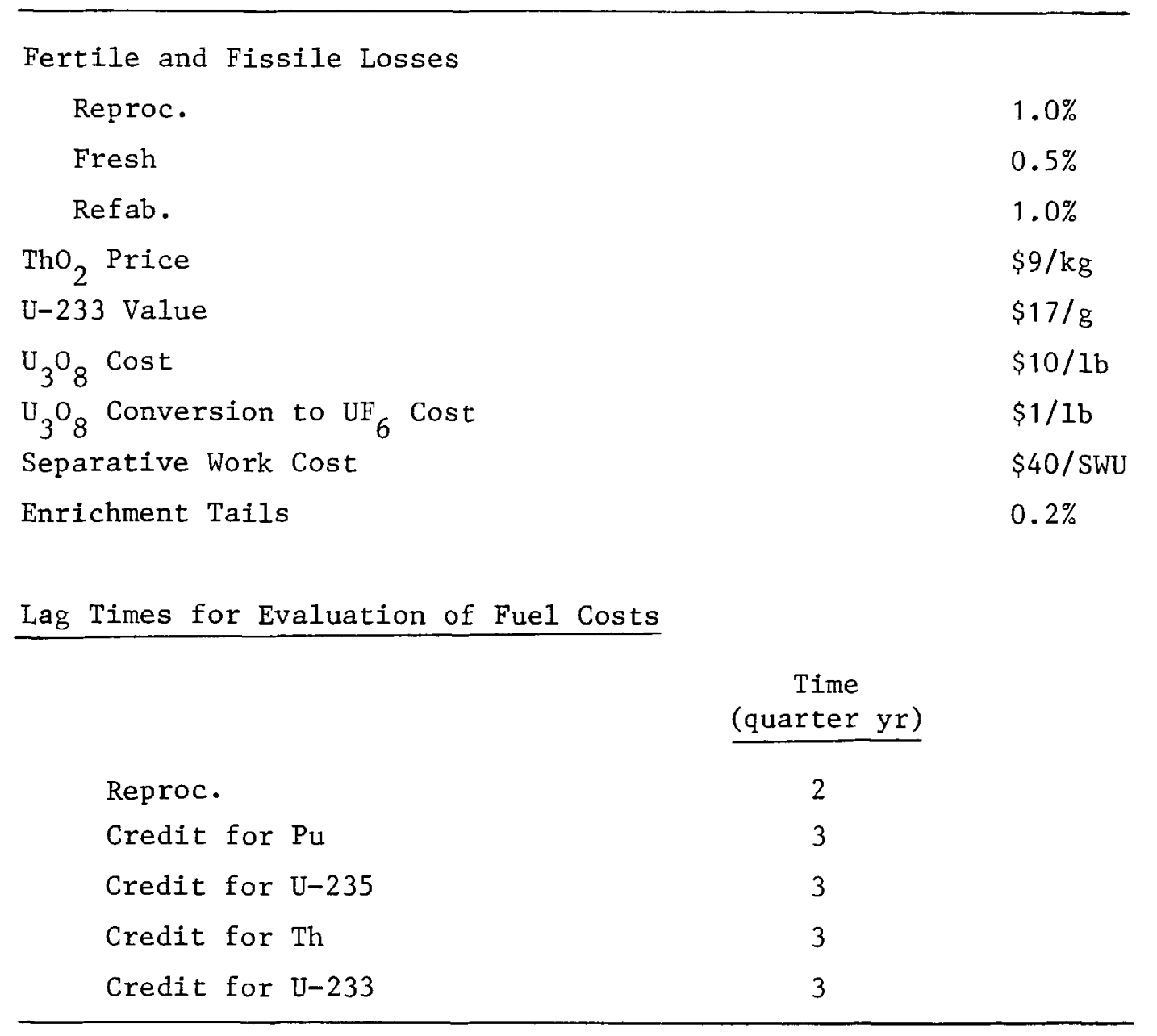

* Based on Los Angeles Department of Water and Power public bid.

(a) Assumptions: July 1974 dollars; no escalation; fixed charge on working capital and fuel inventory of $10 \% ; 80 \%$ plant factor.

(b) Recycle U-235 retired after second cycle. 
TABLE 8-3

FUEL CYCLE COST BASED ON AEC GUIDELINE AND LADWP PUBLIC BID DATA

\begin{tabular}{|c|c|c|c|}
\hline Process Temp. & $1200^{\circ} \mathrm{F}^{(\mathrm{a})}$ & $1400^{\circ} \mathrm{F}$ & $\begin{array}{l}1600^{\circ} \mathrm{F} \\
\text { and Above }\end{array}$ \\
\hline Cycle Description & $\begin{array}{c}\text { 4-Yr Annual } \\
\text { Cycle, No Recycle, } \\
\text { 2-Particle }\end{array}$ & $\begin{array}{c}\text { 4-Yr Annual Cycle, } \\
\text { No Recycle, } \\
\text { 2-Particle }\end{array}$ & $\begin{array}{c}\text { 3-Yr Annual } \\
\text { Cycle, No Recycle, } \\
\text { 2-Particle(b) }\end{array}$ \\
\hline Running Cost, $c / 10^{6} \mathrm{Btu}$ & & & \\
\hline Fabrication & 4.50 & 4.84 & 6.11 \\
\hline Depletion & 9.20 & 9.20 & 8.96 \\
\hline Shipping & 0.71 & 0.71 & 0.91 \\
\hline Reprocessing & 1.72 & 1.72 & 2.18 \\
\hline Subtotal R.C. & 16.13 & 16.47 & 18.16 \\
\hline Working Capital, $c / 10^{6} \mathrm{Btu}$ & & & \\
\hline Fabrication & 0.82 & 0.93 & 0.95 \\
\hline Depletion & 4.27 & 4.27 & 7.36 \\
\hline Shipping & -0.15 & -0.15 & -0.16 \\
\hline Reprocessing & -0.37 & -0.37 & -0.41 \\
\hline Subtotal W.C. & 4.57 & 4.68 & 7.74 \\
\hline Fuel Cycle Cost, $c / 10^{6}$ Btu & 20.70 & 21.15 & 25.90 \\
\hline
\end{tabular}

(a) 8-row fuel block; all others use 10-row fuel block.

(b) SiC coating for thorium. Cycle costs are assumed to be the same at higher temperatures. 
TABLE 8-4

ANNUAI, OPERATTON AND MALNTENANCE COSTS

(Thousands of Dollars)

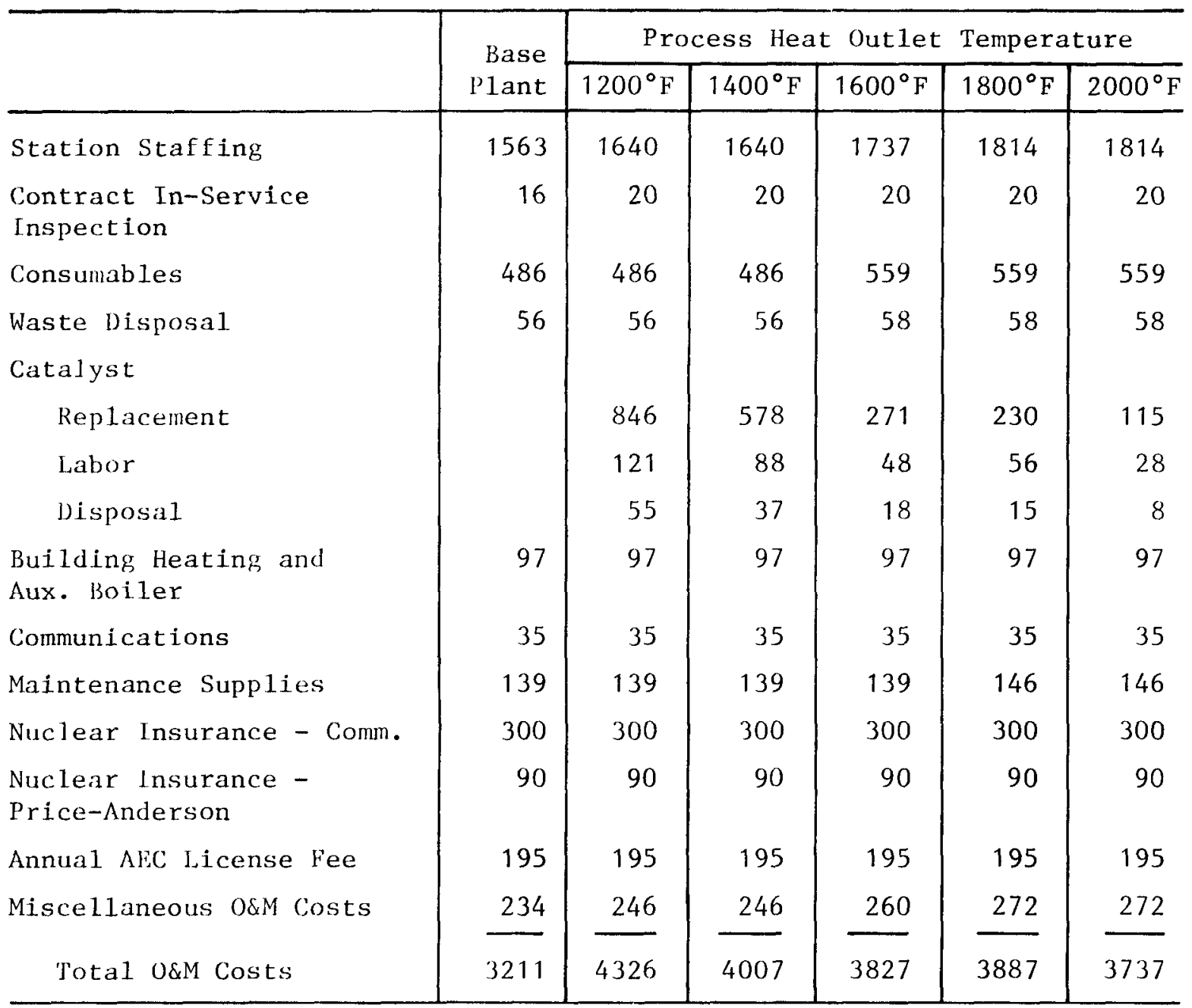




\subsubsection{Contract In-Service Inspection}

The present ASME Code is being modified for in-service inspection requirements of the HTGR. The HTGR is inherently adaptable to inspection techniques that can be carried out during operation. The structural members of the PCRV, tendons and wire-winding, are readily accessible for inspection and are monitored during operation. Inspection of the penetrations, closures, etc. can be carried out concurrently with refueling because of the shielding provided by the PCRV. Hence, no additional downtime is required for in-service inspection of an HTGR. A1so, dose rates are low enough to allow ample time for inspection without personne1 receiving maximum allowable doses during the course of the work.

Approximately 300 man-hr per year are required by the standard steam plant for in-service inspection. If a productivity factor of $70 \%$ is used, 11 man-weeks are required for the work. Allowing 10 weeks for travel and preparation brings the total to 21 man-weeks charged to the plant. The annual cost per man is $\$ 40,000$, including fringe benefits, overhead, and amortization of equipment. The total cost of in-service inspection for the standard steam plant is then $21 \times \$ 40,000 \div 52=\$ 16,000$. For the nuclear process heat plant, an estimate of 150 additional man-hours has been made for inspection of the reformers and reformer penetrations and closures. Using the same productivity factor, labor rate, and travel and preparation time, the annual cost of in-service inspection for the process heat plant is $\$ 20,000$.

\subsubsection{Consumables}

The standard steam plant HTGR requires replacement of items such as control rods, physics instrumentation, and in-core instrumentation periodically during the life of the plant. Other consumables are required to maintain primary coolant purity and inventory. The HTGR also requires replacement of some reflector blocks during refueling. The total cost of annual consumables for the standard steam plant is $\$ 486,000$. For the nuclear process heat plant, the consumables remain fairly constant and 
equal to those for the steam plant up to the $1600^{\circ} \mathrm{F}$ process outlet gas case. At this temperature, the fuel cycle changes from 4 to $3 \mathrm{yr}$. Increased consumable costs attributable to reflector blocks, in-core flux mapping sensors, in-core thermocouples, and refueling penetration seals account for the increase in cost to $\$ 559,000$ per year.

\subsubsection{Waste Disposal}

Recent decisions by the AEC make the installation of systems to limit power reactor radioactive emissions to as low as practical virtually mandatory. These systems are required to augment standard waste disposal systems incorporated in basic plant designs. Limitation of releases is accomplished relatively easily in the HTGR by the radioactive gas recovery system, which is included as part of the NSS. Gaseous wastes consist mainly of inert gases produced a few times a year as a result of the regeneration of the helium purification system and refueling purge operations. The system used to handle these wastes consists primarily of compressors and tanks required for storage of the gas for decay prior to release.

No high-level liquid wastes are produced by the HTGR. Hence, the liquid waste system consists primarily of holdup tanks and a monitor tank.

A solid waste system does not exist as such for the HTGR. Solid wastes are replaced graphite reflector blocks, spent control rods, in-core instruments, miscellaneous solid wastes such as clothing, and absorbers and charcoal required for operation in the minimum release mode.

The total cost for waste disposal in a standard steam plant is $\$ 56,000$ per year. For the process heat plant, this is the cost for waste disposal in the first two temperature cases. At $1600^{\circ} \mathrm{F}$, the fuel cycle changes to $3 \mathrm{yr}$, thus increasing solid wastes such as reflector blocks, control rods, etc. An additional $169 \mathrm{ft}^{3}$ of solid waste must be disposed of at an annual cost of $\$ 2,440$. 


\subsubsection{Catalyst}

Catalyst life increases at higher temperatures because of lower carbon deposition rates. The catalyst change-out schedule is as follows:

$\begin{array}{llllll}\begin{array}{l}\text { Process gas outlet } \\ \text { temperature, }{ }^{\circ} \mathrm{F}\end{array} & 1200 & 1400 & 1600 & 1800 & 2000 \\ \begin{array}{l}\text { Catalyst replacement frequency, } \\ \text { reformers/yr }\end{array} & 6 & 3 & 1 & 1 & 1 / 2 \\ \begin{array}{l}\text { Number of catalyst tubes per } \\ \text { reformer }\end{array} & 828 & 828 & 1433 & 1746 & 1746 \\ \begin{array}{l}\text { Catalyst volume per reformer, } \\ \text { ft }{ }^{3}\end{array} & 1438 & 1965 & 2770 & 2344 & 2344 \\ & & & & & \\ \text { Labor hours per reformer } & 105 & 152 & 250 & 291 & 291\end{array}$

Replacement cost is $\$ 98 / \mathrm{ft}^{3}$. Contract labor is utilized at an annual charge of $\$ 40,000$ per man, including fringe benefits, overhead, and amortization of equipment. Ten men per reformer are required. Disposal of the catalyst as a low-level radioactive waste has been assumed at a rate of $\$ 6.35 / \mathrm{ft}^{3}$, which includes shipping charges and drum and liner costs. Contamination of the catalyst is possible if a tube fails. If no such contamination has occurred during the lifetime of the catalyst, the manufacturer may agree to buy it back for regeneration and resale. For the purposes of this study, however, it has been treated as a low-level radioactive waste.

\subsubsection{Building Heating and Auxiliary Boiler and Communications}

Building heating and auxiliary boiler requirements for the standard steam plant are $\$ 97,000$ per year. No change is expected for the nuclear process heat plant. 
Communication requirements such as in-plant telephones, two-way radio communicators, etc., cost $\$ 35,000$ per year for the steam plant. The nuclear process heat plant requirements for communication devices should not exceed this annual charge.

\subsubsection{Maintenance Supplies}

The cost of maintenance materials for a standard steam plant is $\$ 139,000$ per year. Smaller and conventional turbine plant equipment, increased accessibility to components, and a non-corrosive coolant are factors which facilitate and reduce normal maintenance operations and periodic overhauls. Because the HTGR operates with modern high-temperature, high-pressure steam conditions, balance of plant equipment is similar to that found in a fossil fuel plant. Years of operating experience have already been accumulated on this equipment, thus facilitating operator training. Also, the use of inert non-corrosive helium gas as the coolant reduces maintenance and repair costs normally associated with chemical attack and corrosion.

For the process heat plant, no attempt has been made to reduce the amount allotted for maintenance supplies because of the uncertainty of the steam utilization equipment. The cost is constant until after the $1600^{\circ} \mathrm{F}$ case. After this temperature, some of the high-temperature equipment, such as the PCRV pressure relief valve, will be made of a stabilized austenitic stainless steel. A $5 \%$ increase in costs for maintenance supplies associated with high-temperature material parts is provided.

\subsubsection{Nuclear Insurance and Annual License Fee}

The cost of nuclear liability insurance varies greatly with location and reactor thermal power. For a low-population-density site such as the Middletown, U.S.A. site proposed for this study, the annual cost of the commercial portion of this insurance is approximately $\$ 300,000$ per year. This figure is based on a reactor thermal power of $3000 \mathrm{MW}(t)$. The annual 
premium for the government portion of this insurance is $\$ 30$ per thermal megawatt, or $\$ 90,000$.

The annual AEC licensing fee is also calculated on the basis of reactor thermal power. According to the revised 10 CFR 170, the annual rate is $\$ 65 / \mathrm{MW}(t)$, or $\$ 195,000$ for a $3000-M W(t)$ plant. The annual insurance premium and license fee are not expected to change for the nuclear process heat plant.

\subsubsection{Miscellaneous Operating and Maintenance}

An annual allowance of $15 \%$ of the cost of plant staffing is provided for miscellaneous costs. These include such items as travelling expenses, license and fees for various technical organizations, public relations, office supplies, postage, and plant laundry. No increase is expected for the nuclear process heat plant.

\subsubsection{Scaling Factors}

Figure 8-3 shows the scaling factor versus reactor thermal power curve to be used in determining the ratio of NPS operating and maintenance costs to various plant sizes. 


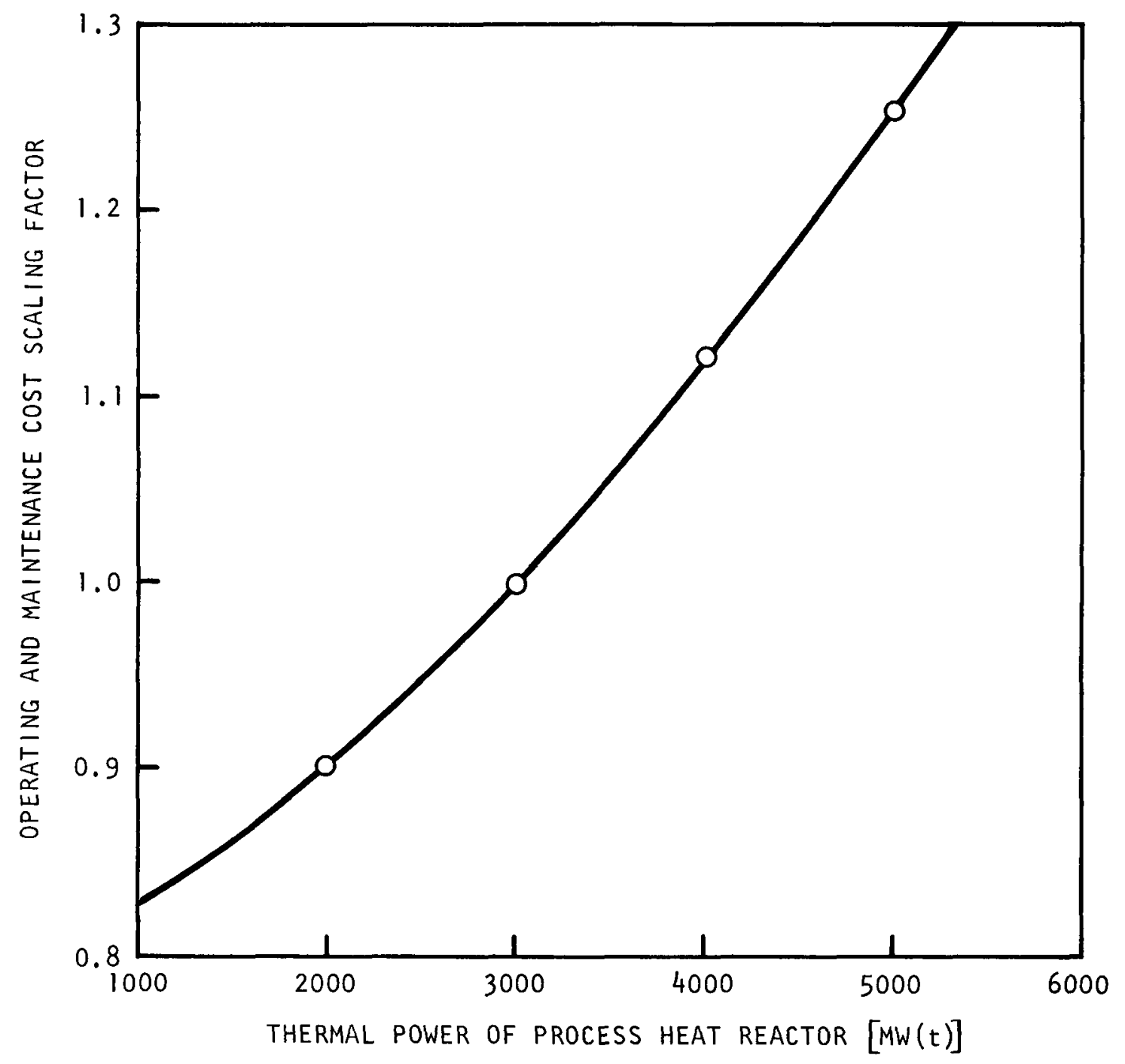

Fig. 8-3. Operating and maintenance cost scaling factor versus process heat reactor thermal power 
-

0

0 


\section{SAFETY CONSIDERATIONS}

\subsection{DESIGN BASIS DEPRESSURIZATION ACCIDENT}

The catastrophic failure of the primary coolant boundary is considered incredible, since neither the PCRV penetration closures nor the PCRV itself is susceptible to catastrophic failure. However, the design basis depressurization accident (DBDA) is assumed to be the depressurization of the primary coolant system through a 100 -in. ${ }^{2}$ flow area at any of the possible locations. An investigation of the consequences of depressurization at various locations for the steam-generating HTGR indicates that failure at the hot portion of the cycle results in the highest containment pressures, containment temperatures, activity release from the PCRV, and hence largest offsite doses. For this reason, the process heat HTGR DBDA was assumed to occur from a break where the reactor outlet gas can be discharged to the containment.

The analysis presented in this section was based on the standard process heat plant with $1600^{\circ} \mathrm{F}$ reactor outlet temperature. Where possible, trends for important parameters are supplied for the higher-temperature plants.

From Fig. 5-1, it can be seen that there is no penetration at the bottom of the reformer cavity; neither are there penetrations in the bottom of the reactor cavity or the bottom of the auxiliary loop cavities. Consequently, there is no potential for a primary coolant boundary failure at the hot end except for gross failure of the PCRV. 


\subsubsection{Sequence of Events}

The sequence of system events following a DBDA are as follows:

1. The containment is isolated following a high activity signal. This activity results from gas-borne activity circulating in the PCRV, and, depending on rupture location, a small fraction of the radioactivity which had previously plated out on internal surfaces may be lifted off and blown into the reactor containment owing to increased shear forces.

2. The reactor trips within $10 \mathrm{sec}$ on low PCRV pressure set at 550 psia. (This low PCRV signal locks out the high containment pressure main loop isolation condition.)

3. Control rods are fully inserted and core power is reduced to decay heat levels within $35 \mathrm{sec}$.

4. The core cooling capability of the main loops is limited by the heat transferred to the steam generators to supply circulator power. If auxiliary boilers are not available, the core auxiliary cooling system is activated to supply core cooling.

\subsubsection{Primary System Depressurization}

The flow rate through the postulated failure is based on the expression for the maximum (critical) adiabatic and isotropic flow of an ideal gas through an orifice:

$$
\dot{\mathrm{m}}=\mathrm{CA} \frac{\mathrm{P}}{\sqrt{\mathrm{T}}} \sqrt{\frac{\mathrm{kg}}{\mathrm{R}}\left(\frac{2}{\mathrm{k}+1}\right)^{\mathrm{k}+1 / \mathrm{k}-1}}
$$




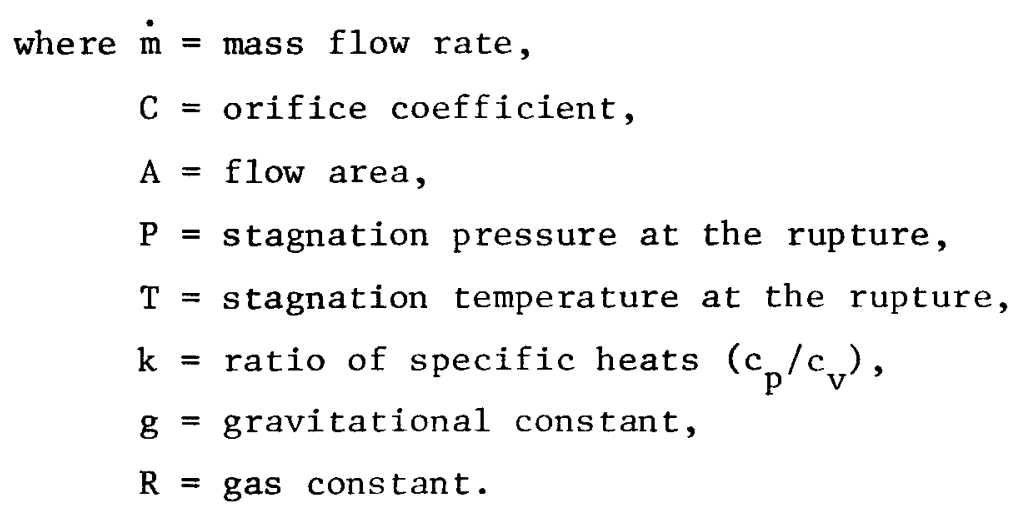

During the DBDA, $\mathrm{P}$ and $\mathrm{T}$ in Eq. 9-1 represent the PCRV pressure and temperature, respectively.

During the DBDA, helium temperatures and pressures throughout the PCRV are continuously changing with time, and therefore the leak rate through the rupture is also a function of time. The CONTEMP-G computer code (Ref. 9-1) is used to analyze both the PCRV and containment response during the blowdown.

Based on the assumed leakage flow area of $100 \mathrm{in.}^{2}$ and an assumed orifice coefficient of 1.0, Eq. 9-1 for helium becomes

$$
\dot{\mathrm{m}}=\frac{21 \mathrm{P}}{\sqrt{\mathrm{T}}},
$$

where $\dot{\mathrm{m}}, \mathrm{P}$, and $\mathrm{T}$ are expressed in $1 \mathrm{~b}_{\mathrm{m}} / \mathrm{sec}$, psia, and ${ }^{\circ} \mathrm{K}$, respectively. For the specified internal conditions, the initial leakage flow rates $\left(\dot{m}_{o}\right)$ for the cold $\left(770^{\circ} \mathrm{F}\right)$ and hot $\left(1600^{\circ} \mathrm{F}\right)$ helium are 434 and $328 \mathrm{lb} / \mathrm{sec}$, respectively.

Equations $9-1$ and $9-2$ are valid as long as the ratio of containment pressure $\left(P_{c}\right.$ to $P$ ) is less than or equal to the critical pressure ratio, $\mathrm{R}_{\mathrm{cr}}$, which is defined as

$$
\mathrm{R}_{\mathrm{cr}}=\left(\frac{2}{\mathrm{k}+1}\right)^{\mathrm{k} / \mathrm{k}-1}
$$

for an ideal gas. By the time the critical pressure is reached, almost $90 \%$ of the helium inventory is released into the containment and the maximum containment temperature and pressure are reached. Therefore, the subcritical flow regime is of little interest. 
Primary system pressure is plotted as a function of time in Fig. 9-1. Flow rates into the containment are shown in Fig. 9-2.

\subsubsection{Containment Pressure and Temperature Reponse}

The CONTEMPT-G computer code was utilized to evaluate the reactor containment response to the DBDA. The CONTEMPT code evaluates the transient heat transfer occurring in the containment subsequent to the depressurization. The primary heat sinks are the PCRV, the containment walls, and miscellaneous equipment located in the containment.

Calculated containment pressures and temperatures are shown in Figs. 9-3 and 9-4, respectively, for a depressurization through a postulated 100-in. ${ }^{2}$ hole in the hot portion of the primary coolant system. The magnitude of the peak temperatures and pressures depends on the net flow of energy into the containment as specified in Fig. 9-5. Long-term equilibrium pressure depends upon the initial PCRV helium inventory, containment free volume, and containment initial temperature. Table 9-1 shows containment variables assumed for the present analysis. Table 9-2 gives the peak containment temperature and pressure as well as the equilibrium containment pressure for the various reactor outlet temperatures investigated.

\subsubsection{Core Cooling Using Auxiliary Cooling Loops}

The expected mode of operation during a DBDA is for continued reactor core cooling using the main loop circulators driven initially by nuclear steam. In an HTGR steam plant, complete flood-out of the steam generators occurs in the first few minutes of the transient. Steam from the flash tanks can be used to drive the circulators for several more minutes. At this point, auxiliary steam is required to continue with main loop cooling. Alternatively, the CACS is initiated to supply core cooling. A similar scenerio is expected for the process heat HTGR. The dynamic response of the main loops has not been analyzed for the process heat HTGR; this section presents the cooling transient assuming complete loss of main loop cooling at the beginning of the DBDA followed by initiation of the CACS after a period of $20 \mathrm{~min}$. 


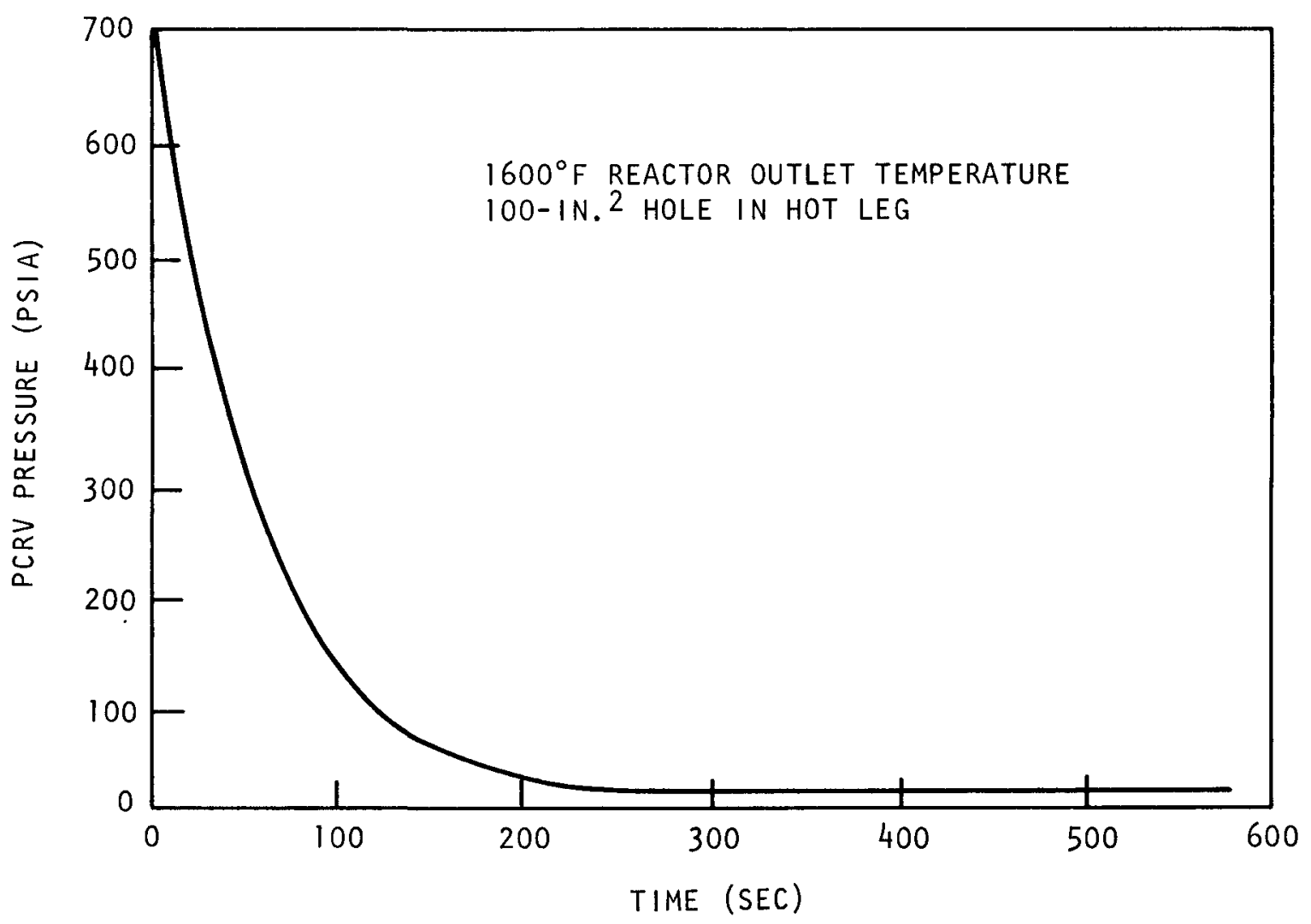

Fig. 9-1. Primary system pressure as a function of time 


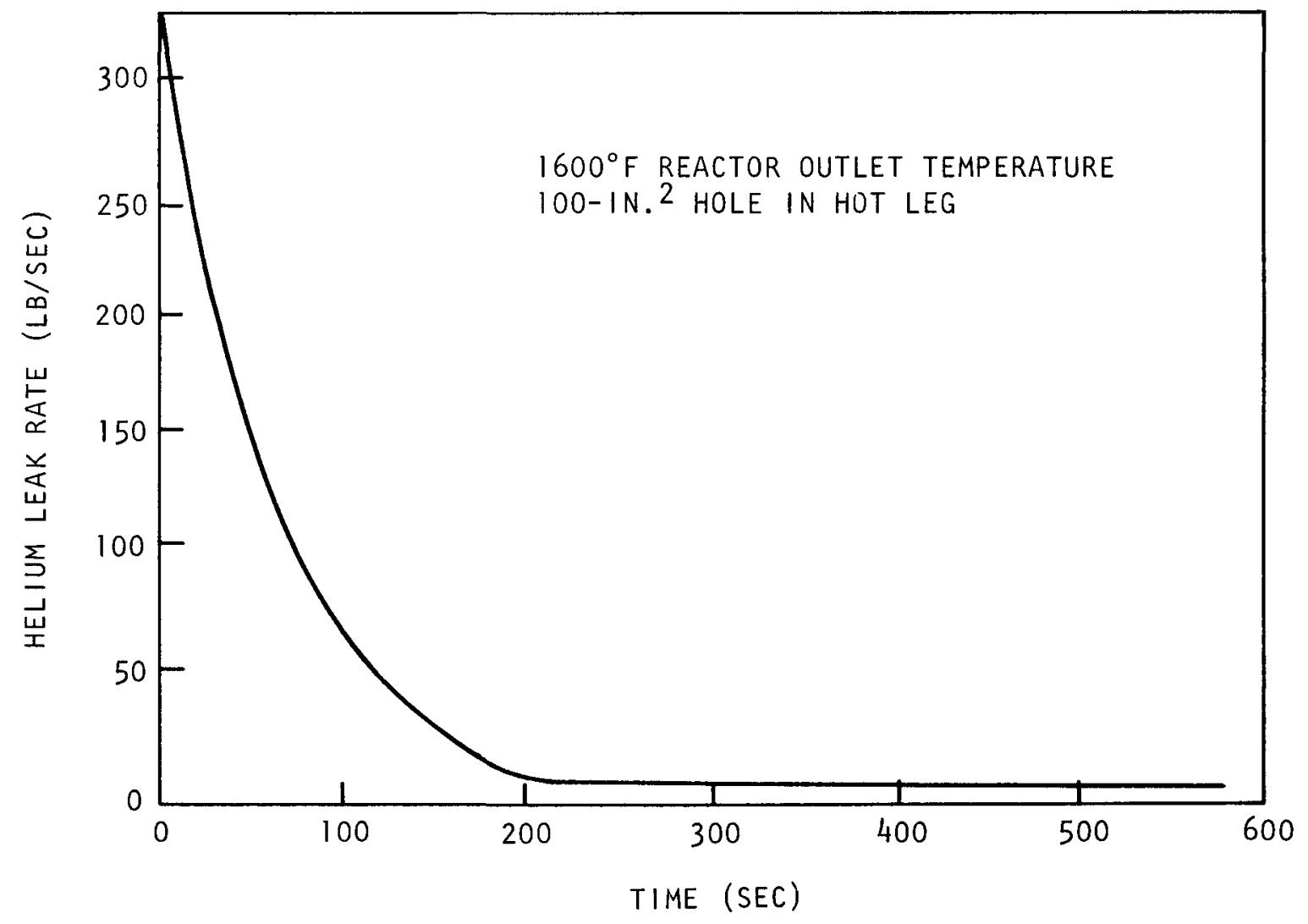

Fig. 9-2. Helium leak rate as a function of time 


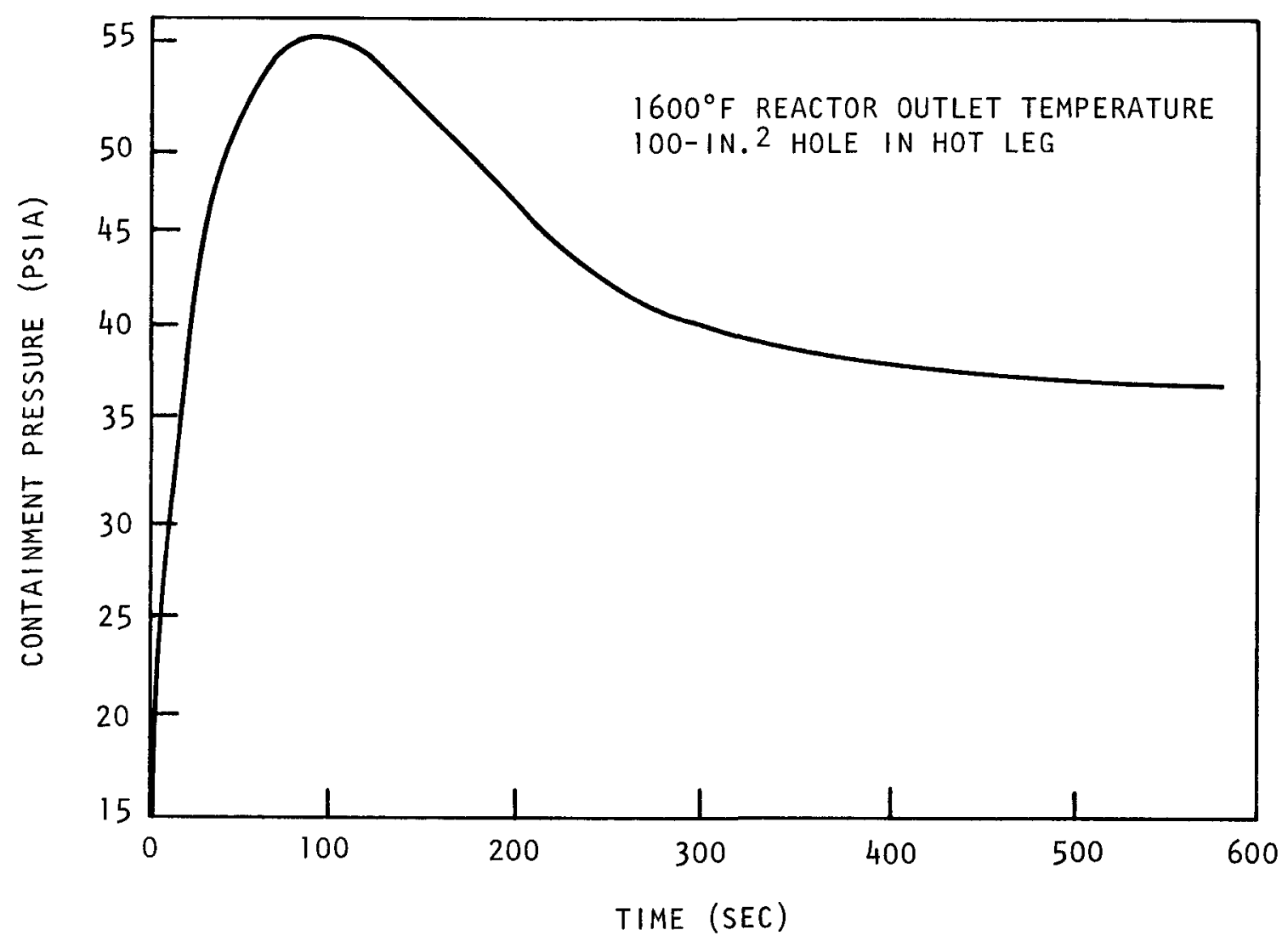

Fig. 9-3. Containment pressure as a function of time 


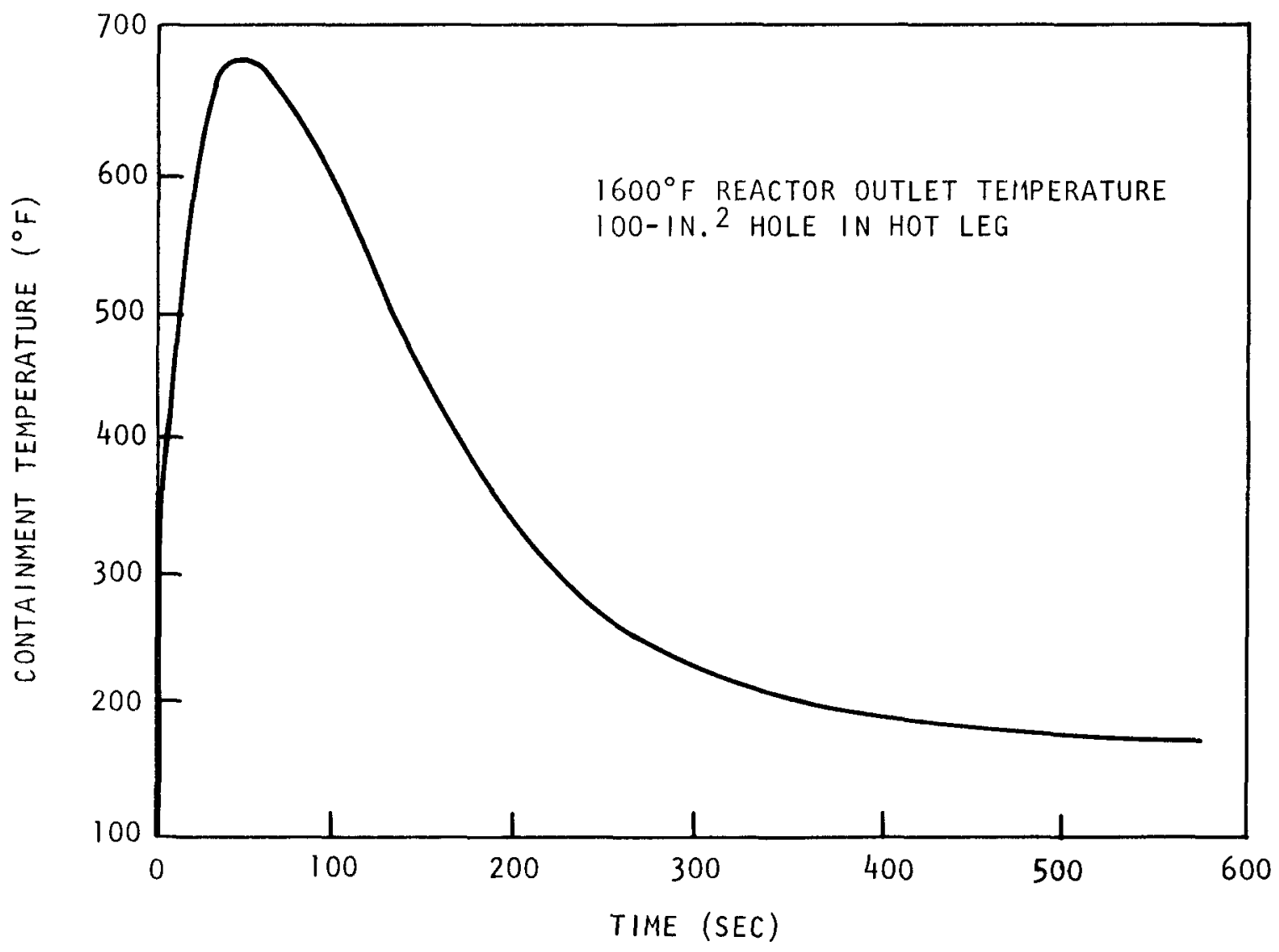

Fig. 9-4. Containment temperature as a function of time 


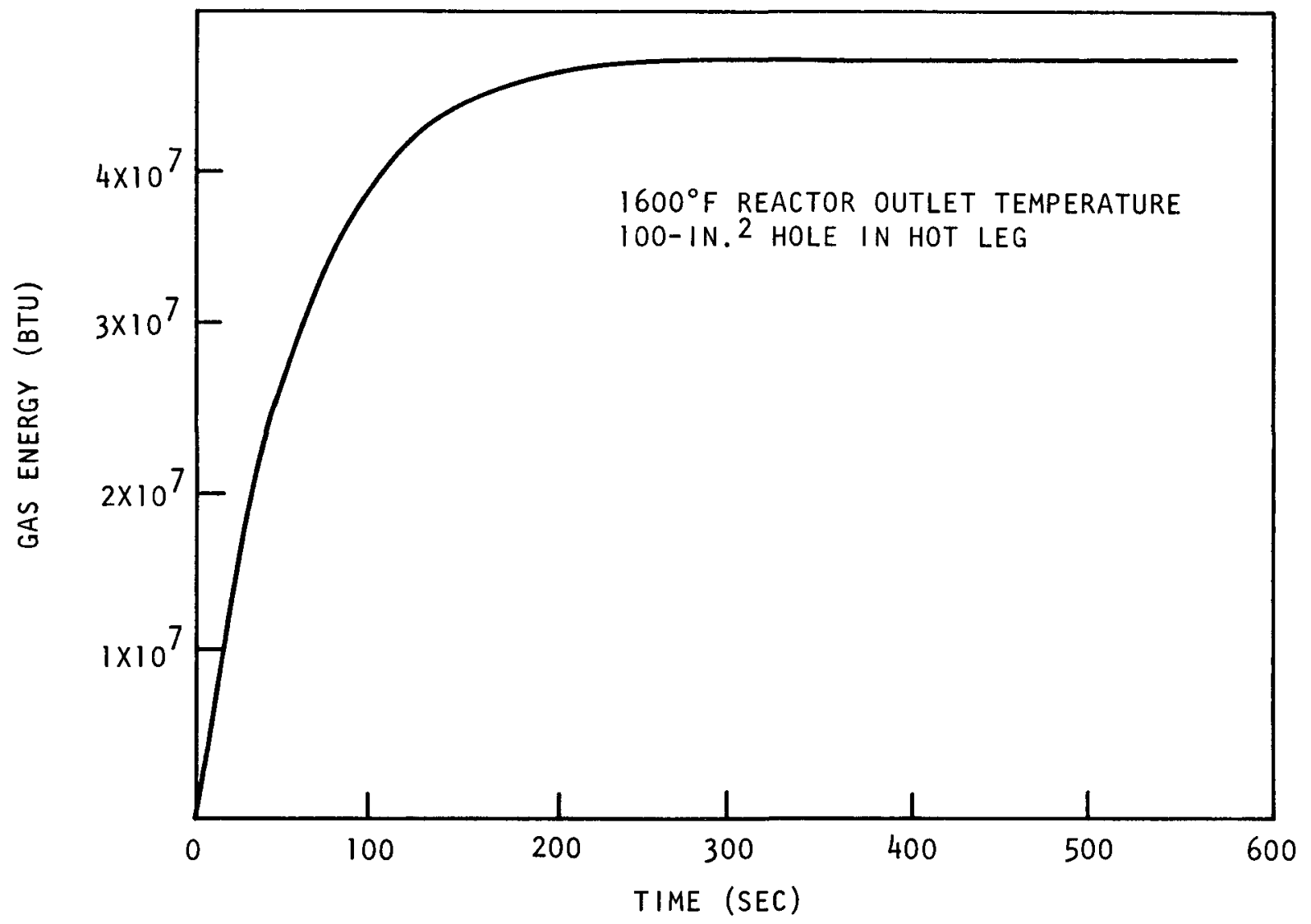

Fig. 9-5. Energy input into containment as a function of time 
TABLE 9-1

INITIAL CONTAINMENT CONDITIONS

\begin{tabular}{lr}
\hline Free volume & $1,763,000 \mathrm{ft}^{3}$ \\
Temperature & $100^{\circ} \mathrm{F}$ \\
Pressure & $14.5 \mathrm{psia}$ \\
Humidity & $50 \%$ \\
\hline
\end{tabular}

TABLE 9-2

CONTAINMENT VARIABLES AS A FUNCTION OF REACTOR OUTLET TEMPERATURE

\begin{tabular}{lrrrrr}
\hline & & & & & \\
$\begin{array}{l}\text { Reactor outlet tempera- } \\
\text { ture, }{ }^{\circ} \mathrm{F}\end{array}$ & 1400 & 1600 & 1800 & 2000 & 2200 \\
$\begin{array}{l}\text { PCRV helium inventory, 1b } \\
\begin{array}{l}\text { Maximum containment } \\
\text { temperature, }{ }^{\circ} \mathrm{F}\end{array}\end{array}$ & 24,044 & 22,540 & 20,460 & 19,064 & 17,686 \\
$\begin{array}{l}\text { Maximum containment } \\
\text { pressure, psia }\end{array}$ & 649 & 693 & 729 & 765 & 797 \\
$\begin{array}{l}\text { Equilibrium containment } \\
\text { pressure, psia }\end{array}$ & 35.8 & 56.0 & 55.3 & 55.2 & 55.0 \\
\hline
\end{tabular}


The CACS utilized for the process heat HTGR is similar to the design developed for the steam-generating HTGR. The CACS consists of multiple parallel loops, each containing an auxiliary heat exchanger, an auxiliary circulator (electric motor driven), and appropriate helium ducting and valves. The water side of the heat exchanger includes pumps, reject heat exchangers, and various instrumentation and water quality equipment. Onsite auxiliary power systems are provided to ensure an adequate supply of electrical power. Table 9-3 gives the major design parameters for the system. For a $3000-\mathrm{MW}(t)$ reactor, three $50 \%$ capacity loops are supplied. Satisfactory cooldown is obtained using any two of the three loops.

Figure 9-6 shows the PCRV gas composition and heat capacity as a function of time. The nitrogen results from the continued mixing of containment air with the PCRV gas. Similarly, the carbon monoxide results from oxidation of core graphite with the oxygen present in the containment. The system pressure used for this analysis was 34.0 psia.

Figure 9-7 shows the average core outlet and core inlet temperatures during the transient. The maximum average core outlet temperature of $1970^{\circ} \mathrm{F}$ occurs at about $2 \mathrm{hr}$. In Fig. 9-8, the supplied flow, heat generation, and heat removal rates are plotted as a function of time.

The temperatures occurring during this transient for the process heat HTGR are approaching the critical safety limits for several components developed for the steam-generating HTGR. Specifically, the maximum core average outlet temperature of $1970^{\circ} \mathrm{F}$ is close to the $2000^{\circ} \mathrm{F}$ limit for the core auxiliary heat exchanger inlet temperature. Similarly, the bottom thermal barrier temperature is approaching its limit. If detailed account were taken of the local hot streaks, the bottom cross duct thermal barrier temperature limits established by the steam plant would be expected to be exceeded, indicating that an upgraded thermal barrier design may be needed for the $1600^{\circ} \mathrm{F}$ reactor outlet temperature reference plant. 
TABLE 9-3

CACS PARAMETERS

(Per Loop)

Auxiliary Heat Exchanger

Heat transfer surface area

$2100 \mathrm{ft}^{2(\mathrm{a})}$

Water-side flow

$643,000 \mathrm{lb} / \mathrm{hr}$

Design water-side $\Delta \mathrm{T}$

$260^{\circ} \mathrm{F}$

Design heat duty

$175 \times 10^{6} \mathrm{Btu} / \mathrm{hr}$

Auxiliary Circulator

Type

Driver

Maximum torque

Maximum speed
Single-stage axial flow

Electric motor variable speed

$880 \mathrm{ft}-1 \mathrm{~b}$

$3550 \mathrm{rpm}$

(a) $80 \%$ of installed area to account for tube plugging and fouling. 


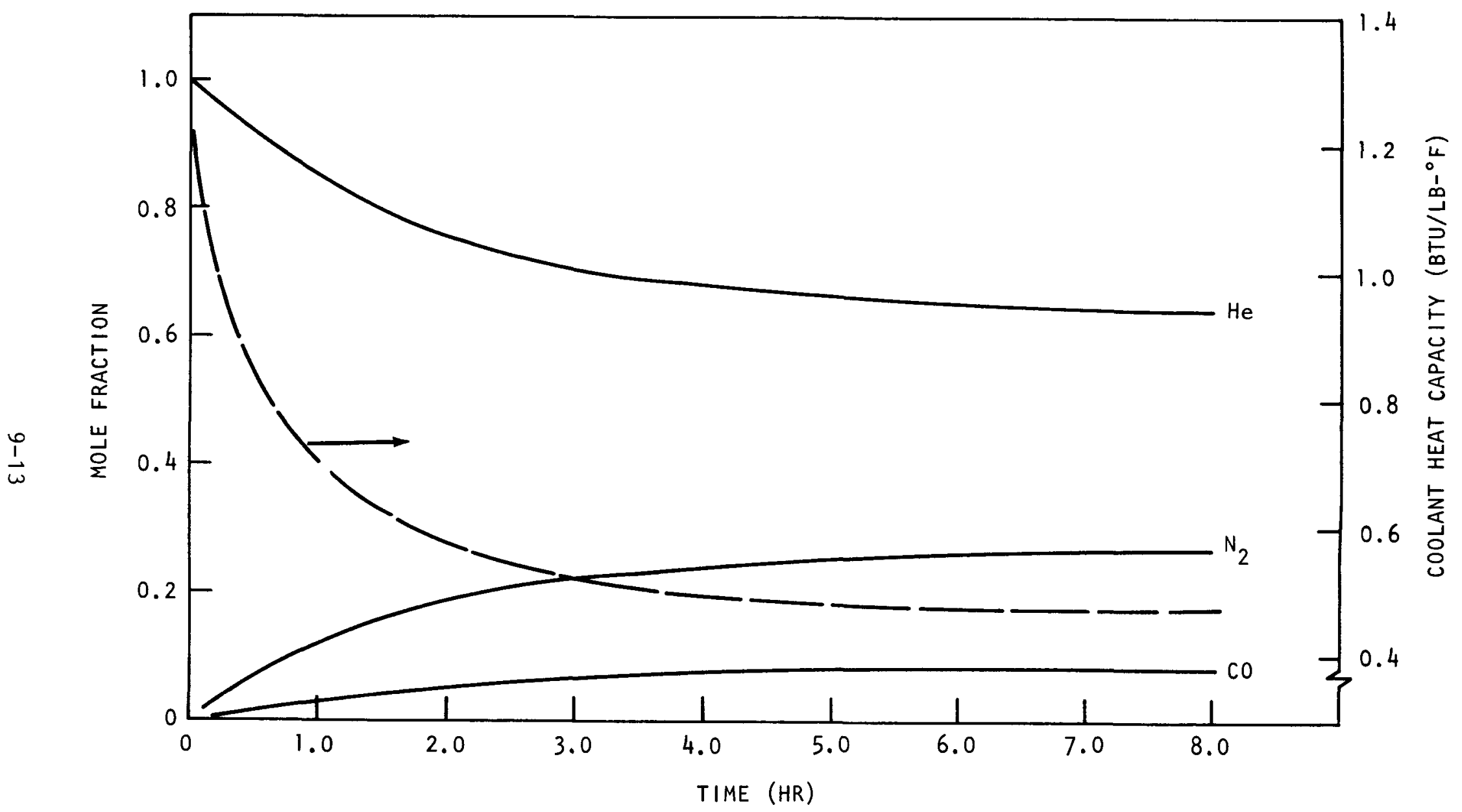

Fig. 9-6. PCRV gas composition and heat capacity as a function of time for DBDA; based on $1600^{\circ} \mathrm{F}$ reactor outlet temperature, 34.0-psia pressure, two CACS loops operating 


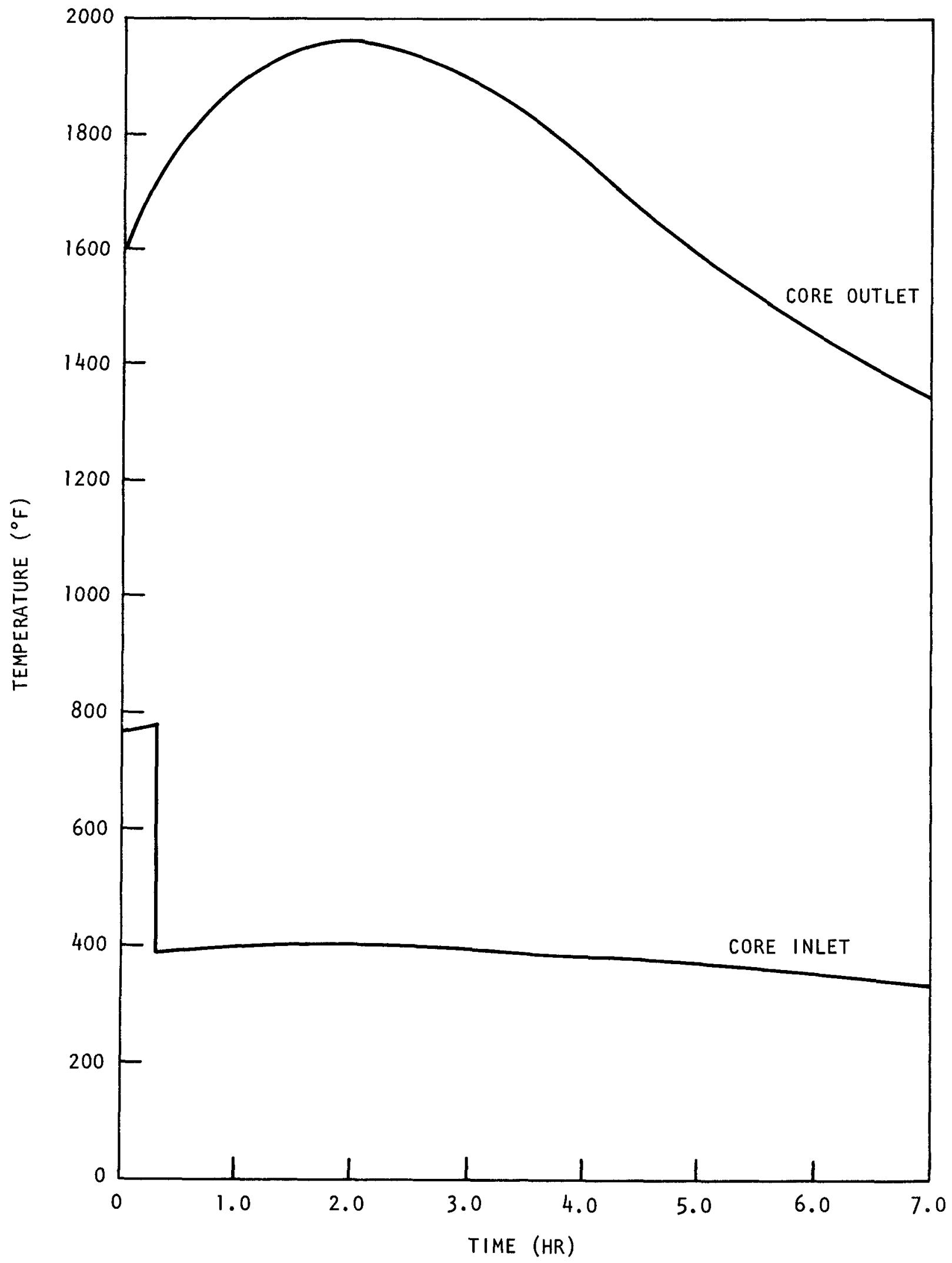

Fig. 9-7. Core outlet and inlet temperatures as a function of time for DBDA; based on $1600^{\circ} \mathrm{F}$ reactor outlet temperature, 34.0-psia pressure, two CACS loops operating 

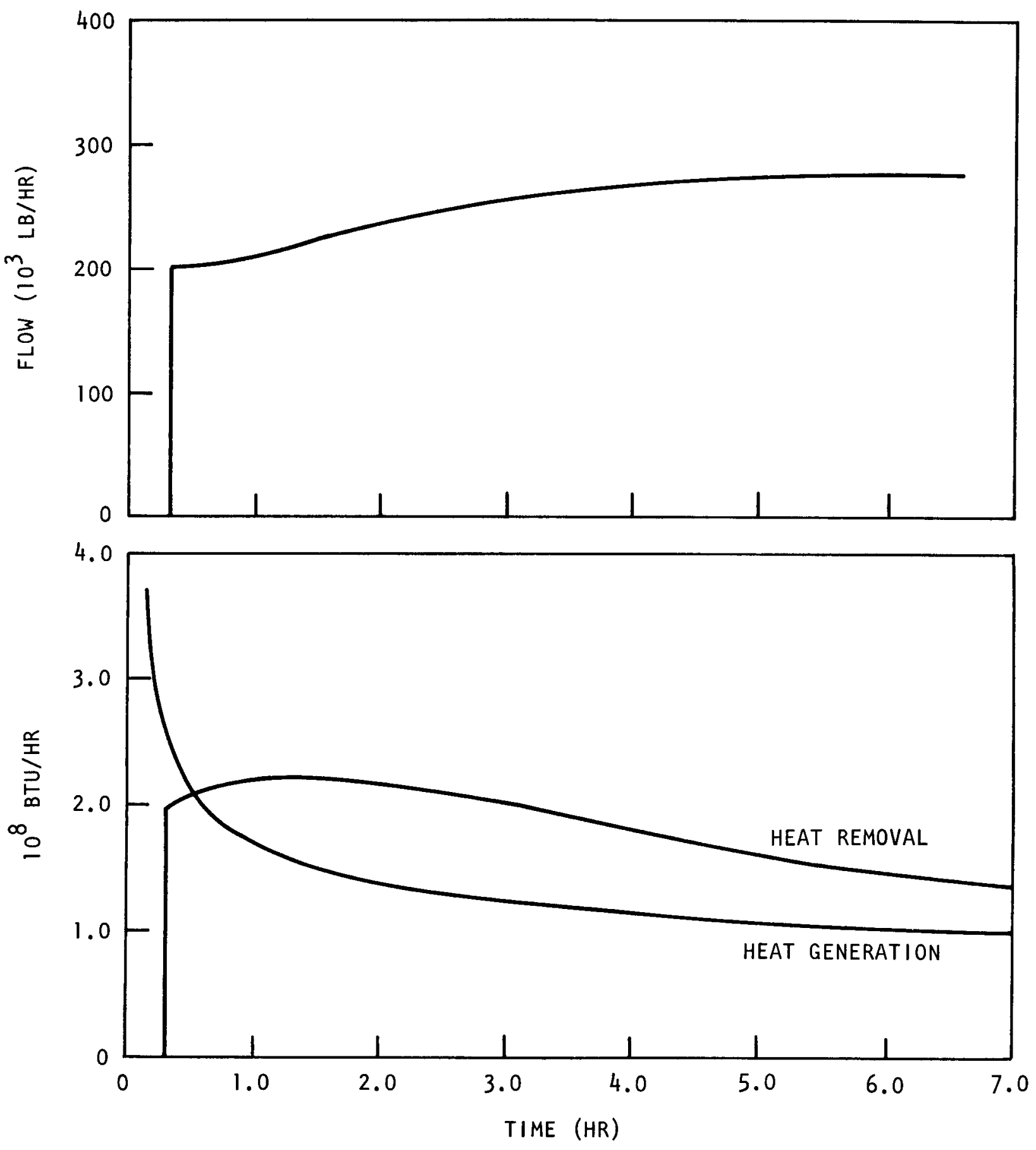

Fig. 9-8. Flow, heat removal, and heat generation as a function of time for $\mathrm{DBDA}$; based on $1600^{\circ} \mathrm{F}$ reactor outlet temperature, 34.0-psia pressure, two CACS loops operating 
As the reactor outlet temperature is raised for the process heat reactor, additional upgrading of components will be required to ensure safe shutdown for a postulated DBDA. This will include better thermal barrier designs and higher-temperature materials for the auxiliary heat exchanger and control rod cladding and spine.

If an axial push-through core is developed for these deviated temperatures, two additional advantages can be obtained. The hot streaking will be reduced owing to a flatter power profile, and a reduced pressure drop occurring in the core will allow greater coolant flow rate. The latter benefit results from removal of the flow control orifices.

\subsubsection{Design Bases}

The containment and all necessary components in it will be designed to withstand the pressure and temperature effects of the DBPA. This accident produces the maximum deleterious pressure and temperature effects on the reactor containment. The reactor containment will be designed to be leaktight. For the purpose of analyzing exposures to the public, the containment will be assumed to leak at a rate of $0.1 \%$ of contained free volume per day at the calculated peak accident pressure. This leakage rate is reduced to $0.05 \%$ per day after $24 \mathrm{hr}$. With this leakage rate, public exposure will be far below the guidelines specified in 10 CFR 100 .

\subsubsection{Radioactivity Release Sources}

The radioactivity released into the containment during the DBDA can come from three sources within the PCRV: (1) the circulating activity present in the primary coolant, (2) a fraction of the activity plated out on the structures within the PCRV which is lifted off by the depressurization forces, and (3) any activity which might be released from the fuel following the accident. 


\subsubsection{Coolant Inventory}

During normal operation, a small percentage of the more volatile fission products diffuse from the reactor core fuel particles and the core graphite into the primary coolant. This fission product release, coupled with the removal of fission products by decay, plateout, and helium purification system operation, determines the activity levels in the circulating primary coolant. Table 9-4 compares the coolant design activity inventories for the DBDA for the various process heat reactor designs.

\subsubsection{Summary of Radioactivity Released to Containment}

Since core cooling with only two CACS loops effectively limits temperature rise so that no activity is released from the fuel, the total activity potentially releasable from the PCRV during a DBDA is composed of the design circulating gaseous activity plus that from liftoff. For purposes of the present study, it was assumed that the scaling of the doses and releases was directly proportional to the increase in circulating activity. No detailed analysis was made of liftoff versus temperature.

\subsubsection{Environmental Consequences}

The environmental consequences of a DBDA are analyzed using the primary coolant and plateout releases to the containment as defined in Ref. 9-2 and modified by the factors in Table 9-4. The doses for this event are computed for the exclusion area boundary (EAB) (2500 ft) and the low population zone (LPZ) (1.5 miles) using the following specific assumptions which govern the release of activity to the environment:

1. This event conservatively assumes that all the circulating activity is released to the containment over the first $200 \mathrm{sec}$ of the accident.

2. Fifty percent of the iodines released to the containment are assumed to settle, plate out, or otherwise be unavailable for release from the containment. 
TABLE 9-4

RELATIVE ACTIVITY RELEASED FROM PCRV TO REACTOR CONTAINMENT DURING DBDA (a)

\begin{tabular}{cc}
\hline $\begin{array}{c}\text { Process Gas } \\
\text { Temp. }\left({ }^{\circ} \mathrm{F}\right)\end{array}$ & $\begin{array}{c}\text { Activity Relative to } \\
\text { Commercial HTGR }\end{array}$ \\
\hline 1200 & 0.48 \\
1400 & 0.51 \\
1600 & 0.79 \\
1800 & 1.13 \\
2000 & 1.55 \\
\hline
\end{tabular}

(a) Assumes halogens and noble gas are primary source of containment activity and resulting dosages. 
3. The released iodine activity is in the form of $90 \%$ elemental and $10 \%$ methy 1 iodine.

4. The containment cleanup system removes the iodines and particulates with an air recirculation flow rate of one containment volume per hour. This air flow is passed through filters with efficiencies of 90\% for elemental iodines, $70 \%$ for methy 1 iodines, and $99.97 \%$ for particulates. A conservative delay of $2 \mathrm{hr}$ is assumed for starting the containment cleanup system in order to protect the filters from the initial temperatures which would occur in the containment following this event.

5. Credit is taken for decay in the containment in determining the activity available for release to the offsite environment.

6. The activity in the containment available for release which has not been removed through radioactive decay or filtration is assumed to leak from the containment at a rate of $0.1 \%$ per day for the first $24 \mathrm{hr}$ after the onset of the accident and at a rate of $0.05 \%$ per day for the following 29 days.

7. Fifty percent of the activity leaking from the containment is assumed to be collected by the supplementary leak collection system and exhausted through filters with efficiencies of $90 \%$ for elemental iodines, $70 \%$ for methyl iodines, and $99.97 \%$ for particulates. The supplementary leak collection system consists of an enclosure surrounding the containment penetrations with a controlled ventilation system. A conservative delay of $2 \mathrm{hr}$ is assumed for actuating this system. No credit is taken for mixing or decay in this penetration enclosure.

The assumption that $50 \%$ of the containment leakage is collected by the supplementary leak collection system is conservative, since all penetrations (except the equipment hatch) are enclosed by this system. These penetrations are considered to be the major source of any leakage from the containment. 
Based on the above assumptions, the calculated activities released to the offsite environment during various time intervals from this event are given in Table $9-5$.

The $X / Q$ values used for atmospheric dispersion in computing the $E A B$ and LPZ doses are:

\section{$\underline{\mathrm{EAB}}$}
1. 0 to $8 \mathrm{hr}$
$X / Q=8.8 \times 10^{-4} \mathrm{sec} / \mathrm{m}^{3}$
2. 8 to $24 \mathrm{hr}$
$X / Q=3.1 \times 10^{-4} \mathrm{sec} / \mathrm{m}^{3}$
3. 1 to 4 days
$X / Q=1.6 \times 10^{-4} \mathrm{sec} / \mathrm{m}^{3}$
4. 4 to 30 days
$X / Q=3.5 \times 10^{-5} \mathrm{sec} / \mathrm{m}^{3}$

\section{$\underline{\mathrm{LPZ}}$}

1. 0 to $8 \mathrm{hr}$

2. 8 to $24 \mathrm{hr}$

3. 1 to 4 days

4. 4 to 30 days

$$
\begin{aligned}
& X / Q=3.3 \times 10^{-4} \mathrm{sec} / \mathrm{m}^{3} \\
& X / Q=4.3 \times 10^{-5} \mathrm{sec} / \mathrm{m}^{3} \\
& X / Q=2.2 \times 10^{-5} \mathrm{sec} / \mathrm{m}^{3} \\
& X / Q=4.8 \times 10^{-6} \mathrm{sec} / \mathrm{m}^{3}
\end{aligned}
$$

The above $X / Q$ values are taken from Ref. 9-2. These values, which take credit for the building wake with a shape factor of 0.5 , are more conservative than the corresponding AEC Regulatory Guide 1.4 X/Q values.

The breathing rates used for thyroid dose calculations are consistent with Safety Guide 1.4. These breathing rates are as follows:
1. 0 to $8 \mathrm{hr}$
$\mathrm{BR}=3.47 \times 10^{-4} \mathrm{~m}^{3} / \mathrm{sec}$
2. 8 to $24 \mathrm{hr}$
$B R=1.75 \times 10^{-4} \mathrm{~m}^{3} / \mathrm{sec}$
3. 1 to 4 days
$B R=2.32 \times 10^{-4} \mathrm{~m}^{3} / \mathrm{sec}$
4. 4 to 30 days
$B R=2.32 \times 10^{-4} \mathrm{~m}^{3} / \mathrm{sec}$ 
TABLE $9-5$
DBDA DOSES AT EAB AND LPZ

\begin{tabular}{c|c|c|c|c}
\hline \multirow{2}{*}{$\begin{array}{c}\text { Process Gas } \\
\text { Temp. }\left({ }^{\circ} \mathrm{F}\right)\end{array}$} & \multicolumn{2}{|c|}{ EAB (mrem) } & \multicolumn{2}{c}{ LPZ (mrem) } \\
\cline { 2 - 5 } 1200 & Whole Body & Thyroid & Whole Body & Thyroid \\
1400 & 7.3 & 48 & 5.2 & 27.1 \\
1600 & 7.8 & 51 & 5.5 & 28.8 \\
1800 & 12.0 & 79 & 8.5 & 44.6 \\
2000 & 17.2 & 113 & 12.2 & 63.9 \\
& 23.6 & 155 & 16.7 & 87.6 \\
\hline
\end{tabular}

(a) $\mathrm{EAB}=$ exclusion area boundary, $2500 \mathrm{ft}$ from reactor center, 2-hr dose (mrem)

$\mathrm{LPZ}=1$ ow population zone, 1.5 miles from reactor center, 30-day dose (mrem) 
The mathematical models used to calculate the whole body exposure are defined in Safety Guide 1.4. The beta dose calculation assumes an infinite cloud model, while the gamma dose calculation makes use of a semi-infinite cloud model. The specific equations used for the whole body dose are

$$
\begin{aligned}
& \beta^{D \infty}=0.23 \bar{E}_{\beta} Q_{i} \quad X / Q, \\
& \gamma=0.25 \bar{E}_{\gamma} Q_{i} \quad X / Q,
\end{aligned}
$$

where $\beta^{D_{\infty}}=$ infinite cloud whole body beta dose (rem),

$\gamma^{D}=$ semi-infinite cloud whole body gamma dose (rem),

$\overline{\mathrm{E}}_{\beta}=$ average energy of the beta particles (MeV/dis),

$\overline{\mathrm{E}}_{\gamma}=$ average energy of the gamma particles (MeV/dis),

$Q_{i}=$ Curies of the $i^{\text {th }}$ isotope released during the time interval of interest,

$X / Q=$ atmospheric dispersion factor $\left(\mathrm{sec} / \mathrm{m}^{3}\right)$,

0.23 = beta dose conversion factor (rem-dis-cc) (sec- $\mu \mathrm{Ci} ;-\mathrm{MeV})$,

$0.25=$ gamma dose conversion factor (rem-dis-cc) $(\mathrm{sec}-\mu \mathrm{Ci} ;-\mathrm{MeV})$.

The mathematical model used to calculate the thyroid dose employs the model, equations, and iodine dose conversion factors discussed in TID-14844. The basic model is represented by the equation

$$
D_{t}=[B R] \frac{D_{\infty}}{A_{T}}(X / Q) Q_{i}
$$

where $\mathrm{D}_{\mathrm{t}}=$ thyroid dose $(\mathrm{rem})$,

$$
\begin{aligned}
B R & =\text { breathing rate }\left(\mathrm{m}^{3} / \mathrm{sec}\right) \\
D_{\infty} / A_{\Gamma} & =\text { thyroid dose conversion factor }(\mathrm{rem} / \mathrm{Ci}) .
\end{aligned}
$$

The thyroid dose conversion factors are derived from the standard man parameters recommended in ICRP. 


\subsubsection{Summary of Results}

Analysis of the DBDA indicates that radioactive releases to the environment results in doses at the $\mathrm{EAB}$ and the LPZ boundary that are significantly less than the guidelines of 25-rem whole body and 300-rem thyroid given in $10 \mathrm{CFR}$ 100. The EAB and LPZ doses are listed in Table 9.5.

The analysis also indicates that the temperatures and pressures in the reactor containment during and after the accident do not exceed the design values.

Adequate forced circulation core cooling is maintained following the depressurization by use of main loops or the auxiliary loops operating with reduced primary coolant density. No damage to either main or auxiliary circulators occurs during the depressurization.

\subsection{LOSS OF MAIN LOOP COOLING (LOMLC)}

In the unlikely event of loss of all main loop cooling, the CACS is available to provide cooling. (The CACS is discussed in Section 9.1.4.) For such pressurized cases, the CACS is heat-exchanger-limited, with the circulator speed varied to maintain maximum heat rejection.

Figure 9-9 shows the average core outlet and core inlet temperatures as a function of time for an LOMLC. For this analysis, a period of $20 \mathrm{~min}$ was assumed before initiation of cooling with two CACS 1oops. Figure 9-9 shows the reactor upper plenum temperature increasing from $770^{\circ}$ to about $1125^{\circ} \mathrm{F}$ before initiation of the CACS. The average core outlet temperature peaks at $1700^{\circ} \mathrm{F}$ about three-quarters of an hour into the transient.

Figure 9-10 shows the supplied flow, heat generation, and heat removal rates as a function of time for an LOMLC. The circulator speed is varied to maintain a constant water outlet temperature from the auxiliary heat exchanger. During the first part of the transient, the flow is gradually 


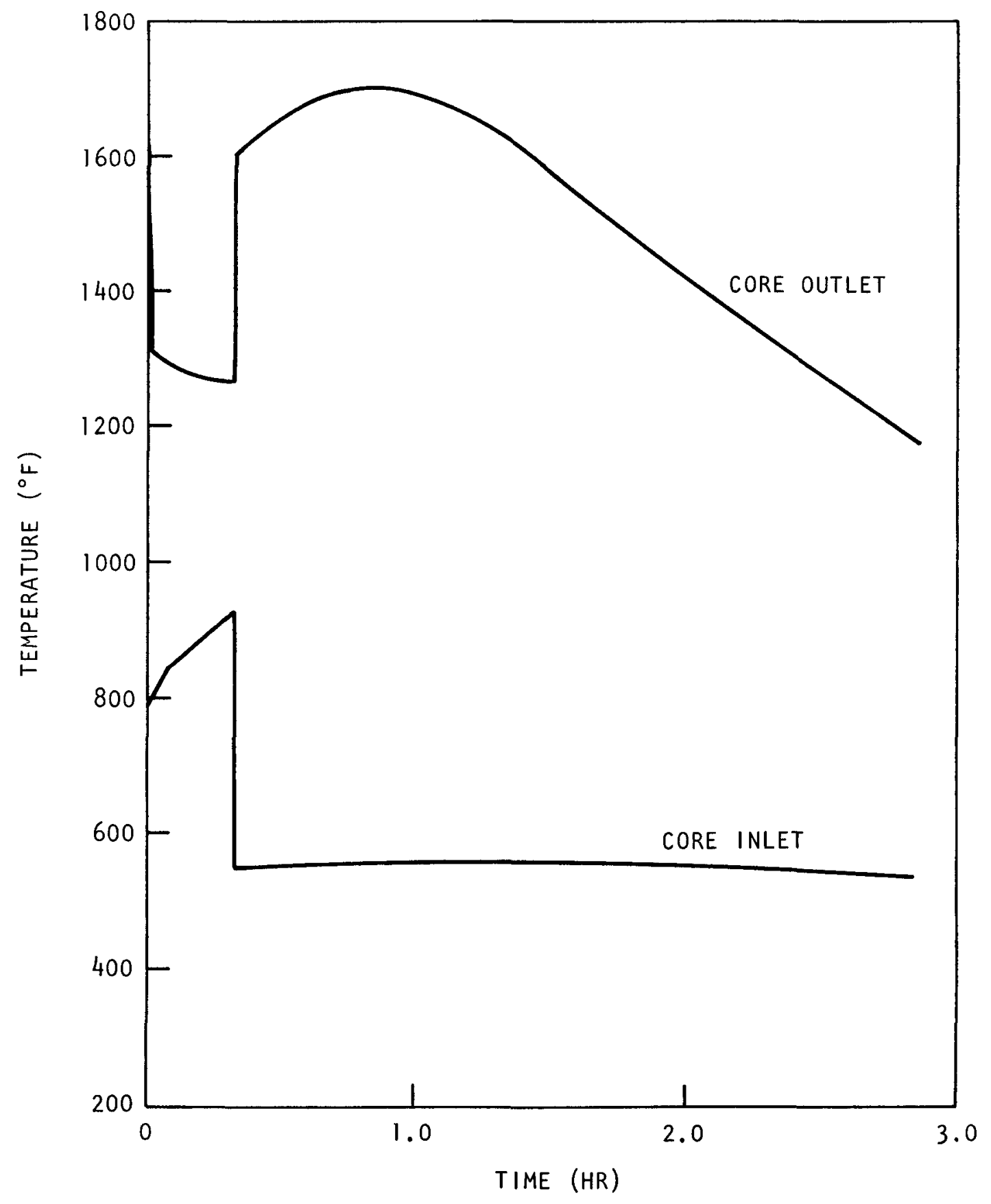

Fig. 9-9. Core inlet and outlet temperatures as a function of time for LOMLC; based on $1600^{\circ} \mathrm{F}$ reactor outlet temperature 

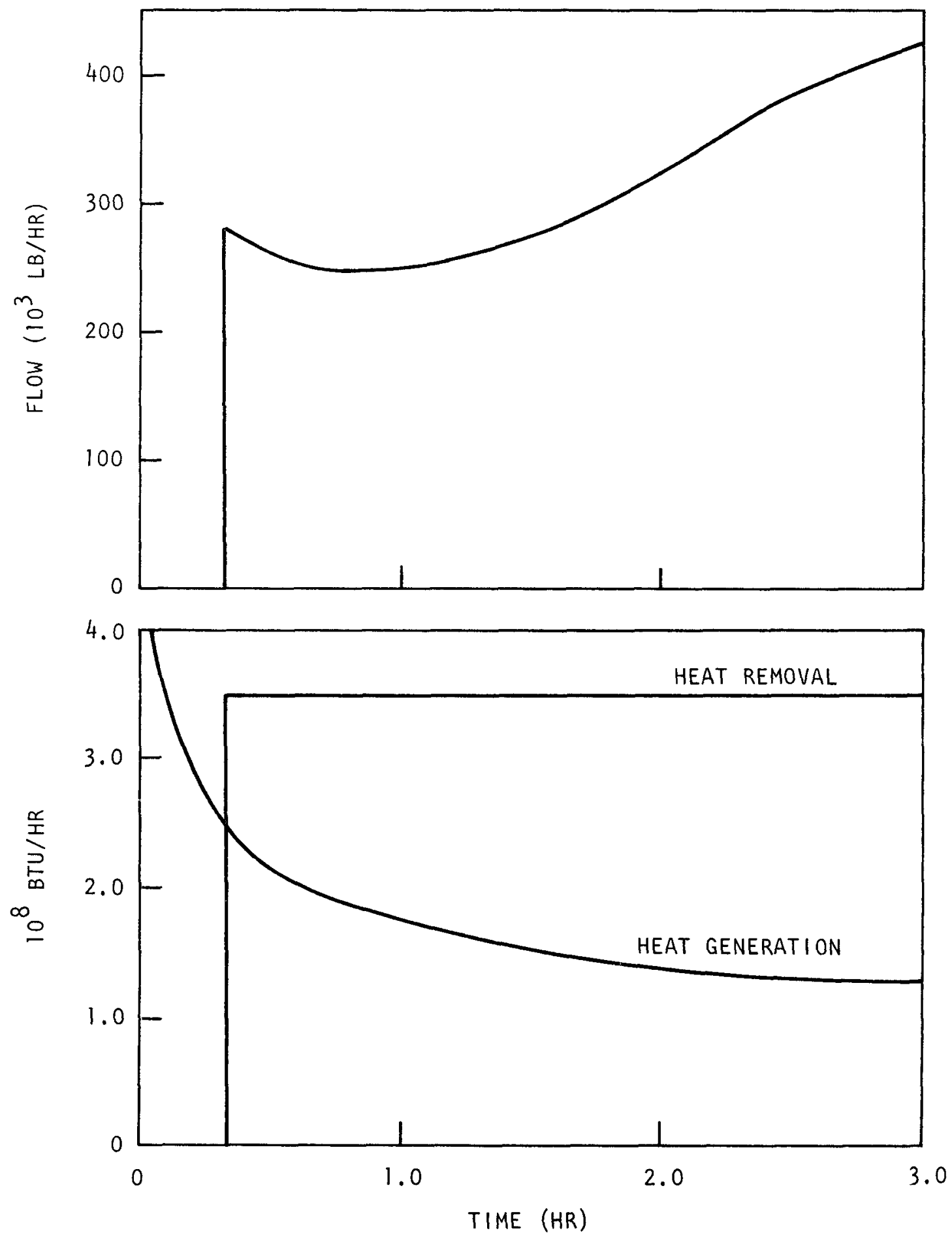

Fig. 9-10. Flow, heat removal, and heat generation as a function of time for LOMLC; based on $1600^{\circ} \mathrm{F}$ reactor outlet temperature 
reduced as the reactor outlet temperature increases. fifter the maximum temperature is reached, the circulator speed is gradually increased, producing greater flow as the transient proceeds. At some point, the maximum circulator speed will be reached and the water outlet temperature from the auxiliary heat exchanger will drop as the heat removal falls from its maximum.

The PCRV pressure for this transient gradually decreases from 725 psia as the reactor is cooled.

For pressurized LOMLC accidents, the upper plenum thermal barrier cover plate temperature is usually limiting. For the transient shown, the upper plenum temperature of $\sim 1125^{\circ} \mathrm{F}$ exceeds the damage limit for carbon steel cover plates. Consequently, an alloy material will be specified for the process heat HTGR. The normal operating temperature of the upper plenum for this reactor is more than $100^{\circ} \mathrm{F}$ above the equivalent temperature for the steam-generating HTGR. This temperature continues to increase as the reactor outlet temperature is increased for higher process heat temperatures. The maximum average reactor outlet temperature of $21700^{\circ} \mathrm{F}$ is we11 below the critical temperatures for the hot end of the reactor.

\subsection{PRODUCT CONTAMINATION}

Although the primary coolant is continuously purified via the helium purification system and the highly retentive fuel particles keep fission product release to the helium minimized, small amounts of fission products are continuously present in the primary circuit. For the purpose of this study, the reformer is assumed contained within the PCRV and in contact with the primary coolant. Therefore, if a reformer tube should fail, fission products circulating in the primary helium could contaminate the proccess gas. Corrective action to be taken in the event of a reformer tube failure is discussed in Section 9.3.2. Preliminary analysis indicates that the rare occurrence of a tube failure can be tolerated without presenting a safety hazard to the public. 
The primary coolant also contains small amounts of the hydrogen- 3 isotope, tritium. All materials show some degree of permeability for hydrogen, and this permeability increases with increasing temperature. Accordingly, some permeation of hydrogen from the process side of the steam-methane reformer through the tube walls and into the helium system can be expected. The same permeation mechanism will permit a small quantity of tritium to diffuse in the other direction, from the primary system through the tube walls of the steam generator and reformer. The diffusion of tritium through the reformer tubes into the hydrogen production circuit would ultimately lead to tritium in the gas produced by the plant, although the quantities would be very low and great dilution would occur. For the purpose of safety analysis, it has been assumed that the hydrogen produced in the reformer will be used to produce substitute pipeline gas (SPG).

\subsubsection{Tritium and Hydrogen Permeation}

9.3.1.1. Diffusion Data. Although there is a large body of data on the diffusion of hydrogen through various materials, several further assumptions are necessary for the particular conditions encountered here, with a consequent uncertainty in the calculation. These assumptions are considered in the following discussion.

The transport rate of hydrogen through metals can depend markedly on the surface condition of the metals. Oxides have much lower permeabilities than most metals, and a thin oxide film can be a significant barrier. Transport in metals generally involves hydrogen atom migration, whereas molecular migration predominates in oxides and glasses (Refs. 9-3 through 9-6). Generally, this implies that in metals permeation rates are proportional to the square root of pressure, while in oxides the rates are directly proportional to pressure. This is true when diffusion in the solid is rate-limiting and the solubility limit has not been approached, in which case permeabilities are also inversely proportional to the thickness of the barrier. 
These pressure dependencies have been demonstrated for permeation of steels in the pressure and temperature range of interest (Refs. 9-7, 9-8), although a deviation is observed for low hydrogen pressures of perhaps 1 to 10 Torr (Refs. 9-8 through 9-10). However, no data could be found on the pressure dependence of permeation of steel-based oxides, and therefore, linear pressure dependence was assumed for the low-Torr tritium permeation and a square root pressure dependence for the high-Torr $\mathrm{H}_{2}$ permeation. This linear dependence is contrary to evidence for $\mathrm{ZrO}_{2}$ films on zirconium metal (Ref. 9-6), where saturation is observed at less than 1 atm, but holds true for $\mathrm{SiO}_{2}$ at 1 atm and below and also for high pressures (Ref. 9-3).

The physical form of the oxide layers on steels has not been fully characterized. The expected direct proportionality of oxide permeation on pressure would lead to an expectation of change in pressure dependence as wel1 as reduction in permeability when oxide layers develop. This pressure dependence change has not been consistently observed. A permeation reduction without change in pressure dependence is consistent with an incomplete film model in which entry to the metel is through film imperfections. The transport is entirely through metal, but the film produces a surface layer of reduced effective cross section.

It is probable that the reformer tubes will have a protective oxide film. Flint (Ref. 9-11) measured the reduction in hydrogen permeability resulting from forming stable oxide layers on membranes of various materials in wet $\mathrm{H}_{2}\left(20\right.$ Torr $\mathrm{H}_{2} \mathrm{O} / 720$ Torr $\mathrm{H}_{2}$ ). Dramatic changes were observed for some materials but not for others. The permeabilities of samples of Type $304,316,347$, and 410 stainless steels were reduced substantially, while Type 321 stainless steel and $\mathrm{Fe}(49) \mathrm{Ni}(44) \operatorname{Cr}(7)$ alloy were virtually unaffected. Huffine and Williams (Ref. 9-12) found a stable oxide film on an $\mathrm{Fe}(75) \mathrm{Cr}(20) \mathrm{Al}(5)$ alloy to be very effective. A transient test on Type 446 stainless steel suggested a similarly protective oxide film was produced, and Steigerwald (Ref. 9-13) found similar results on Type 303 stainless steel and a cobalt-based alloy. Reduction in permeability was also noticed by Russian workers on an 18-8 stainless steel (Ref. 9-14). 
In general, it seems reasonable to assume the benefit of a protective oxide layer on the reformer tube walls, although this assumption would ilLinately have to be demonstrated for a specific tube material and specific conditions of oxygen potential and temperature. This is particularly true because small changes in oxygen potential can alter the metallic constituents incorporated into an oxide film and thereby strongly influence the protective nature of the oxide film with regard to further oxidation (Ref. 9-15). Possibly the efficacy of the oxide film in the reformer will also be influenced by the rate and temperature of formation and by the degree of temperature or stress cycling or abrasion.

9.3.1.2. Hydrogen Permeation. The actual calculation of hydrogen permealiun is quite simple. It seems reasunable tlial the effect of the oxide film is the same whether it is on the front or back surface of the metal membrane. The metal permeability is large by comparison, and the metal-oxide interface should be nearly in equilibrium with the gas phase at the gas-metal interface. (However, Ref. 9-16 does not appear to be in complete agreement.)

The total permeated volume $\mathrm{R}$ is taken as (assuming planar geometry)

$$
R=\sum_{i=i}^{N} \Delta S \emptyset\left[f\left(p_{1}\right)-f\left(p_{2}\right)\right] \text {, }
$$

where $\Delta S$ is an incremental area $(N * \Delta S=$ total area of the heat exchanger), $\emptyset$ is the permeation rate of hydrogen at 1 atm as a function of temperature, and $f(p)$ is a pressure correction function for calculating the pressure dependence of permeation. $f(p)=p^{1 / 2}$ for metals and incomplete oxide films, $f(p)=P$ for complete oxide films or ceramics, and $f(p)$ is constant if the pressure is constant and/or an experimentally obtained value is used. (For low-pressure $\mathrm{H}_{2}$ permeation in the $1200^{\circ} \mathrm{F}$ or $1400^{\circ} \mathrm{F}$ process gas case, the experimental values in Ref. 9-17 were used.) $P_{1}$ is the hydrogen pressure (atm) at the area increment on the process side, and $\mathrm{P}_{2}$ is the hydrogen pressure (atm) in the helium primary coolant. Values of $\emptyset$ and $f(p)$ are calculated for each area increment, and the calculated permeation rate for 
each area increment is summed over the total surface area. The backdiffusion term, $f\left(p_{2}\right)$, can be neglected without significant error.

The resulting hydrogen permeation rates with and without an oxide are shown in Table 9-6. The oxide case is treated on an incomplete film basis. In the case of the silicon carbide reformers, data from Ref. 9-18 are utilized and a linear pressure dependence is assumed. The oxidized conditions are believed more realistic than bare metal. The hydrogen concentrations in the primary system are based on purification flows specified in Table 9-6. Tritium permeation rates in SiC are said to be $10^{-8}$ of niobium permeation rates at $1100^{\circ} \mathrm{C}$, according to Ref. 9-18. Consequently, the tritium concentrations are extremely small in the process gas out of the silicon carbide reformers.

The possible effects of hydrogen in the primary coolant are not clearly understood at this time. It is known that hydrogen will react with the graphite core to form small quantities of methane, and limited tests in the Peach Bottom HTGR have suggested that the methane may under certain conditions have some undesirable effects on metal components of the system.

A predicted hydrogen concentration of less than $100 \mathrm{ppm}$ is believed to be quite acceptable; it is consistent with the design levels in existing HTGR plants. The helium flow rate through the purification unit was increased from $2000 \mathrm{lb} / \mathrm{hr}$ in the standard HTGR to the rates in the proposed process heat HTGR plant, primarily to achieve this relatively low hydrogen leve1.

9.3.1.3. Tritium Permeation. Tritium is formed in the HTGR system in three ways: by ternary fission in the core, by neutron reaction with lithium impurities in core materials, and by neutron reaction with $\mathrm{He}-3$ in the helium coolant. Tritium from the first two sources is largely retained within core materials, so that the He-3 reaction becomes the principal source of tritium in the coolant. 
TABLE 9-6

HYDROGEN AND TRITIUM PERMEATION

\begin{tabular}{|c|c|c|c|c|c|c|c|}
\hline $\begin{array}{c}\text { Process } \\
\text { Gas } \\
\text { Temp. } \\
\left({ }^{\circ} \mathrm{F}\right) \\
\end{array}$ & $\begin{array}{c}\text { Core } \\
\mathrm{H}_{2} \\
(\mathrm{ppm})\end{array}$ & $\begin{array}{c}\mathrm{H}_{2} \text { Permeation } \\
\text { Rate From } \\
\text { Reformer } \\
\text { (cc STP/hr) (a) }\end{array}$ & $\begin{array}{l}\text { Tritium } \\
\text { Permeation } \\
\text { Rate } \\
(\mathrm{cc} / \mathrm{hr})\end{array}$ & $\begin{array}{l}\text { Tritium } \\
\text { Concentration } \\
\text { In Home } \\
(\mu \mathrm{Ci} / \mathrm{cc})\end{array}$ & $\frac{\text { Man-Rem }}{\mathrm{Yr}}$ & $\begin{array}{c}\text { He Cleanup } \\
\text { Rate } \\
(1 \mathrm{~b} / \mathrm{hr})\end{array}$ & Material \\
\hline \multicolumn{8}{|c|}{ Oxidized Surfaces } \\
\hline 1200 & 37 & $4.9 \times 10^{5}$ & 0.0056 & $5 \times 10^{-12}$ & 2.3 & 4,000 & $\mathrm{HK}-40$ \\
\hline 1400 & 76 & $1.6 \times 10^{6}$ & 0.03 & $1 \times 10^{-12}$ & 11.5 & 4,000 & $\mathrm{HK}-40$ \\
\hline 1600 & 14 & $<6 \times 10^{3}$ & $3 \times 10^{-7}$ & $2 \times 10^{-17}$ & 0.0002 & 4,000 & $\mathrm{SiC}$ \\
\hline 1800 & 14 & $<6 \times 10^{3}$ & $3 \times 10^{-7}$ & $2 \times 10^{-17}$ & 0.0002 & 4,000 & $\mathrm{SiC}$ \\
\hline 2000 & 14 & $<6 \times 10^{3}$ & $3 \times 10^{-7}$ & $2 \times 10^{-17}$ & 0.0002 & 4,000 & $\mathrm{SiC}$ \\
\hline \multicolumn{8}{|c|}{ Reduced Surfaces } \\
\hline 1200 & 183 & $3.6 \times 10^{6}$ & 0.0084 & $3 \times 10^{-13}$ & 3.5 & 4,000 & $\mathrm{HK}-40$ \\
\hline 1400 & 187 & $1.2 \times 10^{7}$ & 0.03 & $10^{-12}$ & 11.5 & 12,000 & $\mathrm{HK}-40$ \\
\hline
\end{tabular}

(a) The steam generator permeates $3 \times 10^{5} \mathrm{cc} \mathrm{STP/hr}$ of $\mathrm{H}_{2}$ into the primary loop. 
Tritium production in the 3000-MW(t) HTGR from this source is estimated to be $0.7 \mathrm{Ci} / \mathrm{hr}$. This value is based on an assumed He-3/He-4 ratio of $4 \times 10^{-7}$. Recent measurements on a sample of Peach Bottom helium indicate that $\mathrm{He}-3 / \mathrm{He}-4=1.6 \times 10^{-7}$.

The tritium is assumed to equilibrate isotopically with the hydrogen in the primary coolant. It is nearly indistinguishable chemically from hydrogen, and so the permeation out of the primary coolant into the process gas is given by the back-diffusion term of Eq. 9-4 weighted by the isotopic abundance of tritium to hydrogen. This approximation is acceptable as long as the back-diffusion term is small compared with the forward term. A correction factor, $1 / \sqrt{3}$, is applied to allow for the mass dependence of the diffusion jump frequency (Refs. 9-4, 9-9, 9-19).

Since it is probable that an oxide film will exist on the reformer tube surface, the estimated rate of tritium permeation through the reformer is acceptable, assuming the conservative incomplete film model. Since tritium is chemically similar to normal hydrogen, it appears unlikely that an economic means of removing it from the process stream could be developed. Because approximately two-thirds of the hydrogen in the reformer effluent gas is in the steam, only one-third of the tritium permeating the reformer ends up in the product gas leaving the plant.

\subsubsection{Effects of Tritium in Pipeline Gas. The investigation of the} effects of tritium in pipeline gas was greatly facilitated by the considerable body of work which has been accomplished under the AEC Plowshare Program. Under this program, nuclear explosives are used to stimulate natural gas production. In 1967, a field test designated Project Gas Buggy was made using a 26-kT device. More recently, a similar test was carried out under Project Rulison. Data from these tests have been analyzed and various health physics aspects investigated by workers at Oak Ridge National Laboratory and other facilities (Refs. 9-20 through 9-24).

The initial level of tritium in the gas produced by nuclear stimulation was $7 \times 10^{-4} \mu \mathrm{Ci} / \mathrm{cc}$ for the Gas Buggy Test and $1.7 \times 10^{-4} \mu \mathrm{Ci} / \mathrm{cc}$ for 
the Rulison Test. The tritium decays as gas is withdrawn from the wells. For example, it has been estimated that the average tritium concentration in gas produced from a series of Gas Buggy type we11s would be on the order of $10^{-5} \mu \mathrm{Ci} / \mathrm{cc}$. Furthermore, there is some indication that improvements in technique might reduce this figure to as low as $10^{-6} \mu \mathrm{Ci} / \mathrm{cc}$. In any case, it is clear that the values estimated for an HTGR coal gasification plant compare quite favorably with the levels expected in natural gas produced by nuclear stimulation.

Under the Plowshare Program, various pathways by which tritium contamination of pipeline gas could give rise to radiation exposure have been under investigation. These include (1) contamination of the atmosphere in residences due to use of gas in residential heating units conservatively assumed to be unvented, (2) contamination of the atmosphere in residences due to gas usage in kitchen ranges, water heaters, and other unvented appliances, (3) contamination of food cooked on gas ranges, (4) atmospheric contamination around power plants and other industrial plants using gas, (5) contamination of petrochemicals and other products derived from natural gas, and (6) general atmospheric contamination in urban areas due to gas usage in both residential and industrial applications. The conclusion drawn from these studies is that air contamination in residences due to gas usage in heating units and other appliances represents the most serious pathway for radiation exposure.

The extent to which the atmosphere in a residence could become contaminated with tritium would depend greatly upon a number of factors, such as climate, home construction, usage of gas appliances, and the extent to which appliances were vented. Based upon work done by Barton et al. (Ref. 9-24), it was estimated that the worst situation for the case of an unvented gas heating unit and unvented gas appliances would lead to a dilution factor of 170 . In other words, the average tritium level in the residence atmosphere would be a factor of 170 below the tritium concentration in the gas being supplied. 
Recently, the AEC has adopted new guidelines (Ref. 9-25) for radioactive releases from light water reactors. Basically, these guidelines set dose levels a factor of 100 below the previous limit. Although these guidelines apply only to light water reactors at present, it is considered prudent to apply the same philosophy to the proposed coal gasification plant. In this case, the allowable air concentration would be reduced to $2 \times 10^{-9}$ $\mu \mathrm{Ci} / \mathrm{cc}$. This allowable concentration is still well above the predicted leve1.

The new AEC regulations also suggest that the integrated population dose from a nuclear facility be considered. This is the product of the average dose received times the number of people receiving the dose. To make this calculation, it will first be assumed that the entire production from the proposed coal gasification plant is used for domestic purposes and that all users receive the maximum calculated dose. Based on these very conservative assumptions, the integrated population dose for 5 million customers is estimated to be a maximum of $180 \mathrm{man}-\mathrm{rem} / \mathrm{yr}$.

Barton points out that in modern construction, appliances other than ranges are vented, and he suggests a weighted value based on unvented ranges and $10 \%$ unvented heating units. This more realistic assumption reduces the average dose of a domestic user by a factor of five. Further, both on the basis of Barton's data for Los Angeles and American Gas Association data for the United States as a whole (Ref. 9-26), less than a third of gas consumption is for domestic purposes. Since Barton has shown that other uses make minor contributions compared with residential exposure, an additional factor-of-three reduction is appropriate. By combining these factors, an integrated population maximum dose of 12 man-rem/yr is estimated.

Even the conservative $180 \mathrm{man}-\mathrm{rem} / \mathrm{yr}$ figure is lower than the $400 \mathrm{man}-$ $\mathrm{rem} / \mathrm{yr}$ limit suggested by the AEC for large central station power plants, and the more realistic $12 \mathrm{man}-\mathrm{rem} / \mathrm{yr}$ value compares very favorably with that limit. 
On the basis of the above considerations, it is concluded that radiation doses to the general public resulting from a nuclear coal gasification plant would be well within all $\mathrm{AEC}$ regulations and guidelines and would, in fact, represent negligible radiation exposure.

\subsubsection{Fission Product to Product Gas Leak}

The reformer will be designed to high-quality standards with large design safety margins. However, the consequences of a reformer tube failure must be analyzed in the interest of public safety even though such failure will be improbable. For the purpose of this study, it is assumed that the reformer tube suffers a guillotine break. If sonic flow is assumed and it is further assumed that no isolation occurs until $5 \mathrm{sec}$ after the failure (consistent with HTGR reheater isolation practice), then $0.7 \%$ of the circulatory activity in the primary loop will be released to the product gas. Because there will be converters and other equipment between the reformer and the distribution lines, only the noble gas will reach the home.

Using the dilution factors of Section 9.3.1.4., the doses shown in Table 9-7 are conservatively estimated. The dose per person as a maximumaverage dose and the man-rem results are maximum. In reality, there will probably be isolation valves some distance downstream of the reformer which are activated by radiation signals at the reformer outlet and, because they are in a cool environment, can close in less than $1 \mathrm{sec}$. The gas in the process lines flows on the average at approximately $460 \mathrm{ft} / \mathrm{sec}$. If the cool isolation valves were more than $460 \mathrm{ft}$ from the reformer outlet, little or no fission products would reach the home. However, the fact is that, even if the isolation requires $5 \mathrm{sec}$, the dose will be within $10 \mathrm{CFR} 100$ guidelines.

After a failure has been isolated, all the contaminated gas in the lines will be routed to the gaseous radwaste system for proper decontamination and disposal. 
TABLE 9-7

DOSES DUE TO REFORMER FAILURE ${ }^{(a)}$

\begin{tabular}{c|c|c|c}
\hline $\begin{array}{c}\text { Process Gas } \\
\text { Temp. }\end{array}$ & $\begin{array}{c}\text { Whole } \\
\text { Body } \\
\text { (mrem) }\end{array}$ & $\begin{array}{c}\text { Thyroid } \\
\text { (mrem) }\end{array}$ & $\begin{array}{c}\text { Maximum } \\
\text { (man-rem) }\end{array}$ \\
\hline 1200 & 0.01 & 0.0 & 44.0 \\
1400 & 0.01 & 0.0 & 46.5 \\
1600 & 0.015 & 0.0 & 75 \\
1800 & 0.02 & 0.0 & 100 \\
2000 & 0.025 & 0.0 & 125 \\
\hline
\end{tabular}

(a) Assumes $5 \mathrm{sec}$ until isolation is completed. 
9.4. PROCESS GAS AND SECONDARY SYSTEM LEAK TO CONTAINMENT

\subsubsection{Process Leak to Containment}

The process gas contains methane and hydrogen. If a reformer inlet or outlet line fails in an uninerted containment, there could be an explosive mixture in the containment if proper precautions are not taken. The simplest precaution is to ensure that adequate steam is always present in the process stream to prevent the formation of an explosive mixture. A further possibility is to use only double-walled pipes in the containment. Then, if one pipe failed, the back-up pipe would contain the gas and via pressure signals inform the plant operator or plant protection system to shut down and/or add explosion retardents to the loop feed lines. As a final alternative, the containment could be inerted with nitrogen. However, this solution has significant disadvantages in terms of maintenance procedures. Nonetheless, it is important to note that the potential hazard of having combustible material in the containment can be safely controlled by various methods.

\subsubsection{Secondary System Leaks to Containment}

Like the commercial 3000-MW(t) HTGR, the process gas HTGR contains four to six steam generators for process steam and power production. The lines in the containment going to and coming from the steam generator are designed with large safety margins and are not expected to fail throughout the life of the plant. However, because the flow rates, temperatures, and pressures associated with these steam generators are similar to those in the commercial HTGR, their failure has the consequences associated with the failure of a commercial HTGR steam generator line failure. The results presented in Ref. 9-2 indicate that the pressure and temperature transients in the containment are much less than those associated with a DBDA and that the doses to the public from tritium release are well within acceptable limits. 


\subsection{PROCESS HEAT EXCHANGER FAILURE IN THE PCRV}

As stated in Section 9.4., it appears that there will be adequate steam in a reformer to prevent the possibility of an explosive mixture even if air should enter the reformer gas stream. Also, because the reformer is at pressures greater than atmospheric ( 300 to 600 psia), air ingress to the process lines is improbable. Although an explosion in the reformer is highly improbable owing to code requirements, design, and inspection, such a failure has been analyzed.

Preliminary analysis indicates that the differential pressure across a reformer tube wall during an explosion is approximately four times the process gas pressure. The safety margins incorporated into designs ensure that the reformers can withstand these transient loads. The closure and piping in the containment as well as isolation valves are also designed to withstand these transient pressures.

Further analysis has been performed to demonstrate the integrity of the PCRV and core structures if the reformer were to fail. Preliminary analysis indicates that a PCRV overpressure of only 1 atm is expected. The shock wave generated by the explosion will not propagate strongly into adjacent cavities, since it will be attenuated by bends in the ducting. The cavity of the affected reformer cavity will possibly suffer damage to its liner, and the closure plug will receive severe pressure loadings. Further analysis will be required to determine if any damage will occur and if so, how extensive it will be.

\subsection{CONTAINMENT ISOLATION CRITERIA}

The process heat HTGR containment must withstand accidents with consequences no different from those of the commercial HTGR. Therefore, the isolation criterion is the same as that of the commercial HTGR. These criteria are described in Ref. 9-27. 


\subsection{STEAM LEAK INTO PCRV}

Even though steam conditions and steam generator designs for the process heat HTGR are the same as those for the commercial HTGR, the higher temperatures in the core enhance the steam-graphite reaction and hydrolysis of the fuel. Presently, the commercial HTGR limits the ingress of steam to the primary system to $1900 \mathrm{lb}$. This value is based in the flammability limits of the $\mathrm{H}_{2}$, $\mathrm{CO}$ mixture formed from the steam-graphite reaction. At the highest temperature, this reaction rate is increased $10^{5}$-fold (see Fig 9-11). However, the prime concern is with how much steam reacts, and in the commercial HTGR the ingress limit is based on a $58 \%$ complete reaction. Therefore, the highest-temperature process heat HTGR steam ingress limit may be at worst one-half of the commercial HTGR limit despite higher reaction rates. Preliminary estimates indicate that even if all the stream reacts with the core graphite, the core integrity will be unimpaired. However, further analysis will be required to determine if any heavy local oxidation wi11 occur.

Because TRISO/TRISO fuel will be used at process temperatures of $1600^{\circ} \mathrm{F}$ and above in the process heat HTGR, preliminary studies indicate increased fuel hydrolyzation of the core will not present a significant problem.

\subsection{EFFECTS OF FISSION PRODUCT INCREASE}

As temperatures in the HTGR core increase, the release of both metallic and gaseous fission products into the primary coolant increases. However, as shown in Table 9-8, the increase of gaseous fission product activities increases weakly with temperature. Because gaseous products produce the primary doses during a DBDA, the increased temperatures have a relatively small effect on the consequences of the accident.

The metallic fission products plate out on the surfaces of the primary circuit. As temperatures increase, the amount of metallic fission products released to the circuit increases rapidly. However, because the temperatures 


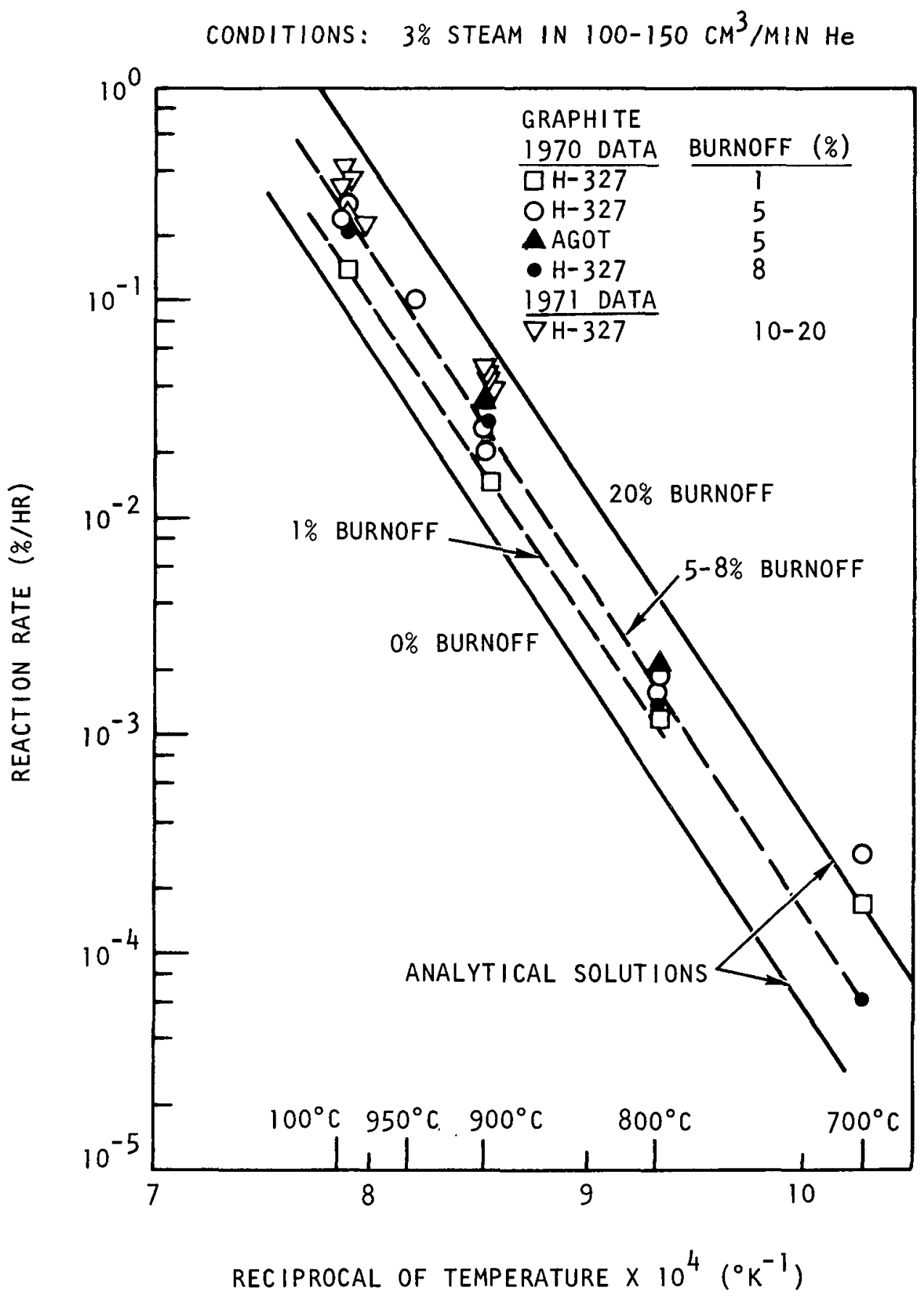

Fig. 9-11. Steam/graphite reaction rates 
TABLE 9-8

RELATIVE CHANGE IN FISSION PRODUCT PRIMARY CIRCUIT ACTIVITY, PLATEOUT, AND REFORMER TUBESHELT DOSES

\begin{tabular}{|c|c|c|c|c|c|}
\hline \multirow{2}{*}{$\begin{array}{c}\text { Process } \\
\text { Gas } \\
\text { Temp. } \\
\left({ }^{\circ} \mathrm{F}\right)\end{array}$} & \multicolumn{2}{|c|}{$\begin{array}{l}\text { Relative Circuit Activity } \\
\text { Above Commercial HTGR }\end{array}$} & \multirow{2}{*}{$\begin{array}{l}\text { Plateout at } \\
\text { Reformer Inlet } \\
(\mathrm{Ci} / \mathrm{cc})\end{array}$} & \multirow{2}{*}{$\begin{array}{c}\text { Dose Above } \\
\text { Reformer Tubesheet }(\mathrm{a}) \\
(\mathrm{mr} / \mathrm{hr})\end{array}$} & \multirow{2}{*}{$\begin{array}{l}\text { Inches of Steel } \\
\text { to Reduce Dose } \\
\text { to } 2.5 \mathrm{mr} / \mathrm{hr}\end{array}$} \\
\hline & Metallic & Gas eous & & & \\
\hline 1200 & 0.6 & 0.48 & $5 \times 10^{-5}$ & 2.1 & 0 \\
\hline 1400 & 5.5 & 0.51 & $6 \times 10^{-5}$ & 2.4 & 0 \\
\hline 1600 & 1.5 & 0.79 & $8 \times 10^{-5}$ & 29 & 3.5 \\
\hline 1800 & 17 & 1.13 & $2 \times 10^{-5}$ & 9 & 2 \\
\hline 2000 & 146 & 1.55 & $2 \times 10^{-5}$ & 7 & 2 \\
\hline
\end{tabular}

(a) Dose due to gamma streaming up exchanger tubes. Tubesheet limits any direct dose. 
of the circuit increase, the plateout per unit of concentration in the circuits goes down and the overall effect keeps plateout from drastically changing. Both the plateout at the reformer process gas inlet and the increase in metallic circulating activity are shown in Table 9-8. These plateout concentrations assume that the governing sorption isotherms are Freundich in nature. They are also based on plateout on Type 304 stainless steel. Adequate data exists for Type 304 stainless steel, whereas for HK40 and silicon carbide, no data were found. Thus, these plateout concentrations represent a "best guess."

Calculated increases in circulating activity assume a constant fuel failure of 0.001 and a changeover from TRISO/BISO fuel for the $1200^{\circ}$ and $1400^{\circ} \mathrm{F}$ cases to TRISO/TRISO fuel for the higher-temperature cases.

The plateout on the reformer has an effect on reformer maintenance and catalyst replacement. Although the reformer tubesheet is more than thick enough to stop all significant radiation, the tube holes in the tubesheet allow gamma streaming. The HK-40 tubes act as effective shields for the $1200^{\circ}$ and $1400^{\circ} \mathrm{F}$ cases. However, for the $1600^{\circ}$ case, the reduced shielding properties of silicon carbide cause excessive doses above the reformer and require the shielding shown in Table 9-8. Because the plateout is reduced at the higher temperatures, the dose rates decrease to the point where only 2 in. of stee 1 shielding is needed at process temperatures of $1800^{\circ}$ and $2000^{\circ} \mathrm{F}$.

\section{$\underline{\text { References }}$}

9-1. Macnab, D. I., "The CONTEMPT-G Computer Program and its Application to HTGR Containments, General Atomic Report GA-A12692, February 1, 1974 .

9-2. "Fulton Generating Station Preliminary Safety Analysis Report," Chapter 15, "Safety Analysis."

9-3. Barrer, R.M., Diffusion In and Through Solids, The University Press, Cambridge, England, 1951. 
9-4. Lee, R. W., R. C. Frank, and D. E. Swets, J. Chem. Phys. 36, 1062 (1962).

9-5. Roberts, E. W., and J. P. Roberts, Bul1, Soc. Franc. Ceram. 77, 3 (1967).

9-6. Smith, T., J. Nuc1. Mat. 18, 323 (1966).

9-7. Webb, R. W., "Permeation of Hydrogen through Metals," USAEC Report NAA-SR-10462, Atomics International, July 25, 1965.

9-8. Archakov, Yu I., I. D. Grebeshkova, and V. P. Teodorovich, Zh. Prik1. Khim. 34 (4), 821 (1961).

9-9. Randa11, D., and O. N. Salmon, "Diffusion Studies. I. The Permeability of Type 347 Stainless Steel to Hydrogen and to Tritium," USAEC Report KAPL-904, Knolls Atomic Power Laboratory, March 17, 1953.

9-10. Smithe11s, C. J., and C. E. Ransley, Proc. Roy. Soc. (London) A150, 172 (1935).

9-11. Flint, P. S., "The Diffusion of Hydrogen Through Materials of Construction," USAEC Report KAPL-659, Knolls Atomic Power Laboratory, December 14, 1951 .

9-12. Huffine, C. L., and J. M. Williams, Corrosion 16, 102 (1960).

9-13. Steigerwald, E. A., "The Permeation of Hydrogen Through Materials for the Sunflower System," NASA Report NASA-CR-54004 (TRW-ER-5623), Thompson Ramo Wooldridge, November 15, 1963.

9-14. Subbotin, V. I., et al., At. Energ. (USSR) 30 (1), 46 (1971).

9-15. Sharp, W. B. A., Corrosion Sci. 10, 283 (1970).

9-16. Belyakov, Yu I., Yu I. Zvezdin, and A. A. Kurdyumov, Fiz. Khim. Mekt. Mater. 6 (3), 37 (1970).

9-17. Yang, Ling, General Atomic Company, "Calculations of Tritium Permeation Rates Through HTGR Heat Exchangers," unpublished data.

9-18. Hopkins, G. R., "Fusion Reactor Applications of Silicon Carbide and Carbon," USAEC Report GA-A12999, General Atomic Company, Apri1 16, 1974.

9-19. Frank, R. C., R. W. Lee, and R. L. Williams, J. App1. Phys. 29, 898 (1958). 
9-20. Jacobs, D. G., et al., "A Preliminary Assessment of the Radiological Implications of Commercial Utilization of Natural Gas from a Nuclearly Stimulated Well," in Proceedings of the Symposium on Engineering with Nuclear Explosives, Las Vegas, Nevada, January 14-16, 1970, American Nuclear Society, Hinsdale, Illinois, May 1970 (CONF-700101).

9-21. Jacobs, D. G., et a1., "Dose Estimation Related to Peaceful Uses of Nuclear Explosives, Health Physics Division Annual Progress Report for Period Ending July 31, 1969," USAEC Report ORNL-4446, Oak Ridge National Laboratory, October 1969.

9-22. NcNelis, D. N., and R. G. Patzer, "Exposure-Dose Research for Radionuclides in Natural Gas," in Symposium on Public Health Aspects of Peaceful Uses of Nuclear Explosives, Las Vegas, Nevada, 1969 (CONF690406).

9-23. Barton, C. J., et al., "Quarterly Progress Report on Radiological Safety of Peaceful Uses of Nuclear Explosives: Hypothetical Exposures to Rulison Gas," USAEC Report ORNL-TM-3601, Oak Ridge National Laboratory, October 1971.

9-24. Barton, C. J., et al., Nuc1. Technol. 11, 335 (1971).

9-25. Federal Register, U.S. Government Printing Office, Vo1. 36, No. 111, June 9, 1971 (10 CFR 50).

9-26. 1972 Gas Facts, American Gas Association, Department of Statistics, Arlington, Virginia.

9-27. "Fulton Generating Station Preliminary Safety Analysis Report," Chapter 16, "Engineered Safety Features." 
10. RESEARCH AND DEVELOPMENT REQUIREMENTS

The Research and Development Program includes six major areas: fuel, core components, materials research, the thermal barrier, the reformer, and the helium circulator turbine. For convenience, the discussion of the program has been divided into two sections. Section 10.1, "Research and Development Program," includes basic research required for preliminary and detailed design. Section 10.2, "Design Development Program," includes extraordinary systems analysis and design studies required for development of the first process heat reactor. Demonstration plants, if needed, have not been considered.

10.1. RESEARCH AND DEVELOPMENT PROGRAM 10.1.1. Development of Advanced HTGR Fuel Systems for Process Heat Appli-

In the design of HTGR systems for process heat applications, helium outlet temperatures of $1400^{\circ}$ to $2200^{\circ} \mathrm{F}\left(760^{\circ}\right.$ to $\left.1205^{\circ} \mathrm{C}\right)$ are being considered. As the field of potential use broadens and the chemical conversion efficiency increases with temperature, the advantage of a higher helium outlet temperature is obvious. However, a higher helium outlet temperature demands a higher fuel temperature. Even with improved fuel element block design and fuel management strategy, maximum nominal fuel temperatures of $2300^{\circ}$ to $2950^{\circ} \mathrm{F}\left(1260^{\circ}\right.$ to $\left.1620^{\circ} \mathrm{C}\right)$ are required to attain the helium outlet temperatures described above. The fuel of the current HTGR reference design (TRISOcoated $\mathrm{UC}_{2}$ as fissile kernels and BISO-coated $\mathrm{ThO}_{2}$ as fertile kernels) is at the limit for reliable performance with a maximum nominal core temperature of $1350^{\circ} \mathrm{C}$. Although the current reference fuel system performs satisfactorily during transients to higher temperatures, improved fuel systems are needed to meet the more severe temperature requirement of the 
process heat reactor. The primary objective of the advanced fuel program described in this section is to develop HTGR fuel systems of improved chemical, mechanical, and thermal stability and reduced metallic fission product release rates at high temperatures. Such advanced fuel systems are needed to broaden the potential of the HTGR system as a process heat source.

10.1.1.1. Factors Limiting Operating Temperature of HTGR Fuel system. Extensive in-pile studies carried out at General Atomic Company and by other workers during the past several years have shown that when HTGR fuel particles operate in a reactor environment, a number of physiochemical and mechanical processes occurring in the kernel and the coating are detrimental to fuel performance and fuel particle integrity. The detrimental effects of these processes increase with temperature and thus set the operating temperature limit of the fuel system. Among the most influential processes are:

1. Diffusion of metallic fission products (e.g., cesium and strontium) through pyrolytic carbon coatings.

2. Chemical reactions between rare earth fission products and silicon carbide coatings.

3. Migration of fuel kernels and transport of carbon coating in a thermal gradient.

4. Dimensional changes of pyrolytic carbon coatings under fast neutron irradiation.

The specific effects of each of these processes on the life and performance of fertile particles, fissile particles, and fuel rod matrix are discussed below. 
Fertile Particles

The HTGR fertile particles consist of $\mathrm{ThO}_{2}$ kernels coated with a porous carbon buffer layer to attenuate fission recoils and to provide void for accommodation of gaseous fission products and an isotropic pyrolytic carbon layer to contain fission products. The major problems anticipated in raising the operating temperature limit of such BISO-coated $\mathrm{ThO}_{2}$ particles are as follows.

Diffusion of Metallic Fission Products Through Pyrolytic Carbon Coatings. Although an intact BISO coating can contain the fission gases, it is not a complete barrier to the diffusion of metallic fission products, such as cesium and strontium (Ref, 10-1). The complete release of these fission products to the helium coolant could cause plant maintenance and safety problems. The use of a TRISO coating (i.e., addition of a silicon carbide layer and an outer isotropic pyrolytic carbon layer to the BISO-coating design) could reduce such release, but a severe penalty would have to be paid in fabrication cost, plant investment, and silicon neutron poisoning.

Dimensional Change of Pyrolytic Carbon Coating Under Fast Neutron Irradiation. The isotropic pyrolytic carbon coating undergoes dimension changes during irradiation which are initially isotropic but which subsequently become anisotropic (Ref. 10-2). The dimensional change rates increase with temperature. These dimensional changes lead to a shrinkage of the individual particles and thus to a shrinkage of the fuel rod which deteriorates the heat transfer characteristics between the fuel rod and the graphite block. Also, increasing dimensional change rates of the pyrolytic carbon coatings increase the likelihood of coating failure.

Migration of $\mathrm{ThO}_{2}$ Kernel and Transport of Carbon Coating in a Thermal Gradient--the Amoeba Effect. The mechanism for such transport phenomena for oxide kernels has not been well established, although it is generally accepted that it is related to an increased oxygen activity created by burnup. Empirical correlation of $\mathrm{ThO}_{2}$ kernel migration data has been made 
with temperature and thermal gradient on the same basis as for carbide kernels (Ref. 10-3). In general, the coated particles are assumed to fail when the kernel migrates through the porous buffer coating. The experimental data indicate that while the migration of the $\mathrm{ThO}_{2}$ kernel is insignificant during in-pile operation at $1250^{\circ} \mathrm{C}$, the situation may become worrisome at $1500^{\circ} \mathrm{C}$.

\section{Fissile Particles}

Particles Containing Carbide Kernels. The reference HTGR fissile particles consist of $\mathrm{UC}_{2}$ kernels prepared by the ion-exchange resin process and coated with a TRISO coating. The use of a TRISO coating ensures low metallic fission product release and dimensional stability under fast neutron irradiation at high temperatures. The major problems associated with operating TRISO-coated $\mathrm{UC}_{2}$ kernels at high temperatures are as follows:

1. Chemical reaction between rare earth fission products and the silicon carbide coating. In TRISO-coated $\mathrm{UC}_{2}$ fissile particles at high burnups (e.g., 70\% FIMA) and high temperatures (e.g., $1350^{\circ} \mathrm{C}$ ), it has been observed that the rare earth fission products (e.g., neodymium, cerium, lanthanum, praseodymium) migrate down the temperature gradient and react with the silicon carbide coating at the cooler side (Ref. 10-3). The reaction, probably involving the formation of rare earth silicides, leads to the degradation of the silicon carbide coating and the premature failure of the coated particle.

2. Migration of the $\mathrm{UC}_{2}$ kernel and transport of the carbon coating in a thermal gradient--the amoeba effect. The mechanism for carbide kernel migration is well understood (Ref. 10-4). Carbon is taken into solution in the kernel from the adjacent carbon coating on the hot side, transported across the fuel phase by solid state diffusion under the influence of a thermal gradient, and 
rejected as graphite on the cool side. As a result, the kernel is displaced toward the hot side. Existing data (Ref. 10-5) on carbide kernel migration indicate that the kernel may migrate through the 85 microns of buffer coating in $4 \mathrm{yr}$ at about $1400^{\circ} \mathrm{C}$, assuming a thermal gradient of $50^{\circ} \mathrm{C}$ per $\mathrm{cm}$. At the higher temperatures of the process heat reactor, kernel migration may be excessive.

Particles Containing Oxide Kernels. Although oxide kernels are not selected as the HTGR reference fissile kernel, they are of interest to the advanced fuel developmental program because of their high melting points and high-temperature stability, especially the $\mathrm{ThO}_{2}-\mathrm{UO}_{2}$ systems.

The major problems anticipated during the operation of $\mathrm{ThO}_{2}-\mathrm{UO}_{2}$ fuel kernels at high temperatures are similar to those described above for the $\mathrm{ThO}_{2}$ kernels. However, because of the higher burnup in the $\mathrm{ThO}_{2}-\mathrm{UO}_{2}$ kernels, the metallic fission product release and the kernel migration problems are expected to be more severe.

Fuel Rod

The HTGR fuel rod consists of fissile and fertile particles dispersed in a matrix of graphite filler and petroleum pitch coke binder. For a given helium outlet temperature, the fuel particle temperature depends on the thermal conductivity of the fuel rod matrix material. Since the thermal conductivity of the fuel rod matrix material increases with the graphite filler content, there is strong incentive for increasing the graphite filler content of the reference HTGR fuel rod in order to avoid excessive fuel temperature at the high helium outlet temperature in a process heat reactor.

10.1.1.2. Advanced HTGR Fuel Program Plan. The anticipated problem areas in the development of advanced HTGR fuel systems for process heat applications are described above. Specific material improvements for the fertile particle, the fissile particle, and the fuel rod matrix material are needed to overcome these problems. General Atomic Company has been engaged in the 
development of advanced fuel materials for improving the performance of the steam cycle HTGR fuel system since 1963. The program has been accelerated during the past 2 yr to meet the advanced HTGR system requirements. Special fuel kernel, coating, and fuel rod matrix materials are under development for an advanced HTGR fuel system capable of operating at temperatures $150^{\circ}$ to $200^{\circ} \mathrm{C}$ higher than the current HTGR fuel system. With a strong base already established on material development and out-of-pile evaluation, the most urgent work needed consists of the irradiation qualification of the advanced fuel materials. The various steps required in irradiation qualffication of an advanced fuel system from initial conception through to fullscale production are as follows:

1. Initial demonstration to provide enough confidence for a decision to commit additional irradiation space.

2. Integral demonstration to provide a firm enough data base for considering the fuel a viable candidate to meet the highertemperature performance goals.

3. Preliminary definition of fuel thermal performance to provide a basis for core thermal design and safety studies.

4. Statistically valid demonstration of fuel performance to provide support for fuel specifications, and eventually to convince licensing authorities of the adequacy of the fuel and of the preliminary fuel specifications.

5. Final definition of fuel thermal performance for the Final Safety Analysis Report.

6. Proof testing of pilot plant and production fuel to provide the final confirmation of the performance of fuel made to the specifications. 
It is believed that the tasks to be immediately undertaken should concern only the first two 1tems, i.e., the initial demonstration tests and the integral demonstration tests. Irradiation plans related to the rest of these items will be made only after the results from these tests have been evaluated.

The purpose of the initial demonstration tests is to define the optimum fuel kernel chemistry and coating compositions and structures for reducing metallic fission product release and improving the chemical and mechanical stabilities of the coated fuel particles under irradiation at high temperatures. The test samples will be in the form of loose fertile and fissile particles. Following irradiation to full burnup and fast neutron exposure in the temperature range of interest for process heat applications, the microstructures of these test samples will be examined in the hot cell for any kernel migration and chemical reaction between fission products and coating. The release of fission products will be determined from burnup data and radiochemical analysis and gamma-counting results of the 1rradiated particles, and particle dimensional changes will be measured by determining changes in density. Following hot cell examinations, the test samples will be further annealed out-of-pile to determine their fission product release and kernel migration behaviors. The results will be used to select the compositions, structures, and temperature range for the integral demonstration tests.

The purpose of the integral demonstration tests is to study the hightemperature performance of HTGR fuel rods containing fertile and fissile particles of optimum compositions and structures and fuel rod matrix materials of improved thermal conductivity. This will serve as a check of how individual fuel components (i.e., the fertile particles, the fissile particles, and the fuel rod matrix) containing all the improved features will work cooperatively as an integral fuel rod. Following irradiation to full burnup and fast neutron exposure at selected temperatures, the irradiated fuel rod samples will be examined in the hot cell for dimensional changes, macroscopic appearance, and microstructures of fuel kernels, coatings, and fuel 
rod matrix materials. The test results will be used as the basis for planning irradiation tests for the definition of fuel thermal performance and fuel specifications and the proof tests of the pilot plant and production fuel.

In view of the number of variables to be studied and the work currently being performed at General Atomic Company, it is concluded that a minimum of three irradiation capsules will be needed for the initial demonstration tests of the loose particles, and that a minimum of two additional irradiation capsules will be required for the integral demonstration tests of the fuel rods. The schedule for these tests is shown in Table 10-1.

The ground rules for the schedule shown in Table 10-1 are as follows:

1. The three capsules for the initial demonstration tests will contain loose particle samples to cover all the variables to be screened. The capsule schedules will be controlled by the fabrication schedule.

2. The fabrication of the samples for the integral demonstration tests on fuel rods will not be initiated until all the initial demonstration results, including both the hot cell and the postirradiation data, are fully evaluated.

3. The two capsules for the integral demonstration tests will contain fuel rods incorporating improved features selected from the initial demonstration test results. The capsule schedules will be controlled by the fabrication schedule.

Assuming that the irradiation program can be initiated at the beginning of calendar year 1975, the tests will be completed by the end of calendar year 1979. The total time needed to complete the initial and the integral demonstration tests is thus about $5 \mathrm{yr}$. It is estimated that probably another $5 \mathrm{yr}$ are needed to complete the rest of the irradiation program for 
ABLE $10-1$

SCHEDULE FOR INITIAL AND INTEGRAL IRRADIATION TESTS OF ADVANCED HTGR FUEL SYSTEM

\begin{tabular}{|c|c|c|c|c|c|c|c|c|c|c|c|c|c|c|}
\hline \multirow{2}{*}{\multicolumn{2}{|c|}{$\begin{array}{c}\text { Calendar } \\
\text { Year }\end{array}$}} & \multicolumn{3}{|c|}{1975} & \multicolumn{2}{|c|}{1976} & \multicolumn{2}{|c|}{1977} & \multicolumn{3}{|c|}{1978} & \multicolumn{3}{|c|}{1979} \\
\hline & & & & & & & & & & & & & & \\
\hline \multirow{3}{*}{$\begin{array}{c}\text { Initial } \\
\text { Demonstration } \\
\text { Tests } \\
\text { (1oose particles) }\end{array}$} & Capsule 1 & \begin{tabular}{l|l}
$D$ & $F$
\end{tabular} & $\mathrm{~A}$ & \multicolumn{3}{|c|}{$\operatorname{Irr}$} & \multicolumn{8}{|l|}{$\mathrm{HC}+\mathrm{PA}$} \\
\hline & Capsule 2 & & $\mathrm{~F}$ & A & \multicolumn{2}{|c|}{$\operatorname{Irr}$} & \multirow{2}{*}{\multicolumn{2}{|c|}{\begin{tabular}{|l|l|}
\multicolumn{2}{|l|}{$\mathrm{HC}+\mathrm{PA}$} \\
& $\mathrm{HC}+\mathrm{PA}$ \\
\end{tabular}}} & & & & & & \\
\hline & Capsule 3 & & & $F$ & $A$ & $\operatorname{Irr}$ & & & & & & & & \\
\hline \multirow{2}{*}{$\begin{array}{l}\text { Integra1 Demonstra- } \\
\text { tion Tests (fuel } \\
\text { rods) }\end{array}$} & Capsule 4 & & & & & & & D & $\mathrm{F}$ & A & \multicolumn{2}{|r|}{$\operatorname{Irr}$} & $\mathrm{HC}$ & \\
\hline & Capsule 5 & & & & & & & & & $F$ & A & Irr & & $\mathrm{HC}$ \\
\hline
\end{tabular}

\footnotetext{
Note: $\quad \mathrm{D}=$ capsule design

$F=$ sample fabrication

$\mathrm{A}=$ capsule assemb1y

$\operatorname{Irr}=$ capsule irradiation

$\mathrm{HC}=$ hot cell examination

$\mathrm{PA}=$ postirradiation annealing studies
} 
defining fuel thermal performance and fuel specifications and for proof testing the pilot line and production fuel. Thus, the development of the advanced HTGR fuel system will require a period of about 10 yr (1975 - 1984).

\subsubsection{Core Components}

Research and development efforts for core components will center primarily around metallic components in the core. At temperatures above the current HTGR steam plant temperatures, the iron-base alloys presently used for the cladding and support spine for the control rods will require replacement with improved materials. The plenum elements and orifice mechanisms which see service at the core inlet temperature will probably require only minor design changes for the temperatures considered in this study. No major difficulties are foreseen in graphite fuel blocks and reflector elements, although detailed stress analysis and some design changes will be required. An improved grade of near-isotropic graphite, H-451 manufactured by Great Lakes Carbon Company, is recommended for use at the higher core outlet temperatures. Development and qualification of high-temperature thermocouples for in-core instrumentation will be required for process temperatures above $1400^{\circ} \mathrm{F}$ or core outlet temperatures above $1600^{\circ} \mathrm{F}$.

\subsubsection{Control Rods}

\section{Design Changes}

The design changes required for control rods are as follows:

1. The outer cladding, now an iron-base alloy, would have to be replaced because of the higher temperatures $\left(1900^{\circ}\right.$ to $2100^{\circ} \mathrm{F}$ ) involved. Design may require oxidation-resistant boronated graphite compacts, coated refractory metals, or some non-metallic cladding material. 
2. Support spine temperatures of $1300^{\circ}$ to $1400^{\circ} \mathrm{F}$ are near the point where strength begins to fade off rapidly for iron-base alloys. Above $1500^{\circ} \mathrm{F}$, carburization becomes a potential problem. A new design may involve a change to a refractory metal with some type of carburization-resistant plating or a developmental program of a non-metallic support material.

3. Abrasion-resistant coatings now being considered (chromium carbide) would have to be evaluated under the new conditions. Self-welding of metallic components and abrasion of metal against graphite are more severe at higher temperatures, making the design requirements for the coatings more stringent.

4. The distribution of coolant flow will have to be evaluated and optimized for peak temperatures and thermal gradients in the compacts and support structure.

Development Program for Process Temperatures of $1600^{\circ}$ to $2000^{\circ} \mathrm{F}$

An outiine of the control rod development program for process temperatures of $1600^{\circ}$ to $2000^{\circ} \mathrm{F}$ is given in the following table: 
1. Preliminary Study

a. Thermal analysis: examine temperatures 10,000 of current design based on changes in core conditions.

b. Design and materials analysis: review 25,000 current design concept and alternatives to find "best solution." Review candidate materials.

2. Design and Development

a. Preliminary design

(1) Conceptual study 15,000

(2) Preliminary testing 50,000

(3) Thermal and flow analysis 25,000

b. Materials evaluation and testing

Tota1 Cost: $\$ 360,000$ 
10.1.2.2. In-Core-Instrumentation. Chrome1-Alumel thermocouples currently used in the HTGR steam plant core will be unacceptable for use in process heat reactors with core outlet temperatures above $1600^{\circ} \mathrm{F}$. At present, no thermocouples have been qualified at these temperatures for use in the nuclear core.

An outline of the in-core instrumentation development program for process gas temperatures of $1600^{\circ}$ to $2000^{\circ} \mathrm{F}$ is given below.

$\begin{array}{lc}\text { 1. Preliminary scouting tests of thermocouple } & \$ 50,000 \\ \text { materials in neutron flux environment } & \\ \begin{array}{l}\text { 2. Development, testing, and calibration of } \\ \text { thermocouples }\end{array} & \$ 250,000 \\ \text { Total Cost } & \$ 300,000 \\ \text { Time Required } & 6 \mathrm{yr}\end{array}$

10.1.3. Materials Research

In this section the materials research and development discussion is presented in two parts; "Metallic Materials" and "Ceramic Materials." Together, these comprise a comprehensive assessment of candidate structural materials and test plans for the necessary detailed design of gas-cooled reactor/reformer systems producing process temperatures of $1200^{\circ}$ to $2000^{\circ} \mathrm{F}$. The metallic materials program is generally applicable to all temperature leve1s. The ceramic materials program focuses on the development of reformer materials for the cases with process temperatures of $1600^{\circ}, 1800^{\circ}$, and $2000^{\circ} \mathrm{F}$.

\subsubsection{Metallic Materials}

\section{Introduction}

High temperature, gas-cooled reactors are being considered as a heat source for driving endothermic reactions to produce chemicals demanded by 
industry and society. A particularly promising application incorporates the HTGR with a steam/light-hydrocarbon reformer, the latter being heated b) the high-temperature helium gas coolant as it leaves the reactor core. Since reaction temperatures of $1200^{\circ}$ to $2000^{\circ} \mathrm{F}$ are of interest, the immediate question of material capabilities must be addressed in considering feasible reactor/reformer systems. The present HTGR design can probably deliver a temperature of $1400^{\circ} \mathrm{F}$ within a process stream with minor design changes. Conventional reformers are used at temperatures up to $1600^{\circ} \mathrm{F}$. These conditions represent the early base-line condition but require further qualification prior to the combining or extrapolating of current designs. 'ncreasing the temperature of the reactor immediately curtails use of many of its present structural materials. Futhermore, reformers are generally designed for 5- to 10-yr lifetimes and have the capability of being maintained and readily repaired if premature failure should occur. Thus, these two qualifications impose a substantial degree of materials consideration for designing a high-temperature long-term (30 yr) reactor/reformer.

The proposed program will identify problems encountered in selecting materials for reactor/reformer systems as a function of process stream temperature, design-load requirements, potential environment interactions, and design lifetime requirements.

\section{Process Heat HTGR/Reformer: Requirements of Materials}

The process heat $\mathrm{HTGR} /$ reformer system will be required to operate for approximately $260,000 \mathrm{hr}$. Each component will be designed for this service lifetime in order to ensure reliability and to minimize inspection, maintenance, and repair requirements. The proper selection and application of structural materials in the high-temperature, high-pressure helium environment of the HTGR as well as the reformer process environment will be primary factors in attaining these design goals. Conventional structural and high-temperature alloys will be employed in the system when possible, but in the cases of high operating temperatures, evaluation will 
be required of dispersion-strengthened alloys, superalloys, molybdenum TZM, and ceramic materials for certain areas of the core ducting/thermal barrier system. Use of ceramic reformer tubes may be mandatory for longterm operation at $1800^{\circ} \mathrm{F}$ and above. The long-term behavior of these materials in the HTGR helium environment must be characterized, and possible environmental effects on design properties must be quantified. Active degradation mechanisms such as internal oxidation or carburization of alloying elements must be identified and understood to adequately predict and ensure the required service lifetimes. Conventional reformers are generally designed for 5- to 10-yr lifetimes at internal pressures up to 500 psig. As a result, additional considerations will be necessary for long-term usage of the conventional reformer tubing materials. In addition, reformer tubes within an HTGR will have an external pressure greater than the internal pressure, $\Delta \mathrm{P} \cong 400 \mathrm{psig}$, which will result in both compressive hoop stress and creep.

A brief review of a process heat HTGR/reformer system is presented here to identify the major components which will require materials study as a function of increasing design temperature. In the process heat HTGR (see Fig. 10-1), helium flows downward through the core, where it is heated. The helium passes through one of the radial ducts going to the reformer and then passes upward through the reformer cavity. Heat is transferred through the reformer tube walls to the steam-methane mixture. The helium then flows through the circumferential duct (not shown in Fig. 10-1) to the adjacent steam generator cavity, where it passes downward over the steam generator coils. It next passes upward around the steam generator and into the helium circulator, where it is compressed. It then passes through the upper horizontal duct and back into the core.

Most of the features of the process heat HTGR/reformer system are identical to those of the HTGR used for electric power generation. A significant difference is the addition of a reformer unit in a wall cavity of the PCRV. This reformer is similar in size to existing steam generators and can be installed and removed in the same manner. 


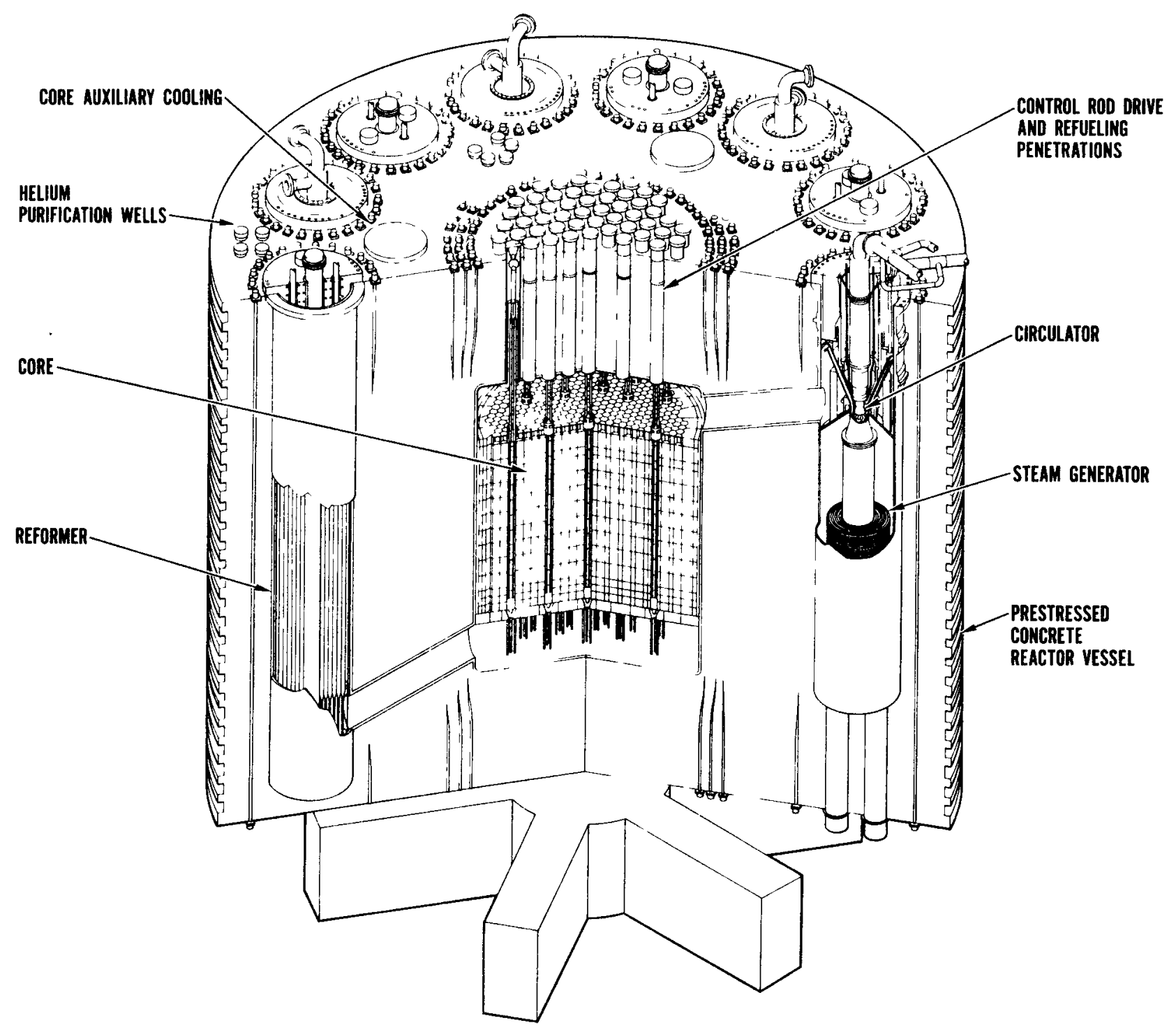

Fig. 10-1. Process heat HTGR/reformer system 
The major structural components affected by higher temperatures of operation are the thermal barriers and core ducting from the core floor into the reformer and the reformer tubes and connecting components. Figures 5-1 and 5-4 show a cross section through these areas. The anticipated service conditions and the important material property requirements for these components are summarized in Table 10-2. A partial list of the alloys currently being considered for application is included in the table. The candidate materials include austenitic stainless steels, iron-chromium-nicke1, heat-resistant casting and wrought alloys, nicke1base superalloys, dispersion-strengthened nickel alloys, molybdenum TZM, and ceramic $\mathrm{SiC}, \mathrm{Si}_{3} \mathrm{~N}_{4}$, and $\mathrm{Al}_{2} \mathrm{O}_{3}$, depending upon nominal service and maximum temperature requirements, which range from $1000^{\circ}$ to $2800^{\circ} \mathrm{F}$.

For materials of interest, creep and stress-rupture properties will be important for the design of components, since operating temperatures will generally be above $1000^{\circ} \mathrm{F}$. Oxidation rate will be important for components exposed to the process stream.

\section{Background}

Environmental Interaction in Helium-Cooled Reactors. Gas-cooled nuclear reactors which have used a helium environment as the primary coolant have not experienced failure of metal components which could be attributed to environmental/metal interaction (Ref. 10-6). While this statement shows merit for helium environments, there has been experimental evidence of high-temperature materials being oxidized, carburized, or a combination of both by helium-containing impurities of $\mathrm{H}_{2}, \mathrm{CO}, \mathrm{CO}_{2}, \mathrm{H}_{2} \mathrm{O}$, $\mathrm{CH}_{4}$, and $\mathrm{O}_{2}$ (Refs. 10-6 through 10-9). The potential for reduced integrity due to gaseous interaction with the structural materials of a reactor at high temperatures must be addressed in order to predict service behavior. The HTGR helium environment is likely to be weakly oxidizing or, in some instances, may be reducing, depending upon the amounts and ratios of impurities, which include $\mathrm{H}_{2}, \mathrm{H}_{2} \mathrm{O}, \mathrm{CO}, \mathrm{CO}_{2}$, and $\mathrm{CH}_{4}$. The impurity content of the helium coolant is determined by the HTGR graphite core, 
TABLE 10-2

HTGR/RFFORMFR COMPONENT MATERTAL REQUTREMENTS

\begin{tabular}{|c|c|c|c|c|}
\hline Component & $\begin{array}{l}\text { Typical Service } \\
\text { Conditions }\end{array}$ & $\begin{array}{c}\text { Important Material Froperties } \\
\text { for Design }\end{array}$ & $\begin{array}{l}\text { Important Considerations in } \\
\text { Materials Selection }\end{array}$ & $\begin{array}{c}\text { Typıcal } \\
\text { Candidate Materıals }\end{array}$ \\
\hline Reformer & Process gas temp. $+\Delta \mathrm{T}$ & & & \\
\hline Tubes & $+200^{\circ} \mathrm{F}$ & $\begin{array}{l}\text { Stress rupture, ductility, creep } \\
\text { resistance }\end{array}$ & $\begin{array}{l}\text { Possible effects of HTGR He environment } \\
\text { Effects of reformer environment } \\
\text { Weldability }\end{array}$ & $\begin{array}{l}\text { HK-40, Incoloy } 800,807 \\
\text { IN519, } \mathrm{SIC}, \mathrm{S1}_{1} \mathrm{~N}_{4} \\
\text { Inconel MA753, } \\
\text { Hastelloy } \mathrm{X}\end{array}$ \\
\hline Pigtalls & $+200^{\circ} \mathrm{F}$ & $\begin{array}{l}\text { Stress rupture, ductility, creep } \\
\text { resistance }\end{array}$ & Fornability & $\begin{array}{l}\text { Incoloy } 800,807 \\
\text { Hastelloy } x\end{array}$ \\
\hline Tubesheet & $+200^{\circ} \mathrm{F}$ & $\begin{array}{l}\text { Yield strength, creep resistance, } \\
\text { tensile strength }\end{array}$ & $\downarrow$ Fabricability & 304L SS \\
\hline $\begin{array}{l}\text { Cylindrical } \\
\text { cover plate }\end{array}$ & $+200^{\circ} \mathrm{F}$ & $\begin{array}{l}\text { Yield and ultimate strength, } \\
\text { creep resistance }\end{array}$ & & 316 SS, Incoloy 800 , Hastelloy $\mathrm{X}$ \\
\hline $\begin{array}{l}\text { Process } \\
\text { 1n-duct }\end{array}$ & $-200^{\circ} \mathrm{F}$ & $\begin{array}{l}\text { Stress rupture, ductility, creep } \\
\text { resistance }\end{array}$ & & $\begin{array}{l}\mathrm{HK}-40 \text {, Incoloy } 800,807 \\
321 \text { SS, Incoloy } 800\end{array}$ \\
\hline $\begin{array}{l}\text { Process } \\
\text { out-duct }\end{array}$ & $+200^{\circ} \mathrm{F}$ & $\begin{array}{l}\text { Stress rupture, ductility, creep } \\
\text { resistance }\end{array}$ & $\downarrow$ & $\begin{array}{l}\mathrm{HK}-40 \text {, Incoloy } 800,807, \\
\text { IN519, S1C, S1 } 3_{4}, \\
\text { InconeI MA753, Hastelloy X }\end{array}$ \\
\hline Ducting Coverplate & Core outlet ternp & Creep resistance & $\left.\right|^{\text {Fabricability }}$ & $\begin{array}{l}\text { Hastelloy X, Mo-TZM, SiC, } \\
\mathrm{S}_{3} \mathrm{~N}_{4}\end{array}$ \\
\hline Valves & & $\begin{array}{l}\text { Yield strength, tensile strength, } \\
\text { ductility }\end{array}$ & +1 & $\begin{array}{l}347 \mathrm{SS}, 321 \mathrm{SS}, 2-1 / 4 \mathrm{Cr}-1 \mathrm{Mo} \text {, } \\
316 \mathrm{SS}\end{array}$ \\
\hline
\end{tabular}


temperature, the ingress of impurities, purification rates, and irradiation effects. It has been shown that the nature and composition of the oxide film, which normally contributes to the long-time structural integrity of these alloys, may be altered in this environment: strengthening constituents can be depleted from the matrix (particulary titanium), and intergranular attack can be initiated (Refs. 10-7 through 10-9). In addition, selective alloying element loss due to vaporization, which has been shown to affect properties in a vacuum (Ref. 10-10), may be an important consideration in flowing high-pressure helium. Although the data are limited, it appears that the extent of these possible effects depends on the helium impurity content, alloy type and composition, exposure time, and temperature.

Genera1 Atomic Company is presently investigating materia1/gas interactions in helium environments simulating or bracketing that in the Fort St. Vrain reactor or those anticipated in the commercial HTGRs. Also, as part of the design studies for the direct-cycle gas turbine program, a creep-compatibility screening test is in the final stage of preparation for incorporation with the Dragon Reactor Experiment in England. At the very low impurity levels found, the rates of reaction are anticipated to be significantly dependent on the partial pressure of the impurity gases within the helium coolant.

After various exposures to the different controlled atmospheres, specimens are cross-sectioned and examined. Both optical and scanning electron microscopy are used to establish the oxidation and/or carburization which occurred internally or at the exposed surfaces. Quantitative analysis of alloying elements within the reaction zone are established using an electron microprobe analyzer.

Conventional Reformer Materials - Present Technology. Typically, the selection of reformer components is based on stress to produce rupture in $100,000 \mathrm{hr}$. The main component in terms of quantity and weight is the reformer tube. A typical life history of a reformer tube consists of the 
following. Under pressure at high temperature, hoop stress within the reformer tube imparts strain and thus steady-state creep commences. However, both cyclic conditions and nonuniform heating through the wall can occur during startup and shutdown sequences. When these conditions occur in conjunction with steady-state creep, the straining capability of the tube material is often prematurely consumed, resulting in early failure by the mechanism of strain limitation. Currently used reformer materials, basically iron-chromium-nickel alloys either in wrought or cast form, are found to be adequate for intended service conditions, which are typically up to $1850^{\circ} \mathrm{F}$ and 500-psi internal temperature and pressure. The results of industry studies (Refs. 10-11 through 10-13) indicated that a broad selection of metallic materials are viable candidates for reformer systems where process stream temperature reaches $1850^{\circ} \mathrm{F}$. These are the standard cast iron-chromium-nickel heat-resistant alloys (e.g., HK-40), the wrought iron-chromium-nickel alloys (e.g., Incoloy 800), the cast nickel-chromium alloys, and the nickel- and cobalt-base superalloys.

A typical reformer tube unit is about $40 \mathrm{ft}$ long and is fabricated by welding together four 10-ft-long tubes. A tube is generally made by the centrifugally casting process. Wrought tubing is usually extruded. In the petrochemical industry, a conventional reforming furnace may enclose 50 to 100 reformer tubes.

Present practices for the design and retirement of reformer tubes operating at elevated temperatures $\left(1200^{\circ}\right.$ to $\left.1900^{\circ} \mathrm{F}\right)$ and under internal pressure often to 500 psi are not uniform within the petroleum industry and do not necessarily conform with the ASME Boiler and Pressure Vessel Code. The ASA recommended formula is considered the most practical one and is generally used as follows once an allowable stress is set (from stress-rupture data), a pressure is established, and a tube diameter is selected:

$$
t=\frac{P D}{2 S+2 y P}
$$




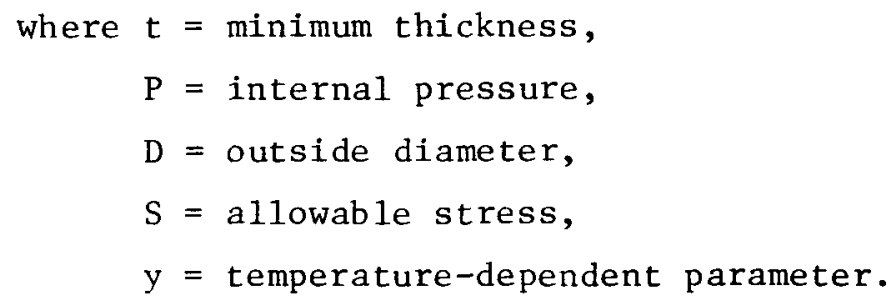

The parameter $\mathrm{y}$ has the following values:

\begin{tabular}{|c|c|c|c|c|c|c|}
\hline Temp. $\left({ }^{\circ} \mathrm{F}\right)$ & $\begin{array}{c}900 \text { And } \\
\text { Below }\end{array}$ & 950 & 1000 & 1050 & 1100 & $\begin{array}{r}1150 \\
\text { And } \\
\text { Above } \\
\end{array}$ \\
\hline$y$, ferritic steels & 0.4 & 0.5 & 0.7 & 0.7 & 0.7 & 0.7 \\
\hline$y$, austenitic & & & & . & & \\
\hline steels & 0.4 & 0.4 & 0.4 & 0.4 & 0.5 & 0.7 \\
\hline
\end{tabular}

Allowance for corrosion is taken into account when corrosion data or experience is available. Stress considerations related to thermal gradients and shock during interrupted cycles are not taken into account. However, a considerable history of satisfactory experience has been developed with tube design based on internal pressure considerations only (Ref. 10-14).

Molybdenum Alloy TZM and Its Application in Helium Environment. The use of molybdenum or its alloys for steam/methane reforming processes does not appear to be attractive owing to the high oxidation rate anticipated by steam-rich mixtures. The oxidation tendencies of the molybdenum alloy TZM depend on a time-temperature relation as well as on the partial pressure of oxygen and water vapor in the surrounding atmosphere. However, in high-temperature, nonoxidizing reforming atmospheres, the use of molybdenum components has potential merit. According to the major molybdenum producer in the United States, AMEX Corporation, two of their customers are making strong commitments in the use of approximately 4-in.diameter seamless pipe and tubing at temperatures of $1830^{\circ} \mathrm{F}\left(1000^{\circ} \mathrm{C}\right)$ and above. This product form is made by the roll extrusion (cold forming) process. Lengths up to $20 \mathrm{ft}$ can be made with reported thickness tolerance 
of $\pm 2 \%$. Molybdenum TZM pipe costs are in the $\$ 20 / 1 b$. range at the present time, and considering its very high conductivity, stiffness, and creep resistance properties, a detail design analysis may show TZM to be a competitor with iron-chromium-nickel or superalloy materials for longterm exposure within the range of $1800^{\circ}$ to $2100^{\circ} \mathrm{F}$.

A review of Refs. 10-15 through 10-18 has shown TZM to have many physical and mechanical properties which seem very attractive for application within the ducting of the HTGR core outlet. It is anticipated that an HTGR helium environment would not rapidly oxidize this molybdenum alloy.

\section{Materials for Testing: Selection Rationale}

An initial materials selection criterion for HTGR/reformer systems and the metallic materials selected for testing are covered in Section 5.3.

\section{Materials Investigation Requirements}

For all of the candidate materials, some data on long-term mechanical properties exist, and a review of these data indicates that further evaluation is necessary, particularly in the operating environments. Test data have generally been obtained in air or oxidizing environments where the oxide layer plays a key role in the life of the material. A few alloys have had lengthy conventional reformer service, in particular HK-40 and Incoloy 800. Extrapolation of existing data would be the basis for designing with these alloys.

The ceramic materials and the new dispersion-strengthened nickel alloys, whose properties are very appealing, require reformer environmenta1 exposure and extensive life testing, since data for these alloys are not as extensive as for the iron-chromium-nickel alloys or the supera1loys. 
All of these materials will be exposed to the HTGR helium environment, which is likely to be weakly oxidizing or, in some instances, may be reducing, depending upon the amounts and ratios of impurities, which include $\mathrm{H}_{2}, \mathrm{H}_{2} \mathrm{O}, \mathrm{CO}, \mathrm{CO}_{2}$, and $\mathrm{CH}_{4}$, and on operating temperature. In addition, fission products will be within the circulating helium envi ronment.

It seems clear that both the effects of the HTGR and the process stream environments as well as temperature will be primary factors in determining material applicability in a system design. The investigation planned in these areas can be summarized as follows:

\section{HTGR Helium Environment/Material Interaction}

- Surface stability - including surface oxidation and scale formation; gross surface material loss; selective alloying element vaporization or depletion; decarburization or deboronization; fission product compatibility; and intergranular attack leading to crack initiation.

\section{Process Stream Environment/Materials Interactions}

- Surface stability - including surface oxidation and scale formation; uniform surface material.

\section{Temperature-Time Exposure}

- Microstructural (thermal) stability - including time-temperature dependent changes in microstructure of precipitation of embrittling phases leading to long-term mechanical property degradation.

- Creep behavior - including both short-time creep rupture and long-time precision creep rates. 
It is clear that the materials employed in an HTGR plant/reformer system must be selected with a thorough knowledge of their possible degradation, mechanisms, and failure modes, and that they must be qualified based on quantitative property data obtained in realistic HTGR helium and reformer test environments. Furthermore, if the effects of these environments are found to be significant, components should be designed based on minimum properties derived from impure helium data rather than from existing air data.

The pertinent property tests required to select and qualify a material for main components of the process heat HTGR/reformer, based on their particular service environments, are summarized in Table 10-3.

\section{Program Objectives}

The objectives of the process heat HTGR/reformer materials testing program are threefold:

1. Experimentally establish the capability of materials to withstand typical stress/environment requirements of a HTGR/reformer system as a function of temperature and time.

2. Establish mechanisms controlling environment/material interaction to provide a basis for the rational selection of optimum structural materials to be employed in systems as a function of temperature.

3. Provide reliable material property data required for design of components and for initial qualification of materials for longterm service.

\section{Approach}

The general approach will be to conduct qualitative, short-time alloy screening tests, early in the program, on candidate alloys for 
TABLE $10-3$

SUMMARY OF HTGR/REFORMER MATERIALS TESTINC REOL IREMLVIS

\begin{tabular}{|c|c|c|c|c|c|c|c|c|c|}
\hline \multirow[b]{3}{*}{ Component } & \multicolumn{9}{|c|}{ Test } \\
\hline & \multirow{2}{*}{$\begin{array}{l}\text { Elemental } \\
\text { Vaporization, } \\
\text { HTGR Helium } \\
\text { Environment }\end{array}$} & \multirow{2}{*}{$\begin{array}{c}\text { Fission Product } \\
\text { Compatibility, } \\
\text { HTGR Helium } \\
\text { Environment }\end{array}$} & \multirow{2}{*}{$\begin{array}{c}\text { Creep } \\
\text { Rupture, } \\
\text { HTGR Helium } \\
\text { Environment }\end{array}$} & \multirow{2}{*}{$\begin{array}{l}\text { Oxidation } \\
\text { Rate, } \\
\text { Process } \\
\text { Stream } \\
\text { Environment }\end{array}$} & \multirow[b]{2}{*}{$\begin{array}{l}\text { Long-Term Precision Creep, } \\
\text { Tensile and Compressive, } \\
\text { HTGR Helium Environment }\end{array}$} & \multicolumn{3}{|c|}{$\begin{array}{l}\text { Microstructural Stability } \\
\text { at Hish lemp and } R \text { l } \\
\text { After } 1 \mathrm{n}_{b} \text { in HTCR } \\
\text { Heliul tnvironment }\end{array}$} & \multirow{2}{*}{$\begin{array}{l}\text { Thermal or } \\
\text { Low-Cycle } \\
\text { Fatigue, } \\
\text { HTGR Helıum } \\
\text { Environment }\end{array}$} \\
\hline & & & & & & $\begin{array}{r}\text { Fracture } \\
\text { Toughness }\end{array}$ & $\begin{array}{c}\text { lensile } \\
\text { Properties }\end{array}$ & $\begin{array}{l}\text { Notch } \\
\text { Iensile } \\
\left(k_{t} 3\right)\end{array}$ & \\
\hline Reformer & & & & & & & & & \\
\hline Tubes & $\mathrm{x}$ & $\mathrm{x}$ & $\mathrm{x}$ & $\mathrm{x}$ & $\mathrm{x}$ & $\mathrm{x}$ & $\lambda$ & $\lambda$ & $\mathrm{x}$ \\
\hline Pigtalls & $\mathrm{x}$ & $\mathrm{x}$ & $\mathrm{Y}$ & $\mathrm{x}$ & $\lambda$ & $\mathrm{x}$ & $\mathrm{X}$ & $\mathrm{x}$ & $\mathrm{x}$ \\
\hline Tubesheet & $\mathrm{x}$ & $\mathrm{x}$ & -- & -- & -- & $x$ & s & $x$ & -- \\
\hline $\begin{array}{l}\text { Cyl. cover } \\
\text { plate }\end{array}$ & $\mathrm{x}$ & $\mathrm{x}$ & $\mathrm{x}$ & -- & $x$ & $x$ & ' & $\mathrm{x}$ & -- \\
\hline $\begin{array}{l}\text { Process } \\
\text { 1n-duct }\end{array}$ & $\mathrm{x}$ & $\mathrm{x}$ & $\mathrm{x}$ & $\mathrm{x}$ & 1 & y & $\mathrm{Y}$ & $\mathrm{x}$ & $\mathrm{x}$ \\
\hline $\begin{array}{l}\text { Process } \\
\text { out-duct }\end{array}$ & $\mathrm{x}$ & $\mathrm{x}$ & $\mathrm{x}$ & $\mathrm{x}$ & ג & $\mathrm{x}$ & 1 & $\mathrm{x}$ & $\lambda$ \\
\hline $\begin{array}{l}\text { Thermal Barrier } \\
\text { Ducting } \\
\text { cover plate }\end{array}$ & $\mathrm{x}$ & $\mathrm{x}$ & $\mathrm{x}$ & -- & $\lambda$ & $\mathrm{x}$ & $\mathrm{x}$ & $\mathrm{x}$ & -- \\
\hline $\begin{array}{l}\text { Valves } \\
\qquad \text { Components }\end{array}$ & -- & -- & $\mathrm{x}$ & -- & $x$ & -- & -- & -- & -- \\
\hline
\end{tabular}


system components. Reducing the number of candidate alloys will be accomplished based on further knowledge of design requirements, on available information pertaining to possible impure helium/alloy interactions, and on results from screening tests to be conducted under compression in simulated HTGR helium and air at anticipated service temperatures.

Thorough diagnostic analyses of screening test specimens along with those from initial vaporization and fission product compatibility tests should enable the early identification of potential degradation mechanisms and/or failure modes. The relationship of alloy composition to long-term degradation will be of particular interest, and this information will be used to reduce the number of candidate alloys and to suggest modified alloy compositions or advanced materials which will be evaluated for possible application.

Pertinent short- to intermediate-term design property tests, including tensile, compression, and creep rupture, will be performed on candidate alloys that appear promising in the initial screening tests. Long-term precision-creep design property tests will be employed to qualify alloys selected as baseline or alternate materials for components. Detailed data analyses and post-test specimen evaluation will be conducted to verify degradation mechanisms and rates, failure modes, and quantitative effects on properties. The data will then be employed to modify or define life prediction methods applicable to materials in process heat HTGR/reformer systems.

A1l design property tests will be performed in realistic system environments as we11 as in air under otherwise identical conditions. The composition of the helium test environment will be established from current HTGR gas composition measurements and from theoretical predictions for higher-temperature HTGR systems. It should be emphasized that the experimental techniques employed to simulate a realistic HTGR helium environment will determine the quality and applicability of the test results. 
The composition of the process stream environment will be based on typical anticipated steam/methane process stream compositions.

The number of temperatures and alloys will generally be greatest in the screening tests and will be reduced in subsequent testing. The initial plan for tests subsequent to the screening test phase is based on a near minimum of materials and specimens, i.e., two materials and two specimens each for each of the required property tests. Expansion to a greater number of materials and specimens for this latter phase would be most likely. To the extent possible, test specimens will duplicate the form, microstructure, and cross section of the specified component for which the alloy is being considered.

\section{Program Description}

Although the emphasis of the program could shift to different areas depending on the temperature level considered, the general magnitude, scope, and cost of the program apply to all temperature levels considered in this report. An anticipated schedule for the performance of individual test types is shown in Table 10-4. The minimum number of specimens for each test is specified in Table 10-5. Tests conducted in an air atmosphere are included for comparison of some materials properties with HTGR helium environment tests. Estimated man-hours and costs are included in Table 10-5 for each fiscal year. Tests and selected test materials are principally devoted to narrowing down and establishing candidate materials for reformer components. The greatest uncertainty at this time rests in the reformer material question.

At present, a11 testing would be conducted at Genera1 Atomic Company except the reformer process stream oxidation test for nonconventiona1reformer materials. Test apparatus, facilities, and creep rupture frames will be required at General Atomic. Environmental chambers, furnaces, and vacuum systems will be available for the most part. 
TABLE $10-4$

ESTIMATED TIME FRAME AND COSTS FOR PERFORMING REQUIRED TESTS

$\underline{\text { Preparation and Testing Period }}$

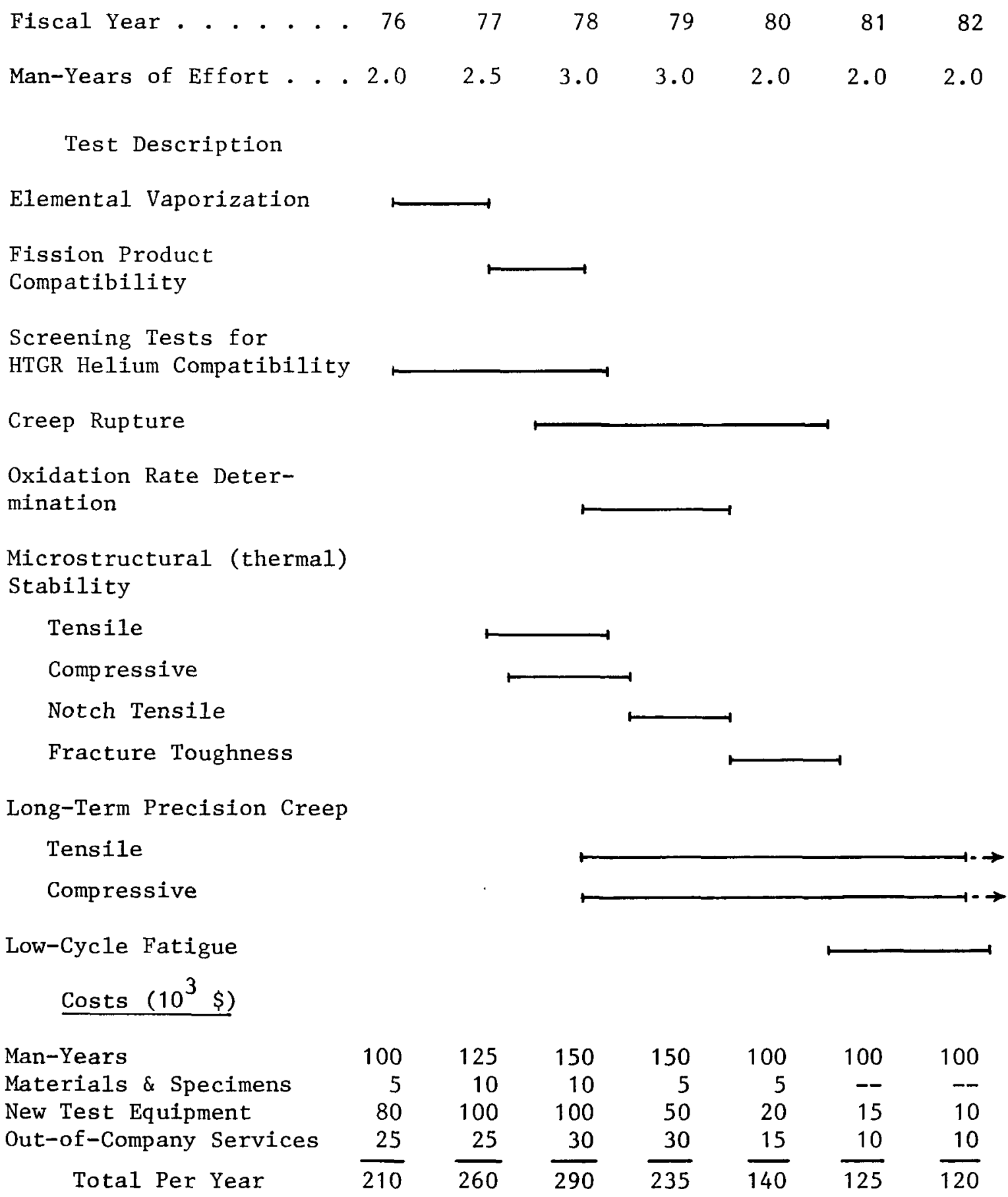


TABLE 10-5

ESTIMATE OF MINIMUM NUMBER OF SPECIMENS FOR EACH REQUIRED EXPOSURE TEMPERATURE (1)

\begin{tabular}{|c|c|c|c|c|c|}
\hline \multirow[b]{2}{*}{ Test Description } & \multicolumn{5}{|c|}{ Exposure Temperature $\left({ }^{\circ} \mathrm{F}\right)$} \\
\hline & 1400 & 1600 & 1800 & 2000 & 2200 \\
\hline Elemental vaporization (2) & -- & 10 & -- & 10 & -- \\
\hline Fission product compatibility (2) & -- & 25 & -- & 25 & -- \\
\hline $\begin{array}{l}\text { Screening tests for HTGR helium } \\
\text { compatibility (2) (3) }\end{array}$ & -- & 150 & 150 & 150 & -- \\
\hline Creep rupture (4) & -- & 8 & 8 & 8 & 8 \\
\hline $\begin{array}{l}\text { Oxidation rate determination (5) } \\
\text { Microstructure (thermal) } \\
\text { stability ( } 4)\end{array}$ & 4 & 4 & 4 & -- & -- \\
\hline Tensile & -- & 16 & 16 & -- & -- \\
\hline Compressive & -- & 16 & 16 & -- & -- \\
\hline Notch tensile & -- & 16 & 16 & -- & -- \\
\hline Fracture toughness & -- & 16 & 16 & -- & -- \\
\hline Long-term precision creep (4) & & & & & \\
\hline Tensile & 8 & 8 & 8 & 8 & -- \\
\hline Compressive & 8 & 8 & 8 & 8 & -- \\
\hline Low-cycle fatigue (4) & 8 & 8 & 8 & 8 & -- \\
\hline Specimen Totals & 28 & 285 & 250 & 217 & 8 \\
\hline
\end{tabular}

Assumptions :

(1) After the screening tests establish favorable candidates, two candidate materials for each temperature will be fully tested at two specimens/condition/alloy.

(2) Two different HTGR helium environments.

(3) In the screening tests, 25 alloys will be examined, each for two different stresses and at zero stress.

(4) There will be one HTGR helium and one air environment for each exposure temperature.

(5) Process stream mixture. 
The uncertainty of the outcome of many early tests and the early stage of detail design suggests that a presupposition of specific material requirements for each anticipated system component at this time may not only be incorrect technically, but could result in a misconception of the real materials investigation budget requirements. However, within 2 yr and essentially near the end of the screening phase, a firm assessment of the number of credible candidate alloys as a function of design temperature would seem quite reasonable. Further assistance will be provided by additional data becoming available from current HTGR and the gas-turbine material studies (up to $1600^{\circ} \mathrm{F}$ ), particularly information shedding light on the operating and controlling reaction mechanisms of impurity interaction with materials at high temperatures.

It is anticipated that for one high-temperature process heat HTGR/reformer system, at least six alloys would require creep rupture and precision creep measurements and standard tensile and compression tests to fully qualify for ASME Nuclear Code design. A rule-of-thumb estimate of cost for full qualification is $1 / 2$ million dollars for each alloy over a 5-yr period. In addition to this predicted 3 million dollar, 5-yr effort would be a continuation of curve generation for long-term designs.

\section{Test Rationale and Description}

The purpose of each type of test included in the program, the procedure to be employed, and the resulting data are discussed below. The diagnostic procedures which will be employed to conduct thorough posttest analyses of test specimens are also presented. The information derived from post-test specimen evaluations will form the basis of degradation and failure mechanism studies.

Screening Compatibility and Stability. This will be a relatively low-cost, qualitative test with the dual purpose of screening alloys and identifying potential HTGR environmental damage mechanisms. The tests will be run under compressive stress for 1000 and $5000 \mathrm{hr}$. Either constant load or no load testing will be employed. 
Figure $10-2$ is a schematic presentation of a straightforward technique for studying the effect of applied compressive stresses on gas/metal interaction in a controlled atmosphere at a high temperature. A desired helium environment would be established in a helium-plusimpurities supply system (see Fig. 10-3) which is presently under construction at General Atomic Company. The helium environment would flow (once-through system) through the chamber containing the alloy specimens (with or without applied stress). Upon completion of a test run, specimens would be removed, mounted, cross-sectioned, and polished.

Post-test evaluation of the scale/metal interface will include conventional metallography, scanning electron microscope (SEM) examination, electron microprobe analyses, and possibly photoelectron spectroscopy. The effect of impure helium on the nature of surface and subsurface oxidation and scale formation will be determined as a function of stress. Also, characterization of alloy element depletion tendencies, microstructural thermal stability and phase formation, and the morphology of subsurface attack will be conducted. The results will be correlated with alloy composition and will be employed to qualitatively predict possible effects on structural properties. All results will be referenced to similar specimens exposed to an air environment. Based on these tests, severely attacked alloys will be removed from consideration, and additional tests on modified or promising advanced materials will be performed as required.

Creep Rupture. These tests will be the conventional creep-rupture type in accordance with ASTM E139-70 and will be performed in both helium and air environments to obtain data for estimating design property curves. Stresses will be selected to produce rupture in approximately 1000,3000 and $10,000 \mathrm{hr}$. Creep strains will be measured in the rupture section and perhaps in a thicker section after rupture. Rupture times and creep strains will be compared for air and impure helium data to determine possible quantitative differences between short-time rupture and creep behavior in air and HTGR helium. Post-test analyses of specimens will be similar to those described for the screening tests, but 


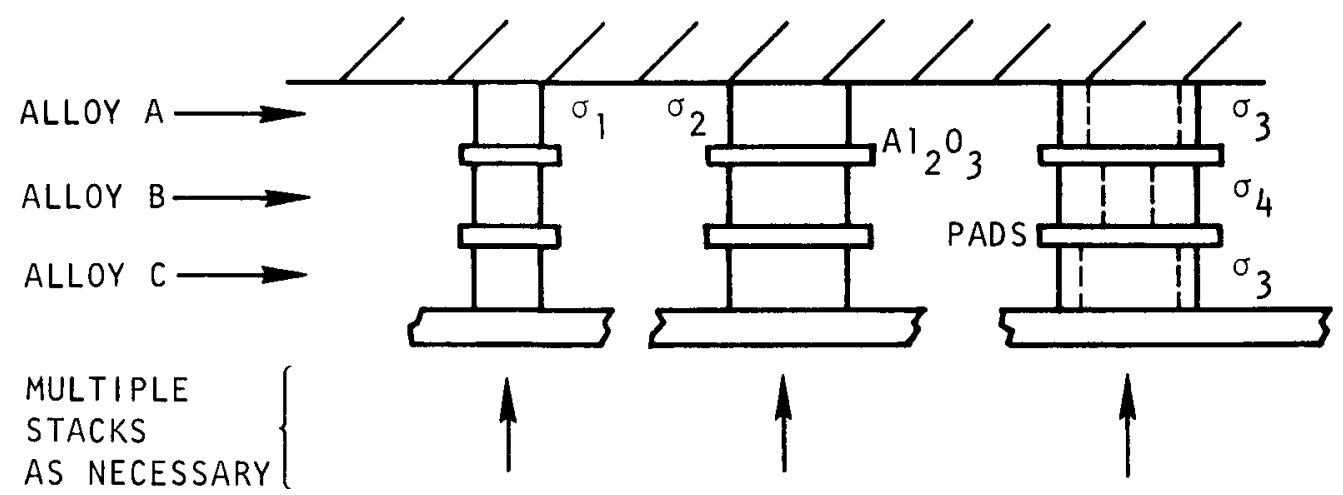

FORCE

SOURCES FOR LOADING:

(1) DEAD LOAD WEIGHTS

(2) HYDRAULIC PRESS

SPECIMENS :

(1) CYLINDRICAL SHAPE

(2) CROSS-SECTIONAL AREA VARIED FOR ESTABLISHMENT OF DIFFERENT APPLIED STRESS
CONTROLLED ATMOSPHERE :

(1) $A \mid R$

(2) HELIUM + CONTROLLED IMPURITIES

(3) EVACUATION CAPABILITY

TEMPERATURE SOURCE:

CHAMBER SURROUNDED BY RESISTANCE-HEATED FURNACE

Fig. 10-2. Schematic of technique for compression loading many specimens to different stresses under controlled atmosphere and high temperatures 
日 QUICK CONNECT

Q car 10 pressure regulator

(8) on-off valve

(1) pressure gage

$\square$ vacoa valve (metering)

$\triangle$ needle valve (metering

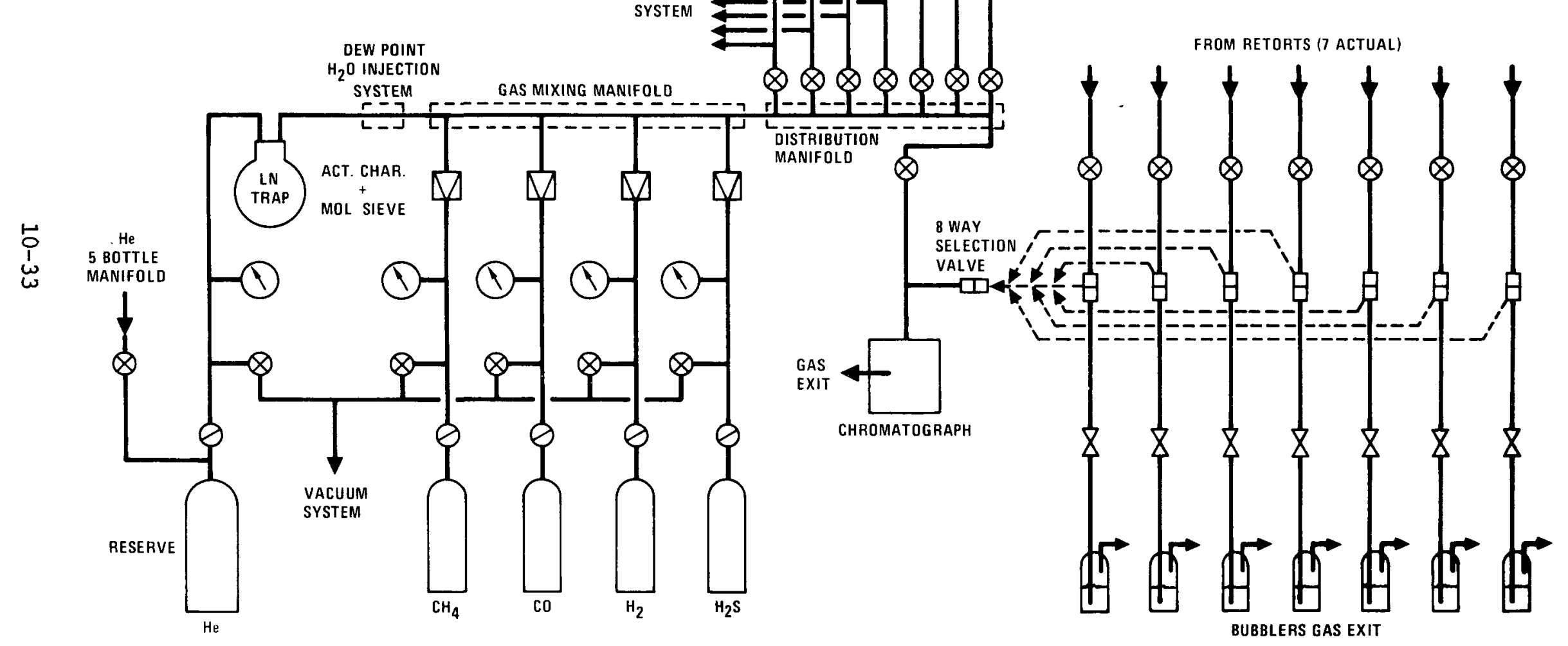

Fig. 10-3. Simulated HTGR helium supply system (once-through flow) 
will also include fractographic analyses of rupture surfaces to determine possible differences in crack initiation or propagation modes.

Tensile Properties. The effect of exposure in an HTGR helium environment on short-time tensile properties will be determined in these tests. Tests will be conducted at temperature in air and HTGR helium in accordance with ASTM E21-70 after pre-aging for about $2000 \mathrm{hr}$ or 1onger in the respective environments. A few specimens will be pre-aged under compressive stress and then tested to determine the combined effect of exposure and stress on property degradation. About $25 \%$ of the specimens will be notched $\left(\mathrm{K}_{t} \approx 3\right)$ to determine the effect of a stress concentration on the short-time high-temperature tensile properties. Several specimens will be tested unaged to permit initial baseline property comparisons.

Test data will include stress-strain curves, modulus of elasticity (Young's modulus), yield strength, ultimate strength, elongation and reduction in area, and notch/unnotch strength ratio. The relative effects of impure helium and air environments on these properties will be quantified and air/helium factors will be derived, if required.

Compression Behavior. The effect of exposure in the HTGR environment on short-time compression behavior will be determined in these tests. Tests will be conducted at temperature in air and HTGR helium per ASTM E209 after pre-aging for about $2000 \mathrm{hr}$ or longer in these environments. A few specimens will be pre-aged under stress and then tested to determine the effect of stress. Several specimens will be tested unaged to permit initial baseline property comparisons.

Oxidation Rate. Determination of the effect of exposure in a steam/ methane process stream on alloys appearing attractive in HTGR helium environment screening tests would be necessary to establish rate of material loss per year as a function of temperature for design purposes. Details for establishment of a test facility are still undetermined. Suggestions have been made with regard to either a cooperative two-company 
effort or subcontracting the exposure specimens to a company presently performing commercial steam/methane reforming processes.

Fracture Toughness. This test will characterize the resistance of candidate alloys to fracture in the presence of a sharp flaw or crack which might be pre-existing or develop in a component through environmental surface attack. Tests will be conducted in air and HTGR helium at room temperature. The specimens will be pre-aged in these environments for a least 2000 hours subsequent to pre-cracking but prior to fracture testing. Procedures for thicker materials will conform to ASTM E399-72, and valid plane-strain fracture toughness values $\left(\mathrm{K}_{\mathrm{Ic}}\right)$ will be obtained if possible. Tests will be conducted on notched and fatigue precracked compact tension type specimens. Surface-flaw (partial through-crack) tension-type fracture tests, which yield comparative fracture toughness values $\left(\mathrm{K}_{\mathrm{IE}}\right)$ and are traditionally employed for thinner pressure vesse1 materials, will be employed for thin-section candidate alloys. Fractographic analyses will be performed on failed specimens. The effect of pre-aging on resistance to fracture will be compared for air and HTGR helium environments to determine if significant differences are indicated.

Fission Product Compatibility. The possible detrimental effects of fission products on the structural integrity of candidate materials will be examined in these tests. Applicable computer codes will be used to predict the types and quantities of fission products that will deposit on the surface. Several of the potentially harmful elements will then be deposited on specimens which will be aged for $2000 \mathrm{hr}$ or longer in HTGR helium at temperature. Specimens will be examined metallurgically to determine mode and depth of attack and effects on microstructure. Tensile tests will be performed to obtain a qualitative measure of degradation. Additional tests will be designed and performed as required.

Elemental Vaporization. Many of the candidate alloys, employed in a high-temperature air envirunment, have a continuous adherent oxide film at the surface that suppresses vaporization of the more volatile alloying 
elements (chromium and aluminum). In the flowing HTGR environment, the possibly non-continuous, less protective film may permit significant loss of these materials. The purpose of these tests is to determine the extent of this effect. Tests will be run at high temperatures $\left(>1500^{\circ} \mathrm{F}\right)$ in a vacuum to closely simulate the weight loss the material would experience in flowing HTGR helium. The vacuum environment will serve to isolate the vaporization effect from other material depletion modes possible in the HTGR. Tests will be run at from 1000 to $8000 \mathrm{hr}$ with weight loss and depletion depth being evaluated.

Precision Long-Time Creep. The purpose of these tests will be to obtain precision low-deformation, long-time creep curves in tension and compression for design, and to initiate qualification of baseline alloys for long-term service in an HTGR. The tests will be conducted for a minimum of $30,000 \mathrm{hr}$ in air and HTGR helium at material service temperatures, in accordance with ASTM E139-70. Instrumentation will be employed to obtain real-time strain measurements during testing. Complete metallurgical analyses of specimens will be conducted after termination of testing to determine long-time microstructural changes, surface stability, alloy depletion, phase precipitation, etc. Creep curves for air and HTGR helium environment exposure will permit the establishment of reduction factors (if indicated) for allowable stresses in HTGR service.

Low-Cycle or Thermal Fatigue. These tests will characterize damages caused by in-service temperature variations and the resultant thermo mechanical strain cycles. Several test types have been suggested, and the selection of a procedure will be made at a later date.

\section{Additional Tests}

There are several areas of concern in the design of process heat HTGR/reformer systems and the associated selection and application of materials that the proposed test plan does not yet include. It is anticipated that meaningful tests in a simulated HTGR helium environment (where 
required) would be defined and scheduled early in the program with respect to the following.

1. Structural properties of welds for materials passing screening test.

2. Physical properties (for design) of the newer alloys.

3. Molybdenum TZM/coating properties.

Other areas of possible concern which may require investigation but for which tests have not been proposed are:

1. Selection of optimum carbon-reinforced composite materials for thermal barriers. Further definition of both design property and test requirements.

2. $\mathrm{MoO}_{3}$ vaporization and reaction with structural materials.

3. ASME Nuclear Code approval requirements for high-temperature long-term usage.

\section{Cost Summary}

The research and development program outlined in Table 10-4 applies to all temperature levels considered in this report. The total estimated program cost is $\$ 1,380,000$. 


\subsubsection{Ceramic Materials}

\section{Introduction}

The proposed use of ceramic materials in high-temperature reformers or any other process heat application is not new and has been considered by many investigators. In all cases, the designer wanted to increase the temperature and/or pressure so that much larger efficiencies could be attained, but was prevented from doing so for the following reasons:

1. The iron-, nicke1-, or cobalt-base alloys that are available have a maximum operating temperature of $\sim 1900^{\circ} \mathrm{F}$ when used in air. (When used in helium, the maximum temperature should be reduced, since the oxide surface film is not present and the degradation mechanisms discussed in Sections 10.1.3.1 wil1 lower the performance of the alloy. Thus, the impetus for initiating the ceramic materials program is even more important.)

While the refractory metals (molybdenum-, uranium-, tantalum-, and niobium-base alloys) exhibit satisfactory mechanical properties above $1900^{\circ} \mathrm{F}$, they are for the most part unacceptable because they oxidize catastrophically. In some non-oxidizing process heat applications (such as ethylene reformers) molybdenumbase alloys might be acceptable. The platinum metals (platinum, rhodium, iridium, and palladium), even if they were economical, would be unsatisfactory because of their tendency to form lowmelting eutectics with trace elements such as silicon and lead.

2. The designer realized that although ceramic materials with hightemperature strength were available, a whole new concept in design and fabrication technology was needed to implement ceramic materials into the high-temperature process heat industry. It will not be possible to simply substitute some high-strength . ceramic tube in place of some HK-40 tube. Ceramic materials, 
while possessing high-temperature strengths, extremely low creep rates, and very low thermal expansions, are difficult to fabricate and join and also exhibit poor fracture toughness, especially when loaded in tension. The designs will probably attempt to keep the ceramic materials in compression at all times, and the fabricated shapes will be held more in a cantilever fashion than in a tightly fixed geometry. With this type of design philosophy, the ceramic shapes will not have to relieve stresses by bending, nor will they be heavily loaded in tension.

In the HTGR, the helium pressure is considerably greater on the outside diameter than on the inside diameter, which is the opposite of the situation in non-nuclear reformers. This added pressure differential on the outside diameter will ensure that the ceramic tubes are held in compression and will also be utilized in joining the ceramic tubes as discussed below.

While the goal of designing, fabricating, and operating a ceramic reformer appears formidible, it is equally impressive to note the tremendous strides that have been achieved in ceramic technology as applied to the development of the all-ceramic gas turbine engine by Ford and Westinghouse under sponsorship of the Advanced Research Project Agency. Both silicon carbide and $\mathrm{Si}_{3} \mathrm{~N}_{4}$ have been pursued for this application and will operate at $2500^{\circ}$ to $2600^{\circ} \mathrm{F}$. Ford and Westinghouse are fabricating different size engines and are now in their early testing phase. Probably no other program in either the United States or Europe has given the hightemperature ceramic industry such a formidable yet realistic goal as this all ceramic gas turbine engine.

In the following sections the major characteristics of the ceramic materials silicon carbide, $\mathrm{Si}_{3} \mathrm{~N}_{4}$, and $\mathrm{Al}_{2} \mathrm{O}_{3}$ will be discussed, and the technology effort that is needed to qualify them for process heat applications will be described. 


\section{Material Requirements}

While a wide assortment of different ceramic materials can be considered for the reformer application, silicon carbide and $\mathrm{Si}_{3} \mathrm{~N}_{4}$ tend to possess the most desirable properties of the available materials. Ideally, a designer would choose a material for the reformer application that had minimal thermal expansion and high thermal conductivity, high strength and good creep resistance, inert behavior with regard to the surrounding atmospheres (either helium or reformer gases), and desirable fabrication qualities. $\mathrm{Si}_{3} \mathrm{~N}_{4}$ and silicon carbide are very favorable with respect to expansion, conductivity, and strength. Compatibility with gaseous atmospheres may not be a problem, but experimental data are lacking and must be generated. The fabrication of $\mathrm{Si}_{3} \mathrm{~N}_{4}$ and silicon carbide shapes is not easy but may be acceptable, while the joining area is probably solvable but remains to be developed. $\mathrm{Al}_{2} \mathrm{O}_{3}$ has also been considered, but in general does not offer the promise of either silicon carbide or $\mathrm{Si}_{3} \mathrm{~N}_{4} \cdot$ Many of the physical, mechanical, and thermal properties of silicon carbide and $\mathrm{Si}_{3} \mathrm{~N}_{4}$ are listed in Appendix C. In the discussion below, the properties discussed are directed toward the reformer application and are based upon data taken from Appendix C and Refs. 10-19 through 10-21.

\section{Compatibility with the Processes}

When used at high temperatures, silicon carbide, $\mathrm{Si}_{3} \mathrm{~N}_{4}$, and $\mathrm{Al}_{2} \mathrm{O}_{3}$ have typically been operated in air. In this oxidizing atmosphere, both silicon carbide and $\mathrm{Si}_{3} \mathrm{~N}_{4}$ form a surface of $\mathrm{SiO}_{2}$ that is dense and pin-hole free. This $\mathrm{SiO}_{2}$ layer essentially protects these materials from any appreciable degradation while at temperature. The $\mathrm{SiO}_{2}$, which is initially vitreous, becomes crystalline with age while at temperature, and if cooled below $200^{\circ} \mathrm{C}$ undergoes a volume change due to a phase transformation. Thus, in reheating, the microcrack formed in cooling is healed by further oxidation of the parent material. 
If the environment is modified so that the $\mathrm{O}_{2}$ available is very limited, the normally present $\mathrm{SiO}_{2} \mathrm{film}$ is not retained because of the formation of the volatile compound Sio. In this environment, it is possible to have very high weight losses of silicon compounds if the $\mathrm{O}_{2}$ containing gases is plentiful but not enough to form a $\mathrm{SiO}_{2}$ layer. In general it is expected to follow the same type performance as that noted with elemental silicon and shown in Fig. 10-4.

In the process heat environment of a nuclear HTGR/reformer, two atmospheres are present, the outer wall and the inner wall environments. These atmospheres are discussed below.

\section{Outer Wall Helium Atmosphere}

This atmosphere has the following typical composition:

$$
\mathrm{He}, \mathrm{H}_{2}, \mathrm{CO}, \mathrm{CO}_{2}, \mathrm{H}_{2} \mathrm{O}
$$

SiC. The outside diameter HTGR helium will contain some oxygen tied up as $\mathrm{H}_{2} \mathrm{O}$, $\mathrm{CO}$, or $\mathrm{CO}_{2}$. The amount of reaction between these impurities gases and silicon carbide is totally unknown and needs to be quantified. Below $1900^{\circ} \mathrm{F}$, the reaction rate would probably be minimal, whereas at $2500^{\circ} \mathrm{F}$, it would be readily apparent. Presumably, the silicon carbide could react to form gaseous species of $\mathrm{SiH}_{4}$, silicon oxide, and $\mathrm{CO}$ that would lead to a mass transfer of material from the hot zone. Of these three products, the silicon oxide would be the most undesirable, since it would tend to condense below $\approx 800^{\circ} \mathrm{C}$ and could possibly cause clogging.

$\mathrm{Si}_{3} \mathrm{~N}_{4}$. For the past 2 to $3 \mathrm{yr}$, General Atomic Company has been conducting a study (umder AEC sponsorship) of the compatibility of $\mathrm{Si}_{3} \mathrm{~N}_{4}$ with other materials and environments at temperatures up to $1150^{\circ} \mathrm{C}$. The experience gained from this study is directly applicable to the HTGR helium atmosphere as well as to the use of silicon carbide. The evaluation of $\mathrm{Si}_{3} \mathrm{~N}_{4}$ in vacuum is particularly interesting, since any material will vaporize essentially the same whether it is in flowing helium or vacuum. 


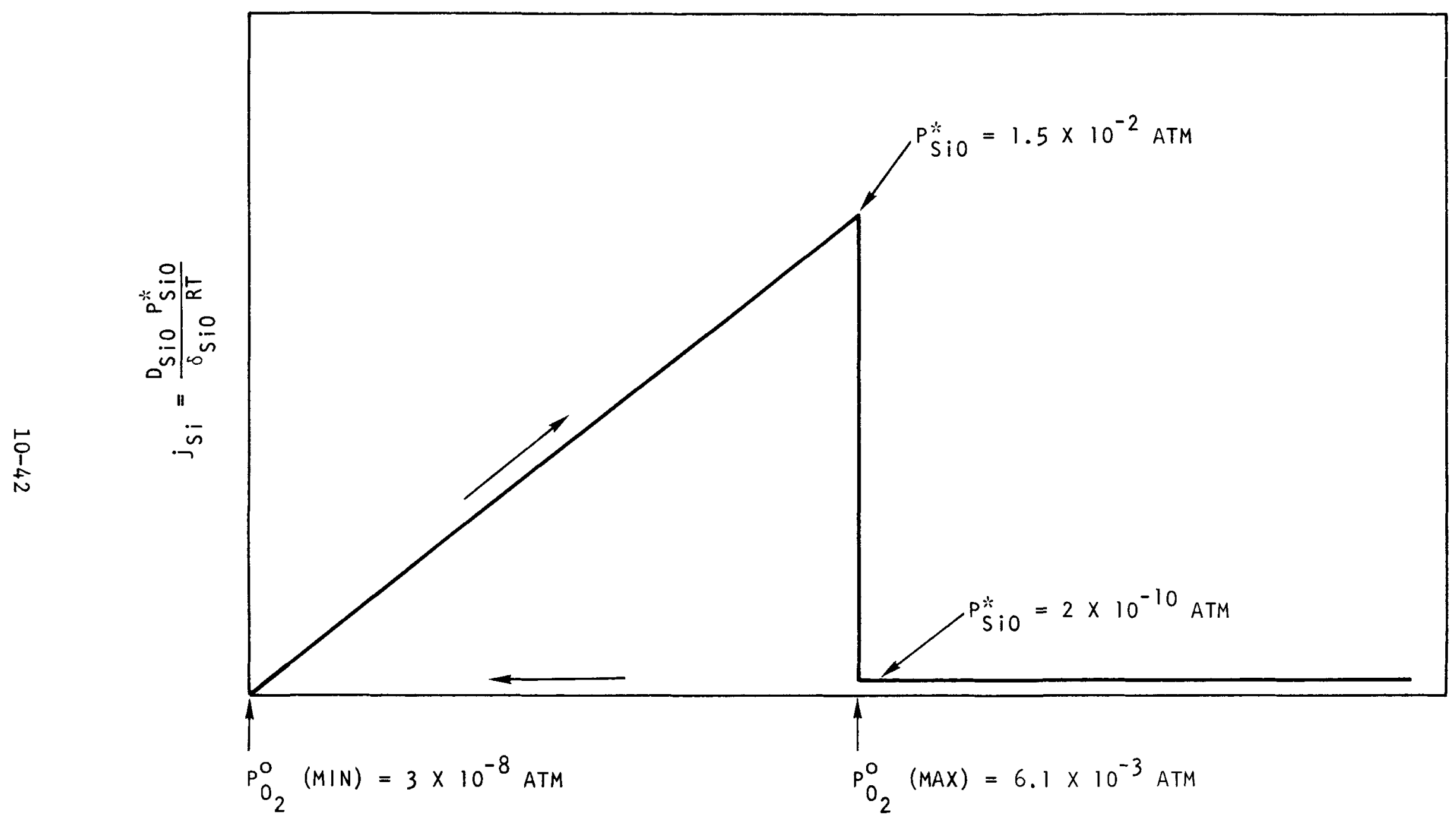

Fig. 10-4. Rate of attack $\left(j_{\mathrm{Si}}\right)$ of silicon in oxygen-helium mixtures of constant total pressure at $1410^{\circ} \mathrm{C}$ as a function of oxygen partial pressure, $\mathrm{P}_{\mathrm{O}_{2}}^{\mathrm{O}}$ 
The results thus far have shown that $\mathrm{Si}_{3} \mathrm{~N}_{4}$ (at $1000^{\circ}$ to $1150^{\circ} \mathrm{C}$ ) is kinetically very sluggish in either vaporizing or reacting with other materials. Based upon vaporization properties (measured at $21600^{\circ} \mathrm{C}$ ), $\mathrm{Si}_{3} \mathrm{~N}_{4}$ was expected to yield weight losses many times greater than those measured at $1000^{\circ}$ to $1150^{\circ} \mathrm{C}$. Thermodynamic calculations on the interaction of $\mathrm{Si}_{3} \mathrm{~N}_{4}$ with $\mathrm{SiO}_{2}$ at $1100^{\circ} \mathrm{C}$ predicted that considerable consumption of both materials would occur; experimenta11y, little or no loss was observed in either vaporization or reaction. Conversely, it is interesting to note that silicon is very sluggish in forming $\mathrm{Si}_{3} \mathrm{~N}_{4}$, and temperatures of $1400^{\circ} \mathrm{C}$ for several days are required in fabricating reaction-sinter preformed silicon shapes into hardened $\mathrm{Si}_{3} \mathrm{~N}_{4}$ shapes. As mentioned above, for silicon carbide it remains to be determined if the impurity gases in the helium will cause any adverse effects, such as through the formation of gaseous silicon compounds ( $\mathrm{SiO}$ and $\mathrm{SiH}_{4}$ ).

$\mathrm{Al}_{2} \mathrm{O}_{3}$. The compatibility of $\mathrm{Al}_{2} \mathrm{O}_{3}$ with the minor gaseous species in the helium is also undefined but will be dependent upon the $\mathrm{H}_{2} / \mathrm{H}_{2} \mathrm{O}$ ratio: the higher the ratio, the easier it is to reduce the $\mathrm{Al}_{2} \mathrm{O}_{3}$. Up to $1800^{\circ} \mathrm{F}$, 1ittle or no reduction is expected, but above these temperatures kinetic data must be generated as a function of $\mathrm{H}_{2} / \mathrm{H}_{2} \mathrm{O}$ ratios.

Inner Wal1 - Process Heat Environment. The atmosphere for the inside of the tube will be comprised of the make-up feed $\mathrm{H}_{2} \mathrm{O}$ and $\mathrm{CH}_{4}$ and the reaction products $\mathrm{CO}_{2}, \mathrm{CO}$, and $\mathrm{H}_{2}$. These gases are essentially the same as those in HTGR helium but obviously are in much greater concentration. The reactions to be encountered between silicon carbide, $\mathrm{Si}_{3} \mathrm{~N}_{4}$, and $\mathrm{Al}_{2} \mathrm{O}_{3}$ and these gases are essentially the same as in the outer wall atmosphere, but will be influenced by:

1. The reducing gas/oxidizing gas ratios, e.g., $\mathrm{H}_{2} / \mathrm{H}_{2} \mathrm{O}$ and $\mathrm{CO} / \mathrm{CO}_{2}$.

2. The temperature of operation.

3. Other trace gases, such as sulfur. 
As mentioned above, silicon oxide and $\mathrm{SiH}_{4}$ are the products that would contribute to the degradation of the tube. Data of this nature are not available, and experimental studies (not just thermodynamic calculations) will be required to generate kinetic data.

\section{Fabrication of Basic Shapes}

Many manufacturing techniques are available for fabricating ceramic shapes. However, the results obtained with each process vary widely with respect to cost, mechanical properties, physical properties, permeability, and other characteristics. The reason for choosing a manufacturing process is usually to obtain one or more of the above criteria; for the process heat application, the technical criteria require the reformer tube to be structurally strong (includes creep and thermal shock criteria) and nonpermeable. It will be seen as the different processes are discussed below that it may be necessary or desirable to use one or more processes to obtain a tube that can be manufactured to perform under the required conditions.

Reaction-Sintering. As with most nitrides and carbides, silicon carbide, and $\mathrm{Si}_{3} \mathrm{~N}_{4}$ are difficult materials to sinter, and as a consequence, special techniques and very high temperatures are required to fabricate these materials into useful shapes. Conversely, it is because of these non-reactive properties that both silicon carbide and $\mathrm{Si}_{3} \mathrm{~N}_{4}$ have such appealing properties.

$\mathrm{Si}_{3} \mathrm{~N}_{4} \cdot$ Reaction-sintering is employed in fabricating simple or complex shapes of $\mathrm{Si}_{3} \mathrm{~N}_{4}$, primarily because it is an inexpensive process and may be the only way to fabricate some shapes. The silicon is comminuted, and then blended with a plasticizer. In this form, the material can be shaped into any configuration and then fired at low temperature to remove the plasticizer. Subsequent firings of the silicon in $\mathrm{N}_{2}$ at $1400^{\circ} \mathrm{C}$ (just below the melting point of silicon) allows a small amount of $\mathrm{Si}_{3} \mathrm{~N}_{4}$ to form and prevent the shape from sagging when the temperature is increased above the melting point of silicon to complete the nitriding. $\mathrm{Si}_{3} \mathrm{~N}_{4}$ is 
even more difficult to machine in the final-fired state than silicon carbide; since $\mathrm{SiC}$ is conductive, it may be machined by electrical discharge machining techniques. On the other hand, $\mathrm{Si}_{3} \mathrm{~N}_{4}$ is insulating and ultrasonic machining techniques are normally employed.

Silicon Carbide. The reaction-sintering technique employed for silicon carbide differs considerably from the technique used for $\mathrm{Si}_{3} \mathrm{~N}_{4}$. In this technique, the starting silicon carbide powder is blended with elemental carbon and silicon and a plasticizer. The blended mixture is then formed into the desired shape, such as extrusions for tubing. After extruding, the tubes are heated to temperatures ranging from $1900^{\circ}$ to $2200^{\circ} \mathrm{C}$. Above $1410^{\circ} \mathrm{C}$, the elemental silicon melts and also exhibits a high vapor pressure at the sintering temperature. The free silicon is fairly active and reacts with the free carbon to form additional silicon carbide and also bond the initial silicon carbide powder together. The end product contains both free silicon and carbon interspersed in a silicon carbide matrix. It is this free silicon that is responsible for the dropoff in strength above the melting point of silicon $\left(2570^{\circ} \mathrm{F}\right)$; the free silicon is also thought to be responsible for increasing the creep rate of silicon carbide. The free carbon is thought to be responsible for initiating stress concentrations that lead to lower than expected flexure strengths, but at the same time excess carbon retards grain growth, which is necessary for maintaining high strengths.

Additives to both $\mathrm{Si}_{3} \mathrm{~N}_{4}$ and silicon carbide are made to increase their sinterability, namely to increase density and strength and decrease permeability. The additives to silicon carbide and $\mathrm{Si}_{3} \mathrm{~N}_{4}$ may include a wide variety of materials, such as $\mathrm{SiO}_{2}, \mathrm{Al}_{2} \mathrm{O}_{3}, \mathrm{M} \sigma \mathrm{O}$, boron (as $\mathrm{B}_{2} \mathrm{O}_{3}$ or $\mathrm{H}_{3} \mathrm{BO}_{4}$ ), $\mathrm{CaO}$, and others. In general, the additions promote fabricability but tend to decrease the properties from what can be obtained with stoichiometric, fully dense material. For example, in $\mathrm{Si}_{3} \mathrm{~N}_{4}$, the $\mathrm{CaO}$ tends to segregate at the grain boundaries, forming a complex glassy phase, which causes the material to exhibit a high creep rate. With silicon carbide, the same result will occur if excessive oxygen or boron is used. 
Many manufacturers purposely use boron additions, but the emphasis recently has been to minimize the additions in order to minimize the formation of second phases and their adverse effect on mechanical properties. The $\mathrm{O}_{2}$ is always present on the surface of the powder particles and is removed through the formation of the volatile compound silicon oxide. The major concern regarding reaction-sintered material as far as process heat is concerned is that low-density, high-permeability structures be obtained. Reaction-sintered $\mathrm{Si}_{3} \mathrm{~N}_{4}$ is never non-permeable although silicon carbide manufactured by Carborundum (KT-SiC) and by the British (Refel) is claimed to be non-permeable. The techniques used for the measurements were not sensitive and further measurements are required. Presently, silicon carbide tubes are extruded 66 in. long with a 4-in. ID. The technology for making 40-ft-long tubes is the same. However, 1arger extrusion presses would have to be designed and built. In addition, furnaces for handling these tubes would be required.

$\mathrm{Al}_{2} \mathrm{O}_{3}$. The reaction-sintering of $\mathrm{Al}_{2} \mathrm{O}_{3}$ is similar to that of other ceramic materials. However, compared with $\mathrm{Si}_{3} \mathrm{~N}_{4}$ and silicon carbide, much lower temperatures can be utilized and densities are obtained that are close to theoretical. Additives to $\mathrm{Al}_{2} \mathrm{O}_{3}$ also increase its sinterability, with $\mathrm{SiO}_{2}$ and $\mathrm{MgO}$ being typical additive materials.

Hot Pressing. Both silicon carbide and $\mathrm{Si}_{3} \mathrm{~N}_{4}$ are hot pressed to obtain close to theoretical densities, very high strengths, controlled grain size, and non-permeable structures. Typically, the loads required are quite high, and additives (the same as noted under reaction-sintering) are sometimes used to facilitate fabrication. The main difference between the reactionsintered and hot-pressed materials is that hot-pressed starting material is stoichiometric power to begin with and contains very small amounts $(<1 \%)$ of additives. Thus, the material can be produced with a closer control of mechanical and physical properties.

Most hot pressing is performed in graphite or refractory type dies. However, in the past few years isostatic pressing has been utilized for applications where complex shapes were required. In some cases, the powder 
containing a binder is formed into the complex shape. This body is then enclosed in a collapsible medium such as rubber and isostatically cold pressed in an autoclave at extremely high pressures. The component is subsequently sintered to achieve its strength. Alternate methods are used in isostatic pressing, such as performing the pressing at temperature in a high-pressure autoclave. The collapsible medium in this case can be thin metal cans. Even quartz has been used by General Atomic Company in hightemperature isostatic pressing of SiGe alloys. In this latter case, the isostatic gas pressure load was not applied until $1200^{\circ} \mathrm{C}$, where the quartz is plastic.

\section{Chemical Vapor Deposition (CVD)}

Silicon Carbide. The fabrication of silicon carbide by CVD is in large production at General Atomic Company for depositing a "pressure vesse1" coating around the nuclear fuel particles used in the HTGR. Approximately 5 tons of leak-tight CVD-produced silicon carbide is used in the Fort St. Vrain HTGR and has been under intensive investigation at General Atomic Company for over $12 \mathrm{yr}$. One technique for forming silicon carbide is to react silane $\mathrm{SiH}_{4}$ with methane at approximately $1300^{\circ} \mathrm{C}$. The experimental studies carried out in developing the silicon carbide utilized today will be of great benefit in developing tubes to be used as the reformers.

The CVD utilization can be visualized in two modes: commercially available silicon carbide tubes could be seal coated to give the tubes the low permeability rates they will require, or the tubing can be made by CVD techniques. The former method appears more attractive from a cost standpoint, since only a few mils of silicon carbide would probably be required. As noted in the discussion on mechanical properties, this smooth CVD coating provides a veneer that greatly increases the total strength $(\sim 50 \%)$ of the tube by eliminating surface imperfections.

In CVD coating, it is not necessary to heat and coat the whole tube simultaneously. Chemical vapor deposition coatings are applied routinely, 
by passing the tube through an RF field with the gases flowing over the part; coating takes place at the zone that is heated.

$\mathrm{Si}_{3} \mathrm{~N}_{4} \cdot$ Deposition of $\mathrm{Si}_{3} \mathrm{~N}_{4}$ by CVD techniques has received wide attention, especially in the electronic industry, where its insulating characteristics are desired. Techniques for laying down $\mathrm{Si}_{3} \mathrm{~N}_{4}$ have been developed by numerous investigators, and there appears no reason the porous reaction-sintered $\mathrm{Si}_{3} \mathrm{~N}_{4}$ tubing could not be seal coated by this technique in a similar fashion to the technique described for silicon carbide.

$\mathrm{Al}_{2} \mathrm{O}_{3}$. Techniques for CVD deposition of $\mathrm{Al}_{2} \mathrm{O}_{3}$ are available and could be utilized if desired.

Ion Plating. In this process, a material is evaporated with an electron beam gun into a gas plasma. The evaporant is partially ionized, and the ions are driven into the substrate under an applied potential. The evaporation species also gains energy by collisions with high-energy ions in the gaseous discharge. This latter process increases the throwing power of the deposition.

At General Atomic Company, $\mathrm{Si}_{3} \mathrm{~N}_{4}$ coatings are being deposited at approximately $250^{\circ} \mathrm{C}$ by evaporating silicon into an $\mathrm{NH}_{3}$ plasma and forming the $\mathrm{Si}_{3} \mathrm{~N}_{4}$ in place. Thus, the process as applied to $\mathrm{Si}_{3} \mathrm{~N}_{4}$ in the true sense is a combination of both physical and chemical vapor deposition. For depositing silicon carbide, a carbonaceous gas such as propylene is substituted for $\mathrm{NH}_{3}$.

The ion plating process is relatively new and has been pursued by investigators only during the past few years. Since the process allows an "activated" chemical vapor deposition to proceed simultaneously, many avenues for depositing complex composites over a wide range of temperature are at the disposal of the materials engineer. As with conventional CVD, tubes of $\mathrm{SiC}$ and $\mathrm{Si}_{3} \mathrm{~N}_{4}$ can be readily seal coated. 
Other materials ion-plated at General Atomic Company include carbon and $\mathrm{Al}_{2} \mathrm{O}_{3}$. The carbon is deposited just above room temperature on delicate organic materials; yet adherent dense films are obtained. $\mathrm{Al}_{2} \mathrm{O}_{3}$ has been ion plated by evaporating the aluminum into an oxygen plasma.

\section{Joining}

As noted in previous sections, success in using ceramic materials necessitates that the materials be used in compression or under low loads in tension. In the area of joining, the same criterion has been utilized in fabricating high-temperature $\left(1100^{\circ} \mathrm{C}\right)$ metal-ceramic seals, such as for the thermionic diodes. In the reformer application, where tube lengths of $40 \mathrm{ft}$ must be accommodated, the thermal stresses developed can be large; however, they can be relieved or alleviated as they occur through proper design. A case where design ingenuity has been successful in dealing with a ceramic-type material is the area of nuclear-powered thermoelectric generators. Here, the thermoelectric materials have tensile strengths of $<1000$ psi and nil ductility. By using the materials either in compression (Fig. 10 5), such as in Teledyne or 3M designs, or free floating in cantilever (Fig. 10-6), as in General Atomic design, generators have been fabricated that have been launched into orbit and have exhibited successful performance. In the area of high-temperature $\left(2000^{\circ} \mathrm{F}\right)$ ceramic reformer technology, discussions with vendors and reviews of the literature have revealed no prior experimental experience in high-temperature tube joining, although many investigators have considered the application.

Some techniques for joining ceramic tubes are discussed below. These techniques were derived from:

1. Techniques developed by General Atomic for brazing silicon carbide to itself.

2. A thermionic thermal stability test designed, fabricated, and operated by General Atomic in the temperature range from $800^{\circ}$ to $1400^{\circ} \mathrm{C}$. 


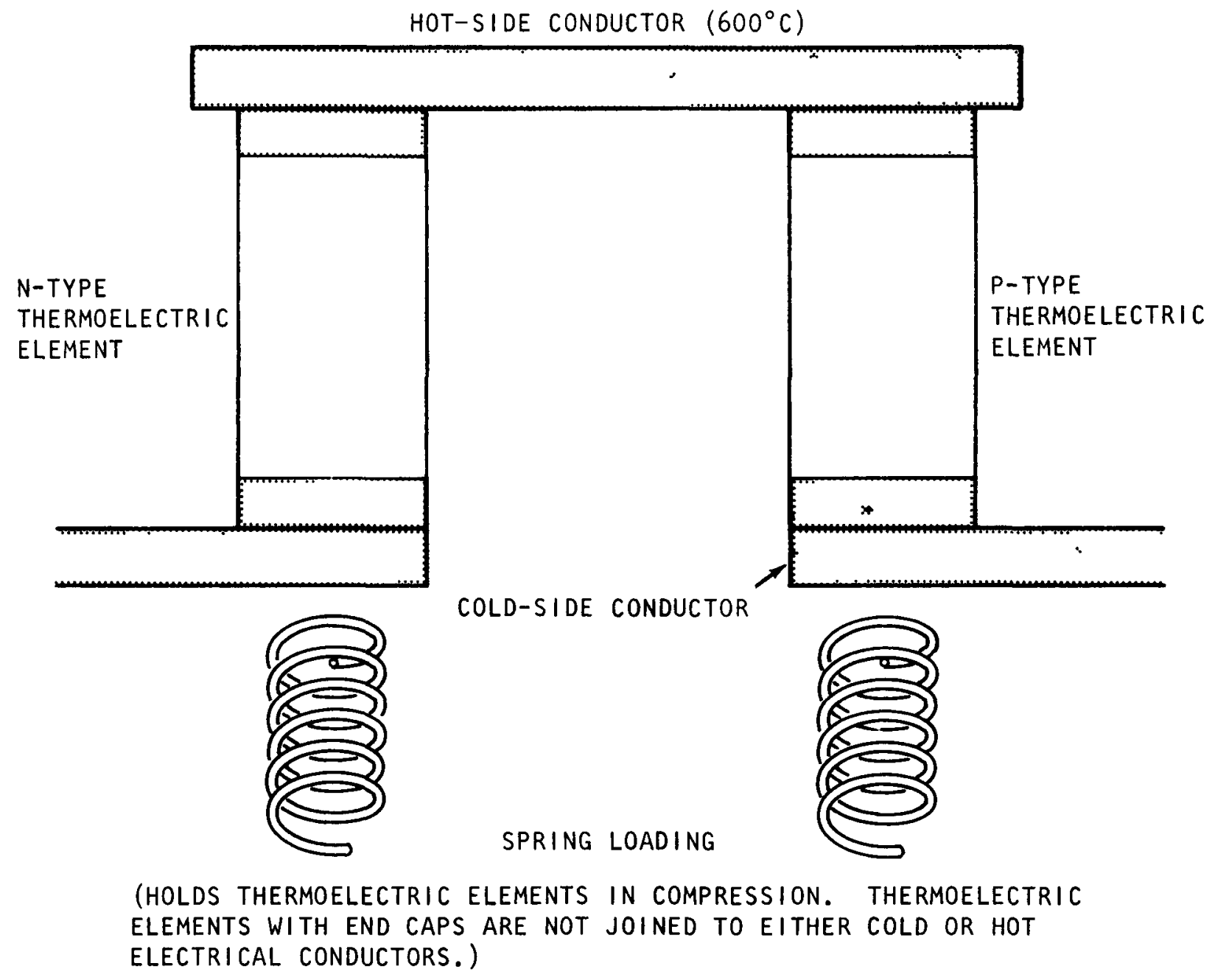

Fig. 10-5. Schematic of thermoelectric generator showing how materials are held in compression 


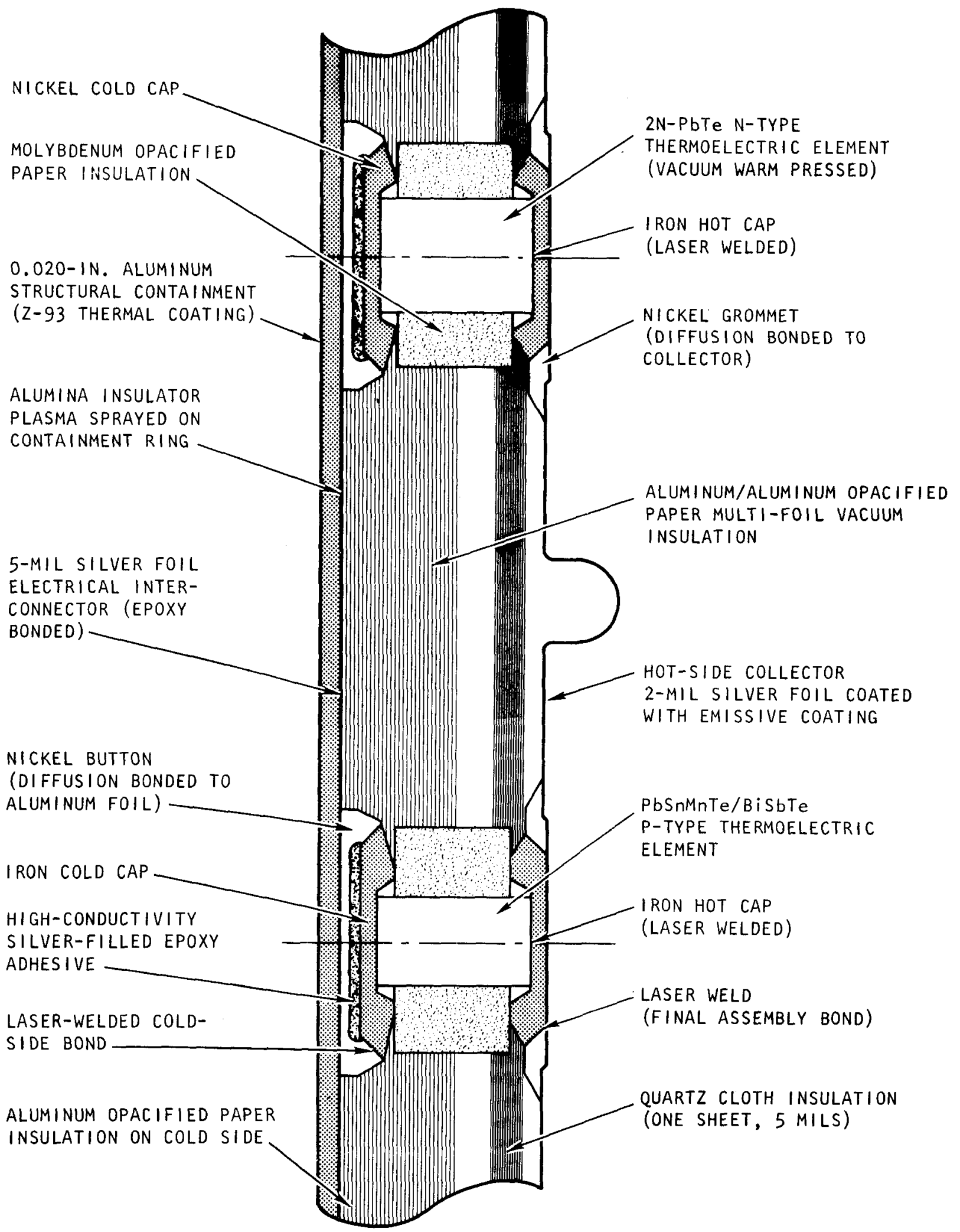

Fig. 10-6. Schematic of ring converter thermoelectric couple cross section. The thermoelectric elements are supported in cantilever, and the 2-mil silver collector is flexible enough to absorb any stresses. The temperature differential across the system is $250^{\circ} \mathrm{C}$. 
3. A design obtained from Carborundum that is used at low temperatures and can probably be utilized at high temperatures.

4. Designs conceived by General Atomic as a result of its experience with high-temperature ceramic fuels, thermionic cel1 (to $1800^{\circ} \mathrm{C}$ ) design and fabrication, and thermoelectric design and fabrication (to $1100^{\circ} \mathrm{C}$ ).

Straight Tubes, Cold Mechanical Seals. Figure 10-7 shows a straight reformer tube with cold mechanical seals on the ends. The inside ceramic tubes act as guides for the reformer gases through the cold seal ends. The tube ends are rigidly mounted to withstand internal gas pressures. Thermal expansion in the tube is accommodated by the axial tube movement allowed by the cold seals. Ceramic insulation and spacers between the inside and outside ceramic tubes restrict gas flow next to the outer ceramic tube at the cold seals. Auxiliary cooling at the cold seals may or may not be needed. Cold seal gaskets are made from Viton A, Teflon, or similar materials.

A major advantage of this system is its simplicity. Except for ground surfaces at each end of the ceramic, tubes are as-extruded. A system similar to this was used for a thermionic thermal stability test that was designed, fabricated, and operated at General Atomic. The ceramic tubes in this test were made of Mullite, with Viton A 0 -ring sealed ends. These tubes operated from $800^{\circ}$ to $1400^{\circ} \mathrm{C}$ with ion pumped internal pressures of $<10^{-7}$ Torr. Samples were frequent1y removed from the system, which subjected the tubes to thermal cycle fatigue. Tube lives were approximately $2000 \mathrm{hr}$ at $1200^{\circ} \mathrm{C}$, but with the use of silicon carbide and $\mathrm{Si}_{3} \mathrm{~N}_{4}$, it is expected that 1ifetimes of many years could be obtained.

For high-temperature operation of the joint, the 0-ring or gasket can be materials such as aluminum, copper, gold, nicke1, lead, platinum, Grafoil, or graphite metallized cloth, depending upon the operating temperature of the seal. To form the leak-tight joint, the gasket deforms to fill any voids. In the design shown in Fig. 10-7, the above-mentioned materials would deform satisfactorily, but how these materials would behave 


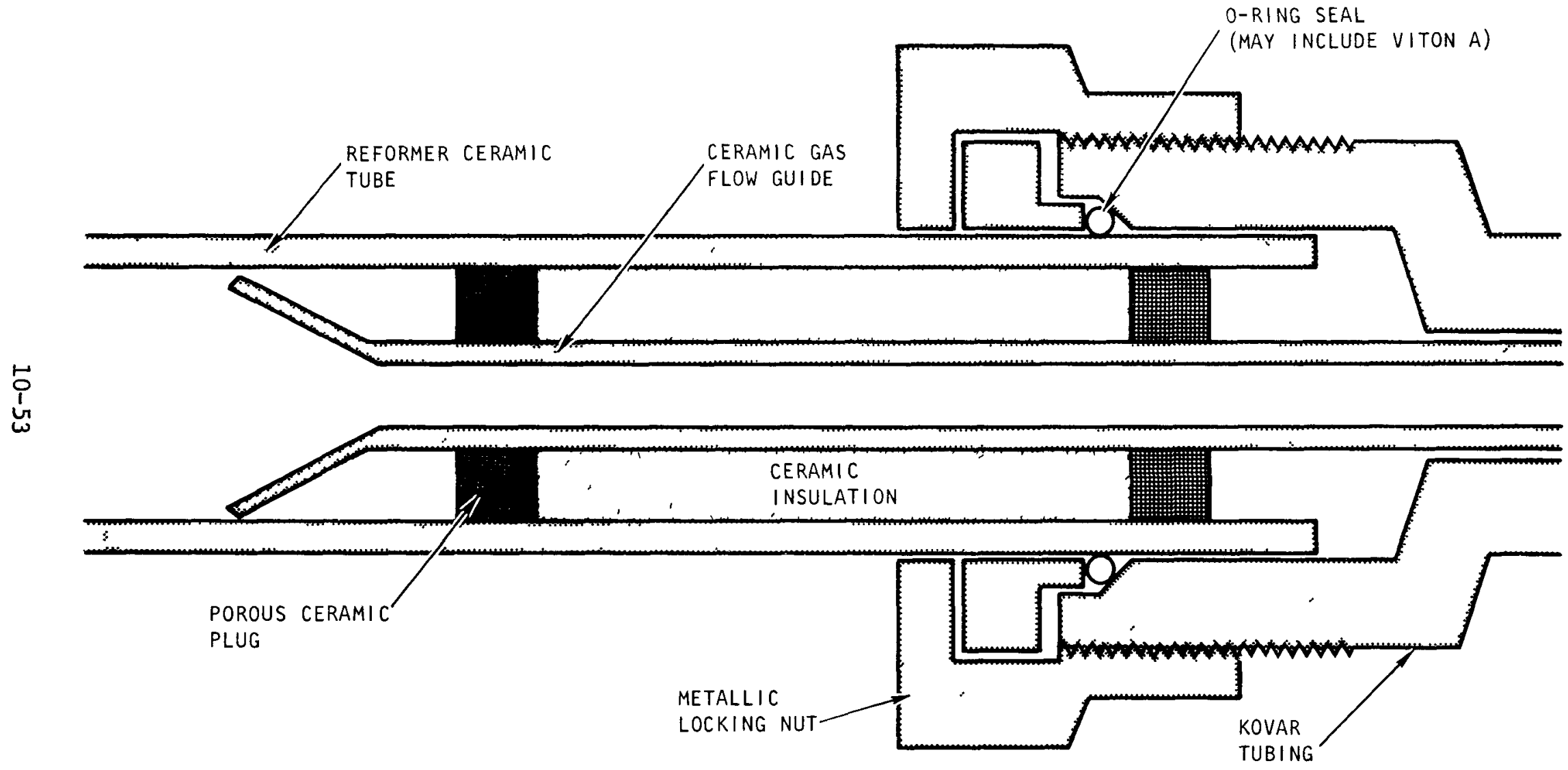

Fig. 10-7. Ceramic reformer tube joined to metallic tube with mechanical joint 
under long-term creep or as a function of thermal cycling has not been determined. As with ultra-high vacuum systems that use deformable metallic seals (usually copper), it is necessary to replace the gasket if the joint is taken apart.

Straight Tubes, Cold or Hot Sea1s, Carborundum Approach. Carborundum is using ceramic-to-metal joints (see Fig. 10-8) for heat exchangers. The seal is provided by thread pressure on a Teflon ring. A commercial heat exchanger being produced by Carborundum operates at hydrostatic pressures up to 75 psi or 50 psi-steam pressure at $340^{\circ} \mathrm{F}$. This design is not directly applicable for operation above $1800^{\circ} \mathrm{F}$, since no provision is made to maintain a thermal gradient between the tube ends and the tube hot zone. Their Teflon seals provide for a sliding fit between the silicon carbide tubes and the heat exchanger jacket. For high-temperature operation, the seal materials can be upgraded using aluminum, copper, nickel, lead, platinum, Grafoil, and graphite.

Thimble Design, Straight Tubes, Warm Seals, One Closed End. As shown in Fig. 10-9, a refractory metal joint and a metal gasket are used to seal the ceramic tube to the cooler-temperature connecting metallic tube. Reformer gas enters the system from a central ceramic or metal tube. A metallic alloy such as Kovar would be used to connect the ceramic to conventional metal ducting. The warm seals operate $300^{\circ}$ to $400^{\circ} \mathrm{C}$ colder than the ceramic reformer tube.

The advantage of this system is ease of installation and removal. Difficulties may include sealing the end of the tube and stresses in the ceramic at the metal gasket end. The metal gaskets might be attacked by the reformer gases, but the small exposed surface should minimize this attack during the service life of the system. Other gasket materials, such as platinum, nickel, copper, and gold, might also be used.

Straight Tubes, One Fixed Joint, One Sliding Joint. If axial growth due to thermal expansion can be relieved, then little or no thermal stresses except stresses across the wall due to differential temperature, are 

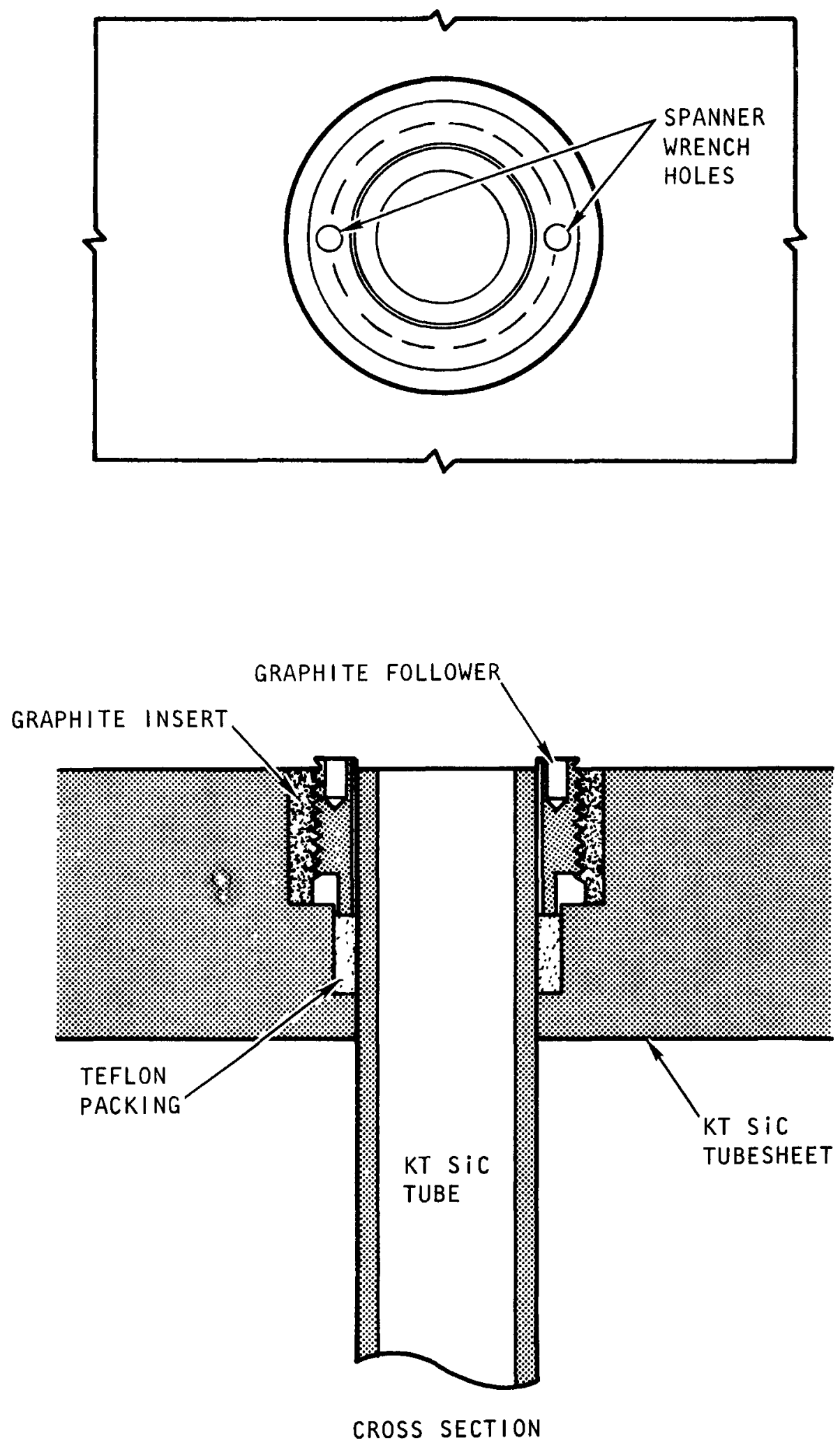

Fig. 10-8. Carborundum Company design for mechanical joining of SiC tube to SiC tubesheet 


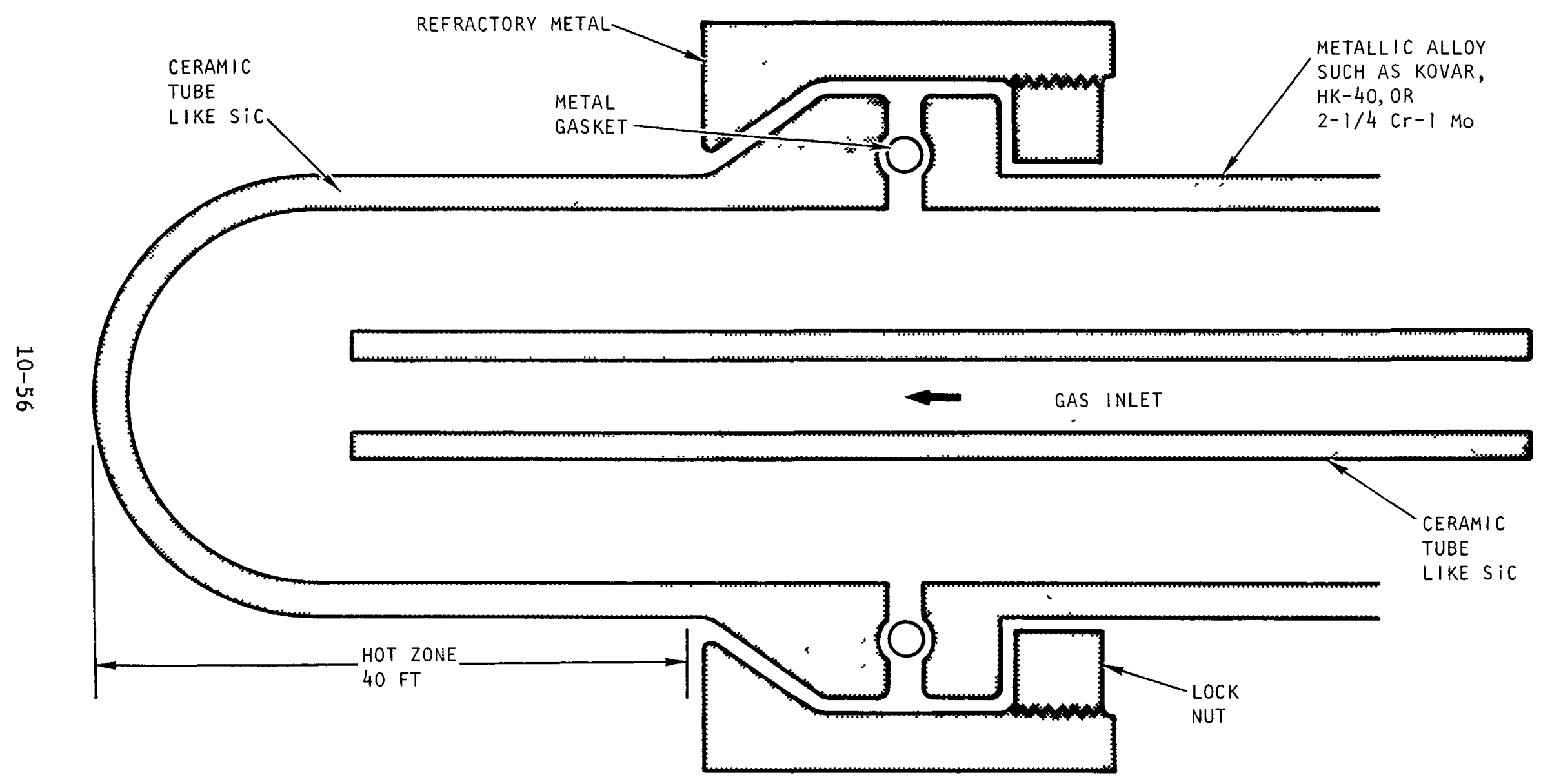

Fig. 10-9. Thimble design of ceramic tube allowing free axial expansion 
retained in the structure at temperature. With the sliding joint shown in Fig. 10-10 the stresses should be relieved during heating, while the stresses developed in cooling should be minimal.

The sliding hermetic seal is formed by making use of the greater gas pressure on the outside diameter of the tubing. This isostatic pressure on the seal holds the joint in compression yet allows the tubing to grow or contract. If a liquid metal or molten glass is used (in place of a soft solid metal) as the hermetic seal, the joint tolerance becomes much more critical because of possible extrusion of the sealant material through the seal. To avoid this extrusion, it may be possible to use a foil.

The other end of the tube in this design could be either a sliding or a fixed joint. If a fixed joint is required, however, it can be brazed. Silicon carbide to silicon carbide joints have been brazed at General Atomic by using an equal atom ratio of silicon and carbon powders. The silicon initially forms the brazed joint, but then continues to react with the elemental carbon to form silicon carbide. Joints of this nature have proved leak-tight and successful in retaining fission gas products in experimental capsules.

Hot-Pressed Discs Bonded to Connecting Tubes. The advantage of this design as shown in Fig. 10-11 is the use of fully dense tubes and joints. The reformer tube length made by this technique is unrestricted.

Tube segments are formed during disc hot pressing and brazed with silicon-carbon as discussed above.

The major disadvantage of this design is the need for a multiple, simultaneous joint preparation. Ceramic-to-metal joints are still needed in this design, but since they can be quite cold, they can be mechanical joints as similar to those used in designs discussed above. 


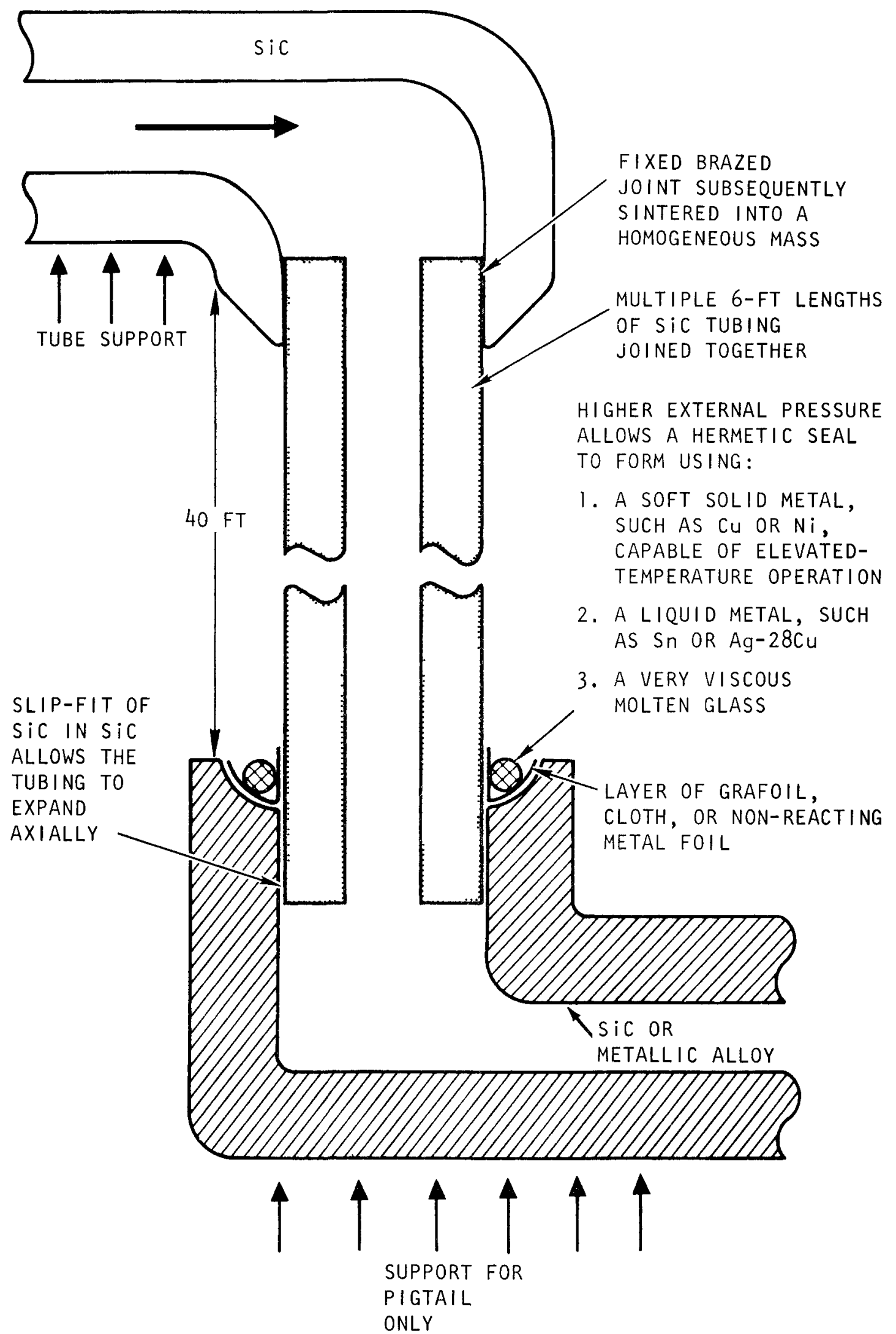

Fig. 10-10. Ceramic tube with one fixed end and one sliding seal (possibly both ends could use sliding seals) 

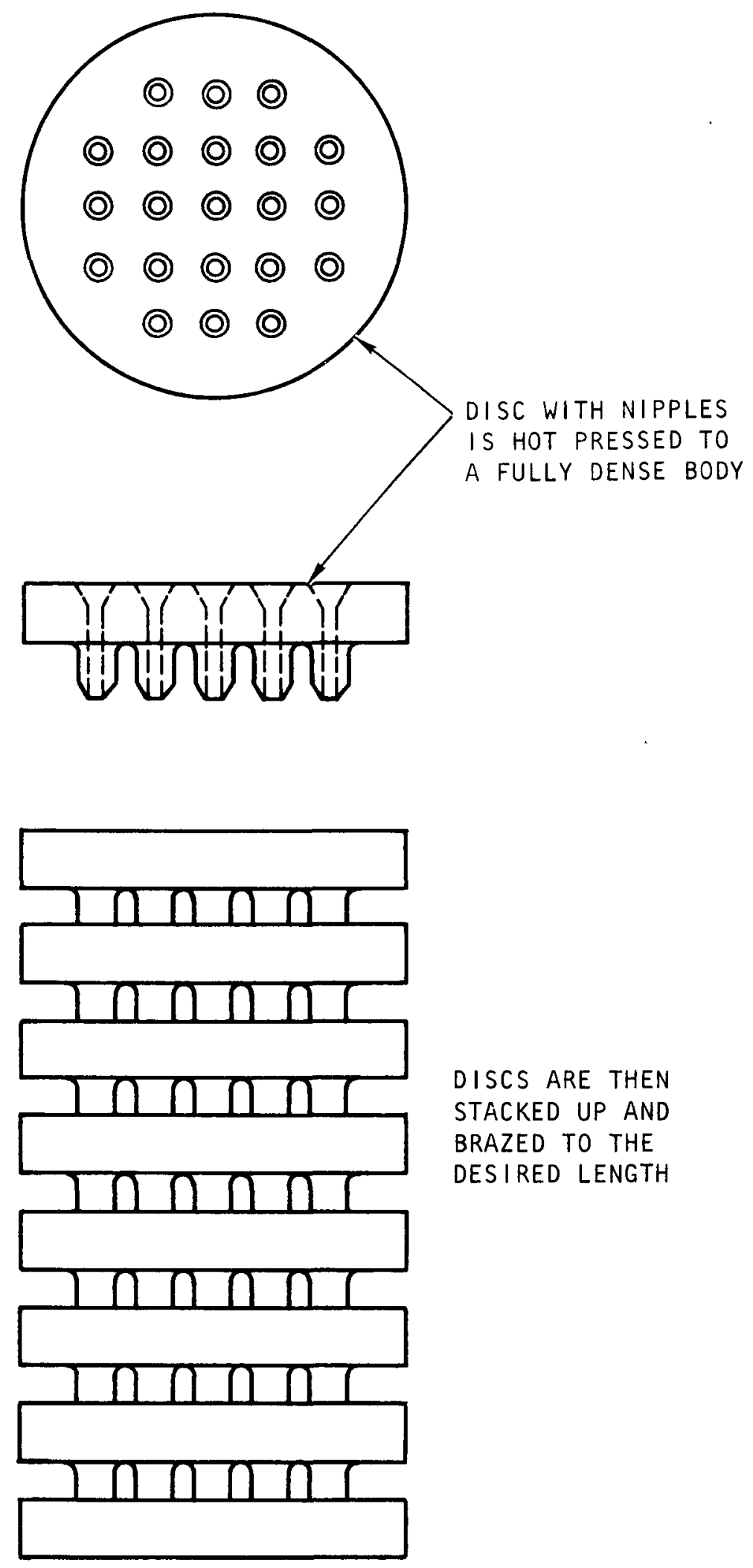

DISCS ARE THEN

STACKED UP AND

BRAZED TO THE

DESIRED LENGTH

Fig. 10-11. Formation of ceramic tubes by brazing together many smaller shapes 


\section{Mechanical Properties}

Most ceramic materials exhibit a much greater spread in mechanical properties data than metallic alloys, and as a result most designers utilize strength values that are very conservative compared with the nominal values. This use of lower strength value not only takes into account the wider distribution of mechanical properties exhibited by ceramic materials, but also allows for the decrease in strength as a function of time (the phenomenon referred to as delayed fracture). The fact that these materials would be utilized somewhat conservatively is not in itself very important, since an increase in cross-sectional area can be readily accommodated and also the strength and creep resistance of these materials are many times greater than those of metallic alloys used at the conventional reformer temperatures.

Silicon Carbide and $\mathrm{Si}_{3} \mathrm{~N}_{4}$. The flexural strength of silicon carbide and $\mathrm{Si}_{3} \mathrm{~N}_{4}$, as shown in Appendix $\mathrm{C}$, varies between 80,000 and 100,000 psi. Between room temperature and $\sim 1800^{\circ} \mathrm{F}$, their tensile strength is essentially constant and remains satisfactory up to $2600^{\circ} \mathrm{F}$. The creep behavior of both silicon carbide and $\mathrm{Si}_{3} \mathrm{~N}_{4}$ up to $2000^{\circ} \mathrm{F}$ has been shown to be extremely low, and there is no reason to believe that both materials would not exhibit acceptable creep rates up to the melting point of silicon $\left(2570^{\circ} \mathrm{F}\right)$. Well defined stages of primary and secondary creep behavior should permit a structural design approach similar to that used for metals.

Since silicon carbide and $\mathrm{Si}_{3} \mathrm{~N}_{4}$ are manufactured in so many varieties (hot pressing, reaction sintered, chemical vapor deposition), mechanical properties such as creep and flexural strength are essentially controlled by the fabrication techniques employed. For example, in the work reported in Ref. 10-23, the flexural strength of silicon carbide was increased by approximately $50 \%$ at both room temperature and elevated temperature by simply surface coating the test specimens $(0.10 \times 0.09$ in. in cross section) with 6 mils of chemically vapor deposited silicon carbide (CVD). In a small way, the CVD silicon carbide layer may contribute a composite effect to the strength of the material. More likely, the uniform, defect-free CVD 
coating has filled in and thus eliminated the ever-present microdefects or surface imperfections on the surface of the manufactured silicon carbide material, thereby allowing the specimen to be stressed considerably closer to its high theoretical tensile strength. Since ceramic materials have low fracture toughness, the fracture strength is strongly influenced by the surface finish, and the designs should therefore require that the materials be used mostly in compression and under light loads in tension.

$\mathrm{Al}_{2} \mathrm{O}_{3}$. Fu1ly dense $\mathrm{Al}_{2} \mathrm{O}_{3}$ is structurally stable and capable of extended high-temperature operation with respect to strength and creep. Although these properties are attractive, they are no better than the properties of silicon carbide or $\mathrm{Si}_{3} \mathrm{~N}_{4}$. The relatively high thermal expansion and poor thermal conductivity of $\mathrm{Al}_{2} \mathrm{O}_{3}$ contribute to the development of higher thermal stresses and make the material less attractive than either silicon carbide and $\mathrm{Si}_{3} \mathrm{~N}_{4}$.

\section{Thermal Shock Resistance}

Ceramic materials that demonstrate a high resistance to thermal shock are usually characterized by low thermal expansion coefficients, high thermal conductivities, and a high tensile strength and modulus of elasticity. While the latter properties are fundamental considerations in analyzing different materials, the thermal shock resistance will be influenced by the fabrication techniques.

Silicon Carbide. The thermal expansion of silicon carbide $(4.8 \mathrm{x}$ $\left.10^{-6}{ }^{\circ} \mathrm{C}\right)$ is not quite as 1 ow as that of $\mathrm{Si}_{3} \mathrm{~N}_{4}\left(3.2 \times 10^{-6}{ }^{\circ} \mathrm{C}\right)$. However, it is still very low, and silicon carbide is used in many applications that require frequent thermal cycling at rates that would greatly exceed the conditions anticipated for the process heat applications. In the ceramic gas turbine, the silicon carbide will sustain harsh starts as well as quick cooldowns. 
Because of its resistance to thermal shock, silicon carbide is used as heater elements in high-temperature, electrical-resistance-heated furnaces. Twenty years ago, nearly $80 \%$ of the gas generators for forging and heat treatment operations were made from silicon carbide. Retorts 15 to $30 \mathrm{ft}$ high used in the reduction of zinc were also lined with silicon carbide at that time. These early structures did not have the refinements in density, purity, impermeability, and grain structure that enhance the performance of recent CVD- $\beta$ silicon-carbide structures. Silicon carbide produced dramatic improvements in the operating temperatures, corrosion resistance, heat release rates, and mechanical wear resistance previously obtained with metal alloys for the same applications.

$\mathrm{Si}_{3} \mathrm{~N}_{4}$ and the SIALONS. $\mathrm{Si}_{3} \mathrm{~N}_{4}$ has the lowest coefficient of expansion of any of the usable ceramics and typically demonstrates a better thermal shock resistance than silicon carbide. $\mathrm{Si}_{3} \mathrm{~N}_{4}$, which comes in both the lowdensity reaction-sintered and hot-pressed configurations, would be more desirable for use in the hot-pressed condition. However, it is not expected that $\mathrm{Si}_{3} \mathrm{~N}_{4}$ tubes can be manufactured by hot pressing techniques, and properties of the reaction-sintered material should be utilized.

The SIALONS are a relatively new variation of $\mathrm{Si}_{3} \mathrm{~N}_{4}$ that have aluminum substituting for silicon and oxygen for nitrogen. These ceramic alloys supposedly have greater thermal shock resistance than $\mathrm{Si}_{3} \mathrm{~N}_{4}$, but additional data are required to characterize this class of material for the process heat applications.

$\mathrm{Al}_{2} \mathrm{O}_{3} \cdot$ While $\mathrm{Al}_{2} \mathrm{O}_{3}$ and ceramic alloys of $\mathrm{Al}_{2} \mathrm{O}_{3}$ (Mullite) have seen considerable service at elevated temperature, these materials have demonstrated marginal performance in thermal cycling. $\mathrm{Al}_{2} \mathrm{O}_{3}$ has a much higher coefficient of expansion than silicon carbide and $\mathrm{Si}_{3} \mathrm{~N}_{4}$ (twice that of $\mathrm{Si}_{3} \mathrm{~N}_{4}$ ), and apparently the added stresses (due to the higher expansion rate) that develop in $\mathrm{Al}_{2} \mathrm{O}_{3}$ have limited the use of this material. In the anticipated environment, $\mathrm{Al}_{2} \mathrm{O}_{3}$ could be considered because the rate of heating and cooling can be slow. However, it is doubtful that this material would be committed to a system. 


\section{Program Required}

Research and development for ceramic reformer materials will be required for process temperatures of $1600^{\circ} \mathrm{F}$ and above. A program is required that would (1) experimentally determine if silicon carbide and $\mathrm{Si}_{3} \mathrm{~N}_{4}$ are definitely suitable for consideration in the HTGR helium and reformer environments, and (2) enable a design effort that would go beyond the conceptual stage that has been considered in this report. Specifically, the program study areas should be concentrated in the following areas:

1. Compatibility of silicon carbide and $\mathrm{Si}_{3} \mathrm{~N}_{4}$ with the trace impurities in the helium and the reformer gases, specifically, what ratios of $\mathrm{H}_{2} \mathrm{O}$ to $\mathrm{H}_{2}$ and $\mathrm{CO}$ to $\mathrm{CO}_{2}$ generate attack (if any) and how the rates and uniformity of attack vary with temperature. Helium test loops with controlled gaseous impurities are under construction at General Atomic (both AEC and GA funded) that will be used for studying effects on metallic alloys. These same type loops are required to evaluate silicon carbide and $\mathrm{Si}_{3} \mathrm{~N}_{4}$, but at higher temperatures and at impurity levels that are representative of the inner and outer reformer wall environments. A schematic of such a system is shown in Fig. 10-3.

2. Materials evaluation. The materials available today from various vendors are in a period of upgrading, or could be upgraded to some specification if a market was created. The most favorable silicon carbide and $\mathrm{Si}_{3} \mathrm{~N}_{4}$ shapes available must be characterized. It must be determined whether one of these materials is suitable with respect to its mechanical properties and permeability and, if not, what effort would be required to make this material suitable.

3. High-temperature tube joining. The joining of the tubes will probably be the major problem in qualifying a ceramic system, since these joints must not only be leak-tight but must be able 
to endure the thermal stresses of operation and cycling that a normal plant encounters. The proposed designs described earlier in this section, as well as other configurations, should be evaluated in simulated environments. The setups needed to accomplish this task are relatively inexpensive, and meaningful design data could be obtained on representative joints as a function of thermal cycles, thermal gradients, and permeability.

The above three areas of investigation could be accomplished in a 1-yr technology program. This screening program would allow a decision to be made upon the feasibility of a ceramic system and a detailed test plan to be formulated on qualifying the materials for the process heat application. The program, which is summarized in Table 10-6, could be accomplished at a cost of $\$ 200,000$ to $\$ 250,000$.

A realistic test program required to qualify ceramic reformer materials cannot be formulated until the above feasibility study is completed. The cost for such a program is believed to be on the order of about $\$ 2,000,000$.

\subsubsection{Thermal Barrier}

The thermal barrier in conjunction with the liner cooling system maintains the concrete temperatures and temperature gradients within acceptable limits while minimizing heat losses from the primary coolant. The thermal barrier design is strongly dependent on service temperature. A substantial research and development effort will be required to develop thermal barriers for temperatures higher than those in the HTGR steam plant. The principal limitations of the present thermal barriers are the acceptable service temperatures of the metal cover plates used to contain and compress fibrous insulating blankets.

10.1.4.1. Limitation of HTGR Steam Plant Thermal Barriers. The thermal barriers in the standard HTGR steam plant can be divided into three classes (designated A, B, and C) based primarily on service temperature. Within 
TABLE $10-6$

SUMMARY OF 12-MONTH CERAMIC MATERIALS DEVELOPMENT PROGRAM

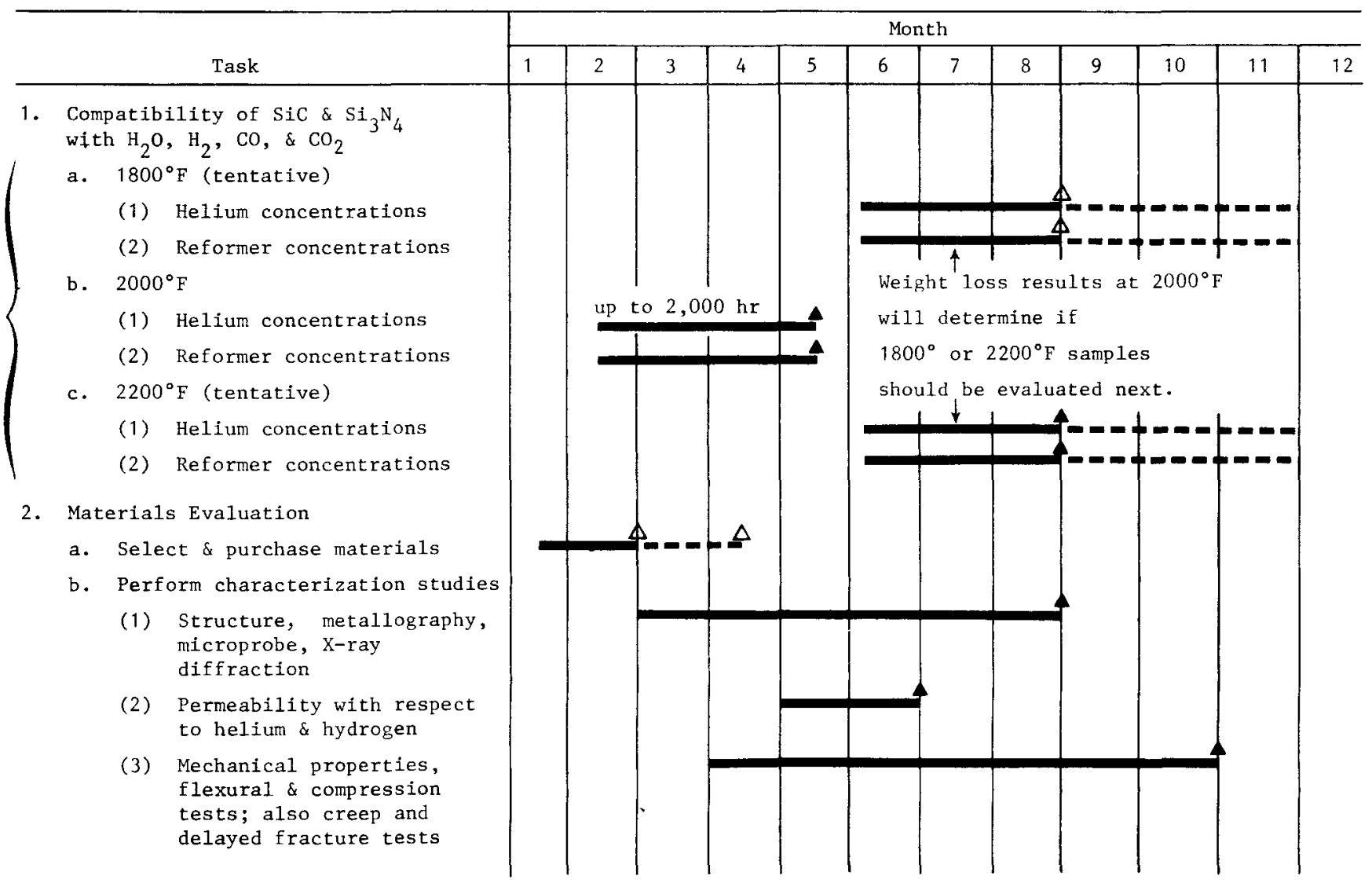

Weight loss measurements, metallography \& microprobe of samples. Flexure o testing at room temperature of unaged and aged specimens. 
TABLE 10-6 (Continued)

\begin{tabular}{|c|c|c|c|c|c|c|c|c|c|c|c|c|c|}
\hline \multirow{2}{*}{\multicolumn{2}{|c|}{ Task }} & \multicolumn{12}{|c|}{ Month } \\
\hline & & 1 & $\overline{2}$ & 3 & 4 & 5 & 6 & 7 & 8 & 9 & 10 & 11 & 12 \\
\hline \multirow[t]{4}{*}{3.} & High-Temperature Tube Joining & & & & & & & & & & & & \\
\hline & $\begin{array}{l}\text { a. Complete design of } 2 \text { or } 3 \\
\text { mechanical-type joints \& } \\
\text { one brazed-type joint }\end{array}$ & & & & & & & & ial & & & & \\
\hline & $\begin{array}{l}\text { b. Fabricate \& evaluate mechanical } \\
\text { tube joints with respect to } \\
\text { thermal cycling, thermal } \\
\text { gradients, \& permeability, at } \\
\text { temperatures up to } 2200^{\circ} \mathrm{F}\end{array}$ & & & & & & & & & & & & \\
\hline & $\begin{array}{l}\text { Fabricate \& evaluate } \mathrm{Si}-\mathrm{C} \\
\text { brazing technique on tube } \\
\text { joints with respect to } \\
\text { items in b, above }\end{array}$ & & & & & & & & & & & & \\
\hline 4. & $\begin{array}{l}\text { Preparation of Detailed Test Plan } \\
\text { for Qualification of Ceramic } \\
\text { Materials for Nuclear Reformer } \\
\text { Applications }\end{array}$ & & & & & & & & & & & & \\
\hline 5. & $\begin{array}{l}\text { Preparation of Final Report \& Final } \\
\text { Briefing }\end{array}$ & & & & & & & & & & & & \\
\hline
\end{tabular}


each class, different designs are required based on geometry and the nature of the helium environment. A more detailed description of thermal barrier design in the steam plant is given in Section 5.

\section{Class A}

Class A thermal barrier consists of Kaowool, a fibrous insulating blanket, compressed by carbon steel cover plates. Where needed, metals are nitrided to facilitate sliding to accommodate thermal expansion. The class A thermal barrier is suitable for service in helium up to $800^{\circ} \mathrm{F}$. The Kaowool blankets are suitable for service up to $1000^{\circ} \mathrm{F}$. Above this temperature, the blankets will not maintain sufficient resiliency over a $30-y \mathrm{r}$ life.

\section{Class B}

The Class B thermal barrier is similar to class A but has improved materials suitable for higher temperatures. Hastelloy $X$ cover plates and Quartz et Silice fibrous blankets are used. Class $B$ thermal barrier is suitable for continuous service in helium up to $1700^{\circ} \mathrm{F}$. At higher temperatures, the strength of the Hastelloy $X$ cover plates is inadequate.

\section{C1ass C}

Class $C$ thermal barrier is designed to withstand the hot streak helium temperatures of $2000^{\circ} \mathrm{F}$ at the core support floor and is capable of temporary service at $2060^{\circ} \mathrm{F}$. It consists of Class A thermal barrier covered with layers of slip-cast silica blocks.

10.1.4.2. General Research and Development Requirements. The PCRV areas requiring research and development at higher temperatures are the core support floor, the lower core cavity, the core outlet duct, and the reformer cavity. 
The thermal barriers for the lower core cavity and core outlet duct will require research and development for core outlet temperatures of $1600^{\circ} \mathrm{F}$ and above, and thermal barriers for the reformer cavity and core support floor will require research and development for core outlet temperatures of $1800^{\circ} \mathrm{F}$ and above.

The core outlet duct presents the most demanding design conditions for the thermal barrier, owing to a combination of high temperature, geometry, and helium pressure drops in regions around the duct. Limiting design conditions are strongly dependent on hot helium streak temperatures from the core and transients following major accidents. Maximum streak temperatures under normal operating conditions can be over $200^{\circ} \mathrm{F}$ above the average core outlet temperature. After the design basis depressurization accident (DBDA), helium temperatures at the core outlet duct rise several hundred degrees for short periods of time. Under these conditions, damage to the thermal barrier must be limited to the extent that it does not jeopardize the ability to cool the core. In addition, significant pressure differences are present in the region around the core outlet duct under normal operating conditions. Consequently, the thermal barrier must have a large resistance to forced convection of helium to preserve its insulating properties.

The core support floor thermal barrier sees the most severe temperatures which result from hot streaks of helium from the core. However, the simple geometry has facilitated thermal barrier design by enabling development of an all-ceramic thermal barrier where contact with the hot helium is encountered. Higher temperatures may require improved materials, but the basic design would still be adequate.

The thermal barrier reformer cavity will require additional development for higher service temperatures. Design conditions are less demanding than for the core outlet duct because streak temperatures are reduced. Thermal barrier designs for the core support floor can be adapted for the reformer cavity floor but would not be suitable for vertical surfaces. 
10.1.4.3. Research and Development Program. Development of suitable thermal barriers for high temperatures will center largely in research and development of new materials, which is discussed in Section 10.1.3. In certain cases, similar designs can probably be used with improved materials. For the higher-temperature levels considered in this study, the nature of acceptable materials may dictate redesign or use of composite designs.

\section{Program for Process Temperatures of $1400^{\circ} \mathrm{F}$}

The PCRV areas requiring research and development for process temperatures of $1400^{\circ} \mathrm{F}$ are the core outlet duct and the lower core cavity. An outline of the research and development program is given below.

Selection of Candidate Materials. An evaluation and screening of candidate materials will be conducted based on available data and additional testing where needed. Suitable candidate materials will then be selected.

The results of an initial analysis of high-temperature materials are shown in Table 10-7. Molybdenum TZM appears to be a possible replacement for Hastelloy $X$ cover plates at high temperatures, possibly up to $2500^{\circ} \mathrm{F}$. other candidate materials are silicon carbide and $\mathrm{Si}_{3} \mathrm{~N}_{4}$ ceramics. The temperature limits of Quartz et Silice fibrous blankets are not accurately known, but their stability against sintering, resiliency, and volatility are questionable at higher temperatures. An attractive replacement for high-temperature service is carbon felt.

Establishment of Reference Design. Based on materials analysis, operating conditions, and performance requirements, suitable thermal barrier designs will be established.

Analysis and Testing of Thermal Barrier. Analysis and testing of the thermal barrier will include flow permeation tests, friction and wear tests, thermal cycling tests, detailed stress analysis, thermal performance tests, and determination of performance under accident conditions. Major accidents of concern are depressurization accidents and major steam leaks. 
TABLE 10-7

PROPERTIES FOR THERMAL BARRIER CANDIDATE MATERIALS

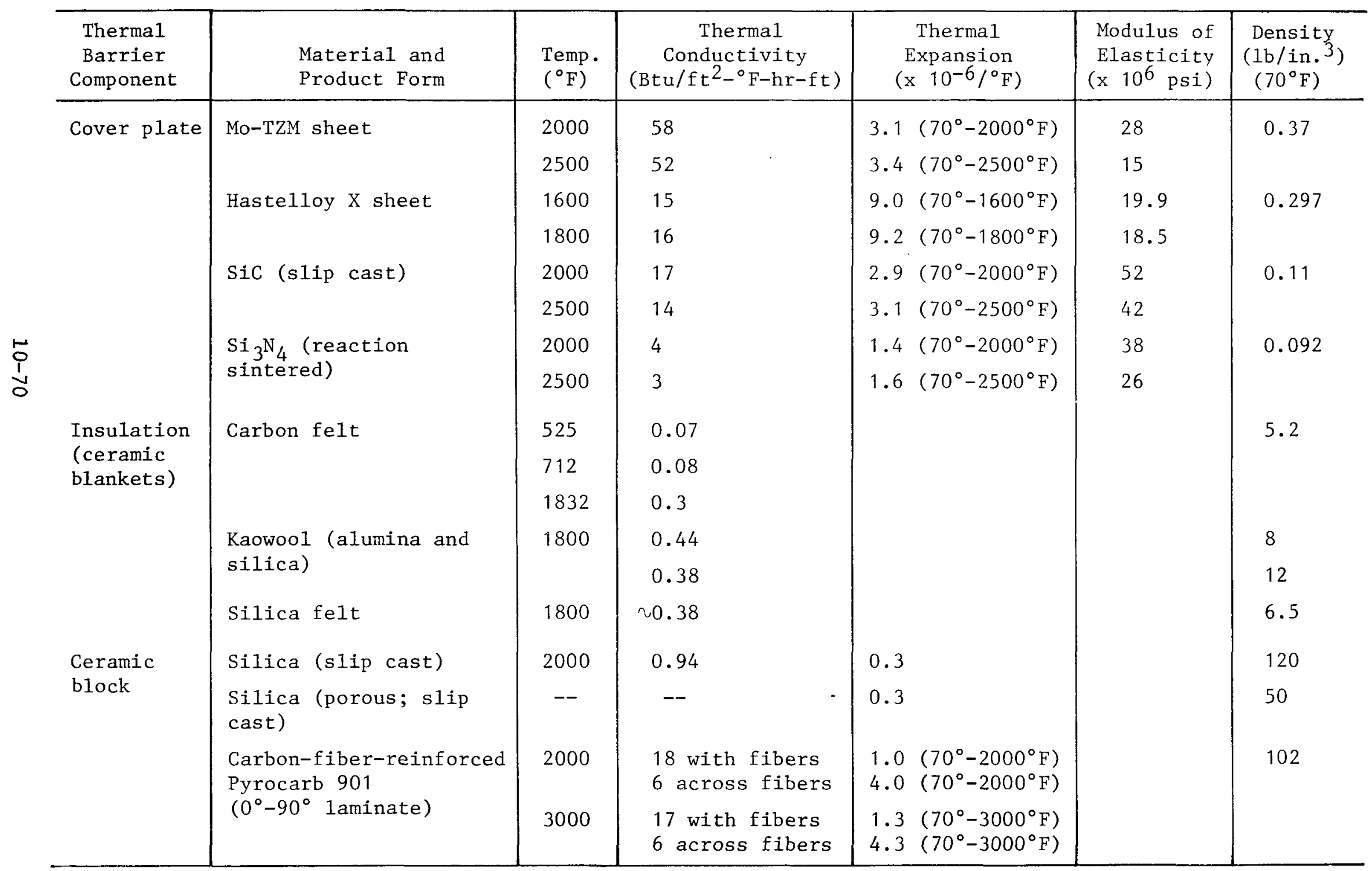


The total program cost is estimated to be $\$ 1,500,000$ in addition to the materials program previously discussed. The program would extend over a period of about $5 \mathrm{yr}$.

\section{Program for Process Temperatures of $1600^{\circ}$ to $2000^{\circ} \mathrm{F}$}

This program will be similar to that required for process temperatures of $1400^{\circ} \mathrm{F}$. However, additional areas of the PCRV will require thermal barrier development, and a broader scope of materials and designs will be considered and tested. Substitute materials for the core support floor, which sees the most severe temperatures, will have to be considered. An attractive candidate for the presently used fused silica blocks is carbonfiber-reinforced laminate composites.

The total program cost is estimated to be $\$ 2,500,000$ and will extend over a period of about $5 \mathrm{yr}$.

\subsubsection{Reformer Catalysts and Reformer Performance Testing}

Research and development will be required at all temperature levels considered in this study to establish fundamental data required for reformer design and to test reformer performance. Although adequate design methods are available for design of conventional reformers, the use of convective heating introduces significant differences affecting the design and performance. Heat transfer coefficients in packed catalyst beds and catalyst behavior are affected by several variables and are difficult to estimate from first principles. Methods adequate for design of conventional reformers cannot necessarily be relied on for accurate prediction of the performance of convectively heated reformers. The high cost associated with space inside the PCRV easily justifies the development of accurate design methods.

Reformers for the two highest process temperatures, $1800^{\circ}$ and $2000^{\circ} \mathrm{F}$, depart significantly from conventional reformer practice. Process gas temperatures are over $200^{\circ} \mathrm{F}$ higher than in conventional reforming, and 
catalyst behavior is uncertain. Catalyst testing will be required to obtain data on reaction rates, catalyst activity, carbon deposition rates, and resistance to sintering and poisoning.

In addition to the above research and development requirements, a study of alternate catalysts and catalyst configurations should be conducted. The reformer designs in this study closely copy conventional practice with regard to catalysts and catalyst configurations. However, some of the differences between nuclear-heated reformer and conventional fossil-fired reformers, suggest that alternate catalysts and catalyst configurations might afford more optimum designs for convectively heated reformers. These differences are as follows:

1. In convectively heated reformers, the heat source temperature of the hot helium must drop substantially along the length of the reformer tube. In contrast, fossil-fired reformers have a nearly constant heat source temperature over the length of the reformer tube. Consequently, convectively heated reformers have a lower driving force in the low-temperature end of the reformer and are more sensitive to the low-temperature activity of the catalyst.

2. The high cost associated with space inside the PCRV emphasizes compact reformer design. In conventional reformer practice, large catalyst pellets and large tubes are used to maintain acceptable pressure drops. Catalyst configurations allowing the use of small tubes without excessive pressure drops would afford more efficient packing and more compact reformers.

3. Catalyst replacement for reformers inside the PCRV is complicated by the presence of fission products which have plated out on the reformer tubes and by limited access in the PCRV. Thus, catalysts with long life or greater ease of replacement are of greater value in nuclear-heated reformers which are located inside the PCRV. 
Testing of tritium diffusion through the reformer tube walls will also be required. Tritium entering the process side of the reformer will ultimately become incorporated into the product gas and thus distributed to the processing plant and final product. Initial studies show that the radiological hazard would be negligible owing to the very low levels of tritium present, but it is important to obtain confirmation of this conclusion.

Measurement of hydrogen diffusion into the helium loop in the reformer test will provide some information relative to tritium diffusion. In addition, it may be possible to add trace quantities of tritium to the helium loop and measure tritium diffusion directly.

The research and development program and a summary of the costs involved are given below.

Process Temperature $-1200^{\circ}$ to $2000^{\circ} \mathrm{F}$

1. Preliminary Work

Review of previous reforming practice catalyst scouting studies and studies of catalyst configurations and designs. $(\$ 60,000)$

2. Catalyst Testing

Experimental determination of catalyst properties and behavior required for design. Reaction rate studies, poisoning and catalyst life studies, determination of physical properties of the catalyst. $(\$ 75,000)$

3. Establishment of Reformer Design and Design Conditions. $(\$ 30,000)$

4. Reformer Testing

A full-scale reformer test to establish and confirm methods of predicting reformer performance. $(\$ 3,300,000)$ 
Process Temperatures $-1800^{\circ}$ and $2000^{\circ} \mathrm{F}$

Because of a complete lack of reforming experience at these temperatures, additional catalyst development and testing will be required. $(\$ 75,000)$

Summary of R\&D Costs

\begin{tabular}{cc}
$\begin{array}{c}\text { Process Temp. } \\
\left({ }^{\circ} \mathrm{F}\right)\end{array}$ & Time $(\mathrm{yr}) / \operatorname{Cost}(\$)$ \\
\hline 1200 & $4 / 3,465,000$ \\
1400 & $4 / 3,465,000$ \\
1600 & $4 / 3,465,000$ \\
1800 & $5 / 3,540,000$ \\
2000 & $5 / 3,540,000$
\end{tabular}

10.1.6. Helium Circulator Drive Turbine Testing

The steam turbine used to drive the circulator operates with steam at $a^{\prime}$ density two to three times greater and at a temperature $250^{\circ} \mathrm{F}$ hotter than the HTGR power plant and thus requires development testing. (See Table 10-8. Current GCFR design conditions are shown; however, the GCFR circulatorturbine has yet to be built and tested.)

Two main test programs will be carried out. One will result in a new thrust bearing design, which is necessary to accommodate the higher steam pressure. The other will be a performance and qualification test of a ful1scale circulator assembly.

10.1.6.1. Thrust Bearing Test. Present circulator bearings and seals are maintained at primary helium conditions. Except for thrust, bearing loads should be close to existing designs. Hence, the only required major redesign of seals and bearings other than for the thrust bearing will be for the seal between the steam and primary helium. This would involve an increase in the number of or redesign of the labyrinth seals and accommodation in the 
TABLE $10-8$

COMPARISON OF HELIUM CIRCULATOR CHARACTERISTICS

(100\% POWER)

\begin{tabular}{|c|c|c|c|}
\hline & $\begin{array}{c}\text { Fort St. Vrain } \\
\text { 330-MW(e) } \\
\text { HTGR } \\
\end{array}$ & $\begin{array}{c}1160-\mathrm{MW}(\mathrm{e}) \\
\text { HTGR } \\
\end{array}$ & $\begin{array}{c}\text { Demonstration } \\
\text { Plant } \\
\text { GCFR } \\
\end{array}$ \\
\hline Speed, rpm & 9,550 & 6,750 & 13,000 \\
\hline Circulator & 5,201 & 13,600 & 22,300 \\
\hline Helium flow, 1b/sec & 242 & 500 & 509 \\
\hline \multicolumn{4}{|l|}{ Compressor diameter } \\
\hline Hub, in. & 18 & 30.75 & 20.4 \\
\hline Tip, in. & 27.1 & 41.0 & 27.0 \\
\hline Helium inlet pressure, psia & 686 & 680.5 & 1190 \\
\hline Helium outlet pressure, psia & 700 & 700 & 1250 \\
\hline Compressor pressure, psi & 14 & 19.5 & 60 \\
\hline Helium inlet temperature, ${ }^{\circ} \mathrm{F}$ & 742 & 624 & 569 \\
\hline Steam inlet temperature, ${ }^{\circ} \mathrm{F}$ & 738 & 708 & 875 \\
\hline Steam inlet pressure, psia & 853 & 913 & 2,900 \\
\hline Steam flow, $1 \mathrm{~b} / \mathrm{sec}$ & 155 & 368 & 240 \\
\hline
\end{tabular}


helium/steam drains for increased leakage of steam through the seals -- a task which would not require subcomponent testing.

Increased thrust on the circulator shaft produced by the high-pressure steam will require a subcomponent thrust bearing test. The test will consist of a rotating mock-up of a circulator shaft, with thrust balancing provided by large pressurized tanks of fluid. Fu11-load, part-load, and transient operating conditions will be imposed on the thrust bearing, simulating expected plant conditions. Results of the thrust bearing tests will be factored into the design and testing of the circulator assembly test.

10.1.6.2. Circulator Assembly Test. Aerodynamic design of the steam turbine poses no significant problems and requires no experimental verification prior to assembly testing. Likewise, blade stresses through blade loading, centrifugal forces, and vibration are not limiting factors in the design. A prototype circulator assembly, including the steam turbine, can be designed and constructed with a high degree of confidence based on experience with existing HTGR circulators. Depending on design details, nozzle testing may be desirable, but the difficulty of conducting such tests is small, so the expense and time needed for possible nozzle tests are consistent with the contingencies included in the program.

It is appropriate to test the circulator assembly and auxiliaries. Testing at full temperature, but at reduced pressure corresponding to a maximum of about 25\% load, will be accomplished in the test facilities under construction for conventional circulator testing at General Atomic. By reducing the steam supply pressure to maintain the design volume flow, the new aerodynamic characteristics at full speed can be modeled. Confirmation of the turbine, circulator, bearings, seals, and auxiliary systems designs will be accomplished. After refinements to the designs as necessary, long-term qualification tests will be conducted, simulating full-1oad, partload, and transient plant operation. 
Assuming that minor modifications to the General Atomic test facility will allow testing of the process heat circulator, the costs for circulator testing are estimated to be $\$ 3,000,000$ for al1 cases considered in this study.

\subsection{DESIGN DEVELOPMENT PROGRAM}

The program described below accounts for development and design work in addition to the Research and Development Program which is required for the first process heat reactor. The program applies to all temperature levels considered in this study. Differences between the process heat reactors at different temperature levels have been included in the Research and Development Program.

\subsubsection{Schedule}

The first portion of preliminary design will be devoted to analyzing cycle conditions, identifying component design requirements, and evaluating systems and safety problems. By the end of the preliminary design phase, preliminary component designs should be in hand and should reflect tradeoffs between maximizing system performance, minimizing component design problems, and minimizing development program time and expense. Upon completion of preliminary design, the system should be defined well enough to support detail design.

A major concern in plant design will be the required performance of the reformer and the characteristics of the catalyst. In the program schedule given in Fig. 10-12, initial testing on the reformer is shown beginning after $1 / 2 \mathrm{yr}$ of preliminary design and extending for a total of 4-1/2 yr. Initially, the test work will be used to obtain basic performance data and catalyst characteristics in support of reformer design studies. The test program will evolve to a demonstration and proof test on a full-scale reformer tube(s). This work has been considered to be part of the Research and Development Program. The total component test program, 
Years

Preliminary Design

Detail Design

Component Testing

5
1
0

Reformer

Circulator-turbine

Plant Licensing \&

Construction

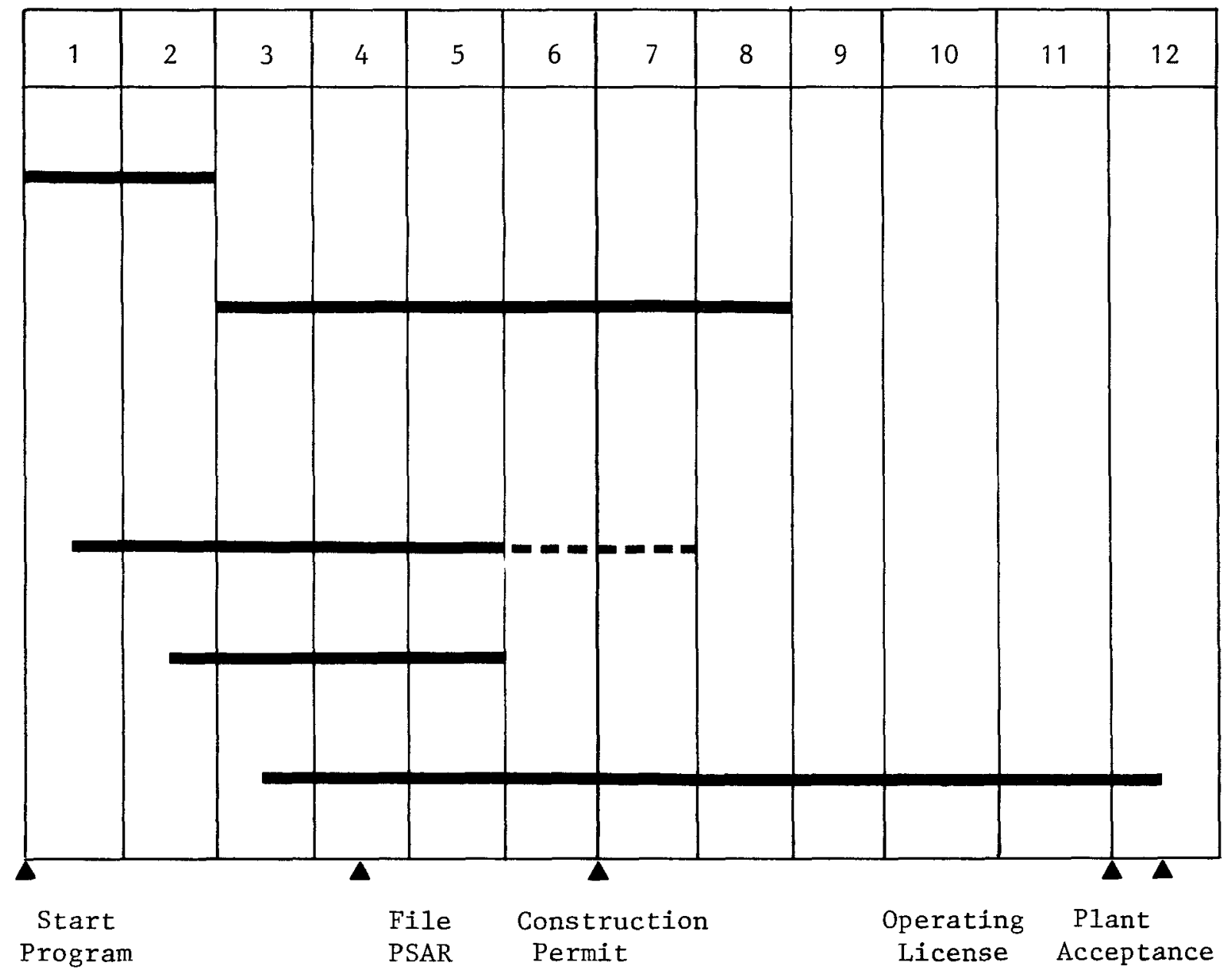

Fig. 10-12. Program schedule for hydrocarbon reforming 
including tests on the circulator-drive turbine, will be completed before the construction permit is issued.

The licensing and construction segment is more time-consuming than any other phase of the program. Because of the unique combination of nuclear reactor and reformer, the construction licensing process is considerably longer than for conventional HTGR power plants.

\subsubsection{Program Cost}

Cost estimates for the program and the way they are expected to vary with temperature are shown below:

$\begin{array}{llllll}\text { Process temp., }{ }^{\circ} \mathrm{F} & 1200 & 1400 & 1600 & 1800 & 2000 \\ \begin{array}{l}\text { Design development } \\ \text { cost, } \$ 1000\end{array} & 45,000 & 45,000 & 55,000 & 58,000 & 58,000\end{array}$

Some of the plant design is identical to commercial HTGR plants. Design work necessary to engineer proven designs for a specific customer and site is not included in the estimate. These costs would normally be reflected in the purchase price. Hence, the costs shown represent extraordinary costs necessary to develop and introduce the first commercial size process heat HTGR.

Some first-of-a-kind support may be needed over and above the costs shown to encourage the purchase of the first commercial plant. The need for such support, if any, will be determined later in the program.

\subsubsection{Significant Components}

Major development work centers about three basic changes to conventional HTGR designs. The major change is the addition of a helium-heated steam-methane reformer in a wall cavity of the PCRV. The reformer itself represents the one new piece of equipment in the HTGR. Although this reformer is similar in size to the existing steam generators and can be 
installed and removed much as they are, it is expected that the design will differ significantly from that of the steam generators. However, the experience and technical information gained in developing the HTGR steam generator will be most valuable.

The second major change is the helium temperature. The presence of helium temperatures above the standard steam plant temperatures will require additional work on core design. Differences between temperature levels have been taken into account in the Research and Development Program.

The elimination of the reheat portion of the steam generator is significant. (A high-efficiency steam cycle enhanced by a reheater is not thought necessary.) The main steam conditions are nearly the same as for the electrica1 HTGR plants, but the steam turbine used to drive helium circulator sees much different steam conditions. The inlet pressure is increased from 900 to $2500 \mathrm{psia}$ and the temperature is increased from $700^{\circ}$ to $955^{\circ} \mathrm{F}$. In both instances, the turbines would be single-stage, large-flow machines driving nearly identical helium circulators.

The safety implications of coupling a nuclear reactor with a chemical processing plant will require careful technical analysis. The operational requirements and limitations of the two plants must be identified, and a suitable control and safety system must be developed. It is expected that reformer catalyst will have to be replaced periodically. Plant design and safety evaluations will be greatly influenced by this requirement.

\subsubsection{Preliminary Design Phase}

10.2.4.1. Optimization. The cycle conditions and component designs which constitute the current reference plant were chosen as the most promising among a number of alternatives. It is appropriate to reexamine alternatives in greater depth as more detailed information becomes available, namely information generated by more refined component and system design work and by systems analysis. Real cycle losses, computed component efficiencies, 
capital and operating cost, etc., may significantly influence the choice of the cycle conditions and basic design features of the plant.

10.2.4.2. Component and Systems Design. The reformer design is the most critical component insofar as it has no direct counterpart in current nuclear plants. It will influence markedly the overall plant configuration. The catalyst used in the reformer has, in turn, the most critical influence on reformer design.

Reformer design work must begin with fundamental examination of chemica1 and transport phenomena important to catalytic reactions. A major question to be resolved is whether widely used catalysts and reformer designs are adaptable to nuclear reactors, or whether better designs can be developed. Reformer design will be supported by and will closely parallel reformer test programs under the Research and Development Program. Initially, these tests would be fundamental bench-scale tests of catalyst materials and geometries, the influence of flow, temperature, and chemical constituents on conversion, etc. Of course, the reformer design would also have to consider structural, mechanical, and thermal performance.

The circulator drive turbine must be sized according to allowable stresses. Its bearings, seals, structural support, and auxiliary systems must be designed and analyzed. Also, its performance at off-design conditions must be determined.

Adjustments for increased core outlet temperature must be made. Core and fuel design and fuel management must be specified, and insulation and thermal barrier protecting the reactor vessel must be examined for possible adverse conditions.

Major characteristics of balance-of-plant systems must be determined, including piping sizes, pressure losses, electrica1 power requirements, water system designs, plant buildings and structures, etc. 
10.2.4.3. System Analysis. Systems analysis will provide information regarding full-load, off-design, and transient performance and will support plant safety studies and licensing. Such studies will provide insights into the characteristics of such a process heat plant as well as help to establish design requirements of plant systems and components.

It is expected that computer codes developed for the steam cycle HTGR power plant can be used as the basis of a methods development effort suitable for the HTGR/reformer.

Incorporating the reformer in the reactor vessel in series with the steam generators could have an effect on the helium pressure drop. This would be an important factor to examine early in the program, since a large change in the helium flow circuit could influence the design of the helium circulator. For the purposes of this report, the assumption is made that any increase in helium pressure drop is moderate enough not to require extensive circulator development.

The chemical process has a large potential influence on system characteristics. The most obvious is in the area of licensing and safety, where accidents could be very different for those postulated for an electrical HTGR plant. Hydrogen diffusion through the reformer tube walls has been identified as a potential problem and will be examined as part of the reformer test program.

It is important to establish safe and licensable design guidelines as soon as possible so that plant design can proceed in the most expeditious manner.

As analysis continues and design details are more fully identified, the development program will be appropriately updated. 
10.2.4.4. Evaluation. Preliminary design work will provide the basis for initiating economic evaluation of the nuclear hydrocarbon reformer concept. Plant costs will be estimated and preliminary cost/benefit or profitability analyses will be performed, based on projected market conditions for such process heat reactors.

10.2.5. Detail Design Phase

The objective of the detail design phase is to refine and specify plant design completely, preparatory to construction of the first commercial HTGR/reformer. In addition to critical components whose design and development will have been well under way, specifications and/or designs for the following plant systems will have to be developed:

1. Circulator and circulator turbine auxiliaries

2. Helium purification system

3. Plant protection and control systems, especially as required by the reformer

4. Helium and steam systems instrumentation

5. Feedwater/steam piping, pumps, valves, etc.

6. Cooling water systems

7. Plant buildings and structures

8. Electrical system

9. Water treatment

10. Steam turbine/electrical generator system 
A Preliminary Safety Analysis Report, a Final Safety Analysis Report, an environmental impact statement, and other assistance that may be required by the plant owner in obtaining licenses will be provided.

\subsection{RESEARCH AND DEVELOPMENT SUMMARY AND CONCLUSIONS}

The research and development costs are summarized in Table 10-9 as a function of process gas temperature. The six major areas requiring a research and development program are fuel, core components, general materials research, the thermal barrier, the reformer, and the helium circulator turbine. The major departures from existing technology begin to appear at process gas temperatures of $1600^{\circ} \mathrm{F}$ and above. Below $1600^{\circ} \mathrm{F}$, a modest research program is required which is associated primarily with development of the reformer and helium circulator turbine. Above this point, development of a ceramic reformer will be necessary, and any significant increase in process gas temperature above $1600^{\circ} \mathrm{F}$ will require a substantial fuel development program or extensive core design development studies involving axial fuel shuffling.

Since no research and development program is assured of success, an attempt is made here to evaluate the likelihood of the success of programs necessary for development of a process heat reactor at the various temperature levels.

\section{$1200^{\circ}$ and $1400^{\circ} \mathrm{F}$ Process Temperatures}

High chances of success are foreseen here. A new insulation cover plate material must be proven, but several candidate materials exist and the prospects of finding an acceptable one are very good. Reformer technology development is more in the nature of obtaining engineering design information than establishing feasibility, and circulator testing is confirmatory in nature. Material technology development is required for the reformer. Operating procedures must be established, and a considerable amount of safety-related analysis must be performed. Brief studies to date have not uncovered any large problems. The reformer 
TABLE 10-9

SUMMARY OF ESTIMATED RESEARCH AND DEVELOPMENT COSTS

(In $\$ 1000)$

\begin{tabular}{|c|c|c|c|c|c|}
\hline & \multicolumn{5}{|c|}{ Process Gas Temperature } \\
\hline & $1200^{\circ} \mathrm{F}$ & $1400^{\circ} \mathrm{F}$ & $1600^{\circ} \mathrm{F}$ & $1800^{\circ} \mathrm{F}$ & $2000^{\circ} \mathrm{F}$ \\
\hline Fue1 & -- & -- & -- & 10,000 & 10,000 \\
\hline Core components & -- & -- & 530 & 660 & 660 \\
\hline \multicolumn{6}{|l|}{ Materials } \\
\hline Metallic & 1,380 & 1,380 & 1,380 & 1,380 & 1,380 \\
\hline Ceramic & -- & -- & 2,250 & 2,250 & 2,250 \\
\hline Thermal barrier & -- & 1,500 & 2,500 & 2,500 & 2,500 \\
\hline Reformer & 3,465 & 3,465 & 3,465 & 3,540 & 3,540 \\
\hline Helium circulator turbine & 3,000 & 3,000 & 3,000 & 3,000 & 3,000 \\
\hline Total R\&D & 7,845 & 9,345 & 13,175 & 23,330 & 23,330 \\
\hline Design development & 45,000 & 45,000 & 55,000 & 58,000 & 58,000 \\
\hline TOTAL & 52,845 & 54,345 & 68,175 & 81,330 & 81,330 \\
\hline
\end{tabular}


integral with the PCRV must be considered as uncertain and could conceivably prove to be a risk with regard to future licensability. An intermediate loop offers a potential back-up position. Siting problems are not appreciably different from those encountered for commercial HTGRs. The interaction of the process plant and nuclear plant poses some new problems with regard to safety considerations from both a personnel and equipment protection standpoint.

\section{$1600^{\circ}$ to $2000^{\circ} \mathrm{F}$ Process Temperatures}

Risks are greatly increased in the technical areas. The high-temperature ceramic reformers present a whole spectrum of technology and technical challenges ranging from material ductility problems to development of fabrication techniques to lack of any shop equipment capabilities for large sizes. It is not clear whether or not a large-size ceramic heat exchanger operating in a helium environment for $30 \mathrm{yr}$ under pressure and transient thermal conditions can be successfully developed. Thermal barrier design and materials are increasingly difficult and will lead into material areas where few longterm operating data exist. However, this problem is believed to be solvable with a fair degree of certainty. Fuel particle development involves a fair degree of risk, since it is something of a "cut and try" method with longerterm testing required to prove out promising candidates. Since the fuel is designed to be removed periodically, the effects of fuel failure can be lessened by changing the replacement frequency. Core inlet temperatures increase to much higher values and may dictate design changes to standard components, e.g., control rods and drives, circulator materials, and steam generator parts. The risk lies more in the extent of the changes rather than the technical feasibility. Plant availability may be adversely affected, since nearly all components are now operating in the material creep range. Control safety analysis and process interactions are not markedly changed by the higher temperatures. 


\section{References}

10-1. Gulf General Atomic Incorporated, "HTRDA Fuel and Fuel Cycle Development Program Semiannual Report for the Period July 31, 1967 to December 31, 1967," unpublished data.

10-2. Kaae, J. L., D. W. Stevens, and J. C. Bokros, "Dimensional Changes Induced in Poorly Crystalline Isotropic Carbons by Irradiation," Carbon, 10561 (1972).

10-3. Stansfield, O. M., "HTGR Fuel Design and Performance," USAEC Report GA-A13072, General Atomic Company, July 12, 1974.

10-4. Gulden, T. D., "Carbon Thermal Diffusion in the UC $\mathrm{UC}_{2}$ System," J. Am. Ceram. Soc. 55, No. 1, 14 (1972).

10-5. Stansfield, O. M., C. B. Scott, and J. Chin, "Kernel Migration in Coated Carbide Fuel Particles," USAEC Report GA-A12970, General Atomic Company, May 31, 1974.

10-6. Pearce, R. J., R. A. U. Huddle, and P. Kofstad, "Fundamenta1 Aspects of the Interaction of HTR Helium with Metals and Alloys," CEGB Report RD/B/R2866, January 1974.

10.7. Tyzack, C., et al., "The Behavior of Constructional Materials in Mark III Helium Cooled Reactors," Conference on Component Design in High Temperature Reports Using Helium as a Coolant, May 3-4, 1972.

10-8. Ikegami, H., and Y. Mori, "Preliminary Study on High Temperature Heat Exchanger for Nuclear Stee1 Making," Iron Stee1 60, No. 8 (1974).

10-9. Wood, D. S., M. Farrow, and W. T. Burke, "A Preliminary Study of the Effect of Helium Environment on the Creep and Rupture Behavior of Type 316 Stainless Steel and Incoloy 800," UKAEA, Risley Engineering and Materials Laboratory, 1972.

10-10. Bourgette, D. T., "Evaporation of Radioisotope Capsule Materials in Vacuum," Oak Ridge National Laboratory, Metals and Ceramics Division, 1967. 
10-11. Jackson, R. J., et al., "Technical Report on a Compilation of the Properties of Reformer Furnace Materials," Battelle Columbus Laboratories, July 31, 1973.

10-12. Van Echo, J. A., and D. B. Roach, "Technical Report on Materials for Steam Reformer Furnaces; Investigation of Mechanica1, Physical and Creep-Rupture Properties of Reformer Materials, Tasks 2, 3 and 4," Battelle Columbus Laboratories, Ju1y 30, 1973.

10-13. Heat Resistant Castings, Corrosion Resistant Castings: Their Engineering Properties \& Applications, The International Nicke1 Company, Inc., p. 29.

10-14. Imgram, A. G., "The Effects of Temperature on the Mechanical Properties and Microstructure of HK-40 Hydrogen Reformer Furnace Tubes," Gulf Research \& Development Company Report 561RB022, November 1971.

10-15. Muller, E. 0., "The Properties of Some Mo-base Alloys under Helium High Temperature Conditions," Brown, Boveri and Cie, Mannheim, Germany .

10-16. Briggs, J. Z., and R. Q. Barr, "Arc-cast Molybdenum-base TZM Alloy: Properties and App1ications," High Temperatures-High Pressures, 3, 363 (1971).

10-17. "Molybdenum Meta1," Climax Molybdenum Company, 1960.

10-18. "Development Data, Climelt TZM," Climax Molybdenum Company, 1962.

10-19. Proceedings of the British Ceramic Society, Ceramics for High Temperature Engineering, No. 22, June 1973.

10-20. Battelle Memorial Institute (compiler), Engineering Properties of Selected Ceramic Materials, The American Ceramic Society, 1966.

10-21. Popper, P., "Special Ceramics 5," British Ceramic Research Association. 


\section{CONCLUSIONS AND RECOMMENDATIONS}

\section{1. CONCLUSIONS}

1. Process temperatures up to the $1400^{\circ}$ to $1500^{\circ} \mathrm{F}$ range are achievable with today's technology and would require a minimum of development.

2. Process temperatures in the range of $1500^{\circ}$ to $2000^{\circ} \mathrm{F}$ are potentially achievable with large development programs.

3. The major risks for the higher-temperature development are the ceramic heat exchanger, the thermal barrier, and the advanced fuel capable of sustained operation at $3000^{\circ} \mathrm{F}$ with acceptable fission product release.

4. Fuel cycle costs up to the $1600^{\circ} \mathrm{F}$ case are, to a large degree, independent of temperature level and are not a determining factor in overall costs.

5. Assuming successful technical development of higher-temperature fuel, conclusion 4 is generally valid to $2000^{\circ} \mathrm{F}$.

\subsection{RECOMMENDATIONS}

1. The first-generation HTGR development for process heat applications should be directed toward a process temperature of $1400^{\circ}$ to $1600^{\circ} \mathrm{F}$.

2. Development efforts should be started immediately to refine and verify the design of the nuclear heat source. 
3. Studies on hydrogen production facilities should be initiated to extend the information presented in this report in order to determine the cost of producing hydrogen.

4. Survey efforts should be expanded to more accurately establish the market potential for process heat as a function of temperature. 


\section{APPENDIX A}

EFFECT OF LOWERING THE HTGR HELIUM CORE

OUTLET TEMPERATURE ON THE ECONOMICS

OF HYDROGEN PRODUCTION FOR A COAL GASIFICATION PLANT 


\section{PREFACE}

As part of the temperature parameter study done for this contract, a special investigation was performed under subcontract by Stone \& Webster Engineering Corporation. This work focused specifically on the lowest process temperature $\left(1200^{\circ} \mathrm{F}\right)$ corresponding to the current commercial HTGR core outlet temperature $\left(1400^{\circ} \mathrm{F}\right)$. The study investigated the technical feasibility and estimated the cost of producing hydrogen at the low process temperature. The object of the study was to determine if such a temperature could be considered in the future as a commercial possibility. The incentive is that the reactor development work would be minimized, since core outlet temperatures and all metal temperatures are within current operating conditions for HTGRs and the development work would thus be primarily related to the reformer. Also, if an intermediate loop were considered, these lower process temperatures would result even if the core outlet temperature were raised above the $1400^{\circ} \mathrm{F}$ level.

The process conditions were established in a manner that enabled the results to be directly compared with previous work, namely, the coal gasification study prepared for the State of Oklahoma and the office of Coal Research.

Conclusions drawn from this study as they relate to the major temperature parameter work are:

1. It is technically feasible to produce large quantities of hydrogen at a process temperature of $1200^{\circ} \mathrm{F}$ with a cryogenic methane-hydrogen separation system.

2. The approximate cost increase over the reference $1350^{\circ} \mathrm{F}$ process temperature is $\$ 75 \mathrm{million}$ for the same hydrogen output. 
3. If relatively impure hydrogen ( $89 \%$ by volume) is acceptable, low-pressure reforming may be a lower-cost alternate to a cryogenic separation step. This low-purity hydrogen is acceptable for ammonia production and some coal gasification processes.

4. Even with a cryogenic separation step, reformer pressures lower than 300 psi may be desirable to reduce the cost of the cryogenic system. 


\section{EFFECT OF LOWERING THE HTGR HEIIUM CORE}

OUTLET TEMPERATURE ON THE ECONOMICS

OF HYDROGEN PRODUCTION FOR A COAL GASIFICATION PLANT

Prepared for

General Atomic Company

\section{By}

A. Nihalani, J.J. Williams and H.N. Woebcke

Stone \&c Webster Engineering Corporation

Corporate Development Division

Boston, Massachusetts 02107

25 September 1974 
○

0

0 


\section{SUMMARY}

In utilizing the helium coolant loop of General Atomic's HTGR nuclear reactor for process heat for hydrogen production via steammethane reforming, the temperature level of the helium has an effect on the capital and operating costs of the hydrogen facilities.

The original purpose of this study was to assess the effects on capital and operating costs comparing a base case using an HTGR Helium core outlet temperature of $1650 \mathrm{~F}$ for steam methane reforming at 300 PSIA, $1350 \mathrm{~F}$ outlet conditions (4.5 steam/carbon ratio in the feed) to four alternate cases at varlous reforming conditions and Hellum core outlet temperature of $1650 \mathrm{~F}$ or $1400 \mathrm{~F}$. (See table below).

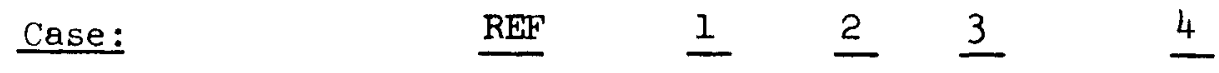

Core outlet temp., $\mathrm{F}$

Heat to Reformer BTU/hr

Reformer Outlet Pressure,

Reformer Outlet Temp., F

Steam/Carbon Ratio, Feed
Reformer inlet temp, F

Reformer process $\triangle P$, psia

\begin{tabular}{|c|c|c|c|c|}
\hline 1650 & 1650 & 1400 & 1400 & 1400 \\
\hline $112 \overleftarrow{300}$ & 700 & 300 & 700 & $?$ \\
\hline 1350 & 1350 & 1200 & 1200 & 1200 \\
\hline olal) 4.5 & 4.5 & $\begin{array}{c}? \\
105{ }^{\circ}\end{array}$ & $?$ & $?$ \\
\hline
\end{tabular}

The bases of comparison of the various cases were a constant hydrogen production rate and for all cases, except the reference case, the total gasifier effluent going through the reformer and the use of an auto-refrigerated cryogenic separation step to upgrade the lower purity hydrogen stream to the desired purity hydrogen and methane streams (the latter being the SPG product).

After preliminary evaluation of the various cases it was evident that the operating conditions for case 3 resulted in unnecessarily high capital/operating costs. This was mainly because the process steam requirements more than doubled compared to the reference case. Thus it was decided not to try the 700 psia reformer outlet pressure case but instead to try lower pressures of $200 \mathrm{psia}$ and $500 \mathrm{psia}$. Also for case $I$ to produce the same amount of $\mathrm{H}_{2}$ as the reference case the steam/carbon ratio was 2.50 (on the basis of total gasifier effluent through the reformer) instead of 4.5. The HTGR core-outlet temperature in the Table has been changed from 1650F to 1620F (the temperature used in the Oklahoma Study, the reference case). The operating conditions for the various cases are listed in the Table on the following page. 


\begin{tabular}{|c|c|c|c|c|c|}
\hline Case: & Ref. & 1 & 2 & 3 & 4 \\
\hline Core Outlet Temp., Fq & 1620 & 1620 & 1400 & 1400 & 1400 \\
\hline Heat to Reformer, $10 \mathrm{BTU} / \mathrm{hr}$ & 4.54 & 4.82 & 3.92 & 4.00 & $\overline{4} .16$ \\
\hline Reformer Outlet Pressure,psia & 300 & 700 & 200 & 300 & 500 \\
\hline Reformer Outlet Temperature, $F$ & 1350 & 1350 & 1200 & 1200 & 1200 \\
\hline Steam/Carbon Ratio,Feed (mola) & $1) 4.50$ & 2.50 & 2.35 & 3.01 & 4.08 \\
\hline Reformer Inlet Temperature.,F & & & & & \\
\hline Reformer Process $\triangle \mathrm{P}, \mathrm{psi}$ & & & & & \\
\hline
\end{tabular}

For each of the above cases, four sub-cases with different cryogenic unit inlet pressures were studied. In three of the sub-cases, the gases were compressed and fed to the cryogenic unit while in the fourth sub-case an expander was used in the hydrogen rich stream(with no compression of cryogenic unit feed).

The horsepower requirement, the HTGR heat requirement and the total cost of the unit were found for each case and compared with the reference case. It was found that the heating value of the methanerich otream(SPG) was lower in all cases compared to the reference case and decreased with an increase in cryogenlc unit inlet pressure. The horsepower was highest but the HTGR heat duty was the lowest for the case with the lowest reformer outlet pressure.

It was determined that to produce 540 M SCFD of SPG (same as in the: reference case) with a fixed heat availability from the HTGR helium loop of $10.52 \times 10^{9} \mathrm{Btu} / \mathrm{hr}$, the reformer would have to be operated at an outlet pressure of about 110 psia.

At these conditions, the lowest cost of the hydrogen plant was for a cryogenic system inlet pressure of $1000 \mathrm{psia}$ and a reformer outlet pressure of 110 psia and was $\$ 505 \mathrm{MM}$ compared to the reference case cost of $\$ 385 \mathrm{MM}$ ( $\$ 120 \mathrm{MM}$ increase - $15 \%$ increase in the total installed cost of a $\$ 800 \mathrm{MM}$ plant). This figure of $\$ 505 \mathrm{MM}$ is extrapolated from the total cost curves. A cursory analysis of the unit with reformer operating at an outlet pressure of 110 psia and. taking into account increased volumetric flows shows the total cost to be about $\$ 550 \mathrm{MM}$.

The expander cases have not been worked out in detail but preliminary study shows that using an expander in the cryogenic unit instead of compressing the cryogenic unit feed may reduce the total cost of the unit by about $\$ 40 \mathrm{MM}$ for the higher pressure reformer cases. 
It is recammended that the lowest cost case developed in the present study should be looked at in more detail. To increase the heating value of SPG, it is suggested that $C_{2}$ and heavier fractions, which have a higher heating value than pure methane, be separated from the reformer feed and then added to the methane rich stream coming out of the cryogenic unit. 
INTRODUCTION:

Stone \& Webster Engineering Corporation's Coal Solution vasification Process uses Teneral Atomic's HTCR (High Temperature Gas-cooled Reactor) as a heat source for hydrogen and steam production. In 1972 GA \& SWEC carried out a study for the State of Oklahoma for production of $540 \mathrm{MM} \mathrm{SCFD} \mathrm{of} \mathrm{synthetic} \mathrm{pipeline} \mathrm{gas} \mathrm{(SPG)} \mathrm{from} \mathrm{Oklahoma}$ coal. The helium core-outlet temperature from the HTGR was taken as $1620 \mathrm{~F}$. About half of the methane-rich gas from the Hydrogasifier entered the reformer (the balance being SPG Product) and the conversion to $\mathrm{H}_{2}$ was $67.2 \%$. This hydrogen stream after shift conversion and carbon dioxide removal was about 89 mole $\% \mathrm{H}_{2}$ and was recycled to the coal liquefaction, hydrocracking and hydrogasification units.

At present, the helium core-outlet temperature available from the HTGR is $1400 \mathrm{~F}$ and General Atomic is working on the metallurgical aspects of the HTGR to raise the core-outlet temperature to $1620 \mathrm{~F}$. In the present study initiated by General Atomic, several cases were established with a helium core-outlet temperature of $1400 \mathrm{~F}$ and with the total gasifier effluent passing through the reformer at a lower conversion. The methane and hydrogen were to be separated by cryogenic means to yield the SPG Product and the $\mathrm{H}_{2}$ recycle stream. The Oklahoma study was taken as the reference case, and the capital eosts for the varlous cases were determined and compared with the reference case.

\section{SETTING UP THE VARIOUS CASES:}

Four cases were set up in addition to the reference case. Since in these cases all the hydrogasifier effluent was sent through the reformer, the amount of hydrogen after shift conversion was made equal to the sum of hydrogen after shift conversion plus hydrogen in SPG in the reference case. This required a conversion of $35.8 \%$ of carbon in cases 1 to 4 compared to $67.2 \%$ in the reference case.

Percentage conversion in the reformer is a function of reformer outlet pressure and temperature, and steam to carbon ratio in the feed. Higher conversion will be obtained with lower pressures, higher temperatures and higher steam to carbon ratio. The hellum core-outlet temperature in case 1 was fixed at $1620 \mathrm{~F}$. The pressure in case 1 was set at 700 psia while in cases 2 to 4 1t varied from 200 to 500 psia and correspondingly the steam to carbon ratios varied. With helium core-outlet temperature of $1400 \mathrm{~F}$, higher pressures than 500 psia were not studied in detail since the process steam requirement more than doubled compared to the reference case. The conditions for various cases are given in Table 1. It should be noted that the total feed to the cryogenic unit is constant for all cases $(263,000 \mathrm{Lb} \mathrm{Mole} / \mathrm{Hr}$.). 
ALTERNATE METHODS OF USING HTGR FOR H? PRODUCTION

\begin{tabular}{|c|c|c|c|c|c|c|c|c|c|c|c|c|c|c|c|c|c|}
\hline & Ref. & \multicolumn{4}{|c|}{1} & \multicolumn{4}{|c|}{$\underline{2}$} & \multicolumn{4}{|c|}{3} & \multicolumn{4}{|c|}{4} \\
\hline Reformer Outlet Pressure,psia & 300 & \multicolumn{4}{|c|}{700} & \multicolumn{8}{|c|}{300} & \multicolumn{4}{|c|}{500} \\
\hline Reformer Outlet Temp., F & 1350 & \multicolumn{4}{|c|}{1350} & \multicolumn{8}{|c|}{1200} & \multicolumn{4}{|c|}{1200} \\
\hline HTGR Core Outlet Temp., F & 1620 & \multicolumn{4}{|c|}{1620} & \multicolumn{8}{|c|}{1400} & \multicolumn{4}{|c|}{1400} \\
\hline Reformer Inlet Temp., $F$ & 1050 & \multicolumn{4}{|c|}{1050} & \multicolumn{8}{|c|}{1050} & \multicolumn{4}{|c|}{1050} \\
\hline Stm/Carbon mole Ratio (Ref.Feed) & 1) 4.5 & \multicolumn{4}{|c|}{2.50} & \multicolumn{4}{|c|}{2.35} & \multicolumn{4}{|c|}{3.01} & \multicolumn{4}{|c|}{4.08} \\
\hline $\begin{array}{l}\text { Process Steam to Reformer, } \\
\text { lb mole } / \mathrm{hr}\end{array}$ & 292,200 & \multicolumn{4}{|c|}{325,960} & \multicolumn{8}{|c|}{392,690} & \multicolumn{4}{|c|}{531,230} \\
\hline Reformer Feed, lb mole/hr & 60,600 & \multicolumn{4}{|c|}{120,300} & \multicolumn{8}{|c|}{120,300} & \multicolumn{4}{|c|}{120,300} \\
\hline Heat to Reformer, Btu/hr & $4.54 \times 10^{9}$ & \multicolumn{4}{|c|}{$4.82 \times 10^{9}$} & \multicolumn{8}{|c|}{$4.00 \times 10^{9}$} & \multicolumn{4}{|c|}{$4.16 \times 10^{9}$} \\
\hline of Conversion in Reformer & $67.2 \%$ & & & $5.8 \%$ & & & & $5.8 \%$ & & & & $35.8 \%$ & & & $35.8 \%$ & & \\
\hline $\begin{array}{l}\mathrm{H}_{2} \text { EXPANDER USED IN } \\
\text { CRYOGENIC } 3 \text { YSTTEM }\end{array}$ & & $\underline{\text { YES }}$ & & No & & $\underline{\text { YES }}$ & № & $\underline{0}$ & & YES & & No & & YES & No & & \\
\hline $\begin{array}{l}\text { Inlet Pressure to Cryogenic } \\
\text { Uait, psia }\end{array}$ & -- & 640 & 1,000 & 1,500 & 2,000 & 140 & 1,000 & 1,500 & 2,000 & 240 & 1,000 & 1,500 & 2,000 & 440 & $1, \infty 00$ & 1,500 & 2,000 \\
\hline 2nd Core Exch. AVG $\Delta T, F$ & -- & 15 & 7.9 & 10.4 & 12.8 & 15 & 7.9 & 10.4 & 12.8 & 15 & 7.9 & 10.4 & 12.8 & 15 & 7.9 & 10.4 & 12.8 \\
\hline Relat1ve Total Exch. Surface, $\mathrm{Ft}$ ? & 2 & $0.80 \times 10^{6}$ & $1.51 \times 10^{6}$ & $61.12 \times 1$ & $0^{6} 0.86 \times 10^{6}$ & $0.80 \times 10^{6}$ & $61.51 \times 10$ & $0^{6} 1.12 \times 10$ & $0^{6} 0.86 \times 10$ & $0^{6} 0.80 \times 10$ & $10^{6} 1.51 \times$ & $\times 10^{6} 1.12$ & $10^{6} 0.86 \times 1$ & $0^{6} 0.80 \times 1$ & $10^{6} 1.51 \times 1$ & $10^{6} 1.12 x$ & $110^{6} 0.86 x$ \\
\hline PRESSURE OUT/IN $\mathrm{H}_{2}$ COMP, PSIG & $1500 / 240$ & $1500 / 462$ & & & & $1500 / 93$ & & & & $1500 / 1$ & & & & $1500 / 338$ & & & \\
\hline Compressor Loads & & & & & & & & & & & & & & & & & \\
\hline Cryogenic Feed, HP & -- & 0 & 70,270 & 139,370 & 189,150 & 0 & 328,910 & 397,230 & 449,930 & $0 \quad 23$ & 238,140 & 306,460 & 359,160 & 0 & 133,7102 & 203,010 & 255,710 \\
\hline Methane Product ${ }^{(1)}$, HP & 0 & 121,080 & 95,630 & 85,060 & 85,450 & 121,080 & 95,630 & 85,060 & 85,450 & 121,080 & 95,630 & 85,060 & 85,450 & 121,080 & 95,630 & 85,060 & 85,450 \\
\hline Hydrogen Stream, HP & 228,600 & 140,980 & 48,110 & 0 & 0 & 349,110 & 48,110 & 0 & 0 & $271,270 \mathrm{~L}$ & 48,110 & 0 & 0 & 186,480 & 48,110 & 0 & 0 \\
\hline Expander Credit, HP & -- & $-5,280$ & 0 & 0 & $-19,700$ & $-7,160$ & 0 & 0 & $-19,700$ & $-6,820$ & 0 & 0 & $-19,700$ & $-5,510$ & 0 & 0 & $-19,700$ \\
\hline Total & 228,600 & 256,780 & 214,010 & 224,430 & $254,900 \quad 4$ & 463,060 & 472,650 & $482 ; 290$ & 515,680 & 385,530 & 381,880 & 391,520 & 424,910 & 302,050 & 277,4502 & 288,070 & 321,460 \\
\hline HTGR Duty, $10^{9} \mathrm{Btu} / \mathrm{Hr}(2)$ & 10.52 & 10.89 & 10.61 & 10.68 & 10.88 & 11.32 & 11.38 & 11.44 & 11.66 & 12.34 & 12.32 & 12.38 & 12.60 & 14.40 & 14.24 & 14.31 & 14.53 \\
\hline $\mathrm{HHV}$ of SPG, Btu/SCF & 1080 & 984 & 965 & 933 & 892 & & 965 & 933 & 892 & & 965 & 933 & 892 & & 965 & 933 & 8.92 \\
\hline
\end{tabular}

NOTES: (1) Includes Booster Compressor Load

(2) Includes He Compression Duty 


\section{PROCESS SCHEME:}

The reformer effluent is fed to a shift converter, where $95 \%$ of $\mathrm{CO}$ is converted to $\mathrm{CO}_{2}$, and then to a $\mathrm{CO}_{2}$ removal system. The gases are then fed to a cryogenic unit where separation of $\mathrm{H}_{2}$ and $\mathrm{CH}_{4}$ takes place. Figure 1 shows the processing sequence.

The cryogenic feed is cooled in the 2nd core exchanger and enters the first flash drum where it separates into two streams- methane rich and hydrogen rich streams. The methane rich stream is let lown in pressure and produces the refrigeration effect to cool down the incoming feed. The hydrogen rich stream enters the first core exchanger where it is further cooled down and then flashed in the 2nd. drum where further separation of $\mathrm{H}_{2}$ and $\mathrm{CH}_{4}$ takes place. The $\mathrm{H}_{2}$ stream from the and drum contains $90 \mathrm{~mol} \phi_{0}^{4} \mathrm{H}_{2}$. More than $2 / 3^{2}$ of $\mathrm{CH}_{4}$ is separated in the lst. drum. The temperatures in the lst. drum vary from - $200 \mathrm{~F}$ to $-216 \mathrm{~F}$ and in the 2nd drum from - 229F to - $232 \mathrm{~F}$. The pressure of the methane stream (39) from the second drum is lower than the pressure of methane stream (41) from the first drum. Thus stream (39) is brought up to the pressure of stream (41) by a booster compressor before being mixed with it and fed to the methane compression system.

Originally when calculations were carried out for case 1 (inlet pressure to cryogenic unit of $640 \mathrm{psia}$ ) it was found that the desired separation was achieved in the unit but the temperature difference between the feed and the product (warm end $\Delta \mathrm{T}$ for 2 nd core exchanger) was less than $5 \mathrm{~F}$. To avold temperature crosses and to keep the exchanger surface area to reasonable levels it was decided to keep $\Delta \mathrm{T}$ betwwen the warm and cold streams to more than $5 \mathrm{~F}$.

Thus 640 psia inlet pressure was not sufficient to provide enough refrigeration to give a reasonable temperature difference in the second core exchanger. The molal feed to the cryogenic unit is about $2 / 3$ hydrogen and $1 / 3$ methane and the refrigeration effect for the whole stream is provided only by the methane. Extra cooling could be provided by either having an auxiliary refrigeration system or compressing the cryogenic feed to higher pressures. It was decided to follow the latter scheme and have the cryogenic feed compressed to $1,000,1500$ and 2000 psia. Benedict-Webb-Rubin equation of state was used for above calculations.

It was also decided to carry out calculations with no compression of the cryogenic feed but using an expander to let down the pressure in the hydrogen stream from the 2nd drum. The resulting lower temperature of hydrogen provided the extra cooling effect to give enough $\Delta T$ in the exchangers. 
It was found that the lst core heat exchanger surface area was less than $2.5 \%$ of the 2nd core exchanger area. This was because of less heat duty, better heat transfer coefficient and a larger temperature difference between the two streams in the first core exchanger.

The hydrogen and cryogenic feed compressors have a compression ratio of 2.0 with interstage coolers to prevent temperature rise over $300 \mathrm{~F}$. The methane compressors have compression ratio of 2.5 . The hydrogen and methane streams are compressed to 1500 and 1000 psia respectively.

DETAILED HEAT BALANCE:

In the reference case power steam was produced from the HTGR and after producing power for the process, the turbine exhaust was utilized to raise process steam by heat exchange. In the four cases developea for this study the compression horsepower is increased because of cryoseric feed being brought up to 1000 to 2000 psia. Moreover, the amount of process steam requirement is also increased since the reformer outlet temperature is lower (1200F for cases 2 to 4 as compared to $1350 \mathrm{~F}$ in the reference case), and this has to be compensated by higher steam to carbon ratios to produce the same amount of hydrogen as the reference case. Thus a oreater amount of power and process steam is required resulting in a higher duty requirement from the HTGR.

Detailed calculations involve setting up power steam and process steam loops, finding the amount of power steam by trial and error and then calculating the HTGR duty. To simplify the calculations, the power and process steam were set up as shown in Figure 2. Power and process steam are both raised in the HTGR and fed to the turbine. Process steam is taken out of the turbine at an intermediate stage and fed to the reformer with the hydrocarbon feed. The rest of the steam is expanded to 2 'bf $\mathrm{Hg}$ and then condensed. This is then mixed with boiler feed water makeup and recycled. The steam outlet conditions from initif is $1795 \mathrm{psia}$, 975F. This is the same condition after the compression and reheat of power steam in the reference case. The process steam is taken out of the turbine at 200 psi above the required reformer outlet pressure. This is done to account for the pressure drop through the reformer as well as for the fact that only one steam loop is used as compared to two in the reference case. The power produced by the process steam portion is calculated with $80 \%$ turbine efficiency. The rest of the power is provided by power steam at an overall efficiency of $38.5 \%$. This amounts to $6600 \mathrm{BTU} / \mathrm{HR}$ per HP.

The heat requirements for the various cases were calculated by this method, and as a check for the reference case, the heat requirement calculated by this simplified method was within $1 \%$ of the heat requirement calculated by setting up two steam loops in the Oklahoma Study. 


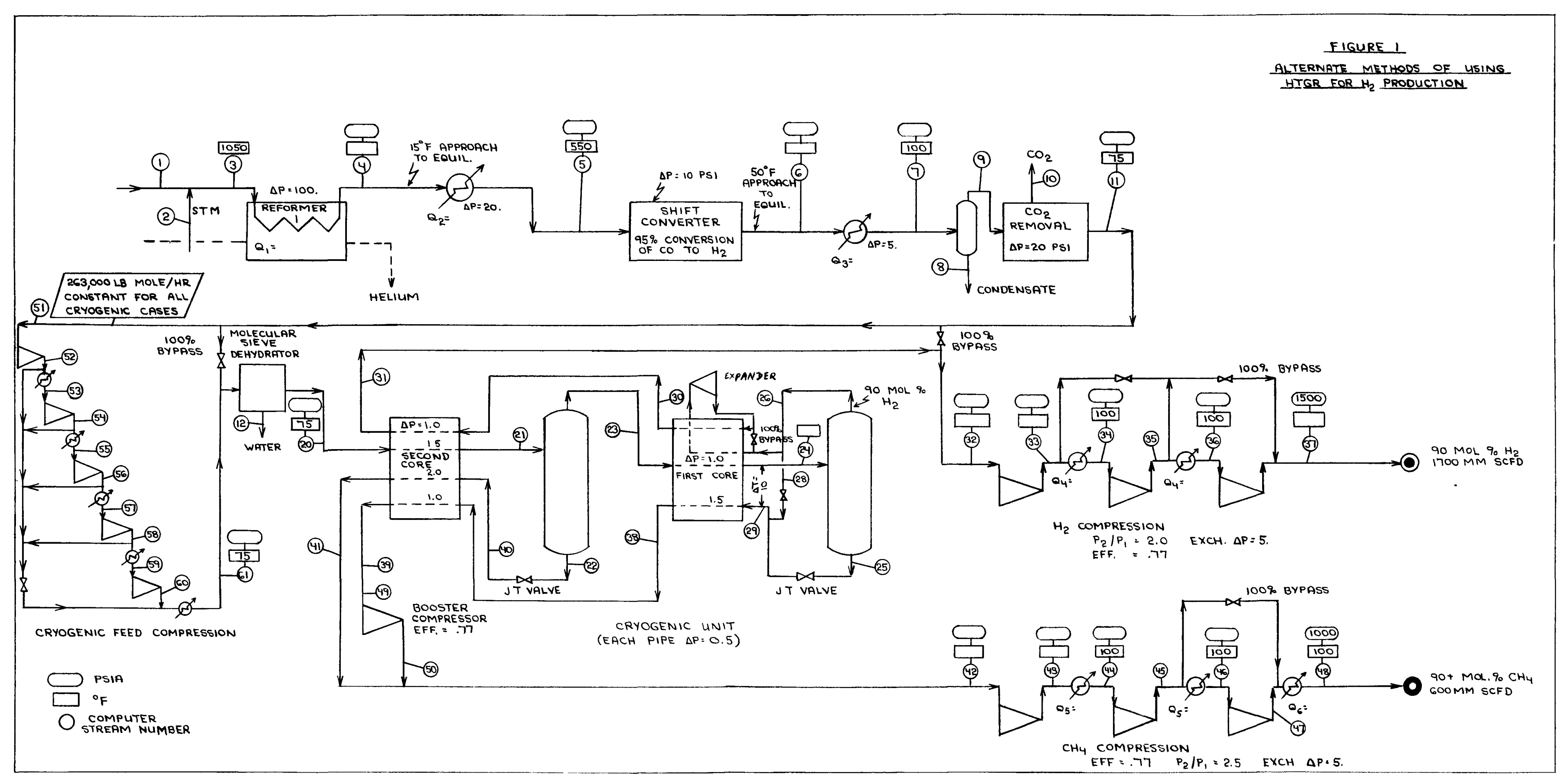


FIGURE 2

SIMPLIFIED STEAM LOOP FOR HTGR HEAT DUTY CALCULATION

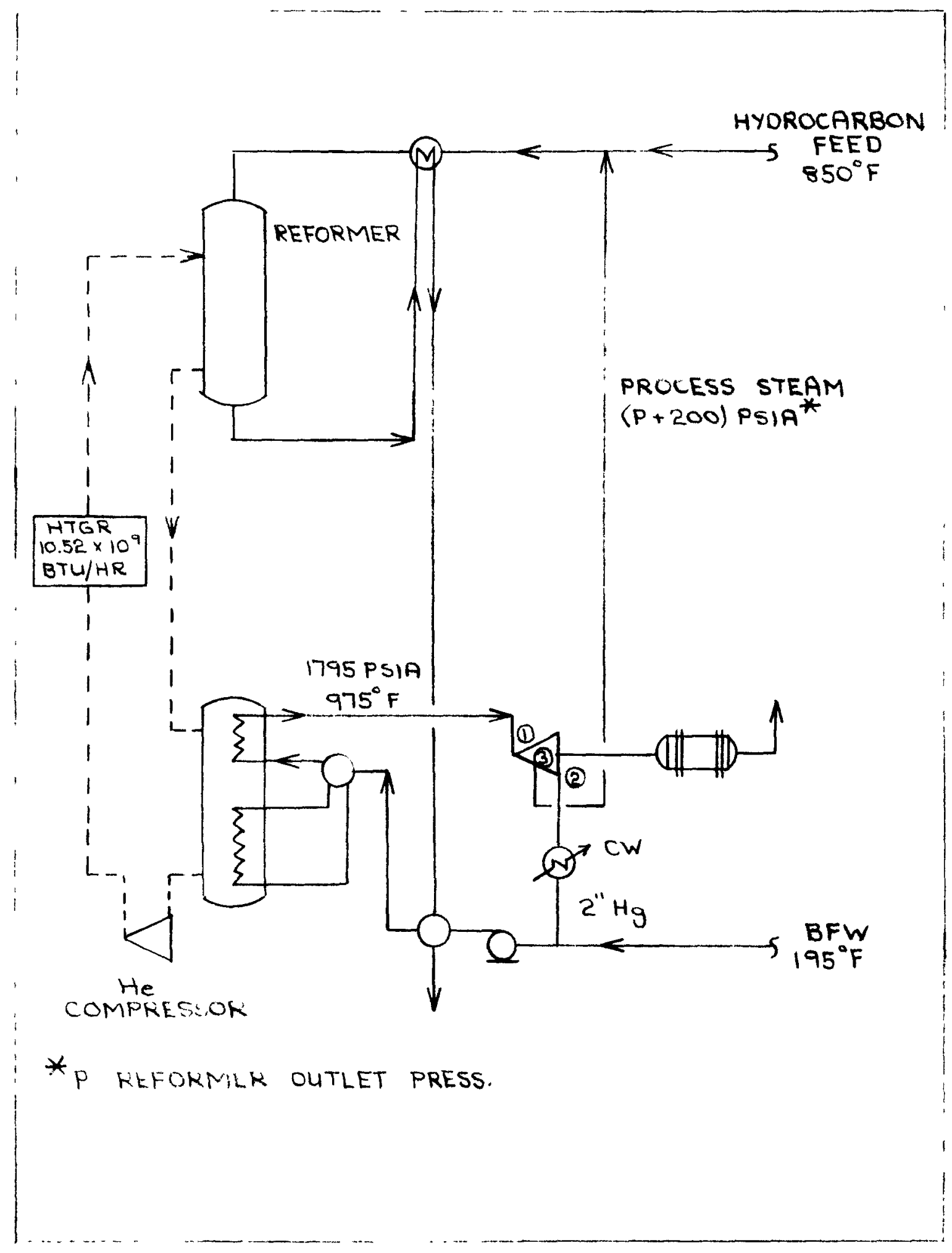


For cases 2 to 4 , the heat requirements to produce $540 \mathrm{MM} \mathrm{SCFD}$ of SPG with HTGR helfum core outlet temperature of $1409 \mathrm{~F}$ varled from $11.32 \times 10^{9}$ to $14.53 \times 10^{9} \mathrm{BTU} / \mathrm{hr}$ as compared to $10.52 \times 10^{9} \mathrm{BTU} / \mathrm{hr}$ for the reference case. Correspondingly, the process steam requirements varied from 30,000 to $53,000 \mathrm{lb}-\mathrm{mol} / \mathrm{hr}$ vs $29,000 \mathrm{lb} \mathrm{mole} / \mathrm{hr}$ in the reference case.

\section{COST BASIS (May 1974 Costs):}

Based on internal Stone and Webster information the following bases for installed cost of equipment were arrived at:

(A) For reformer, shift converters and $\mathrm{CO}_{2}$ removal units. cost of the unit $=\left[\frac{\text { Actual Reformer Feed }}{\text { Reformer feed in Reference Case }}\right] 0.25$ $x$ cost in the reference case

(B) For compressors including drive - $\$ 125 / \mathrm{HP}$

(C) For expanders $\$ 25 / \mathrm{HP}$ for the range $20,000-25,000 \mathrm{HP}$ $\$ 35 / \mathrm{HP}$ for the range $5,000-7,500 \mathrm{HP}$

(D) For cryogenic heat excahngers

\begin{tabular}{ll} 
Pressure Rating & Cost \\
\hline Up to $700 \mathrm{psi}$ & $\$ 17.5 / \mathrm{ft}^{2}$ \\
$1000 \mathrm{psi}$ & $\$ 37: 0 \mathrm{ft}^{2}$ \\
$1500 \mathrm{psi}$ & $\$ 50.0 \mathrm{ft}^{2}$ \\
$2000 \mathrm{psi}$ & $\$ 7.0 \mathrm{ft}^{2}$
\end{tabular}

\section{DISCUSSION:}

The operating conditions for the various cases including the power and BTGR heat requirement are shown in Table 1 while the cost figures are shown in Table 2. Furthermore, the variation of power requirement, cost etc. for different cases is shown graphically in Figures 3 to 8 .

(a) The amount of SPG and its higher heating value for various cryogenic unit inlet pressures is shown in Figure 3. The amount of SPG produced goes up with higher cryogenic unit inlet pressures while the heating value of the gas goes down. The reason being at higher pressures the amount of $\mathrm{H}_{2}$ in the SPG increases, increasing the total amount of product but decreasing the total heating value of SPG.

In general, the heating value of SPG in the present cases is much lower than the heating value of SPG in the reference case ( $1080 \mathrm{BTU} / \mathrm{SCF})$. This is because SPG in the reference case contains about $17 \% \mathrm{C}_{2}$ and higher fractions which having a higher heating value than methane increase the total heating value of the product. In the present cases since all the hydrogasifier effluent is sent through the reformer, the higher fractions decompose completely and the SPG Product contains only methane and hydrogen. Thus the highest heating value of SPG in present cases cannot be more than $1010 \mathrm{BTU} / \mathrm{SCF}$ - the heating value of pure methane. 
TABLE II

\section{CAPITAL COST FOR VARIOUS METHODS OF H2}

CASE

Reformer Outlet Press.,psia Reformer Outlet Temp., F

Cryogenic Unit Inlet

Methane Outlet Pressure,

COST (\$ MM) $)^{(6)}$

Reformer $(1)$

Shift Converter ${ }^{(1)}$

$\mathrm{CO}_{2}$ Removal Unit (1)

Compressor Costs

(Including Drive)

Cryogenic Feed $(2)$

Methane Product (2)

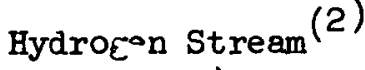

Expander ( 3 )

Cryogenic Heat Exch. ${ }^{(4)}$

$\mathrm{HTGR}(5)$

Total (\$ MM)

Cost Difference From
Ref.

300

1350

$--$

$\begin{array}{rrr}36.30 & 38.50 & 38.5 \\ 8.68 & 9.21 & 9.21 \\ 45.85 & 48.62 & 48.6\end{array}$

--

-- $\quad 15.14$

$32.21 \quad 17.62$

14.07

$\underline{261.54}$

268.87

$\frac{1}{700}$
1350

$\underline{2}$

200

1200

$640 \quad 1,000 \quad 1,500 \quad 2,000$

$140 \quad 1,000$

$1,500 \quad 2,000$

$240 \quad 1,000$

3

300

1200

1,500

2,000

$440 \quad 1,000 \quad 1,500$

2,000

384.58

0

$\begin{array}{llll}27.63 & 58.62 & 60.39 & 79.86\end{array}$
$38.06 \quad 38.06 \quad 38.06$

$\begin{array}{lll}9.10 & 9.10 \quad 9.10\end{array}$

$48.07 \quad 48.07 \quad 48.07$

$\begin{array}{lll}8.78 & 17.42 & 23.64\end{array}$

$11.95-10.63-10.68$

$6.01 \quad$

0.49
64.62

$43.64 \quad 6.01$

0.25

$--$

$49.65 \quad 56.24$

10.63

$--$

10.68

0.4

0.49

0.24

\begin{tabular}{rr}
14.07 & 56.80 \\
277.33 & 278 \\
\hline
\end{tabular}

$445.66 \quad 489.61 \quad \frac{491.06}{511.24} \frac{560.25}{501.04} \frac{502.47}{522.58} \frac{194.81}{530.58} \frac{332.30}{552.28}$ $\begin{array}{lll}6.01 & -- & -.49\end{array}$

61.

Notes: (1) Cost of Unit $=\left[\frac{\text { Actual Flow Rate, Lb mole/Hr }}{\text { Ref. Flow Rate, Lb mole/Hr }}\right]^{0.25} \times \begin{aligned} & \text { Cost of the Unit in } \\ & \text { Reference Case }\end{aligned}$

(2) $\$ 125 / \mathrm{HP}$ Including Drive $5,000-7,500 \mathrm{HP}$ Expander $\$ 35 / \mathrm{HP} ; 15,000-20,000 \mathrm{HP}$ Expander $\$ 25 / \mathrm{HP}$

(4) $140-700$ psi Heat Exchanger - $\$ 17.5 / \mathrm{ft}^{2}$

1000 psi" " "

2000 psi " " $\quad-\$ 75.0 / \mathrm{ft}^{2}$

(5) Includes cost of power and process steam generation equipment and process

heat exchangers.

$$
\text { Cost of HTGR }=\left[\frac{\text { Actual HTGR Heat Duty }}{\text { Ref. Case HTGR Heat Duty }}\right]^{0.8} \times \text { HTGR Cost in Ref'erence Case }
$$

(6) All the cost figures are May 1974 costs 


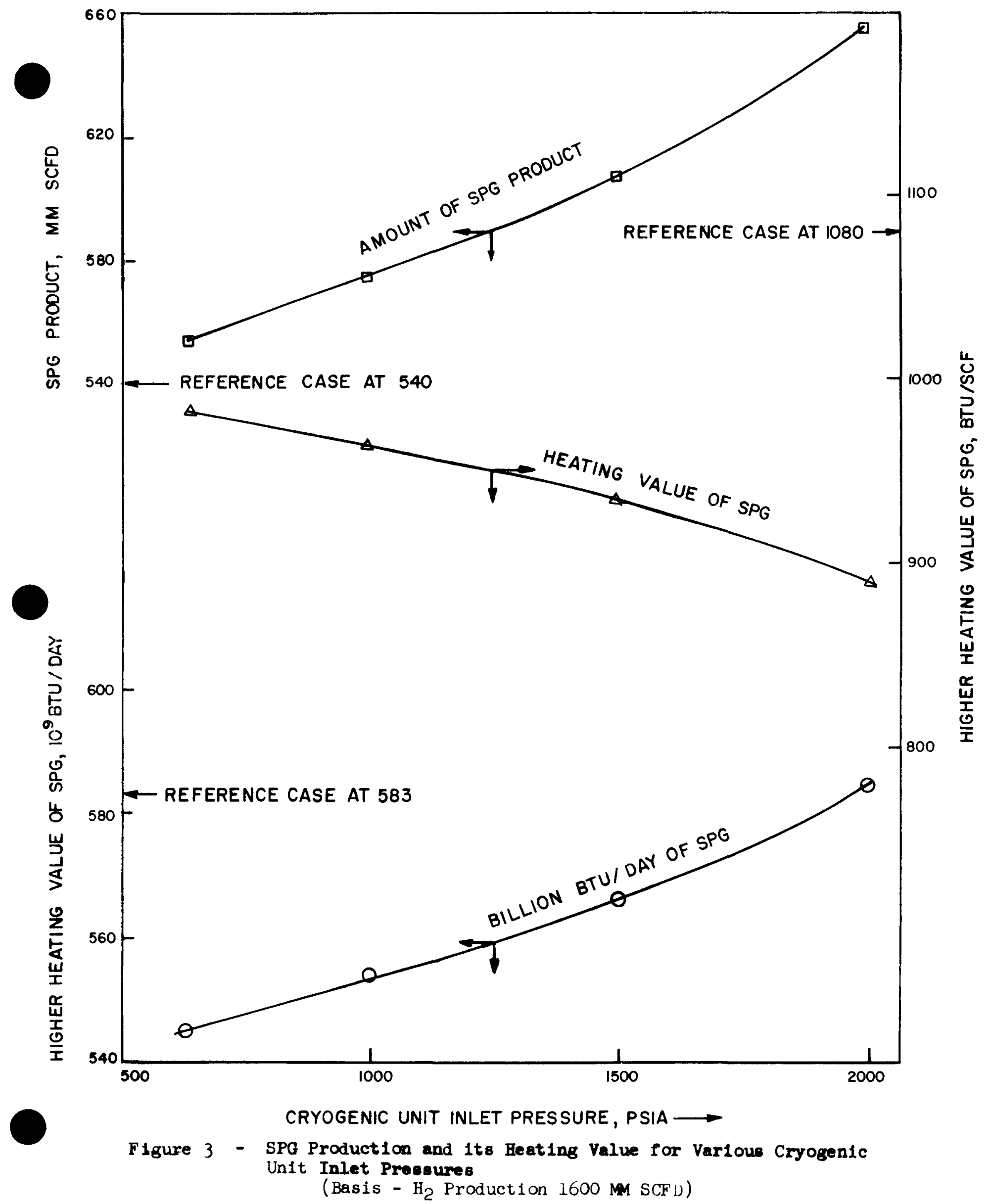


The cases using an expander have not been calculated in deta1l. The heating value of SPG in these cases would depend on the percentage of $\mathrm{H}_{2}$ in the methane stream, but in any case would be lower than the value in the reference case for reason discussed before. The only expander case in which the heating value of SPG was calculated is case 1 and the heating value is $984 \mathrm{Btu} / \mathrm{scf}$.

(b) The power requirements, HTGR heat requirements and process steam requirements for the various cases have been plotted in Figures 4,5 and 6 . At lower reformer outlet pressures, the horsepower requirement increases considerably $(277,450 \mathrm{HP}$ at 500 psi vs $472,650 \mathrm{HP}$ at 200 psi for 1000 psi cryogenic unit inlet pressure). However, the total heat requirement for the process goes down with a decrease in reformer outlet pressure (11.38 x $10^{9} \mathrm{Btu} / \mathrm{hr}$ at 200 psia vs $14.24 \times 10^{9}$ $\mathrm{Btu} / \mathrm{hr}$ at $500 \mathrm{psia}$ for cryogenic unit inlet pressure if 1000 psia). This is attributed to the fact that the process steam requirements go down with a decrease in reformer outlet pressure and the heat duty for process steam outwelghs the heat duty for power requirements in the process.

Fram Figure 5, it is clear that the total HTGR heat requirement for the various cases approaches $10.52 \times 10^{9} \mathrm{Btu} / \mathrm{hr}$ (the value in reference case) around 110 psia reformer outlet pressure.

(c) The variation of total cost of the process and the cost of compressors and expanders is shown in Figures 7 and 8 . At higher reformer outlet pressures, the compression horsepower and the compressor costs decrease. However, the total cost goes up because of the extra HTGR cost (due to the higher process steam requirements for high reformer outlet pressures). As the cryogenic unit feed pressure approaches $O$ psia, the horsepower requirements and consequently the total cost of the plant approaches infinity. Reformer outlet pressure at these conditions is 60 psia and the graphs for the total cost and the compressor costs have been drawn approaching infinity at 60 psia. The lowest cost curve is for 1000 psi cryogenic unit inlet pressure. At this condition to produce 540 MM SCFD of SPG with a fixed HTGR duty of $10.52 \times 10^{9} \mathrm{Bt} / \mathrm{hr}$, the reformer would have to be operated at an outlet pressure of 110 psia, and the total cost of the unit would be $\$ 505 \mathrm{MM}$ compared to the reference case cost of $\$ 385 \mathrm{MM}$ ( $\$ 120 \mathrm{MM}$ increase-15\% increase over the total plant cost of $\$ 800 \mathrm{MM})$.

The cost of the reformer, shift converter and $\mathrm{CO}_{2}$ removal unit has been calculated as

$$
\left[\frac{\text { Actual flow rate, lb mole } / \mathrm{hr}}{\text { Reference flow rate, Ib mole } / \mathrm{hr}}\right]^{0.25} \quad \begin{aligned}
& \text { cost of the unit } \\
& \mathrm{x}
\end{aligned} \text { in the Reference case. }
$$

This would give only an approximate cost of the unit and would be most accurate at 300 psia reformer outlet pressure (the pressure in the reference case). For a more detalled calculation, the effect of pressure on the actual volumetric flow rate and the heat and mass transfer rates would have to be accounted for in the cost of the units. At 110 psi reformer 


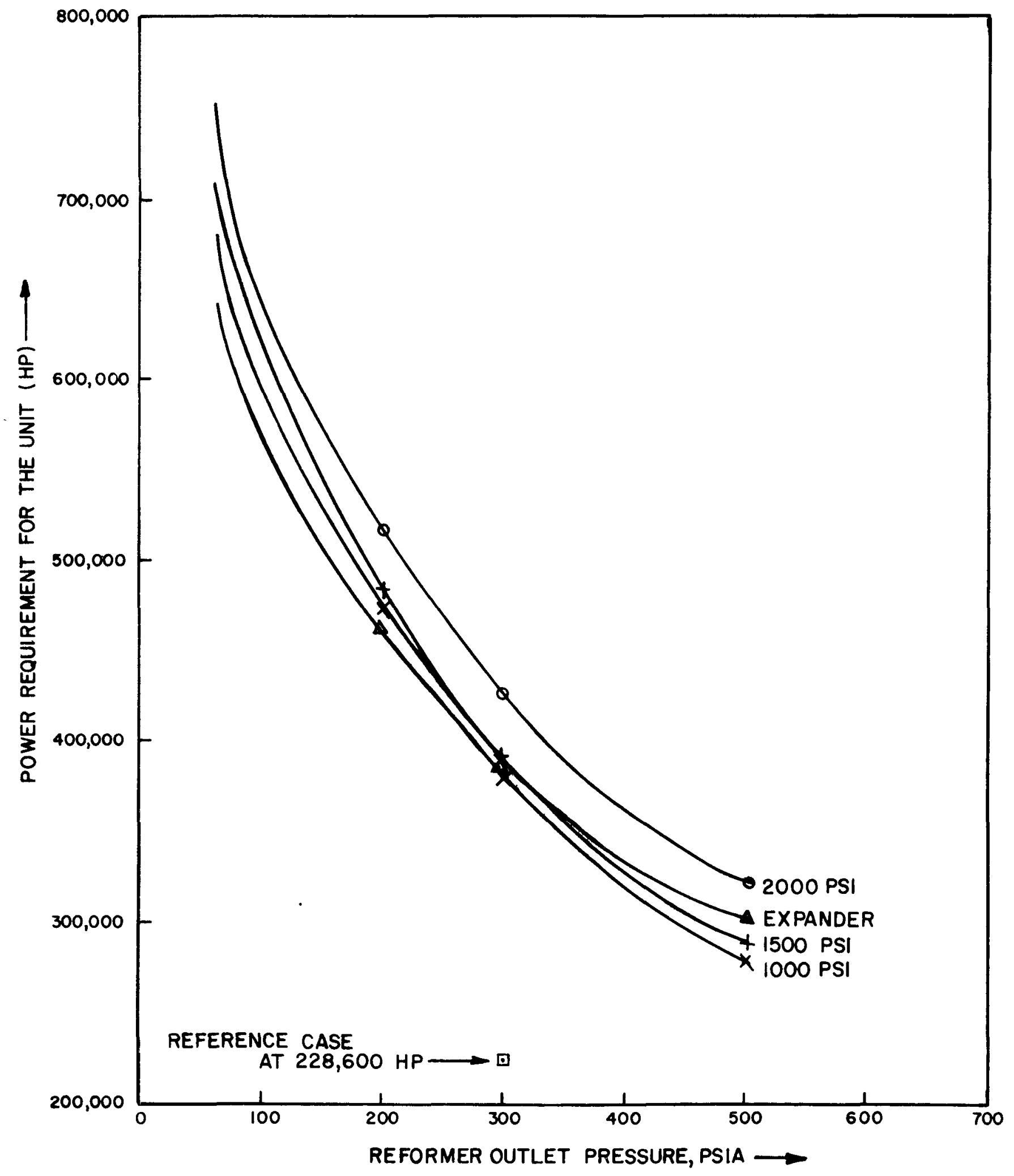

Figure 4 - Power Requirements for He Product1on Vs. Reformer Outlet Pressure (Bas1s - H2 Product1on 1600 MA SCFD) 


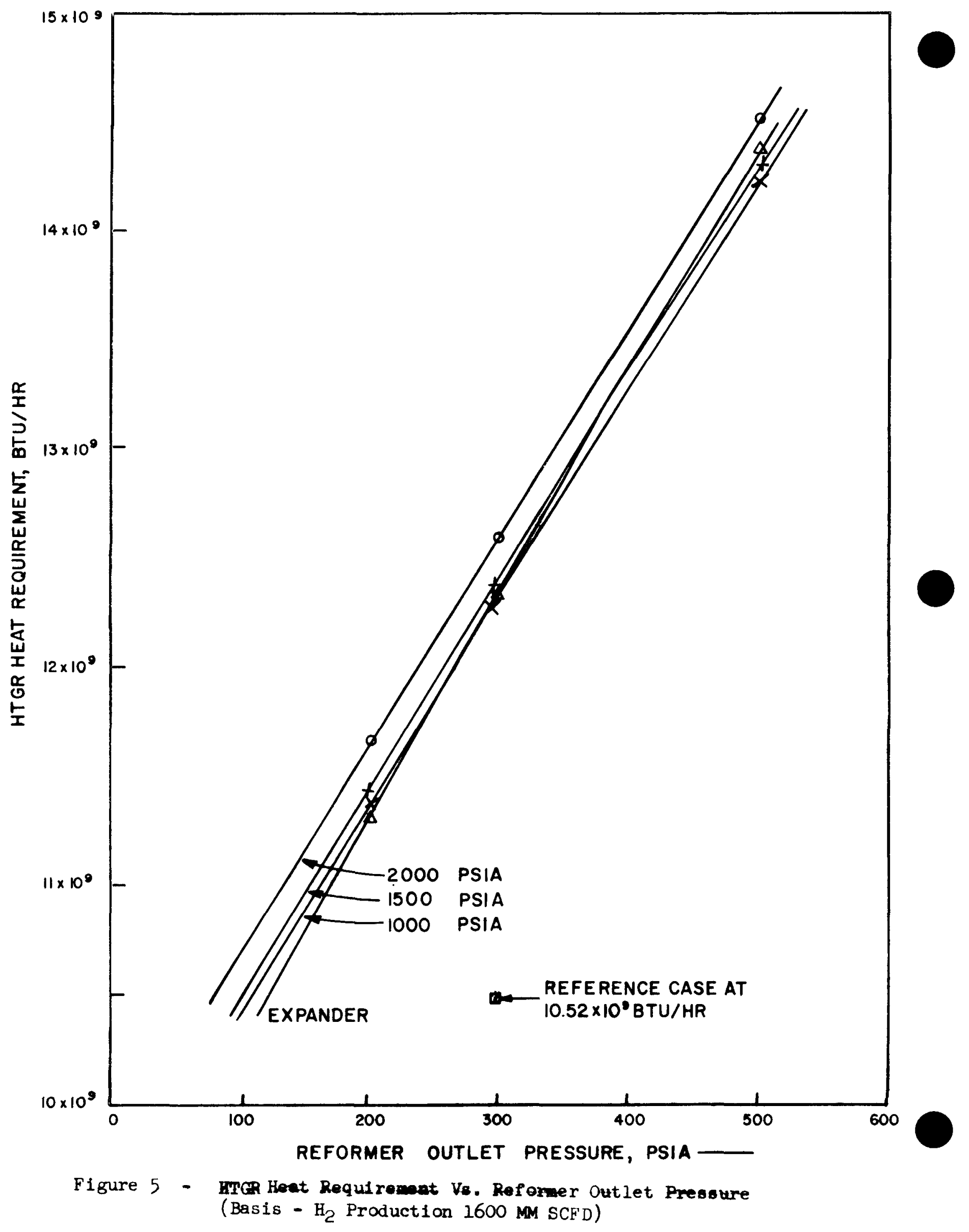




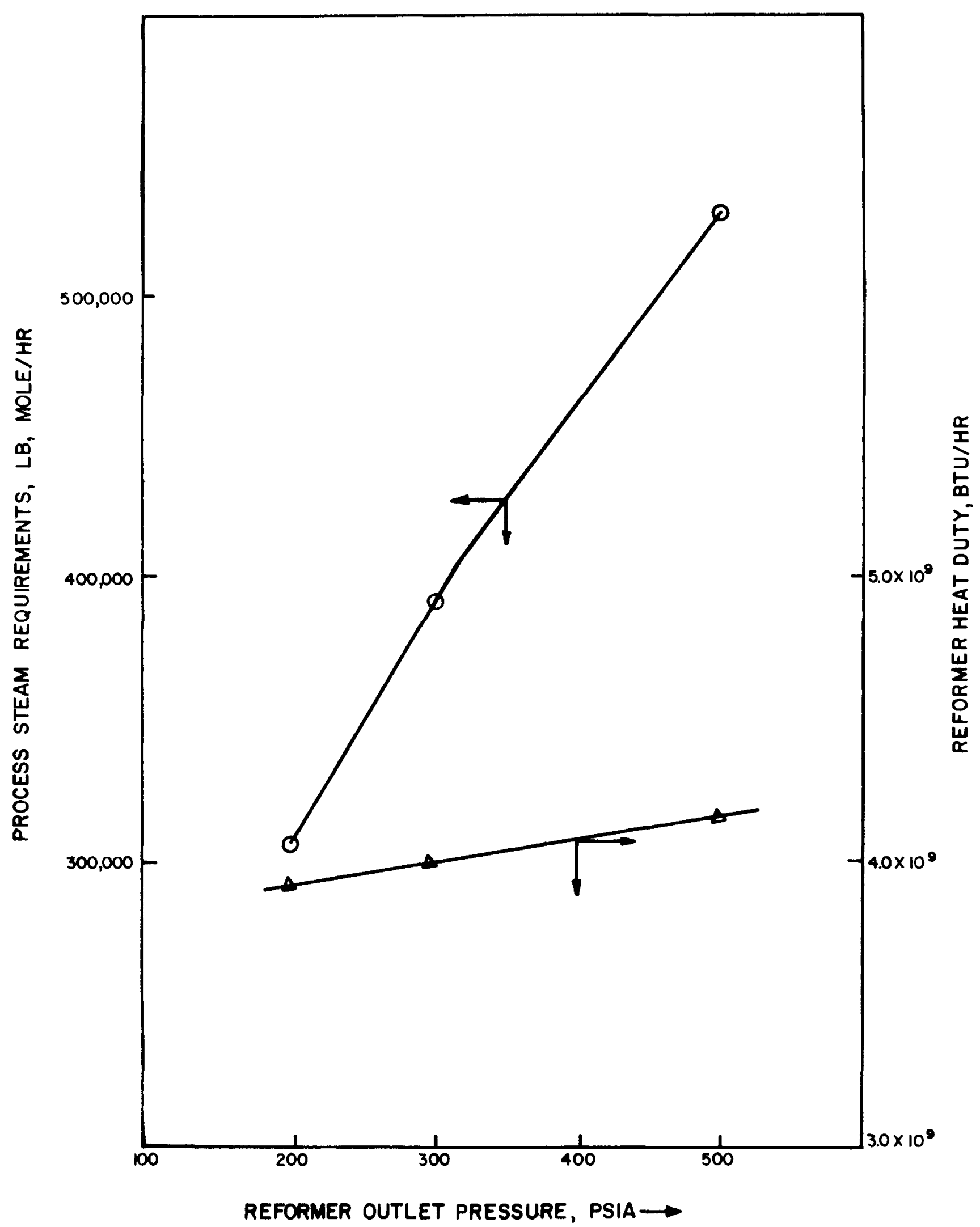

Figure 6 - Variation of Process Steam Requirement and Reformer Heat Duty with Reformer Outlet Pressure (Basis - $\mathrm{H}_{2}$ Production 1600 MMSCFD) 


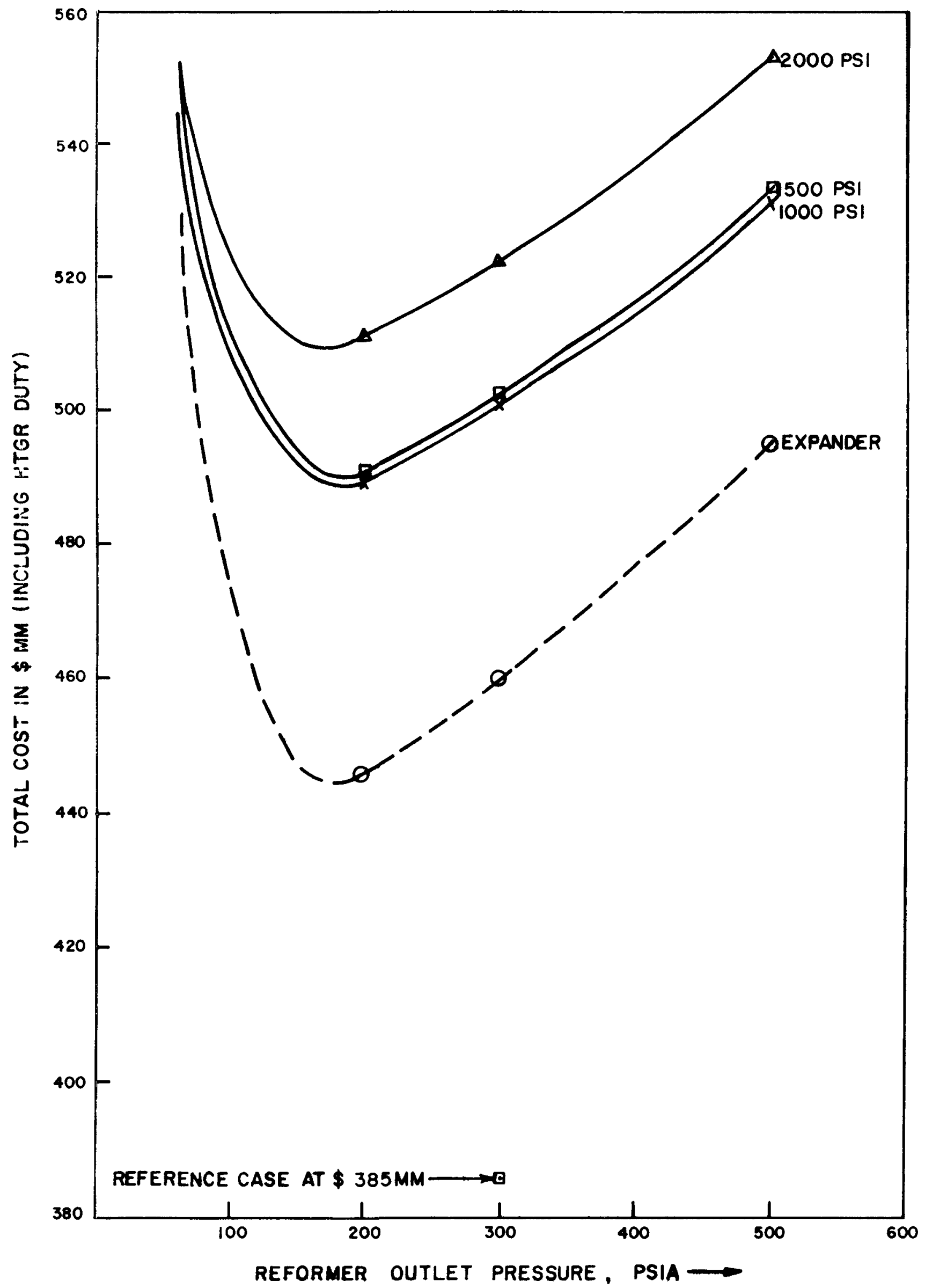

F1gure 7 - Total Cost of $\mathrm{H}_{2}$ Production Vs. Reformer Outlet Pressure (Basis - $\mathrm{H}_{2}$ Production 1600 SCFD) 


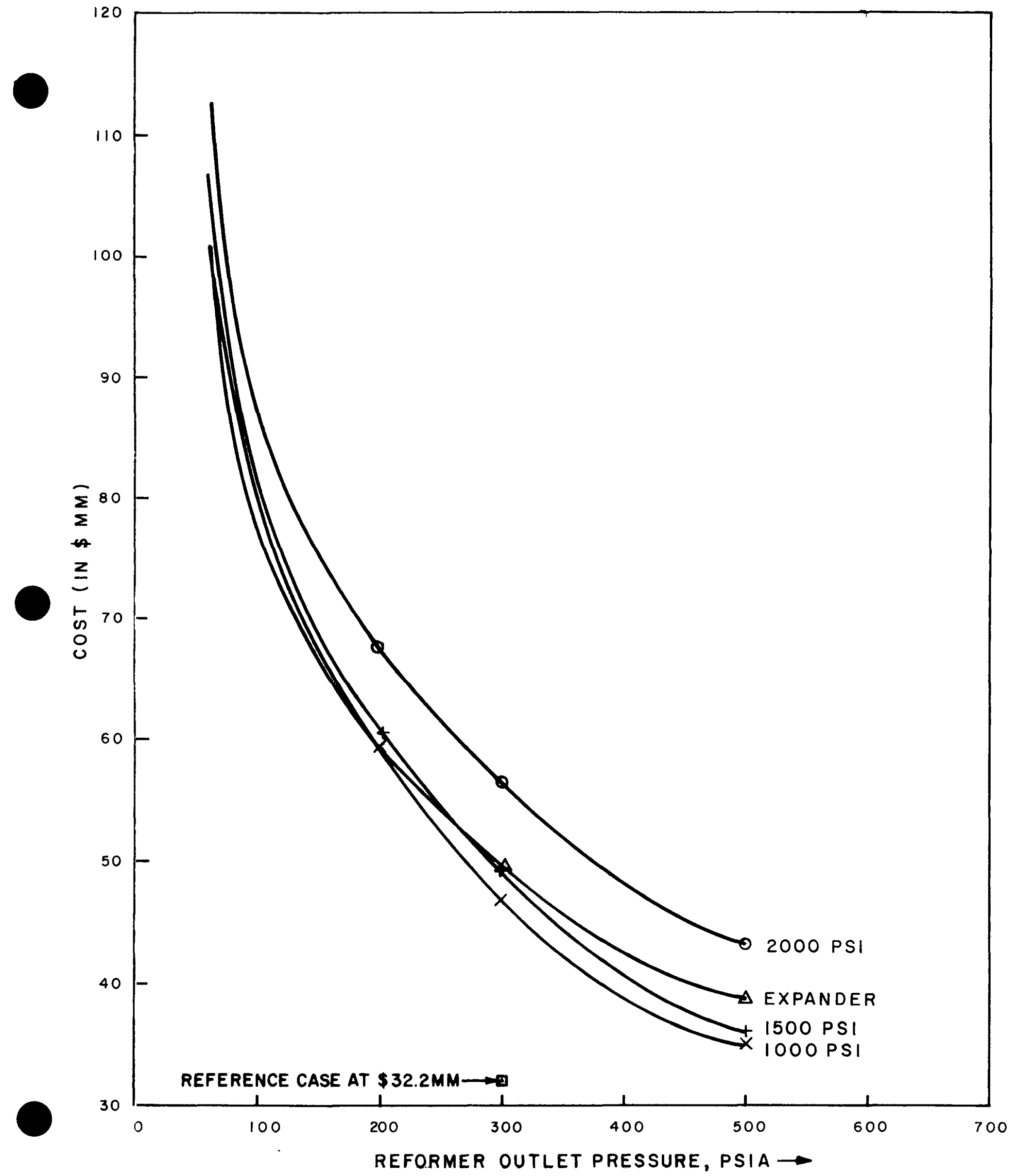

Figure 8 - Capital Cost of Compressors Plus Expanders Vs. Reformer Outlet lressurt (Basis $-\mathrm{H}_{2}$ Production 1600 MMSCFD) 
outlet pressure, a cursory analysis, taking into account the actual volumetric flow rates, shows the total cost of the plant to be about $\$ 550 \mathrm{MM}$.

The preliminary calculations of the expander cases show that using an expander in the cryogenic system may reduce the total capital cost of the unit by about $\$ 40 \mathrm{MM}$.

RECOMMENDATIONS:

(I) The cryogenic unit case with reformer outlet pressure of 110 psia should be worked out in more detail and some other alternatives to the cryogenic unit should also be explored.

(2) The heating value of SPG in the various cases using cryogenic separation varies from $892 \mathrm{Btu} / \mathrm{scf}$ to $984 \mathrm{Btu} / \mathrm{scf}$. This is much lower than the value of $1080 \mathrm{Btu} / \mathrm{scf}$ in the reference case. One way to increase the heating value of $S P G$ in these cases is to separate $\mathrm{C}_{2}$ and heavier fractions from methane and hydrogen before the gases enter, the reformer and mix them with SPG coming out of the cryogenic unit.

(3) In the Oklahoma study heat from the exothermic hydrogasification reaction has been utilized in the coal solution step and solvent recovery. Recent technology such as the GR\&DC liquefaction process (CCL) shows the coal solution/hydrogenation step to be exothermic and no distillation required for solvent separation. With the lower temperature HTGR, extra heat is required for $\mathrm{H}_{2}$ production and the possiblity of using hydrogasifier heat in the $\mathrm{H}_{2}$ production section should be looked into. 


\section{APPENDIX.}

The vartous assumptions used in the nresent studv are listed in this section.

'1) Efficiency of Compressors and Expanders Efficiency of compressors $=77 \%$ Efficlency of expanders in cryogenic unit $=70 \%$

\section{(2) Cryogenic Heat Exchangers}

The heat transfer coefficients for the first and second rore heat. exchangers were taken as $100 \mathrm{Btu} / \mathrm{hr} \mathrm{ft}^{2} \mathrm{O}_{\mathrm{F}}$ and $60 \mathrm{Btu} / \mathrm{hr} \mathrm{ft}^{2} \mathrm{O}_{\mathrm{F}}$ base $^{\prime}$ on Stone : Webster's revlous experience with cryogenic unita. The inlet and outlet temperatures of various streams through the cryogenic heat exchangers were determined but the actual temperature distribution within the exchangers were not calculated, but rather based on the temperature distributions in the demethanizer ystem in ethylene nlonts bullt hy Stone \& rebster.

\section{(3) Expanders}

Fxnander rases have been worked out to give a temperature difference of 15 between the rrycgenic unit feed and the methane and hydrogen streams. Further calculations are required to find the exact separation of methane and hydrogen.

(4) Approach to Equilibrium

A $15 \mathrm{~F}$ and $50 \mathrm{~F}$ approach to equilibrium has been assumed for the reformer and shift converter respectively.

\section{(5) Cost}

The cost of the equipment in the reference case was calculated by taking the 1972 cost figures and escalating them @ $10 \%$ a year to 1974. The cost basis of the equipment in cases 1 to 4 is given on Fage 4.

(6) Power and Process Steam Duty

For simplicity only one steam loop was set up in the present cases compared to two in the reference case. The process steam was taken off at an intermediate stage from the turbine while the power steam was expanded to $2^{\prime \prime}$ of $\mathrm{Hg}$ pressure. Details are given on page 3 . 


\section{(7) Heating Values}

The heating values of methane and hydrogen are taken from NGPSA Engineering Data Book and the standard conditions refer to 14.696 psia and $60^{\circ} \mathrm{F}$. 
APPENDIX B

CORE FUEL ELEMENT AND THERMAL PARAMETER DETAILS

$\mathrm{B}-1$ 


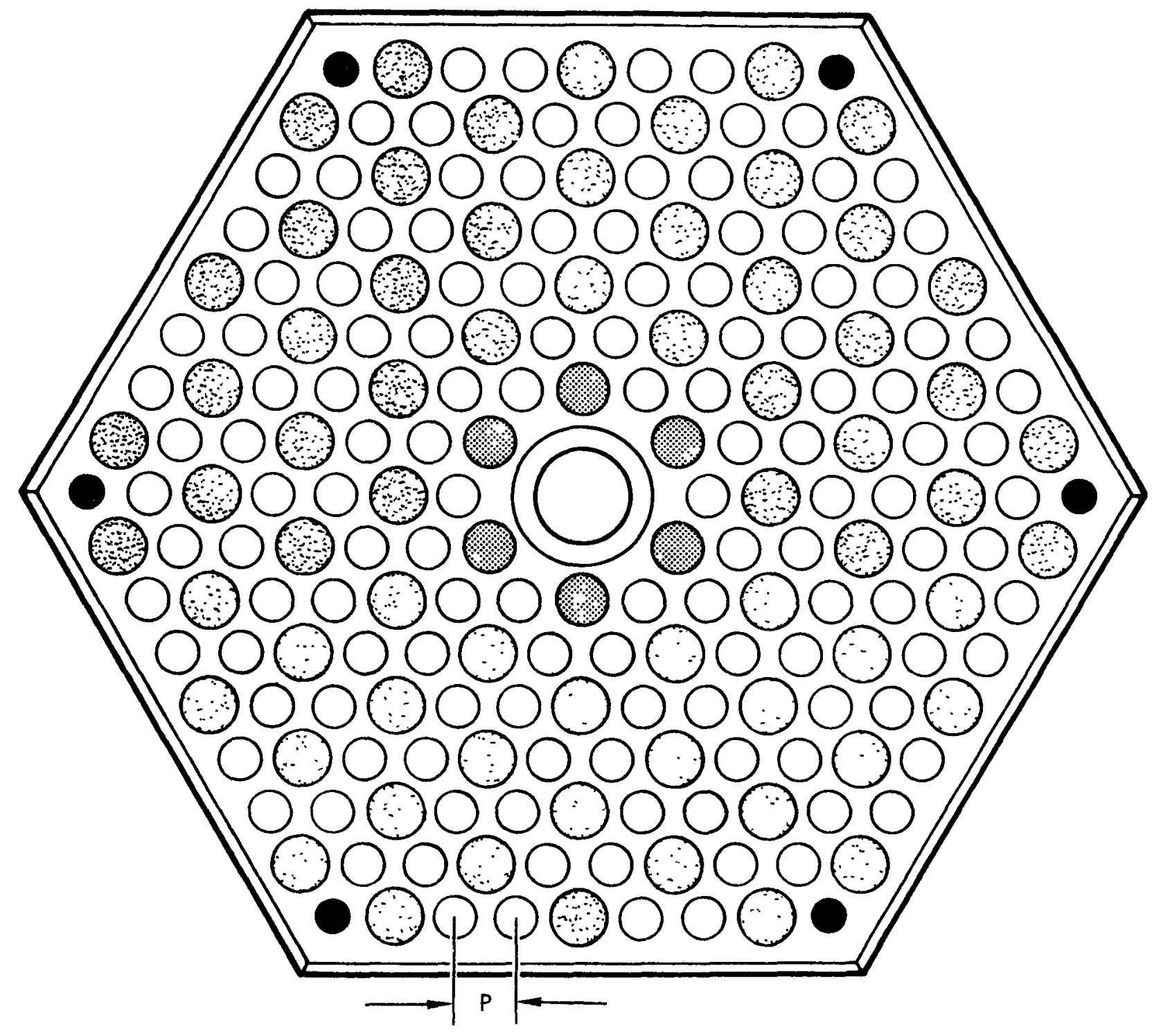

$P=P I T C H=22.99 \mathrm{~mm}$

POISON HOLES

$\bigcirc$ Fuel hOles $15.85 \mathrm{~mm}$ dia. (132)

COOLANT hOLES $18.26 \mathrm{~mm}$ dia.(6)

3 COOLANT HOLES $20.98 \mathrm{~mm}$ dia. (66)

Fig. B-1. Standard 8-row fuel block, 132 fuel holes 


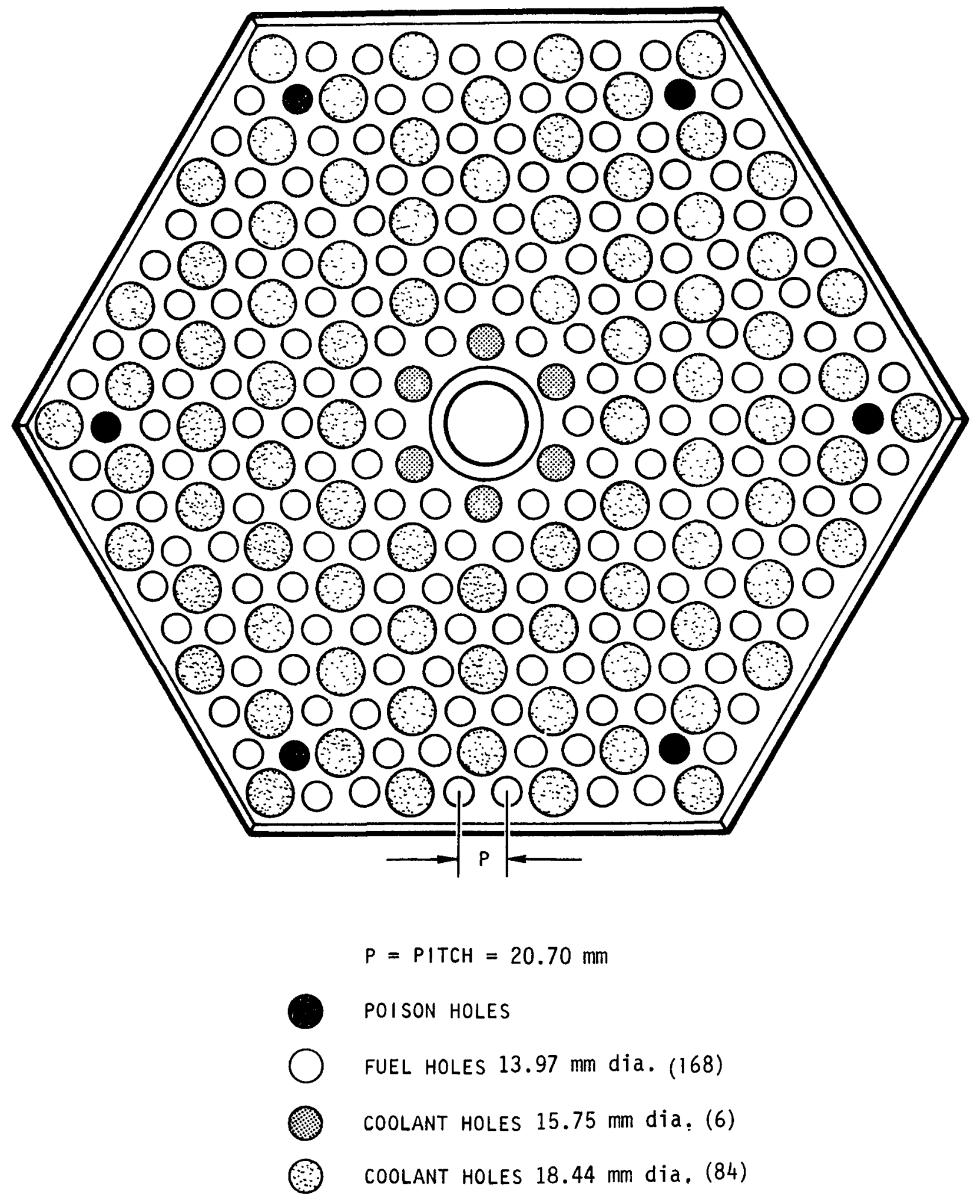

Fig. B-2. Standard 9-row fuel block, 168 fuel holes 


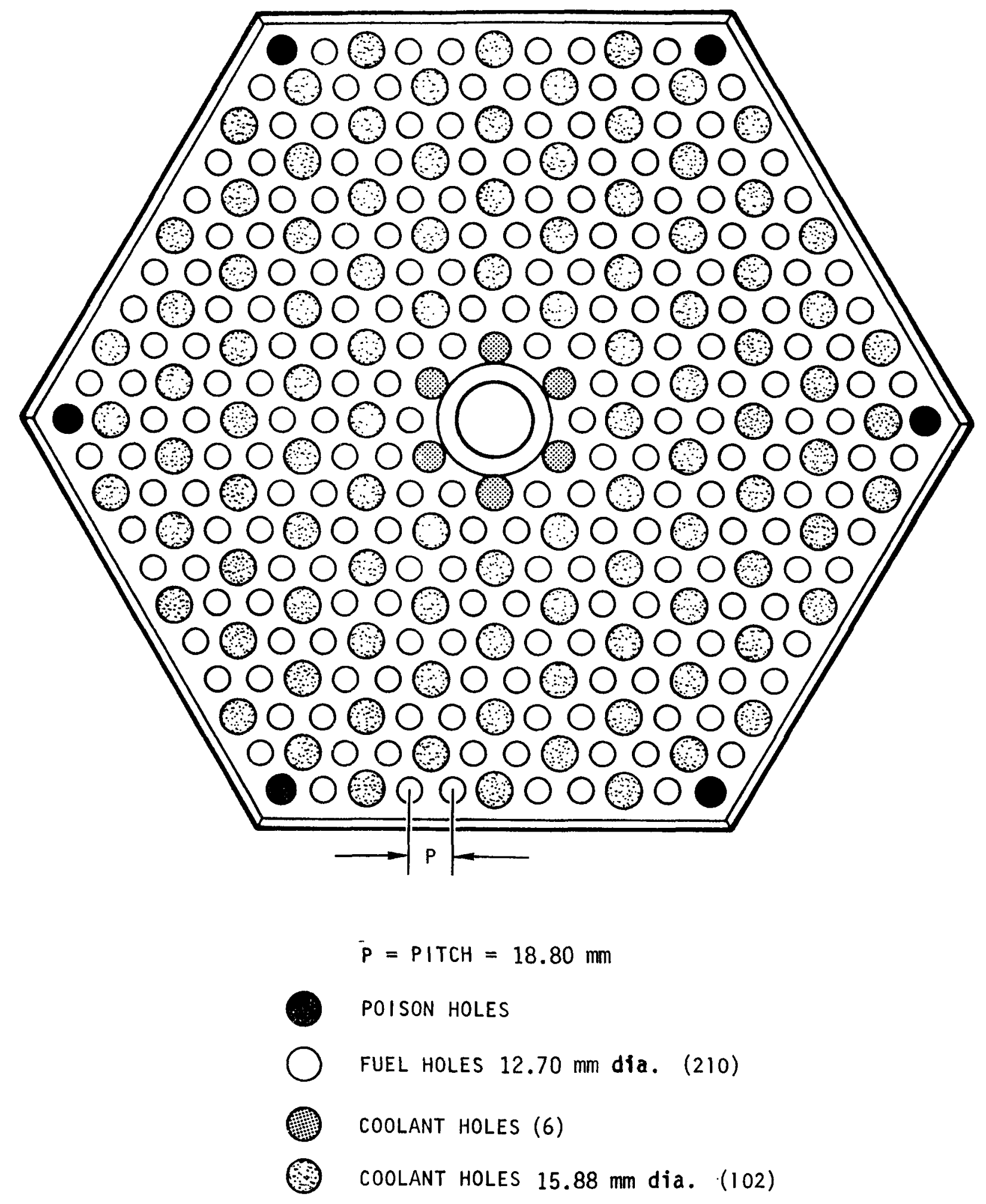

Fig. B-3. Standard 10-row fuel block, 210 fuel holes 
DESIGN I AVERAGE CHANNEL

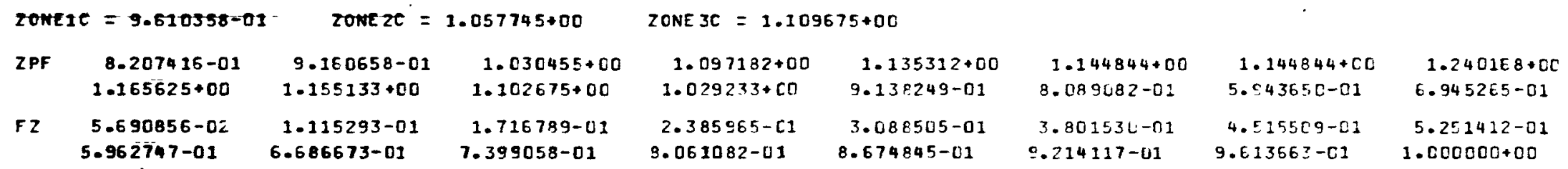

ZONEIC $=9.964223-0 I \quad$ ZONE $2 C=9.97 E 536-0 I \quad Z O N E 3 C=1.033753+00$

\begin{tabular}{|c|c|c|c|c|c|c|c|c|c|}
\hline ZPF & $\frac{8.179328-01}{1.163072+00}$ & $\begin{array}{r}9.129308-01 \\
-1 . \overline{1} 5260 \overline{3}+00\end{array}$ & $\begin{array}{l}1.026928+00 \\
1.10 C 259+00\end{array}$ & $\begin{array}{l}1.093427+00 \\
1.026979+C 0\end{array}$ & $\begin{array}{l}1.131426+00 \\
9.118230-01\end{array}$ & $\begin{array}{l}1.14 U 92 E+00 \\
\text { a.073JE1-01 }\end{array}$ & $\begin{array}{c}1.14 C 926+C O \\
6.14 E 223-C I\end{array}$ & $\begin{array}{l}1.235924+00 \\
7.18080 .7-01\end{array}$ & $\begin{array}{l}\text { AXIAL } \\
\text { PROFILE }\end{array}$ \\
\hline$F Z$ & $\begin{array}{c}5.671381-0 z \\
5.943217-01\end{array}$ & $\begin{array}{l}1.111477-01 \\
6.665557-01\end{array}$ & $\begin{array}{l}1.710914-01 \\
7.276381-01\end{array}$ & $\begin{array}{l}2.377800-C 1 \\
8.036956-01\end{array}$ & $\begin{array}{l}3.077935-01 \\
8.640374-01\end{array}$ & $\begin{array}{l}3.788521-01 \\
9.187465-01\end{array}$ & $\begin{array}{l}4.500056-02 \\
9 . E 00560-01\end{array}$ & $\begin{array}{l}5.23344 C-01 \\
1.000000+C 0\end{array}$ & \\
\hline
\end{tabular}

TOTAL CORE POWER: $3000 \mathrm{MH}$

PONER FACTORS
FRACTION OF POHER $=1.040$
FRACITON OF FLOW $=1.077$
REGION POWER FACTOR $=1.000$
COLUMN POHER FACTOR $=1.000$
COLUMN TILT

LB AHR NUMBER PSI OEO F

TR $322.7 \quad 74407$.

322.773453

$\begin{array}{ll}322.7 & 71668 \\ 322.7 & 69939 .\end{array}$

$\begin{array}{ll}322.7 & 69939 . \\ 322.7 & 68142 .\end{array}$

322.766325 .

322.764572 .

322.762916 .

322.761338 .

322.759922.

322.750658 .

322.757458.

322.756365.

322.754553 .

322.753904 .

322.753389.

PSI CEE F

.433

.129745.

.133
.140

.14888.

.155943.

$\begin{array}{ll}.162 & 1000 . \\ .168 & 1056 .\end{array}$

.1751114.

.1781165 .

.1841217.

.193126.

.197 1359.

.1991398.

.1981425.

.2001451.

TEMPERATURES F

********************)

CORE INLET $=300 . \mathrm{C}$

CORE OUTLET $\quad=1451.4$

REGION OUTLEI $\quad=1451.4$

COLUMN OUTLET $=1451.4$

$\begin{aligned} \text { GRA AVG TEMF } & =1671.5 \\ \text { GITE AVE TEMF } & =1419.4\end{aligned}$
FLOW RATES LE/HR

$* * * * * * * * * * * * * * * * * * *$

CCRE AVERACE FLOW

REGION AVERAGE FLOW $=322.7$ REGION FRESSURE DROF

COLUMN AVERAGE FLOW $=322.7$ COLUMN FRESSURE DROF

$\begin{aligned} & =4.059 \\ & =4.040\end{aligned}$

PERCENTAGE CONVEREENCE $=4.040$ OPEN ORIFICE FRESSURE DROF $=.897$
FRESSURE OROFS FSI
**

* Lb/hr NUMEer

\# $322.7 \quad 74407$.

$* 322.7 \quad 73500$.

*** $322.7 \quad 71799$.

*** $322.7 \quad 70147$.

*** $322.7 \quad 68424$.

*** 322.7 E6673.

** $322.7 \quad E 4988$.

*** 322.7 E185\%。

*** $322.76042 \mathrm{C}$.

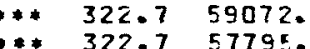

** $322.7 \quad 56535$

* 322.7 55609.

$\because 322.754720$.

$\because 322.754012$

$\begin{array}{rrr}* \quad 322.7 & 53424 . \\ * \quad 7549.2 & 205373 .\end{array}$
LOCAL OR

OR

\begin{tabular}{|c|c|c|c|c|c|}
\hline$F$ & TCOOL & 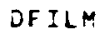 & $D G R A$ & $D G A$ & \\
\hline II & $D E G \quad F$ & OEC F & $D E \in F$ & $D E C F$ & DLG \\
\hline & 700. & & $* * *$ & & \\
\hline & 743. & 5. & $E 5$. & 142. & 28 \\
\hline & 784. & & 73. & 157. & 12 \\
\hline & 229. & & 82 . & 4. & \\
\hline & $\begin{array}{l}379 . \\
931 .\end{array}$ & & $\begin{array}{l}37 . \\
90 .\end{array}$ & & \\
\hline & $\begin{array}{r}985 . \\
1038 .\end{array}$ & & $\begin{array}{l}91 . \\
91 .\end{array}$ & & \\
\hline 172 & 1093. & 328. & 99. & 162. & 19 \\
\hline 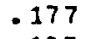 & $1147^{\circ}$ & & & & \\
\hline $\begin{array}{l}183 \\
189\end{array}$ & $\begin{array}{l}1261 . \\
1254 .\end{array}$ & $\begin{array}{l}30 \\
28\end{array}$ & $\begin{array}{l}92 . \\
98 .\end{array}$ & $\begin{array}{l}140 . \\
128 .\end{array}$ & \\
\hline & $1 \geq 04$. & 26 & 82 & 115. & \\
\hline & 1350. & & & & \\
\hline 19 & $\begin{array}{l}1390 . \\
1421 .\end{array}$ & $\begin{array}{l}20 \\
15\end{array}$ & E4 & $\begin{array}{l}34 . \\
62 .\end{array}$ & $12 E$ \\
\hline & & & 5 & EE & 11 \\
\hline & & & & & \\
\hline
\end{tabular}

CONDUC TANCES

E/HR, FT2, F
$* *$
ERROR
TEMFE RA TURE DROFS

DEG $F$
$* *$

$* *$

\begin{tabular}{|c|c|c|c|c|}
\hline ERROR & TF UE L & CRAD & VEL & $* * *$ \\
\hline$D E G \quad F$ & CEC F & $F / I N$ & FSI & $* * *$ \\
\hline *** & $* * * * *$ & $* * * * *$ & .2685 & . \\
\hline 0. & 1302 . & 838.2 & .2789 & $* * *$ \\
\hline c. & $14 \mathrm{CE}$. & $936 . E$ & .2820 & $* * *$ \\
\hline c. & 1524. & 1054.4 & $.300 \mathrm{CL}$ & $* * *$ \\
\hline $\begin{array}{l}\text { D. } \\
\text { c. }\end{array}$ & $\begin{array}{l}1612 . \\
1631 .\end{array}$ & $\begin{array}{l}1122.9 \\
1161.5\end{array}$ & & $* * *$ \\
\hline $\begin{array}{l}0 . \\
0 .\end{array}$ & $\begin{array}{l}1731 . \\
1774 .\end{array}$ & $\begin{array}{l}1170.5 \\
1169.4\end{array}$ & & $* * *$ \\
\hline 0. & 1875 . & $12 E E .1$ & .3649 & $* * *$ \\
\hline 0. & $187 E$. & 1189.7 & $.37 f 8$ & $* * *$ \\
\hline 0. & 19 & 1178 & .3800 & $* *$ \\
\hline C. & 1930. & 1123 & $.40<9$ & $* * *$ \\
\hline 0. & $1929^{\circ}$ & 1048.1 & .4120 & $* * *$ \\
\hline c. & 1974. & 822 & & \\
\hline ח & 1787. & 625.2 & & $\cdots$ \\
\hline 0 & 1972 & 729.7 & .4441 & ** \\
\hline & & & $.181 \mathrm{C}$ & \\
\hline
\end{tabular}

MIGRATICN LIFETIME (HRS) **

TRISO 
DESIGN I AVERAGE CHANNEL (Continued)

\begin{tabular}{|c|c|c|c|c|c|c|c|c|c|c|c|c|c|c|c|c|c|}
\hline $\mathbf{N}$ & FLUX & HTC & EKG & HEAP & EKROD & SOLEK & $* * *$ & ECOOL & EFILM & ESOL & Esum & $* * *$ & TIMES & TIMEC & TIMES & TIMEC & $\cdots$ \\
\hline 1 & $6.59+04$ & 292.7 & 1007.7 & 283.9 & 322.9 & $18 \mathrm{U} .7$ & $* * *$ & .0 & .0 & .0 &.$c$ & $* *$ & $1.05+11$ & $6.4=+1 E$ & $9.69+07$ & $2.15+C 8$ & $* * *$ \\
\hline 2 & $7 \cdot 35+04$ & 294.1 & 1007.7 & 285.5 & 312.9 & 181.0 & $* * *$ & .0 & .0 & .0 & .0 & $* * *$ & $1.28+10$ & $7.92+c 9$ & $2.95+[7$ & $6.55+[7$ & *** \\
\hline 3 & $8.27+04$ & 295.5 & 1007.7 & 291.3 & $3: 2.9$ & 382.6 & $* * *$ & .0 & .0 & .0 & .0 & $* * *$ & $1.5 z+09$ & $9.5^{7}+C B$ & $8.8 E+C E$ & $1.96+C 7$ & $* *$ \\
\hline $\begin{array}{l}4 \\
5\end{array}$ & $\begin{array}{l}8.80+04 \\
3-11+04\end{array}$ & $\begin{array}{l}297.0 \\
298.5\end{array}$ & $\begin{array}{l}1007.7 \\
1007.7\end{array}$ & $\begin{array}{l}300.7 \\
313.3\end{array}$ & $\begin{array}{l}312.9 \\
312.9\end{array}$ & $\begin{array}{l}185.0 \\
188.2\end{array}$ & $* * *$ & .0 & .0 & .0 & $\begin{array}{l}.0 \\
.0\end{array}$ & $* * *$ & $\begin{array}{l}3 \cdot 52+08 \\
1.28+08\end{array}$ & $\begin{array}{l}2.35+c 8 \\
8.59+C 7\end{array}$ & $\begin{array}{l}3.38+D E \\
2.11+D E\end{array}$ & $\begin{array}{l}3.25+C E \\
E . C I+C E\end{array}$ & $\because *$ \\
\hline 6 & $\begin{array}{l}9.19+04 \\
9.19+04\end{array}$ & $\begin{array}{l}300.1 \\
301.5\end{array}$ & $\begin{array}{l}1007.7 \\
1007.7\end{array}$ & $\begin{array}{l}327.8 \\
245.9\end{array}$ & $\begin{array}{l}312.9 \\
312.9\end{array}$ & $\begin{array}{l}191.7 \\
195.3\end{array}$ & $* * * *$ & . & .0 & .0 & $\begin{array}{l}.0 \\
.0\end{array}$ & $* *$ & $\begin{array}{l}5.44+07 \\
2.05+07\end{array}$ & $\begin{array}{l}4.38+C 7 \\
2.54+57\end{array}$ & $\begin{array}{l}1.38+5 E \\
9 . E E+C 5\end{array}$ & $\begin{array}{l}3.45+D E \\
2.55+C E\end{array}$ & $* *$ \\
\hline $\begin{array}{l}8 \\
9\end{array}$ & $\begin{array}{l}9.95+04 \\
9.37+04\end{array}$ & $\begin{array}{l}303.0 \\
304.4\end{array}$ & $\begin{array}{l}1007.7 \\
1007.7\end{array}$ & $\begin{array}{l}375.9 \\
387.9\end{array}$ & $\begin{array}{l}322.9 \\
312.9\end{array}$ & $\begin{array}{l}202.1 \\
204.5\end{array}$ & $\because * *$ & . 0 & $\begin{array}{l}.0 \\
.0\end{array}$ & .0 & .0 & $\because * *$ & $\begin{array}{l}7.8]+06 \\
7.012+O E\end{array}$ & $\begin{array}{l}7.07+C E \\
7.4 Z+C F\end{array}$ & $\begin{array}{l}4.58+05 \\
4.44+05\end{array}$ & $\begin{array}{l}1.21+C E \\
1.28+C E\end{array}$ & $* * *$ \\
\hline 10 & $\begin{array}{l}9.28+04 \\
8.86+04\end{array}$ & $\begin{array}{l}305.8 \\
307.1\end{array}$ & $\begin{array}{l}1067.7 \\
100.7 .7\end{array}$ & $\begin{array}{l}405.1 \\
422.6\end{array}$ & $\begin{array}{l}312.9 \\
312.9\end{array}$ & $\begin{array}{l}247.7 \\
210.8\end{array}$ & $* * *$ & .0 & .0 & .0 & .0 & $* * *$ & $\begin{array}{l}4 \cdot C 2+C 6 \\
3.22+06\end{array}$ & $\begin{array}{l}4.79+C E \\
4.3 C+C 6\end{array}$ & $\begin{array}{l}3.31+C E \\
2.9 E+C 5\end{array}$ & $\begin{array}{l}1 . C 1+C E \\
9 . E 7+C E\end{array}$ & $* *$ \\
\hline 12 & $\begin{array}{l}8.27+04 \\
7.34+04\end{array}$ & $\begin{array}{l}348.3 \\
309.3\end{array}$ & $\begin{array}{l}1007.7 \\
1007.7\end{array}$ & $\begin{array}{l}439.2 \\
453.3\end{array}$ & $\begin{array}{l}312.9 \\
312.9\end{array}$ & $\begin{array}{l}213.6 \\
215.8\end{array}$ & $* * *$ & .0 & .0 & .0 & $\begin{array}{l}-c \\
.01\end{array}$ & $\because * *$ & $\begin{array}{l}3.113+06 \\
3.28+05\end{array}$ & $\begin{array}{l}4 . E F+C E \\
7.1 E+C E\end{array}$ & $\begin{array}{l}2.95+0.5 \\
3.57+05\end{array}$ & $\begin{array}{l}3 . C 4+C E \\
1.4 C+C E\end{array}$ & $\because * *$ \\
\hline $\begin{array}{l}14 \\
15\end{array}$ & $\begin{array}{l}6.50+04 \\
4.95+04\end{array}$ & $\begin{array}{l}310.2 \\
310.9\end{array}$ & $\begin{array}{l}1007.7 \\
1007.7\end{array}$ & $\begin{array}{l}468.4 \\
486.6\end{array}$ & $\begin{array}{l}322.9 \\
312.9\end{array}$ & $\begin{array}{l}218.1 \\
220.8\end{array}$ & $* * *$ & .0 & .0 & .0 & $\begin{array}{l}.6 \\
.0\end{array}$ & $\because * *$ & $\begin{array}{l}4.09+a 6 \\
1.20+67\end{array}$ & $\begin{array}{l}1.09+07 \\
4.04+C 7\end{array}$ & $\begin{array}{l}4.34+C 5 \\
8 . E 4+C 5\end{array}$ & $\begin{array}{l}1.87+C E \\
4.3 E+C E\end{array}$ & $\because * *$ \\
\hline 16 & $5.78+04$ & 311.6 & 1607.7 & 532.0 & 312.9 & $22 E .8$ & $* * *$ &.$C$ & .0 & .0 & .0 & $* *$ & $4.25+06$ & $1.2 E+[.7$ & $4.5 C+C 5$ & $2.13+E E$ & $\cdots$ \\
\hline
\end{tabular}


TOTAL CORE POWER: $3000 \mathrm{MH}$

POHER FACTORS $\ldots * \cdots \cdots$

FRACTION OF POWER $=1.000$ FRACTION OF FLOW $=1.077$ REGION POWER FACTOR $=1.297$ COLUMN POHER FACTOR $=1.75$ COLUMN TILT $=1.315$
IEMPERATURES F ** TEM

CORE INLET

CORE OUTLET REOION OUTLET $=1451.4$ GRAPUITE TVG TEMF $=1727.7$
FLOH RATES LB/HR

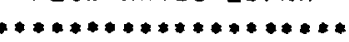

CORE AVERAGE FLOW

REGION AYERAGE FLOH $=419.5$ REGION PRESSURE DROP

COLUMN AVERAGE FLOW $=393.4$ COLUMN PRESSURE DROP OPEN ORIFICE PRESSURE DROP CORE PRESSURE DROP
$=725.0$
$=6.612$
$=6.6 .68$
$=-.008$
$=1.508$
$=8.120$
REEION AVERAGE CONEETIONS
LOCAL OR COLUMN AVERAGE CONDITIONS

\begin{tabular}{|c|c|c|c|c|c|c|}
\hline $\begin{array}{l}\text { FLOR } \\
\text { LB /HR }\end{array}$ & $\begin{array}{c}\text { REY } \\
\text { NUMBER }\end{array}$ & $\begin{array}{l}\text { ROP } \\
\text { PrI }\end{array}$ & $\begin{array}{l}\text { TOOOL } \\
\text { SEG F }\end{array}$ & $* * *$ & $\begin{array}{l}F L O C \\
L B / H R\end{array}$ & $\begin{array}{c}\text { REY } \\
\text { NUMBER }\end{array}$ \\
\hline 428.5 & 96497. & .707 & $7 \mathrm{CC}$. & $* * *$ & 392.4 & 90708. \\
\hline $\begin{array}{l}418.5 \\
418.5\end{array}$ & $\begin{array}{l}95321 . \\
93115 .\end{array}$ & $\begin{array}{l}.209 \\
.214\end{array}$ & $\begin{array}{l}743 . \\
784 .\end{array}$ & $* * *$ & $\begin{array}{l}393.4 \\
393.4\end{array}$ & $\begin{array}{l}\text { E91E3. } \\
\text { E6335. }\end{array}$ \\
\hline $\begin{array}{l}418.5 \\
418.5\end{array}$ & $\begin{array}{l}96973 . \\
887 \geq 9 .\end{array}$ & $\begin{array}{r}.225 \\
.237\end{array}$ & $\begin{array}{l}820^{\circ} \\
370^{\circ}\end{array}$ & $* * *$ & $\begin{array}{l}393.4 \\
393.4\end{array}$ & $\begin{array}{l}8364 \% . \\
80885 .\end{array}$ \\
\hline $\begin{array}{l}418.5 \\
418.5 \\
418.5\end{array}$ & $\begin{array}{l}86474 . \\
84292 \\
8: 207\end{array}$ & $\begin{array}{l}.248 \\
.258 \\
.268\end{array}$ & $\begin{array}{r}321 . \\
355 . \\
1038 .\end{array}$ & $\begin{array}{l}* * \\
* * * \\
* * *\end{array}$ & $\begin{array}{l}393.4 \\
393.4 \\
393.4\end{array}$ & $\begin{array}{l}78159 . \\
75576 . \\
73165 .\end{array}$ \\
\hline 418.5 & 84224 . & .278 & 1092. & $\cdots$ & 393.4 & 74907. \\
\hline 418.5 & 73358. & .287 & 1147. & $* * *$ & 393.4 & 58818. \\
\hline $\begin{array}{l}438.5 \\
438.5\end{array}$ & $\begin{array}{l}75 E 09 . \\
74953 .\end{array}$ & $\begin{array}{l}.297 \\
.306\end{array}$ & $\begin{array}{l}1201 . \\
1254^{\circ}\end{array}$ & $* * *$ & $\begin{array}{l}393.4 \\
393.4\end{array}$ & $\begin{array}{l}6688 \% . \\
65080^{\circ}\end{array}$ \\
\hline $\begin{array}{l}418.5 \\
418.5 \\
418.5\end{array}$ & $\begin{array}{l}73449 . \\
72118 . \\
70965 .\end{array}$ & $\begin{array}{r}.312 \\
.318 \\
.322\end{array}$ & $\begin{array}{l}1304 . \\
1350^{\circ} \\
1390^{\circ}\end{array}$ & $\begin{array}{l}* * * \\
* * * \\
* *\end{array}$ & $\begin{array}{l}393.4 \\
393.4 \\
393.4\end{array}$ & $\begin{array}{l}\varepsilon 3473 . \\
620 E c . \\
\varepsilon 0849 .\end{array}$ \\
\hline $\begin{array}{l}418.5 \\
418.5\end{array}$ & 70047 & $0 \geq 21$ & 1421 & $\cdots$ & 393.4 & $59890^{\circ}$ \\
\hline $\begin{array}{r}418.5 \\
0790\end{array}$ & 63285. &.$\geq 2 E$ & $145:$ & $\cdots$ & $39 \geq .4$ & $\$ 9100$. \\
\hline 9790.4 & 260345. & .355 & 1451. & $* *$ & 9203.4 & 226941. \\
\hline
\end{tabular}

SDF TCOOL DFILM DSRA JGAP DROD FSI DEG F DEG F CEG F DECF DEG F DEGF DEGF FRAN FEL \#

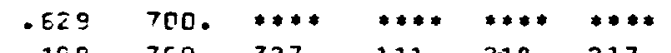
. 199 760. 327. 111. 218. 217. - 2TE 317. 3E?. 124. 239. 243. .219880 .405 .2140 .260 .273$. .235 350. 429. 149. 265.291. $\begin{array}{llllll}.248 & 10244^{\circ} & 44 \mathrm{C} . & 154^{\circ} & 261 . & 301 . \\ .2 E 1 & 1498^{\circ} & 441 . & 150^{\circ} & 250 . & 303 .\end{array}$ $\begin{array}{llllll}.2 E 1 & 1498 . & 441 . & 15 E . & 250 . & 303 . \\ .273 & 1173 . & 438 . & 156 . & 235 . & 303 .\end{array}$ $\begin{array}{llllll}.273 & 1173 . & 438 . & 156 . & 235 . & 303 . \\ .286 & 1250 . & 473^{\circ} & 168 . & 231 . & 329 .\end{array}$ $\begin{array}{llllll}.286 & 1250 . & 470^{\circ} & 168 . & 231 . & 329 . \\ .297 & 13250^{\circ} & 44 ?^{\circ} & 153 . & 231 . & 309 .\end{array}$ 3101401.435 .457 .139 .306$. .321 1475. 413. 150. 132. 293. .230 1545. 384. 140. 163. 273. .327 1609. 339. 124. 141. 242. $.3421666 .290^{\circ}$ 110. 121. 215. .341 1709. 22?. 84. 20. 163. .347 1751. 265. 98. 95. 191.

$* \ldots$.
0.
0.
0.
0.
0.
$c$.
0.
0.
$c$.
0.
0.
0.
$c$.
$c$.
0.
0.
$* \ldots$

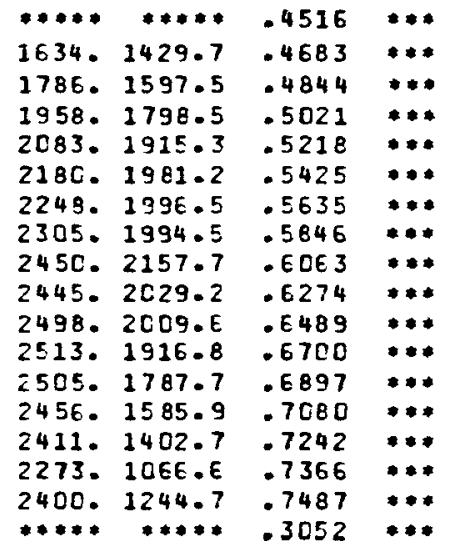

\section{CONCUCTANCES}

E/HR, FTZ, F

N FLUX

$11.12+0$ $21.25+65$ $31.41+05$ $4.50+05$
5
$1.55+05$ $5,1.57+05$ $\begin{array}{lll}6 & 1-57+05 \\ 7 & 1-5 & -5+05\end{array}$ $71.57+05$ 8 $1.70+05$ $91.60+05$ $10 \quad 1+58+05$ $311 .-51+05$ $121.41+05$ $131.25+05$ $14 \quad 1-11+05$ $158.44+04$
$* *$

ERROR

TEMFE RA

\begin{abstract}
DEC $F$
\end{abstract}
eccol efilm esol esum

$343.7 \quad 10167.7 \quad 214.2 \quad 322.9 \quad 188.5 \quad * 0$ $345.81007 .7 \quad 220.0 \quad 3: 2.9 \quad 190.6 \quad * *$ $348.0 \quad 1047.7 \quad 332.4 \quad 322.9 \quad 192.7 \quad \cdots$ $350.41607 .7 \quad 747.1 \quad 312.9 \quad 19 E .0 \quad * *$

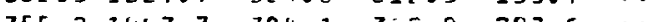
$\begin{array}{llllll}355.2 & 1067.7 & 204.1 & 2.2 .0 & 202.6 & * \\ 357.5 & 1067.7 & 407.3 & 312.5 & 207.9 & * *\end{array}$ $350.71007 .7 \quad 447.8 \quad 312.5 \quad 214.7$ ** $\begin{array}{llllll}350.7 & 1007.7 & 447.8 & 312.5 & 214.7 & * * * \\ 3 E 1.8 & 1007.7 & 4 E 2.1 & 312.9 & 215.9 & * *\end{array}$ $\begin{array}{llllll}3 E 1.8 & 1007.7 & 4 E 2.1 & 312.9 & 21 F .9 & * * \\ 3 E 3.8 & 1007.7 & 424.6 & 312.0 & 220.2 & * *\end{array}$ $\begin{array}{lllll}363.8 & 1607.7 & 484.6 & 3.2 .0 & 220.2\end{array}$ $3 E 7.51 U 67.7 \quad 225 . \varepsilon \quad 32.5 \quad 225.8$ ** $3 E 9.0$ 1UU7.7 $540.5 \quad 312.9 \quad 227.6 \quad * *$ $\begin{array}{llllll}370.4 & 1007.7 & 556.5 & 322.9 & 229.6 & * * * \\ 371.4 & 1007.7 & 572.0 & 312.9 & 231.4 & * *\end{array}$ $\begin{array}{llllll}372.4 & 16.07 .7 & 529.3 & 332.9 & 237.4 & \cdots\end{array}$

.0
.0
.0
.0
.0
.0
.0
.0
.0
.0
.0
.0
.0

MIGRATICN LIFETIME (HRS) TRISO

TIMES TIMEC TIMES TIMEC ** $4.32+08 \quad 1.35+08 \quad 3.89+0 E \quad 5.85+0 E$ $4.68+07 \quad 1 . E 1+07 \quad 1.10+0 E \quad 1.72+0 E$ $5.28+06 \quad 1.99+06 \quad 3.15+05 \quad 5.11+05$ $\begin{array}{llll}5.28+06 & 1.99+06 & 3.15+05 & 5.11+05 \\ 1.24+06 & 5.28+05 & 1.37+05 & 2.36+05\end{array}$ $4.30+05 \quad 2.09+05 \quad 7.53+04 \quad 1.38+05$ $2.17+05 \quad 1.15+05 \quad 4.98+04 \quad 9.78+04$ $1.13+05 \quad 7.18+04 \quad 3.56+04 \quad 7.47+04$ $3.25+04 \quad 2.19+04 \quad 1.70+043.65+04$ $3.04+04 \quad 2.42+04 \quad 1.68+04 \quad 3.98+04$ $1.85+04 \quad 1.67+04 \quad 1.28+04 \quad 3.22+04$ $1.52+04 \quad 1.58+04 \quad 1.16+04 \quad 3.18+04$ $1.47+04 \quad 1.79+04 \quad 1.18+C 4 \quad 3.52+04$ $1.94+D 4 \quad 2.8 E+04 \quad 1.45+04 \quad 4.85+D 4$ $2.56+04 \quad 4.51+C 4 \quad 1.79+C 4 \quad 6.65+04$ $7.36+04 \quad 1.75+05 \quad 3.67+04 \quad 1.62+C 5$ $2.58+04 \quad 5.52+04 \quad 1.90+047.85+04$ 
DESIGN II AVERAGE CHANNEL

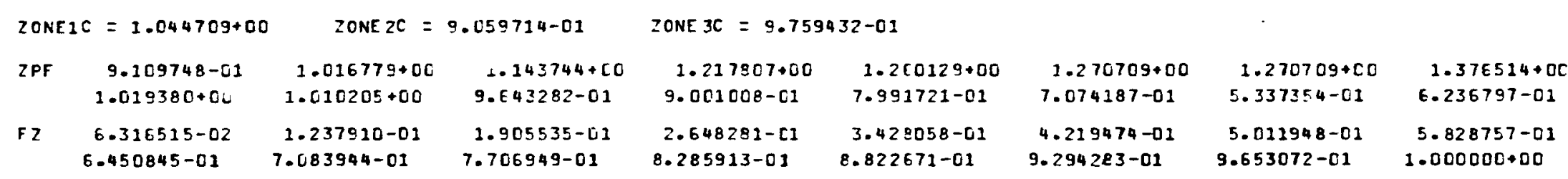

ZONEIC $=1.00315 C+00 \quad$ ZONE ZC $=1.008218+00 \quad$ ZONE $3 C=9.442295-01$

\begin{tabular}{|c|c|c|c|c|c|c|c|c|c|}
\hline ZPF & $\begin{array}{r}9.131612-11 \\
1.025989+00 \\
\end{array}$ & $\begin{array}{l}1.019219+0 C \\
1.017745+00\end{array}$ & $\begin{array}{l}1.146489+C 0 \\
9.715260-01 \\
\end{array}$ & $\begin{array}{l}1.220730+00 \\
9.0 E 8192-c 1 \\
\end{array}$ & $\begin{array}{l}1.263153+00 \\
8.051371-01 \\
\end{array}$ & $\begin{array}{l}1.273759+00 \\
7.126989-01 \\
\end{array}$ & $\begin{array}{l}1.273759+C C \\
5.035920-01 \\
\end{array}$ & $\begin{array}{r}1.379817+00 \\
5.884566-01 \\
\end{array}$ & $\begin{array}{l}\text { AXIAL } \\
\text { PROFILE }\end{array}$ \\
\hline F $\mathbf{Z}$ & $6.331675-02$ & $1.24[881-01$ & $1.91[108-01$ & $2.654637-01$ & $3.436286-01$ & $4.229602-01$ & $5.023978-01$ & $5.84274 \pi-01$ & \\
\hline & $E .469478-01$ & $7.107 .302-01$ & $7.73495^{2}-01$ & $\varepsilon .318243-01$ & $8.859[0]-01$ & $9.334139-01$ & $9.672665-C 1$ & $1.00000 C+00$ & \\
\hline
\end{tabular}

TOTAL CORE POWER: $300 \mathrm{CHW}$

POWER FACTORS

$* * * * * * * * * * * * * * * * * *$

FRACIION OF POLER $=1.0 L C$

FRACTION OF FLOW $=.908$

REGION POLER FACTOR $=1.000$ COLUMN PONER FACTOR $=1.005$ COLLMN TILT $=1.000$
TEMPERATURES $F$

*******************1

CORE INLET $\begin{array}{ll}\text { CORE INLET } & =770.6 \\ \text { CORE OUTLET } & =1660.9\end{array}$ = $=1660.9$ COLUMN OUTLET $=1 E 6 \mathrm{C} .5$ FUEL AVG TEMF $=1693.0$ ORAPHITE AVG TEMF $=3541.3$
FLOW RATES LE/HR *.****************n

CORE AVERAGE FLOW $=178.1$ CORE INLET PRESSURE REGION AVERAGE FLOW $=178.1$ REGION FRESSURE DROF COLUMN AVERAGE FLOH $=178.1$ COLUMN PRESSURE DROF COLUHN ERROR FLOH $=$.D PERCENTAGE CONVERGENCE OPEN ORIFICE PRE SSURE OROP OPEN ORIFICE PRE SSURE
CORE FRE SSURE OROP

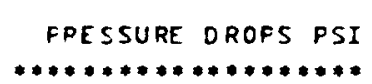

$=725.0$

$=5.038$

$=5.069$

$=-.006$

$=5.982$
REEION AVERAGE CONDITIONS

FLCR REY RDP TEOCL

IR $17 P .1$ 521E5.

178.15 .418$.

178.155029 .

170.1 4EE?

178.147312.

78.145927.

$178.1 \quad 44598$.

178.142169.

178.141115

178.140377

178.139291.

178.133487.

178.137776

178.137161.

179.136687

178.135313.

QR E416.8 162595 .
RDP TEOCL

$.54977 \mathrm{U}$.

$.172 \quad 823$.

.179874 .

.188
.199 931.0

.199 99?.

.213 1125.

.230 12E1.

$.245 \quad 1321$.
$.254 \quad 132^{\circ}$

$\begin{array}{ll}.254 & 138=. \\ .263 & 144 ?\end{array}$

$\begin{array}{ll}.289 & 1496 . \\ .276 & 1552\end{array}$

$.276 \quad 1552$.
$.280 \quad 1557$.

.280 I531.
.284 1EE?

.169 I6EJ.
LOCAL OR COLUMN aVERAGE CONDITIONS $\cdots$

** Floc pey
* Lg/hr number

*** 178.1 KZ1EE.

* 179.151374.

** 178.1 4930E.

$\because \quad 178.14850 \mathrm{C}$.

$\because \quad 17 E .1 \quad 47054$.

* 172.144224 .

$\because \cdots 178.1429310$

$\because 178.1$ 41716.

$\because 178.1$ 4l69E.

$* * 178.139035$.

$\because * 178.1 \geq 8302$.

$\because \quad 178.1 \quad 37087$.

* 178.1 3E301.

* $5416.8 \quad 1 \equiv 2595$. $\because 178.1$ 37552.

\begin{tabular}{|c|c|c|}
\hline CDF & TEOOL & OFILM \\
\hline FSI & DEE $F$ & JEE $F$ \\
\hline $54 \Xi$ & 770. & $* * * *$ \\
\hline .074 & 826. & 216. \\
\hline $\begin{array}{r}.180 \\
.191\end{array}$ & $\begin{array}{l}381 . \\
340 .\end{array}$ & $\begin{array}{l}2320 \\
266 .\end{array}$ \\
\hline $\begin{array}{l}.202 \\
.213\end{array}$ & $\begin{array}{l}\text { IUU7. } \\
107 E \text {. }\end{array}$ & $\begin{array}{l}275 \\
283\end{array}$ \\
\hline $\begin{array}{r}.224 \\
.234\end{array}$ & $\begin{array}{l}1147 . \\
1218^{\circ}\end{array}$ & $\begin{array}{l}284^{\circ} \\
282 .\end{array}$ \\
\hline .245 & 1291. & 304. \\
\hline $\begin{array}{l}.247 \\
.256 \\
.267\end{array}$ & $\begin{array}{l}1346^{\circ} \\
14030^{\circ} \\
14590^{\circ}\end{array}$ & $\begin{array}{l}225 \\
222 \\
211\end{array}$ \\
\hline $\begin{array}{l}.270 \\
.275\end{array}$ & $\begin{array}{l}1511 . \\
1559 .\end{array}$ & $\begin{array}{l}197 . \\
174 .\end{array}$ \\
\hline $\begin{array}{l}.280 \\
.220\end{array}$ & $\begin{array}{l}1602 . \\
1632 .\end{array}$ & $\begin{array}{l}154 . \\
108 .\end{array}$ \\
\hline $\begin{array}{r}.284 \\
.169\end{array}$ & $\begin{array}{l}1661 . \\
16 E 1 .\end{array}$ & $12 E$ \\
\hline
\end{tabular}

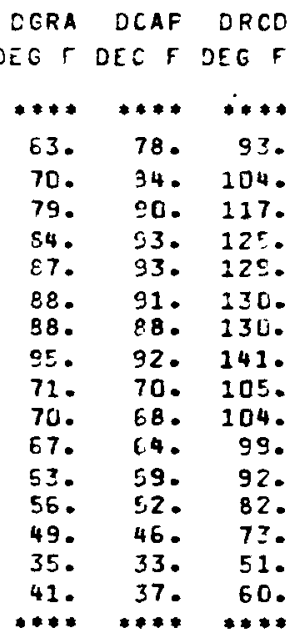

CCNDUETANEES

$B / H R, F I Z, F$
*: efror temperature orofs
$* *$ $\begin{array}{lllll}\text { EPROR TFUEL } & \text { CRAL } & V: 1 & \ldots \\ \text { OFCF DEG F FIIN } & -5 I & \ldots\end{array}$

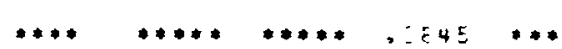

0. 1271. 7EC.4 .271: \#

D. $1372 . \quad 348.7 \quad .2871$...

C. $1487.354 .7 \quad .2992 \ldots$

0. $1583.101 E .5 \quad .3128 \ldots$

D. $1568.1051 .8: 3270 \ldots$

C. $\quad 1739.10 E 0.6 .3415$ **

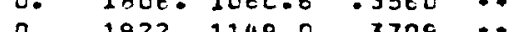

0. 1922. 1140.0 .3709

D. $1817.355 .2 \quad .3840$

18E7. $847.5 \quad .3974$

1900.859 .0 .4106

$\begin{array}{lll}1922 . & 755.1 & .4229 \\ 1923 . & 670.4 & .4343\end{array}$

1923 . $593.5 \quad .4449$

$195^{\circ} .419 .3 \quad .4516$

1925. 490.0 . .458E

$* \ldots * * * * * .2451$ 
DESIGN II AVERAGE CHANNEL (Continued)

\begin{tabular}{|c|c|c|c|c|c|c|c|c|c|c|c|c|c|c|c|c|c|}
\hline N & FLUX & HIC & EKG & HGAP & EKROD & SOLEK & $* *$ & $\varepsilon \mathrm{COOL}$ & EFILM & E SOL & ESUM & 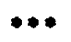 & TIMES & TIMEC & TIMES & TIMEC & $* *$ \\
\hline 1 & $6.36+04$ & 303.3 & 1007.7 & 465.5 & 391.8 & 250.6 & $* * *$ & .0 & .0 & .0 & .0 & & $1.08+11$ & $1 \cdot 36+11$ & $1.03+08$ & $3 \cdot 37+08$ & $* *$ \\
\hline 2 & $7-10+04$ & 305.0 & 1007.7 & 485.0 & 391.8 & 254.1 & $* * *$ & .0 & .0 & .0 & .0 & $* * *$ & $1 \cdot 30+10$ & $1.65+20$ & $3 \cdot 12+07$ & $1.02+08$ & $* * *$ \\
\hline 3 & $\begin{array}{l}7.98+04 \\
8.50+04\end{array}$ & $\begin{array}{l}30 E .8 \\
308.7\end{array}$ & $\begin{array}{l}1007.7 \\
1007.7 \\
1007.7\end{array}$ & $\begin{array}{l}507.3 \\
527.1 \\
545.4\end{array}$ & $\begin{array}{l}391.8 \\
391.8 \\
391.8\end{array}$ & $\begin{array}{l}257.9 \\
261.1 \\
263.9\end{array}$ & $* *$ & $\begin{array}{l}.0 \\
.0\end{array}$ & $\begin{array}{l}.0 \\
.0\end{array}$ & $\begin{array}{l}.0 \\
.0\end{array}$ & $\begin{array}{l}.0 \\
.0\end{array}$ & $\because *$ & $\begin{array}{l}1.51+09 \\
2 \cdot 91+08\end{array}$ & $\begin{array}{l}1.93+09 \\
3.98+08\end{array}$ & $\begin{array}{l}9.23+06 \\
3.66+06\end{array}$ & $\begin{array}{l}3.01+07 \\
1.23+07\end{array}$ & $* * *$ \\
\hline $\begin{array}{l}5 \\
6 \\
7\end{array}$ & $\begin{array}{l}8.80+04 \\
8.87+04 \\
8.87+04\end{array}$ & $\begin{array}{l}310.6 \\
312.5 \\
314.3\end{array}$ & $\begin{array}{l}1007.7 \\
1007.7 \\
1007.7\end{array}$ & $\begin{array}{l}545.4 \\
561.9 \\
577.5\end{array}$ & $\begin{array}{l}391.8 \\
351.8 \\
351.8\end{array}$ & $\begin{array}{l}263.9 \\
266.3 \\
268.5\end{array}$ & $* * *$ & $\begin{array}{l}.0 \\
.0 \\
.0\end{array}$ & $\begin{array}{l}.0 \\
.0 \\
.0\end{array}$ & $\begin{array}{l}.0 \\
.0 \\
.0\end{array}$ & $\begin{array}{l}.0 \\
.0 \\
.0\end{array}$ & $* *$ & $\begin{array}{l}7.56+07 \\
2.59+07 \\
1.01+07\end{array}$ & $\begin{array}{l}1.14+08 \\
4.36+07 \\
1.89+07\end{array}$ & $\begin{array}{l}1.73+06 \\
9.59+05 \\
5.71+05\end{array}$ & $\begin{array}{l}6.12+06 \\
3.59+06 \\
2.26+06\end{array}$ & 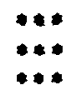 \\
\hline $\begin{array}{l}8 \\
9\end{array}$ & $\begin{array}{l}9.61+04 \\
7.15+04\end{array}$ & $\begin{array}{l}316.2 \\
317.5\end{array}$ & $\begin{array}{l}3007.7 \\
1007.7\end{array}$ & $\begin{array}{l}601.8 \\
598.1\end{array}$ & $\begin{array}{l}391.8 \\
391.8\end{array}$ & $\begin{array}{l}271.8 \\
269.9\end{array}$ & $* * *$ & $\begin{array}{l}.0 \\
.0\end{array}$ & .0 & .0 & $\begin{array}{l}.0 \\
.0\end{array}$ & $* * *$ & $\begin{array}{l}2-3 E+06 \\
7-68+06\end{array}$ & $\begin{array}{l}4.57+06 \\
2.05+C 7\end{array}$ & $\begin{array}{l}2.47+05 \\
5.41+05\end{array}$ & $\begin{array}{l}9.91+C 5 \\
2.60+C E\end{array}$ & $* *$ \\
\hline 10 & $\begin{array}{l}7.09+04 \\
6.77+04\end{array}$ & $\begin{array}{l}318 \cdot 8 \\
32 n-1\end{array}$ & $\begin{array}{l}1007.7 \\
1007.7\end{array}$ & $\begin{array}{l}600.3 \\
609.7\end{array}$ & $\begin{array}{l}391.8 \\
351.8\end{array}$ & $\begin{array}{l}271.6 \\
272.8\end{array}$ & $* *$ & .0 & .0 & .0 & .0 & $* *$ & $\begin{array}{l}4.00+06 \\
2.63+06\end{array}$ & $\begin{array}{l}1-15+07 \\
8-27+06\end{array}$ & $\begin{array}{l}3.79+05 \\
3-05+05\end{array}$ & $1.89+06$ & $* *$ \\
\hline 12 & $6.31+04$ & 321.3 & 1007.7 & 616.9 & 351.8 & 273.7 & $* * *$ & .0 & .0 & .0 & .0 & $* *$ & $2.01+06$ & $7.01+06$ & $2.73+05$ & $1.51+06$ & $* *$ \\
\hline 13 & $5.61+04$ & 322.3 & 1007.7 & $E 20.5$ & 391.8 & 274.1 & $* *$ & .0 & .0 & .0 & .0 & $\cdots \infty$ & $1.98+06$ & $7.78+C 6$ & $2.84+C 5$ & $1.69+06$ & $\cdots$ \\
\hline $\begin{array}{l}14 \\
15\end{array}$ & $4.96+04$ & 323.2 & 1007.7 & 623.5 & 391.8 & 274.5 & $* *$ & - 0 & .0 & .0 & .0 & $\cdots *$ & $2 \cdot 00+06$ & $8.80+06$ & $3.02+05$ & $1.91+06$ & $\cdots *$ \\
\hline $\begin{array}{l}15 \\
16\end{array}$ & $3.51+04$ & 323.8 & 1007.7 & 614.9 & 391.8 & 273.4 & $* *$ & -0 & -0 & .0 & $\begin{aligned}-0 \\
-0\end{aligned}$ & $* *$ & $4-E .9+C 6$ & $c 7$ & $5.66+05$ & $.04+C 6$ & $\because$ \\
\hline 16 & $4.10+04$ & 324.4 & 1007.7 & 28.1 & 91.8 & 75.1 & $* * *$ & .0 & .0 & .0 & .0 & $* *$ & $2.03+06$ & $1.04+07$ & $3.32+05$ & $.28+06$ & $*$ \\
\hline
\end{tabular}


TOTAL CORE PONER: 3000 ML

POMER FACTORS

RACTION OF PONER $=1.000$

FRACTION OF FLOW $=.908$

REGION PONER FACTOR $=1.297$

COLUMN POHER FACTOR $=1.706$

COLUMN TILT
TEMPERATURES F

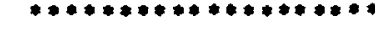

CORE INLET $=770.0$

CORE OUTLET

COLUMN OUTLET

$=1660.9$

$=1660.9$

FUEL AYG TEMF

$=2124.6$

\section{FLOM RATES LB/HR

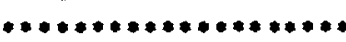

CORE AYERAGE FLOW

REGION AYERAGE FLOU $=178.1$ CORE INLET PRESSURE

COL

COLUMN ERROR FLON = .0 PERCENTAGE CONYERGENCE

OPEN ORIFICE PRESSURE DROP

CORE PRESSURE DROF

\section{PRESSURE DROPS PSI}

AETITE AVG TEMF $=1873.2$
REGION AVERAGE CONDITIONS

\begin{tabular}{|c|c|c|c|c|}
\hline $\begin{array}{l}\text { RDP } \\
\text { PSI }\end{array}$ & $\begin{array}{l}\text { TCOOL } \\
\text { DEG F }\end{array}$ & $* *$ & $\begin{array}{l}F L O C \\
\text { LB/HR }\end{array}$ & $\begin{array}{c}\text { REY } \\
\text { NUMBE }\end{array}$ \\
\hline 392 & 770. & & 215.9 & 63255. \\
\hline 292 & 326. & & 215.9 & 61915. \\
\hline $\begin{array}{l}.292 \\
.309\end{array}$ & $\begin{array}{l}881 . \\
940 .\end{array}$ & & $\begin{array}{l}215.9 \\
215.9\end{array}$ & \\
\hline $\begin{array}{l}.328 \\
.345\end{array}$ & $\begin{array}{l}1007 . \\
1076 .\end{array}$ & & $\begin{array}{l}215.9 \\
215.9\end{array}$ & $\begin{array}{l}54940 \\
52721 .\end{array}$ \\
\hline $\begin{array}{r}.362 \\
.378\end{array}$ & $\begin{array}{l}1147 . \\
1218 .\end{array}$ & $\because *$ & $\begin{array}{l}215.9 \\
215.9\end{array}$ & 50651 \\
\hline $\begin{array}{r}.395 \\
.399\end{array}$ & $\begin{array}{l}1291 . \\
1346 .\end{array}$ & $* * *$ & $\begin{array}{l}215.9 \\
215.9\end{array}$ & $\begin{array}{l}47004 . \\
45559\end{array}$ \\
\hline $\begin{array}{l}.413 \\
.425\end{array}$ & $\begin{array}{l}1403 . \\
1459 .\end{array}$ & $* * *$ & $\begin{array}{l}215.9 \\
215.9\end{array}$ & $\begin{array}{l}44383 . \\
43278 .\end{array}$ \\
\hline $\begin{array}{r}.435 \\
.444\end{array}$ & $\begin{array}{l}1511 . \\
1559 .\end{array}$ & $\ldots$ & $\begin{array}{l}215.9 \\
215.9\end{array}$ & $\begin{array}{l}42282 . \\
41408 .\end{array}$ \\
\hline .451 & 1602 & & 215.9 & 40655. \\
\hline $\begin{array}{l}.451 \\
.458 \\
.296\end{array}$ & $\begin{array}{l}1632 . \\
1661 . \\
1661 .\end{array}$ & $\because \cdots$ & $\begin{array}{r}215.9 \\
215.9 \\
7773.7\end{array}$ & $\begin{array}{r}40075 . \\
39617 . \\
177282 .\end{array}$ \\
\hline
\end{tabular}

LOCAL OR COLUMN AVERAGE CONDITIONS

\begin{tabular}{|c|c|c|c|c|c|c|c|c|c|c|}
\hline$P$ & $\mathrm{OL}$ & ILM & GRA & GAP & $R O D$ & ERROR & IFUEL & RAD & VEL L & 10 \\
\hline$S I$ & $=6 \mathrm{~F}$ & $=\mathrm{CF}$ & DEG $F$ & DEG $F$ & DEG $F$ & DEG F & DEG $F$ & $F / I N$ & PSI & ** \\
\hline 8 & o. & $*$ & $\Leftrightarrow$ & $\Leftrightarrow$ & * & $* *$ & * & $\ldots$ & 4449 & $* \ldots$ \\
\hline 65 & 9 & 6. & 108. & 123. & 159. & o. & 544. & 1296.9 & .4655 & $\cdots$ \\
\hline 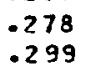 & & & $\begin{array}{l}120 . \\
135 .\end{array}$ & & & D. & & & & $\because *$ \\
\hline & & & $\begin{array}{l}144 . \\
149 .\end{array}$ & $\begin{array}{l}139 . \\
138 .\end{array}$ & & 0. & & & & $* * *$ \\
\hline 36 & 30 & & 150. & 134. & 222 & c. & 2216 . & .2 & & $\because *$ \\
\hline 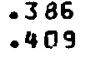 & & & & $\begin{array}{l}129 . \\
133 .\end{array}$ & & $\begin{array}{l}0 . \\
0 .\end{array}$ & & & & $\because *$ \\
\hline 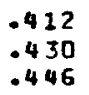 & $\begin{array}{l}158 \\
166 \\
173\end{array}$ & $\begin{array}{l}324 . \\
319 . \\
303 .\end{array}$ & $\begin{array}{l}121 . \\
120 . \\
115 .\end{array}$ & $\begin{array}{r}102 . \\
99 . \\
32 .\end{array}$ & & 0. & & & & $\because *$ \\
\hline $\begin{array}{r}458 \\
.470 \\
.479\end{array}$ & $\begin{array}{l}182 \\
188\end{array}$ & $\begin{array}{l}282 . \\
249 . \\
220 .\end{array}$ & $\begin{array}{r}107 . \\
95 . \\
84 .\end{array}$ & $\begin{array}{l}35 . \\
75 . \\
56 .\end{array}$ & & & & & & $\because * *$ \\
\hline $\begin{array}{l}479 \\
487 \\
295\end{array}$ & $\begin{array}{l}1982 \\
2023 \\
2023\end{array}$ & & & 48. & 88 . & 0 & $\begin{array}{l}2332 . \\
2430 .\end{array}$ & $\begin{array}{l}.2 \\
.8 \\
8\end{array}$ & & $* \infty$ \\
\hline
\end{tabular}

8314. 47078 .

CONDUCTANCES $B / H R$, FT2, F

N FLUX

$12.08 \cdot 05$

$21.21+05$

$31.36+05$

$41 \cdot 45+05$

$\begin{array}{ll}5 & 1.50+05 \\ 6 & 1.51+05\end{array}$

$71.51+05$

$1-64+05$
$91-22+05$

$101-21+05$

$121.15+05$

$121.08 \cdot 05$

$148.46+04$

$15 \quad 5.98+04$

$16 \quad 6.99+04$
HIC EKG HGAP

354.71007 .7507 .2

$\begin{array}{llllll}360.3 & 1007.7 & 568.1 & 391.8 & 267.2 & * *\end{array}$

$\begin{array}{llllll}363.3 & 1007.7 & 597.1 & 331.8 & 271.1 & * * *\end{array}$

$\begin{array}{llllll}366.3 & 1007.7 & 623.9 & 331.3 & 274.5 & \ldots *\end{array}$

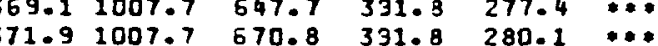

$\begin{array}{llllll}374.6 & 1007.7 & 707.8 & 391.8 & 284.0 & * *\end{array}$

$378.51007 .7 \quad 702.8 \quad 331.9 \quad 283.5 \quad * *$

$380.41007 .7 \quad 716.6 \quad 331.3 \quad 284.9 \ldots$

$\begin{array}{llllll}382.1 & 1007.7 & 727.0 & 331.8 & 285.9 & *\end{array}$

$\begin{array}{llllll}383.6 & 1007.7 & 731.7 & 391.3 & 285.4 & \ldots\end{array}$

$\begin{array}{llllll}384.9 & 1007.7 & 735.6 & 391.8 & 286.8 & \ldots\end{array}$

$\begin{array}{llllll}385.8 & 1007.7 & 721.0 & 391.8 & 285.3 & \cdots \\ 385.7 & 1007.7 & 741.7 & 391.8 & 287.4 & \cdots\end{array}$
* ERROR TEMFERATURE DROPS

DEG $F$

$\cdots$

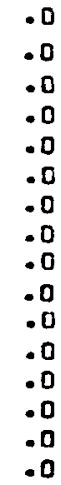

.0
.0
.0
.0
.0
.0
.0
.0
.0
.0
.0
.0
.0
.0
.0
.0

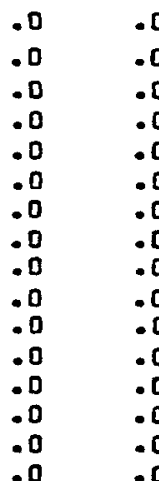

$\rightarrow \infty$

$\bullet$

$* *$

$* \cdots$

$* *$

$\ldots$

$\because \cdots$

$\because *$

$\because \ldots$

$\because *$

$\because \cdots$

$\because *$

$\because *$

$\because *$

$\because *$
MIGRATION LIFETIME IHRSI

TRISO

TIMES TIMEC

$8.35+085.65+08$

$8.18+076.01+07$

$8.20+06 \quad 6.53+06$

$3.86+05 \quad 1.09+05$

$1.35+05 \quad 1.67+05$

$5.43+047.78+04$

$1.31+04$
$4.54+049.72+04$

$2.43+045.70+04$

$1.64+04 \quad .33+04$

$1.30 \cdot 0 \times 3.85+04$

$1.32+049.48+04$

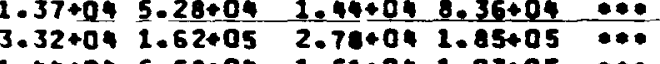

8.247

8.313

$=1.085$ 
DESIGN III AVERAGE CHANNEL

ZONE IC $=1.008192+00$

ZONEZC $=9.832713-01$

ZONE3C $=9.339484-01$

\begin{tabular}{|c|c|c|c|c|c|c|c|c|c|}
\hline$Z P F$ & $\begin{array}{l}9.226005-01 \\
1.011957+00\end{array}$ & $\begin{array}{l}1.029755+00 \\
1.002849+00\end{array}$ & $\begin{array}{l}1.153340+00 \\
9.573062-01\end{array}$ & $\begin{array}{l}1.233349+00 \\
8.935465-01\end{array}$ & $\begin{array}{l}1.276211+00 \\
7.933527-01\end{array}$ & $\begin{array}{l}1.286926+00 \\
7.022674-01\end{array}$ & $\begin{array}{c}1.286926+00 \\
4.965628-01\end{array}$ & $\begin{array}{l}1.394080+00 \\
5.802428-02\end{array}$ & $\begin{array}{l}\text { AXIAL } \\
\text { PROFILE }\end{array}$ \\
\hline$F Z$ & $\begin{array}{c}6.397126-02 \\
6.520701-01\end{array}$ & $\begin{array}{l}1.253708-01 \\
7.149190-01\end{array}$ & $\begin{array}{l}1.929853-01 \\
7.767658-01\end{array}$ & $\begin{array}{l}2.682078-01 \\
8.342407-01\end{array}$ & $\begin{array}{l}3.471807-01 \\
8.875255-01\end{array}$ & $\begin{array}{c}4.273323-01 \\
9.343434-01\end{array}$ & $\begin{array}{l}5.075910-01 \\
9.677234-01\end{array}$ & $\begin{array}{c}5.903143-01 \\
1.000000+00\end{array}$ & - \\
\hline
\end{tabular}

POWER FACTORS

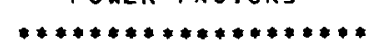
$\begin{array}{ll}\text { FRACTION OF POWER } & =1.000 \\ \text { FRACTION OF FLOH } & =.369 \\ \text { REGION POHER FACIOR } & =1.000 \\ \text { COLUMN POWER FACTOR } & =1.000 \\ \text { COLUHN TILT } & =1.000\end{array}$
IEMPERATURES $F$

\section{$* * * * * * * * * * * * * * * * *$}

CORE INLET

CORE CUTLET

REGION OUTLET

COLUMN OUTLET

FUEL AYG TEMF

$\begin{aligned} \text { GRAPHITE AVS TEMF } & =1885.3 \\ & 1734.3\end{aligned}$
FLOW RATES LB/HR

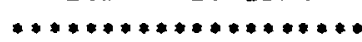

CORE AVERAGE FLOH

COLUMN AVERAGE FLOH $=170.3$ COLUMN FRESSURE DROP

- PERCENTAGE CONVERGENCE

OFEN ORIFICE PRESSURE OROP CORE PRESSURE OROP
$=725.0$

5.206

$=5.212$

$=-.001$
REGION AVERAGE CONOITIONS

LG/HR NUMGER

170.345890 .

170.345246.

170.344047.

$\begin{array}{ll}170.3 & 42832 . \\ 170.3 & 41637 .\end{array}$

170.344496

$\begin{array}{ll}170.3 & 44496 . \\ 170.3 & 33343 .\end{array}$

170.339260.

$170.3 \quad 37233$.

$170.3 \quad 36363$.

$170.3 \quad 34958$.

$170.3 \quad 34344$.

$170.3 \quad 33789$.

$170.3 \quad 33306$.

$170.3 \quad 32632$.

6130.2146136.
$17 \pi .3 \quad 33551$.

\begin{tabular}{|c|c|c|c|c|}
\hline $\mathbf{P}$ & 002 & & $-C c$ & EY \\
\hline $5 I$ & OEO F & $* *$ & LB/HR & NUMBER \\
\hline 30 & 939. & & $7 u \cdot 3$ & 5890. \\
\hline $\begin{array}{l}182 \\
133\end{array}$ & $\begin{array}{r}991 . \\
1043 .\end{array}$ & & $\begin{array}{l}70.3 \\
70.3\end{array}$ & $\begin{array}{l}45240 . \\
44029 .\end{array}$ \\
\hline $\begin{array}{l}.193 \\
.210\end{array}$ & $\begin{array}{l}111 \\
117\end{array}$ & $* *$ & & \\
\hline $\begin{array}{l}.220 \\
.230\end{array}$ & $\begin{array}{l}125 \\
132\end{array}$ & $* *$ & & \\
\hline 240 & 1400. & $* 1$ & 3 & 7. \\
\hline 251 & 147 & * & & 4. \\
\hline 33 & 1535. & 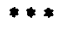 & 3 & \\
\hline .262 & 153 & 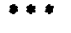 & 3 & $50 u$. \\
\hline .269 & 1653 & ** & 170.3 & 34929. \\
\hline & & & & \\
\hline 20 & 18 & & & \\
\hline & & & & \\
\hline & $\begin{array}{l}135 \\
136\end{array}$ & $* *$ & $\begin{array}{r}170.3 \\
E 130.2\end{array}$ & $\begin{array}{r}32531 . \\
145196 .\end{array}$ \\
\hline
\end{tabular}

LOCAL OR

ESR

TE JEG E FIIN FSI ***

.580 932. \#...

.189 1049. 240 .

.1991112 .263$.

.2101182 .294$.

.221 1255. 293.

.2411405 .291$.

$\begin{array}{lll}.252 & 1492 . & 314 . \\ .254 & 1540 . & 227 .\end{array}$

.254 1540. 227.

.2591656 .213$.

.2751703 .199$.

.2851803 .155$.

.2851334 .100$.

.170 1964. 128.

$\begin{array}{rrr}* * * & * * & * * * \\ 54 . & 73 . & 94 . \\ 71 . & 79 . & 105 . \\ 30 . & 35 . & 115 . \\ 35 . & 27 . & 125 . \\ 38 . & 37 . & 136 . \\ 39 . & 35 . & 131 . \\ 39 . & 93 . & 131 . \\ 96 . & 36 . & 142 . \\ 71 . & 54 . & 103 . \\ 59 . & 02 . & 102 . \\ 56 . & 38 . & 98 . \\ 52 . & 54 . & 91 . \\ 55 . & 47 . & 81 . \\ 40 . & 42 . & 72 . \\ 34 . & 30 . & 51 . \\ 40 . & 34 . & 59 . \\ * * & * * * & * *\end{array}$

***********.2737

c. $1439.768 .2 .2854 \ldots$

D. $1543.857 .5 \quad .2966$ ***

D. $1663.964 .5 \quad .3039 \quad * *$

o. 1754. $1627.0 \quad 03227$

0. 1953. $1062.7 \quad 03371 \quad \ldots$

o. 1928.2071 .5 .3518 1999. 1071.6 .3665 .*. $2120.1160 .3 \quad .3817$ *** 2003. $842.5 \quad .3933 \quad * * *$ 2055. $\$ 35.1 \quad .4052 \quad * * *$ 2091 . $797.1 \quad .4269$ *** 2114 . $744.0 \quad .4277 \quad * * *$ 2118. 660.6 .4373 **: 2119. $584.9 \quad .4468 \quad * * *$ $2059.413 .5 \quad .4532 \ldots$

2125: $433.2 \quad .4594 \quad * * *$

\section{CONDUCTANCES}

B/HR, FIZ, F

*. epror temferature crops OEG $F$

N FLUX

HTC EKG HGAP

$* *$

ELM ES ESUM

$* *$

$* *$

MIGRA

$\begin{array}{lllllll}1 & 6.42+04 & 237.4 & 1007.7 & 503.5 & 331.8 & 257.3\end{array} \ldots$

$27.17+04 \quad 239.0 \quad 1007.7 \quad 524.1 \quad 331.8 \quad 260.5 \quad \ldots$

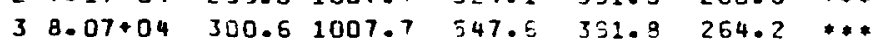

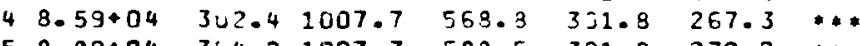

$\begin{array}{lllllll}5 & 8.99+04 & 344.2 & 1007.7 & 588.5 & 391.8 & 270.0\end{array}$

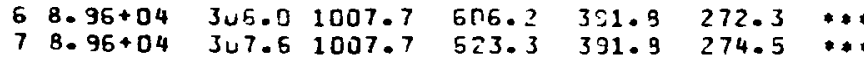

.0
.0
.0
.0
.0
.0
.0

.0
.0
.0
.0
.0
.0
.0

.0
.0
.0
.0
.0
.0

$\begin{array}{ll}.0 & .0 \\ .0 & .0 \\ .0 & .0 \\ .0 & .0 \\ .0 & .0 \\ .0 & .0 \\ .0 & .0\end{array}$

*** 3.05+09 $5.4 ?+29$

$* 4.90+08 \quad 8.68+08$

** $7.56+071.33+09$

*** $1.78+07 \quad 3.30+07$

$* \quad 5.41+061.08+07$

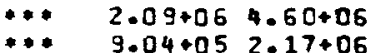

\begin{tabular}{|c|c|}
\hline \multicolumn{2}{|c|}{ BISO } \\
\hline TIMES & TIMEC \\
\hline $1.49+C 7$ & $5.84+07$ \\
\hline $5.25+06$ & $2.04+07$ \\
\hline $\begin{array}{l}1.80+06 \\
7.90+05 \\
4.04+05 \\
2.38+05 \\
1.49+05\end{array}$ & $\begin{array}{l}6.94+05 \\
3.12+06 \\
1.66+06 \\
1.03+06 \\
6.74+05\end{array}$ \\
\hline
\end{tabular}


DESIGN III AVERAGE CHANNEL (Continued)

$\begin{array}{rllllllll}8 & 9.71+04 & 309.3 & 1007.7 & 649.6 & 391.8 & 277.6 & \cdots * & .0 \\ 9 & 7.05+04 & 310.5 & 1007.7 & 533.4 & 391.8 & 275.7 & * * & .0 \\ 10 & 6.98+04 & 311.3 & 1007.7 & 546.5 & 391.8 & 277.3 & * * & .0 \\ 11 & 6.67+04 & 312.9 & 1007.7 & 656.6 & 391.8 & 279.5 & * * & .0 \\ 12 & 6.22+04 & 314.0 & 1007.7 & 564.5 & 391.8 & 279.3 & * * & .0 \\ 13 & 5.52404 & 314.9 & 1007.7 & 568.5 & 391.8 & 279.8 & * * & .0 \\ 14 & 4.89+04 & 315.8 & 1007.7 & 672.1 & 391.8 & 280.2 & * * & .0 \\ 15 & 3.46+04 & 316.3 & 1007.7 & 653.5 & 391.8 & 279.2 & * * & .0 \\ 16 & 4.04+04 & 316.9 & 1007.7 & 677.4 & 391.8 & 280.8 & \cdots * & .0\end{array}$

.0
.0
.0
.0
.0
.0
.0
.0
.0

.0
.0
.0
.0
.0
.0
.0
.0
.0

.0
.0
.0
.0
.0
.0
.0
.0
.0

** $2.49+05 \quad 6.14+05$

\# $7.95+05 \quad 2.64+06$

$7.03+04 \quad 3.19+05$

** $4.49+051.53+06$

$1.55+058.35+05 \quad \cdots$

$3.10+051.19+06$

$\because \cdots$

$2.45+051.01+06$

$9.37+04 \quad 5.43+05 \ldots$

$0.46+045014+05$

$\because \quad 2.41+051.11+059.93+045.69+05$

$2.44+051.11+05$ $9.337+045059+05$

$164.04+04$

*.. $\quad 2.43+051.41+06$

$1.67+051.25+06$

$+$. 
DESIGN III HOT CHANNEL

TOTAL CORE PONER: $3000 \mathrm{MH}$

$\begin{aligned} & \text { POHER FACTORS } \\ & * * * * * * * * * * * * * * * * * \\ & \text { FRACIION OF POWER }=1.000 \\ & \text { FRACTION OF FLON }=. .868 \\ & \text { REGION POUER FACTOR }=1.201 \\ & \text { COLUMN POUER FACTOR }=1.516 \\ & \text { COLUMN TILT }=1.263\end{aligned}$

TEMPERATURES F

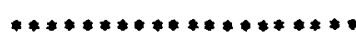

CORE INLET

CORE OUTLET

REGION OUTLET $\quad=1363.7$

COLUMN OUTLET $=2170.3$

$\begin{aligned} \text { GRE AVG TEMP } & =2229.1 \\ \text { GRAPHIE AVG TEMP } & =2009.7\end{aligned}$

\author{
FLOH RATES LB/HR \\ nomon rates lamk \\ CORE AVERAGE FLOH
}

REGION AYERAGE FLON $=204.5$ REGION PRESSURE DROP

COLUMN AYERAGE FLOH $=194.3$ COLUMN FRESSURE DROP OPEN ORIFICE PRESSURE DROP $=1.318$ CORE PRESSURE DROP
PRESSURE OROPS PSI

$=8.657$

$\begin{array}{rrrrr}\text { N } & \text { FLOR } & \text { REY } & \text { ROP } & \text { TCOOL } \\ & \text { LB/HR } & \text { NUMBER } & \text { PSI } & \text { DEG F } \\ \text { TR } & 204.5 & 55110 . & .316 & 932 . \\ 1 & 204.5 & 54329 . & .255 & 992 . \\ 2 & 204.5 & 52875 . & .365 & 1049 . \\ 3 & 204.5 & 51475 . & .279 & 1112 . \\ 4 & 204.5 & 50029 . & .295 & 1182 . \\ 5 & 204.5 & 48575 . & .310 & 1255 . \\ 6 & 204.5 & 47181 . & .324 & 1330 . \\ 7 & 204.5 & 45872 . & .333 & 1405 . \\ 8 & 204.5 & 44630 . & .354 & 1432 . \\ 9 & 204.5 & 43597 . & .355 & 1541 . \\ 10 & 204.5 & 42753 . & .367 & 1598 . \\ 11 & 204.5 & 41947 . & .373 & 1656 . \\ 12 & 204.5 & 41210 . & .335 & 1709 . \\ 13 & 204.5 & 40554 . & .394 & 1759 . \\ 14 & 204.5 & 39984 . & .399 & 1803 . \\ 15 & 204.5 & 39540 . & -399 & 1834 . \\ 16 & 204.5 & 39137 . & .405 & 1854 . \\ 8 R & 7361.8 & 175569 . & .246 & 1354 .\end{array}$

***

LOCAL OR COLUMN AYERAGE CONOITIONS

\begin{tabular}{|c|c|c|c|c|c|c|c|}
\hline OC & REY & $.0 F$ & TCOOL & DF ILM & DGRA & DGAP & DROD \\
\hline B/HR & NUMBE $R$ & PSI & $D E G F$ & $D E G F$ & DEG $F$ & OEG $F$ & DEG $F$ \\
\hline 34.3 & 52355 . & .742 & 932. & $* * * *$ & $* * * *$ & $* * * *$ & $* *$ \\
\hline $\begin{array}{l}194.3 \\
194.3\end{array}$ & $\begin{array}{l}51374 . \\
49578 .\end{array}$ & $\begin{array}{l}.244 \\
.255\end{array}$ & $\begin{array}{l}1011 . \\
1087 .\end{array}$ & $\begin{array}{l}294 . \\
326 .\end{array}$ & $\begin{array}{r}97 . \\
108 .\end{array}$ & $\begin{array}{l}104 . \\
111 .\end{array}$ & $\begin{array}{l}143 . \\
159 .\end{array}$ \\
\hline $\begin{array}{l}194.3 \\
194.3 \\
194.3\end{array}$ & $\begin{array}{l}47884^{\circ} \\
46168 \text {. } \\
44477 .\end{array}$ & $\begin{array}{r}.272 \\
.292 \\
.310\end{array}$ & $\begin{array}{l}1171 . \\
1264 . \\
1362 .\end{array}$ & $\begin{array}{l}364 . \\
385 \\
395 .\end{array}$ & $\begin{array}{l}121 . \\
129 . \\
134 .\end{array}$ & $\begin{array}{l}118 . \\
119 . \\
118 .\end{array}$ & $\begin{array}{l}179 . \\
191 . \\
197 .\end{array}$ \\
\hline $\begin{array}{l}194.3 \\
194.3\end{array}$ & $\begin{array}{l}42885 \\
41417\end{array}$ & $\begin{array}{r}.327 \\
.344\end{array}$ & $\begin{array}{l}1461 . \\
1561 .\end{array}$ & $\begin{array}{l}396 . \\
393 .\end{array}$ & $\begin{array}{l}135 . \\
135 .\end{array}$ & $\begin{array}{l}115 . \\
1110\end{array}$ & $\begin{array}{l}199 . \\
199 .\end{array}$ \\
\hline 194.3 & 4004E. & .363 & 1663. & 423. & 146. & 114. & 216 \\
\hline 3 & 38921 . & .366 & 173 & 30 & 106. & 36. & 15 \\
\hline $\begin{array}{l}194.3 \\
194.3\end{array}$ & $\begin{array}{l}38012 . \\
37153 .\end{array}$ & $\begin{array}{r}.380 \\
.393\end{array}$ & $\begin{array}{l}11917 . \\
1894 .\end{array}$ & $\begin{array}{l}302 . \\
287\end{array}$ & $\begin{array}{l}105 . \\
100 .\end{array}$ & $\begin{array}{l}83 . \\
78 .\end{array}$ & $\begin{array}{l}155^{\circ} \\
148 .\end{array}$ \\
\hline $\begin{array}{l}194.3 \\
194.3\end{array}$ & $\begin{array}{l}363750 \\
35689 . \\
35094 .\end{array}$ & $\begin{array}{l}.403 \\
.412 \\
.419\end{array}$ & $\begin{array}{l}1965 . \\
2031 . \\
2089 .\end{array}$ & $\begin{array}{l}265 . \\
236 . \\
208\end{array}$ & $\begin{array}{l}94 . \\
83 . \\
74 .\end{array}$ & $\begin{array}{l}71 . \\
63 . \\
550^{\circ}\end{array}$ & $\begin{array}{l}138^{\circ} \\
123{ }^{\circ} \\
109^{\circ}\end{array}$ \\
\hline 4.3 & 3463 & .4 & 2130 . & 147. & 52. & 40. & 77 \\
\hline 4.3 & 3427 & 42 & 217 & 171. & 51. & 15. & \\
\hline
\end{tabular}

CONDUCTANCES

BIHR, FT2. F

N FLUX

$19.74+04$

$21.09+05$

$31-22+05$

$\begin{array}{ll}4 & 1-30+05 \\ 5 & 1-35+05\end{array}$

6
7
$1.36+36+05$

$71 \cdot 36+05$

$81.47+05$

9 $1.07+05$

$111.01+05$

$129.43+04$

$147.41+04$

$16 \quad 6.13+04$
EKG TGAP

$331.1 \quad 1007.7 \quad 536.5$

$38.31007 .7 \quad 626.1$

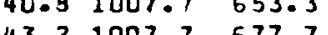

$\begin{array}{lll}343.2 & 1007.7 & 677.7 \\ 345.6 & 1007.7 & 701.5\end{array}$

$\begin{array}{lllll}.7 & 738.9 & 391.8 & 287.1 & * * *\end{array}$

$\begin{array}{llllll}351.2 & 1007.7 & 732.6 & 391.3 & 286.5 & * *\end{array}$

$\begin{array}{llllll}32.8 & 1007.7 & 746.9 & 391.8 & 287.9 & * *\end{array}$

$\begin{array}{llllll}354.2 & 1007.7 & 757.7 & 331.8 & 288.9 & * * *\end{array}$

$\begin{array}{llllll}356.5 & 1007.7 & 757.7 & 391.8 & 289.8 & \ldots\end{array}$

$\begin{array}{llllll}357.3 & 1007.7 & 754.6 & 391.8 & 288.6 & \cdots\end{array}$

$358.13007 .7 \quad 774.8 \quad 391.8 \quad 290.4$
$* *$

ERROR TEMPERATURE DROPS

OEG $F$

ecool efilm esol esum

.0

.0

.0

.0

.0

.0
.0

.0

.0
.0

.0
.0
.0

.0
.0
.0

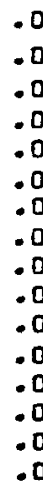

.0
.0
.0
.0
.0
.0
.0
.0
.0
.0
.0
.0
.0
.0
.0
.0
$* *$

$* *$

$* *$

$* * 1.15+0811.34+08$
$* * \quad 1.53+071.85+07$

$\because \quad 2.03+062.57+06$

$\because \quad 4.43+056.17+05$

$\cdots \quad 1.30+052.03+05$

$* * \quad 4.96+048.78+04$ $2.14+04 \quad 4.26+04$ $5.87+031.23+04$ $1.97+045.64+04$ $\begin{array}{ll}1.12+04 & 3.44+04 \\ 7.30+03 & 2.63+04\end{array}$ $6.24+03 \quad 2.31+04$ $6.22+03 \quad 2.59+04$ $6.38+032.95+04$

$1.39+047.80+04$

$6.59+033.50+04$
FUEL GRAD VEL ***

*******.0\%** .3947 ***

1649. $2164.8 .4118 \quad * *$

1791. $1300.1 \quad .4282 \quad \ldots$

1953. $1462.5 \quad-4462 \quad \cdots$

$2088 \cdot 1557.2 \quad-4663 \quad * *$

$2207 \cdot 1611.3 .4874$

2306 • 1624.8 .5089 **

2399. 1624.3 .5304

2562. $1760.1 \quad .5526$ ***

$2394.1277 .7 \quad .5692 \quad * *$

2462.1266 .2 .5862 ***

2506. 1208.7 .5029 **

2535. 1128.2 .6185 **

2535. $1001.7 .6330 \quad * 0$

2535. 886.7 .5458 **

2446. $626.9 .6550 \quad * *$

$2537.732 .5 \quad .5640$ ***

********.2101

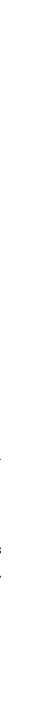

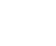


DESIGN IV AVERAGE CHANNEL

ZONE IC $=1.012011+00 \quad$ ZONEZC $=9.756416-01 \quad$ 20NE3C $=9.730149-01$

\begin{tabular}{|c|c|c|c|c|c|c|c|c|c|}
\hline ZPF & $\begin{array}{l}9.365491-01 \\
9.903396-01\end{array}$ & $\begin{array}{l}1.045324+00 \\
9.814257-01\end{array}$ & $\begin{array}{l}1.175853+00 \\
9.368560-01\end{array}$ & $\begin{array}{l}1.251995+00 \\
8.744583-01\end{array}$ & $\begin{array}{l}1.295505+00 \\
7.764049-01\end{array}$ & $\begin{array}{l}1.306383+00 \\
6.872654-01\end{array}$ & $\begin{array}{c}1.306383+00 \\
4.846468-01\end{array}$ & $\frac{1.415157+00}{5.663187-01}$ & $\begin{array}{l}\text { AXIAL } \\
\text { PROFILE }\end{array}$ \\
\hline$F Z$ & $6.493842-02$ & 1.272662-01 & $1.959030-01$ & $2.722627-01$ & 3.524296-01 & $4.337930-01$ & $5.152651-01$ & 5.992391-01 & \\
\hline
\end{tabular}

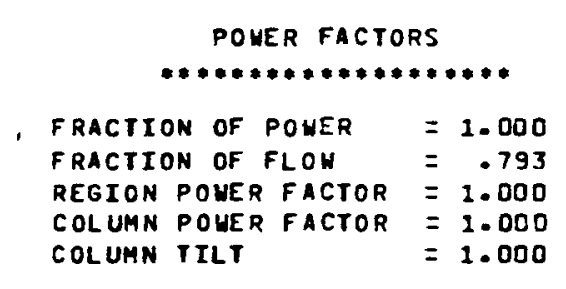

$\begin{array}{ll}\text { TEMPERATURES } & F \\ * * * * * * * * * * * * * * * * \\ \text { CORE INLET } & =1050.0 \\ \text { CORE OUTLET } & =2069.8 \\ \text { REGION OUTLET } & =2069.8 \\ \text { COLUMN OUTLET } & =2069.7 \\ \text { FUEL AVG TEMP } & =2069.2\end{array}$

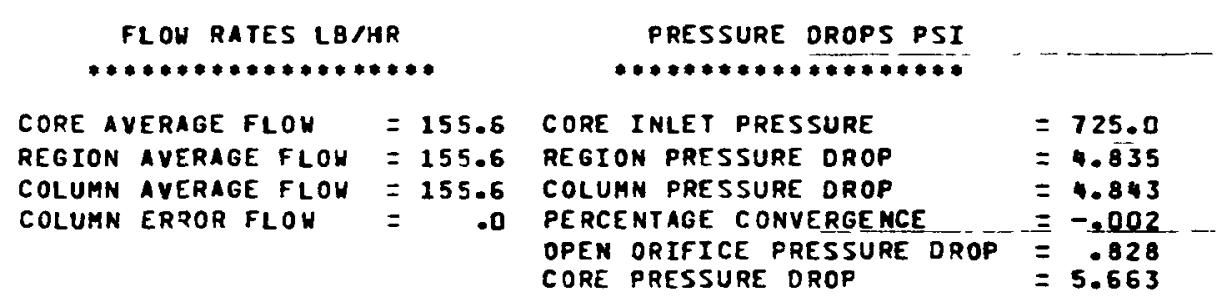

REGION AVERAGE CONOITIONS

$\ldots$

LOCAL OR COLUMN AVERAGE CONDITIONS

$\begin{array}{rrr}N & \text { FLOR } & \text { REY } \\ & \text { LB/HR } & \text { NLMBER } \\ \text { IR } & 15 E .6 & 39692 . \\ 1 & 155.6 & 39124 . \\ 2 & 155.6 & 38068^{\circ} \\ 3 & 155.6 & 37052 . \\ 4 & 155.6 & 36003 . \\ 5 & 155.6 & 34949 . \\ 6 & 155.6 & 33939 . \\ 7 & 155.6 & 32990^{\circ} \\ 8 & 155.6 & 32092 . \\ 9 & 155.6 & 31344 . \\ 10 & 155.6 & 36733 . \\ 11 & 155.6 & 30150 . \\ 12 & 155.6 & 29618 . \\ 13 & 155.6 & 25144 . \\ 14 & 155.6 & 28731 . \\ 15 & 155.6 & 28411 . \\ 16 & 155.6 & 28156 . \\ 8 R & 5601.0 & 126144 .\end{array}$

\begin{tabular}{|c|c|c|c|c|}
\hline DP & $=00 \mathrm{~L}$ & $\because$ & LOC & REY \\
\hline $5 I$ & DEE $F$ & $\cdots$ & LB /HR & NUMBER \\
\hline$E 37$ & $105 \mathrm{C}$. & $* *$ & 255.6 & 39692 \\
\hline $\begin{array}{l}169 \\
175\end{array}$ & $\begin{array}{l}1115 . \\
1178 .\end{array}$ & $\because *$ & $\begin{array}{l}155 . E \\
155.6\end{array}$ & $\begin{array}{l}39116 . \\
38044 .\end{array}$ \\
\hline $\begin{array}{l}185 \\
195 \\
206\end{array}$ & $\begin{array}{l}1247 . \\
1324 . \\
1404 .\end{array}$ & $\because *$ & $\begin{array}{l}155.6 \\
155.6 \\
155.6\end{array}$ & $\begin{array}{l}37015 . \\
35952 \\
34888\end{array}$ \\
\hline $\begin{array}{l}215 \\
224 \\
235\end{array}$ & $\begin{array}{l}1496 . \\
1568^{\circ} \\
1652^{\circ}\end{array}$ & $\because *$ & $\begin{array}{l}155.6 \\
155.6 \\
155.6\end{array}$ & $\begin{array}{l}33867 \\
3291 \mathrm{C} \\
32004 .\end{array}$ \\
\hline $\begin{array}{l}236 \\
244\end{array}$ & $\begin{array}{l}1715 . \\
1779 .\end{array}$ & $* * *$ & $\begin{array}{l}155.6 \\
155.6\end{array}$ & $\begin{array}{l}31261 . \\
30667 .\end{array}$ \\
\hline $\begin{array}{l}.251 \\
.257 \\
.262 \\
.266\end{array}$ & $\begin{array}{l}1842 . \\
1901 . \\
1955 . \\
2003 .\end{array}$ & $\because * *$ & $\begin{array}{l}155.6 \\
155.6 \\
155.6 \\
155.6\end{array}$ & $\begin{array}{l}30099 . \\
2958 \mathrm{C} . \\
29118 . \\
28715 .\end{array}$ \\
\hline $\begin{array}{l}266 \\
.270 \\
.155\end{array}$ & $\begin{array}{l}2037 . \\
2070 . \\
2070 .\end{array}$ & $\because *$ & $\begin{array}{r}155.6 \\
155.6 \\
5601.0\end{array}$ & $\begin{array}{r}28402 . \\
28153 . \\
126144 .\end{array}$ \\
\hline
\end{tabular}

\begin{tabular}{|c|c|c|}
\hline CDF & $\mathrm{COOL}$ & DF IL.M \\
\hline FSI & DEG F & DEG $F$ \\
\hline .537 & 1050 . & $\bullet * *$ \\
\hline $\begin{array}{l}. J E 9 \\
.176\end{array}$ & $\begin{array}{l}1116^{\circ} \\
1180^{\circ}\end{array}$ & $\begin{array}{l}233 \\
259 .\end{array}$ \\
\hline $\begin{array}{r}185 \\
.196 \\
.206\end{array}$ & $\begin{array}{l}1250^{\circ} \\
1320^{\circ} \\
1409^{\circ}\end{array}$ & $\begin{array}{l}280^{\circ} \\
300^{\circ} \\
3150^{\circ}\end{array}$ \\
\hline $\begin{array}{l}.21 E \\
.226 \\
.236\end{array}$ & $\begin{array}{l}1492^{\circ} \\
15750^{\circ} \\
16610^{\circ}\end{array}$ & $\begin{array}{l}316 . \\
314 . \\
338 .\end{array}$ \\
\hline $\begin{array}{r}.237 \\
.244\end{array}$ & $\begin{array}{l}1723 . \\
17855^{\circ}\end{array}$ & $\begin{array}{l}236 . \\
233 .\end{array}$ \\
\hline $\begin{array}{l}.251 \\
.257 \\
.262 \\
.266\end{array}$ & $\begin{array}{l}1847^{\circ} \\
1904^{\circ} \\
1958^{\circ} \\
2004^{\circ}\end{array}$ & $\begin{array}{l}2210^{\circ} \\
200^{\circ} \\
1820^{\circ} \\
161 .\end{array}$ \\
\hline $\begin{array}{r}.2 E 6 \\
.275\end{array}$ & $\begin{array}{l}2038 \\
2070\end{array}$ & $\begin{array}{l}113 . \\
132 .\end{array}$ \\
\hline & & \\
\hline
\end{tabular}

\begin{tabular}{|c|c|c|}
\hline GRA & DCAF & DROD \\
\hline$F$ & $D E G F$ & OEG F \\
\hline & $* \infty$ & $\cdots$ \\
\hline & $\begin{array}{l}70 . \\
75 .\end{array}$ & $\begin{array}{r}96 \\
107 .\end{array}$ \\
\hline & $\begin{array}{l}80 . \\
82 .\end{array}$ & $\begin{array}{l}120 . \\
128 .\end{array}$ \\
\hline 0. & 82. & 132. \\
\hline $\begin{array}{l}90 . \\
90 . \\
98 .\end{array}$ & $\begin{array}{l}80 . \\
78 . \\
81 .\end{array}$ & $\begin{array}{l}1330^{\circ} \\
1330^{\circ}\end{array}$ \\
\hline $\begin{array}{l}68 . \\
68 .\end{array}$ & $\begin{array}{l}58 . \\
57 .\end{array}$ & $\begin{array}{l}101 . \\
100\end{array}$ \\
\hline $\begin{array}{l}65 . \\
60 .\end{array}$ & $\begin{array}{l}53 . \\
49 .\end{array}$ & $\begin{array}{l}96 . \\
89 .\end{array}$ \\
\hline $\begin{array}{l}54 . \\
47 .\end{array}$ & $\begin{array}{l}43 . \\
38 .\end{array}$ & $\begin{array}{l}79 . \\
70 .\end{array}$ \\
\hline $\begin{array}{l}33 . \\
39 .\end{array}$ & $\begin{array}{l}27 . \\
31 .\end{array}$ & $\begin{array}{l}49 . \\
58 .\end{array}$ \\
\hline & & $* * * *$ \\
\hline
\end{tabular}

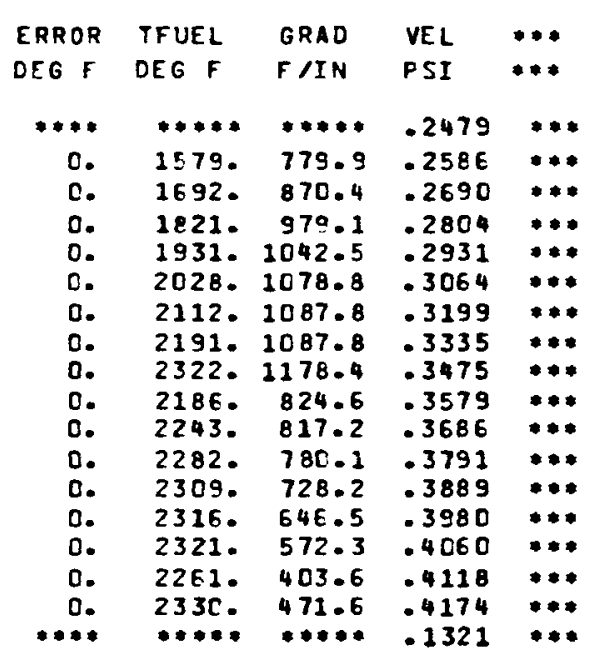

CONDUCTANCES

$B / H R, F T 2, F$

$\begin{array}{ll}N \quad \text { FLUX } \\ 1 & 6.52+04 \\ 2 & 7.28+04 \\ 3 & 8.19+04 \\ 4 & 8.72+04 \\ 5 & 9.02+04 \\ 6 & 9.10+04 \\ 7 & 9.10+04\end{array}$
$* *$

ERROR

TEMPE RATURE DE $G$

$279.8 \quad 1007.7 \quad 535.4$

$\begin{array}{lllll}282.9 & 1007.7 & 584.2 & 351.8 & 2 E 9.4\end{array}$

$\begin{array}{llllll}284.6 & 1007.7 & E C 7.9 & 351.8 & 272.5 & * * *\end{array}$

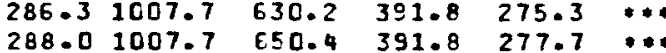

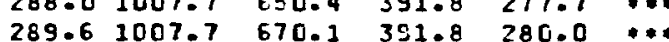

ECOOL EFILM ESOL ESUA

.0
.0
.0
.0
.0
.0
.0

.0
.0
.0
.0
.0
.0
.0
.0
.0
.0
.0
.0
.0

.0
.0
.0
.0
.0
.0

$*$
$*$
$*$
$\because *$
$\because$
$\because \cdots$
$\because$

MIG

TRISO

BISO

TIMES TIMEC

TIMES TIMEC

$2.48+08 \quad 5.49+08 \quad 3.79+06 \quad 1.66+07$

$4.48+07 \quad 9.87+07 \quad 1.41+06 \quad 6.1 E+0 E$

$7.81+06 \quad 1.71+07 \quad 5.14+05 \quad 2.22+06$ $2.00+06 \quad 4.5 C+06 \quad 2.35+05 \quad 1.04+06$ $6.50+05 \quad 1.60+06 \quad 1.24+05 \quad 5.66+05$

$\begin{array}{llll}2.64+05 & 7.06+05 & 7.46+04 & 3.56+05 \\ 1.19+05 & 3.45+05 & 4.77+04 & 2.37+05\end{array}$

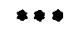

$\cdots$

$\bullet$

$* * *$ 


$\begin{array}{rrlllllll}8 & 9.85+04 & 291.2 & 1007.7 & 699.9 & 391.8 & 283.2 & * * & .0 \\ 9 & 6.90+04 & 292.3 & 1007.7 & 579.4 & 391.8 & 281.0 & * * & .0 \\ 10 & 6.83+04 & 293.5 & 1007.7 & 694.0 & 391.8 & 282.6 & * * & .0 \\ 11 & 6.52+04 & 294.5 & 1007.7 & 705.5 & 391.8 & 283.8 & * * & .0 \\ 12 & 6.09+04 & 295.5 & 1007.7 & 714.6 & 391.8 & 284.7 & * * & .0 \\ 13 & 5.41+04 & 296.4 & 1007.7 & 719.7 & 391.8 & 285.2 & * * & .0 \\ 14 & 4.79+04 & 297.2 & 1007.7 & 723.9 & 391.8 & 285.6 & * * & .0 \\ 15 & 3.37+04 & 297.7 & 1007.7 & 715.2 & 391.8 & 284.8 & * * & .0 \\ 16 & 3.94+04 & 298.2 & 1007.7 & 730.3 & 391.8 & 286.3 & * & .0\end{array}$

$\begin{array}{ll}.0 & .0 \\ .0 & .0 \\ .0 & .0 \\ .0 & .0 \\ .0 & .0 \\ .0 & .0 \\ 0 & -0 \\ .0 & .0 \\ .0 & .0 \\ .0 & .0\end{array}$

.0
.0
.0
.0
.0
.0
.0
.0
.0

.0
.0
.0
.0
.0
.0
.0
.0

\begin{tabular}{|c|c|c|c|c|c|}
\hline & & & $=$ & $1.17+05$ & \\
\hline & $20 *$ & $74+05$ & $5.91+0.4$ & $3.20+05$ & $* *$ \\
\hline & $7.09+04$ & $2.94+05$ & $4.03+04$ & $2.45+05$ & $\theta$ \\
\hline & $5 \cdot 01 * 04$ & $2.22 * 05$ & $3 \cdot 38+04$ & $2+13+05$ & $\because$ \\
\hline & +04 & $1+05$ & $3.07+04$ & $2 \cdot 01+05$ & $* *$ \\
\hline & $\begin{array}{l}3 \cdot 91+04 \\
3-92+04\end{array}$ & $\begin{array}{l}2-03+05 \\
2-21+05\end{array}$ & $\begin{array}{l}3-18+04 \\
3-36+04\end{array}$ & $\begin{array}{l}2-19+05 \\
2-02+05\end{array}$ & *** \\
\hline$\because \approx$ & $7.78+04$ & $5.12+0.5$ & $5.77+04$ & $4.54+05$ & $* *$ \\
\hline & $3.99+04$ & $2.50+05$ & $3.69+04$ & $2.82+05$ & $\cdots$ \\
\hline
\end{tabular}


DESIGN IV HOT CHANNEL

TOTAL CORE POWER: $3000 \mathrm{MH}$

POLER FACTORS

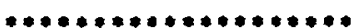

FRACIION OF POWER $=1.000$ FRACIION OF FLON $=.793$ REGION PONER FACTOR $=1.201$ $\begin{aligned} \text { COLUMN FOHER FACIOR } & =1.516 \\ \text { COLUMN TILT } & =1.2 E 3\end{aligned}$
TE MPERATURES F *******************

CORE INLET

CORE OUTLET

REGION OUTLET

COLUMN OUTLET

TEL AVG TEMP

GRAPHITE AVG TEMF $=2220.5$
FLON RATES LB/HR

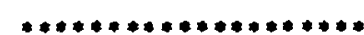

CORE AYERAGE FLOH REGICN AVERAGE FLOH

$\begin{array}{ll}\text { COLUMN AYERAGE FLOW } & =177.5 \\ \text { COLUMN ERROR FLOW } & .0\end{array}$
PRESSURE DROPS FSI

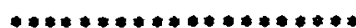

CORE IMET PRESSURE

PERCENTAGE CONYE RGENCE PECENAGE CONVERGNCE $\quad=6.873$

OPEN ORIFICE FRE SSURE DROP $=1.194$
725.0
REGION A VERAGE CONOITIONS

\begin{tabular}{|c|c|}
\hline $\begin{array}{l}\text { FLOR } \\
\text { LE/HR }\end{array}$ & $\begin{array}{c}\text { RE Y } \\
\text { NLMBER }\end{array}$ \\
\hline 186.8 & $47 E 66$ \\
\hline 186.8 & 46975 . \\
\hline 186.8 & 45688 \\
\hline $18 E .8$ & 44452. \\
\hline $\begin{array}{l}186.8 \\
186.8\end{array}$ & $\begin{array}{l}43177 \\
43897\end{array}$ \\
\hline $\begin{array}{l}18 E .8 \\
186.8\end{array}$ & $\begin{array}{l}40672 . \\
39522 .\end{array}$ \\
\hline $\begin{array}{l}386.8 \\
386.8\end{array}$ & $\begin{array}{l}38434 \\
37542\end{array}$ \\
\hline $\begin{array}{l}18 E .8 \\
18 E .8\end{array}$ & \\
\hline $\begin{array}{l}18 E .3 \\
186.8\end{array}$ & $\begin{array}{l}35523 . \\
34968 .\end{array}$ \\
\hline $\begin{array}{l}18 E \cdot 8 \\
186.8\end{array}$ & $\begin{array}{l}34484 . \\
34108 .\end{array}$ \\
\hline $186 \cdot 8$ & 33809. \\
\hline & 3 \\
\hline
\end{tabular}

LOCAL OR

OR COLUAN AVERAGE CONDITIONS

\begin{tabular}{|c|c|c|c|c|c|c|c|c|c|c|}
\hline $2 D P$ & TCOOL & $\cdots$ & FLOC & REY & CDF & TCOOL & DFILM & DGRA & DGAF & DROD \\
\hline$P S I$ & DEG $\mathrm{F}$ & $\ldots$ & $L B / H R$ & NUMBER & FSI & DEC $F$ & $D E G F$ & DE $6 F$ & $D E G F$ & DEG $F$ \\
\hline .755 & 1050. & 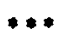 & 177.5 & 45283 & .687 & 1050 & $* *$ & & & 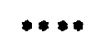 \\
\hline .238 & 1116 & $* *$ & 177.5 & 44415 & .227 & 1138. & 317. & 98. & 99. & 145. \\
\hline .247 & 1180 & $* *$ & 177.5 & 42827 & .238 & 1222 . & $35 ?$ & 120. & 105. & 262. \\
\hline .260 & 1250. & $* * *$ & 177.5 & 41332. & .254 & 1315 & 393. & 123. & 112 & 182. \\
\hline $\begin{array}{l}.275^{\circ} \\
.290\end{array}$ & $\begin{array}{l}1328 . \\
1409 .\end{array}$ & $\because *$ & $\begin{array}{l}177.5 \\
177.5\end{array}$ & $\begin{array}{l}39821 . \\
38335\end{array}$ & $\begin{array}{l}.272 \\
.290\end{array}$ & $\begin{array}{l}1419 . \\
1528 .\end{array}$ & $\begin{array}{l}415 . \\
42 E\end{array}$ & $\begin{array}{l}131 . \\
136 .\end{array}$ & $\begin{array}{l}113 . \\
112 .\end{array}$ & $\begin{array}{l}194 . \\
200 .\end{array}$ \\
\hline $\begin{array}{r}.303 \\
.316\end{array}$ & $\begin{array}{l}1492 . \\
1575 .\end{array}$ & $\because *$ & $\begin{array}{l}177.5 \\
177.5\end{array}$ & $\begin{array}{l}36938 . \\
35652 .\end{array}$ & $\begin{array}{l}.306 \\
.323\end{array}$ & $\begin{array}{l}1638^{\circ} \\
1748 .\end{array}$ & $\begin{array}{l}427 . \\
424 .\end{array}$ & $\begin{array}{l}137 . \\
137 .\end{array}$ & $\begin{array}{l}108 . \\
104 .\end{array}$ & $\begin{array}{l}202 . \\
202 .\end{array}$ \\
\hline $\begin{array}{r}.331 \\
.332\end{array}$ & $\begin{array}{l}1661 . \\
1723 .\end{array}$ & $\because *$ & $\begin{array}{l}177.5 \\
177.5\end{array}$ & $\begin{array}{l}34453 . \\
33484 .\end{array}$ & $\begin{array}{r}.341 \\
.341\end{array}$ & $\begin{array}{l}1862 . \\
1944^{\circ}\end{array}$ & $\begin{array}{l}456 . \\
318 .\end{array}$ & $\begin{array}{l}148 . \\
104 .\end{array}$ & $\begin{array}{r}107 . \\
78 .\end{array}$ & $\begin{array}{l}219 . \\
153 .\end{array}$ \\
\hline $\begin{array}{l}.342 \\
.352\end{array}$ & $\begin{array}{l}1785 . \\
1847 .\end{array}$ & $\because *$ & $\begin{array}{l}177.5 \\
177.5\end{array}$ & $\begin{array}{l}32718 . \\
31992 .\end{array}$ & $\begin{array}{r}.354 \\
.366\end{array}$ & $\begin{array}{l}2027 . \\
2109\end{array}$ & $\begin{array}{l}313 . \\
298\end{array}$ & $\begin{array}{l}103 . \\
98 .\end{array}$ & $\begin{array}{l}75 . \\
70 .\end{array}$ & $\begin{array}{l}152 . \\
145 .\end{array}$ \\
\hline $\begin{array}{r}.360 \\
.367\end{array}$ & $\begin{array}{l}1905 . \\
1958 .\end{array}$ & $\because \because$ & $\begin{array}{l}177.5 \\
177.5\end{array}$ & $\begin{array}{l}31335 . \\
30754 .\end{array}$ & $\begin{array}{r}.376 \\
.385\end{array}$ & $\begin{array}{l}2186 . \\
2256 .\end{array}$ & $\begin{array}{l}277 . \\
245 .\end{array}$ & $\begin{array}{l}92 . \\
81 .\end{array}$ & $\begin{array}{l}65 . \\
57 .\end{array}$ & $\begin{array}{l}135 . \\
120 .\end{array}$ \\
\hline $\begin{array}{r}.372 \\
.372\end{array}$ & $\begin{array}{l}2004 . \\
2038 .\end{array}$ & $* * *$ & $\begin{array}{l}177.5 \\
177.5\end{array}$ & $\begin{array}{l}30251 . \\
29863 .\end{array}$ & $\begin{array}{r}.391 \\
.392\end{array}$ & $\begin{array}{l}2318 . \\
2363 .\end{array}$ & $\begin{array}{l}216 . \\
152 .\end{array}$ & $\begin{array}{l}72 . \\
51 .\end{array}$ & $\begin{array}{l}50 . \\
36 .\end{array}$ & $\begin{array}{r}10 E . \\
75 .\end{array}$ \\
\hline$=$ & 207 & $*$ & ריו & ar & 398 & 200 & 177. & 59. & 41. & 88. \\
\hline 225 & 207 & & 396.1 & 3232 & 31 & 2405. & 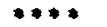 & 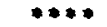 & & \\
\hline
\end{tabular}

.2312405 .
** ERROR TEMPERATURE DROFS DEG F

\section{CONDUC TANCES}

B/HR, FIZ, F

N FLUX

$19.89+04$

$21.10+05$

$31.24+05$

$\begin{array}{ll}4 & 1.32+05 \\ 5 & 1.37+05\end{array}$

$61.38+05$

$7.38 \cdot 05$

$8 \quad 3.49+05$

$91.05+05$

$101.04+05$

$119.89+04$

$\begin{array}{ll}12 & 9.23+04 \\ 13 & 8.20+04\end{array}$

$147.2 E \cdot 04$

$\begin{array}{ll}15 & 5.12+04 \\ 16 & 5.98+04\end{array}$
HTC EKC HEAP EKROD SOLEK ** ECOOL EFILM ESOL ESUM

$\begin{array}{llllll}311.5 & 1007.7 & 570.9 & 331.8 & 267.6 & \cdots\end{array}$ $\begin{array}{llllll}313.7 & 1007.7 & 602.0 & 391.8 & 271.8 & * *\end{array}$ $\begin{array}{llllll}315.9 & 1007.7 & 638.0 & 391.8 & 276.3 & *\end{array}$ $\begin{array}{llllll}318.4 & 1007.7 & 670.9 & 331.8 & 28 \mathrm{C} .1 & * *\end{array}$ $320.81007 .7 \quad 701.9 \quad 391.8 \quad 283.4 \ldots$ $\begin{array}{llllll}323.1 & 1007.7 & 730.2 & 391.8 & 286.3 & * \\ 3=5.4 & 1007.7 & 757.9 & 391.8 & 288.9 & \cdots\end{array}$ 327.61007 .7 800.8 $391.8 \quad 292.7$ $\begin{array}{lllll}329.1 & 1007.7 & 769.4 & 391.8 & 289.9\end{array}$ $\begin{array}{llllll}335.6 & 1007.7 & 790.0 & 391.8 & 291.8 & *\end{array}$ $\begin{array}{lllll}332.1 & 1607.7 & 80.6 .5 & 391.8 & 293.2\end{array}$

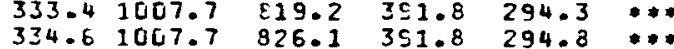
$\begin{array}{llllll}335 . E & 1007.7 & 831.9 & 391.8 & 295.3 & *\end{array}$

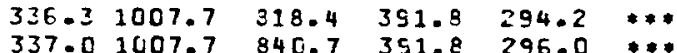

$\begin{array}{llll}.0 & .0 & .0 & .0 \\ .0 & .0 & .0 & .0 \\ .0 & .0 & .0 & .0 \\ .0 & .0 & .0 & .0 \\ .0 & .0 & .0 & .0 \\ .0 & .0 & .0 & .0 \\ .0 & .0 & .0 & .0 \\ .0 & .0 & .0 & .0 \\ .0 & .0 & .0 & .0 \\ .0 & .0 & .0 & .0 \\ .0 & .0 & .0 & .0 \\ .0 & .0 & .0 & .0 \\ .0 & .0 & .0 & .0 \\ .0 & .0 & .0 & .0 \\ .0 & .0 & .0 & .0 \\ .0 & .0 & .0 & .0\end{array}$

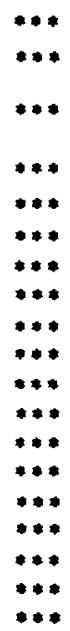

\section{MIGRA}

$\begin{array}{lllll} & \\ \text { RROR TFUEL } & \text { GRAD } & \text { VEL } & *\end{array}$

$* * *$
0.
0.
0.
0.
0.
0.
0.
0.
0.
0.
0.
0.
0.
0.
0.

$0 . \quad 1798.1182 * 0.3575 \ldots$

$0.1951 .1319 .8 .3385 \ldots$

0. 2125, 1484.6 .3885 $2125.1484 .6 \quad .4052$ $2272.1580 .7 \cdot .4238$ $2402.01635 .60 .4434 \ldots$ $2512 \cdot 1649.4 \quad .4632 \quad \ldots *$ 2616. 1649.4 .4832 2792. $1786.7 \quad .5037$ 2597. 125C.4 .5186 $2 E 71.1239 .1 .5337$ 2721. $1182.8 \quad .5487$

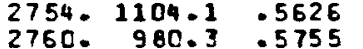
2763. 867.7 .5870 2E76. $611.9 \quad .5952$ 2770. $715.0 \quad .6032$

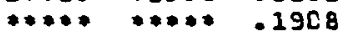

TIMES TIMEC

$1.25+07 \quad 1.87+07$

$1.87+06 \quad 2.92+06$ $2.81+05 \quad 4.58+05$ $6.68+04 \quad 1.19+05$ $\begin{array}{ll}2.09+04 & 4.13+C 4 \\ 8.37+03 & 1.85+C 4\end{array}$ $\begin{array}{ll}8 \cdot 37+03 & 1.85+C 4 \\ 3.76+03 & 9.24+03\end{array}$ $\begin{array}{ll}3.76+03 & 9.24+03 \\ 1.12+03 & 2.90+03\end{array}$ $1.12+03 \quad 2.90+03$ $3.98+03 \quad 1.38+04$ $2.35+03 \quad 8.67+03$ $1.67+03 \quad 6.68+03$ $\begin{array}{ll}1.35+03 & 5.87+03 \\ 1.33+03 & 6.39+03\end{array}$ $1.35+03 \quad 7.08+03$ $1.39+038.23+03$ $2.73+03 \quad 1.70+04$

$$
\begin{aligned}
& \text { TIME IMRS } \\
& \text { BISO }
\end{aligned}
$$

TIMES TIMEC

$6.10+05 \quad 2.14+06$ $2.04+05 \quad 7.26+05$ $6.75+04 \quad 2.43+05$ $2.93+04 \quad 1.10+05$ $1.50+04 \quad 5.92+04$ $\begin{array}{ll}8.84+03 & 3.71+04 \\ 5.59+03 & 2.48+04\end{array}$ $2.69+03 \quad 1.22+04$ $6.49+03 \quad 3.52+04$ $\begin{array}{ll}4.81+03 & 2.70+04 \\ 4.03+03 & 2.36+04\end{array}$ $3.57+032.26+04$ $3.82+03 \quad 2.49+04$ $4.06+03 \quad 2.78+04$
$7.07+03$
$5.35+04$ $4.08+03 \quad 3.29+0.4$
$* *$

$\bullet *$

$\ldots$ $\cdots$

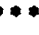
$\ldots$ $* *$ $\because *$ $\ldots$ $\because$ $\because *$ $\because \cdots$ 
DESIGN V AVERAGE CHANNEL

ZOKEIC = I.00EZ78+00

ZONE ZC $=9.854747-01 \quad$ ZONE 3C $=-9.701445-0 I$

\begin{tabular}{|c|c|c|c|c|c|c|c|c|c|}
\hline ZPF & $\begin{array}{l}9.460453-01 \\
9.777570-01\end{array}$ & $\begin{array}{l}1.055923+00 \\
9.689563-01\end{array}$ & $\begin{array}{l}1.387776 * 00 \\
9.249528-01\end{array}$ & $\begin{array}{l}1.264690+00 \\
8.633480-01\end{array}$ & $\begin{array}{l}1.308641+00 \\
7.665403-01\end{array}$ & $\begin{array}{l}1.319629+00 \\
6.785334-01\end{array}$ & $\frac{1.319629+00}{4.710457-01}$ & $\frac{1.429506 \cdot 00}{5.504256-01}$ & $\begin{array}{l}\text { AXIAL } \\
\text { PROFILE }\end{array}$ \\
\hline$F Z$ & $\begin{array}{l}6.559686-02 \\
6.549838-01\end{array}$ & $\begin{array}{l}1.285567-01 \\
7.257086-01\end{array}$ & $\begin{array}{l}1.978894-01 \\
7.854653-01\end{array}$ & $\begin{array}{l}2.750234-01 \\
8.409977-01\end{array}$ & $\begin{array}{l}3.56 \cos 1-01 \\
8.924817-01\end{array}$ & $\begin{array}{l}4.381915-01 \\
9.377173-01\end{array}$ & $\frac{5.204897-01}{9.693820-01}$ & $-\frac{6.053151-01}{1.000000+00}$ & \\
\hline
\end{tabular}

TOTAL CORE POHER: $3000 \mathrm{MH}$

POWER FACTORS

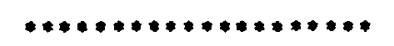

FRACTION OF POUER $=1.000$

FRACIION OF FLOW $=.754$

REGION PONER FACTOR $=1.000$

COLUMN PONER FACTOR $=1.000$

COLUHN TILT
TEMFERATURES $F$

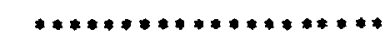

CORE INLET

RECION CUTLET

COLUMN OUTLET

$\begin{aligned} \text { FUEL AVC TEMF } & =2257 . \mathrm{C} \\ \text { GRAPHITE AVG TEMF } & =2133.8\end{aligned}$

\section{FLOH RATES LB/HR \\ ******************}

$=1200.0$

$=2273.4$

$=2273.4$
CORE AVERAGE FLOW

REGI ON AVERACE FLOW

COLUMN AVERAGE FLOW

COLUMN ERPOR FLOW
PRE SSURE DROPS PSI

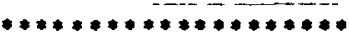

$=147.8$ CORE INLEY PRESSURE

$=147.8$ REGION FRESSURE DROP

COLUMN FRE SSURE DROP

PERCENTAGE CONUERGENCE

$=4.826$

OPEN ORIFICE FRE SSURE DROP $=.821$
REGION AVERAGE CONDITIONS

\begin{tabular}{|c|c|c|c|c|c|c|}
\hline $\begin{array}{l}\text { FLOR } \\
\text { LE/HR }\end{array}$ & $\begin{array}{c}\text { REY } \\
\text { NUMBER }\end{array}$ & $\begin{array}{l}R E P \\
\text { OSI }\end{array}$ & $\begin{array}{l}\text { TCOCL } \\
\text { OEG F }\end{array}$ & $* * *$ & $\begin{array}{l}F L O C \\
L B / A R\end{array}$ & $\begin{array}{c}\text { REY } \\
\text { NUMBER }\end{array}$ \\
\hline 147.8 & $3 \equiv 375$. & .543 & $O L$. & $* * *$ & 147.8 & 35375. \\
\hline 147.8 & 34823. & .170 & 1270. & $* * *$ & 147.8 & $3487 \varepsilon$. \\
\hline 147.8 & 33967. & .177 & 37. & & 147.8 & 33953. \\
\hline 147.8 & 33083. & .186 & 1411. & & 147.8 & 33062 . \\
\hline 147.8 & $321 E 9$. & .196 & 1497 . & & 147.8 & $3214 \mathrm{C}$. \\
\hline $\begin{array}{l}147.8 \\
147.8\end{array}$ & $\begin{array}{l}31250 . \\
3\llcorner 367 .\end{array}$ & $\begin{array}{l}.20 E \\
.216\end{array}$ & $\begin{array}{l}1579 . \\
1666 .\end{array}$ & $\because * *$ & $\begin{array}{l}147.8 \\
147.8\end{array}$ & $\begin{array}{l}31214 . \\
30325 .\end{array}$ \\
\hline $\begin{array}{l}147.8 \\
147.8\end{array}$ & $\begin{array}{l}29537 . \\
28749 .\end{array}$ & $\begin{array}{l}.225 \\
.235\end{array}$ & $\begin{array}{l}175 ? . \\
1843 .\end{array}$ & $\because *$ & $\begin{array}{l}147.8 \\
147.8\end{array}$ & $\begin{array}{l}2949 c . \\
28697 .\end{array}$ \\
\hline $\begin{array}{l}147.8 \\
147.8\end{array}$ & $\begin{array}{l}20102 . \\
27584 .\end{array}$ & $\begin{array}{l}.236 \\
.243\end{array}$ & $\begin{array}{l}1902 . \\
1974 .\end{array}$ & $* *$ & $\begin{array}{l}147.8 \\
147.8\end{array}$ & $\begin{array}{l}2805 \approx \\
2754\end{array}$ \\
\hline 147.8 & 27488. & .250 & $2<30$. & & 147.8 & 27055. \\
\hline 147.8 & $2 E \in 34$. & .255 & 2099. & & 147.8 & 26608 . \\
\hline 147.8 & 26229. & .260 & 2155. & & 147.8 & $z \in 20 \Omega$. \\
\hline 147.8 & 25875 & .264 & 2205 & 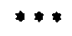 & 147.8 & 25861. \\
\hline $\begin{array}{l}147.8 \\
147.8\end{array}$ & $\begin{array}{l}25601 . \\
25382 .\end{array}$ & $\begin{array}{l}.2 E 4 \\
.268\end{array}$ & $\begin{array}{l}2241 . \\
2273 .\end{array}$ & $* * *$ & $\begin{array}{l}147.8 \\
147.8\end{array}$ & $\begin{array}{l}25592 . \\
25379 .\end{array}$ \\
\hline $5>23 \cdot 0$ & 113743. & .152 & 2273 . & $* *$ & 5321.0 & 113743. \\
\hline
\end{tabular}

LOCAL OR COLUMN AVERACE CONDITIONS

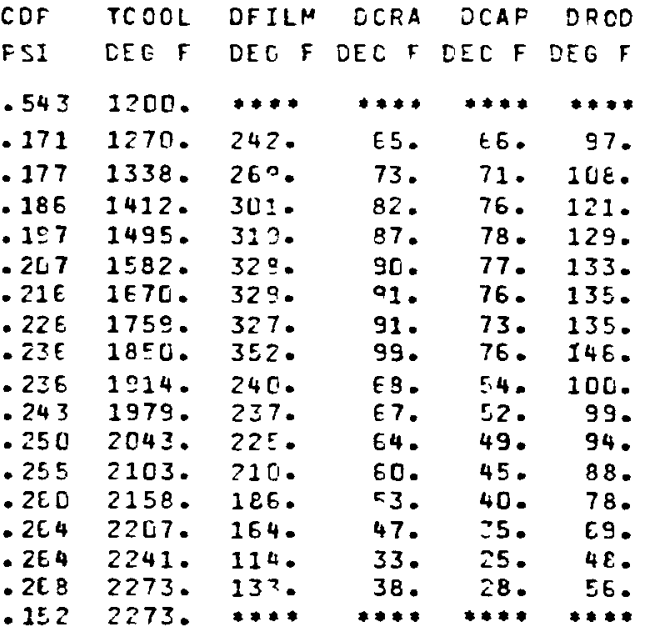

ERROR TFUEL GRAD VEL **

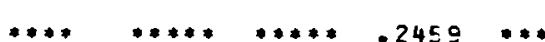

c. $1741.787 .8 \quad .25 E 3$ ***

C. 1858. 879.3 .2EE3 *

D. $1993.989 .1 \quad .2773 \quad * *$

0. 2108. 1053.1 .2895 ***

D. $2211.1089 .7 .3024 \ldots$

o. 2300.1038 .8 . 3154

D. 2385.1698 .8 .3285

0. $2522.1190 .3 \quad 3285$

0. 2375.28140203517

0. $2434 . \quad 8 C E-8$ - 3617 **

$\begin{array}{llll}0 . & 2476 . & 770.2 & .3714 \\ 0 . & 2505 . & 718.9 & 3805\end{array}$

o. 2514. E38.3 3890

0. 2521. 5E5.0 3965

0. $2459.392 .2 \quad 4018$

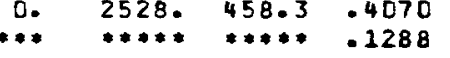

MIGRATION LIFETIME (HRS)

TRISO BISO DEC $F$

E/HR, FT2, F ***

** efrop temfepature trofos

N FLUX

HTC EKC HCAP EKROD SCLEK

***

$16.59+04$

$27.35+04$

$3 .-27+04$
$5,8.81+04$

$59.11+04$

$69.19+04$

$271.9 \quad 1607.7 \quad 572.6 \quad 393.8 \quad 267.8 \quad \ldots$

$273.4 \quad 1007.7 \quad 597.0 \quad 351.8 \quad 271.1 \quad * *$

$274.9 \quad 1007.7 \quad \varepsilon 25.0 \quad 391.8 \quad 274.7 \quad * *$

$27 E .51407 .7 \quad 550.7 \quad 351.8 \quad 277.8 \quad * *$

$278.1 \quad 1007.7 \quad 675.1 \quad 3=3.8 \quad 286.5 \quad *$

$279.7 \quad 1007.7 \quad 997.4 \quad 351.6 \quad 282.9 \quad *$

$281.21007 .7 \quad 719.2 \quad 391.8 \quad 285.2 \ldots$

.0
.0
.0
.0
.0
.0
.0

$\begin{array}{ll}.0 & .0 \\ .0 & .0 \\ .0 & .0 \\ .0 & : 0 \\ .0 & : 0 \\ .0 & : 0\end{array}$

.0
.0
.0
.0
.0
.0
.0

.0
.0
.0
.0
.0
.0
.0

SUM

$* *$

TIMES TIMEC

9.

$\begin{array}{ll}2.12+07 & 5.77+07 \\ 4.54+05 & 1.23+07\end{array}$

$9.39+05 \quad 2.51+06$

$2.72+05 \quad 7.59+05$

$\begin{array}{ll}9.77+04 & 2.89+05 \\ 4.28+04 & 1.36+05\end{array}$

$2.06+04 \quad 7.01+0.4$

TIMES TIMEC

$9.81+05 \quad 4.79+06$ $.00+05 \quad 1.93+06$ $1.58+05 \quad 7.58+05$ $4.27+04 \quad 2.14+05$

$2.67+041.39+05$ .0

$* *$

$1.76+049.50+04$

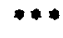

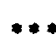


DESIGN V AVERAGE CHANNEL (Continued)

\begin{tabular}{|c|c|c|c|c|c|c|c|c|c|c|c|c|c|c|c|c|c|}
\hline 8 & $9.95+04$ & 282.7 & 1007.7 & 751.8 & 391.8 & 288.3 & $* *$ & .0 & .0 & .0 & .0 & $* *$ & $6.88+03$ & $2.39+04$ & $9.09+03$ & $4.94+04$ & $\cdots$ \\
\hline $\begin{array}{r}9 \\
10\end{array}$ & $\begin{array}{l}6.81+04 \\
6.75+04\end{array}$ & $\begin{array}{l}283.8 \\
284.8\end{array}$ & $\begin{array}{l}1007.7 \\
1007.7\end{array}$ & $\begin{array}{l}728.1 \\
744.0\end{array}$ & $\begin{array}{l}391.8 \\
391.8\end{array}$ & $\begin{array}{l}286.1 \\
287.6\end{array}$ & $\because *$ & $\begin{array}{l}.0 \\
.0\end{array}$ & $\begin{array}{l}.0 \\
.0\end{array}$ & $\begin{array}{l}.0 \\
.0\end{array}$ & $\begin{array}{l}.0 \\
.0\end{array}$ & $\because \cdots$ & $\begin{array}{l}2.26+04 \\
1.40+04\end{array}$ & $\begin{array}{l}2.02+05 \\
6.62+04\end{array}$ & $\begin{array}{l}2.11+04 \\
1.61+04\end{array}$ & $\begin{array}{l}1.34+05 \\
1.05+05\end{array}$ & $\because \cdots$ \\
\hline $\begin{array}{l}11 \\
12\end{array}$ & $\begin{array}{l}6.44+04 \\
6.01+04\end{array}$ & $\begin{array}{l}285.8 \\
286.7\end{array}$ & $\begin{array}{l}1007.7 \\
1007.7\end{array}$ & $\begin{array}{l}756.6 \\
766.7\end{array}$ & $\begin{array}{l}393.8 \\
391.8\end{array}$ & $\begin{array}{l}288.8 \\
289.7\end{array}$ & $\because \cdots$ & .0 & $\begin{array}{l}.0 \\
.0\end{array}$ & .0 & $\begin{array}{l}.0 \\
.0\end{array}$ & $\because * *$ & $\begin{array}{l}1.03+04 \\
8.40+03\end{array}$ & $\begin{array}{l}5.12+04 \\
4.45+04\end{array}$ & $\begin{array}{l}1-38+04 \\
1.26+04\end{array}$ & $\begin{array}{l}9.22+04 \\
8.76+04\end{array}$ & $\because \cdots$ \\
\hline $\begin{array}{l}13 \\
14\end{array}$ & $\begin{array}{l}5 \cdot 34+04 \\
4.72+04\end{array}$ & $\begin{array}{l}287.6 \\
288.3\end{array}$ & $\begin{array}{l}1007.7 \\
1007.7\end{array}$ & $\begin{array}{l}772.6 \\
777.5\end{array}$ & $\begin{array}{l}391.8 \\
391.8\end{array}$ & $\begin{array}{l}290.2 \\
290.7\end{array}$ & $\because *$ & .0 & $\begin{array}{l}.0 \\
.0\end{array}$ & .0 & $\begin{array}{l}.0 \\
.0\end{array}$ & $\because$ & $\begin{array}{l}8 \cdot 21+03 \\
8.26+03\end{array}$ & $\begin{array}{l}4.70+C 4 \\
5.0 E+04\end{array}$ & $\begin{array}{l}1 \cdot 31+04 \\
1.38+04\end{array}$ & $\begin{array}{l}9.51+04 \\
1.04+05\end{array}$ & $\because *$ \\
\hline $\begin{array}{l}15 \\
16\end{array}$ & $\begin{array}{l}3.28+04 \\
3.83+04\end{array}$ & $\begin{array}{l}288.8 \\
289.2\end{array}$ & $\begin{array}{l}1007.7 \\
1007.7\end{array}$ & $\begin{array}{l}767.9 \\
783.8\end{array}$ & $\begin{array}{l}391.8 \\
391.8\end{array}$ & $\begin{array}{l}289.8 \\
291.2\end{array}$ & $\because *$ & .00 & $\begin{array}{l}.0 \\
.0\end{array}$ & .0 & .0 & $\because$ & $\begin{array}{l}1 . E 1+04 \\
8.83+03\end{array}$ & $\begin{array}{l}1.13+05 \\
5.96+04\end{array}$ & $\begin{array}{l}2.37+04 \\
1.57+04\end{array}$ & $\begin{array}{l}1.94+05 \\
1.25+05\end{array}$ & $\because *$ \\
\hline
\end{tabular}


DESIGN $\mathrm{V}$ HOT CHANNEL

TOTAL CORE POWER: $3000 \mathrm{MH}$

POUER FACTORS

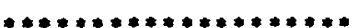

FRACTION OF POWER $=1.000$ FRACTION OF FLOW $=.754$ REGION POWER FACTOR $=1.201$ COLUMN POWER FACTOR $=1.518$ COLUMN TILT
TEMPERATURES $F$

*****************

CORE INLET

CORE OUTLET

COLION OUTLET $=2273.4$

FUEL AVG TEMP $=2634.1$
FLOU RATES LE/HR $* * * * * * * * * * * * * * * * * *$

CORE AVERAGE FLOH $=147.8$ CORE INLET PRE SSURE

REGION AVERAGE FLOH $=177.5$ REGION PRESSURE DROP

COLUMN AYERAGE FLOH $=168.6$ COLUMN FRESSURE DROP

COLUMN ERROR FLOK $=$.O PERCENTAGE CONVERGENCE

$=-.006$

OPEN ORIFICE PRESSURE DROP $=1.185$ CORE PRESSURE DROP
$=725.0$
$=6.790$
$=6.828$
$=-.006$
$=1.185$
$=7.975$
REGION AVERAGE CONOITIONS

\begin{tabular}{|c|c|c|c|c|c|c|c|}
\hline $\mathbf{N}$ & $\begin{array}{l}\text { FLOR } \\
\text { LB/HR }\end{array}$ & $\begin{array}{c}\text { REY } \\
\text { NUMBER }\end{array}$ & $\begin{array}{l}\text { RDP } \\
\text { PSI }\end{array}$ & $\begin{array}{l}\text { TCOOL } \\
\text { DEG F }\end{array}$ & $* * *$ & $\begin{array}{l}F L O C \\
L B / H R\end{array}$ & $\begin{array}{c}\text { RE } Y \\
\text { NUMBE R }\end{array}$ \\
\hline IR & 177.5 & 42433 & 763 & 00 & $* *$ & 68.6 & 40359 \\
\hline 1 & 177.5 & 41896. & .239 & 1270. & $\cdots *$ & 168.6 & 39610 . \\
\hline 2 & 177.5 & $4 \omega$ & 248 & 338. & $* * *$ & 3.6 & 37 \\
\hline 3 & 177.5 & 3 & .261 & 1412 & $* * *$ & 168.6 & 36941 . \\
\hline 4 & 177.5 & 33 & .276 & 15. & $* * *$ & .6 & \\
\hline 5 & 177.5 & 37 & .290 & 2. & $* * *$ & 168.6 & 34333 . \\
\hline $\begin{array}{l}6 \\
7\end{array}$ & $\begin{array}{l}177.5 \\
177.5\end{array}$ & & $\begin{array}{r}.303 \\
.316\end{array}$ & $\begin{array}{l}1670^{\circ} \\
1759 .\end{array}$ & $* * *$ & $\begin{array}{l}168.6 \\
168.6\end{array}$ & $\begin{array}{l}33113 . \\
31985 .\end{array}$ \\
\hline 8 & $177 \cdot 5$ & 344 & .331 & 1950. & $* *$ & 168.6 & 30934 . \\
\hline & & & & & *** & & \\
\hline 10 & 177.5 & 33 & .341 & 1979. & $* * *$ & 6 & 1 . \\
\hline & 17 & & D & & . & & 5. \\
\hline $\begin{array}{l}12 \\
13\end{array}$ & $\begin{array}{l}177.5 \\
177.5\end{array}$ & $\begin{array}{l}319 \\
3: 4\end{array}$ & $\begin{array}{l}.358 \\
.365\end{array}$ & $\begin{array}{l}210 \\
215\end{array}$ & $* * *$ & & 6. \\
\hline 14 & 277.5 & 310 & .370 & 220 & $* * *$ & 16 & 27296 . \\
\hline 15 & 177 & 30 & 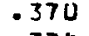 & & & & \\
\hline $\begin{array}{l}16 \\
\text { BR }\end{array}$ & $\begin{array}{r}177.5 \\
6390.1\end{array}$ & $\begin{array}{r}34479 . \\
136536 .\end{array}$ & $\begin{array}{l}.374 \\
.220\end{array}$ & $\begin{array}{l}2273 . \\
2273 .\end{array}$ & $* *$ & $\begin{array}{r}158.5 \\
5070.5\end{array}$ & $\begin{array}{r}26697 . \\
: 19562 .\end{array}$ \\
\hline
\end{tabular}

*..

\begin{tabular}{|c|c|c|c|c|c|c|c|}
\hline N & $\begin{array}{l}\text { FLOR } \\
\text { LB/HR }\end{array}$ & $\begin{array}{c}\text { REY } \\
\text { NUMBER }\end{array}$ & $\begin{array}{l}\text { RDP } \\
\text { PSI }\end{array}$ & $\begin{array}{l}\text { TCOOL } \\
\text { DEG F }\end{array}$ & $* * *$ & $\begin{array}{l}F L O C \\
L B / H R\end{array}$ & $\begin{array}{c}\text { RE } Y \\
\text { NU MBE R }\end{array}$ \\
\hline 8 & 177.5 & 42433. & 763 & ס. & $* * *$ & 168.6 & 40359. \\
\hline 1 & 177.5 & 41896. & .239 & 1270. & $* *$ & 158.6 & 39610 . \\
\hline 2 & 177.5 & 775. & .248 & 38. & $* *$ & 163.6 & 37 \\
\hline 3 & 5 & & .251 & 12. & $* * *$ & .6 & 36941. \\
\hline $\begin{array}{l}4 \\
5\end{array}$ & & & $\begin{array}{l}.276 \\
.290\end{array}$ & & $* * *$ & & \\
\hline $\begin{array}{l}6 \\
7\end{array}$ & $\begin{array}{l}177.5 \\
177.5\end{array}$ & & $\begin{array}{r}.303 \\
.316\end{array}$ & & $* * *$ & & \\
\hline $\begin{array}{r}8 \\
9 \\
10 \\
11\end{array}$ & $\begin{array}{l}177.5 \\
177.5 \\
177.5 \\
177.5\end{array}$ & $\begin{array}{l}34463 . \\
33689 . \\
33077 . \\
32491 .\end{array}$ & $\begin{array}{l}.331 \\
.331 \\
.341 \\
.350\end{array}$ & $\begin{array}{l}1950 . \\
1914 . \\
1979 . \\
2043 .\end{array}$ & $* * *$ & $\begin{array}{l}168.6 \\
168.6 \\
168.6 \\
168.6\end{array}$ & $\begin{array}{l}30934 . \\
30091 . \\
29431 . \\
23805 .\end{array}$ \\
\hline $\begin{array}{ll}12 \\
13\end{array}$ & $\begin{array}{l}177.5 \\
177.5\end{array}$ & $\begin{array}{l}31954 . \\
3: 474 .\end{array}$ & $\begin{array}{l}.358 \\
.365\end{array}$ & $\begin{array}{l}2103 . \\
2153 .\end{array}$ & $* * *$ & $\begin{array}{l}168.5 \\
168.5\end{array}$ & $\begin{array}{l}28236 \\
27733 \text {. }\end{array}$ \\
\hline $\begin{array}{l}14 \\
15 \\
16 \\
\text { BR }\end{array}$ & $\begin{array}{r}177.5 \\
177.5 \\
177.5 \\
6390.1\end{array}$ & $\begin{array}{r}31056 . \\
30734 . \\
35479 . \\
136536 .\end{array}$ & $\begin{array}{r}.370 \\
.370 \\
.374 \\
.220\end{array}$ & $\begin{array}{l}2207 . \\
2241 . \\
22730 \\
2273 .\end{array}$ & $\begin{array}{l}* * * \\
* * * \\
* * *\end{array}$ & $\begin{array}{r}168.5 \\
163.6 \\
168.6 \\
5070.6\end{array}$ & $\begin{array}{r}27296 . \\
26961 . \\
26697 . \\
219562 .\end{array}$ \\
\hline
\end{tabular}

LOCAL OR COLUMN AVERAGE CONOITIONS

\begin{tabular}{|c|c|c|c|c|c|}
\hline$P$ & TCOOL & OFILM & DGRA & $D G A F$ & DROD \\
\hline PSI & $D E G F$ & DEG $F$ & DES $F$ & DEG $F$ & JEG $F$ \\
\hline 594 & 1200 & $* * *$ & $*$ & $* * *$ & 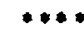 \\
\hline .228 & 1294. & 330. & э9. & 94. & 146. \\
\hline $\begin{array}{l}.239 \\
.254\end{array}$ & & $\begin{array}{l}366 . \\
409 .\end{array}$ & $\begin{array}{l}112 . \\
124 .\end{array}$ & $\begin{array}{r}99 . \\
105 .\end{array}$ & $\begin{array}{l}163 . \\
184 .\end{array}$ \\
\hline $\begin{array}{r}.272 \\
.289\end{array}$ & $\begin{array}{l}1592 . \\
1708 .\end{array}$ & $\begin{array}{l}432 . \\
444 .\end{array}$ & $\begin{array}{l}133 . \\
137 .\end{array}$ & $\begin{array}{l}107 . \\
105 .\end{array}$ & $\begin{array}{l}196 . \\
202\end{array}$ \\
\hline $\begin{array}{r}.306 \\
.322\end{array}$ & $\begin{array}{l}1825^{\circ} \\
19430^{\circ}\end{array}$ & $\begin{array}{l}444 . \\
441 .\end{array}$ & $\begin{array}{l}138 . \\
138 .\end{array}$ & $\begin{array}{r}102 . \\
98 .\end{array}$ & $\begin{array}{l}204 \\
204\end{array}$ \\
\hline $\begin{array}{r}.339 \\
.339 \\
.352 \\
.363\end{array}$ & $\begin{array}{l}2084 . \\
2149 . \\
2235 . \\
2321 .\end{array}$ & $\begin{array}{l}475 . \\
323 . \\
319 . \\
303 .\end{array}$ & $\begin{array}{r}150 . \\
102 . \\
102 . \\
97 .\end{array}$ & $\begin{array}{r}100 . \\
72 . \\
69 . \\
65 .\end{array}$ & $\begin{array}{l}2210^{\circ} \\
1510^{\circ} \\
150 \\
1430^{\circ}\end{array}$ \\
\hline $\begin{array}{r}.372 \\
.381\end{array}$ & $\begin{array}{l}2400^{\circ} \\
2473\end{array}$ & $\begin{array}{l}282 . \\
249\end{array}$ & $\begin{array}{l}90 . \\
30 .\end{array}$ & $\begin{array}{l}59 . \\
52 .\end{array}$ & $\begin{array}{l}134 . \\
119\end{array}$ \\
\hline $\begin{array}{l}.387 \\
.387 \\
.393 \\
.225\end{array}$ & $\begin{array}{l}2538 . \\
2583 . \\
2627 \\
2627^{\circ}\end{array}$ & $\begin{array}{l}220 \\
153 \\
178 \\
*\end{array}$ & $\begin{array}{r}71 . \\
49 . \\
58 . \\
*\end{array}$ & $\begin{array}{r}46 \\
32 \\
37 \\
\end{array}$ & $\begin{array}{r}105 \\
73 \\
85 \\
+0\end{array}$ \\
\hline
\end{tabular}

$E R R O R$
DEG F

0.
0.
0.
0.
0.
0.
0.
0.
0.
0.
0.
0.
0.
0.
0.
0.
0.
$\cdots$

\begin{tabular}{|c|c|c|c|}
\hline$U E L$ & GRAD & VEL & $* * *$ \\
\hline$G F$ & $F / I N$ & FSI & $* * *$ \\
\hline & $* * * *$ & 3547 & \\
\hline & 1194.4 & .3698 & \\
\hline & & .3844 & \\
\hline & 1499.6 & .4005 & $* *$ \\
\hline & & & $* *$ \\
\hline & $\begin{array}{l}165 \\
166\end{array}$ & .45 & $* *:$ \\
\hline & 1804. & .49 & $* * 0$ \\
\hline & & & $\because *$ \\
\hline & 12 & .5 & 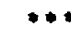 \\
\hline & 1167.8 & .5373 & $*$ \\
\hline & $\begin{array}{r}1090.0 \\
967.8\end{array}$ & & \\
\hline & $\begin{array}{l}856.7 \\
594.7\end{array}$ & & \\
\hline & 694.9 & $\begin{array}{l}.5882 \\
.1851\end{array}$ & \\
\hline
\end{tabular}

CONDUCTANCES

BIHR, FT2, F

N FluX

HTC EKG HGAP

$19.99+04$

$21.11+05$

$\begin{array}{llllll}342.7 & 1007.7 & 509.8 & 391.3 & 272.8 & \ldots\end{array}$

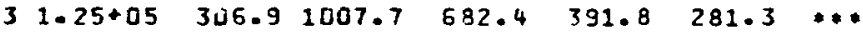

$\begin{array}{lllllll}4.34+05 & 309.2 & 1007.7 & 718.3 & 391.3 & 285.1 & \ldots\end{array}$

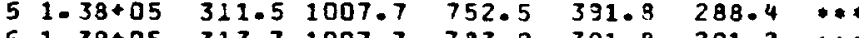

71.39005313 .71007 .7 783.9 $391.8 \quad 291.2 * *$

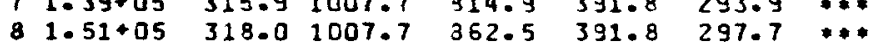

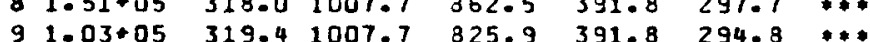

$\begin{array}{cccccccc}9 & 1.03 .05 & 319.4 & 1007.7 & 825.9 & 391.8 & 294.8 & * *\end{array}$

$\begin{array}{llllllll}10 & 1.02+05 & 320.8 & 1007.7 & 348.5 & 391.8 & 296.6 & * * * \\ 11 & 9.77+04 & 322.1 & 1007.7 & 866.7 & 391.8 & 298.0 & * * *\end{array}$

$\begin{array}{llllllll}12 & 9.12+04 & 323.4 & 1007.7 & 881.1 & 391.8 & 299.1 & \ldots\end{array}$

$138.09+04 \quad 324.51007 .7 \quad 889.1 \quad 391.8 \quad 299.6 \quad * *$

$\begin{array}{llllllll}14 & 7.16+04 & 325.4 & 1007.7 & 896.0 & 391.8 & 300.1 & \cdots \\ 15 & 4.97+04 & 325.1 & 1007.7 & 830.8 & 391.8 & 299.0 & \cdots\end{array}$

$\begin{array}{lllllll}16 & 5.31+04 & 326.7 & 1007.7 & 904.6 & 391.3 & 300.8\end{array} * *$
EQROR TEMFERATURE DROFS DEG $F$

ecool efilm esol esum

.0
.0
.0
.0
.0
.0
.0
.0
.0
.0
.0
.0
.0
.0
.0
.0

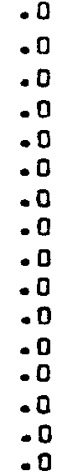

$* *$

$* *$

$\ldots$

$* *$

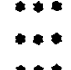

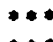

$\because *$

$\because *$

$\cdots$

$\because *$

$\because \ldots$

$\ldots+$

$\because *$

$* *$
MIGRATION LIFETIME (HRS) TRISO

TIMES TIMEC

TIMES TIMEC *..*

$1.48+06 \quad 2.84+06 \quad 1.87+05 \quad 7.46+05$ $2.64+05 \quad 5.22+05 \quad 6.83+04 \quad 2.74+05$ $4.72+04 \quad 9.62+04 \quad 2.46+04 \quad 9.97+04$

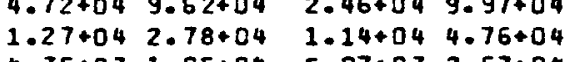
$4.35+03 \quad 1.05+04 \quad 5.07+03 \quad 2.67+04$ $\begin{array}{llll}1.86+03 & 4.95+03 & 3.71+03 & 1.72+04 \\ 9.89+02 & 2.60+03 & 2.42+03 & 1.18+04\end{array}$ $\begin{array}{llll}9.89+02 & 2.60+03 & 2.42+03 & 1.18+04 \\ 2.94+02 & 8.92+02 & 1.23+03 & 6.10+03\end{array}$ $\begin{array}{llll}2.94+02 & 8.92+02 & 1.23+03 & 6.10+03 \\ 1.02+03 & 4.08+03 & 2.96+03 & 1.74+04\end{array}$ $\begin{array}{llll}1.02+03 & 4.08+03 & 2.96+03 & 1.74+04 \\ 5.30+02 & 2.67+03 & 2.25+03 & 1.36+04\end{array}$ $\begin{array}{llll}6.30+02 & 2.67+03 & 2.25+03 & 1.36+04 \\ 4.62+02 & 2.10+03 & 1.92+03 & 1.21+04\end{array}$ $4.62+02 \quad 2.10+03 \quad 1.92+03 \quad 1.21+04$

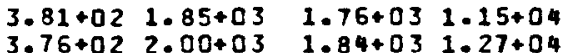
$3.81+02 \quad 2.19+03 \quad 1.95+031.40+04$ $\begin{array}{llll}7.56+02 & 5.05+03 & 3.38+03 & 2.67+04\end{array}$
$* *$ 
APPENDIX C

PROPERTIES OF SELECT CERAMICS

$$
\mathrm{C}-1
$$




\section{PROPERTIES OF SELECT CERAMICS}

by

\section{J. Chin}

Defining the properties of ceramics is an elusive task. The mechanical properties of of these materials are dependent on the ceramic grain size, impurities at grain boundaries, porosity, micro cracks, internal stresses, stability of crystal phases, thermal gradients and the stoichiometry of the major chemical species.

Some literature values for select ceramic properties are presented here along with references. The user should examine the original references before using the data for hardware design. This will give him ceramic fabrication details which are necessary to determine if the information is applicable to his design.

Large differences in property values are usually seen between older and newer literature values. These differences are generally due to differences in additives used as sintering aids and fabrication techniques. The highest density and purity samples have been made by hot pressing and CVD processes. other processes such as extrusion, slip casting and reaction sintering generally produce lower density, weaker materials.

An example of how ceramic preparation effects the mechanical properties is illustrated by SiC modulus of rupture data from Popper and Davies (27). Silicon carbide prepared by older techniques of silicate bonding had a modulus of rupture of $2200 \mathrm{Psi}$ at $1000^{\circ} \mathrm{C}$. Porous, reaction sintered silicon carbide and nitride bonded silicon carbide had more than double the silicate modulus of rupture with values of $5000-5600$ Psi at $1000^{\circ} \mathrm{C}$. If silicon carbide is bonded with silicon, modulus of rupture values double again to 12000 Psi at $1000^{\circ} \mathrm{C}$. Hot pressing $\mathrm{SiC} / \mathrm{C}$ mixtures and siliciding resulted in 68,000 Psi modulus of rupture $\mathrm{SiC}$ at $1000^{\circ} \mathrm{C}$ which is greater than 30 times the modulus of rupture of silicate bonded silicon carbide. 
The prime reason for the $10 \mathrm{w}, 1000^{\circ} \mathrm{C}$ properties of the silicate bonded silicon carbide is the presence of glassy phases at grain boundaries.

The following are Tables and Figures of property data for select ceramic materials. Source references, in parenthesis, are given at the end of this compilation.

1.0 Silicon Carbide

1.1 General Properties of Silicon Carbide

1.2 Thermal Expansion

1.3 Thermal Conductivity

1.4 Poisson's Rates

1.5 Creep

1.6 Flexural Strength

1.7 Mechanical Properties - CVD SiC

1.8 Fracture Stress, Youngs Modulus, Shear Modulus, Tensile Strength

1.9 Bend Strength

1.10 Microhardness

1.11 Oxidation Rate
Table $1.1-1.2$

Figures $1.1-1.4$

Figures $1.5-1.10$

Figure 1.11

Figures $1.12-1.13$

Table 1.3,

Figures $1.14-1.16$

Tables $1.4-1.5$

Figures $1.17-1.23$

Figures $1.24-1.27$

Figures $1.28-1.30$

Figures $1.31-1.33$

\subsection{Silicon Nitride}

2.1 General Properties of Silicon Nitride

2.2 Effect of $\alpha-\beta$ Ratio on the Density

2.3 Thermal Expansion

2.4 Thermal Conductivity

2.5 Electrical Resistivity

2.6 Thermal Shock

2.7 Creep

2.8 Modulus, Shear, Elastic, Youngs

2.9 Strength, Fracture, Flexural, Tensile

2.10 0xidation, Decomposition
Tables $2.1-2.3$

Figure 2.1

Figures $2.2-2.4$

Figures $2.5-2.8$

Figure 2.9

Figure 2.10

Figures 2.11-2.13

Figures $2.14-2.16$

Figures $2.17-2.32$

Figures $2.33-2.37$ 
1.0 SILICON CARBIDE 


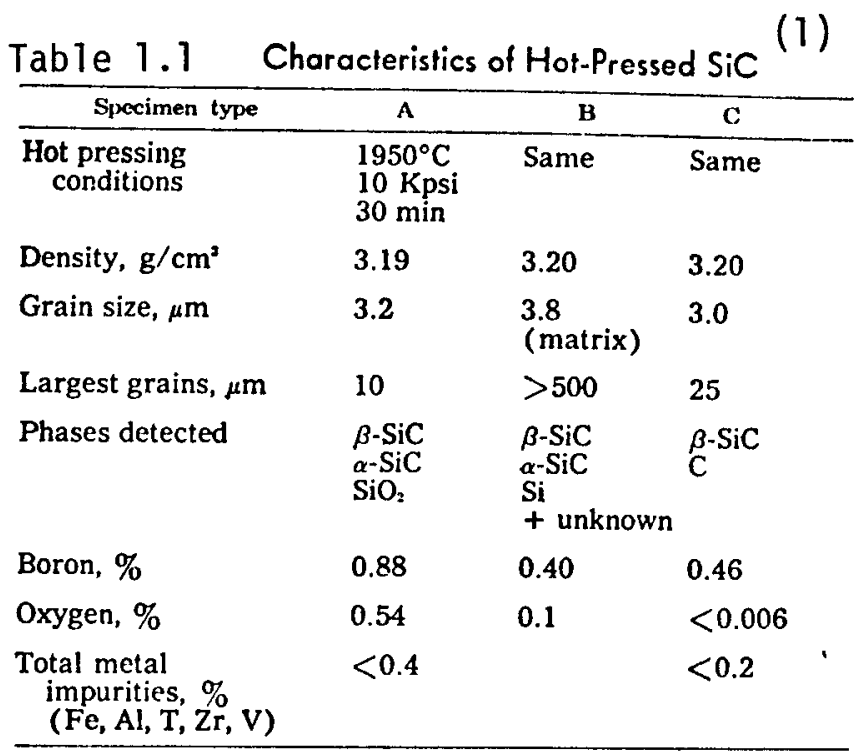

-Table 1.2

CVD $\beta$-Silicon Carbide High Temperature Properties ${ }^{(6)}$

\begin{tabular}{|c|c|c|c|c|c|c|c|}
\hline Property & 20 & 200 & 800 & 2000 & 1200 & 1400 & 2000 \\
\hline $\begin{array}{l}\text { Density } \\
\mathrm{g}-\mathrm{cm}^{-1}\end{array}$ & 3.166 & 3.160 & 3.135 & 3.125 & 3.114 & 3.096 & 3.075 \\
\hline $\begin{array}{l}\text { Specific Heat } \\
\text { Cal } \mathrm{gm}^{-1} \mathrm{OC}^{-1}\end{array}$ & 0.17 & 0.22 & 0.28 & 0.28 & 0.29 & 0.30 & 0.30 \\
\hline $\begin{array}{l}\text { Flexufal Modulus } \\
\times 10^{6} \mathrm{psi}\end{array}$ & 60 & & . & & & & \\
\hline $\begin{array}{l}\text { Compressive } \\
\text { Strength } \\
\quad \text { psi }\end{array}$ & 50,000 & & & & & & \\
\hline
\end{tabular}




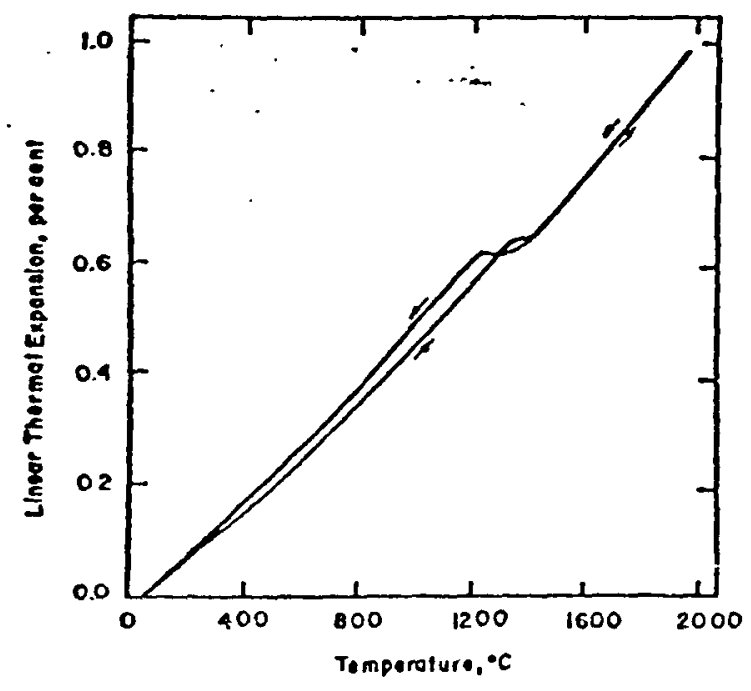

FIG. 1.1

Linear Thermal Expansion-Temperature

Relation for B-Silicon Carbide

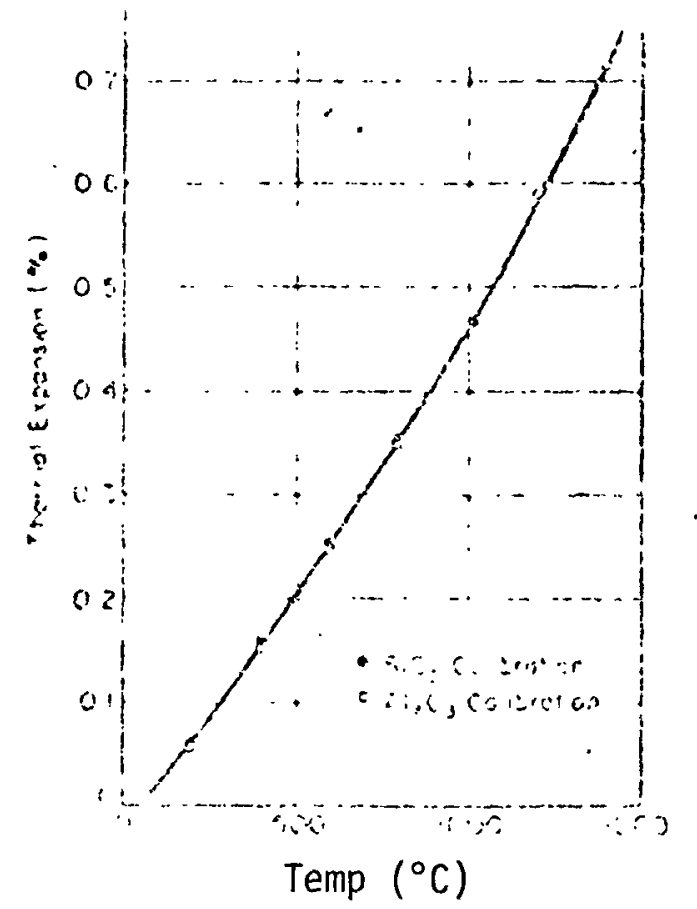

4

(9)

Fig. 1.2 Thermal Expansion of SiC from Dilatometer Calibrated with Fused Silica and Synthetic Sapphire 


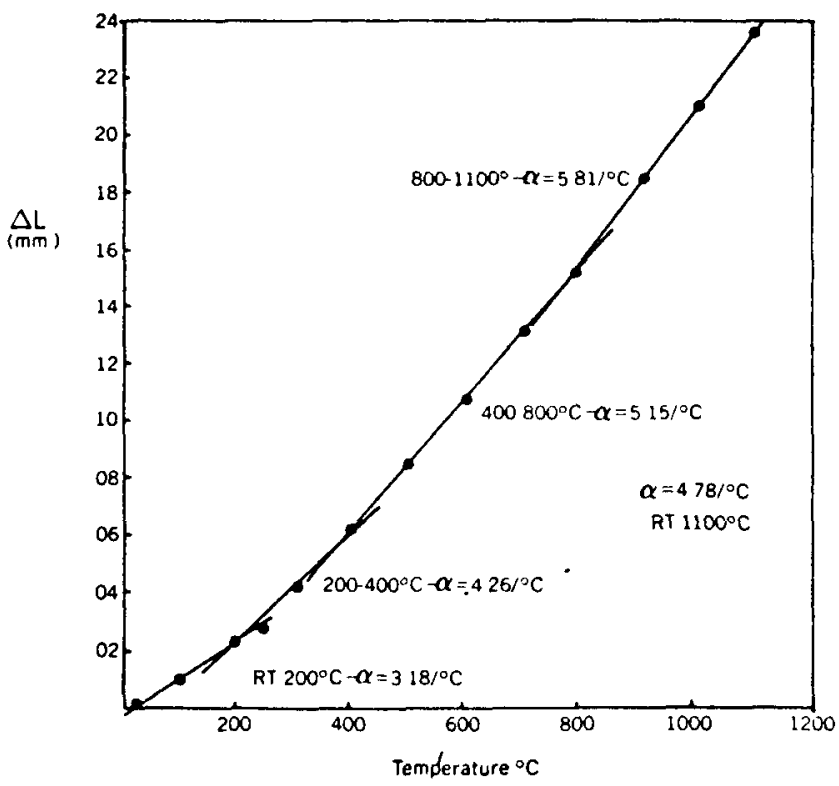

FIGURE 1.3

Thermal expansion curve showing change in length as a function of temperature up to $11000 \mathrm{C}$ and for various regions 
Temperature, ${ }^{\circ} \mathrm{R}$

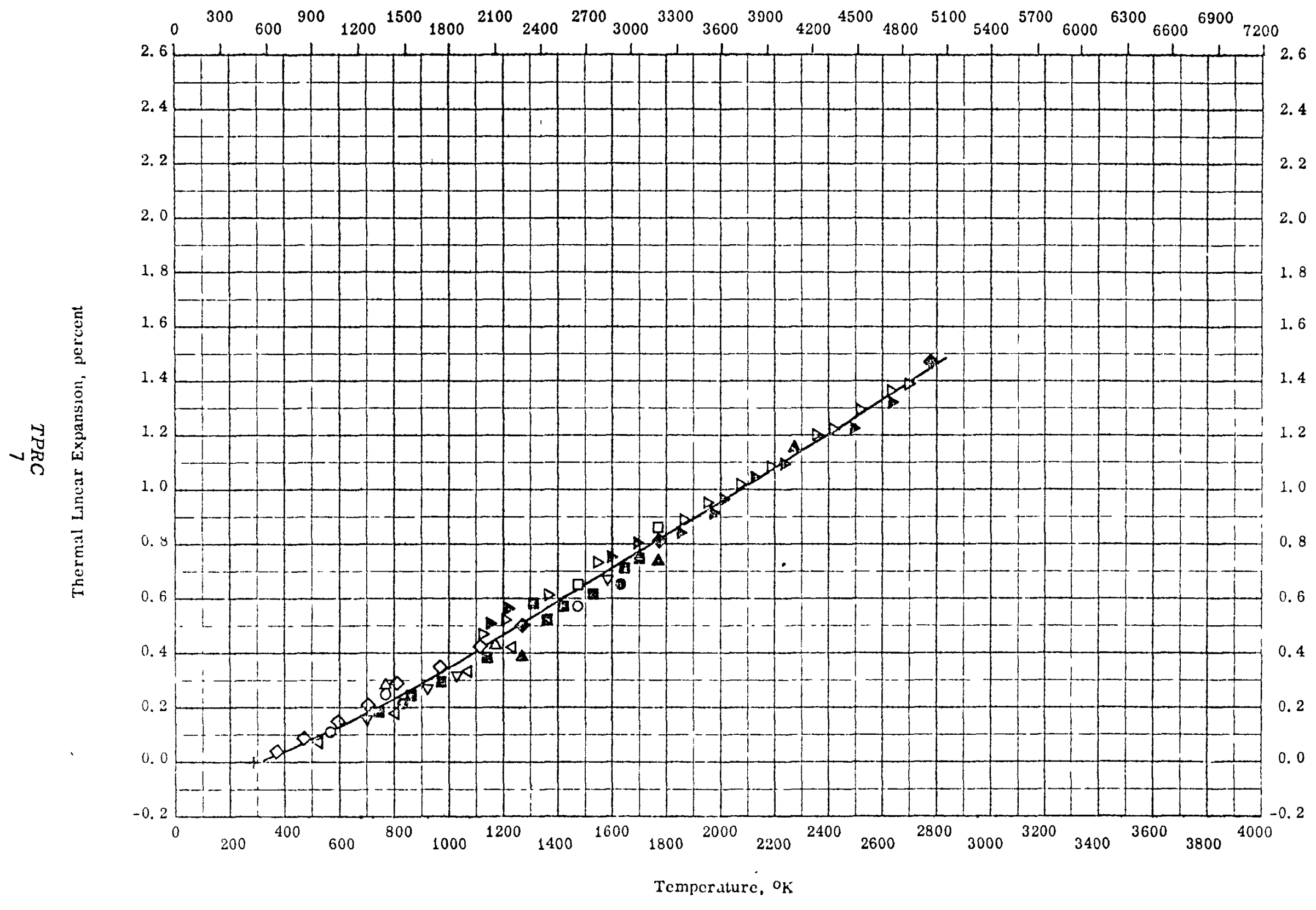

Fig. 1.4

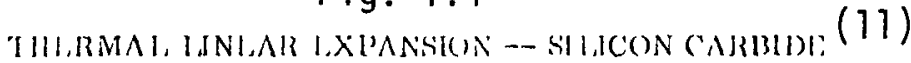




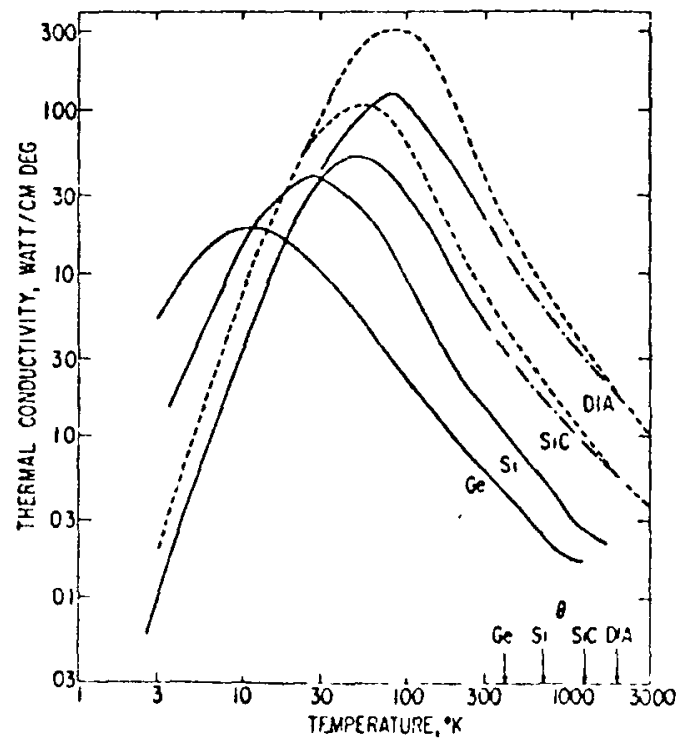

Fig. 1.5 .In intercomparisun of the thermal convincts it $k$ is temperature curres of Cre (pure). St ipure). Sl( IRo6). and

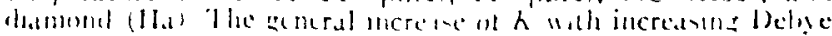

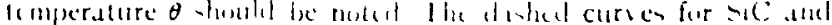

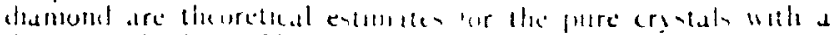

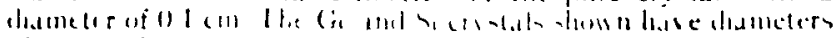

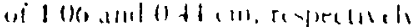

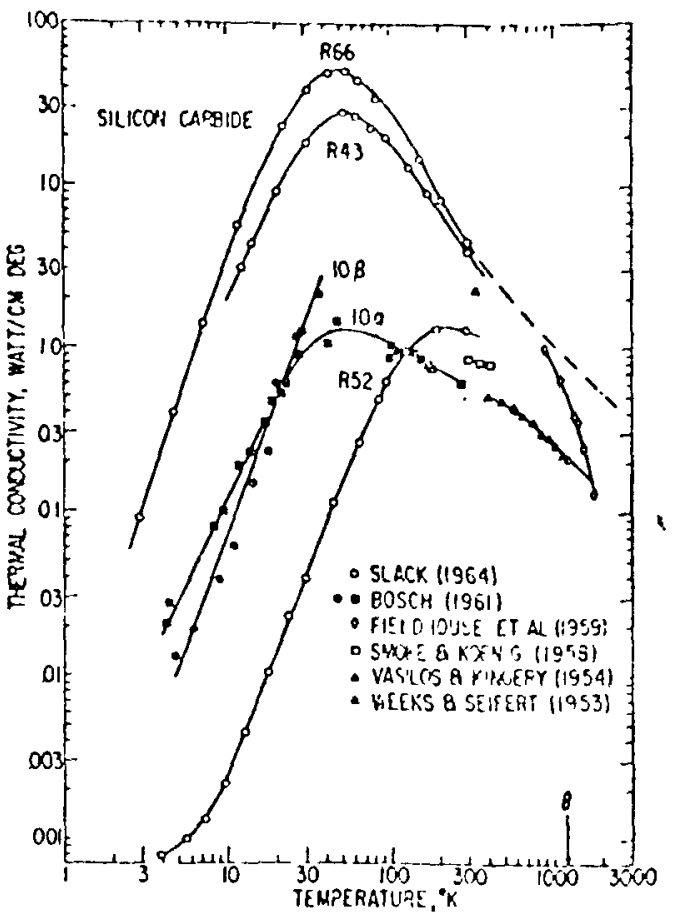

Fig. 1.6 The thermal conductirity $K$ is tempernture of his, $(10)$ purity $\mathrm{SiC}$ (Ro6) and variou- has pure samples. The det thath curre is the estimated extrapolation of $h$ to the Delye temperatture 0 . 


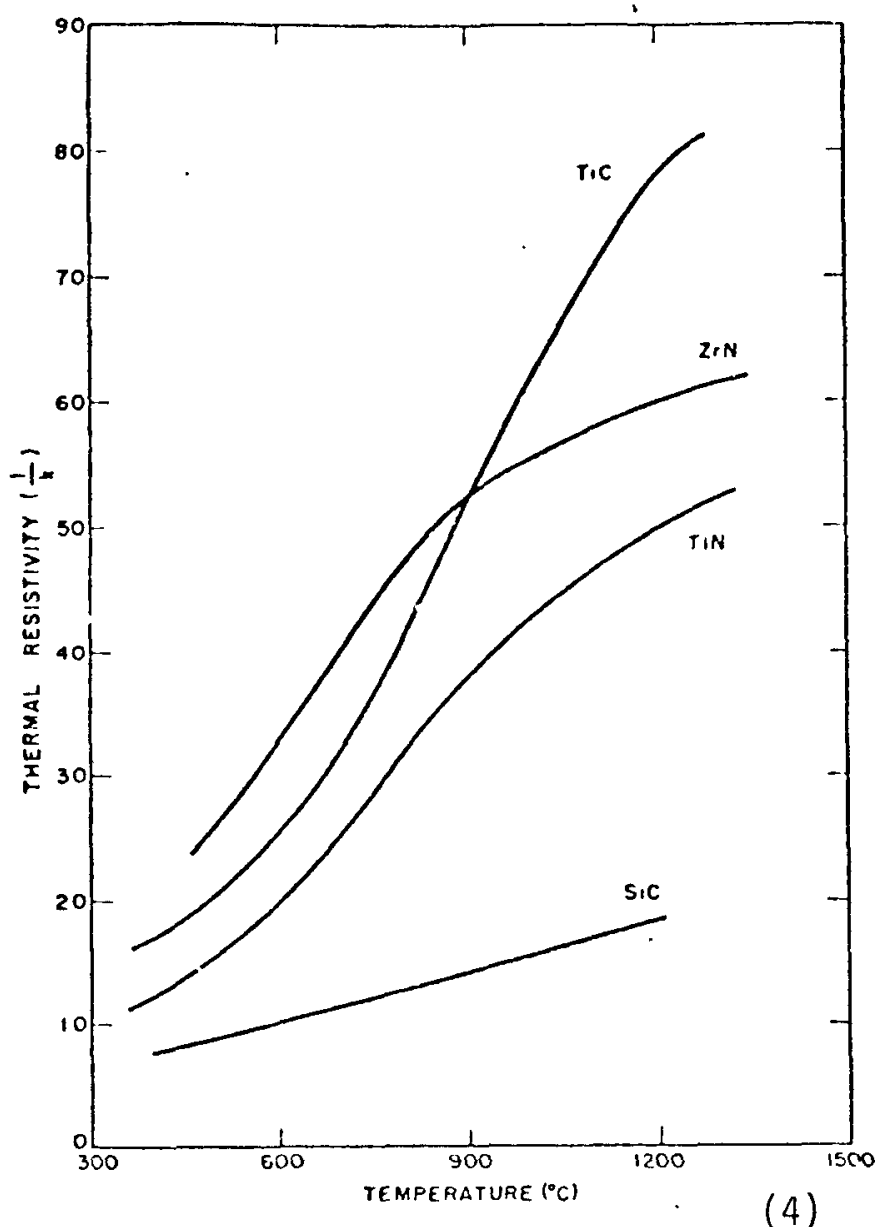

Fig. 1.6 Tharmal resistivity of TiC, TIN, $7, N$, ond SiC.

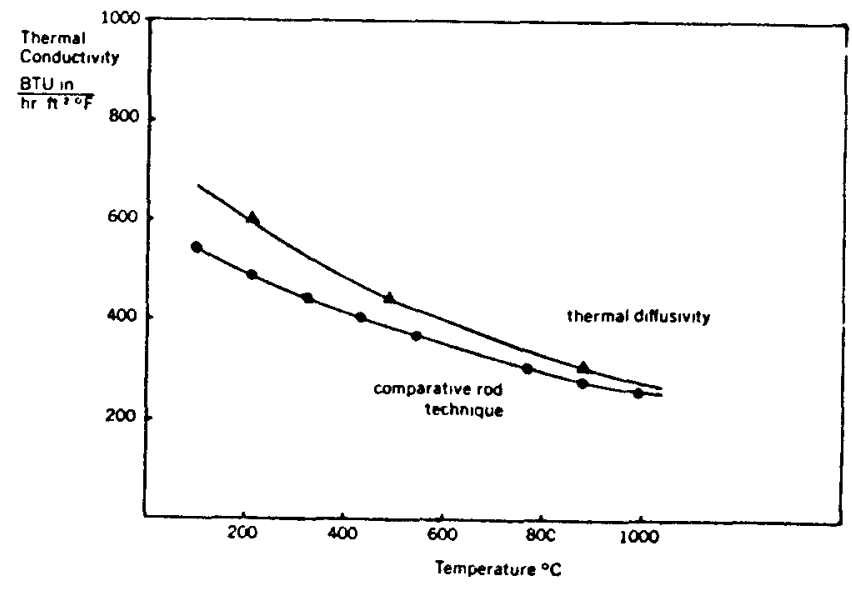

FIGURE 1.7

(2)

Thermal conductivity as a function of temperature up to $1000^{\circ} \mathrm{C}$ 


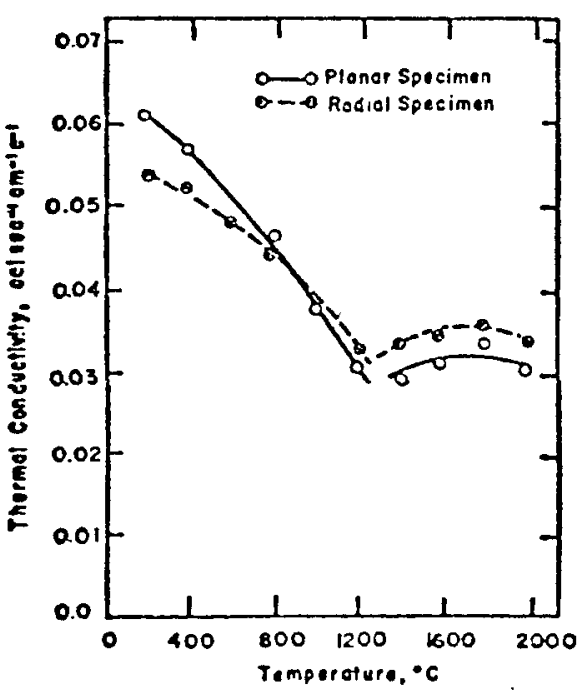

FIG .1 .8

Calculated Thermal Conductivity-Temperature (6)

Relation for $\beta$-SiC

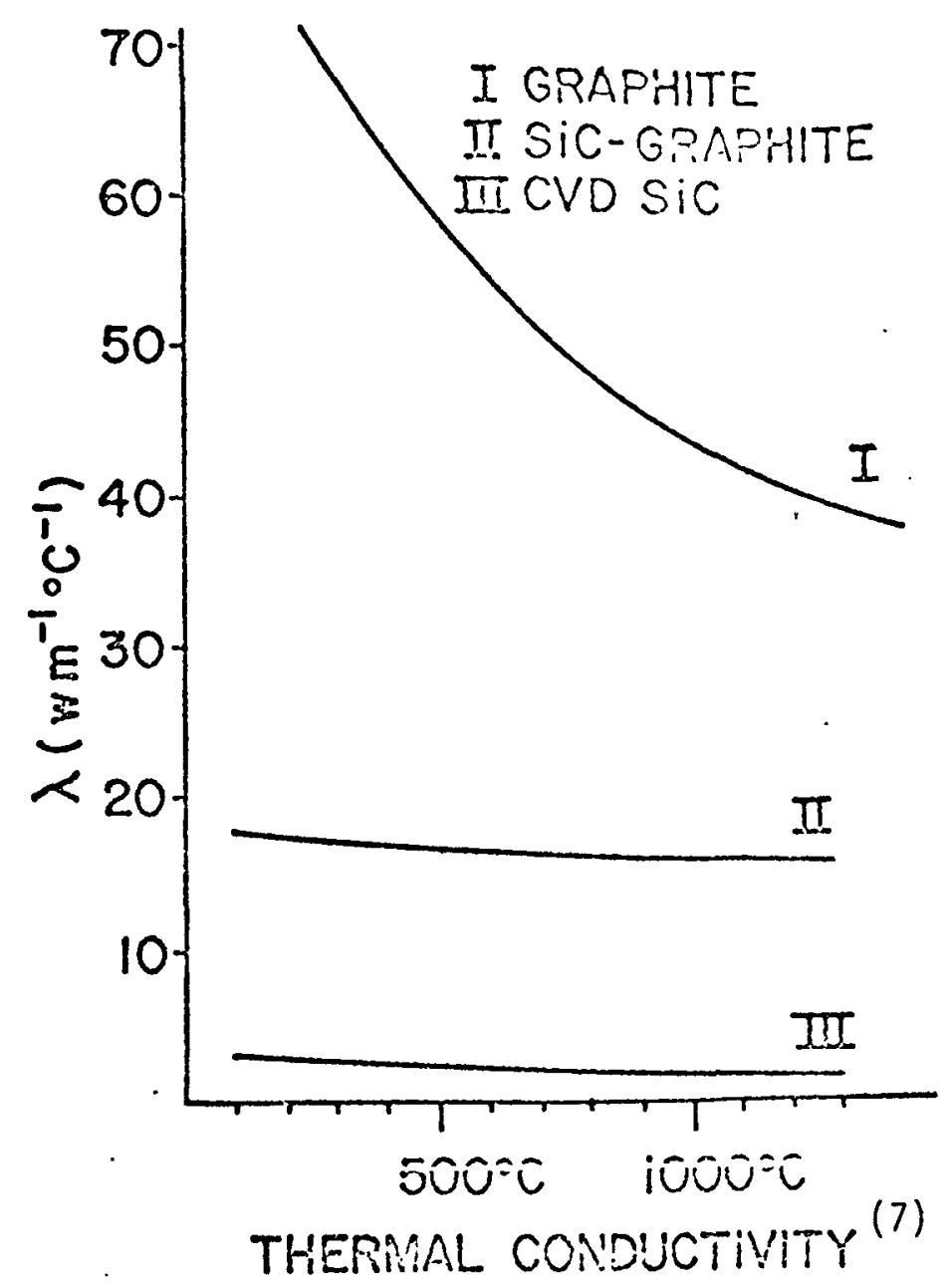

Fig. 1.9 


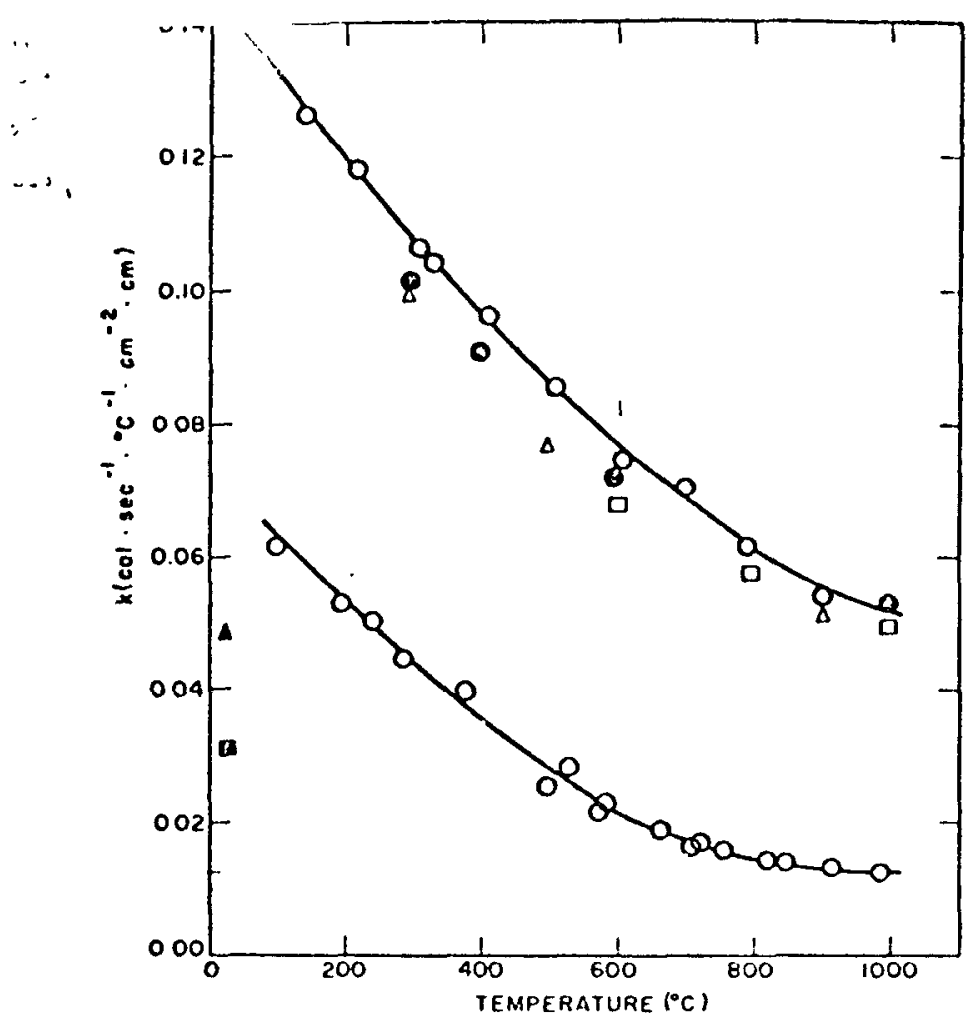

Fig. 1.10 Thermal conductivily of SiC (urper curve) and TiC (lower curve). (7) legend: 10$)$ Wilkes (footnote 9), (!) Norton (footriole 10), $(\triangle)$ Eucken (footnote 8), (O) this investigation, (A) Schwarzkopf ond Kiteffer (footnote $7(a)$ ), (t) Glaser and Ivanick (footnote $7(b)$ ). 


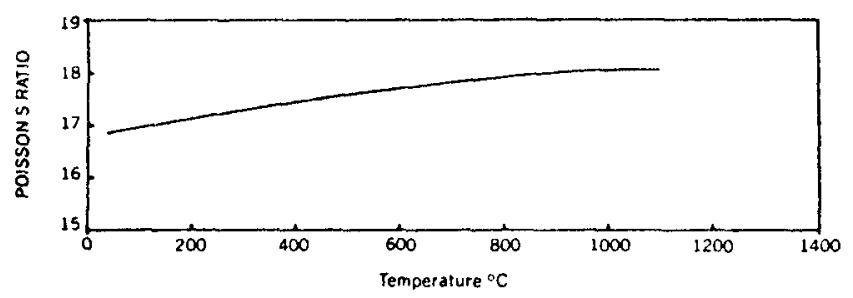

FIGURE 1.11

Poisson's ratio, determined sonically $(2)$

as a function of temperature

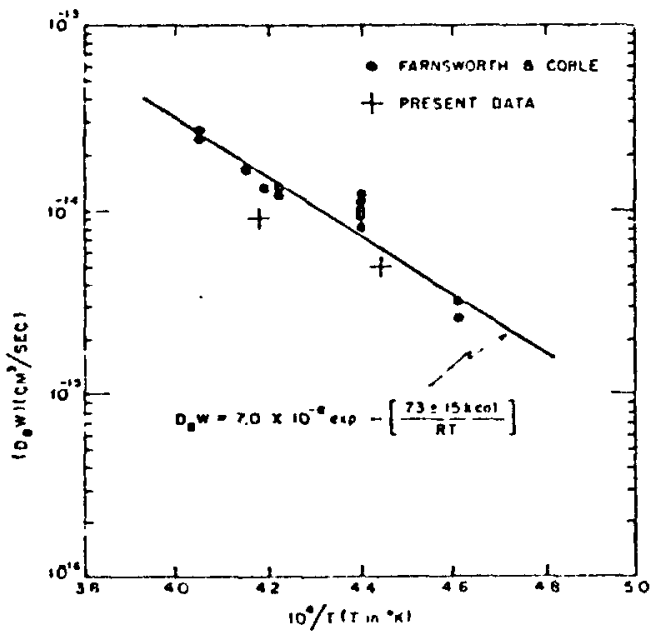

Plot of $\log D_{\text {, }}$ lf vs. $1 / \%$ for dence polycrystalline SiC.

Fig. .1.12 
TEMPERATURE $\left({ }^{\circ} \mathrm{C}\right)$

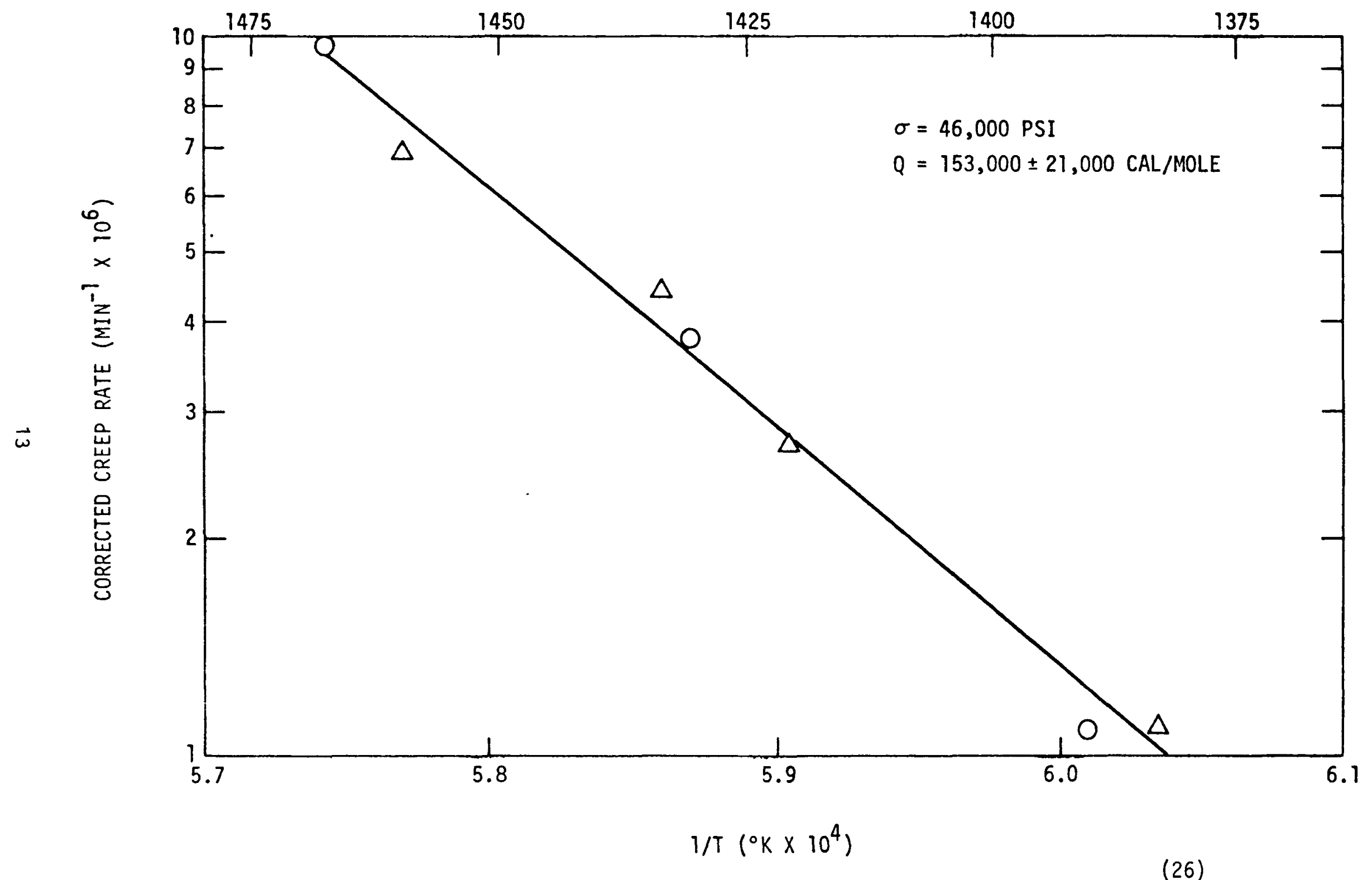

Fig. 1.13 Arrhenius plot of creep rate of two specimens of fine-grained $\beta$-Sic. 
Table 1.3

Flexural Strength of Hot-Pressed $\mathrm{SiC}_{1}$ psi

(1)

\begin{tabular}{|c|c|c|c|c|c|}
\hline Temperature & Room temp & $1300^{\circ} \mathrm{C}$ & $1400^{\circ} \mathrm{C}$ & $1500^{\circ} \mathrm{C}$ & $1600^{\circ} \mathrm{C}$ \\
\hline $\mathrm{SiC}-\mathrm{A}^{*}$ & $\begin{array}{r}82,000(12) \\
\pm 6,600\end{array}$ & $\begin{array}{l}78,900(7) \\
\pm 7,400\end{array}$ & $\begin{array}{l}78,200(7) \\
\pm 4,000\end{array}$ & $\begin{array}{r}67,800(7) \\
\pm 3,400\end{array}$ & $\begin{array}{r}44,000(4) \\
\pm 4,800\end{array}$ \\
\hline $\mathrm{SiC}-\mathrm{B}$ : & $39,000(5)$ & $38,700(5)$ & $37,500(5)$ & $36,600(5)$ & \\
\hline $\mathrm{SiC}-\mathrm{C}^{*}$ & $\begin{array}{l} \pm 8,800 \\
71,900(10) \\
\pm 9,200\end{array}$ & $\begin{array}{l} \pm 9,600 \\
80,000(5) \\
\pm 7,200\end{array}$ & $\begin{array}{r} \pm 11,000 \\
81,900(4) \\
+4,800\end{array}$ & $\begin{array}{l} \pm 5,900 \\
84,100(5) \\
+6,600\end{array}$ & $\begin{array}{r}63,700(6) \\
+9600\end{array}$ \\
\hline $\begin{array}{l}\text { SiC-A } \\
\quad \text { (polished) }\end{array}$ & $\begin{array}{l}103,200 \\
\pm 7,600\end{array}$ & & & $\begin{array}{r}64,400(4) \\
\pm 4,400\end{array}$ & \\
\hline
\end{tabular}

- See Table II for characterization.

Note: Number of specimens tested given in parentheses.

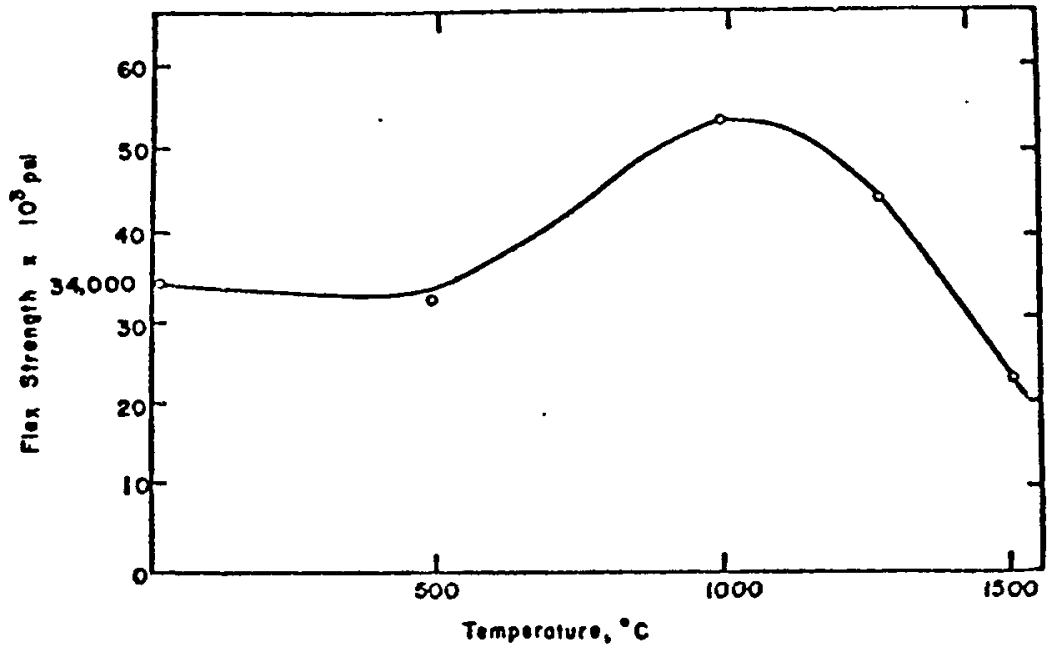

FIG. 1.14

Flexural Strength vs. Temperature for CVD SiC

(6) 


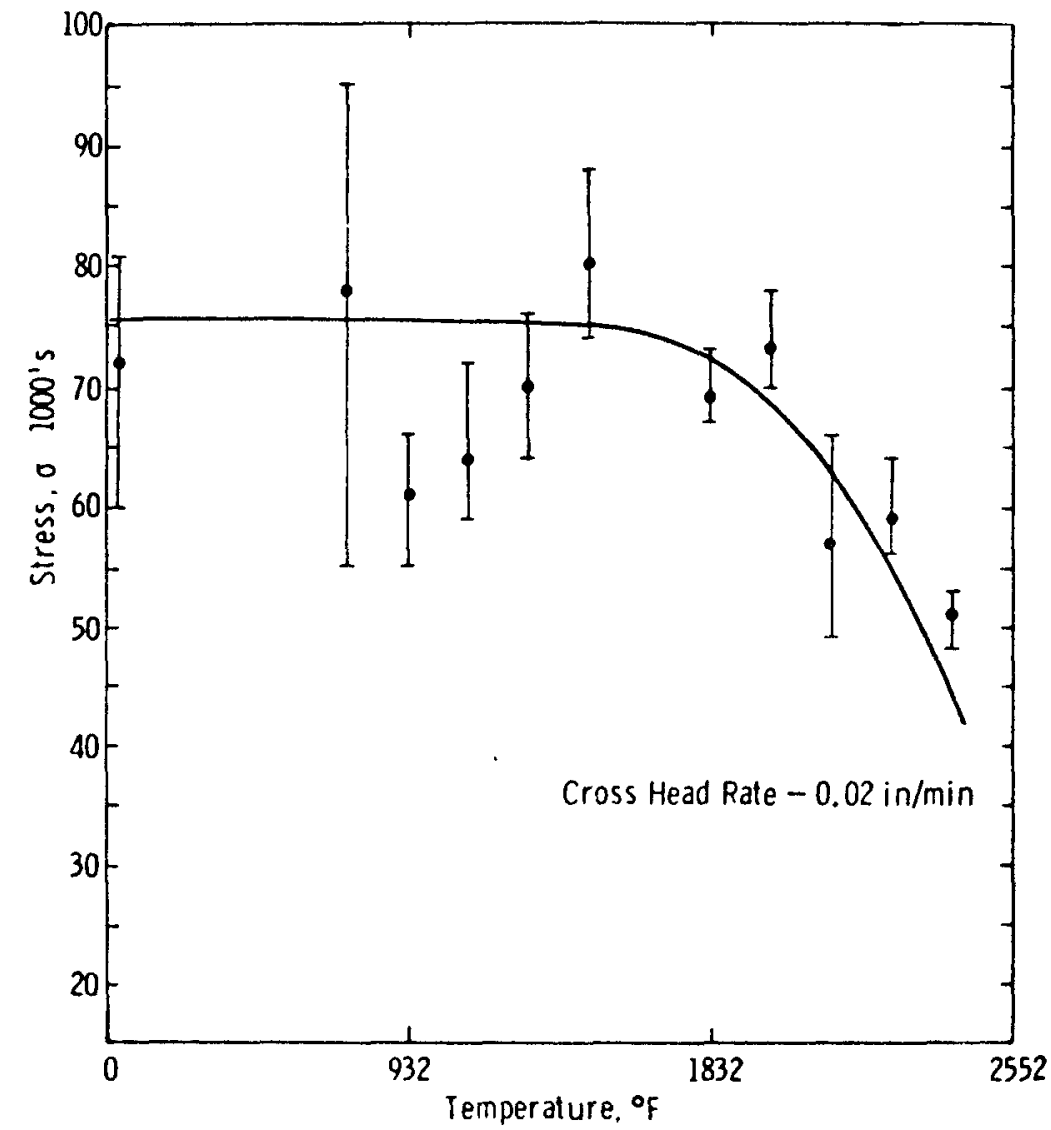

Figure 1.15 Flexural Strength of Hot Pressed Silicon Carbide

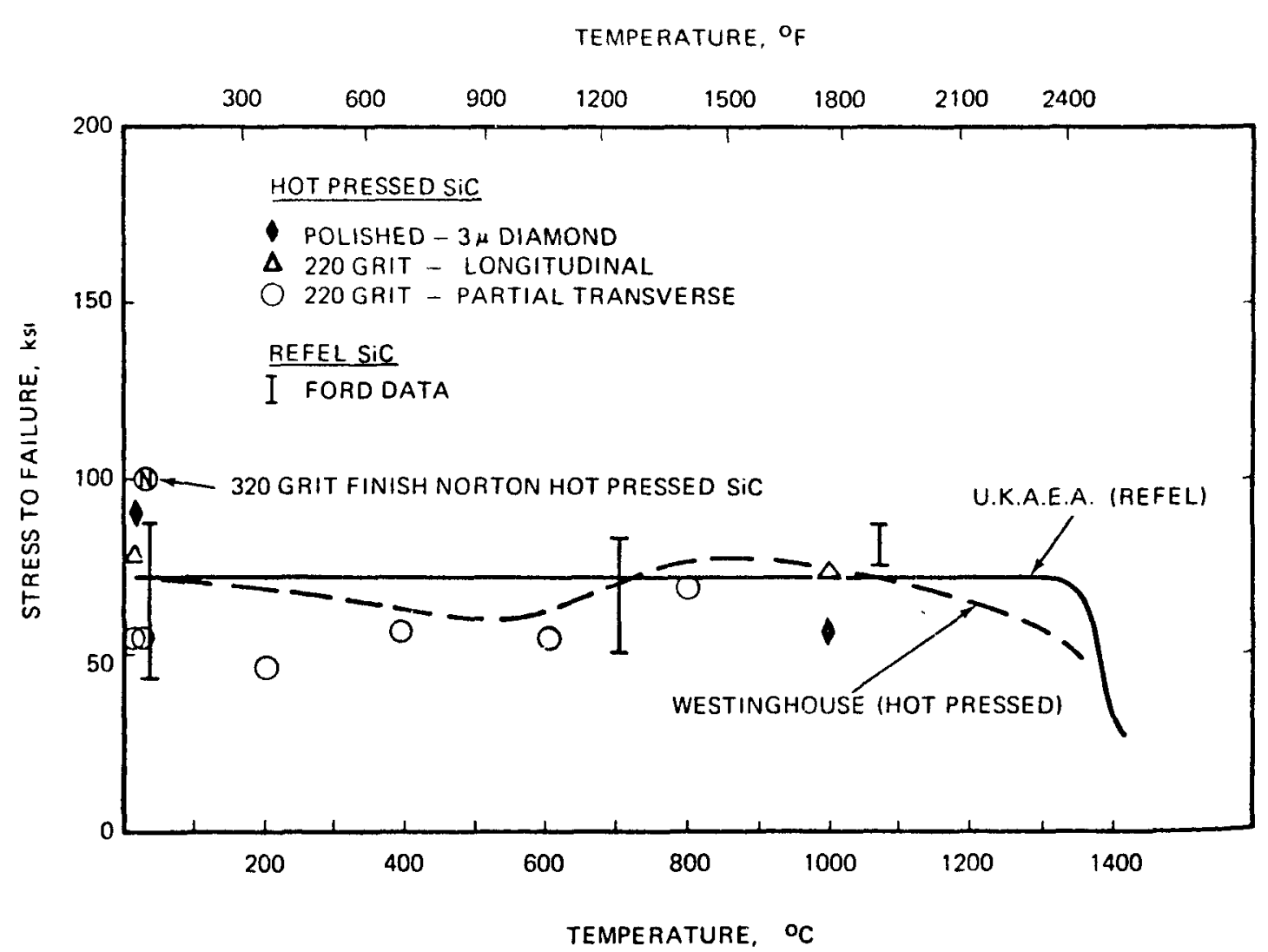

Figure 1.16 Flexural Strength of Silicon Carbide 
Table 1.4 Room-Temperature Mechanical Properties of CVD SiC ${ }^{(25)}$

\begin{tabular}{|c|c|c|c|c|c|c|c|}
\hline $\begin{array}{c}\text { Specimen } \\
\text { No. }\end{array}$ & $\begin{array}{l}\text { Density" } \\
\left(\mathrm{g} / \mathrm{cm}^{3}\right)\end{array}$ & $\begin{array}{c}\text { Grain } \\
\text { diameter } \\
(\mu \mathrm{m})\end{array}$ & $\begin{array}{c}\text { Deposition } \\
\text { temp. } \\
\left({ }^{\circ} \mathrm{C}\right)\end{array}$ & $\begin{array}{c}\text { Number } \\
\text { tested }\end{array}$ & $\begin{array}{l}\text { Mean } \\
\text { fracture } \\
\text { stressi } \\
\text { (psi) }\end{array}$ & $\begin{array}{c}\text { Mean } \\
\text { Young's } \\
\text { modulust } \\
\left(p s i \times 10^{-0}\right)\end{array}$ & \\
\hline $\begin{array}{l}3742-85 \\
3742-89 \\
3662-31 \\
3662-111 \\
3742-83 \\
3742-87 \\
3662-73 \\
3662-71 \\
3662-71 \\
3742-145 \\
4032-99 \\
3605-43 \\
4032-55\end{array}$ & $\begin{array}{l}3.193 \\
3.171 \\
3.199 \\
3.189 \\
3.199 \\
3.191 \\
3.208 \\
3.184 \\
3.184 \\
3.210 \\
3.206 \\
2.959 \\
3.038\end{array}$ & 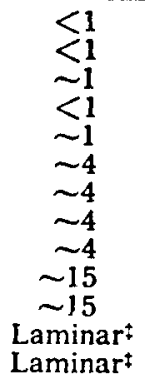 & $\begin{array}{l}1400 \\
1400 \\
1400 \\
1400 \\
1400 \\
1600 \\
1600 \\
1600 \\
1600 \\
1800 \\
1800 \\
1400 \\
1300\end{array}$ & $\begin{array}{r}11 \\
11 \\
8 \\
11 \\
9 \\
9 \\
11 \\
9 \\
5 \\
10 \\
12 \\
5 \\
10\end{array}$ & $\begin{array}{r}109,500 \pm 23,500 \\
137,800 \pm 15,100 \\
109,500 \pm 11,700 \\
144,000 \pm 11,500 \\
121,400 \pm 15,700 \\
106,000 \pm 10,350 \\
135,900 \pm 12,700 \\
106,200 \pm 11,800 \\
113,300 \pm 11,700 \\
106,600 \pm 23,200 \\
134,100 \pm 10,700 \\
70,300 \pm 12,600 \\
98,900 \pm 20,900\end{array}$ & $\begin{array}{l}60.2 \pm 2.9 \\
61.7 \pm 3.7 \\
61.5 \pm 2.2 \\
60.5 \pm 3.3 \\
61.5 \pm 1.6 \\
62.6 \pm 2.4 \\
64.0 \pm 2.9 \\
61.9 \pm 4.7 \\
63.6 \pm 2.3 \\
62.9 \pm 6.1 \\
60.8 \pm 5.1 \\
42.9 \pm 3.3 \\
48.7 \pm 3.6\end{array}$ & . \\
\hline
\end{tabular}

*The $\mathrm{X}$-ray density of $\beta$-SiC is $3.212 \mathrm{~g} / \mathrm{cm}^{2}$.

:Uncertainties are standard deviations.

'Laminar deposits consist of closely spaced laminations parallel to the plane of deposition and contain significant amounts of excess silicon.

Table 7.5 Mechanical Properties of CVD SiC as Functions of Temperature and Grain Diameter

(25)

\begin{tabular}{|c|c|c|c|c|c|}
\hline $\begin{array}{c}\text { Specimen } \\
\text { No. }\end{array}$ & $\begin{array}{c}\text { Grain } \\
\text { diameter } \\
(\mu \mathrm{m})\end{array}$ & $\begin{array}{l}\text { Testing } \\
\text { temp. } \\
\left({ }^{\circ} \mathrm{C}\right)\end{array}$ & $\begin{array}{c}\text { Number } \\
\text { tested }\end{array}$ & $\begin{array}{c}\text { Fracture } \\
\text { stress } \\
\text { (psi) }\end{array}$ & $\begin{array}{c}\text { Young's } \\
\text { modulus: } \\
\left.\text { (psi } \times 10^{-6}\right)\end{array}$ \\
\hline $\begin{array}{l}3742-89 \\
3742-89 \\
3742-89 \\
3742-89 \\
3662-111 \\
3662-111 \\
3662-111 \\
3662-73 \\
3662-73 \\
3662-73 \\
4032-99 \\
4032-99 \\
4032-99 \\
4032-99\end{array}$ & $\begin{array}{l}<1 \\
<1 \\
<1 \\
<1 \\
<1 \\
<1 \\
-4 \\
-4 \\
\sim 4 \\
\sim 15 \\
-15 \\
\sim 15 \\
\sim 15\end{array}$ & $\begin{array}{r}25 \\
940 \\
1250 \\
1400 \\
25 \\
940 \\
1215 \\
25 \\
940 \\
1215 \\
25 \\
940 \\
1215 \\
1400\end{array}$ & $\begin{array}{r}11 \\
8 \\
9 \\
8 \\
9 \\
6 \\
5 \\
11 \\
7 \\
5 \\
12 \\
9 \\
8 \\
6\end{array}$ & $\begin{array}{l}137,800 \pm 15,100 \\
131,200 \pm 11,100 \\
142,100 \pm 14,800 \\
126,000 \pm 7,400 \\
144,000 \pm 11,500 \\
150,500 \pm 21,600 \\
175,000 \pm 18,300 \\
135,900 \pm 12,700 \\
129,700 \pm 17,900 \\
168,800 \pm 16,500 \\
134,100 \pm 10,700 \\
143,400 \pm 13,000 \\
173,250 \pm 14,100 \\
188,750 \pm 7,950\end{array}$ & $\begin{array}{l}61.7 \pm 3.7 \\
54.2 \pm 3.6 \\
52.5 \pm 1.4 \\
28.9 \pm 1.6 \\
60.5 \pm 3.3 \\
55.7 \pm 2.9 \\
48.8 \pm 2.3 \\
64.0 \pm 2.9 \\
55.0 \pm 1.1 \\
48.5 \pm 2.1 \\
60.8 \pm 5.1 \\
54.4 \pm 2.4 \\
49.3 \pm 3.0 \\
39.4 \pm 2.2\end{array}$ \\
\hline
\end{tabular}

*Uncertainties are standard deviations. 


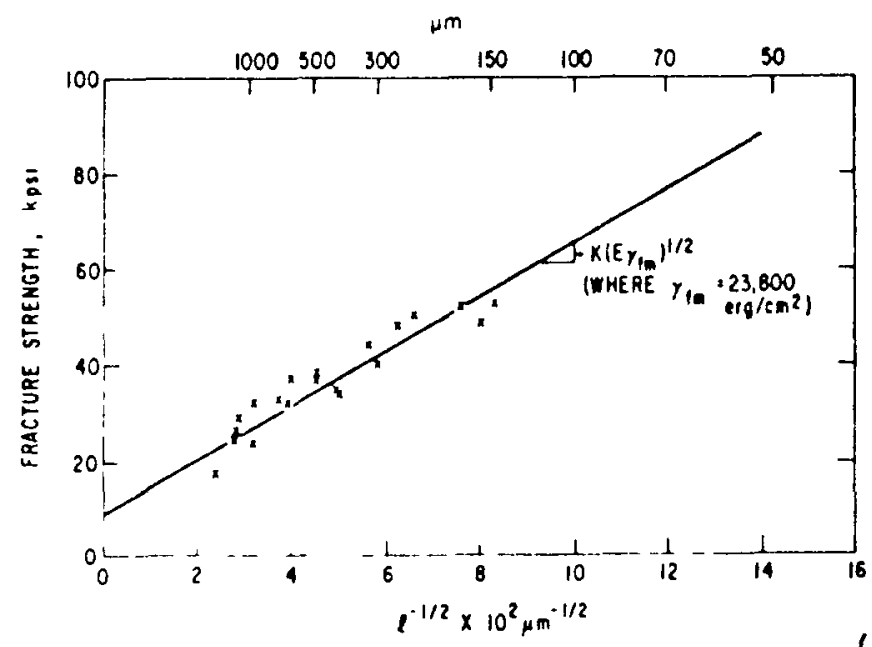

Fig. 1.17 Fracture siress in B-type SiC specimens vs size of groins initiating fracture.

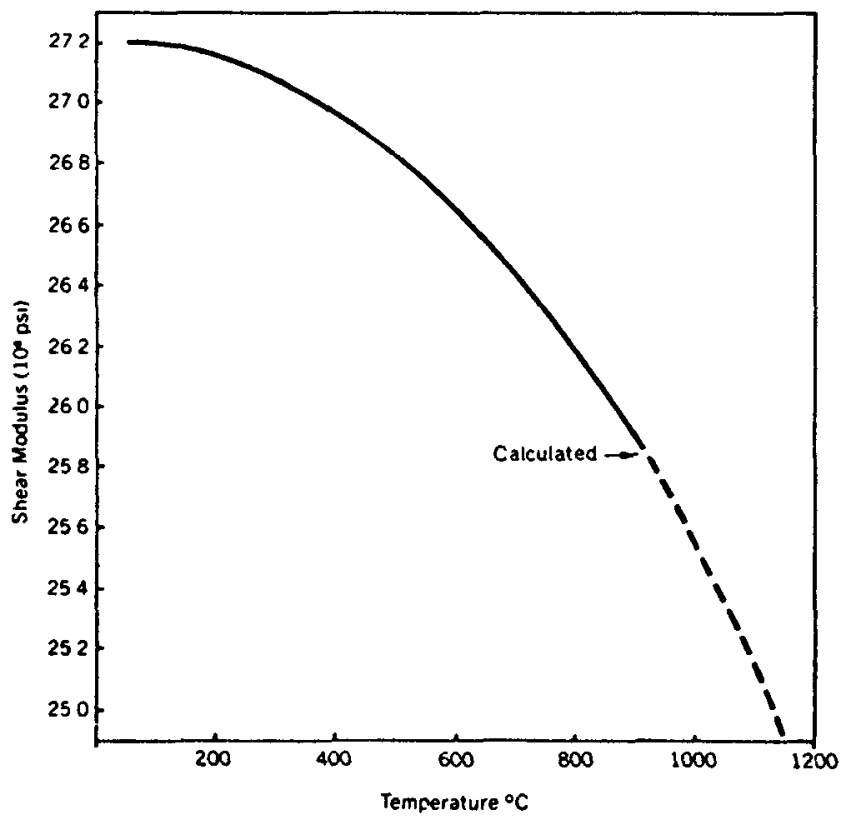

FIGURE 1.19

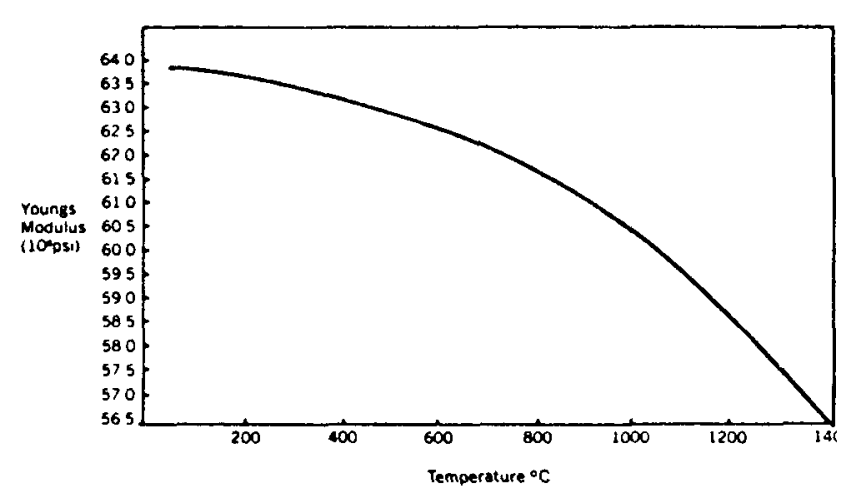

FIGURE 1.18

(2)

Youngs modulus, determined sonically as a function of temperature

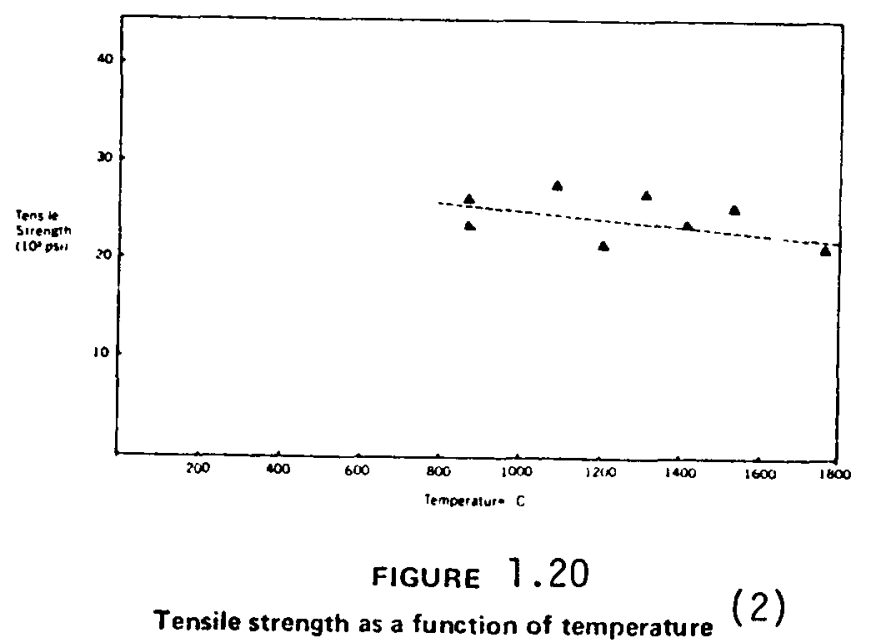

Tensile strength as a function of temperature 


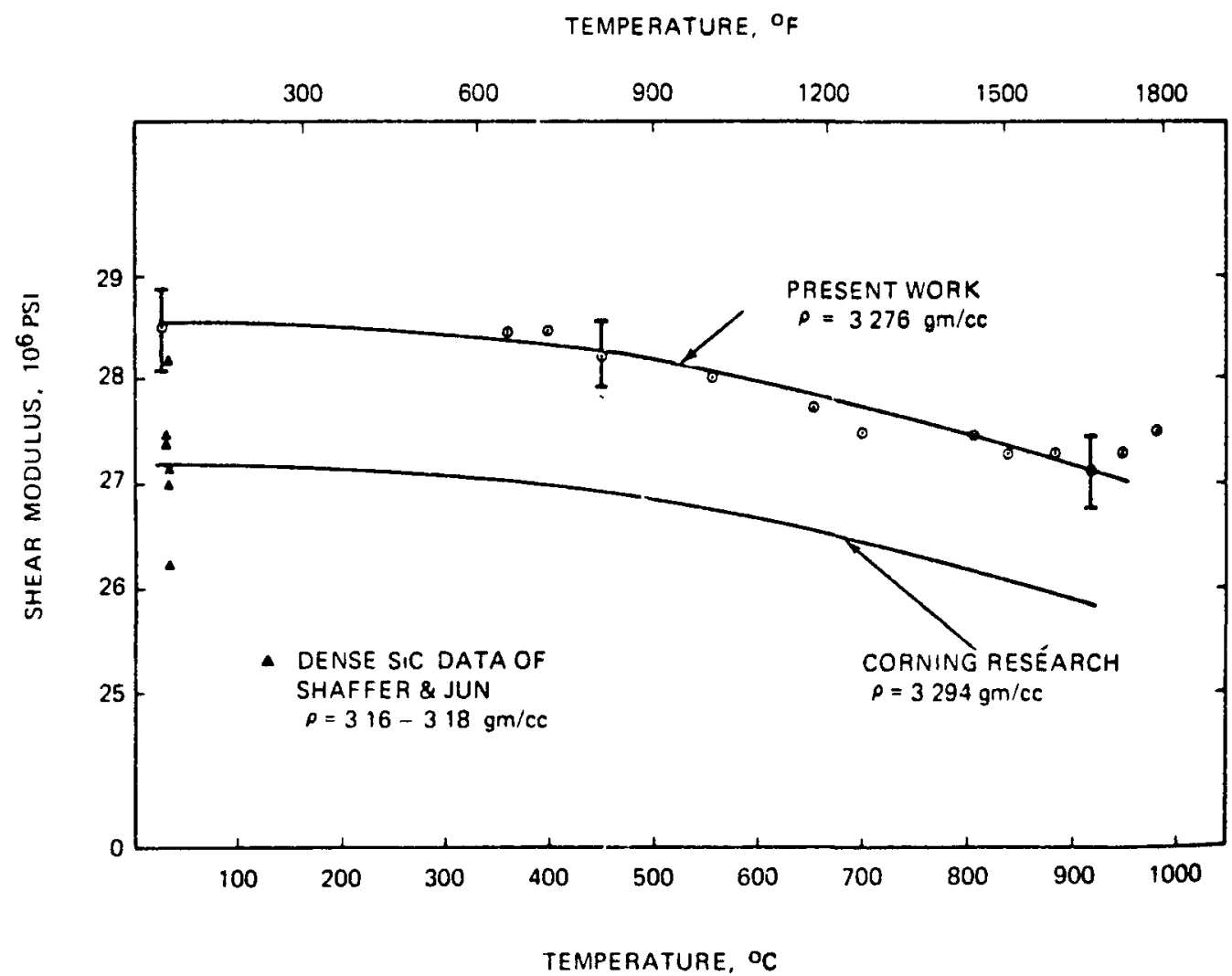

Figure 1.21 Shear Modulus of Hot-Pressed Silicon Carbide(12) 


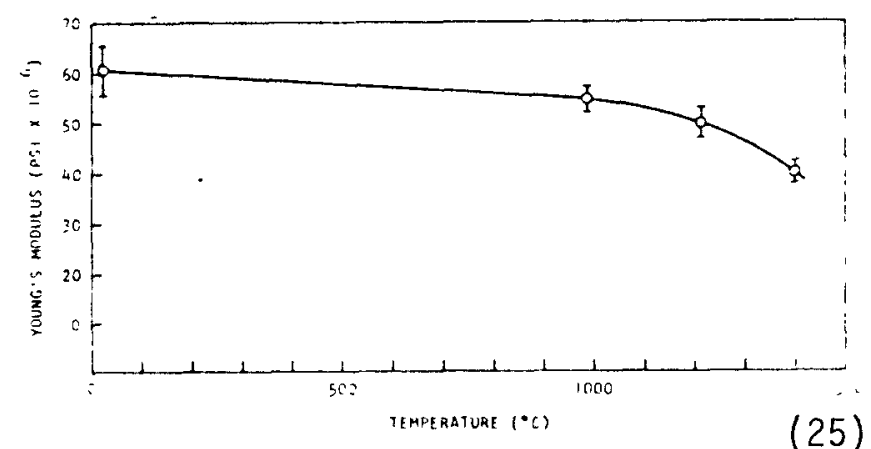

Fig. 1.22 Young's modulus vs temperature for coarse-grained $\mathrm{SiC}$ (grain diameter $15 \mu \mathrm{m}$ ).

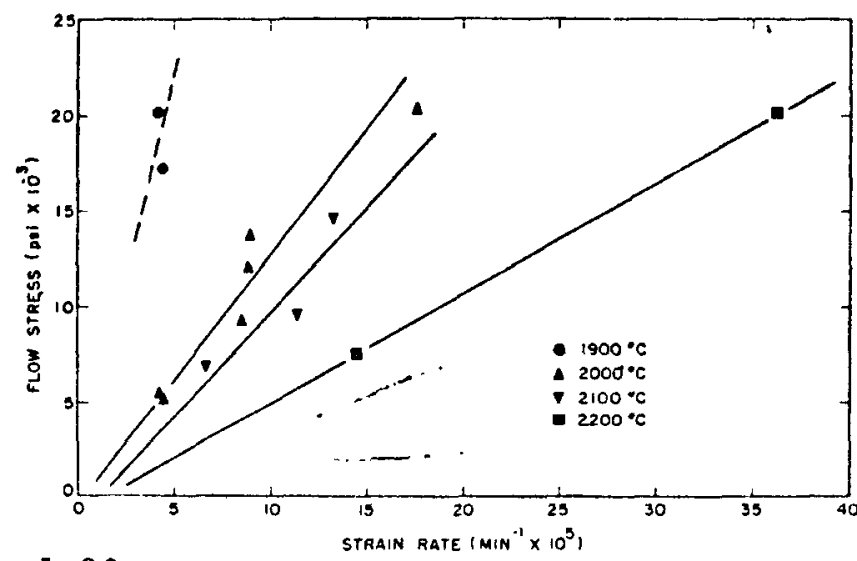

Fig. 1.23 Linear plots of flowystress ys. strain rate for dense (24) polycrystalline $\mathrm{SiC}$.

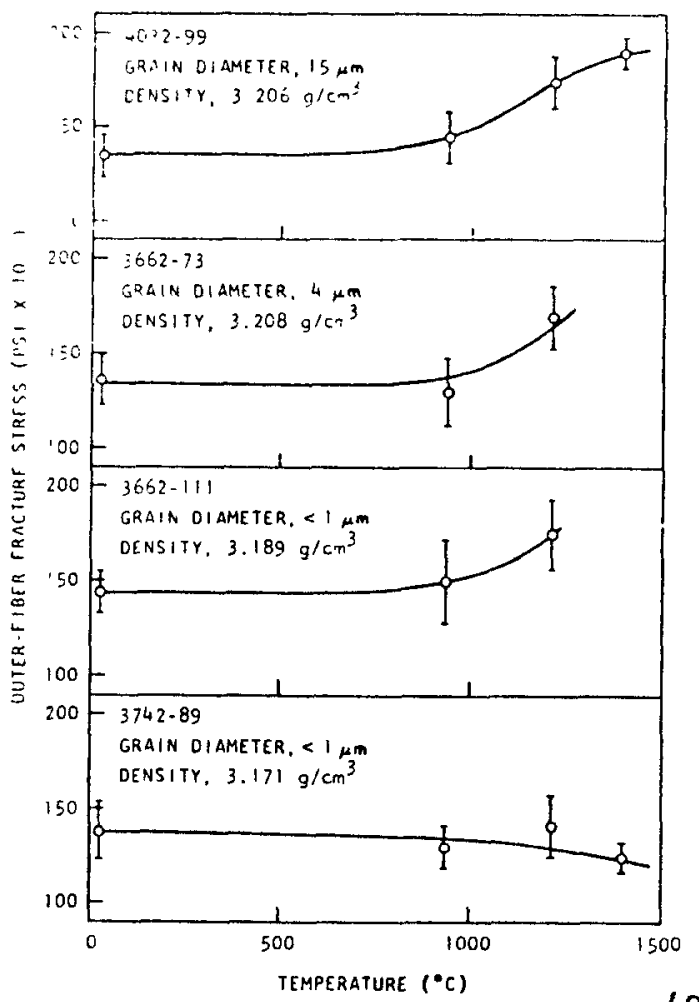

Fig. 1.24 Bend strength is temperalure for CVD SiC of several grain sizes. 


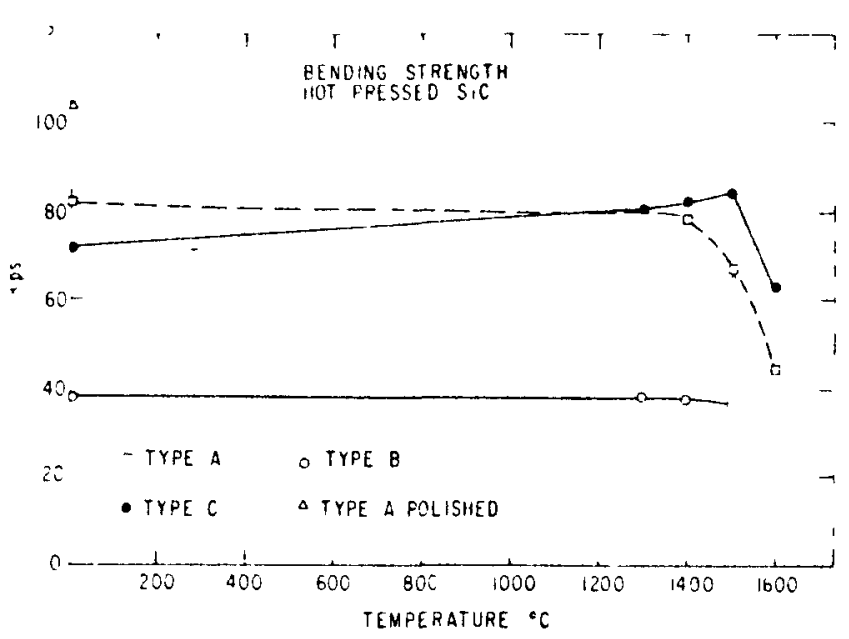

Fig. 1.25 Three point bending strength of hot-pressed SiC. (1)

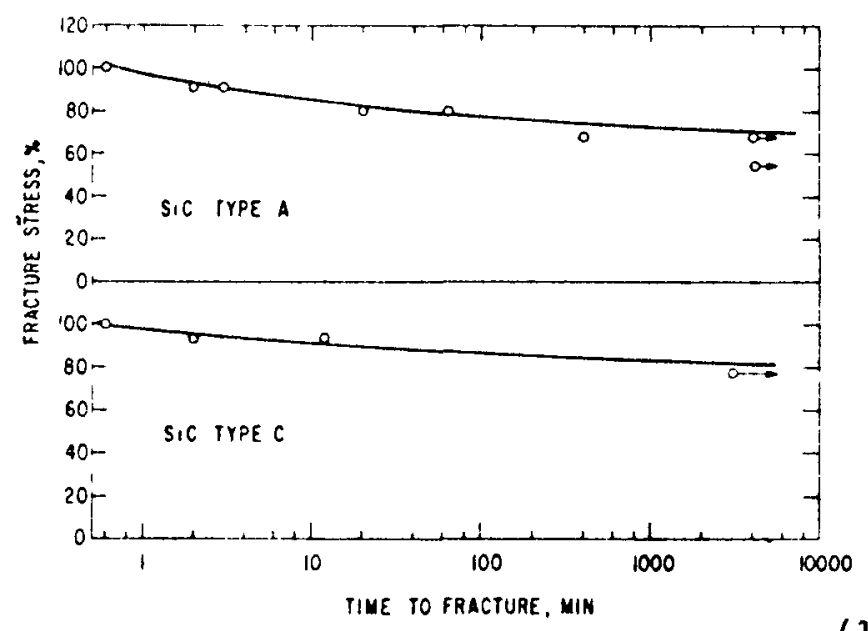

Fig. 1.26 Time to tracture at $1600^{\circ} \mathrm{C}$ of type $A$ and $C$ hat-pressed S.C

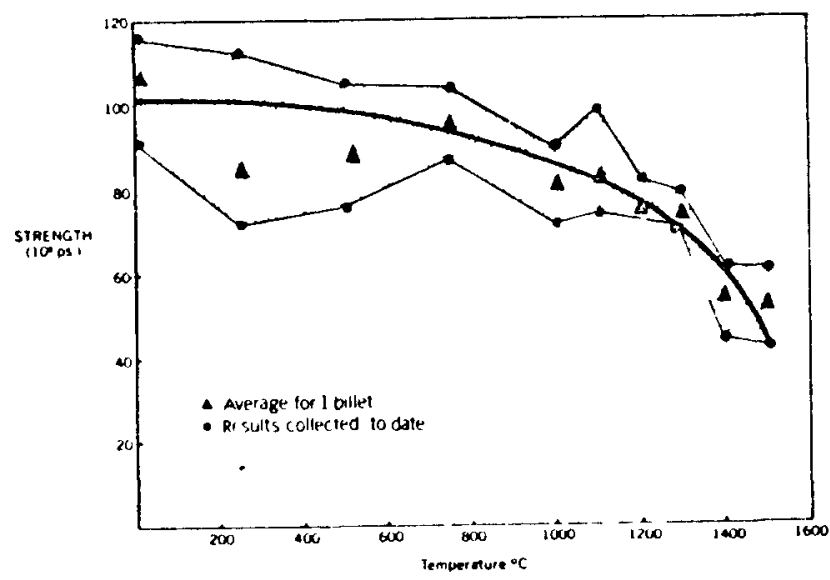

FIGURE 1.27

Cross bending strenjth measured in 3 point lodding as a function of temperature 


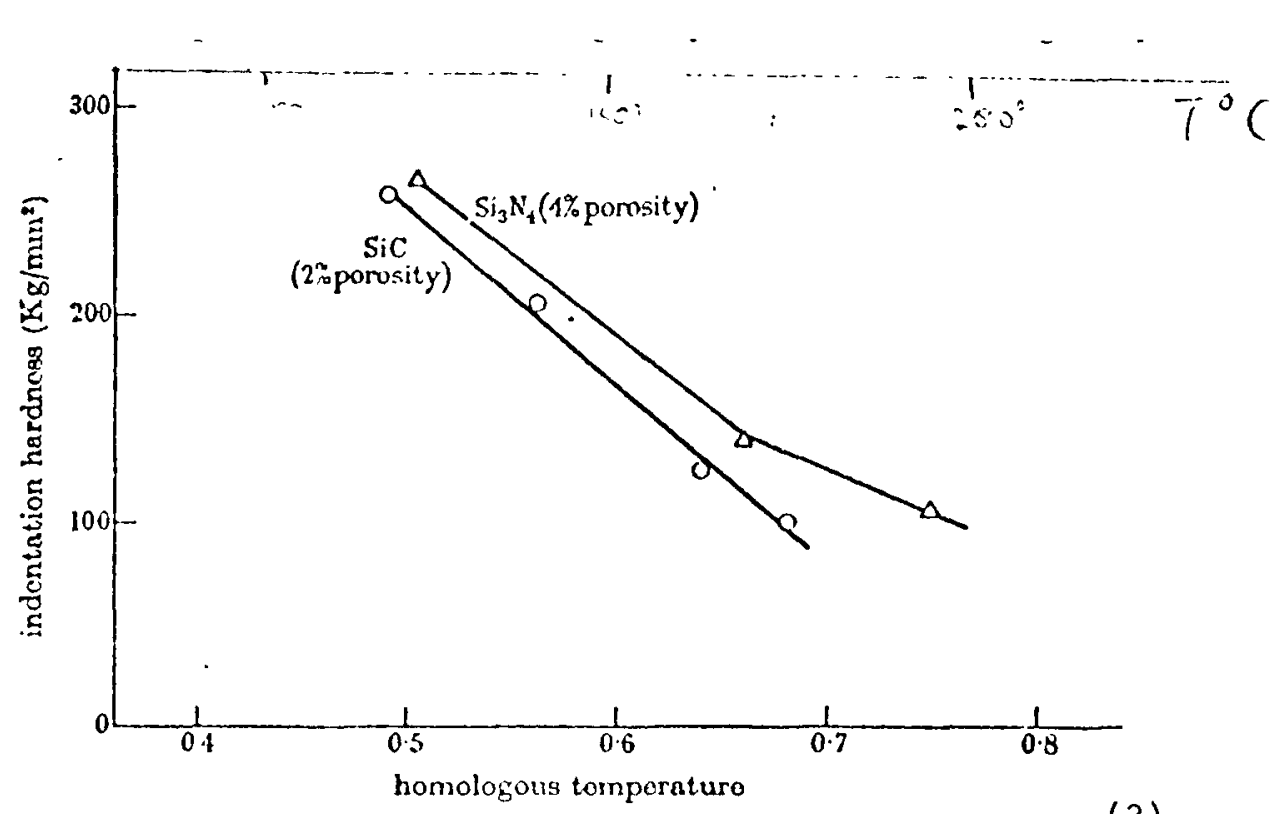

Fig. 1.28 Muturl indentation hud dness as a function of temperature for (3) silicon nitrido (crossed cylisders) and silicon carbicle (crossed wedges).

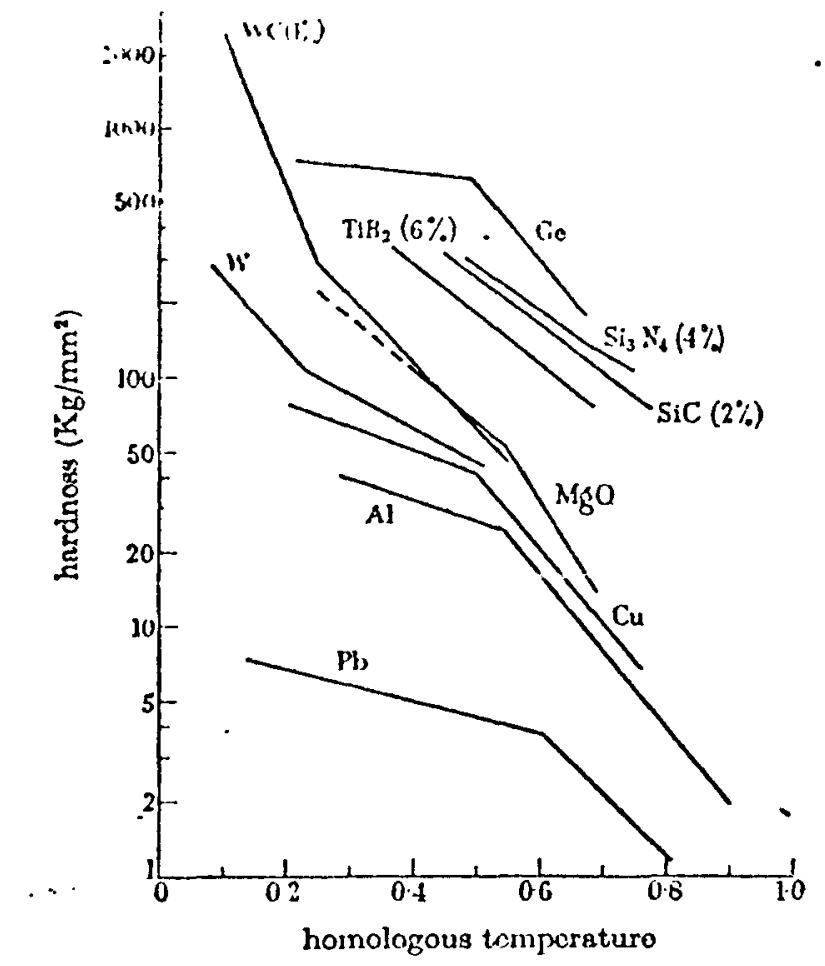

Fig. 1.29 Summar! of inain results showing nffcet of tempernture on the indentation(3) hardness of typicul metals, single crystals of $M_{\tilde{F}} \mathrm{O}$, sintered specimens of carbjides, borides and nitrides. Ifost of tho sintered materinls availallo were porms (porosity indicated in bracketw) but a higher temperatures their behaviour approwehes that of fully compacted

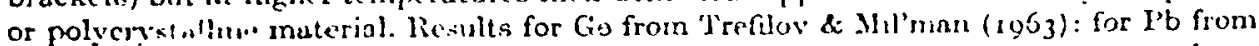

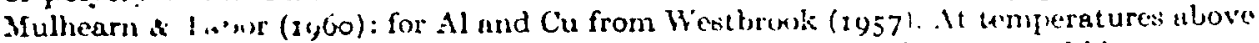

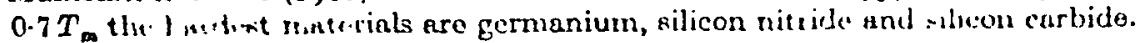




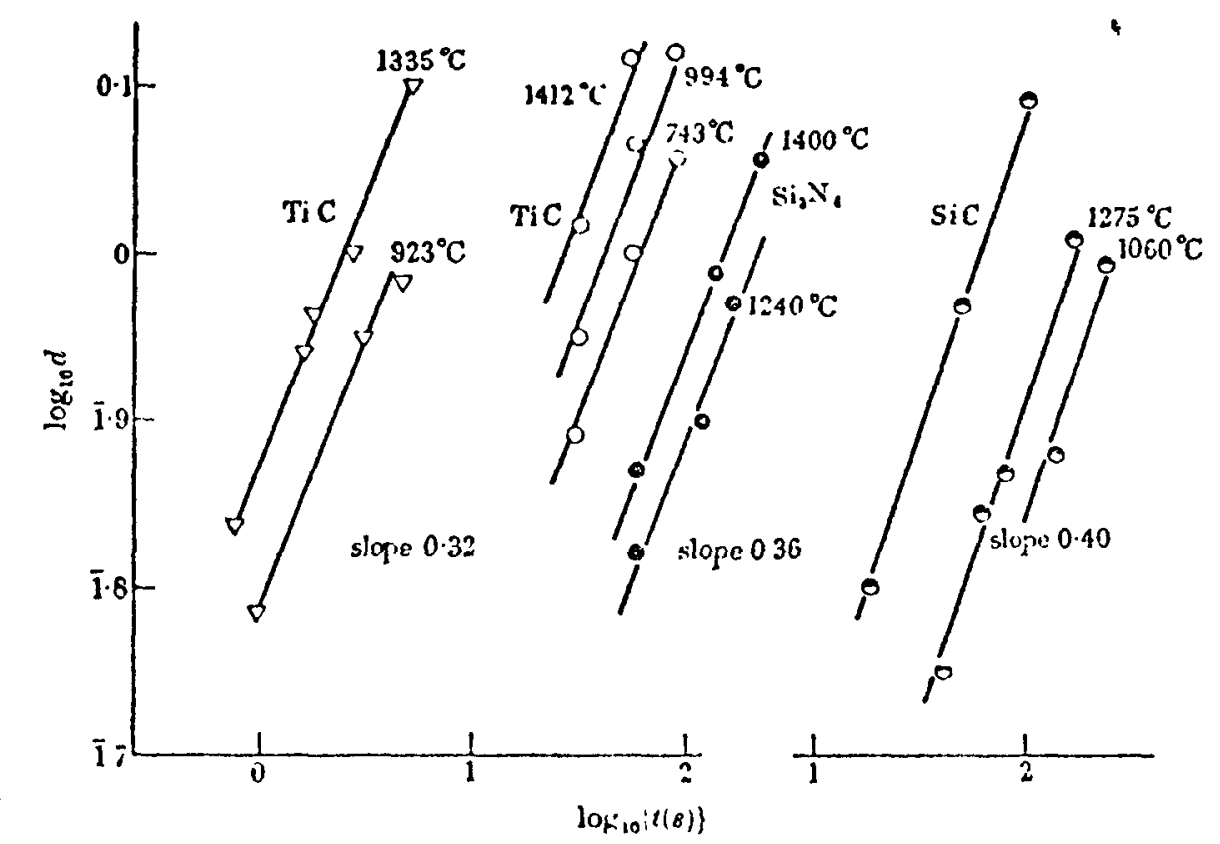

$(3)$

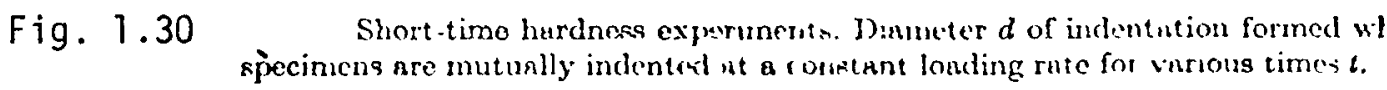


-

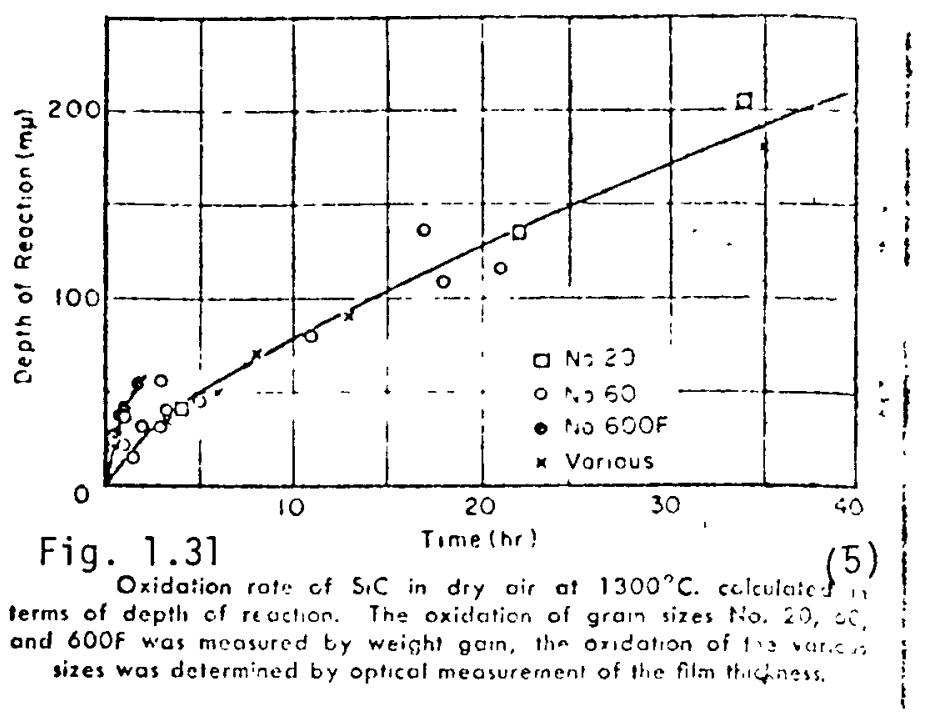

Fig. 1.31

Oxidation rofe of $5, C$ ierms of depth of reaction. The oxidation of gram sizes 10.20 , 30 weight goin tha oxidation of is bute

sizes was determined by optical meosurement of the film thichinss.

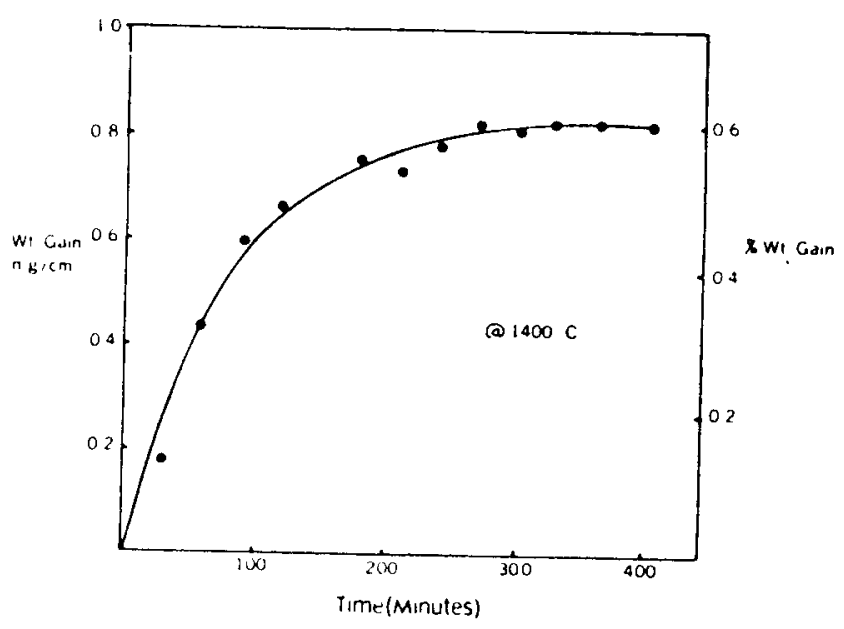

FIGURE 1.32

Oxidation (TGA) curves of NC203 SiC held at $1440^{\circ} \mathrm{C}$ (2) in atmospheric air at approximately 60 percent relative humidity

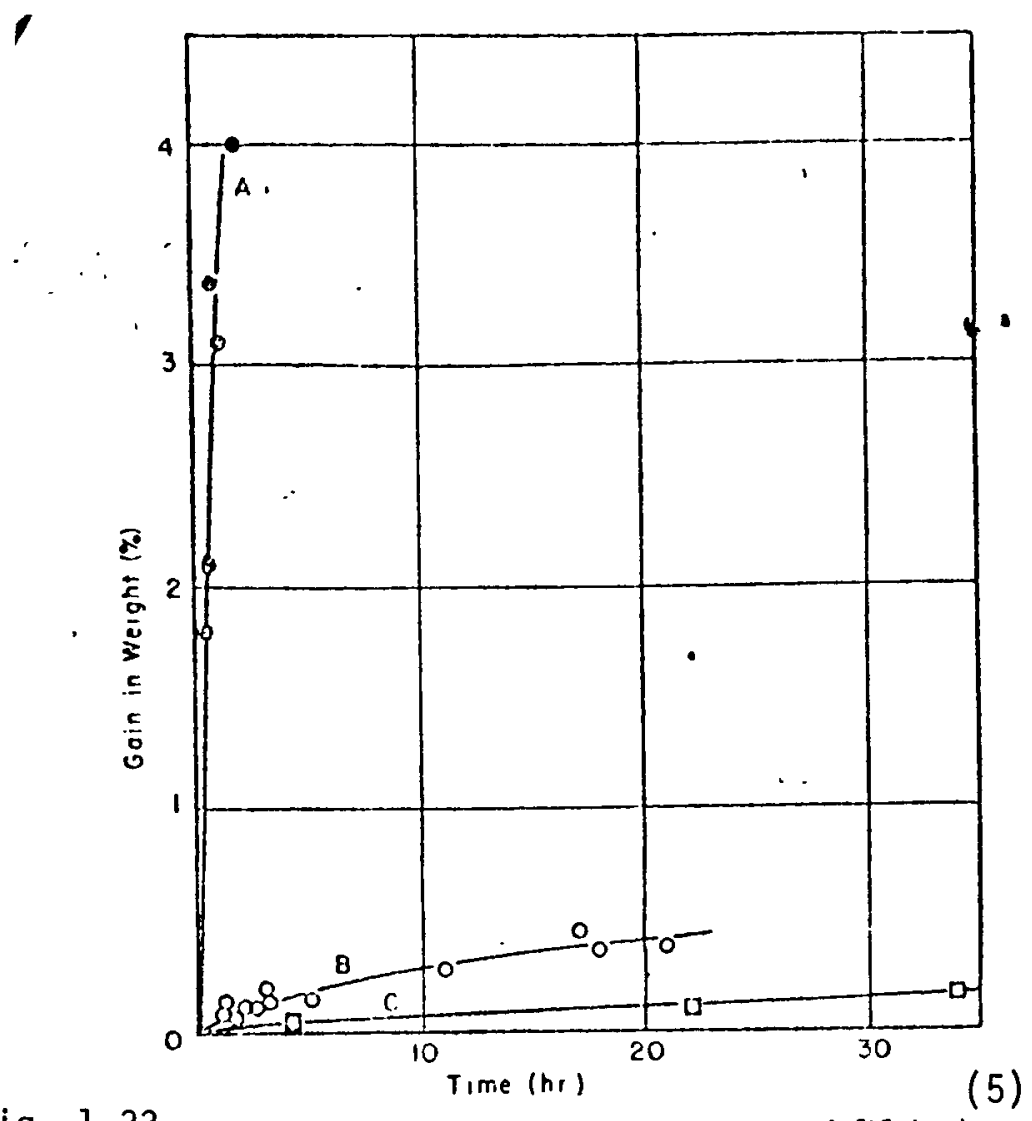

Fig. 1.33 Effect of porticle size on the oxidation rate of $\mathrm{SiC}$ in dry oir of $1300^{\circ} \mathrm{C}$. (A) No. $600 \%, 5000 \mathrm{sq} . \mathrm{cm}$. per gm,; (b) Nn. Co, 200 sq. cm. per gm.; and (C) No. 20,46 sq cin. per gin. 
2.0 SILICON NITRIDE 
Table 2.1

Properfics of Silicon Nitride

Crisial Sirlcil re

"Si+N $N_{4}$ hexdoull $a=77.49 \quad c=5617 p=3184 \mathrm{~g}^{\mathrm{cmg}}$

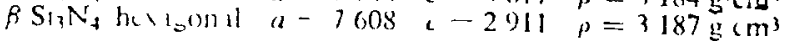

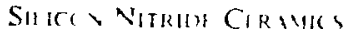

Densitr

Modulus of rupture

Hirdma

7 hicm 3 lexpmion

Themal conducinety

Flectricil rosston ily

(when airy)

$T_{e}$ value

Permuttuity

Deckelek hosettin â

Resstuna to oxitation

Resstant 1 inest kht and

$2326 \mathrm{sm}^{3}\left(24^{\circ} ; 18^{n}\right.$, porosity $)$
$160302000\left(1 \mathrm{ib} \mathrm{in}^{2}\right.$

$>9$ Mols swate

$25 \times 10 \% \mathrm{C}$

$00037 \mathrm{cgs}$

molicn miktihe on plath

$>10^{13} \mathrm{cmm} \mathrm{cm}$

$1050^{\circ} \mathrm{C}$

94

1) $001-001$

cul ir Al

(15)

rood to at hast $1,400 \mathrm{C}$

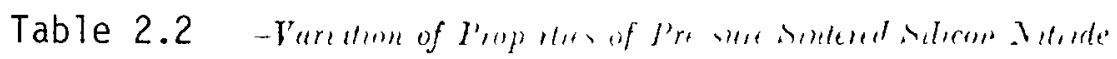

(16)

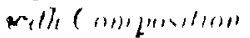

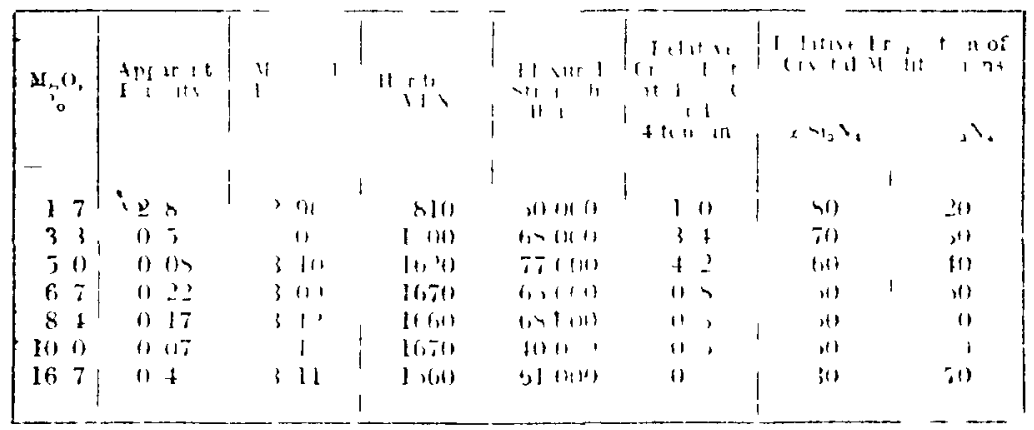

(21)

Table 2.3 Selected Properties of Candidate Ceramic Radome Materials

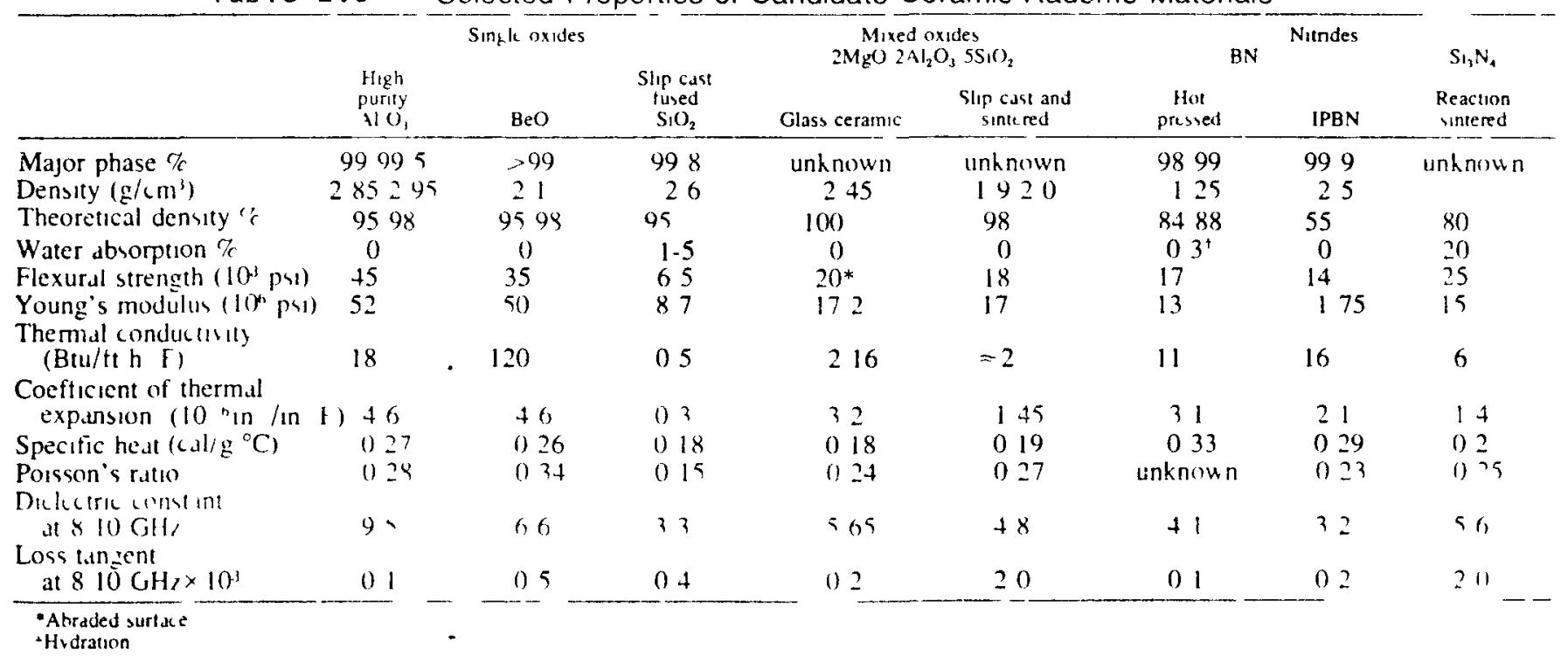




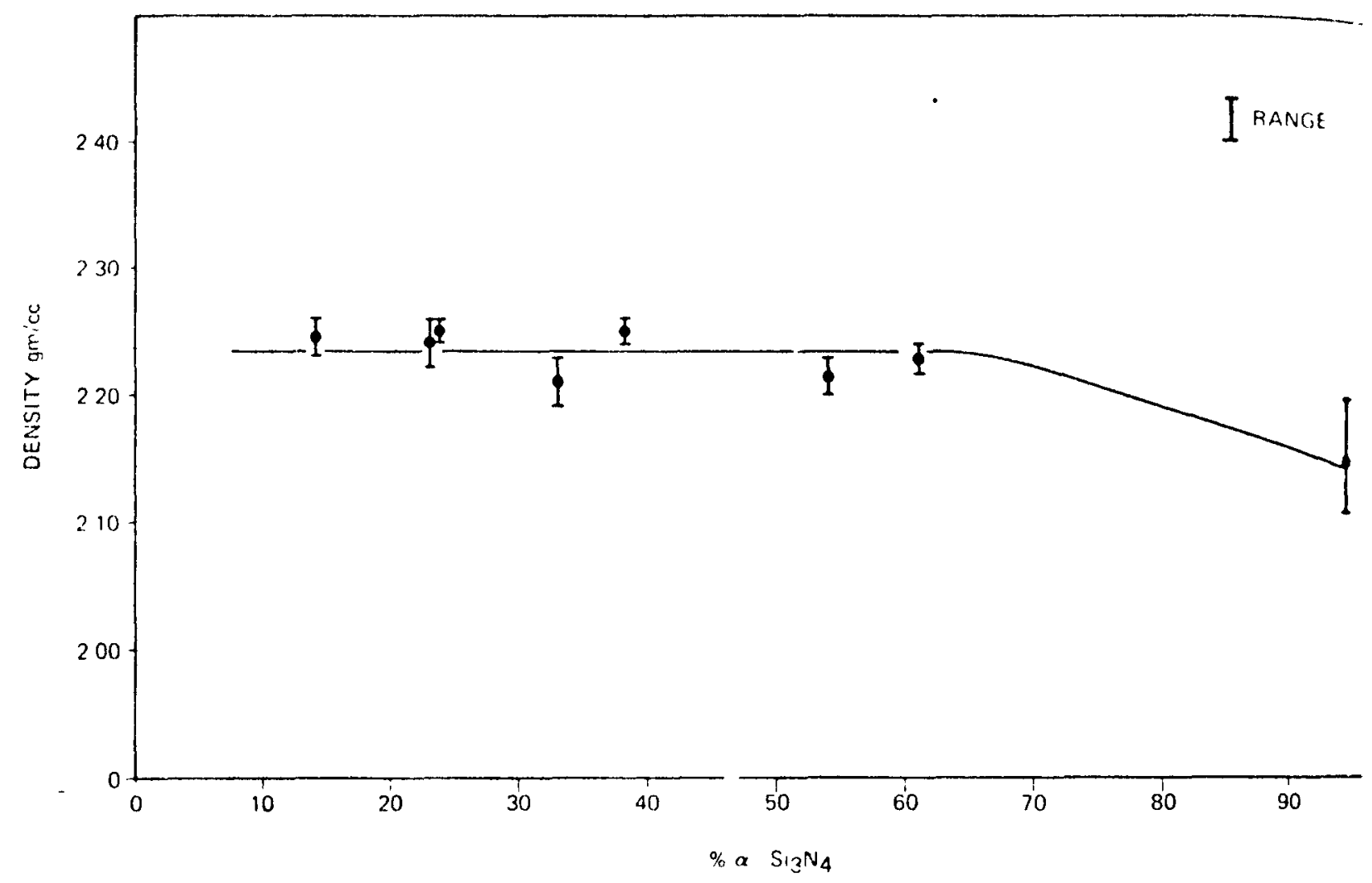

Figure 2.1 The Effect of Alpha-Beta Ratio on the Density (12) of Silicon Nitride 


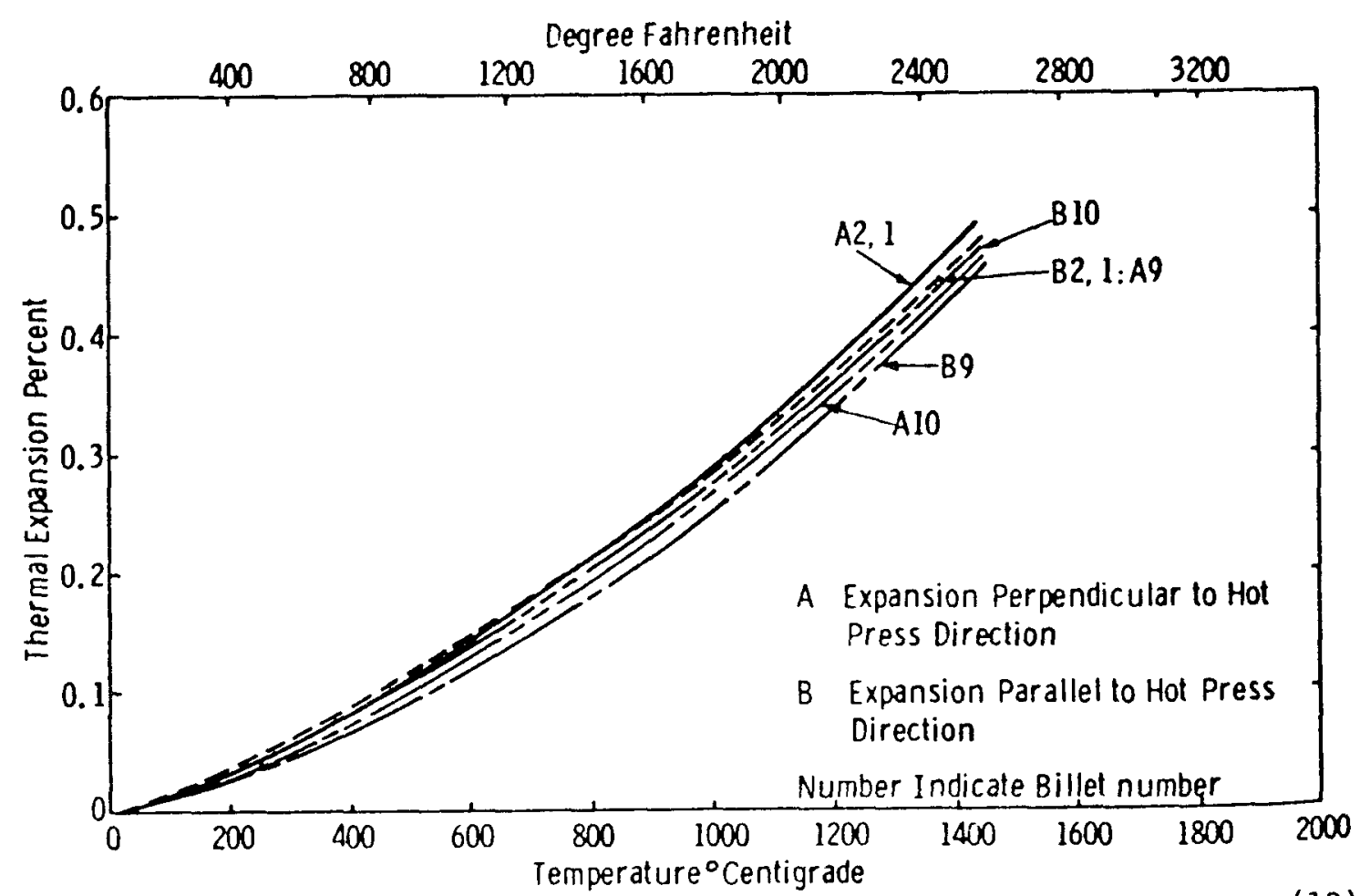

Figure 2.2 Thermal Expansion of Hot Pressed Silicon Nitride as $(12)$ Function of Temperature

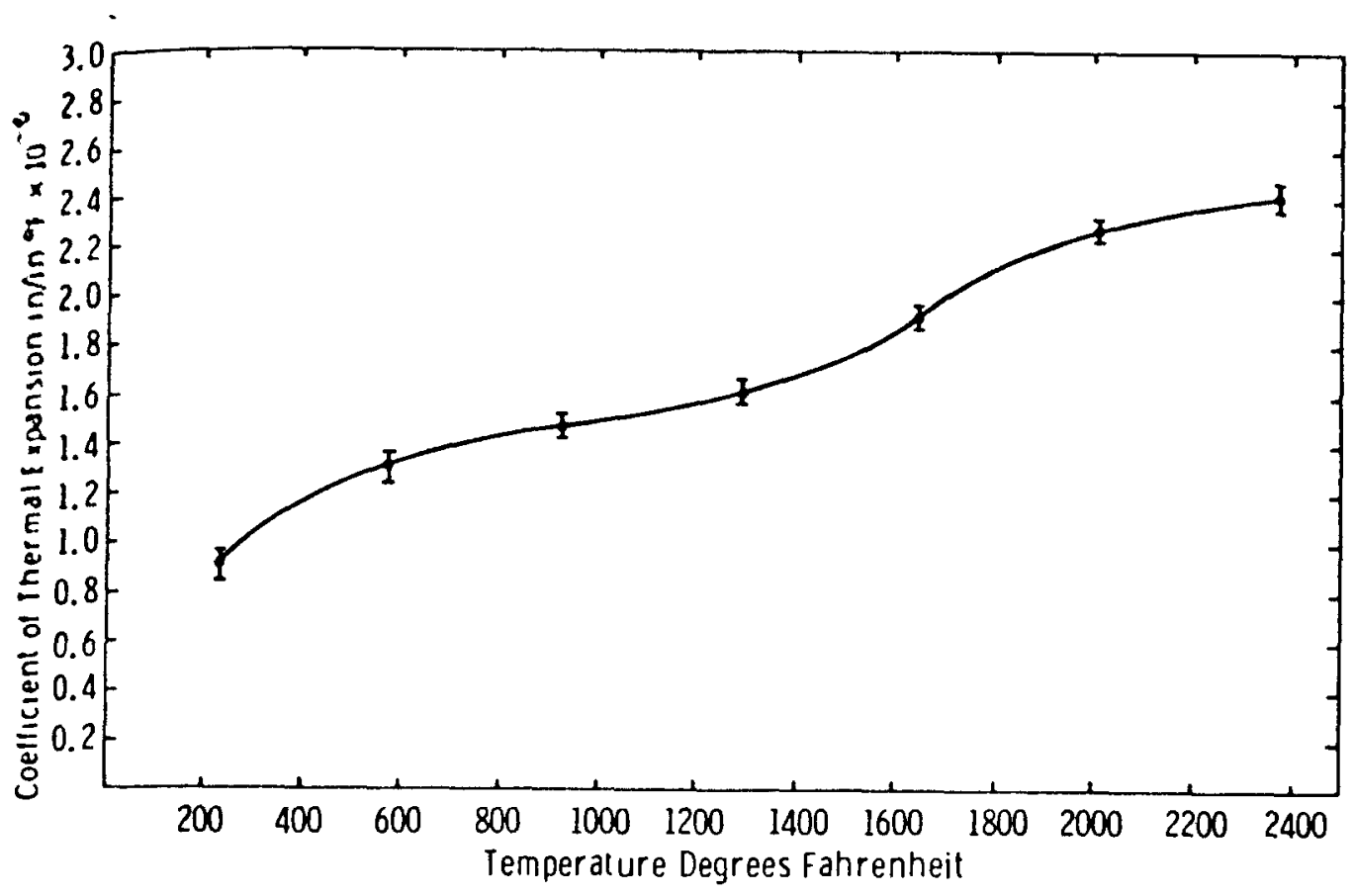

Figure 2.3 Average Coefficient of Thermal Expansion for Norton (12) HS-130 $\mathrm{Si}_{3} \mathrm{~N}_{4}$ 
Temperature, ${ }^{\circ} \mathrm{R}$

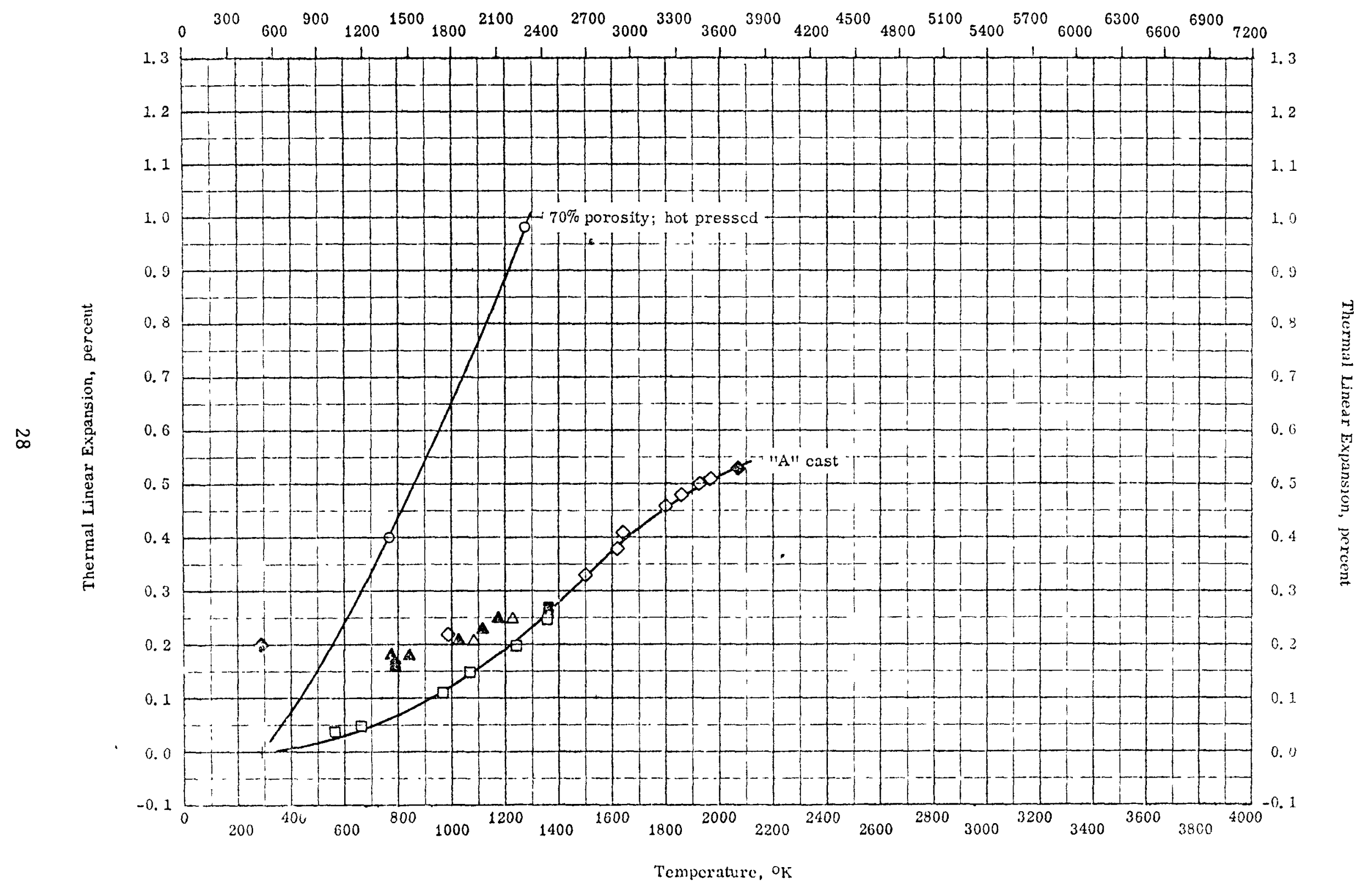

Fig. 2.4 THLRMAL LINEAR EXPANSION -- SILTLON NITRIDE (17) 


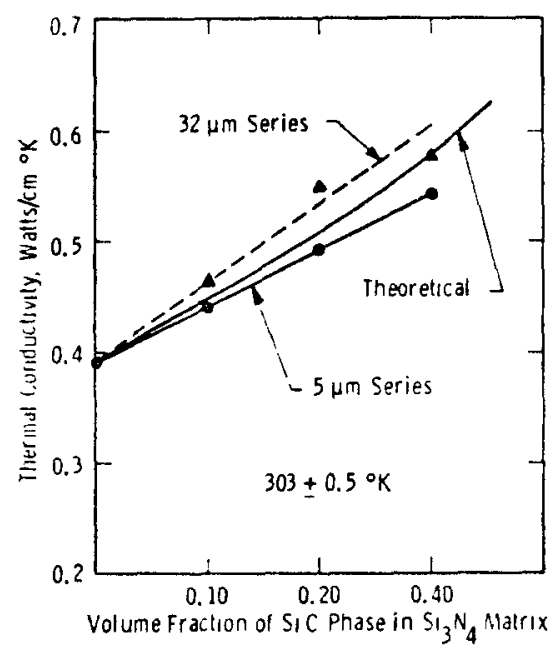

Fig. 2.5

Ther. (13)

mal condurtiv-

ity of $\mathrm{Si}$ Y...iic:

nomponite -2.

tim.

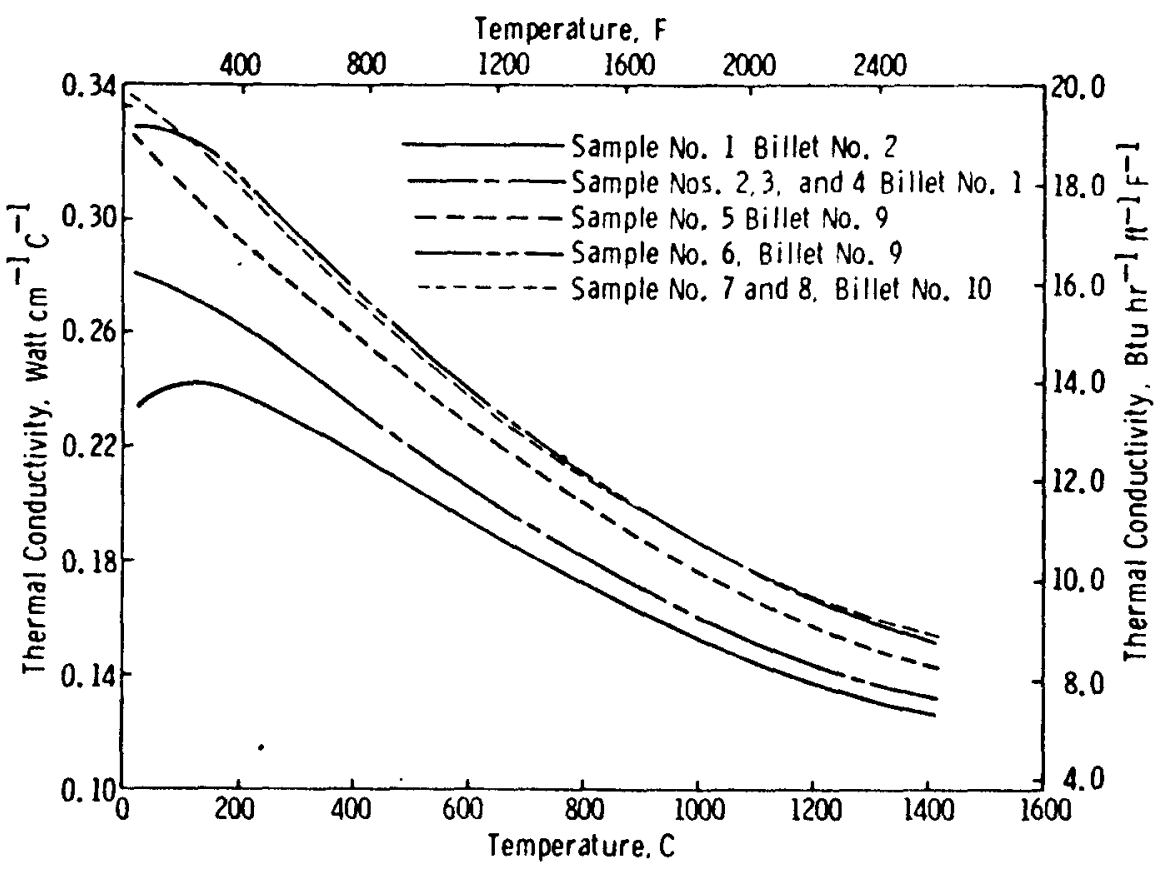

Figure 2.6 Comparison of Thermal Conductivity Values for Hea+.

Conducted Parallel to the Hot Pressing Direction in Silicon Nitride 


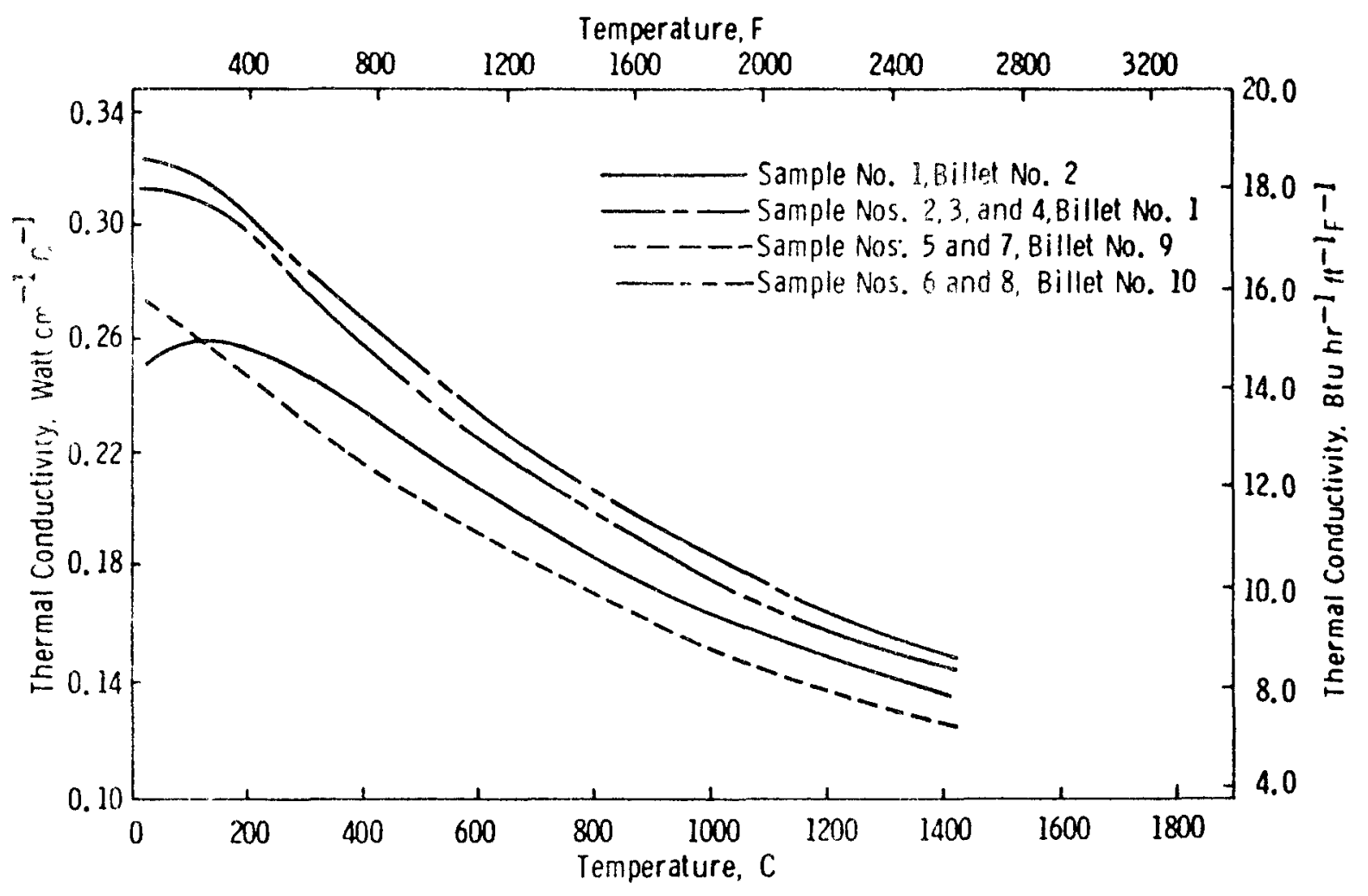

Figure 2.7 Comparison of Thermal Conductivity Values for Heat (12) Conducted Perpendicular to the Hot Pressing Direction in Silicon Nitride 
Temperature, ${ }^{\circ} \mathrm{R}$

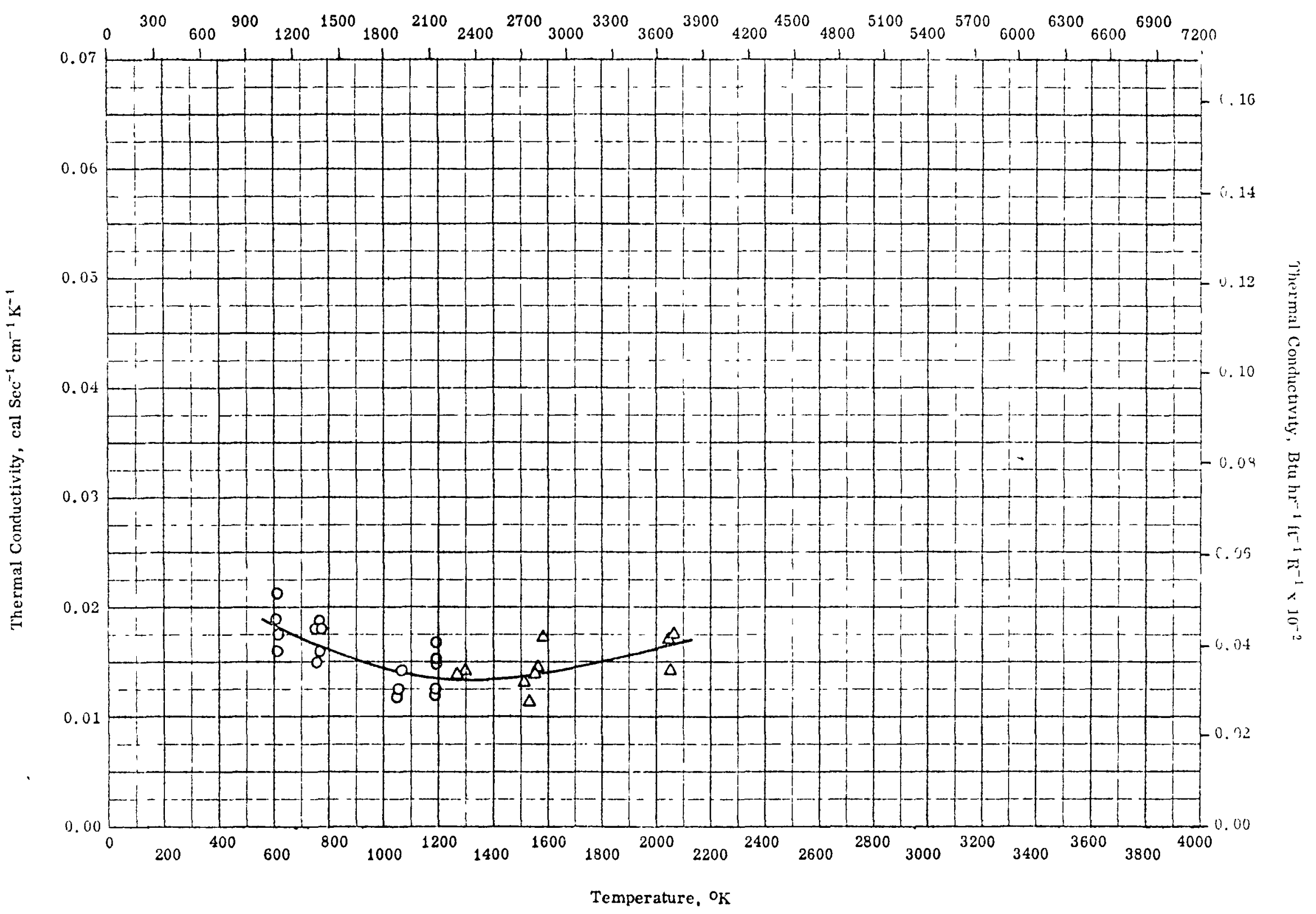

Fig. 2.8

THELNAL CONDUCTIVTTY -- SILICON NITRIDE 

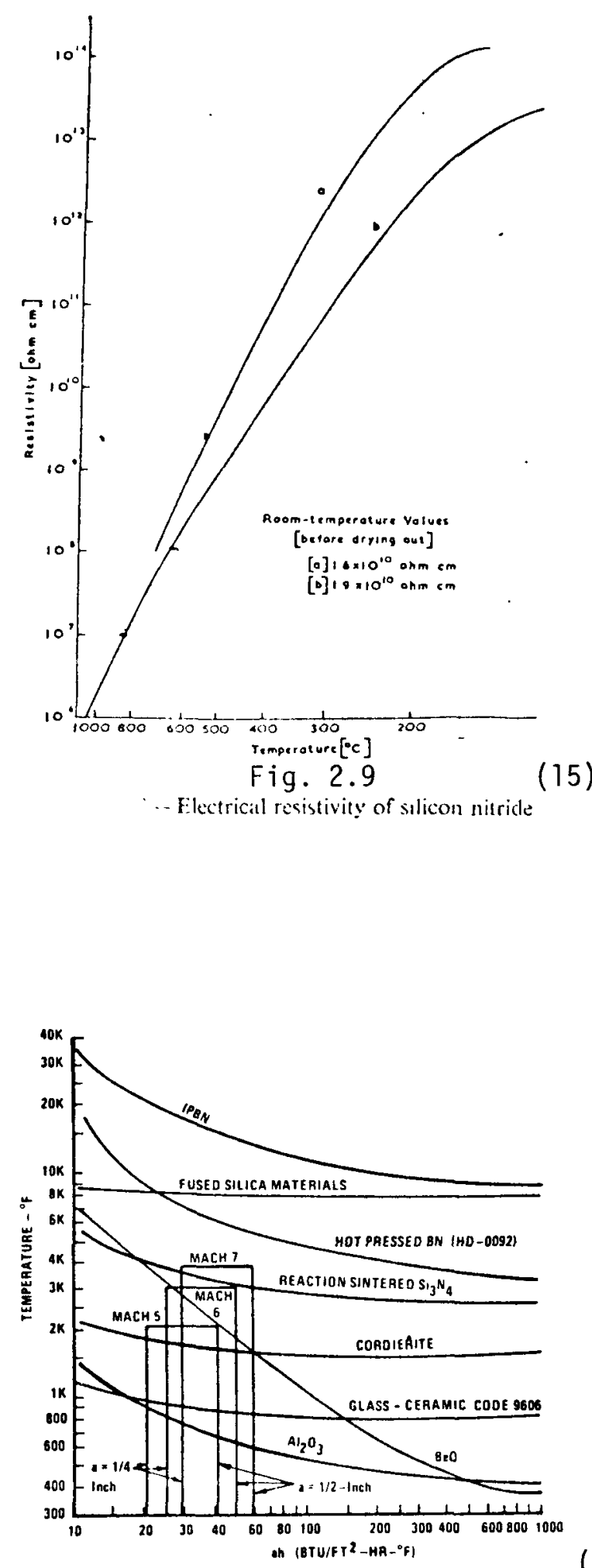

Fig. 2.10Recovery temperature vs heat transfer rate for ceramic radome materials. 


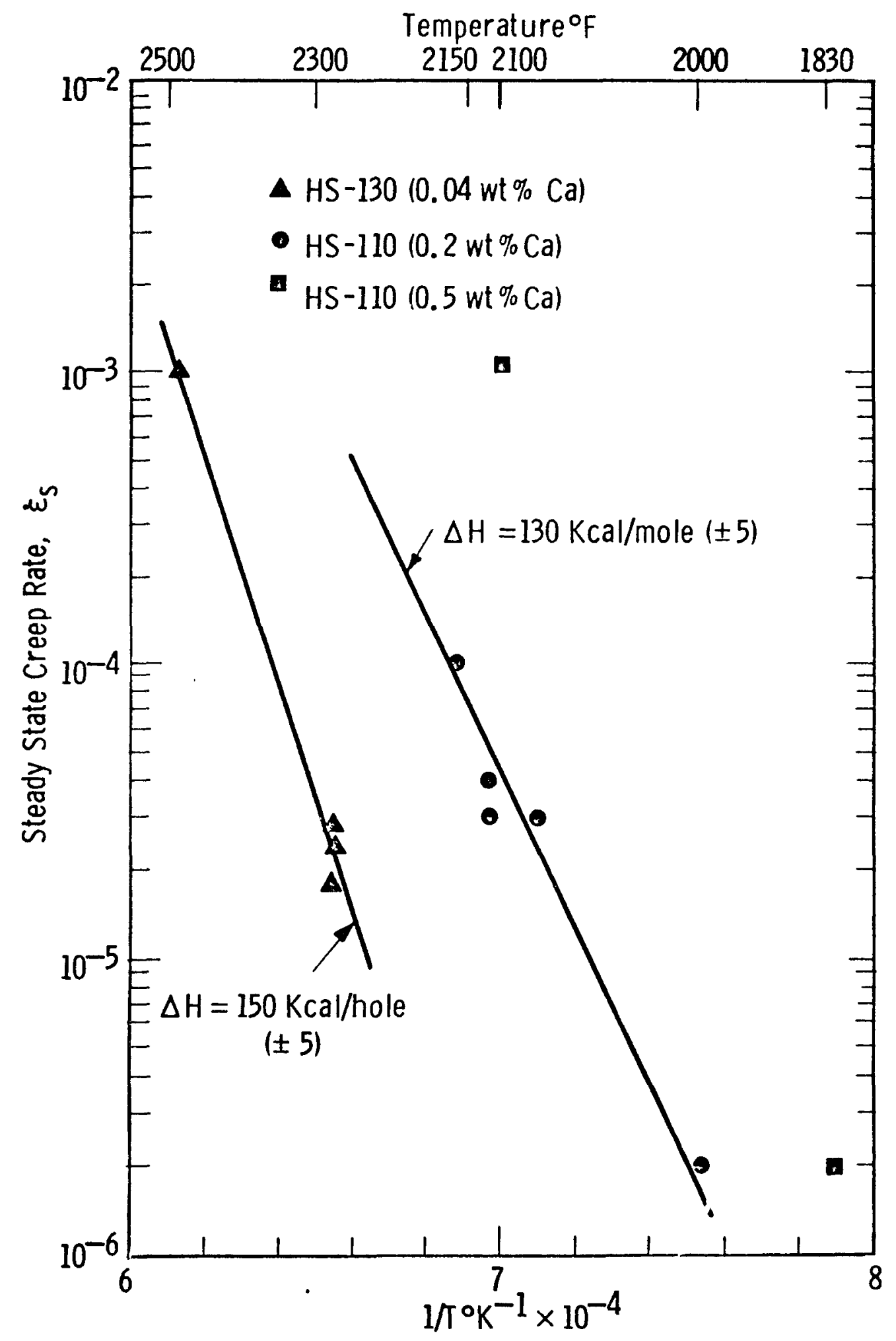

Figure 2.11 Steady State Creep Rate vs $1 / \mathrm{T}$ at, $10,000 \mathrm{psi}$, in He Atmosphere 


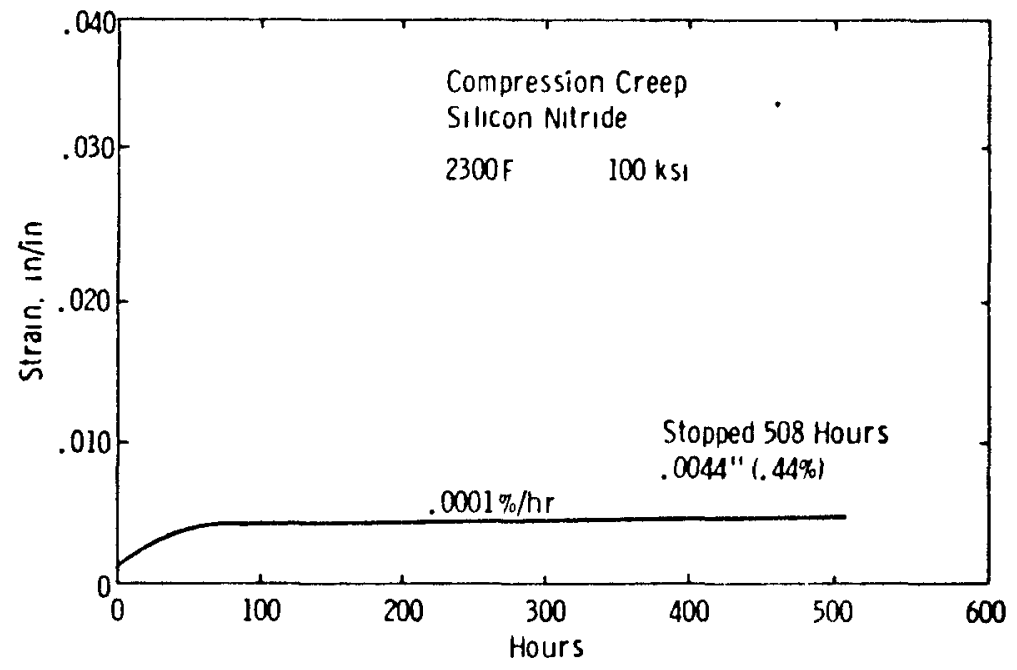

Figure 2.12 Compressive Creep of Silicon Nitride (12)

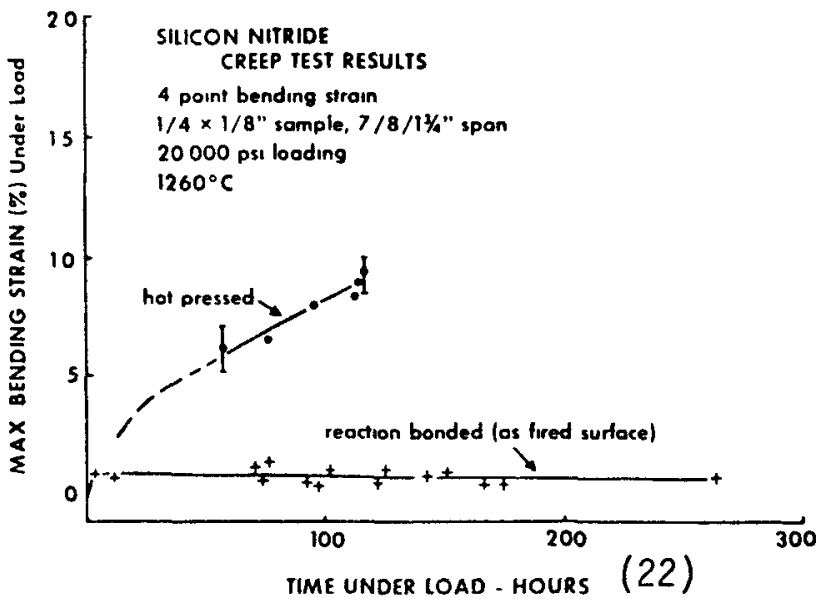

Fig. 2.13 
TEMPERATURE, ${ }^{\circ} \mathrm{F}$

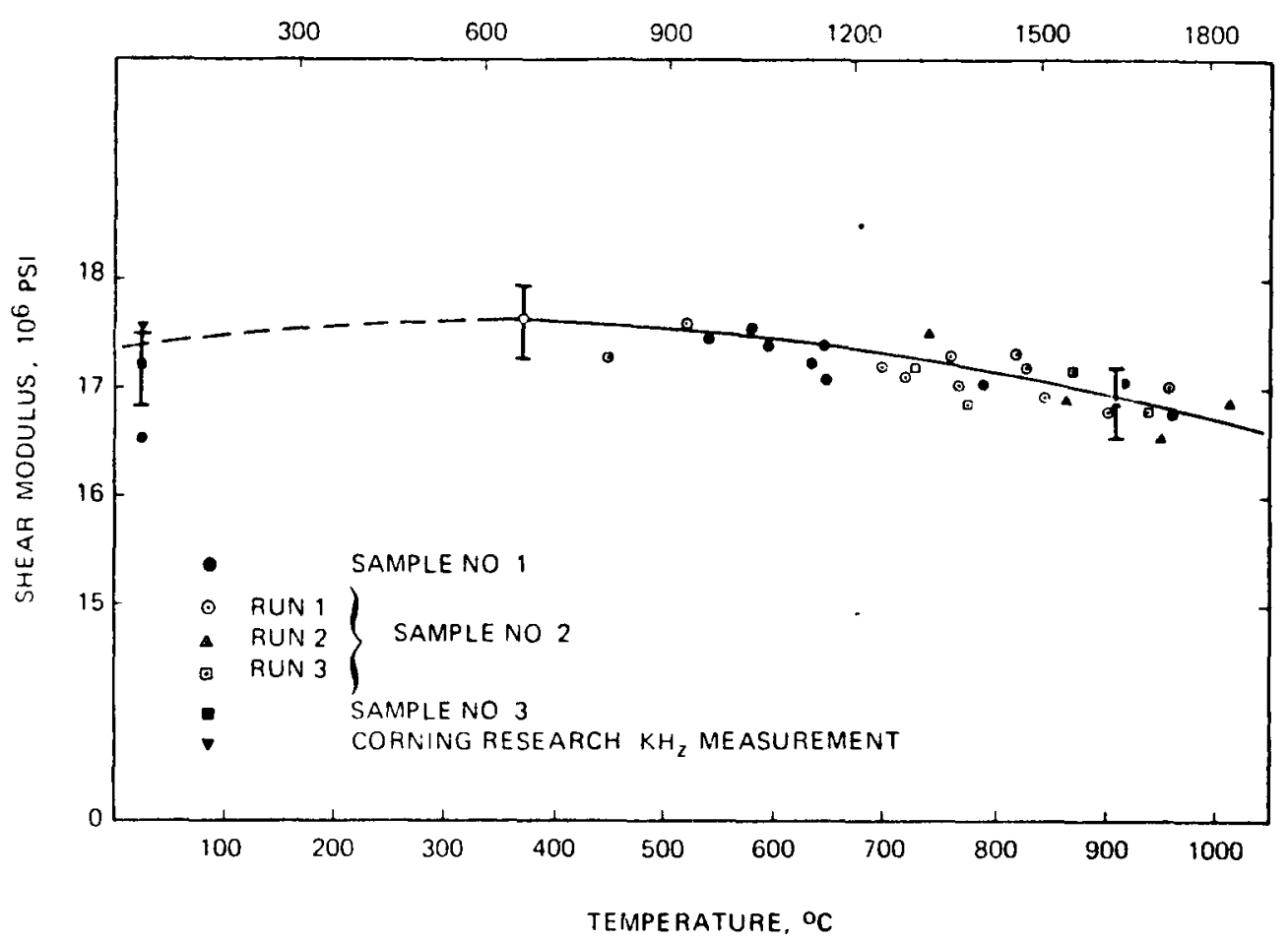

Figure 2.14 Shear Modulus of Hot-Pressed Silicon Nitride (12)

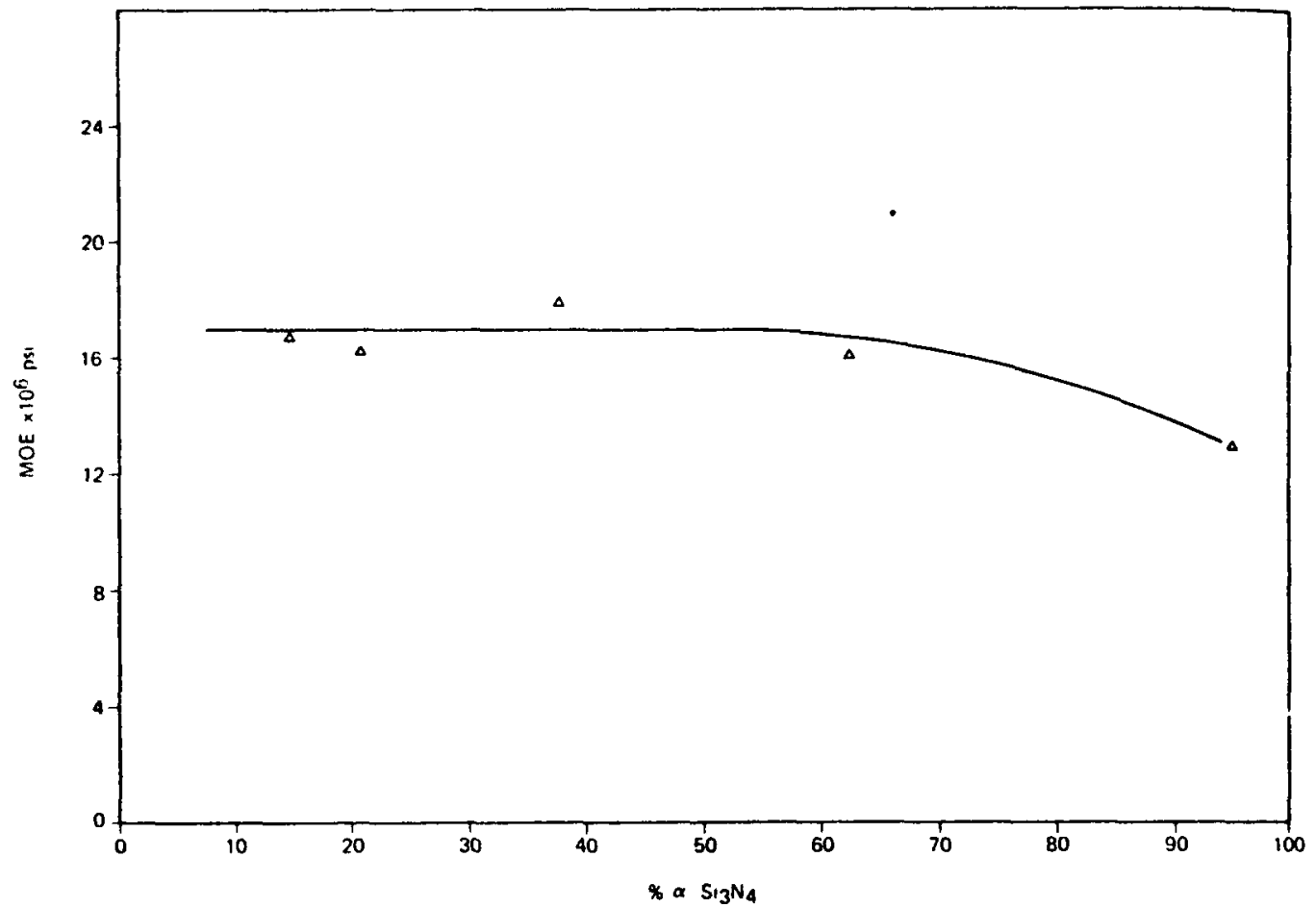

Figure 2.15 The Effect of Alpha-Beta Ratio on the Modulus of (12) Elasticity of Silicon Nitride 


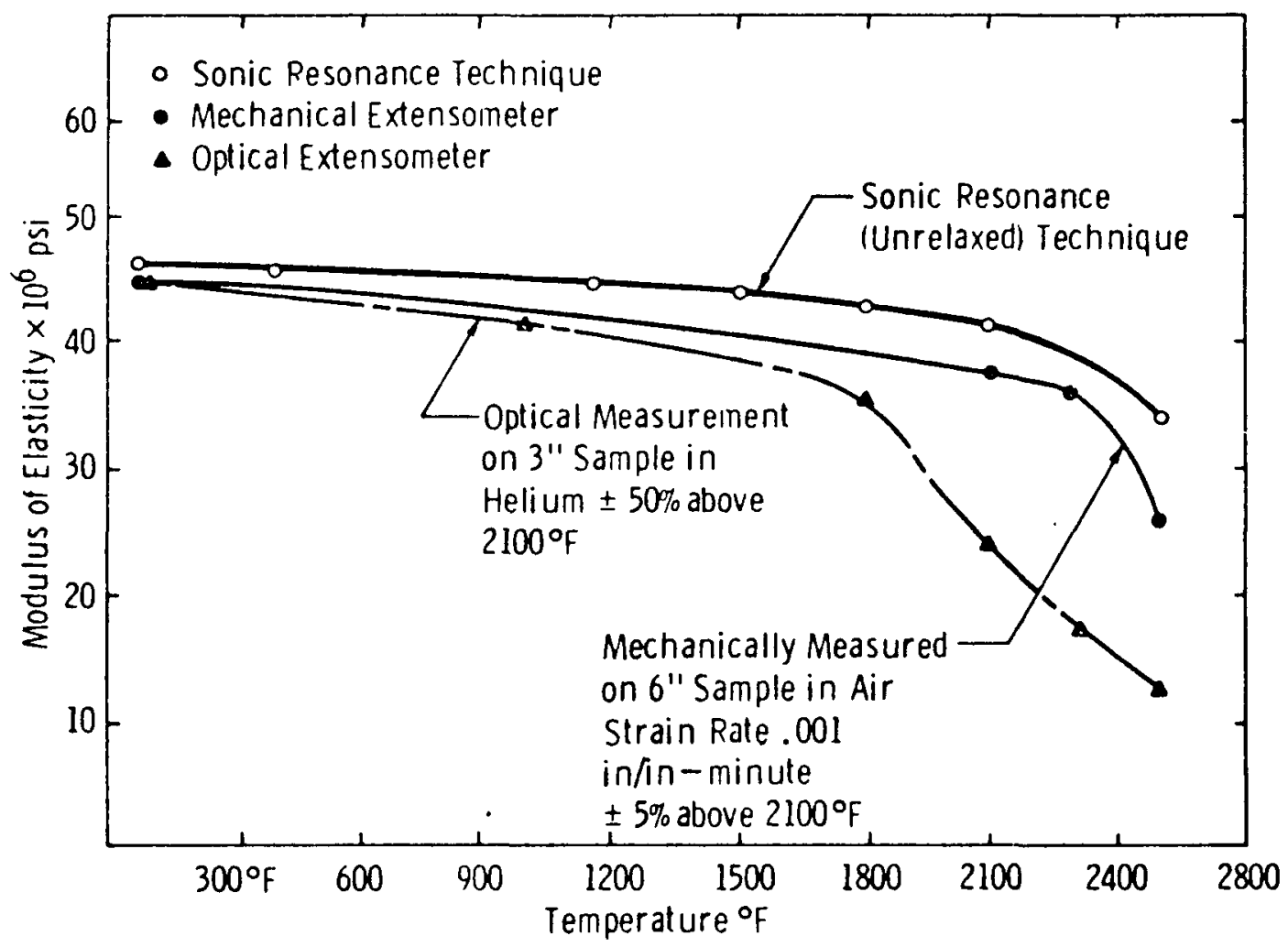

Figure 2.16 Young's Miodulus as a Function of Temperature for Silicon Nitride by Various Methods 

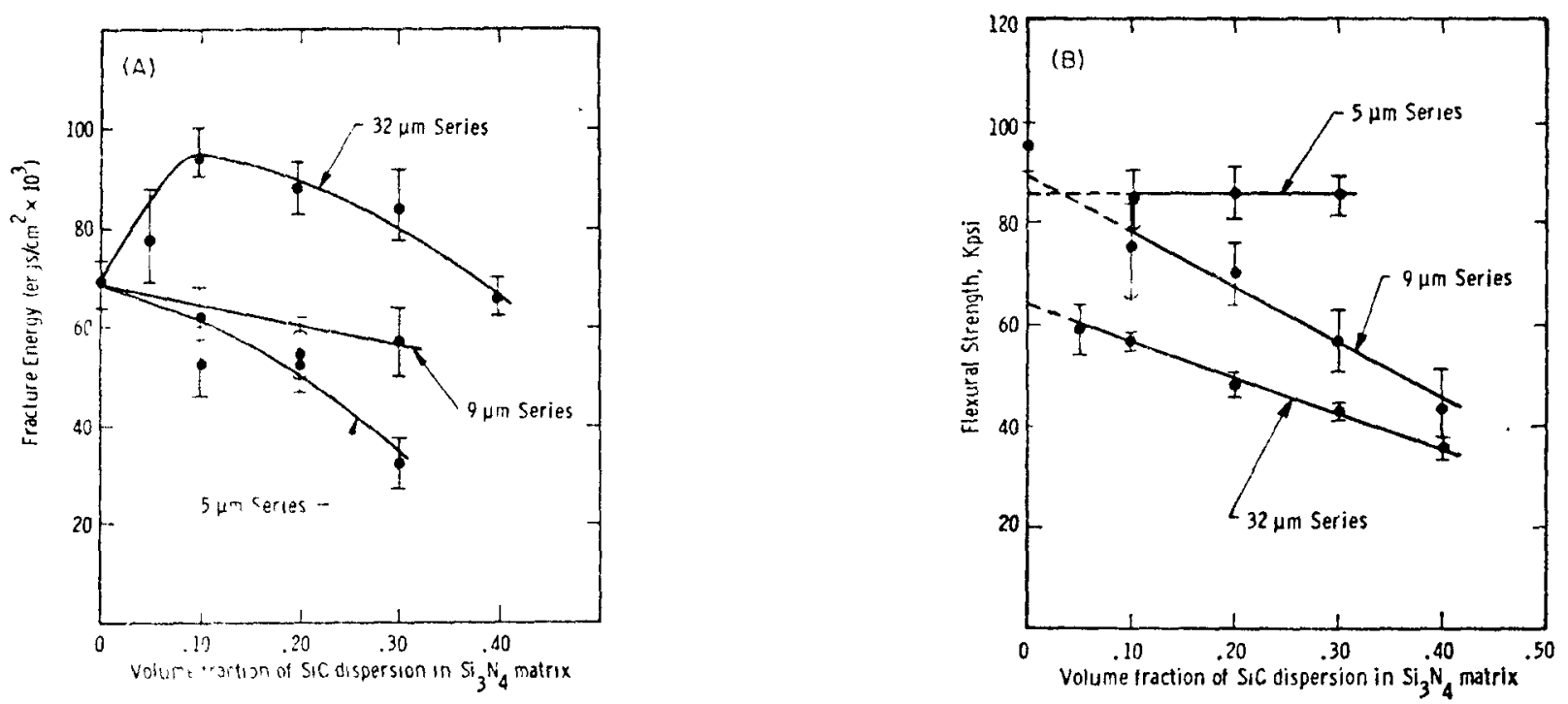

(A) Fracture concray and (B) strength vo volume

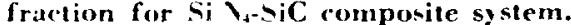

$$
\text { Fig. } 2.17
$$

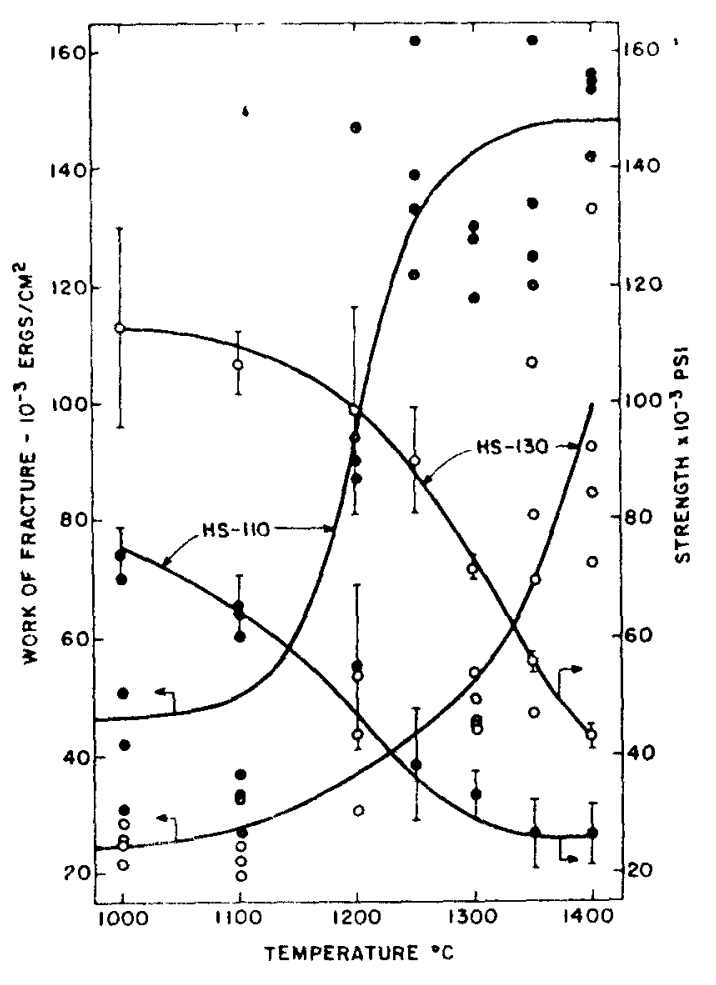

Strength and work-of-fracture vs temperature for two silicon nitrides.

Fig. 2.18 


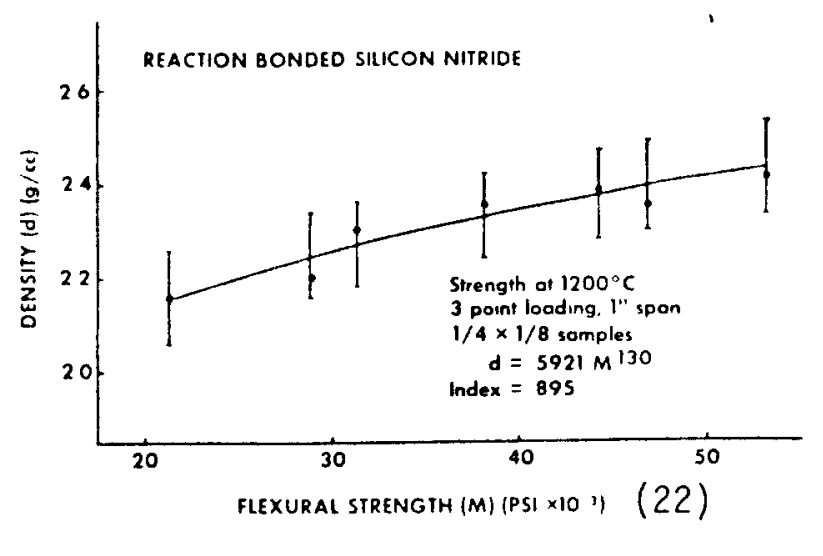

FIGURE 2.19

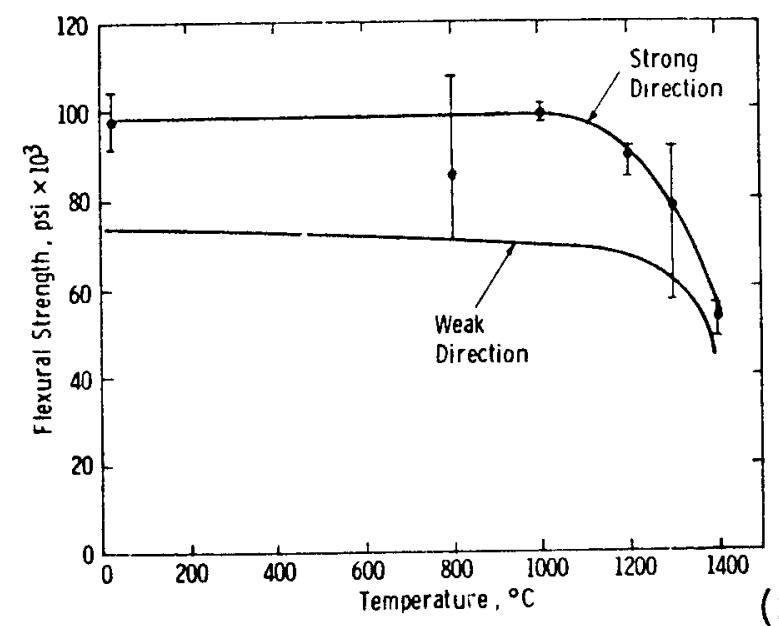

Fig. 2.21 Flexural strength in weak and strong directions vs temperature for $11 S-130$ Si $\mathrm{N}_{4}$ (crosshead speed 0.02 in./min).

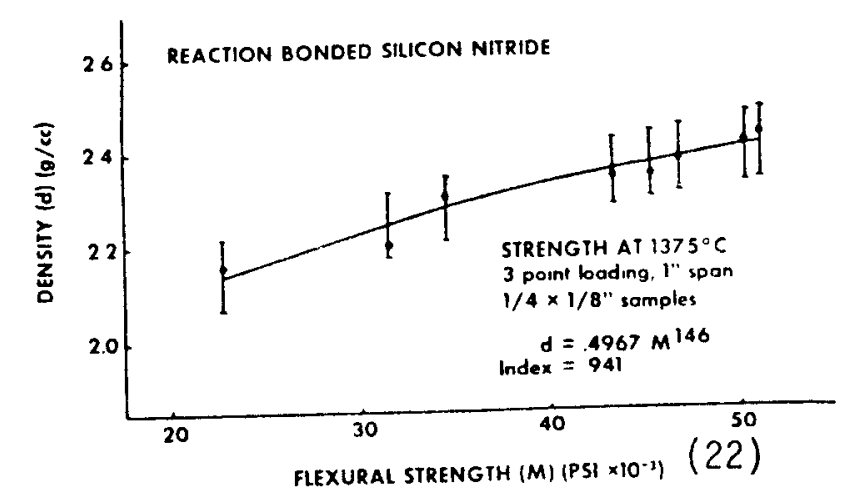

FIGURE $\cdot 2.20$

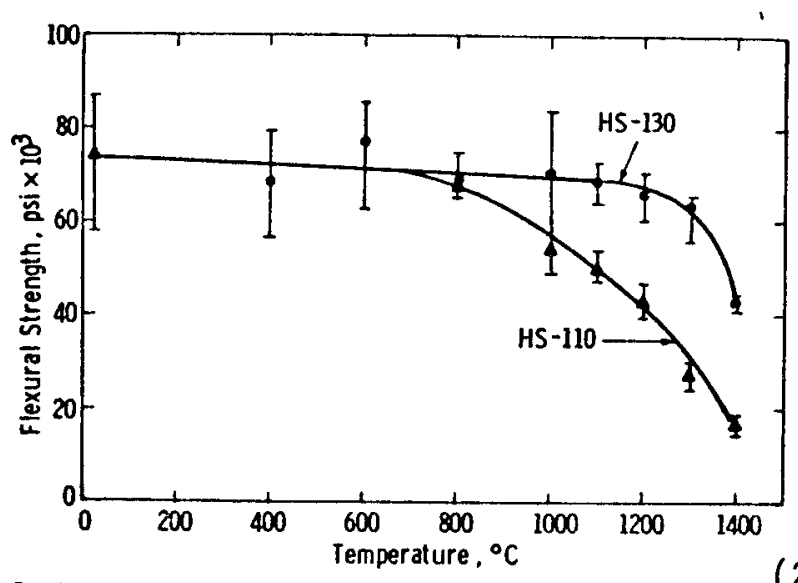

(23)

fig. 2.22 Flexural strength vs temperature for $11 S-110$ and HS-130 hot-pressed $\mathrm{Si}_{3} \mathrm{~N}_{4}$ (specinen configuration, weak direction; crosshead speed, 0.02 in. $/$ min). 


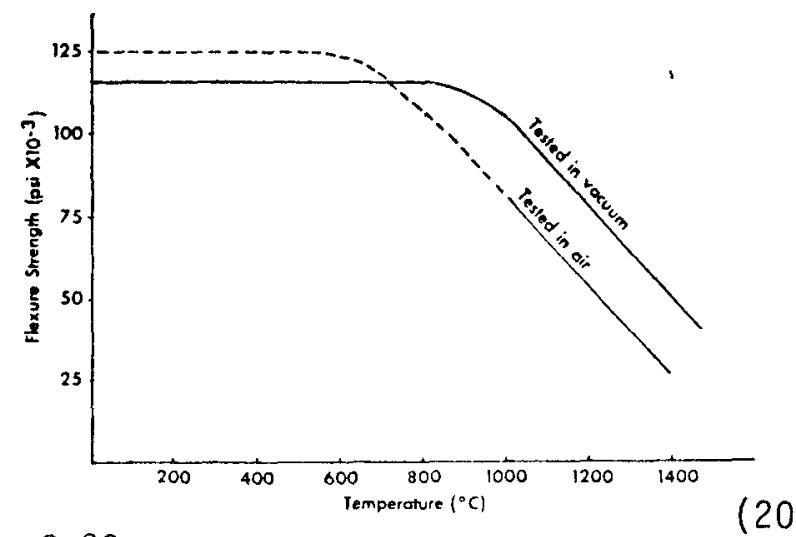

Fig. 2.23Effect of test environment on the strength of $\mathrm{Si}_{3} \mathrm{~N}_{\text {. }}$.

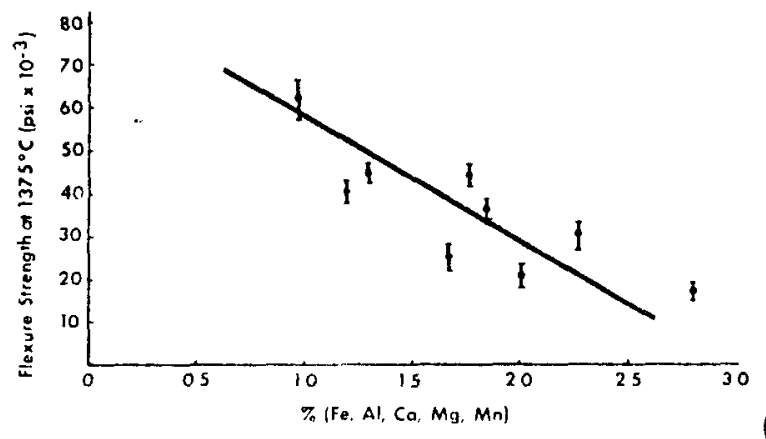

Effect of impurities on high temperature strength.

Fig. 2.24
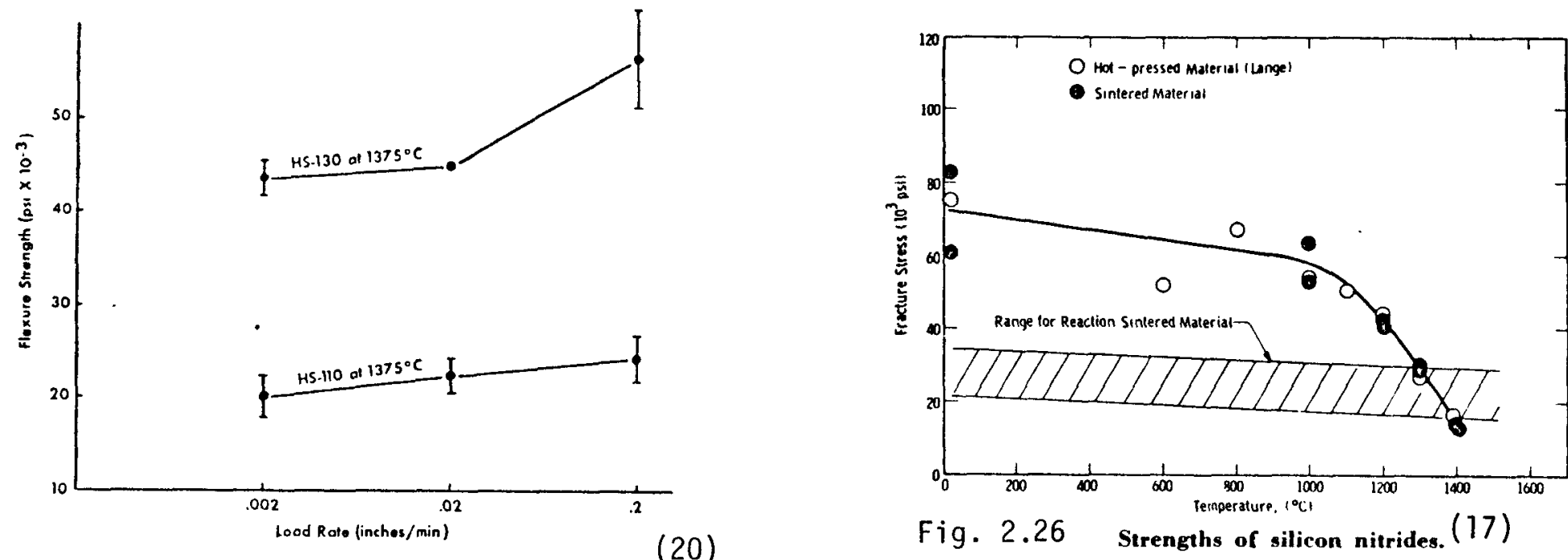

Fig. 2.26 Strengths of silicon nitrides. (17)

Fig. 2.25 


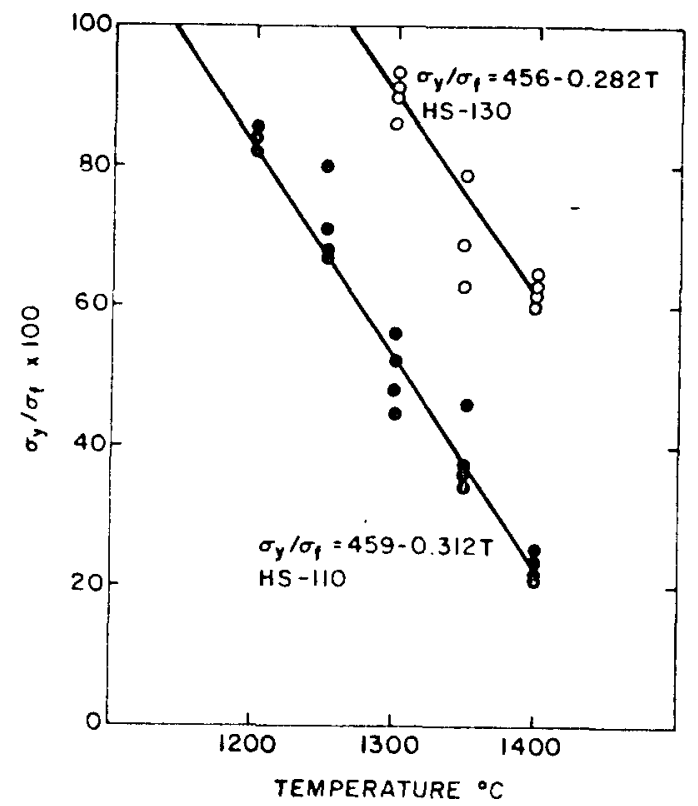

Ratio of apparent yield strength to fracture strength is

temperature.

Fig. 2.27

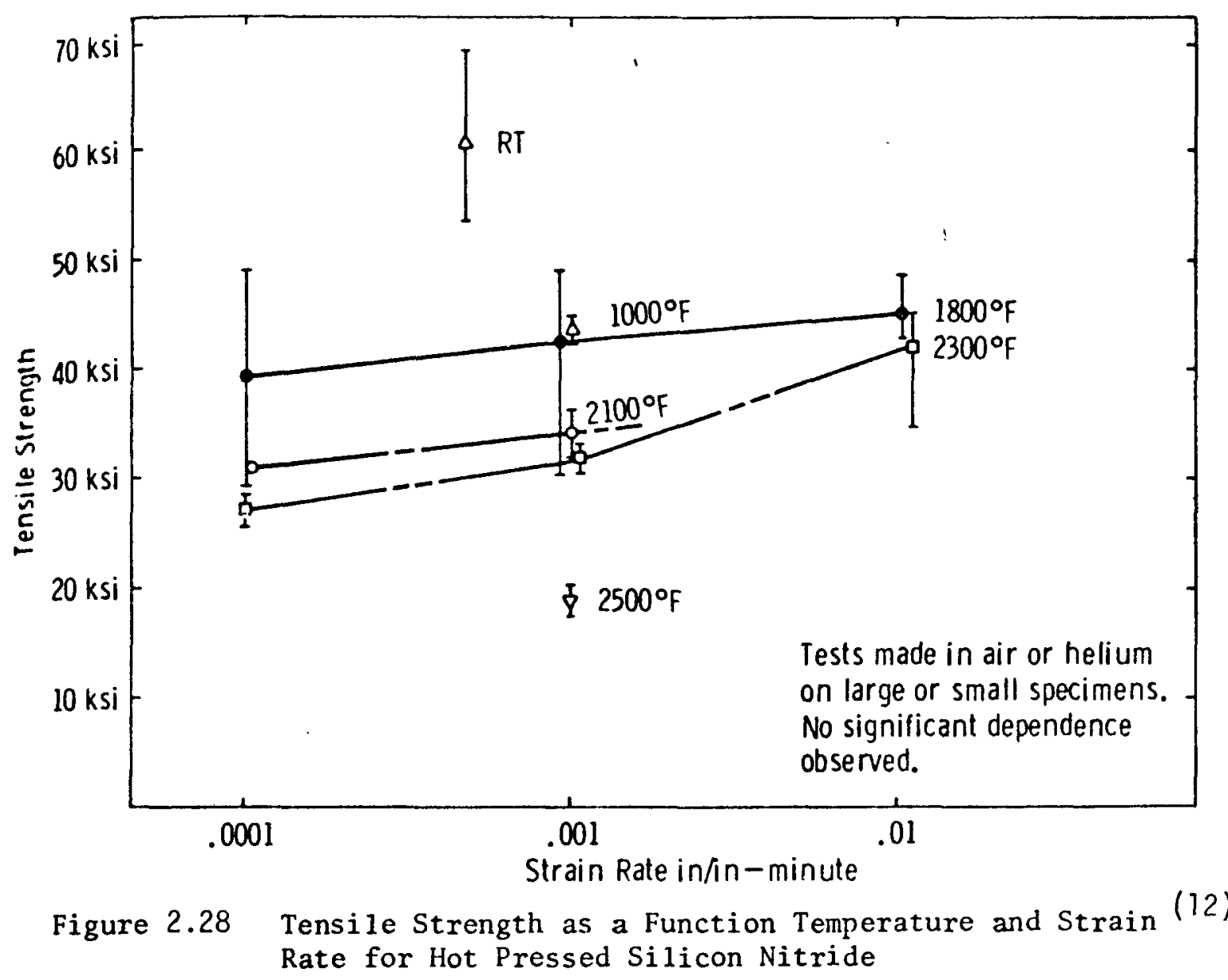




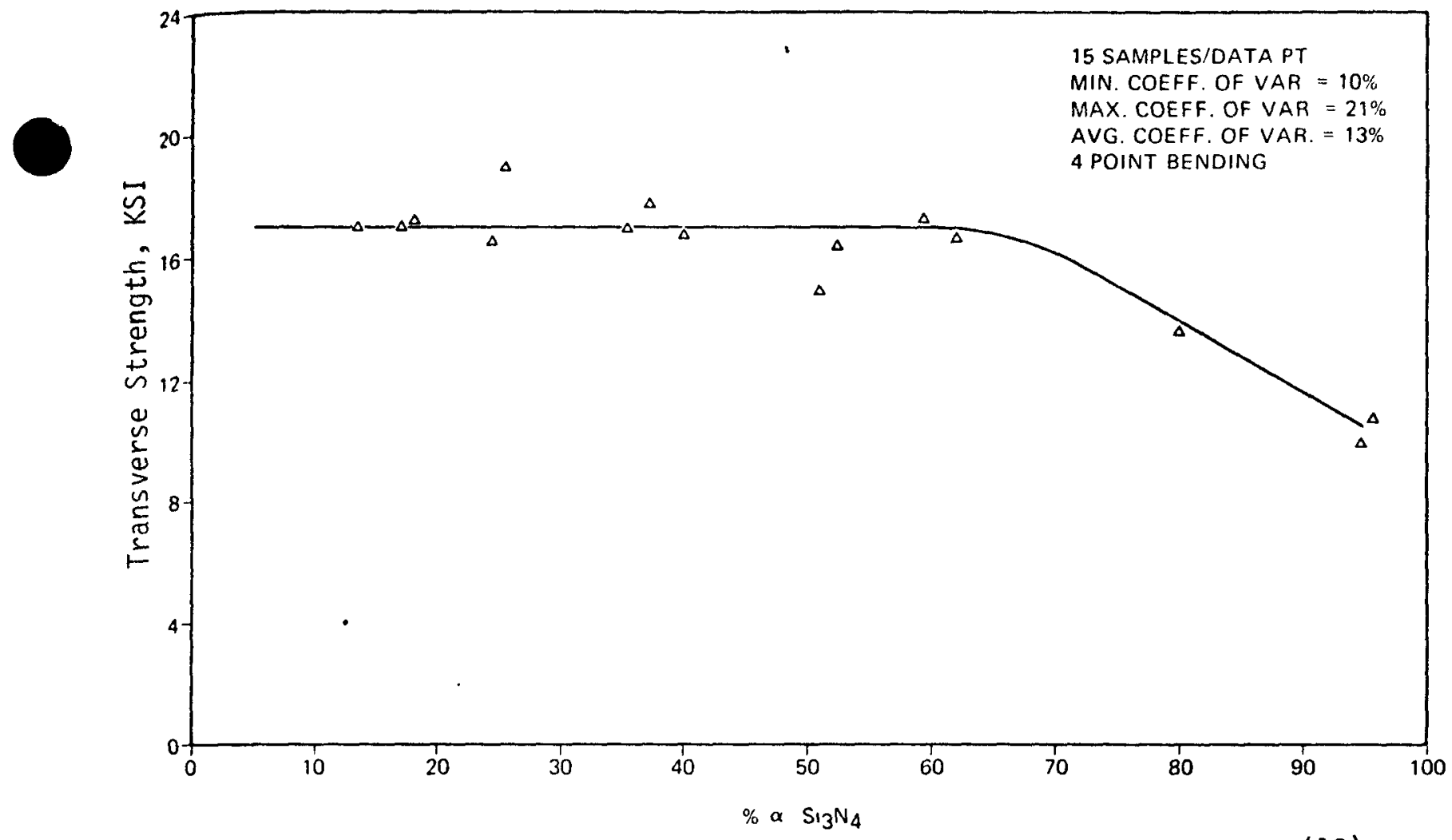

Figure 2.29 The Effect of Alpha-Beta Ratio on The Transverse (12) Strength of Silicon Nitride

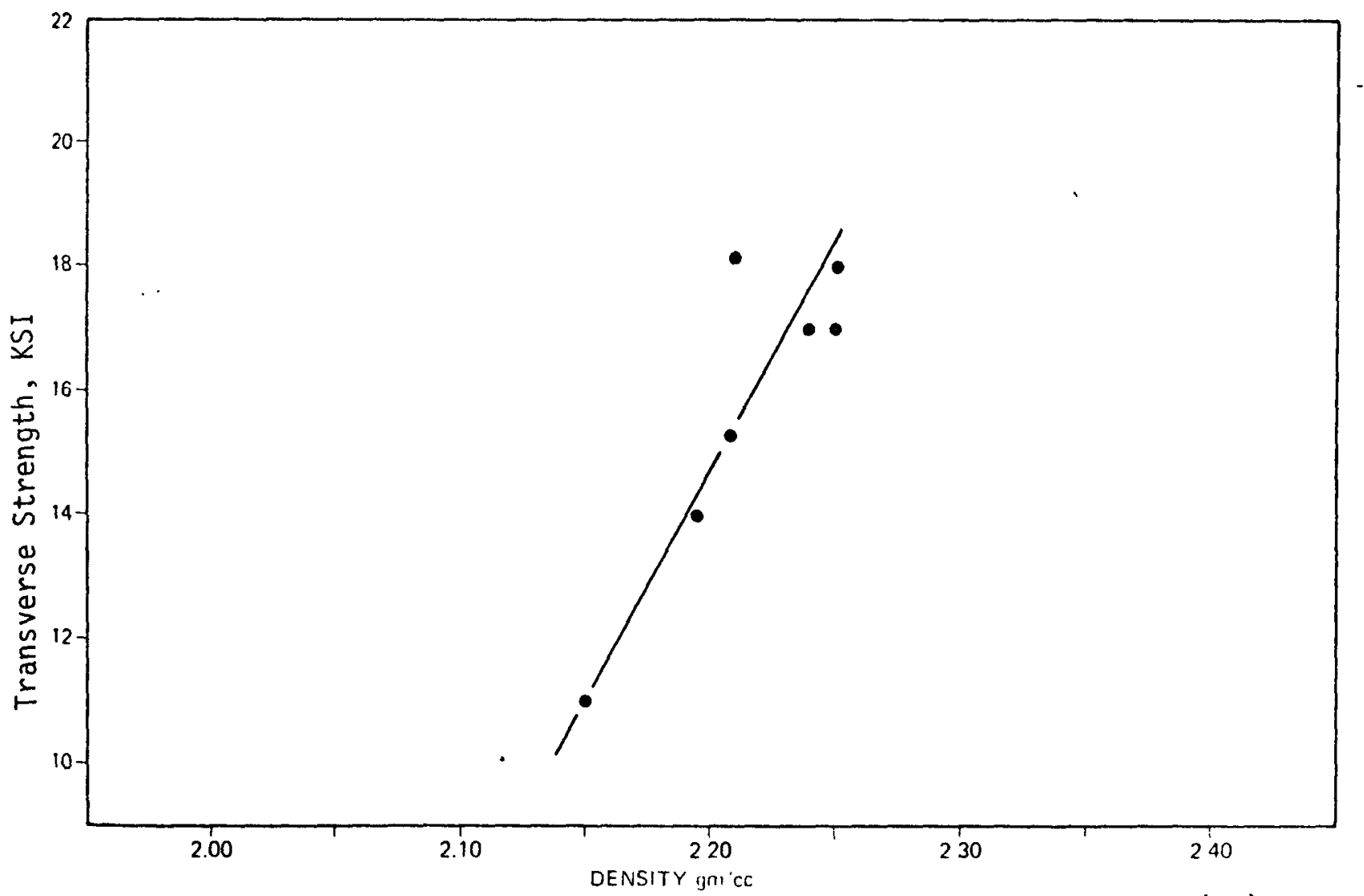

Figure 2.30 The Effect of Density on the Transverse Strength (12) of Silicon Nitride 


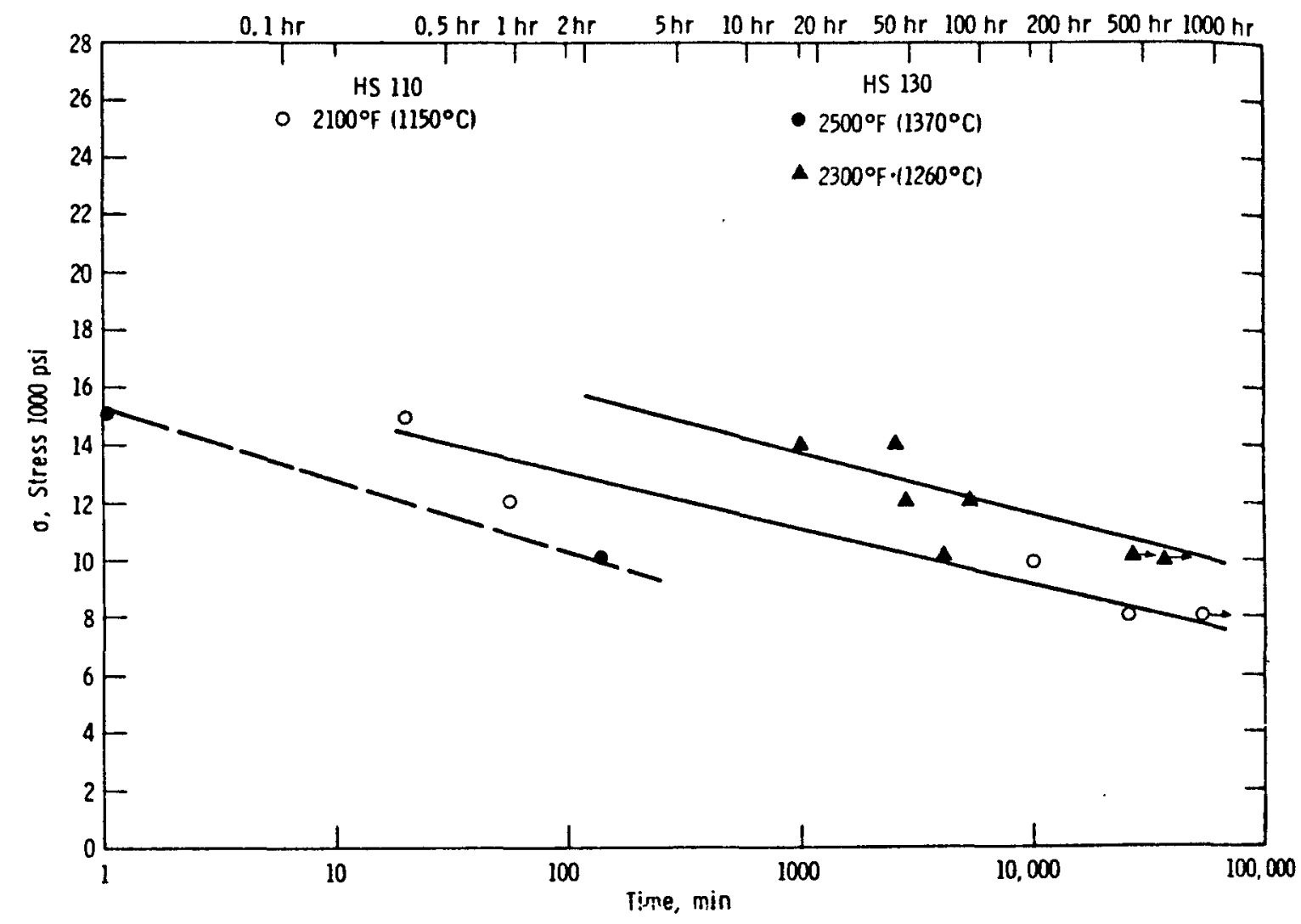

Figure 2.31 Stress-Rupture Properties of Silicon Nitride He (12) Atmosphere

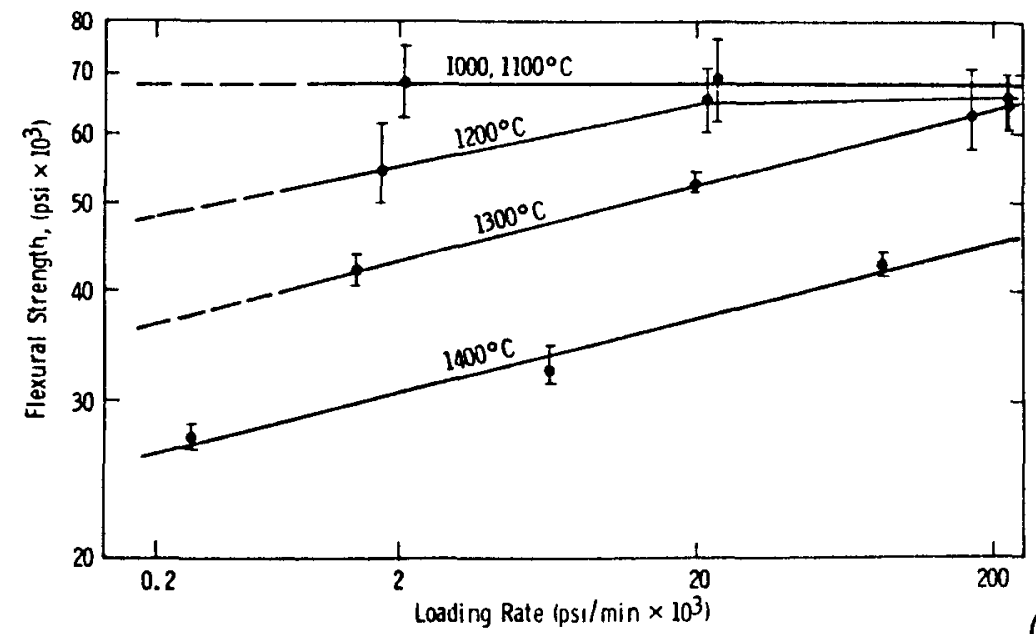

Fig. 2.32 Log-log plots of flexural strength is stressing rate at various (23) temperaiures for HS-130 $\mathrm{Si}_{i} \mathrm{~N}_{4}$ (specimen configuration, weak direction). 


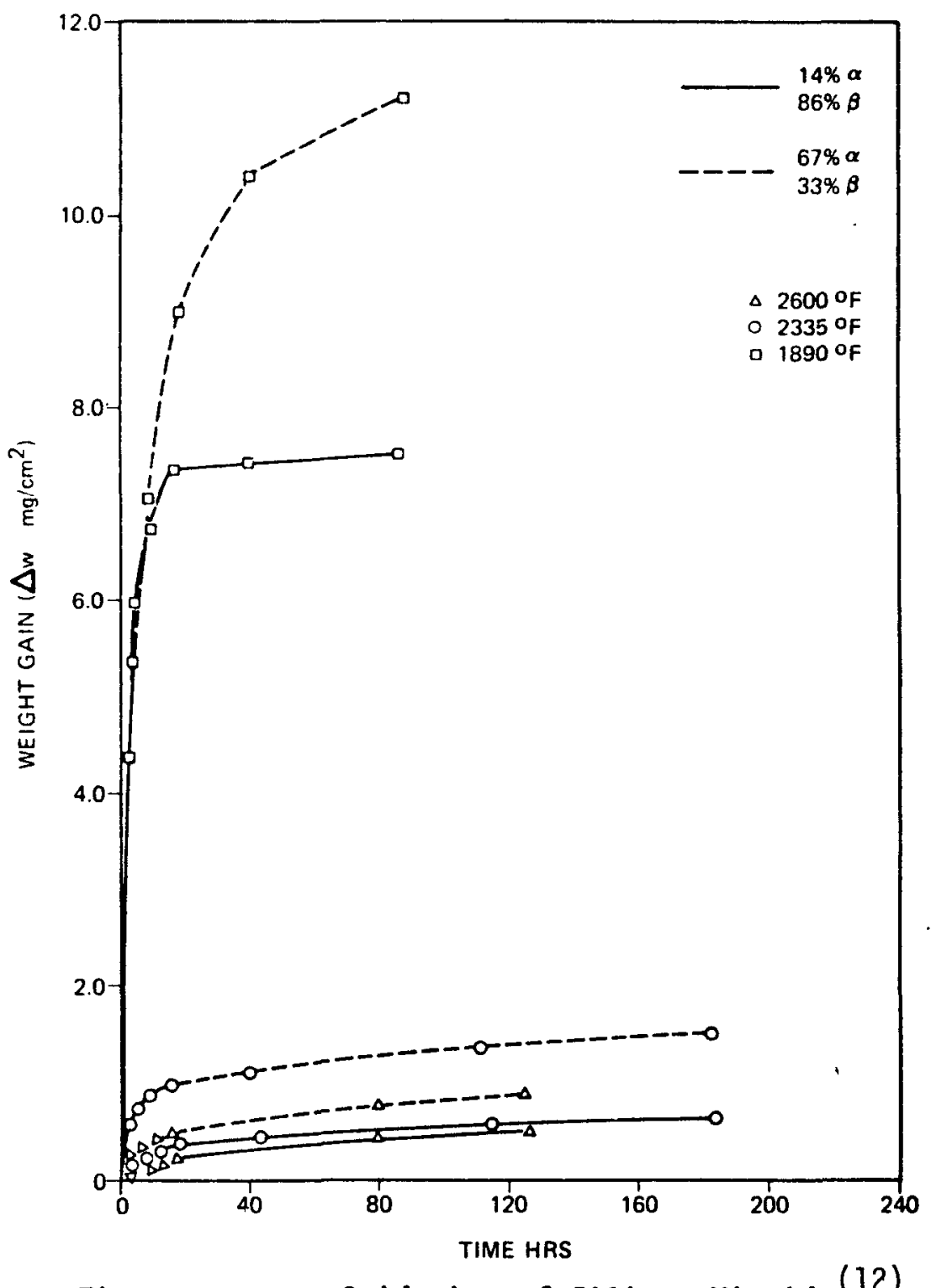

Figure 2.33 Oxidation of Silicon Nitride (12) 


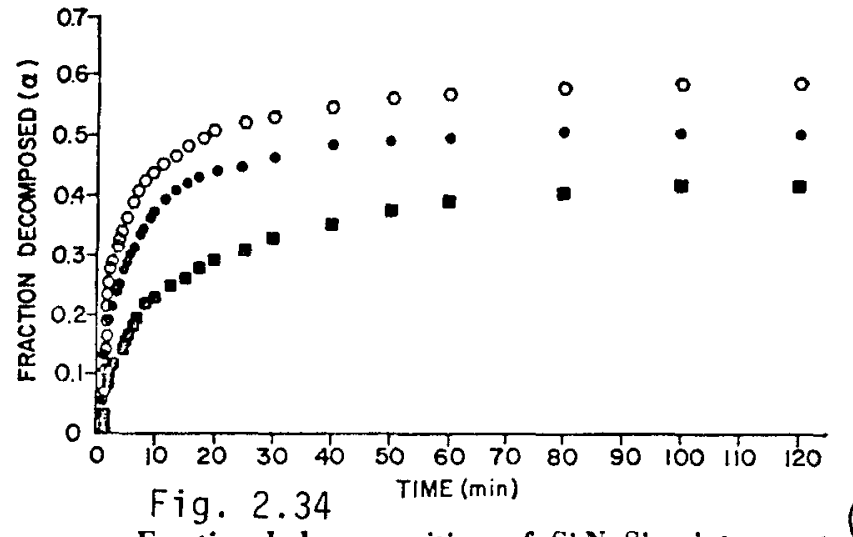

Fractional decomposition of $\mathrm{Si}_{3} \mathrm{Y}_{2}-\mathrm{Si}$ mixtures at $1675^{\circ} \mathrm{C}$ as a function of time for $(0)$ pure $\mathrm{Si}_{3} \mathrm{~N}_{4}$, ((0) $\mathrm{Si}_{3} \mathrm{~N}_{4}: 3 \mathrm{Si}$, and (A) $\mathrm{Si}_{3} \mathrm{~N}_{4}: 6 \mathrm{Si}$

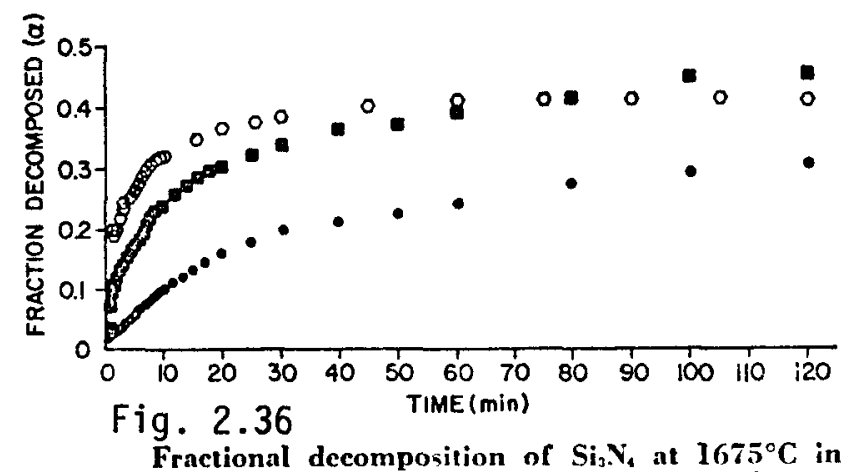

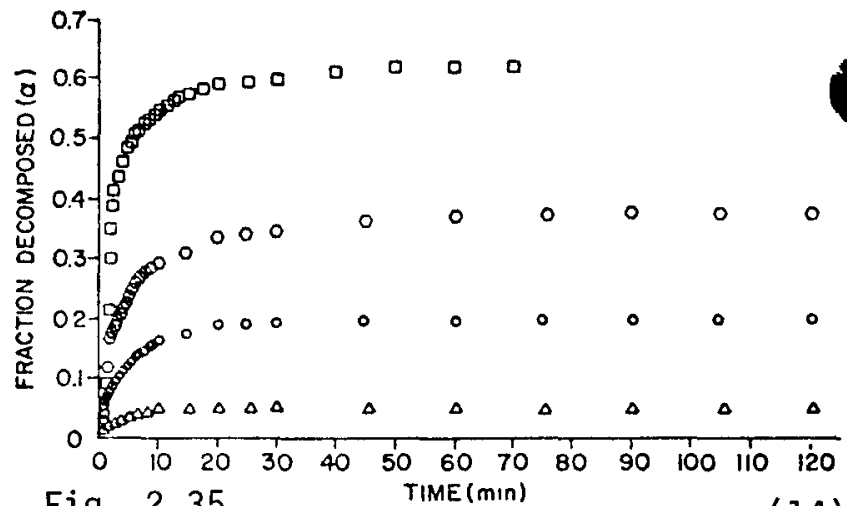

Fig. 2.35

(14)

Fractional decomposition, $\alpha$, of $\mathrm{Si}_{3} \mathrm{~N}_{4}$ as a function of time at $(\triangle) 1510^{\circ},(O) 1625^{\circ},(0) 1675^{\circ}$, and $(\square)$ $1740^{\circ} \mathrm{C}$.

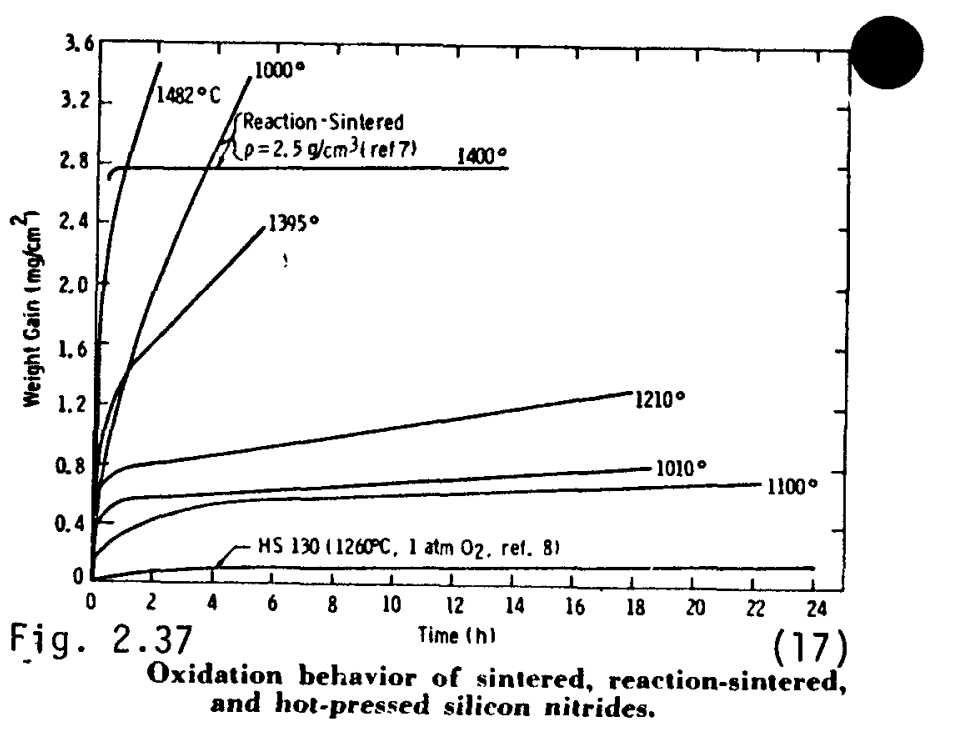




\section{REFERENCES}

1. S. Prochazka and R. J. Charles "Strength of Boron-Doped Hot-Pressed Silicon Carbide", Am Ceram Soc. Bul1. 52 [12] 885-895 (1973).

2. G. Q. Weaver and B. A. 01son, "High Strength Silicon Carbide for use in Severe Environments", Norton Co., Information Bulletin, 1973.

3. A. G. Atkins and D. Tabor, "Hardness and Deformation Properties of Solids at Very High Temperatures", Proc. Roy Soc. 292, 441-457 (1966).

4. T. Vasilos and W. D. Kingery, "Thermal Conductivity XI Conductivity of Some Refractory Carbides and Nitrides", J. Am. Ceram Soc. 37 [9] 409-414 (1954).

5. G. Ervin, Jr., "Oxidation Behavior of Silicon Carbide", J. Am. Ceram. Soc. 41 [9], 347-352 (1957).

6. E. L. Kern, D. W. Hami11, H. W. Deem and H. D. Sheets, "Thermal Properties Properties of B-Silicon Carbide", Mat. Res. Bul1. 4, S 25 - S 32 (1969).

7. R. G. Naum, C. K. Jun and P. T. B. Shaffer, "Thermal Conductivities of Vapor Deposited, Silicon Carbide and Silicon Carbide Graphite Composite", Eleventh International Thermal Conductivity Conference, Alburquerque, New Mexico, 1971

8. T. L. Francis and R. L. Coble, "Creep of Polycrystalline Silicon Carbide". J. Am Ceram. Soc. 51 [2] 115-116 (1968)

9. S. D. Mark, Jr., and R. C. Emanuelson, "Thermal Expansion Apparatus with a Silicon Carbide Dilatometer for Temperatures to $1500^{\circ} \mathrm{C}$ ", Am. Ceram Soc. Bul1. 37 [4] 193-196 (1958)

10. G. A. Slack "Thermal Conductivity of Pure and Impure Silicon, Silicon Carbide, and Diamond", J. Applied Physics 35 [12] 3460-3462 (1964).

11. Touloukian, "Thermophysical Properties of High Temperature Solid Materials", Vol. 5 Macmillan Co., 1967. 
REFERENCES (Cont'd)

12. "Brittle Materials Design, High Temperature Gas Turbine" AMMRC CTR 73-9 (1973).

13. F. F. Lange, "Effect of Microstructure on Strength of $\mathrm{Si}_{3} \mathrm{~N}_{4}-\mathrm{SiC}$ Composite System", J. Amer. Ceram. Soc 56 [9] 445-450 (1973).

14. H. D. Batha and E. D. Whitney, "Kinetics and Mechanism of the Thermal Decomposition of $\mathrm{Si}_{3} \mathrm{~N}_{4} "$, J. Amer. Ceram. Soc. 56 [7] 365-369 (1973).

15. P. Popper and S. N. Ruddlesden, "The Preparation, Properties and Structure of Silicon Nitride", Brit. Ceram. Soc. Trans. 60, 603-626 (1961).

16. G. G. Deeley, J. M. Herbert, and N. C. Moore "Dense Silicon Nitride", Powder Metallurgy 8, 145-151 (1961).

17. G. R. Terwilliger, "Properties of Sintered $\mathrm{Si}_{3} \mathrm{~N}_{4}$ ", J. Amer. Ceram. Soc. 57 [1] 48-49 (1974).

18. W. A. Fate, "High-Temperature Shear Modulus of $\mathrm{Si}_{3} \mathrm{~N}_{4}$ and $\mathrm{SiC}^{\prime}, \mathrm{J}$. Amer. Ceram. Soc. 57 [1] 49-50 (1974).

19. S. D. Hartline, R. C. Bradt, D. W. Richerson and M. L. Torti "Work of Fracture and Apparent Yield Correlation in $\mathrm{Si}_{3} \mathrm{~N}_{4} "$, J. Amer. Ceram. Soc. 57 [4] 190-191 (1974).

20. D. W. Richerson "Effect of Impurities on the High Temperature Properties of Hot Pressed Silicon Nitride", Am. Ceram. Soc. Bu11. 52 [7] 560-562 ( 1973).

21. J. D. Walton, "Reaction Sintered Silicon Nitride for High Temperature Radome Applications", Am. Ceram. Soc. Bul1. 53 [3] 255-258 (1974).

22. M. E. Washburn, and H. R. Baumgartner, "High Temperature Properties of Reaction Bonded Silicon Nitride", Norton Co. Publication (1973).

23. F. F. Lange, "High-Temperature Strength Behavior of Hot Pressed $\mathrm{Si}_{3} \mathrm{~N}_{4}$ : Evidence of Subcritical Crack Growth", J. Amer. Ceram. Soc. 57 [2] 84-87 (1974). 
REFERENCES (Cont'd)

24. P. L. Farnsworth and R. L. Coble. "Deformation Behavior of Dense Polycrystalline SiC J. Am. Ceram. Soc. 49 [5] 264-268 (1966).

25. T. D. Gulden, "Mechanical Properties of Polycrystalline B-SiC", J. Am. Ceram. Soc 52 [11] 585-590 (1969).

26. T. D. Gulden and C. F. Driscol1, "Creep of Chemically Vapor-Deposited B-SiC with an Analysis of Creep in Bending", General Atomic Report GA-10366 (1971).

27. P. Popper and D. G. S. Davies, "The Preparation and Properties of Self-Bonded Silicon Carbide", Powder Metallurgy [8] 113-127 (1961). 